



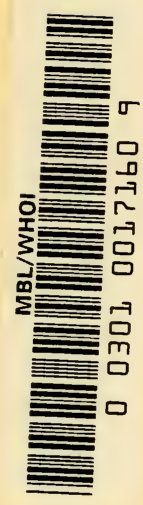



NORTHWESTERN UNIVERSITY STUDIES IN THE BIOLOGICAL SCIENCES AND MEDICINE

NUMBER I 

NORTHWESTERN UNIVERSITY STUDIES IN THE

BIOLOGICAL SCIENCES AND MEDICINE

NUMBER I

\title{
A STUDY IN \\ NEOTROPICAL PSELAPHIDAE
}

\author{
BY \\ ORLANDO PARK \\ NORTHWESTERN UNIVERSITY
}

1942

NORTHWESTERN UNIVERSITY

EVANSTON AND CHICAGO 
NORTHWESTERN UNIVERSITY STUDIES

Editor

JOHN WEBSTER SPARGO

Advisory Board

JAMES WASHINGTON BELL LESLIE BRAINERD AREY

Thomas MOOdY CaMPBEll Harold THaYer DaVIS

Fred DOW FAGG

MELVILLE J. HERSKOVITS

Elmo Paul Hohman

PAUL A. WitTY

COPYRIGHT, 1942

NORTHWESTERN UNIVERSITY 
I DEDICATE THIS PAPER WITH SINCERE AFFECTION To professor Warder Clyde allee, Who has time TO CONSIDER THE SPECIES QUESTION WHILE DOING RESEARCH UPON THE AGgREGATION OF INDIVIDUALS 



\section{Table of Contents}

Preface . . . . . . . . . . . . . . . . . vii

General Considerations and the Collecting of Pselaphidae . . . 1

Preparation of Pselaphidae for Study . . . . . . . . . . 8

Taxonomic and Morphological Considerations . . . . . . . 12

Key to the Tribes of Neotropical Pselaphidae $\quad$ • . . . . . . 31

Subfamily Pselaphinae . . . . . . . . . . . . . . . 34

Division I. Brachyscelia . . . . . . . . . . . 35

Tribe 1. Faronini . . . . . . . . . . . . 35

2. Pyxidicerini . . . . . . . . . . . 37

3. Jubinini . . . . . . . . . . . . . 38

4. Euplectini sensu latiore . . . . . . . . . 63

5. Brachyglutini . . . . . . . . . . . 122

6. Metopiini . . . . . . . . . . . . 204

7. Batrisini . . . . . . . . . . . 214

8. Tychini . . . . . . . . . . . . . 260

9. Goniacerini . . . . . . . . . . . . 283

Division II. Macroscelia . . . . . . . . . . . 286

Tribe 10. Pselaphini . . . . . . . . . . . . 286

11. Holozodini . . . . . . . . . . . . 288

12. Hybocephalini . . . . . . . . . . . . 289

13. Ctenistini . . . . . . . . . . . . 291

14. Tyrini . . . . . . . . . . . . . 295

15. Arhytodini . . . . . . . . . . . . 343

16. Attapseniini . . . . . . . . . . . . 348

Subfamily Clavigerinae: Tribe 17. Clavigerini . . . . . . 350

The Undescribed Species of Motschulsky . . . . . . . 359

Zoögeographic and Statistical Considerations . . . . . . 360

Abstract . . . . . . . . . . . . . . . 378

BIBLIOGRAPHY . . . . . . . . . . . . . . . 381

General Index . . . . . . . . . . . . . . . 389

Index to Plates . . . . . . . . . . . . . . 407 



\section{Preface}

The scope of this paper is limited in two ways. The author has attempted to coordinate and add to the information on the Pselaphidae which inhabit the American tropics. This has never been coordinated, the nearest approach being that of David Sharp, who gave a series of inadequate descriptions of Central American species in 1887 in the Biologia Centrali Americana. Second, this present paper, through the medium of a modified Raffrayan system, bridges the thirty odd years between the generic analysis of this family by Raffray in 1908, in the Genera Insectorum, and 1941. During this time much novel information has accumulated on the anatomy, taxonomy, species ecology and zoögeography of these fascinating beetles.

For the past six years I have received much help from many people, and this opportunity is taken to thank them. I am indebted to Mr. H. S. Barber of the Bureau of Entomology for permission to study the types of neotropical pselaphids described by F. C. Fletcher; to Dr. E. A. Chapin of the National Museum for providing facilities to study at this institution; to Dr. Blackwelder of the same institution for reading and criticizing the section on comparative anatomy; to Mr. J. B. Calhoun of my Department for checking descriptions; to Professor Alfred Emerson of the University of Chicago for the gift of specimens from the Canal Zone and British Guiana, for identification of host termites, and for a reading of the entire manuscript; to the late Mr. H. C. Fall of Tyngsboro, Massachusetts for critical advice; to Mr. W. J. Gerhard of the Field Museum for reading galley proof; to Miss Gloria Hilker and Mr. Raymond Parker of my Department for secretarial aid; to Dr. C. H. Seevers of the Chicago Y.M.C.A. College for the gift of specimens from Mexico and Colombia; to Mr. Henry Dybas of the University of Chicago for the gift of specimens from Mexico; to Mr. J. D. Sherman, Jr. of Mt. Vernon, New York for procuring essential literature; to Dr. H. F. Strohecker of Ohio University for the gift of specimens from Bolivia and Brazil; to Dr. E. C. Williams of the Chicago Academy of Sciences for the gift of specimens from the Canal Zone; to Mr. Rupert Wenzel of the Field Museum for the gift of a specimen from Paraguay; and to Mr. James Zetek, U.S. Department of Agriculture for many facilities in the Panama Canal Zone.

To all of these I am deeply appreciative, but must point out that shortcomings in this paper are to be credited to the author.

This report is not a monograph of neotropical Pselaphidae. It is a summary of data preparatory to monographic study. Many genera are insufficiently known to key out all of the described forms; many type specimens must be examined and redescribed; many species await description; the species ecology and distribution of neotropical pselaphids are little understood. 


\section{PREFACE}

All of the types of the new species described in this paper are in the collection of the author. Paratypes are to be distributed in those species described on a large series. Eventually the author's collection of pselaphidae will be deposited in a museum.

Twenty-one plates are included to illustrate pselaphid anatomy and taxonomy. These have been drawn by the author. Although great care has been exercised, some discrepancies may be found between a given figure and the text. In all such cases the text is to be considered correct since the curvatures of parts makes the exact delineation difficult, or exact drawing may distort habitus. Where discrepancies exist between halves of a bilaterally symmetrical figure, the left side is to be considered in preference to the right side. 


\title{
Studies in American Pselaphidae with Particular Reference to the Tropical Areas
}

\author{
Orlando Park \\ Northwestern University
}

\section{GENERAL CONSIDERATIONS AND THE COLLECTING OF PSELAPHIDAE}

Twenty years ago I collected my first pselaphid beetle. Since then my general interest in Coleoptera has narrowed gradually, and although other groups have held my attention, I invariably returned to a study of the "antbeetles". The last ten years have been spent in a rather constant study of this family of beetles. The word constant is used in a relative sense, implying devotion to these insects as much as feasible amidst the normal confusion of academic duties.

Pselaphidae are difficult to collect. Their habitats are usually dark and secluded. The species are inconspicuously colored, a yellowish or reddish brown being the average color pattern. Pselaphids are of minute size and many crouch when uncovered, often with the head, antennae, and legs more or less concealed by the body. Some of the beetles letisimulate when touched (Tmesiphorus, Rhexidius, Melba).

In general, for the purposes of collecting, the family can be divided into two sections. This division follows a rather basic separation of the family with regard to their ecological requirements, e.g. those forms inhabiting decaying plant debris (the mold species) and secondly, those forms entering into the complex society of ants (the myrmecocolous species). However, some pselaphids appear to be equally at home in both niches, e.g. Tmesiphorus costalis (Park, 1933), Batrisodes globosus (Park, 1929, 1932b, 1935a, b), and again, pselaphids may be found less frequently in the nests of termites and other habitats not enumerated.

I. The Mold Species. The majority of species of the family are found in the various types of mold. The Euplectini and Trichonychini are especially characteristic of plant debris, and with the exception of the Clavigerinae, most of the other genera are found here at one time or another.

Plant mold can be imperfectly divided into two closely related categories: the mold of decaying logs (particularly the more advanced stages of the log decay cycle, in which the sapwood and heartwood have undergone considerable decay and can be easily crumbled with the fingers, although the early stage where the bark is loose and the sapwood still firm and moist may be rich 
in pselaphids, especially the larger species), and the leaf mold of the forest floor. Within my experience I have found log mold to have a higher yield: the mold should be moist but not wet; easily crumbled but not gritty, and brown to black in color rather than red. The moist decaying vegetation of the forest floor, particularly about the base of trees, is good collecting ground. Hollow stumps with several inches of wood bounding the cavity and with a quantity of fine, black mold within the latter are usually infested with microcoleoptera. Again, rotting stumps, with only portions of the heartwood left and the roots rotted away, can be overthrown, and beneath the stump and upon its upturned base pselaphids may be taken.

In other words, dense, heavily shaded forests with a deep leaf mold and abundance of prostrate trees are productive, particularly the deciduous trees such as ash, oak, elm, hickory, beech, and maple. Meadows or dry upland oak-hickory forests are not so rich in pselaphids, but may yield uncommon forms.

Flood plains which are subjected to an annual inundation make poorer collecting ground, although near the top of the flood-line, in the piled debris, some species are to be had, and the uplands of river valleys, especially northfacing slopes, are good hunting. With experience, the pselaphids can be seen and picked up. Two general methods yield the greatest numbers of individuals -sifting and heating. Leaf or log mold can be sifted with great profit by using screens, a practice proved valuable by generations of entomologists. The wire basket with a handle, used for deep-fat frying, having a quarterinch mesh is neither too bulky nor inconvenient to use. With this or some other suitable screen or sieve, several square feet of white cloth should be carried so that the material sifted can fall upon the cloth and be easily seen. Sifting has one great advantage: the mold can be sifted in situ, the specimens collected and another sample tried. In this way unproductive leaves or debris can be discarded, and on the other hand productive material can be worked again and again. The second method for obtaining numbers of individuals is by the application of a gradient of temperature to the contained sample: the Berlese Method. I have used this method with great success. A simple modification of the famous original, which can be constructed easily and at little expense, is as follows: One or more funnels should be made up of stout galvanized iron. These can be of any size but $I$ have found funnels measuring ten to fourteen inches in diameter at the top and from ten to twenty inches long very satisfactory. The spout of the funnel should taper to a tubular piece several inches long and half an inch in diameter. Such a funnel is fixed upright over a finger bowl of 95 per cent ethyl alcohol. A series of circular screens is made up of varying diameters and mesh. I have found three sizes useful, (1) a small screen three inches in diameter with a sixteenth-inch mesh, (2) a medium screen six inches in diameter with a quarter-inch mesh, and (3) a large screen eight inches in diameter with a half-inch mesh. These screens are placed in the funnel at bottom, middle and top thirds respectively. The sample of mold is then inserted on top of the large screen and a heating unit laid 
over the mouth of the funnel above the sample. This heating device may be an electric toaster, stove, or light bulb in the laboratory. In the field where immediate assay of mold is necessary, a frying-pan of live coals or a Thermat pad will give the desired heat. The heat from above will gradually drive the mold animals deeper until they drop through the screens into the alcohol. Although one or two hours will often provide a high yield, two or three days may be necessary. Also, merely allowing the sample to dry in the funnel for a week will give results without the application of artificial heat.

After berlesing a sample I have found that the yield may be augmented by laying a small square of cloth on the now hot debris and putting several drops of carbolic acid on the cloth and then covering the funnel.

The Berlese system, in its many ramifications, has one great advantage, that of thoroughness. Where accurate quantitative data are desired it is in a class by itself in making an assay of floor debris.

Collecting over a period of years has shown that the Pselaphidae are constant constituents of mold. The adults hibernate through the winter in this stratum, copulate therein during the spring and remain active residents during the spring and summer seasons. They are largely nocturnal feeders. Their chief food, at least of the common free-living forms, is the small game that also lives in the mold in such imponderable myriads, insect larvae, the Collembola, Acarina (chiefly Oribatidae, Hoplodermatidae and Parasitidae and other minute mites described admirably by Jacot $(1935,1936 \mathrm{a}, \mathrm{b}, \mathrm{c})$. This general food habit was known to Denny as early as 1825 . Since the mold stratum is always at twilight during the day, the period of activity of pselaphids is not circumscribed by intense illumination, although at night many species fly.

The majority of species of the family have well developed metathoracic wings and fly well, e.g. Bibloplectus, Thesiastes, Rhexius, Rhexidius, Brachygluta, Scalenarthrus, Reichenbachia, Decarthron, et cetera. Such forms usually have well-developed compound eyes. Others, such as Rhinoscepsis, have rudimentary wings and rudimentary eyes. The deep mold forms with rudimentary wings, of course, would not be more appreciably collected during the night than through the day, but the night-flying forms can be collected by lights. Light-traps, then, are also useful in obtaining pselaphids. Such traps may be complex or simple. For example, the standard light suspended in front of a sheet, or a lantern on a square of white cloth, will attract many pselaphids. The yield is dependent upon such factors as the type of habitat, season, and particular weather conditions. Both forests and clearings or meadows will yield these insects. Innumerable species fly to lights at night in the tropics, as descriptions of new species attest (Fletcher, 1928). Light collecting was one of my surest methods in the rain forest of Panama. These mold forms often are quite locally distributed. Thus to our perceptions, of two ecologically equivalent, adjacent logs on the forest floor, one log will consistently yield large numbers of Euplectini, whereas the other log berlesed the same length of time may be barren of species. No general statement can be made as yet concerning such local distribution. It may be coincidence; it may be some 
more subtle but not necessarily more mysterious influence such as aggregation; it may be undiscernible changes in rate or character of chemical decay; some shift in food or water conditions. In such a welter of possibilities, the best approach is calm resignation in the face of barren collecting, and an inquiring state of mind.

Other, more isolated methods of taking free-living pselaphids are by sweeping with a net the meadow grasses, especially bluegrass, inspecting the under side of flat stones and sorting sphagnum moss.

II. The Myrmecocoles. Since many pselaphids are myrmecocolous, ant nests are desirable hunting grounds. No collection of Pselaphidae may be considered complete without full representation of these often highly specialized and always interesting species. Examination of the ant nest requires skill and patience, chiefly the latter.

Although every log or stump may be potentially rich in mold species, few of the many ant nests examined will yield pselaphid inquilines. This is not because these beetles are rare, but rather because they are not so numerous as their prolific hosts. Persistent search will gradually reward one by the accumulation of species to be taken nowhere else, e.g. all of the Clavigerinae (Adranes, Fustiger), Ceophyllus, many species of Batrisodes, Cedius, Cercocerus, et cetera.

The literature dealing with specific collecting records, hosts, and pertinent ecology of these forms is taken up in detail under each species (vide infra), but certain general suggestions can be made here. Some pselaphids are restricted apparently to a single host ant, or to a group of closely related hosts; but since others occur with a wide variety of unrelated hosts, all ant nests should be examined. In general, the more restricted the beetle to a single host or group of hosts, the more specific its requirements and accordingly the more specialized its structural details; some species are found over a wide variety of host ants, and may even lead a free-living existence in mold as well. These are less specialized usually than their restricted cousins, and such a situation bears upon their structure, taxonomy, and ecology, as will be indicated later.

The first general survey of ant and termite guests was that of the indefatigable Wasmann, who described countless new forms, chiefly among Staphylinidae, Paussidae, and the clavigerine Pselaphidae. He was no less interested in the ecology of these guests, and gave to the biology of his day the most complete picture of host-guest interrelations, although he was less admirable in certain of his theoretical interpretations. Wasmann's contributions may be best gleaned from his publications of $1890,1891,1892,1895,1896,1897 \mathrm{a}, \mathrm{b}$, $1904 \mathrm{a}, \mathrm{b}, 1906,1911$, and 1913 of the bibliography. Wasmann (1894) lists over twelve hundred inquilines of ants and termites, and his contribution is further treated by Wheeler $(1923,1928)$. The origin of myrmecophily is discussed by Wasmann (l.c.), Wheeler (l.c.) and Donisthorpe (1909, 1927). Donisthorpe has reviewed (1927) the British ant guests, among which pselaphids are discussed. 
One of the contributions made by Wasmann bears upon the present work. After prolonged study, he suggested a sufficiently elastic classification of guests of social insects. This grouping was essentially ecological, and in the modified form used by Wheeler $(1910,1923)$ may be outlined as follows, with respect to Pselaphidae.

Synechthrans. Guests living within the nest but attacked and killed by the hosts when possible; usually scavengers, or active predators of the host workers, their brood or their food stores and other guests. Such forms are especially numerous in examples among the Staphylinidae, but no bona fide synechthran is known to me within the Pselaphidae. Synechthrans, by the very nature of their role, are strong active species as a rule and are least specialized for life within the nest biocoenose, of the guests.

Synoeketes. Guests living within the society without being actively persecuted by the host; usually indifferently tolerated. Such forms are slower moving as a rule and more specialized for the social group than are the synechthrans. Wheeler subdivided this second type into six categories: (1) Neutral Synoeketes "insects which pay no attention to the ants or their brood, but live on the refuse or nest materials and spend their time seeking these on the walls of the galleries and chambers." (2) Mimetic Synoeketes in which the species show, to the human perceptions at least, structural or ecological characteristics which are quite similar to the hosts. (3) Loricate Synoeketes in which the body is flattened, rounded, and tapered. Usually the species are relatively inconspicuous. (4) Symphiloid Synoeketes in which the species becomes more intimately adjusted to the host, approaching the true guests. (5) Myrmecocleptics, a category formed for the Lepismid, Atelura formicaria, by Janet (1896). This insect is of the loricate body form, but steals up to two regurgitating ants and partakes of the liquid food passing between them. (6) Strigilators, a term proposed by Wheeler (1910) for a group of diverse insects which "lick the surfaces of ants and seem to feed very largely, if not exclusively, on the cutaneous secretions and the thin coating of saliva with which the ants cover one another."

The Pselaphidae number representatives in this second division of guests. Tmesiphorus costalis may be said to be a facultative mimetic synoekete (Park, 1933), and Batrisodes globosus also falls in this type (Park, 1935b). Both species can and do live in mold and under loose bark or stones on the floor, but both are found with ants and are known to feed upon the host brood. They are not persecuted by their hosts, nor are they cared for in any obvious way. The species of Rybaxis, and possibly Ceophyllus and Cedius may also be synoeketes in the strict sense of the word.

Symphiles. These are true guests of the social insects, and are found among the Staphylinidae, Paussidae and Clavigerinae. As has been stated by Wheeler, these are the élite of the guests. All of the clavigerids are symphiles and agree in having certain "symphilic characters and behaviorisms" as far as known, e.g., (1) the peculiar, oily integument, usually yellowish to reddish brown in color, strikingly similar to their hosts; (2) the well-developed, oily, 
golden trichomes or specialized tufts of setae developed frequently on the elytra and abdomen. These trichomes are characteristic of the symphiles, in particular of the clavigerines, and the trichome secretion is highly stimulating to the ant host, the workers of the latter licking and sucking these hair tufts assiduously. (3) The inconspicuous, modified mouth-parts, clothed with golden pubescence fitted for scraping, licking, and sucking. (4) The inordinately modified antennae. (5) The deliberate, rather clock-like precision of their unhurried walk within the hurry of the nest. (6) The habit of twirling the antennae when approached by a host worker. The ecology of the European Claviger has been discussed rather fully by Donisthorpe (1927), Hetschko (1896), Krueger (1910), Mueller (1818) and Wasmann (l.c.), and our own Adranes has been investigated (Park, 1932) sufficiently to state that these clavigerids are cared for by the host, e.g. fed regurgitated liquid food, licked, and even transported back and forth in the nest.

These guest pselaphids have been the subject, then, of considerable research; yet one may confidently state that only a minute part of this fascinating field of comparative ecology has been explored. This is particularly true of the many pselaphid synoeketes and the Clavigerinae. The careful study of the many tropical species will richly repay the patience and ingenuity necessary in this field. Even the tabulation of a complete check-list of American guest insects is lacking. The North American guests of ants, e.g. the myrmecophiles (myrmecocoles in part) were listed by Hamilton (1888) and much more completely by Schwarz (1890). Since then notable contributions have been made by Wickham, one of the best students of our pselaphid fauna $(1892,1896,1898,1900)$, and recently additional records have been given (Park, 1935a).

The collection of this second group of pselaphids, the guest species, requires a great deal of time, since close examination is essential. Once the nest is located, it must be examined with care and piece-meal. Rough handling and breaking of many galleries will allow most if not all of the contained beetles to escape. The latter may be found anywhere in the nest. In general, the synoeketes such as Batrisodes may be more frequent in the superficial galleries, but the symphiles (Adranes, Fustiger) and other synoeketes (Ceophyllus) tend to haunt the brood chambers and must be sought for in the depths of the nest. When the nest is first opened, the beetles are seldom discovered immediately unless their infestation is very high. Rather they tend to crouch against the walls of the galleries, or crawl slowly into intact areas. This is in marked contrast to the hurry and bustle of the host workers. After the latter have adjusted to the emergency and begin the orderly carrying away of their aphids, brood, and food, and begin their normal routine of reconstruction, the pselaphids should be sought for as smaller, much slower-moving forms; their precise, peculiar method of walking will serve to distinguish them. Smoke blown into the mouth of a gallery often drives the inmates forth. If after an hour at a good-sized nest no pselaphids are apprehended, another 
nest should be opened, or the original one placed in a bag and reserved for more detailed study.

One point should be emphasized. When the guest pselaphids are collected, they should be accompanied by a goodly series of the host, and the guests and host should be kept together with a note number so that later the observations recorded in the field can be allocated to the proper specimens. The host should be mounted on the same pin as the beetle. Without this precaution the collection cannot be said to be really complete.

Ant nests on hillsides, meadows, marginal nests in forest clearings, beneath road-side debris, about the borders of ponds and in rich forests will yield interesting pselaphid guests. Nests beneath stones seem to be especially good, as are also the large nests of Lasius aphidicola, flavus, and related forms. The workers of the latter ants are honey yellow in color, numerous, tend aphids and coccids and usually nest in rotting logs and the soil beneath decaying logs and stumps. Their nests often have a characteristic, pleasingly aromatic odor. In these nests Ceophyllus and Adranes are most frequently found.

The log-nesting Aphaenogaster tennesseensis harbors many species of pselaphids (Batrisodes, Tmesiphorus, Cercocerus, Cedius) but the beetles are not easy to obtain, since the host often tunnels in firm wood. The related Aphaenogaster fulva, often nesting in more rotten logs, although the occasional host of Tmesiphorus, is not generally productive of pselaphids.

The clearing ants, building around and in upland forest clearings, e.g. Formica exsectoides and Formica ulkei, hold many guests in their large cone mounds, among which some species of Batrisodes are to be found.

A great variety of guest pselaphids are found, at infrequent intervals, in the nests of the ubiquitous Lasius niger americanus, e.g. Batrisodes, Ceophyllus, Adranes. Details of host-guest relations, where available, are set down with the taxonomic descriptions which follow, and the reader is also referred to the list of hosts and their guests in the cases of certain genera.

Although pselaphids may be collected in cyanide bottles or other standard killing jars, such jars usually allow these tiny insects to become dirty, or even lost, and it is difficult to keep ant host and guest together. I have found numbered vials of 95 per cent ethyl alcohol to be the best collecting medium. The pselaphids should not be picked up with forceps; a suction bottle is good, but a small camel-hair paint brush is superior. Once the pselaphid is discovered, it is the work of a few seconds to moisten the tip of the brush in the alcohol and dab up the specimen. In this way specimens are kept segregated ecologically, clean and unbroken.

Pselaphid collecting equipment then is simple, e.g. a small brush, alcohol vials with note number, several stout sacks for carrying home mold samples or ant nest, a small sharp hatchet and a notebook. A good hand lens of ten diameters' magnification, or better, a watch-maker's eye-glass or a Berger Loop head-glass are helpful for the examination of small pieces of the habitat. This latter is often facilitated by a small electric torch, especially in deep forests or for collecting at dusk. 


\section{Preparation of Pselaphidae for Study}

Once the catch has been returned to the laboratory it should be taken care of promptly. Pselaphids brought in for study, either taken at random, or with ants, must be placed in larger, more suitable containers. They may be placed in one of the many excellent artificial nests described by Wheeler (1910) and their fascinating behavior observed and experimented upon.

For isolated species, or for the particular study of their more intimate relations and requirements with mold or nest co-inhabitants, small petri-dish nests are satisfactory (Park, 1929, 1932a, 1933b). Such nests can be examined under the dissecting binocular with ease, and at length. Far too little is known concerning the life of our small mold insects, and it is a commentary upon our use of the methods available, and our intellectual curiosity, that so much priceless material is killed and identified-often without data of any kindbefore an effort is made to obtain information about the living animal. A properly mounted dead specimen can yield up its taxonomic or morphologic secrets for a span of years, but the chance to gain knowledge of its equally important physiology and ecology has passed for ever.

Entire colonies of ants, or whole sections of logs, can be kept indefinitely in the laboratory if the requisite moisture, temperature, and food are provided.

Since 1818 the problem has been challenged, but practically no data have been collected upon the embryology and post-embryonic stages of Pselaphidae; in fact Mueller in this year discovered more than many recent workers. The larval stages of the Clavigerinae are virtually unknown to science, and but few Pselaphinae have had their larvae discovered (Batrisodes monstrosus LeConte and Euplectus confluens LeConte) and properly keyed and figured (Böving and Craighead, 1931), and this much accomplished in a family of over four thousand species! The food of the pselaphids, their feeding behavior, drinking behavior, breeding behavior, enemies, the place they occupy in the Darwinian web-of-life, their genetics, their period of activity, the critical environmental influences in their lives-these questions and many more are almost if not quite untouched. This, of course, holds for the majority of our species of animals, and must be faced in the light of our rapidly vanishing natural areas in many parts of the world.

So much, then, for the opportunities afforded by the study of living material. For the study of dead material three general methods are to be used: (1) abundant material should be kept preserved in alcohol for study en masse, (2) the bulk of the specimens should be mounted dry upon card points, and (3) for examination of the minutiae of external and internal organization, e.g. sclerites, setae, genitalia, and endoskeleton, microscopic slide-mounts must be made. 
When mounted dry, pselaphids fall into two groups. First, all "large" species (1.5 to $4 \mathrm{~mm}$. in length) should be mounted upon a stiff card triangle of which the point is bent sharply for about a half millimeter (cf. Ross, 1934, for general details). For the small species $(1.5$ to $0.6 \mathrm{~mm}$.) the bent point of the triangle is too broad. Such species should be mounted upon the point of an unbent triangle or upon a bristle; in this case the specimen should not be pushed into the mounting cement but allowed merely to adhere to the outer convexity of the drop of cement.

Such triangle mounting is best done under the dissecting binocular to insure clean work. When mounted, the left side, both ends, and the dorsal and ventral surfaces should be clean of cement and are easily studied with magnifications up to 100 diameters. With experience, the binocular mounting is as rapid as good mounting without the aid of the microscope, and is far more clean and accurate. The mounting can be varied to allow this or that genus to be set in such a way that the essential differential characters can be seen at the greatest advantage, e.g. the ventral face of the tenth antennal segment in one group, the anterior tarsi or mesocoxae in another, and so on.

As to cementing fluid, either a good glue slightly thinned or Canada balsam can be used, and the arrangement of the beetle on the triangle with the cement is best done by specially ground needles. The tools I have found most useful are a small paint brush with the hairs cut away save for a tuft of about three or four bristles remaining; needles made from aluminum wire, sharpened on emery-cloth under the binocular to give one straight needle and one sharply bent needle, each with very slender shafts and as long and fine a point as possible; a micro-dissection knife for genitalia, made by grinding a No. 1 insect pin on both sides near the point until a small, sharp blade is produced.

Length or other dimensions can be best obtained by using a crosslined reticule in an eye-piece of the binocular dissecting microscope; the fine squares of the reticule should have a length and width of between a tenth and a fourteenth of a millimeter. Drawing the entire or a part of the specimen can be greatly facilitated by the use of the reticule. Thus if lightly ruled paper is used, the part to be drawn, whether a wholemount or a microscope slide, can be accurately transferred, square by square, to the paper, from the image covered by the net of lines in the reticule.

In the preparation of microscope slide mounts, which are essential for many taxonomic studies, large pselaphids can be mounted in depression slides or the cover glass held up by bits of glass or rubber; or the pselaphids can be dissected and mounted in sections.

The exact method of mounting on slides depends upon the use for which they are intended. For most taxonomic purposes, the beetles are allowed to remain in 95 per cent ethyl alcohol for twenty-four hours, cleared in cedarwood oil for twenty-four hours, and then mounted in Canada balsam. Such slides can be examined with ease at 400 diameters magnification, and both dorsal and ventral surfaces are at one's disposal by turning the slide over. In order to do this the slides should be very thin, else the higher magnifications 
will not allow a focus of the reverse side of the slide; a wooden slide carrier can be used to advantage which will hold the inverted slide in place without danger to the cover slip.

When Euplectini are mounted in this manner, one is amazed at the detail which has escaped observation of specimens on card points; the pores, pubescence, foveae, sutures, and sensory areas take on a new significance. However, the aspect and detail of depressions, grooves, or sulci are not well shown in slide mounts, unless carefully stained while in the alcohol, and point mounts are best for these and similar structural items. Therefore a combination of alcoholics, triangle mounts, and slides is really necessary for complete estimation of a specimen.

Mouth-parts, antennal structure, eye facets, tarsi, and detail of genitalia of the larger species are also best studied under slides; I have become convinced that future taxonomy will come to depend on slide mounts for taxonomic details between closely related forms, and to this end the micro-coleoptera lend themselves admirably.

Dark species can be bleached by hydrogen peroxide or Chlorox, and then washed thoroughly in distilled water, dehydrated, and cleared as for the nonbleached material.

Where the end is the study of the comparative external morphology of the pselaphids I have found it convenient first to rid the specimens of internal tissue and the following technique has proved satisfactory: either old and dry specimens or fresh material are placed in a cold potassium or sodium hydroxide solution of between 15 per cent and 30 per cent for twenty-four hours. The action can be hastened by placing them in 10 per cent hydroxide solution and boiling for ten minutes. After this the specimens must be washed thoroughly and then can be passed into 95 per cent alcohol directly, or the integument can be stained with eosin, methyl orange, or acid fuchsin. After dehydration the technique is the same as for regular slide mounts. These potashed specimens can be still further cleared by passing them through the bleaching fluids mentioned above. Such mounts show the endoskeleton with great clarity, and are invaluable for study of minute details under oil immersion at 1000 diameters or more.

Genitalia. Specimens brought from the field in alcohol should always be examined for extruded genitalia, especially the males. ${ }^{1}$ Such material may be treated differently, since the structure of the genitalia is hardly known in Pselaphidae and comparative studies of these structures will undoubtedly be valuable for a future, broader view of the taxonomy of the family as a whole.

The extruded genitalia of the male should first be studied in situ to show the relation of the pygidium to penis, orientation of the latter with respect to dorsal, ventral, lateral surfaces, and whether the species belongs to the type in which the pygidium hinges on one side, or whether to the group having the pygidium of two pieces, a right and a left pygidial plate (in the latter case

${ }^{1}$ Or living material may be killed with carbon tetrachloride, followed by ether, as suggested by Valentine (1934), or by ether alone, to initiate extrusion of aedeagus. 
these two plates meet in a so-called pygidial carina), to allow the extrusion of the copulatory apparatus.

After such preliminary study, the genitalia should be excised and run up as slide mounts, where the observations on fresh material can be checked under high magnification. Once on the slide, the type of penis should be discerned, e.g. whether it is bilaterally symmetrical (some Reichenbachia, Batrisodes, Cylindrarctus, Tmesiphorus, etc.) or asymmetrical (some Batrisodes, Pilopius, Dalmosella, etc.).

Where the genitalia are not so extruded, they can be dissected out, working with the dissecting binocular and keeping the specimen under alcohol. Skill acquired through practice in the handling of the small needles and knife is necessary here; after the genital apparatus is cut out it can be cleared and made into a slide mount. Since the appartus is minute, the genitalia are easily lost in the transfer to the slide; this can be overcome by using the brush, the point of which has been dipped into balsam. The brush can then be touched to the genitalia and lifted rapidly into the balsam on the slide. 


\section{Taxonomic and Morphological Considerations}

Not many investigators have devoted their time wholly or in large part to the Pselaphidae. However, this family has had the advantage of treatment by a master's touch in the virtually unique work of Achille Raffray. His first general survey of the pselaphids was his world catalogue (1903-1904). This was followed by his exhaustive treatment of the genera of the world (1908) and finally by a complete catalogue of the species (1911). The majority of the now known species of Pselaphidae were described by Raffray in a long series of papers; the outlines of present classification of the family, its comparative anatomy and most of our information on the zoögeography of the group bear the imprint of his discerning mind.

This is not to say that others have not contributed brilliantly to a knowledge of the family. Following the beginnings by Paykull (1789) and the recognition of the pselaphids as a family by Herbst (1792) which resulted in the description of three species, Tychus niger (Paykull), Pselaphus heisei Herbst, and Pselaphus dresdensis Herbst, information slowly accumulated until 1816, when Reichenbach monographed the family for the first time. This was followed by a treatment of the group by Denny (1825) and by Aube (1833-34). It was not until Reitter's new classification in 1881 that the number of sternites was employed in the taxonomy of Pselaphidae, and the groups within the family partially delimited. In 1890 Raffray proposed the modern system based upon the form and insertion of the mesothoracic coxae, trochanters, and femora. Raffray was followed by Ganglbauer (1895) in his penetrating work, Käfer von Mitteleuropa, and Raffray extended the system (1908) to embrace the world fauna.

The Pselaphidae of North America, particularly those to be found within the political boundaries of the United States, received monographic treatment by John L. LeConte (1850) and little more was accomplished until the monograph by Brendel and Wickham (1888-1890). Both of these studies were well done for their particular era and served to set the stage for the taxonomic genius of Thomas L. Casey.

Casey $(1884,1886,1887,1893,1897,1908)$ described many new North American species and in his full descriptions added much to our general information of the anatomy of the family and its taxonomic possibilities. It is a pity that Casey could not have monographed the North American species at a time when he could have assayed and properly integrated the increase in information since Brendel and Wickham's paper. The failure to do this left our knowledge of Pselaphidae in this country highly unorganized. This was demonstrated by the use of the early Brendel and Wickham treatise as the basis for Pselaphidae in Blatchley's classic Coleoptera of Indiana (1910), 
and also by the necessity of using Raffray's keys to the world fauna in a compilation of genera of pselaphids by Bradley (1930). Both Blatchley and Bradley used the scattered work of Casey where feasible.

Monographically speaking, then, the pselaphids had not been coordinated between 1890 and 1934, when John R. Bowman gathered the scattered literature of the family, and drew up keys from descriptions of species.

Henshaw (1885) numbers 136 species and varieties of pselaphids, divided among 29 genera. Leng (1920) in his admirable Catalogue numbers 364 species and varieties, divided among 63 genera. This was an increase of 167 percent species and 117 percent genera between 1885 and 1920. Taking the 1920 figures of Leng, we find that LeConte described 81 species and 12 genera, Brendel 63 species and 8 genera, and Casey 181 species and 22 genera. Thus these three students described 325 out of 364 species, and 42 out of 63 genera. Since virtually all of the LeConte and Brendel species and genera were listed by Henshaw, we note that the total increase to 1920 was largely a consequence of Casey's taxonomic activity.

In addition our knowledge of North American Pselaphidae has been materially added to since 1900 by shorter contributions, among which may be mentioned the revision of Adranes by Wickham (1901) ; addition of the tribe Holozodini by Schaeffer (1906) to the pselaphid fauna of the United States in the description of the new species Caccoplectus spinipes; the revision of Rybaxis by Fall (1927) and of Rhexidius by Fletcher (1932). In this latter paper, Fletcher described Hamotus (Hamotoides) opimus from Florida. This was the first time that a member of this large, typically neotropical aggregate had been definitely recorded north of Mexico.

That portion of the Americas in which this study is especially concerned, from the Rio Grande southward through Argentina, has received no monographic treatment, nor can any be contemplated for many years. Much of the region is occupied by the neotropics, and the pselaphid fauna of the equatorial rain forest and tropical savanna remains largely unknown. The most ambitious effort was that of David Sharp (1887) in the Biologia, covering the area from the northern boundary of Mexico to Panama. Unfortunately the lack of keys, the short and vague descriptions, and the generalized figures render this study less valuable. Of much more practical worth are the short generic studies and description of new species by Raffray $(1891,1896,1897$, $1903,1904,1909,1911,1917)$ and the modern work of Bruch, Reichensperger, and Fletcher (1927, 1928, 1928a, 1930).

The extent to which the pselaphid fauna of the neotropics remains unknown may be partially realized by considering the amount of new material discovered in several expeditions. In the Biologia, Sharp (1887) listed 98 species, of which 70 were new. In an expedition to Venezuela, Simon found 39 species, of which 33 were new (Raffray, 1891). The Cornell University expedition to South America returned with 11 species of Pselaphidae. Of these two could not be identified beyond the genus, and of the nine which could be identified, seven were new (Fletcher, 1928). In a study of Barro Colorado 
Island, Gatun Lake, in the Panama Canal Zone, to be discussed at length in this report, this artificially isolated mountain peak of only a few square miles yielded 44 species on three expeditions, and of this number 40 were new. From these few instances it will be seen that the pselaphids of the American tropics are incompletely known.

There is no single, qualitative eriterion the application of which will separate all pselaphids from all staphylinids. Such a condition is the rule in studies on classification and is to be expected if we consider the species as by-products of the evolutionary process.

It is apparent that Pselaphidae are highly evolved staphylinoid beetles in which certain structural parts have attained a peculiar degree of specialization, presumably through a differential selection by the environment of genetic combinations over a long period of time. Genetically, nothing is known of the stability or lability of pselaphid structure and function. Therefore we may not check the validity of a pselaphid species by experimental breeding, nor map out the probable lines of taxonomic development with the degree of assurance done for the Drosophilidae (cf. Dobzhansky, 1937) or the Cynipidae (Kinsey, 1936). Classification of Pselaphidae, then, must depend upon comparative anatomy (without the aid of comparative embryology) and the ecological science of zoögeography.

The pselaphids are wholly brachyelytrous, the mesothoracic wings or elytra being short and exposing part of the abdomen. This condition is shared by other families, for example the Staphylinidae, part of Ptiliidae, et cetera.

Their size range is intermediate between staphylinids and ptiliids. The largest pselaphid known to me is the Brazilian Hamotus (Hamotoides) ecitophilus Raffray. This giant measures 5.5 millimeters in length and lives in the society of Eciton army ants. A number of species are small, measuring 0.5 to 0.7 millimeter. The average length for the family is about 1.5 millimeters.

Pselaphidae have a more compact body plan than Staphylinidae. This is one of the best criteria for separating the two families. In pselaphids the head capsule is more solid, and the gular sutures, so well shown in Paederinae, are absent or reduced. Secondly, this consolidation is shown in the prothorax, where the lateral sclerites are generally shorter and of a more rigid construction than in Staphylinidae. Staphylinids generally have six visible sternites (morphologically segments III to VIII). According to Leng (1920) some variation occurs, for example five segments (Micropeplus, Oligota), six segments (Euaesthetus), seven segments (Oxytelini, Aleocharini) and eight segments visible and movable (Omalium). Blackwelder (1936) gives the total number of abdominal segments in Staphylinidae as ten, of which the first is represented by tergite; second by tergite usually and sternite in some species; third, fourth, fifth, sixth, seventh and eight with normal tergite and sternite; ninth and tenth segments variously modified and often considered with the genitalia. 
In Pselaphidae the great majority of species have the abdomen with from five to six visible tergites and sternites. Exceptions occur, but these are a consequence of the general consolidation of the body-a family trait. Thus, Cyathigerini have two visible tergites and sternites; Clavigerinae have a dorsum of three fused tergites, but five to six visible sternites. In other groups the number of sternites varies with sex. In such forms, unevenly distributed through many tribes, the males have a ventro-terminal piece, the penial plate or pygidium. This appears to be a part of the seventh visible sternite. It may be excessively minute or very large and conspicuous. The penial plate may be a single plate (Actium, Bibloplectus, Cedius, Cylindraratus, Dalmosella, Melba, Ramecia, Thesiastes, Thesium, Trimioplectus, Tyrogatunus, Tyrus), varying in shape from narrow-transverse, through quadrate, circular, oval, semi-circular, to narrow-oblong. The penial plate may be divided into two parts, a right and a left piece (Rhinoscepsis, Euplectus). In dried specimens the males of these latter show the two plates as closely appressed, the line of contact being then spoken of as the longitudinal penial or pygidial carina. In Euplectus, the genus can be conveniently divided into two aggregates of subgenera, depending upon whether this carina is convex to the left or to the right. Again, in Sonoma tolulae the males have a seventh sternite, which is divided into three pieces, a right, a left, and a median plate.

The male genitalia and associated penial plate (Plates I, II, III) never have been studied or applied to the classification of the family. This is strange since the male copulatory organ (aedeagus or penis) is large, sclerotized, and easily dissected in fresh or relaxed material. I have found the aedeagus to offer qualitative characters in the separation of closely allied species, and to give at least another criterion for the determination of generic limits as well as the evolution of the family. Protected as it is from frequent contact with the environment (in distinction to mouth-parts and tarsi which are in nealy continual contact), and requiring close adjustment to the female genital tube for successful continuance of the species, the male genital tube offers valuable taxonomic characters.

The pselaphid aedeagus is a further specialization of the staphylinoid plan. It seems to be derivable from the Oxytelinae. Typically, the pselaphid aedeagus consists of a large, heavily sclerotized median lobe. The basal (morphological anterior) part of the median lobe swells into a basal bulb. The dorsal surface of the median lobe quite generally bears two membranous diaphragms, the basal diaphragm is larger, usually oval, and occupies the basal half to two-thirds; the apical diaphragm is smaller, oval to triangular, and occupies the apical part of the median lobe. The free apical end (morphological posterior) of the median lobe is generally narrowed into a sharp-pointed lamina of diverse length and shape. Lateral lobes are present less frequently and are regarded as primitive. These latter are usually small or membranous and may be moved latero-mesiad by bilaterally symmetrical bulbar muscles of the basal bulb, or these muscles may be chiefly concerned in exserting and rotating the relatively large aedeagus from the male genital orifice. Occasionally the median lobe 
gives rise to what I have termed a ventral lobe. The ventral lobe may or may not bear the lateral lobes, and its presence is regarded as a specialized condition. The smaller apical diaphragm noted above is usually associated with the median orifice. In a few cases the median lobe gives off a movable accessory piece. This is a single, asymmetrically placed part and appears to be moved by asymmetrically inserted bulbar muscles. These are the chief parts of the pselaphid aedeagus to be observed at normal binocular magnification of prepared specimens on points. ${ }^{1}$ Slide-mounts bring out a wealth of detail on internal structure.

The median lobe is invariably present; all other parts noted above may be absent or variously modified, as is brought out by a study of the illustrations. Although the aedeagus gives evidence for (a) structural modification at different rates within the same tribe, (b) convergence or parallelism between genera of different tribes, and (c) divergence between species within the same genus, there are two definite trends of specialization to be observed in its comparative anatomy. These are (1) simplification through loss of parts, and (2) progressive asymmetry.

The primitive pselaphid aedeagus has perfect bilateral symmetry, a welldeveloped median lobe in which the diaphragms are invisible from above, a right and left lateral lobe present as sclerotized parts, and no ventral lobe or accessory piece.

The specialized pselaphid aedeagus has the median lobe bilaterally asymmetrical, diaphragms well-formed and visible from above, lateral lobes absent, ventral lobe present or absent, accessory piece present or absent.

Associated with these trends is the penial plate. Since it is considered here as a remnant of the seventh visible sternite, and since we have shown that the Pselaphidae tend towards a consolidated staphylinoid body plan, its presence is primitive, and its absence specialized. Thus it is present as a twicedivided plate (Sonoma tolulae); divided plate (Euplectus); a single plate which must be asymmetrically moved during extrusion of the aedeagus, either to the right (dextral penial plate) or to the left (sinistral penial plate) many genera previously noted belong here, and are either dextral or sinestral while at least one genus (Cedius) has both dextral and sinestral species-and finally this plate drops out in numerous genera.

The aedeagus of Reichenbachia is primitive among Brachyglutini, and is very similar to the Oxytelinae; Pilopius among Ctenistini, and Cylindrarctus among Tychini, are primitive. These three genera have lateral lobes but each presents certain specializations, thus Reichenbachia has a poorly developed basal diaphragm, Pilopius has a slight apical asymmetry, and Cylindrarctus a ventral lobe. The Batrisini are highly specialized, and the dorsal surface of the Pilopius aedeagus is strangely batrisine. Within the large genus Batrisodes a reliable key can be made to species, based on the aedeagus. In the first place,

${ }^{1}$ It will be remembered that when a specimen with exserted aedeagus is examined under the binoculars, it is ventral surface uppermost and therefore the aedeagus, which is exserted, lies with its apical end directed anteriorly and its dorsal surface uppermost. 
no Batrisodes has a primitive aedeagus. This is a genus where reduction of parts is strikingly developed.

Overlaid upon this superficial simplicity is a developing asymmetry. Thus Batrisodes furcatus and riparius are bilaterally symmetrical while globosus, denticollis and schaumi are progressively asymmetrical. The species of this genus studied so far culminate in the aberrant monstrosus. In this latter species the asymmetry is extreme and an accessory piece is developed. The aedeagus of monstrosus is so far removed that it should serve to divide the genus into two subgenera.

The Tyrini appear to have a very specialized penis, with some features common to Batrisini and Ctenistini but little affinity with Brachyglutini and Tychini. Among tyrines studies, Ceophyllus and Tmesiphorus are relatively primitive, with reduced but symmetrical aedeagus; Tyrus is more specialized in its pronounced asymmetry, but the presence of the penial plate is a primitive feature; the system appears to culminate, thus far, in Cedius. In this latter genus there is an extreme asymmetry which is directly correlated with the penial plate. Thus in Cedius ziegleri the asymmetry is to the left and there is a sinistral penial plate; in spinosus the asymmetry is to the right and there is a dextral penial plate.

The Clavigerinae (Fustiger veracruzensis) have an aedeagus which presents no novelties from the tyrine type, being apparently homologous with the bilaterally symmetrical organ of Ceophyllus. This is further important evidence in support of not more than subfamily rank for these symphilic pselaphids.

Contrary to most systems of classification, the Euplectini and Trichonychini are highly specialized as regards the aedeagus. The two genera studied (Rhexidius and Dalmosella) have highly complex, asymmetrical male genitalia -much less oxyteline than the brachyglutine aedeagus. Enough has been said here, in this preliminary study, to demonstrate the importance of male genitalia in the taxonomy of the family. A complete evaluation must await the study of more genera.

The pselaphid abdomen apparently consists of ten segments, which agrees with the opinion of Blackwelder for staphylinids, and of Tanner (1927) for beetles in general. The first and second tergites are either wholly membranous, or slightly sclerotized and more or less folded. The third tergite is usually sclerotized. The first three tergites are generally not visible in dried specimens, being retracted and hidden beneath the elytra in the living condition and remaining so nidden unless potashed preparations are made. The fourth, fifth, sixth, seventh, and eighth are visible and are coinmonly termed the first to the fifth dorsal segments; the third tergite may be visible, in which case sir dorsal abdominal segments can be counted.

The first sternite is apparently absent as a general rule; the second sternite is present as a membranous area aruculating the metasternum to the third sternite, and continuous with the membranous second tergite. The third sternite may or may not be visible; if visible it is sclerotized and may be wholly visible, or visible as a variously modified area between the posterior coxae. 
The fourth, fifth, sixth, seventh, and eighth sternites are usually visible, and are commonly termed the ventral abdominal segments. The ninth and tenth segments are involved in the genitalia.

Therefore the pselaphid abdomen shows evidence for ten segments, but the strongly sclerotized, normally visible segments are five to six dorsals and ventrals, plus the pygidial plate in some males and some females. In the descriptions of species (vide infra) these visible segments are counted from the base of the abdomen apically, and their exact tergite and sternite origin is not counted, unless specifically mentioned. Thus the "first abdominal segment" refers to the first visible segment, the "second ventral segment" refers to the second ventrally visible segment, et cetera.

A physiological character, that of movability of the abdominal segments, has been made the most of in separating the two families. This can be utilized, however, with living material or relaxed specimens, and is relative. Thus within the Staphylinidae some groups (Staphylininae, Aleocharinae, Paederinae) have a highly mobile abdomen, and may carry the apex elevated or move it dorsoventrally in the typical staphylinid gesture; in Steninae this is not so greatly developed as a rule; in the Trilobitideini, a tribe of staphylinids created by Fauvel to hold the species Trilobitideus mirabilis, the abdominal segments are said to be (Raffray, 1908) solidly immovable in appearance, although more or less mobile in the living state. In the Pselaphidae the movability of the abdomen is generally much less, and is antero-posterior in nature (retractile) rather than freely movable in the dorso-ventral plane; however, this is also relative. Thus the Clavigerinae have practicaly no abdominal movement; the Tyrini and Batrisini are more intermediate in this respect; certain Euplectini (the New Zealand Eleusomatus) have an abnormal abdomen for pselaphids, constructed in general on the staphylinid plan: the abdomen is gradually and strongly tapered posteriorly. In Eleusomatus the males have six sternites and the females only five visible. The abdomen in this, and other euplectine genera, as well as Sonoma among Faronini, may be as movable as that of some of the staphylinids.

When everything is considered, however, this mobility of the abdomen and the structural differences which make it possible or impossible, is one of the most important criteria for separating the two families under discussion.

The Pselaphidae have the labial palpi either two-segmented (Pselaphinae) or one-segmented (Clavigerinae). The Staphylinidae generally have threesegmented labial palpi.

The Pselaphidae nearly always have the distal segment of the maxillary palpi provided with an apical or subapical palpal cone; this structure is generally lacking in Staphylinidae. In general it may be said that Staphylinidae have remarkably conservative maxillary palpi, usually four-segmented and filiform although exceptions are known. On the other hand, Pselaphidae have the most variable maxillary palpi known to the author, in fact the name of the genus Pselaphus is derived from the Greek ("I feel my way") and refers to these remarkable organs. The pselaphid palpus is usually four-segmented, 
although it may have three segments in some Goniacerini, Attapseniini; it is apparently one-segmented in Arhytodini and Clavigerinae. In some pselaphids (Euphalepsus) the palpus, although fully formed, is very petite (Park, 1933) and nearly every segment may be grotesquely modified, often forming the most reliable separation of genera (the reader is especially urged to examine the palpi of neotropical Tyrini in this respect, the phylogenetic derivation of which has been attempted on pp. 340-342). The neotropical Ctenistini have four-segmented palpi, but some ctenistine genera (Biotus, Atinus) have twosegmented palpi, while Chennium and Chenniopsis have three-segmented palpi. The nature and extent of palpal modification will become apparent in the following pages and needs no further elaboration here.

In regard to number of tarsal segments the Staphylinidae is more variable than the Pselaphidae. Staphylinidae may have a tarsus of three segments (Micropeplus, Dinopsis, Oxytelini), four segments (Oligota, Euasthetinae), anterior and intermediate with four and posterior tarsi with five (Bolitocharini), anterior with four, intermediate and posterior with five (Myrmedoniini), five segments (Aleocharini, Paederinae, Steninae). The Pselaphidae have threesegmented tarsi, with the exception of the Dimerini which has two-segmented tarsi. The Dimerini, however, holds but a single species, Dimerus staphylinoides Fiori of Italy.

The pselaphid tarsus is generally primitive, the chief variation being in the relative size of the three tarsomeres. Two tribes have very specialized tarsi: the third tarsomere is bilobed in the Schistodactylini and the second tarsomere is bilobed in the Arhytodini. There is some sexual differentiation in the tarsus. Thus the males of certain brachyglutines (Braxyda, Bryaxina, $X y b a r i s$, Achillia) have the second anterior tarsomere laterally dilated, dorsoventrally flattened, and bearing a pad of setae on the ventral surface. Xybarida nasicola has the second tarsomere relatively shorter and thicker on the anterior tarsi than this segment of the other tarsi, and bears on the ventrally flattened face stiff setae in the male sex. The female of this species has the normally slender, unsetose tarsi. On the other hand both sexes of Raxybis have the second tarsomere of the anterior tarsi thicker than the third, and ventrally clothed with long setae. There is considerable variation in the tarsal claws. In general there may be a single claw, two unequally developed claws, or two equally developed claws, and this variation is discussed at length elsewhere.

Thus we may generalize by saying that the number of visible abdominal segments and the number of tarsomeres are relatively variable in staphylinids and conservative in pselaphids; the maxillary palpi are variable in pselaphids and conservative in staphylinids.

Relatively speaking, the antennae are also conservative in staphylinids and notably variable in pselaphids. These appendages vie with the maxillary palpi in extent of modification; they are more variable in pselaphids than in any other family of beetles, with the possible exception of the Paussidae. They range from two to eleven segments, and practically any antennomere can bear sulci, foveae, spines or teeth, peculiar pubescence or specialized appendages. 
This diversity is demonstrated by the plates and in the descriptions which follow, and is not confined to a single subfamily, tribe or genus but extends through the entire family. In many cases special antennal modification is restricted to one sex, usually the male; in many cases both sexes have the antennae modified.

The method of articulation of the pselaphid antenna is notable, and has been previously discussed by Casey, Raffray and other students but has not been sufficiently appreciated by coleopterists as a whole. Pselaphidae have the first antennomere flexed dorsad to articulate on the upper wall of the antennal acetabulum, or where the acetabulum is functionally obsolete (as in the species with contiguous antennae mounted on a median antennal tubercle) then this segment is articulated on the ventral face of the tubercle. Hence the pselaphid antennal articulation is restrictive as contrasted to the articulation of staphylinids. The Staphylinidae show some variation, but quite generally have antennae which do not articulate on the upper wall of the acetabulum and do not have such pronounced antennal tubercles. This may be a prophetic difference, that is, the pselaphid antennal-articulation plan is suggested here and there in the staphylinids-giving yet another hint as to original stock of the pselaphids.

The vertex of the pselaphid head capsule usually bears a pair of vertexal foveae. These foveae are very characteristic of the entire family. They represent invaginations of the integument, and in slide mounts these foveae are seen to have their floors attached to the arms of the V-shaped supratentorium of the endoskeleton, the supratentoria continuing ventrad where the two oblique arms unite ventro-posteriorly to attach to the floor of the median gular fovea. This latter usually is present as an invagination of the integument near the demarcation of the ventral surface of the head proper and the cervicum. Rarely the arms of the supratentorium attach to the ventral surface of the head without forming the gular fovea; at times the single gular fovea bifurcates internally to form two ventrally continuous foveae; in still other cases there are two entirely separate but approximate gular foveae, each attaching to one arm of the supratentorium.

The vertexal foveae are rarely absent (Adranes, Nisaxis), although they may be very minute (Fustiger, Barrojuba, Trimiomelba, Ceophyllus). In some genera these foveae are highly specialized. Thus in Pselaphus they are drawn forward to produce two voluminous subfrontal cavities, the orifices of which are so far anteriad of the supratentorial anchorage that they may be overlooked at first. It is as though in Pselaphus the forward attenuation of the antennal tubercle had pulled the head capsule integument anteriorly between the eyes while, the floor of the foveae being held by the supratentorium, the walls were consequently stretched abnormally. The vertexal foveae as a general rule are normally sized and placed but their walls may be wholly nude or densely pubescent. In some genera (Euplectus, Batrisodes, Hamotus) the foveae may be both nude and pubescent within the same genus, but this is not a common condition. Rarely the foveae are wholly obscured by dense cephalic 
pubescence or squamose areas (Arhytodes). This wealth of detail is made much of in the taxonomy of the family, especially in separating species within a genus.

Staphylinidae do not present this picture, the vertexal foveae being of very rare occurrence (Edaphus).

No comparative treatment would be complete without a discussion of the pubescence. The great range of pselaphid pubescence is suggested by examination of the plates, where a number of setal types are illustrated. These setae vary about a norm, commonly found throughout the family, which may be described as an elongate, aciculate seta which is circular in cross-section. Of great use in pselaphid taxonomy are the extremes developed; the length, thickness, stiffness, amount of taper, apical contour, amount, and degree of inclination are all of value (cf. especially Plate IV).

One of the more striking modifications is the development of trichomes. These are usually thick, tortuous bundles of golden setae which adorn the apical elytral margins and the latero-basal angles of the dorsum and are notably developed in Clavigerinae. Here the trichomes are specifically modified for the conduction of a trichomal secretion which appears to be very stimulating to their formicid hosts. Trichomes are variably developed in the Clavigerinae, and may be absent. What appear to be homologues of clavigerid trichomes, at a lower level of organization, are found in the Attapseniini, also wholly myrmecophilous.

Trichomes occur upon the abdomen of certain symphilic staphylinids (Xenodusa, Lomechusa, Atemeles). Therefore the trichomes may not be considered as a phylogenetic character of use in the separation of clavigerines from pselaphines, since (1) they are not universal in Clavigerinae, (2) they occur on non-clavigerine tribes (Attapseniini), (3) occur in certain symphilic staphylinids. Rather I should regard trichomes as an ecological adjustment to life with social insects.

Tufts of setae, not trichomoid in the symphilic sense but similar in appearance, may be found in other pselaphids, usually the male sex in some Euplectus, Actium, Dalmosella or in the female sex of some Thesium. Such setal tufts usually arise from a tuberculoid area and are usually abdominal.

Some genera are wholly glabrous (Eupsenius); other are nearly glabrous (Eupsenina); others scantily pubescent (Melba, Trimiomelba); many are normally pubescent (Euplectus, Arthmius, Reichenbachia); some are heavily pubescent (many Hamotus, Hamotocellus). In the genus Pselaphus the pubescence is massed upon sterna and ventral face of the head into aggregations of broad, thick, membranous scales more or less agglutinated. This has been described by Casey (1893), and has been aptly described as "sugary" by David Sharp.

Typically squamoid pubescence is found in the Ctenistini. Here the setae are sparse, long, appressed scales. These scales are especially massed in pronotal depressions, elytral apices and base of dorsum. These scales may be very narrow (femora of Pilopius), or conspicuously spade-shaped (elytral apices of 
Pilopius). The normal ctenistine scale is gradually broadened distally, and its integumentary puncture is provided with a tubular extension into the chitin. The Arhytodini and Hybocephalini also have squamous pubescence in part.

The setae may be normally inserted, or may be lodged on small asperities (as on the antennal cones of Tychus), or may be placed upon relatively large tubercles (asperate setae on the distal antennal face of Rybaxis clavata). These antennal cones are present in many of the Pselaphidae examined from various parts of the world, and under oil at high magnification they can be differentiated from the normal antennal setae. When we have more data concerning the antennal cones, they may serve as a taxonomic aid (Park, 1935c), as has been noted for the male genitalia previously. For examination of these cones see the distal antennal segment of Melba, Dalmosella, Euplectus, Bibloplectus, Tychus, Pilopius, Rybaxis and Tmesiphorus among Illinois genera; Central American species examined (Hamotus turalbus) have the antennal cones well developed. In this species the cones are normally transparent and very difficult to see in unstained preparations but appear to be articulated upon rounded asperities; normal antennal setae are usually quite distinct and are smaller than cones and placed in slightly recessed punctures. These cones may be homologous to the distal setiform cone of the last segment of the pselaphid maxillary palpus; at least they appear similarly under magnifications of 1000 diameters, and like the palpal cone, may be sensory in function. It is interesting to note that such cones are also developed upon the antennae of Thysanoptera, Chalcididae, Proctotrupidae, et cetera.

The ventral face of the head may bear knobbed or capitulate setae (Melba, Trimiomelba, Eupsenina) in a definite pattern; in some genera (Thesiastes) these capitulates are few in number, strongly knobbed, and more or less spinoform; in Bibloplectus these setae are truly spinoform processes of the integument. On the other hand the setae on the ventral surface of the head of Rhexidius are very long, very abundant, and only slightly capitulate, e.g. the setal tips are gradual elongate-oval swellings, sometimes absent entirely; in Euplectus, the same area bears sparse, recurved, noncapitate setae.

An extreme in the modification of the setal tip is seen in the maxillary palpi of certain species, for example Pilopius lacustris, where the setae of the distal segment are long, uniformly slender to the apex which flairs into a thin, flat plate at right angles to the shaft. These setae may be termed umbrella-setae. Also the distal palpal segment of Ephimia and Juxtahamotopsis have peculiar setae: short, thick, rigid, blunted, translucent, and appear to be small spikes. In this case we may have a transitional stage from seta to palpal cone.

Almost always one seta arises from a single puncture, but in Adranes the setae of the head, pronotum and elytra appear to be doubled, that is, two divergent setae arising from a single puncture. This is not true, species of Adranes following the general rule, and under high magnification each seta is seen to bifurcate a short distance beyond the puncture, to give two long processes.

The remaining features of this comparative review deal with the sternal areas, the endoskeleton, and the sternal foveae. The Pselaphidae have the pros- 
terum characteristically reduced between the coxae, so that the anterior coxal cavities are large, confluent and opened posteriorly; the anterior coxae are typically large, subconical and either contiguous or narrowly separated.

The mesosternum is characteristically short and wide. Anteriad of the coxal cavities, it presents a highly diverse appearance of great convenience in separating genera; this variation can be appreciated only through concentrated comparative study. As in most beetles, the median portion of the ventral surface of the mesothorax is composed of the unpaired mesosternum, usually wider than long and in a varying degree bounding the coxal cavities posteriorly. It projects in a varying degree between the coxal cavities as the mesosternal process. Laterally the mesosternum is bounded by the episternum. When the mesosternum and episternum are clearly separated, the dividing suture is the sternopleural suture, but there is a varying degree of fusion between the two sclerites, this line of fusion being marked at times by carinae or foveae. Similarly, the epimeron may be present at a distinct sclerite ventrally, or may not be apparent as a discrete element. Anteriorly the mesosternum presents a system of foveae, carinae, ornamented depressions or pubescent areas which make this part of the pselaphid body very different in appearance from the homologous region of the staphylinid. The anteriorly narrowed, "neck-like" portion of the mesosternal area articulates with the prothorax by a folded, extensive membrane; and where this membrane attaches to the mesosternum and mesoepisternum this region of the sternum is elevated generally into a heavily sclerotized collar. This collar may represent the prepectus of staphylinids, and for convenience here is termed the prepectoid area. Since the prepectoid is discussed and figured, no more need be said here save that often it is secondarily depressed or modified to hold the tips of the reposed anterior coxae. The mesothoracic coxal cavities are large, rounded, closed posteriorly by the metasternum, and are wholly confluent, slightly confluent, narrowly separated by the intercoxal lamella, composed of mesosternal and metasternal processes, or finally may be widely separated. The coxae are, therefore, contiguous to separated and moderately distant as in Adranes, for example.

The metasternum is characteristically large. It is often modified by tubercles, spines, teeth, carinae, sulci and foveae. Such elaborations present both specific and sexual differences and are consequently of great use in identification. For example the males of Adranes have the metasternum greatly modified by spines or spinoid tubercles in contrast to the females. This modification reached a peak in Arhytodini where the males may have a pair of tubercles, or a pair of small sharp, hooked spines, or both tubercles and spines in various stages of development and position while the females have a simple metasternal field. On the other hand both males and females of some Neotyrus, Tyrogatunus and other genera have similarly modified metasterna.

Degree of separation of the intermediate coxae is variable, and of importance in tribal separation. Thus Clavigerinae, Pselaphini, Batrisini and Brachyglutini have the coxae usually well separated, but the last mentioned tribe shows several degrees of separation and hence groups of brachyglutine genera 
can be isolated on this character. Tyrini also show considerable variation, but as a tribe come under this first group, while Euplectini have these coxae approximate or contiguous.

The chitinous invaginations of the integument-the endoskeleton-are well formed in pselaphids. We have previously noted the supratentorium of the cephalic capsule, its intimate relationship with the vertexal foveae, and with the gular fovea. The author has been at some pains to check the condition cited, and this study has covered well over a hundred nearctic and neotropical species. Earlier, Stickney (1923) reeorded the supratentorial details for Pilopius lacustris and Fustiger fuchsi.

The endoskeleton of pro-, meso-, and metathorax is less well understood. The prosternum has a one-piece prosternal furoa of the $U$-type which extends internally from the dorsal wall of the coxal cavities, one arm of the furca from each cavity and the two arms broadly joined at their bases. The mesosternal furca is composed of two discrete arms, one extending internally and anteriorly from the dorsal wall of each coxal cavity. The metasternal furca if of the Y-type, with a basal stem invaginating in the center of the posterior metasternal field, and this basal piece bifurcating, with the arms extending dorsad into the thoracic haemolumen and musculature.

Chitinous invaginations of the abdomen, associated with the spiracles, are present in genera investigated, and are notable in certain Euphalepsus. From certain points of view the sclerotized male copulatory apparatus could be considered invaginations, in view of their relation to the ninth and tenth abdominal segments, but this is not involved in the endoskeleton.

Another general morphological subject to be examined here is the foveal system of Pselaphidae. The integument is diversely and richly supplied with small integumental invaginations. Possibly no other single feature is of such use in the identification of genera and species as the foveae--their presence or absence, number, type and distribution. The vertexal and gular foveae have been previously discussed, and are only a few of the many foveae present. The significance of foveae in Pselaphidae has been underestimated, and at least two aspects need emphasis.

In the first place foveae often suggest a general sensory function. The rich pubescence of many foveae lends credence to this hypothesis but careful experiments are necessary before definite ideas can be held on this point.

In the second place, the morphology of foveae is easily studied by slidemount technique and a considerable amount of data are at hand for their evaluation (cf. especially Plate V). The topographic position of many foveae in Pselaphidae tends to indicate that they have arisen where sutures coalesce. Therefore their presence is an indirect argument for the structural consolidation of the body, so well shown in pselaphids, and so conspicuous by its absence in the staphylinids. When a fovea is examined, it is seen to be a thimble-shaped or cylindrical invagination of the hardened integument. Its walls are usually either segmentally creased, or spirally whorled. Usually it is short and conical; in other cases its lumen is long, tubular and sinuate. 
The distribution is diverse. Cervical foveae may occur on the ventral face of the cervicum or neck, where they may mark the posterior area of the gular sclerite (Euplectus interruptus); or on the dorsal face of the cervicum (Melba) where they form a part of the metatentoria of that region.

The prosternum with its ankylosed sidepieces usually presents from one to five foveae, following the general plan of the sutural zones of the insect prosternal area. The more numerous and well-developed the foveae, the more primitive the species, other things being equal, and conversely, with the final disappearance of foveae, leaving an apparently unmodified sheet of integument, the more highly evolved the species. Such a generalized hypothesis must be carefully analyzed in the future to prove or disprove its worth. However, the general idea of (1) developed sclerites, bounded by clean sutures, (2) sclerites becoming consolidated, the sutures vestigial and their more resistant intersections or areas persisting as foveae, and (3) eventual disappearance of foveae, leaving a solid chitinous piece, may serve as a working plan. Obviously not all foveae are to be viewed in the light of this idea, e.g. the elytral foveae and pronotal foveae may have their origin too far removed in evolution to be considered. The fusion of the pronotal sclerites into one pronotal piece is an ancient combination in beetles, and the elytra or wing cases are also greatly modified from the mesothoracic functional wings of other insect stock. The sternal areas, however, offer a promising field, especially when they can be compared with staphylinid areas, admirably reviewed by Blackwelder (1936), whose comparative treatment of the anatomy of the Staphylinidae should serve as a guide in future revisions of the family.

The pselaphid prosternum consists of two sclerotic areas, which are sometimes primitively well defined, and at times fused into one piece. When both are developed, the prosternum has two sclerites. The first is the basisternum and is an anterior piece being bounded by the anterior foramen of prothorax into which the head is inserted, anteriorly; laterally by the notosternal sutures of each side; posteriorly by the anterior coxal cavities in part and in part by the second sclerite, the furcasternum. The furcasternum is variously developed and may be clearly visible under the anterior coxae, or virtually absent externally. This last sclerite or division is chiefly concerned in the endoskeletal invaginations, the diverging arms of which are anchored in the basal furcasternal area.

Returning to the prosternal foveae, we find that these are distributed as follows: (1) Anterior Prosternal Foveae, one on each antero-lateral angle of the basisternum, usually invaginated in the notosternal suture when it is clearly formed. (2) Lateral Prosternal Foveae, one on each postero-lateral angle of the basisternum, usually invaginated in the area where the notosternal suture anastomoses with the sternacostal suture, the transverse suture separating the two prosternal areas. However the lateral prosternal foveae may be located far from this point, and lie, one above each coxal cavity in the sternacostal suture, or, if this is not present or not in its normal position, in the posterior margin of the basisternum above each coxa. Thus the lateral prosternal foveae are essentially related to the anterior coxae, and form an anatomical land- 
mark in the topography of the prosternum. When they are present, these foveae can be seen to best advantage in potashed slide-mounts in which the coxae have been removed. (3) Median Prosternal Fovea, when present, in the posteriorly angulated portion of the basisternum where it forms a slight projection between the anterior coxae, or invaginated in the sternacostal suture medianly between the coxae.

It should be noted that all combinations may exist, from one, three to five of the foveae present or absent, and the foveae may be well-formed invaginations, deeply conical and with their walls segmentally creased or whorled to foveoid depressions. The primitive Sonoma (Rafonus) tolulae has all five present, and not very well developed; the anterior prosternals especially are weak. Here the sutures are more clearly defined, but in Rhinoscepsis bistriatus only the lateral prosternal foveae are present and these are strongly defined and nude, and in Euplectus (Pycnoplectus) interruptus only the lateral prosternals are present and these are pubescent. The figures and descriptions will give other data on these foveae, and we should remember that this classification of foveae is a tentative one upon which a complete picture may be erected for the family as a whole.

Because the foveal system is being elaborated here as a taxonomic aid, rather than as a detailed account of comparative anatomy, the foveae of the meso- and metasterna are considered collectively, inasmuch as the student examining the venter is confronted with a compact region holding the intermediate and posterior coxae. In addition to certain rare or aberrantly placed foveae, the meso- and metasternal field presents a varying number of foveae, from one to eleven, which may be considered here.

I. Prepectoid Foveat. These are invaginations on the prepectoid area, and are very rare. When they are present (Sonoma (Rafonus) tolulae) they lie in a region which would be traversed by the sternopleural suture if it were present, and appear as the most anterior pair of foveae. The prepectoid abounds in complicated depressions; and foveoid depressions are suggested by the topography of Euplectus (Pycnoplectus) interruptus and Adranes lecontei, to name two extremes; true prepectoid foveae are known, however, only in tolulae, among the species studied thus far. Their presence is regarded as a primitive feature, since the prepectus apparently lost its identity, as a discrete element, among pselaphids by fusing more or less with the sternum and episternum of the mesothorax.

II. Lateral Mesosternal Foveae. These are a pair of foveae which appear as invaginations of the sclerotized posterior wall of the prepectoid and also in the region of the sternopleural suture when it is present. They are practically never absent, being the most constant of all the sternal foveae, and traverse the prepectoid wall where it is elevated above the mesosternum. They course medianly, and their apertures are usually difficult to locate in dry triangle mounts because of pubescence in some groups (Ctenistini, Pselaphini, Tmesiphorus, et cetera). In slide mounts, however, under high magnification, they are quickly discerned. 
III. Median Mesosternal Foveae. These foveae also are usually present, but may be widely separated, close together with a common aperture, or fused as one fovea, the median mesosternal fovea. They appear as openings in the mesosternum, just posterior to the prepectoid ridge, and between the usually conspicuous coxal-prepectoid carinae, which run longitudinally on each side of the mesosternum in most species. They penetrate also the prepectoid, invaginating anteriorly. In cleared slide mounts they can be easily found when present, but in dry triangle mounts they usually appear as one median fovea, since many species have a common aperture for these foveae. They are shorter than the lateral mesosternal foveae, and in a number of species the lateral and median mesosternals cross each other on each side because of the median course of the former and the anterior course of the latter.

IV. Lateral Mesocoxal Foveae. These appear as invaginations at the lateral extremity of each mesothoracic coxal cavity. They vary in size from huge invaginations to minute pores; they may lie a short distance from the cavities or be partially lapped by the coxal rim; they may be nude or pubescent, circular to slit-like, and are present in about sixty per-cent of the species. These lateral mesocoxals are important foveae since they invaginate at a topographic area where a number of sclerites, or sclerotic regions, meet, e.g. mesosternum, mesoepisternum, mesoepimeron, metaepisternum and metasternum. Three or more of these regions are usually involved in the formation of the fovea on each side, so that each fovea appears as the hub of a wheel with the sclerotic regions radiating spoke-wise from its cavity. Again, examination of cleared slide mounts, in which one mesothoracic coxa has been removed to show the coxal cavity, usually shows the fovea as a deep, conical, segmentallycreased invagination which penetrates anteromedianly below the coxa. The internal, blind end of the foveal lumen continues as a sclerotized fiber which joins the arm of the mesosternal furca of the endoskeleton above each coxa, and passes dorsal to the lateral articulation of the coxa. These foveae, then, are important topographically and appear also to have a direct connection with the endoskeleton (e.g. Tmesiphorus costalis), as was shown also for the vertexal foveae.

V. Posterior Mesocoxal Foveae. These invaginations may or may not be present. When they occur they should be looked for as a pair of openings along the posterior margin of the coxae, one on each coxal border. The position of these foveae varies considerably. They may be approximate, in which case they lie near the median end of the coxal cavity of each side and their course is anterior into the heavily sclerotized metasternal process or lamina between the coxae; or they may be widely separated, each appearing as an invagination of the posterior coxal border of the metasternum near the lateral mesocoxals noted above; or they may occupy some intermediate position along the posterior coxal margin.

VI. Median Metasternal Foveae or Fovea. These foveae are almost always fused as one fovea which forms an invagination in the metasternal 
process and courses anteriorly between the intermediate coxae. This fovea is uncommon, but in many Tyrini (certain Hamotus, Neotyrus) is large.

The following table is given to show the range and distribution of the foveae in a few representative pselaphids. This selected list is made up of Nearctic species, but is applicable to any other faunal area.

TABLE I

MESO- AND METASTERNAL FOVEAE

\begin{tabular}{|c|c|c|c|c|c|c|c|}
\hline Species & I & II & III & IV & V & VI & Total \\
\hline Sonoma (Rafonus) tolulae $\ldots \ldots \ldots \ldots \ldots \ldots \ldots$ & + & + & + & + & + & $\mathrm{f}$ & 11 \\
\hline Rhinoscepsis bistriatus . . . . . . . . . . . . . & 0 & + & + & + & + & 0 & 8 \\
\hline Rhexidius canaliculatus . . . . . . . . . . . & 0 & + & + & + & + & 0 & 8 \\
\hline Bibloplectus ruficeps . . . . . . . . . . . . . . & 0 & + & $\mathrm{f}$ & + & + & 0 & 7 \\
\hline Melba sulcatula $\ldots \ldots \ldots \ldots \ldots \ldots \ldots \ldots \ldots$ & 0 & + & $\mathrm{f}$ & + & + & 0 & 7 \\
\hline Euplectus interruptus $\ldots \ldots \ldots \ldots \ldots \ldots \ldots$ & 0 & + & + & + & 0 & 0 & 6 \\
\hline Trimiomelba dubia $\ldots \ldots \ldots \ldots \ldots \ldots \ldots$ & 0 & + & $\mathrm{f}$ & 0 & + & 0 & 5 \\
\hline Rhexius insculptus $\ldots \ldots \ldots \ldots \ldots \ldots \ldots \ldots$ & 0 & + & + & + & 0 & 0 & 6 \\
\hline Tmesiphorus costalis . . . . . . . . . . . . . & 0 & + & f & + & 0 & 0 & 5 \\
\hline Pilopius lacustris $\ldots \ldots \ldots \ldots \ldots \ldots \ldots \ldots \ldots$ & 0 & + & + & 0 & 0 & f & 5 \\
\hline Adranes lecontei $\ldots \ldots \ldots \ldots \ldots \ldots \ldots \ldots \ldots$ & 0 & + & 0 & 0 & 0 & 0 & 2 \\
\hline
\end{tabular}

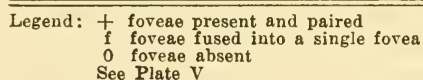

In this table the meso- and metasternal foveal range is from eleven to two. Primitiveness is directly proportional to the number of foveae, if the assumptions set forth here are tenable. Since these eleven species were chosen at random from slides of nearly one hundred species, the confirmation of other lines of evidence is indicative of the phylogenetic value of foveae. Thus the Faronini are the most staphylinoid pselaphids from many points of view, and Sonoma tolulae has eleven out of a possible twelve foveae, whereas the highly specialized Adranes lecontei has but two foveae. In Adranes even the vertexal foveae are lacking; in fact, the dorsal arms of supratentorium do not even reach the epicranium. Sternal foveae also check the relative position of genera within tribes: Rhexidius canaliculatus is more primitive than Rhexius insculptus; Melba more primitive than Trimiomelba; Bibloplectus more primitive than Eupleotus. Thus the foveal system should prove phylogenetically significant when it is more thoroughly studied.

There is one more structural item which should be mentioned, namely the compound eyes. Rediscovery of Mendelism, followed by the establishment of the gene theory, in the present century has placed at the disposal of biologists a logical mechanism for heredity which can be experimentally attacked (Morgan, 1919, 1926). Physiological genetics and cytogenetics have utilized insect material to great advantage within recent years, and the insect eye has played an important rôle in modern problems. Especially pertinent are the experiments which attempt to explain the facet size and number, their heredity and the rôle of ecological factors such as temperature (Hersh, 1934; Margolis, 1935; Zeleny, 1915, 1917). Eventually the interrelation between environment and heredity in the insect eye will be sufficiently understood to allow us to evaluate 
these organs in our taxonomy. Certainly facet number is as good a character as many others now in use.

In Pselaphidae the eye varies from circular, through ovoidal to strongly reniform and its shape, relative position, amount of ocular setosity are all quite constant for a species population except where the sexes have differently formed eyes. The loss or reduction of eyes is considered as a specialized condition, and primitive stocks, therefore, are thought to have the eyes well developed. Often loss or reduction is correlated with loss or reduction of functional metathoracic wings, or both with habitat such as the deep mold or cavernicolous species, occasionally with sex but no invariable rule may be set forth in this respect.

Nevertheless there has been considerable reduction or loss of compound eyes in the Pselaphidae. Thus, in Euplectini, Mirus and Scotoplectus have no eyes, Rhinoscepsis has reduced eyes in both sexes, and Autoplectus and Eutyphlus have reduced eyes in the female sex. In Batrisini, Amaurops (Troglamaurops) and Arianops have no eyes but replacing spines, Amaurops (Amaurops) has neither eyes nor replacing spines, and Bergrothiella has reduced eyes. In Pselaphini, Pselaphiscnus has reduced eyes, and in Pselaphus the eyes vary among the species from well-developed to greatly reduced. In Goniacerini, Bibrax has the eyes represented each by a single facet. In Metopiini, Barrometopia has reduced eyes of ten facets each. In the Clavigerinae, Adranes and Claviger have no eyes.

Number of facets is much less well known, but offers great taxonomic possibilities. In Fustiger the species vary in number of ocular facets from 8 to 30; in Hamotus the facet number varies among the species from 34 to 96 . We are at the threshold of our knowledge in this notable character. The new species described in this paper have the facet number stated, but the implications must await more examples.

A novel feature is the facet structure of a new genus of termitophilous tyrines, Tyrogatunus. Here the reniform eye of 62 facets has the dorsal third of the eye composed of about 22 very flat, significantly wider facets, whereas the ventral two-thirds has the more normal strongly convex type of facet.

In the previous pages, certain salient structures have been discussed comparatively. From this it is obvious that the pselaphids are most nearly allied to Staphylinidae-in fact, they should be regarded as a specialized assemblage of an ancestral staphyliniform ancestor. The pselaphid tribe Faronini is especially staphylinoid. As Casey noted (1893), the tarsus of Faronus is quite similar to many Oxyteline staphylinids. Again, the first visible tergite of Faronus has a transverse pubescent line which is found in some Omaline staphylinids. The general resemblance of euplectines to Euasthetinae is also suggestive. These euasthetine staphylinids have a distinctive pselaphoid habitus, which goes beyond their small size and color, extending to the contour of the 
body; the eleven-segmented antennae and well-developed vertexal foveae of euasthetines are especially pselaphoid.

Finally, a summary of the pselaphid anatomy and ecology suggests the following definition of the family: Pselaphidae is a consistent assemblage of some 4700 described species of brachyelytrous beetles belonging to the superfamily Staphylinoidea; the family has a cosmopolitan distribution, reaching a maximum of speciation and complexity in the tropical regions; the stratum of competition is chiefly the forest floor mold, although grassland and the societies of ants and termites have been invaded; as a group, the family is predaceous, with well-developed mandibles; the active period is during the night, especially the hours at and after dusk; they are characterized by a compact body plan in which there is a tendency for sutures, especially gular and sternal, to be reduced or absent, with foveae abundantly and diversely developed; the vertex almost always bears a pair of vertexal foveae; antennae are highly variable, usually clavicorn, of from two to eleven segments, and diverse in structure; form may be both specific and sexual; the articulation of antennae to head is usually more restrictive than in allied families, being by means of a flexure of the basal antennomere to the dorsal surface of the acetabulum; labial palpi are small and conservative, of from one to two segments; maxillary palpi are peculiarly labile, usually four-segmented, and usually with an apical palpal cone; the abdomen has little dorso-ventral play, and typically has five visible tergites and six visible sternites; the aedeagus is a specialized organ of oxyteline affinities, tending to reduction of parts and bilateral asymmetry; the tarsi are three-segmented with the possible exception of two aberrant genera; the larval stage is staphyliniform, similar to larvae of Bledius in the two species investigated by Böving and Craighead (l.c.); the size range of pselaphid imagines varies from 0.6 to 5.5 millimeters. 


\section{Key to the Tribes of Neotropical Pselaphidae}

At present there are twenty-two tribes of Pselaphidae. In the present paper two tribes (Euplectini and Trichonychini) are united. The Western Hemisphere is represented by seventeen tribes. Four tribes (Dimerini, Mirini, Cyathigerini and Schistodactylini) have no known American species. Four tribes (Jubinini, Metopiini, Arhytodini and Attapsenini) are exclusively American; some tribes are poorly represented in the Western Hemisphere (Faronini, Pyxidicerini, Batrisini, Pselaphini, Ctenistini, Hybocephalini and the subfamily Clavigerinae). These facts of distribution are taken advantage of in the key which follows.

This tribal key (Plates VI and VII), and all other keys in the present study, are artificial in the sense that isolation of specimens is the goal, without reference to evolutionary order. Consequently key characters of little phylogenetic weight may be employed, if by so doing tribes, or parts of tribes, can be separated effectively. Again, this and the keys which follow relate specifically to the Neotropical Region (roughly the Americas south of the Tropic of Cancer, and their associated island groups, to central Argentina) and should not be expected to apply elsewhere.

All seventeen tribes of the Americas are known from this region, and their neotropical components may be separated as follows:

Antennae of not more than three segments (Pl. VI, 5) .......

CLAVIGERINI

(p. 350)

Antennae of more than three segments (Pl. VI, 6, 7) ..........

2. Tarsi with the second segment bilobed, the third segment cylindrical and inserted between the lobes of the second; known only from South America $(\mathrm{Pl}$. VI, 3) .................ARHYTODINI

(p. 343)

Tarsi with the second segment large or small, cylindrical, obconical, compressed or flattened but never bilobed............... 3

3. Tarsi with the first two segments small and the third segment rela-

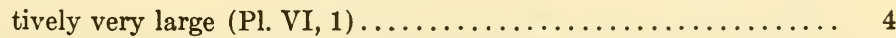

Tarsi with the first segment small and the last two segments rela-

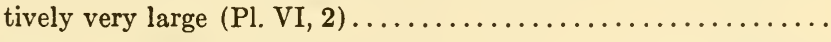

4. Antennae of nine segments................. PYXIDICERINI

(p. 37)

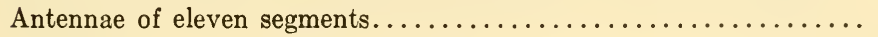


5. Trochanters of intermediate legs short, very obliquely articulated with femora, so that the latter are near the coxae; tarsi with two equal

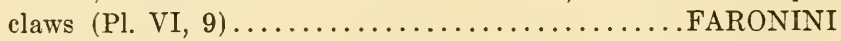

(p. 35)

Trochanters of intermediate legs with the femora articulated at the distal face, so that the femora are relatively distant from the coxae; tarsi with a single claw (Pl. VI, 8) ...........HOLOZODINI

6. Trochanters of intermediate legs with the femora very obliquely articulated, so that the femora are near the coxae (Pl. VI, 9) .... Trochanters of intermediate legs long, more or less clubbed or inflated distally, with the femora articulated at the distal face, so that the femora are relatively distant from the coxae (Pl. VI, 8)..

7. Mentum very wide, covering mouth and mouth-parts in large part; base (cardo) of each maxilla extended obliquely on outer face into a long projection; ventral surface of head usually (but not invariably) provided with two strong carinae which converge basally toward neck to form a $Y$ or a $V(P l$. VII, I) ........JUBININI

Mentum normally small; base of maxillae not so extended; ventral surface of head variably modified but not with a $\mathrm{Y}$ or $\mathrm{V}$-carinal

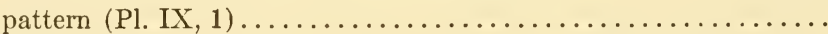

8. Posterior coxae with median face, which articulates with the trochanter, either conical or conically produced (PI. VII, 7) (Euplectini, sensu latiore).......EUPLECTINI and TRICHONYCHINI

Posterior coxae with median face, which articulates with the trochanter, either broadly triangular or globular (Pl. VII, 6) ..........

9. First visible sternite relatively long: at least as long as the posterior coxae, usually extending well beyond these coxae; this sternite always clearly visible for its entire width; with the first sternite

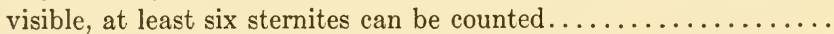

First visible sternite very short: either invisible, or visible laterally but invisible medianly; or visible laterally and also visible medianly as a short plate or minute tubercle between the coxae; with the first sternite thus hidden, at least five sternites can be counted........

10. Tarsi with a single claw...............................

(p 122)

Tarsi with two very unequally developed claws...............

11. Antennae with their articulations distant, and hence the head is not suddenly and strongly constricted anterior of the eyes and not swollen to form a median antennal tubercle; antennae diverse but never having the first segment conspicuously long, hence antennae never geniculate, or sharply bent between the first two segments

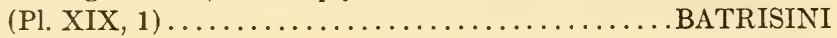


Antennae with their articulations contiguous to subcontiguous; inserted on a median, swollen, antennal tubercle; antennae with a conspicuously elongated first segment, and strongly geniculated

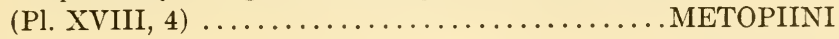

12. Antennae straight, not geniculate.............. TYCHINI (p. 260)

Antennae strongly geniculate.......................... (p. 283)

13. Tarsi with a single claw PSELAPHINI (p. 286)

Tarsi with two equal or unequal claws.

14. Body pubescence in the form of scales (Pl. IV, 6-8) . CTENISTINI ${ }^{1}$ (p. 291)

Body pubescence diverse but never in the form of scales..........

15. Pronotum always with one, two, or three basal foveae which may be free or connected by a transverse, arcuate basal sulcus; elytra usually with basal foveae; maxillary palpi usually large and very conspicuous . . . . . . . . . . . . . . . . . TYRINI ${ }^{1}$

Pronotum and elytra lacking foveae and sulci; the maxillary palpi very minute; known only from the nests of leaf-cutting

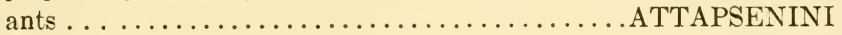

(p. 348)

\footnotetext{
${ }^{1}$ In the Western Hemisphere the Hybocephalini (p. 289) are limited to a single genus (Ephimia). This rare genus is atypical of its tribe, and may belong in the Tyrini. Since Ephimia may not be easily separated from Tyrini and Ctenistini, it is taken care of in both of these tribes.
} 


\section{Subfamily Pselaphinae}

Raffray $(1908$, p. 10) defines this large subfamily in general terms by stating that the mouth-parts are well-developed for chewing; the abdomen with from two to six tergites and six sternites; antennae of from five to eleven segments, with the last segment never having a wholly truncate, setose apex; without trichomes or setose bundles at the base of the first visible tergite and apical elytral margins.

For our purposes, the neotropical Pselaphinae can be separated by having five or more antennal segments. It is possible that in time students may either break the family into a number of subfamilies, or merge the Pselaphinae and Clavigerinae, since the trend is to bridge the gap between these two subfamilies. Thus the Arhytodini and Attapsenini have mouth-parts intermediate between primitive Pselaphinae and Clavigerinae; the Attapsenini have trichomoid setae at the base of the tergum. Therefore the Pselaphinae are with certainty separated from Clavigerinae only by more primitive chewing mandibles, and conversely, the number of abdominal segments, number of antennomeres, and presence of trichomes is of less value than formerly.

The neotropical Pselaphinae number sixteen out of seventeen tribes known for the region, and this subfamily is divisible into two sections, the Brachyscelia and Macroscelia (Raffray, 1908, p. 11). This separation is very consistent, and, since the Clavigerinae are typically macrosceline, it might be more logical to divide the family into two subfamilies, Brachyscelinae and Macroscelinae -or if one prefers, the Pselaphinae (limited to brachyscelines) and the Macroscelinae. For more discussion of the status of clavigerines the student is requested to see page 350 . 


\section{DIVISION I. BRACHYSCELIA (Raffray, 1890)}

In this division all of the trochanters are short, and the femora are very obliquely articulated upon them, so that the femora are very close to their respective coxae.

The neotropical area has nine brachysceline tribes which may be examined as follows:

\section{Tribe 1. Faronini}

\section{RaFFray $(1890,1903,1908)$}

CASEY (1887, 1893, 1897)

Students of the family Pselaphidae are unanimous in regarding the Faronini as a very primitive, generalized tribe, if not the most primitive existing section of the family. The tribe is a small one, and has a wide, discontinuous distribution, with New Zealand holding the large majority of described species. Of some ten or eleven genera, only three are found in the region under discussion. These three genera are all monotypic, and found only in Chile.

The primitive anatomy of the tribe is suggested by the morphology of a North American form, Sonoma (Rafonus) tolulae (LeConte), parts of which are illustrated here (Pl. V, 2, XIII, 4, 5, 7, 9). The body is usually flattened and elongate. The antennae are not highly specialized, but gradually enlarged distally to form a poorly delineated club. The large abdomen is strongly margined, with usually five visible tergites; the sternites visible are six in the females and seven in the males. Casey, speaking of Sonoma (Sonoma), noted that the secondary sexual modifications of the ventral, distal area of the abdomen were bilaterally asymmetrical, and this is not a primitive arrangement. On the other hand the tarsi of Faronus and near allies are quite similar to Oxytelini of the Staphylinidae, with the first two segments small, subequal, and the third segment large and having two equal claws. The conical middle and posterior coxae are staphylinoid, and also euplectine. Casey (1893, p. 433) thought the tribe intermediate between staphylinids and pselaphids, and in addition to the oxyteline tarsus, pointed out that the transverse pubescent line of the first visible tergite was not only a typical faronine condition, but also was frequently seen in the staphylinid Homalini.

\section{Key to the Genera}

Pronotum with a median longitudinal sulcus............... 2 Pronotum with no median longitudinal sulcus............GOLASA

2. First four tergites subequal in length............. PROSAGOLA First three tergites subequal in length, fourth tergite much larger 
GOLASA (Raffray, 1904)

microcephala (Reitter). 1883. Chile. (Sagola)

PROSAGOLA (Raffray, 1904)

elfridae (Reitter). 1885. Chile. (Sagola)

SALAGOSA (Raffray, 1904)

brevipennis (Reitter). 1885. Chile. (Sagola) 


\section{Tribe 2. Pyxidicerini}

\section{RAFFRAY $(1903,1908)$}

This is a small tribe of four genera, one of which (Bythinoplectus) is American. The American species have the body elongate and flattened, and the integument is usually shining. The head has the usual pyxidicerine fossa on each dorso-lateral face, in which repose the peculiar maxillary palpi. These palpi are four-segmented, and the segments are closely articulated irregularly so as to form an oval or elongate-spherical mass. First segment medium; second large, basally slender, and slightly clubbed apically; third articulating on the lateral face of the second, smaller, variable in form, geniculate ventrally and inflated dorsally, this dorsal face being sulcate to receive the fourth or distal segment; fourth segment irregularly elongate transversely and articulating to the third segment by a short petiole on the lower of the two transverse faces. In repose these segments tend to fit into or upon one another, and the palpus lies in the large palpal fossa of the head.

The antennae are nine-segmented, with the distal segment enlarged to form the antennal club; these organs are articulated on either side of the elongate median antennal tubercle which is formed by the vertex and front. The head is triangular, broad through the occiput and narrowing rapidly anteriorly to the antennal insertion.

Abdomen elongate, strongly margined, with six visible sternites of which the first is small and visible only between the diverging but contiguous conical posterior coxae.

The tarsi are three-segmented, but this segmentation can be observed only with difficulty. Dorsally, the tarsi are apparently two-segmented, since only the first and third may be seen. The first segment is small, conical, and broadly sulcate ventrally; second segment minute, triangular, and articulates with the first on its ventral face so that this second segment lies in the ventro-distal cavity of the first; third segment is relatively very large, medianly slightly inflated, bearing a single large claw.

\section{BYTHINOPLECTUS (Reitter, 1881)}

acutangulus Raffray. 1904. Granada, Windward Islands.

denticornis Raffray. 1896. Mexico.

formicetorum Raffray. 1912. Argentina. (con Atta lundi Guer.) Buenos

Aires, cf. Bruch, 1929.

foveatus Reitter. 1883. St. Thomas, Virgin Islands. Genotype.

impressifrons Raffray. 1896. Brazil.

transversiceps Raffray. 1904. Brazil. 


\section{Tribe 3. Jubinini}

\section{RAFFrAY $(1903,1908)$}

The Jubinini are wholly American. The tribe contains eleven genera, and all of these genera and all but one species are found south of the northern border of Mexico. The single species found outside the region discussed here was described by Schaufuss (Stratus ursinus Schaufuss, 1872) from Mexico and with doubt from New Orleans, Louisiana. Inasmuch as no representative of this species has since been reported from the United States, and there seems to be some uncertainty about the Louisiana record, it is possible that ursinus is Mexican and that the Jubinini are wholly neotropical. Certainly the tribe is essentially a southern stock as evidenced by the type localities.

Morphologically the genera have certain features peculiarly developed (Pl. VII) and not found elsewhere in the family. This is especially true of the ventral face of the head and the mouth-parts.

The body is usually elongate and flattened. There is considerable variation in pubescence and in punctation of the integument. The head is generally elongate and more or less triangular, with the insertion of the antennae subcontiguous. The ventral surface of the head is characteristically carinated in most of the genera, and this is a diagnostic feature of great weight. In all but three or possibly four genera, this lower surface of the head has two welldeveloped oblique carinae, which arise on each side of the head, near the mentum, and converge posteriorly. This convergence of the oblique carinae may be anteriad of the neck to form a $Y$-shaped pattern, or the carinae may converge at the neck to form a $\mathrm{V}$-shaped pattern. In a few genera this pattern is absent.

The jubine mentum - a very large, transverse plate which covers the mouth and most of the mouth-parts-is characteristic of the species.

The maxillary cardo is prolonged on the external face into a long, oblique, acute-to-obtuse spine. This projection of the cardo flanks the expanded mentum on either side, and partially obscures the maxillary palpus. The development of cardo and mentum led Raffray to separate the Jubinini into a separate tribe.

The maxillary palpus is typically four-segmented and primitive. The first segment is medium in size; the second elongate and longer than the first; the third segment usually smaller and transverse to triangular; the fourth segment is relatively large, elongate-cylindrical or fusiform and terminates in the usual palpal cone.

The antennae are eleven-segmented, without striking modifications seen in more specialized tribes. The intermediate segments are simple and transverse or quadrate as a rule, and either become gradually larger distally, or the distal three to five segments form a club. 
The pronotum is cordiform, narrowed on each side near the middle or even strongly bilobed, with the marginal invagination at times toothed. In all of the genera but one there is a transverse subbasal sulcus. Barrojuba lacks this transverse sulcus entirely.

The elytra have an entire or subentire sutural stria, a poorly-developedto-vestigial dorsal stria, and often a longitudinal sulcus on the elytral flank. Humeri are well formed, and at times dentate. Elytral base usually has a transverse carina or raised surface. The elytra are often much shorter in the females than in the males of a species, and the female sex often has less well developed metathoracic wings. In some species the females have the wings wholly vestigial.

This sexual difference sometimes seen in elytral size and wing development is paralleled in the eyes. Thus in many species the short-elytral, reduced winged females have conspicuously smaller eyes than males of the same species.

The abdomen is elongate, laterally margined, and has six visible sternites in both sexes.

All three pairs of coxae are conical, and the trochantal-femoral articulation is typically brachysceline, being oblique with the associated femur and coxa relatively close to each other.

The tarsi depart from the oxyteline-faronine type, being more typical of the pselaphids as a whole; that is, the first segment is small, whereas the second and third segments are much larger than the first. Two claws are present at the end of the third tarsomere, and are either equal or slightly unequal in length.

These are more especially forest-floor mold species, and careful collecting in this stratum will undoubtedly reveal many new genera and species.

\section{Key to the Genera}

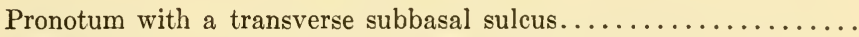

No transverse pronotal sulcus...........BARROJUBA, new genus

2. Antennal club large, distinct, compact and composed of from six to seven segments ....................ENDYTOCERA

Antennal club at most of five segments, usually indistinct.........

3. Ventral surface of the head with two oblique, converging, sharply defined carinae............................. 4

Ventral surface of the head with no oblique, converging carinae... 9

4. Head suddenly constricted before the anterior end, and then dilated to form a blunt, quadrate to rhomboidal tubercle.............

Head elongate, narrowing regularly to the anterior end, and without the suddenly formed apical tubercle.....................

5. Antennae elongate, with the segments much longer than wide; pronotum with two sharply-defined longitudinal sulci ............ .PSELAPHOMORPHUS

Antennae very short, with the segments square to transverse; pronotum with two simple elongate depressions............MACTA 
6. Sides of the head with the ventro-lateral borders sharply defined or carinated; ventral surface of the head with a long, median, longitudinal carina which bifurcates anteriorly........ARCTOPHYSIS Sides of the head with the ventro-lateral borders smoothly or evenly rounded both anteriorly and posteriorly of the eyes, or in some genera (Sebaga) carinated between the eyes and the mentum but evenly rounded posteriorly, behind the eyes; ventral surface of the head with converging carinae which begin near the outer anterior angle of the mentum and unite from a point near the posterior limits of the eyes to the neck, and consequently these carinae form

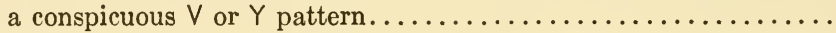

7. Head anteriorly truncate, with the antennae distant from each other

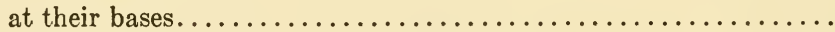

Head subacutely narrowed or attenuated anteriorly, with the antennae very close to each other at their bases, subcontiguous......JUBUS

8. Fronto-antennal tubercle widely, deeply excavated or longitudinally sulcate medianly . ..................JUBOMORPHUS

Fronto-antennal tubercle not medianly, longitudinally sulcate or

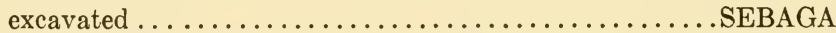

9. Ventral surface of the head with three longitudinal sulci, these consist of an oblique lateral groove on each side, and a median groove; disc of pronotum with a strong median longitudinal sulcus... BALEGA Ventral surface of head with only a single median sulcus, or a median fovea; pronotal disc with or without lateral longitudinal sulci, but lacking a median longitudinal sulcus....................

10. Ventral surface of head with a median longitudinal sulcus; the pubescence thick and abundant but not downy; tarsi with two very unequal claws; sides of pronotum with three lobes, two lateral and a basal lobe being more or less developed............STRATUS Ventral surface of head with an antebasal, large fovea placed medianly and near the mentum; pubescence peculiar, being long, abundant, soft and downy, that is appearing like the nap of a cloth; sides of pronotum constricted; tarsi with two equal claws....PHAMISUS

\section{PSELAPHOMORPHUS (Motschulsky, 1855)}

brevipennis Raffray. 1917. Paraguay.

bruchi Raffray. 1909. Buenos Aires, Argentina. con Solenopsis richteri Forel. cf. Bruch, 1929.

longiceps Raffray. 1890. Brazil. microphthalmus Raffray. 1890. Venezuela. (muticus Raffray) sculpturatus Motschulsky. 1855. Panama. Genotype.

MACTA (Raffray, 1890)

constricta Raffray. 1890. Brazil. Genotype. 


\section{ARCTOPHYSIS (Reitter, 1881)}

gigantea Reitter. 1882. Colombia. Genotype.

JUBOMORPHUS (Raffray, 1890)

simoni Raffray. 1890. Venezuela. Genotype.

\section{SEBAGA (Raffray, 1890)}

Sebaga raffrayi new species

In this description and those following, where width is given with length, length is always given first. Head $0.34 \times 0.36 \mathrm{~mm}$. through eyes; pronotum $0.36 \times 0.48 \mathrm{~mm}$.; elytra 0.56 along suture $\times 0.71$ to 0.73 ; abdomen $0.69 \times 0.72$ to $0.74 \mathrm{~mm}$; tergite I, 0.268 ; tergite II + III, 0.281 . Total length 1.95 to 1.97 $\mathrm{mm}$.; greatest width 0.72 to $0.75 \mathrm{~mm}$. (Pl. XV.)

General body color light red brown, with the antennae, palpi, and tarsi paler; pubescence yellowish white, sparse, long, conspicuous. Average length of body pubescence 0.067 to $0.107 \mathrm{~mm}$. Integument shining, with setae arising from subasperate punctures.

Head rounded-triangular, broadest through eyes, tapering gradually to the broadly rounded front. Eyes large, composed of about 40 coarse facets. Eyes slightly hairy. Occiput sinuate posteriorly, with a median notch; vertex evenly rounded, vertexal foveae large. Intra-foveal distance about equal to distance between an eye and nearest fovea. These vertexal foveae located in the center of the vertex, equidistant from the posterior margin of the occiput and from the anterior margin of the antennal insertions. A broad, well defined sulcus from each fovea to a point above each antennal insertion; margins of the sulcus rounded; sulcus broadest near fovea, not deepening anteriorly, forming as a whole an elongate-oval impression; foveae nude. Front simple, unmodified, evenly declivous. Antennae inserted on front without formation of antennal tubercle, distant at their bases; eleven-segmented. Segment I and II equal in length and width; I regularly ovate; II truncate apically; III, IV, V, VI of about same width; III a little longer than IV, ovate; IV and V moniliform, about same length; V as long as VI; VI subtriangular, asymmetrically slightly produced at anterior basal face; VII about as long as VI, slightly wider, subtriangular, produced more strongly at anterior basal face; VIII, IX, X and XI forming the club; VIII, IX and X of same shapethat is, the basal half of each segment is drum-shaped and the apical half consists of a slender, slightly eccentric, tapering, narrower spindle; VIII slightly shorter and narrower than IX; IX slightly narrower than X; IX and $\mathrm{X}$ of about same length; XI truncate at base, widest through middle third, tapering to subacute apex, slightly wider than X, twice as long as X. Maxillary palpi four-segmented; first segment very minute; second segment elongate, slender basally, gradually inflated apically; third segment much shorter than second, but elongate, roughly elongate-rounded triangular in outline with the inner face much more convex than outer face; fourth segment longest, 
widest medianly, with the mesial face relatively convex and lateral face relatively flat; a short, acute palpal cone inserted at apex of fourth segment. Lower surface of head almost glabrous, shining. Occipital angles well-defined. Sides of ventral face defined and carinated between eyes and mentum; sides evenly and smoothly rounded posteriorly from eyes. Mentum characteristically broad. Cardo of maxilla characteristically produced obliquely into a prominent projection which tends to obscure first segment of maxillary palpi. Lower surface of head with a pair of oblique, strong carinae. Each carina begins near lateral union of mentum and gena, and converges obliquely to join its fellow from the opposite side near the posterior margins of the eyes, forming a long $\mathrm{V}$-shaped pattern; enclosed surface of the $\mathrm{V}$ evenly concave.

Pronotum wider than long, widest medianly, above transverse sulcus. This transverse sulcus is entire, biarcuate. Anterior to sulcus the pronotum narrows evenly, to form a rounded-triangular apical half. Posterior to sulcus the sides are almost straight for a short distance, then become abruptly narrower in basal fifth, giving a highly irregular outline to the lateral margins. No longitudinal sulci. Transverse sulcus with a lateral nude fovea in its floor, near but not at the lateral margin. Disc of pronotum with a conspicuous, regularly transversely oval antebasal platform or saucer. This peculiar platform has the edges carinated, and is elevated above the pronotal disc so that its posterior edge partially overhangs the transverse sulcus. Transverse sulcus curves basally around the antebasal platform and tends to widen medianly, so that from a certain point of view, this platform appears to form a raised, undercut, isolated, transversely oval plateau within the expanded median portion of the transverse sulcus.

Elytra transversely carinated at base. Laterally this carina is produced so that the humeri are dentate. No dorsal stria. Sutural stria entire, deep, ending basally in a sutural fovea. Sutural fovea recessed beneath transverse basal carina. Transverse basal carina shortly arcuate to a point above the recessed median basal fovea, and then straight to the humeral basal fovea, which is recessed beneath the humeral tooth. Each elytron, therefore, has three nude basal foveae. A longitudinal carina on the elytral flank, extending apically from the humeral tooth. Median to the carina is a longitudinal sulcus which extends apically from the humeral fovea. The floor of this sulcus is of uneven depth and there is an accessory fovea in its floor at basal fifth, apical to to the humeral fovea.

Abdomen with five visible tergites, which become gradually narrower to apex. First tergite twice as long as second; second slightly longer than third; third slightly longer than fourth; fifth quite small. Six sternites visible. First sternite very short, largely obscured by the posterior coxae, the sternites regularly narrower to apex; second twice as long as third; third and fourth subequal in length; fifth medianly very short, about half as long as fourth, with a small tubercle at its median, posterior margin; fifth sternite deeply and regularly incised semicircularly to accomodate the large sixth sternite; sixth sternite with a shallow, broad depression in basal half, this depression be- 
coming more well-defined apically with the apical margin elevated obliquely on each side of depression.

Prosternum medianly, longitudinally carinate for a short distance between the anterior coxae, this longitudinal carina bifurcating obliquely to form an arcuate, carinated edge as the anterior limit of each coxal cavity. Prosternum not medianly, longitudinally carinate in anterior half. Mesosternum with a longitudinal carina extending anteriorly from each middle coxal cavity to the prepectoid area, the enclosed space between these mesosternal carinae being very pubescent and concave. This concavity, however, is so obscured by pubescence that it can be discerned only after careful manipulation. In the center of the concavity is an elongate, rounded elevation. Middle coxae subcontiguous. Metasternum weakly concave medianly, with a median, longitudinal carina. This carina is conspicuous because of its dark color, and extends from between and posterior of middle coxae to the end of the medianly produced posterior margin of the metasternum between the slightly separated posterior coxae. Just ventral of the anterior end of the metasternal carina, the rnetasternum is produced into a thin tooth between the middle coxae.

Legs simple. Anterior and middle coxae strongly conical; posterior coxae much shorter. Femora slightly inflated. Tibiae slightly arcuate and slightly inflated. Tarsi very long and very slender, cylindrical, of even diameter throughout. First tarsomere very minute; second very long; third long, about two-thirds the length of second, and bearing two short arcuate slightly unequal claws.

Described from three male cotypes. Two taken at light at night on July 14, 1936; one at light at night on July 17, 1936. All collected by author on Barro Colorado Island, Gatun Lake, Panama Canal Zone.

This species is more closely allied to Sebaga centralis than to any other species of the genus so far known. From centralis it may be readily separated: centralis has the pronotal antebasal platform perfectly circular in outline; the apical half of the pronotum has the posterior lateral corners extended basally and then abruptly apically to form a broad tooth-like extension; last sternite with a simple, shallow fovea; length 1.0 millimeter; raffrayi has the pronotal antebasal platform transversely ovate; the apical half of the pronotum has the posterior lateral corners evenly produced and not extended posteriorly; last sternite of male with depression as described above; length 1.95 millimeters.

Until more information accumulates upon tergite proportions in Sebaga, $J u b u s$, and allied aggregates, the relative lengths of the first and second tergites should be dropped from generic keys. Sebaga centralis Raffray, Sebaga scydmaenilla (Sharp), and the new species of this genus described in this report have the first tergite longer than second. Raffray $(1890$, p. 300 and fig. 3, Plate 6) shows centralis to have this condition. Raffray (1908, p. 26) says that Sebaga has the first tergite not much larger than the second, and Jubus has tergite one much larger than tergite two. The confusion is increased by Raffray (1908, fig. 1, Plate 3 ) in which Jubus tetratomus Reitter is shown 
having the first tergite equal to or slightly shorter than the second, and this does not check with generic diagnosis (Raffray, 1908, p. 30). Distance between antennal bases and the consequent narrowing of front is a much more constant and reliable character in separating these two genera.

\section{Sebaga notonoda new species}

Length: $1.71 \mathrm{~mm}$. Greatest width: $0.59 \mathrm{~mm}$. Color as in raffrayi, with the body pubescence shorter, average length of setae 0.054 to $0.067 \mathrm{~mm}$.

Head rounded-triangular, broadest just posterior to the eyes, the eyes medium in size, composed of about 25 very coarse facets. Occiput less sinuate posteriorly than in raffrayi, with the occipital notch medianly much broader and less pronounced. Vertexal foveae more anteriad in position than in raffrayi, placed on a line opposite the second tier of facets of the eyes, and instead of being equidistant between the occiput and antennal insertions, the vertexal foveae are three-fifths of this distance from the occiput. Antennae with segments I and II equal in length and width; I ovate; II truncate apically; III and IV of the same length; VII a little longer than VI; VI and VII subrhomboidal, slightly produced for entire anterior face; VIII as long and as wide as IX; XI one and one-half times as long as X; otherwise as in raffrayi. Ventral surface of head with the typical V-shaped carinal pattern, but with the $V$ shorter than in raffrayi, the two arms of the $V$ and the posterior margin of the mentum forming an equilateral triangle; these carinae converging posterior of the $\mathrm{V}$ and enclosing an elongate-oval gular fovea. Head otherwise as in raffrayi.

Pronotum with the biarcuate transverse sulcus much deeper than in raffrayi; posterior angles of the anterior rounded-triangular half of the pronotum not evenly rounded as in raffrayi but posteriorly extended at the external-posterior angles to form a short cusp or tooth. Posterior to the transverse sulcus the sides are sub-dentate and then narrow obliquely in basal fifth. Lateral foveae in the transverse sulcus are vestigial, being represented by an indented, darkened area on the sulcal floor, near but not at the edge of the sulcus. Disc of the pronotum with the antebasal platform very different from that described for raffrayi. The antebasal platform, instead of being almost flush with the discal curve of the pronotum and more or less enclosed in the transverse sulcus, projects from the anterior median wall of the sulcus, and consequently the top of the platform is oblique with reference to the pronotal diac, and is parallel with the sharply sloping wall of the sulcus. Antebasal platform $(\mathrm{Pl} . \mathrm{XV}, 10)$ twice as wide as long, slightly dumb-bell shaped, with the median narrower part slightly sulcate; platform edges defined but not projecting over the column of the platform, that is, the top and column of platform not well differentiated; surface of platform slightly roughened, slightly convex. Each latero-basal angle of pronotum with an obscure, triangular fovea. Pronotum otherwise as in raffrayi. 
Elytra with the transverse basal carina not so irregular as in raffrayi, but instead paralleling the basal elytral margin; the three basal foveae less recessed beneath the transverse basal carina, and hence apparently larger than in raffrayi. Elytra otherwise as in raffrayi.

Abdomen with first tergite almost twice as long as second; second longer than third; third longer than fourth; fifth much larger than in raffrayi, twothirds as long as fourth segment. Third sternite somewhat longer than fourth; fifth sternite medianly very short, one-fourth as long as fourth, and consequently the rounded tubercle at middle extending for entire length of the fifth sternite; sixth sternite smaller than in raffrayi, flattened medianly, this flattened area extending for the length of the segment and for one-half of its width, with a small median concavity in this flattened area; posterior margin of sixth sternite less sinuate than in raffrayi. Otherwise as in abdomen of raffrayi.

Prosternum not longitudinally carinated, and the anterior coxal cavities not as sharply defined as in raffrayi. Mesosternum not examined. Metasternum evenly convex, with carina as in raffrayi. Posterior coxae slightly separated at base, the separation a little more pronounced than in raffrayi. Ventral surfaces and legs otherwise as in raffrayi.

Described from one male type. Collected by the author on Barro Colorado Island, Gatun Lake, Panama Canal Zone by sifting leaf mold of the forest floor at Zetek 23. July 27, 1936. 10:00 A.M.

This unique specimen is quickly separated from the male raffrayi by many characters enumerated above, but especially by the strikingly different antebasal platform. The species is also easily separated from the genotype, centralis Raffray, by the antebasal platform.

\section{Sebaga scydmaenilla (Sharp). 1887. Guatemala. (Duciola) (Pl. VII)}

I have two specimens of what I believe to be scydmaenilla. In assigning my specimens to this species, I feel a certain amount of doubt. Sharp (1887, p. 44 and Fig. 24, Plate I) gives a few lines in Latin and a few sentences in English, accompanied by a small, generalized drawing, as his description of this species. These data agree, as far as they go, with my two specimens. However, since scydmaenilla has not been recorded since the original citation of the Guatemalan type, which was a single badly-preserved, doubtfully female specimen, I have redescribed my material for future reference. As in the case of notonoda, this redescription is a comparative account of the differences between scydmaenilla and raffrayi. Such treatment focuses attention on differences, does not waste space, and if the standard of comparison has been described in the same paper there is no loss of accuracy. Redescription follows:

Length: $1.95 \mathrm{~mm}$. (length given by Sharp, loc. cit., $1.5 \mathrm{~mm}$.). Greatest width $0.8 \mathrm{~mm}$. Color as in raffrayi and notonoda, with the body pubescence average length being intermediate between these species, 0.067 to $0.08 \mathrm{~mm}$.

Head rounded-triangular, broadest through posterior third of eyes, the eyes intermediate in size between raffrayi and notonoda, composed of about 
32 facets (since my specimens are females, this eye size is unusual for the tribe, Raffray (1908) having pointed out that the female jubine tends to have smaller eyes than the males sex in the tribe, in the same species; since Sharp had only a female type, no sexual comparison was possible for him in this regard, and the male scydmaenilla may have eyes as large or larger than in raffrayi; certainly my female scydmaenilla have fewer facets than the male raffrayi but more facets than the male notonoda). Antennae quite different from raffrayi or notonoda, segments I and II equal in length and width; I ovate; II truncate apically; III, IV and VI of about same width; V slightly wider than IV or VI; IV, V and VI moniliform, V longer than IV or VI; VII longer and wider than VI, irregularly subquadrate, slightly produced on the anterior face; VIII, IX, X and XI forming a less distinct club than in raffrayi or notonoda; IX and X of about same width; XI nearly twice as long as X. Ventral surface of the head with the typical V-shaped pattern formed by oblique, converging carinae but with these converging carinae having their origin more medianly than in raffrayi or notonoda, and fusing at a point opposite the anterior third of the eyes; enclosed surface of the $V$ evenly concave, but then deepening centrally to form a clearly-defined, perfectly circular, shallow and flat-bottomed fovea. Head otherwise as in raffrayi.

Pronotum with the transverse median sulcus well-defined and perfectly straight for the median four-sixths of its width. Disc of pronotum with no antebasal platform, which instantaneously separates the males of centralis, notonoda, and raffrayi (females unknown) from the females of scydmaenilla (males unknown). Pronotum otherwise as in raffrayi.

Elytra with the transverse basal carina paralleling the basal elytral margin, and the sutural fovea recessed less deeply than in raffrayi. In these respects notonoda is similar to scydmaenilla. Elytra otherwise as in raffrayi.

Abdomen proportionately broader than in raffrayi and notonoda, which may well be a secondary sexual, rather than a species character. First tergite a little more than twice as long as second; fifth tergite small, one-half as long as fourth. Third sternite slightly longer than fourth; fourth and fifth sternites of equal length; no median tubercle on fifth sternite, and with its posterior margin not deeply incised (this latter being typical for females in general); sixth sternite one-fifth longer than the fifth, evenly convex, lacking a median flattened area or a median concavity, and with the posterior margin slightly produced medianly. Abdomen otherwise as in raffrayi.

Prosternum as in raffrayi. Metasternum much shorter than in raffrayi or notonoda, evenly convex, rather granular near posterior coxal articulation and also medianly in a longitudinal line, the effect being that of a subcarinate condition. Posterior coxae short, but longer than in raffrayi or notonoda. Tibiae less arcuate than in these two latter species, but slightly inflated; tarsal claws more unequal than in the two species named above. Ventral surface and legs otherwise as in raffrayi, save that the mesosternum could not be examined.

Redescribed on two females, both taken on Barro Colorado Island, Gatun Lake, Panama Canal Zone. One specimen was collected by the author from 
beneath the loose bark of a prostrate $\log$ on the forest floor, on July 27, 1936 . The second specimen was taken by Dr. E. C. Williams, Jr., from a sample of floor mold (No. 1433) on July 12, 1938.

The genus Sebaga is known imperfectly because the majority of the descriptions are based on one sex, or the sexes are not differentiated. Such a situation makes analysis difficult. Apparently the females have the sixth sternite simple, evenly convex, whereas the males have this sternite variously concave. Sharp described his single specimen in the genus Duciola, but Raffray (1908, p. 29) placed scydmaenilla in Sebaga. This species does not have the conspicuous antebasal platform which was stated as characteristic of the genus Sebaga by its author (Raffray, 1890, p. 300 and 1908, p. 29). Raffray must have known that the antebasal platform was lacking in scydmaenilla when he placed this species in Sebaga, and hence certain possibilities are available for study: (1) Sebaga may include species with and without the antebasal platform in both sexes, in which case subgeneric division would be admissable; (2) the antebasal platform may be diagnostic for males and lacking in all or some females; (3) the genus may have the antebasal platform in all species and both sexes, in which case scydmaenilla (Sharp) is misplaced; (4) the third possibility may be the true one, but Raffray studied the type of scydmaenilla and found that it had the platform but that it was overlooked by Sharp. This latter is hardly tenable, since Sharp would almost certainly have noted in his figure the presence of such a prominent feature.

\section{Key to the Species (Pl. XV)}

Pronotum with a median tubercle, antebasal platform or spinoid process just anteriad of, or associated with the transverse sulcus...

Pronotum with no median tubercle, antebasal platform or spinoid process...........scydmaenilla (Sharp) (females known only) ${ }^{1}$

2. Antebasal platform dorsally slightly concave, glabrous and shining, with carinated edges which project beyond the supporting column. .

Antebasal platform not so formed, tuberculate, spinoid, or transverse but without overhanging carinated margins.............. 4

3. Antebasal platform perfectly circular from above.............. ......................... kentralis Raffray (male known only) Antebasal platform transversely ovate from above............ .................... raffrayi new species (male known only)

4. Antebasal platform a strong spinoid process or tooth............ ..............denticollis (Schaufuss) (sex of type unknown)

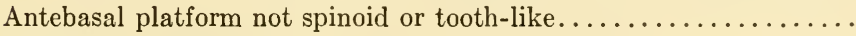

${ }^{1}$ It is perfectly possible that the two females which I have identified as scydmaenilla are in reality females of raffrayi, but I am loath to associate males with females arbitrarily in the same species unless there is substantial data for such an allocation; it is definitely certain that they are not females of notonoda in view of accumulative morphological evidence on many characters. 


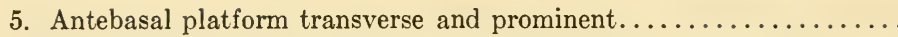

Antebasal platform a minute, transverse tubercle............... dilatata Raffray (male known only)

6. Antebasal platform a prominent, transversely rhomboidal tubercle . lamellata Raffray (male known only) Antebasal platform a prominent, transverse, amphidiscal or dumbbell shaped process, slightly narrower and sulcate medianly...... .notonoda new species (male known only)

The species of the genus Sebaga may be listed as follows:

centralis Raffray. 1890. Venezuela. Genotype.

denticollis (Schaufuss). 1872. Mexico. (Jubus)

dilatata Raffray. 1893. Brazil.

lamellata Raffray. 1893. Mexico.

notonoda new species. Panama Canal Zone.

raffrayi new species. Panama Canal Zone.

scydmaenilla (Sharp). 1887. Senahu, Guatemala (Sharp). Also from

Barro Colorado Island, Panama Canal Zone.

\section{JUBUS (Schaufuss, 1872)}

This the typical genus of the tribe; it has a very wide geographic distribution and many species. Although the species vary in the details of antennal segment proportion and shape, and in features of the pronotum and elytra, the habitus is common to the genus as a whole. Jubus may be easily separated from its ally, Sebaga, by the shape of the head and the amount of separation of the bases of the antennae as set forth in the tribal key to genera. The mouth parts of the genus have been described in some detail (Raffray, 1908, p. 25), and various aggregates (Duciola Reitter, Gasola Reitter, Gamba Schaufuss) have been incorporated in Jubus by Raffray (1903), so that the genus appears to be a natural assemblage, in so far as one may determine such a thing by assay of morphological details alone.

Sexes in Jubus are readily separated by a number of contrasting features. For example, the eyes of the female are distinctly smaller, and are composed of significantly fewer facets; the male generally has the ventral surface of the abdomen variously modified and concave, whereas the female usually has the abdomen simple and more or less evenly convex. Males may or may not have the legs armed with teeth or spines, but the females as a general rule have the legs simple.

Raffray (1903) has separated Jubus into seven groups of species, and this separation I have modified in a few respects to divide the genus into the Raffrayian categories, as follows:

First tergite very large, from one-third to twice as long as the second

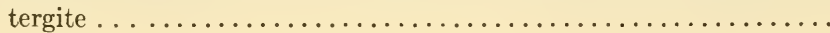


First tergite equal or subequal in length to second tergite; if longer, not more than one-fifth longer than second tergite............

2. Vertex with the median sulci vestigial, absent or just perceptible.... . GROUP I.

Vertex with two well-defined sulci.

3. Antennal club very distinct, clearly defined from rest of the antenna

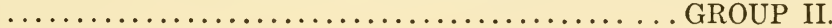

Antennal club indistinct. . .......................

4. Vertex with the sulci narrow, and with the vertexal foveae so small that they are not obvious, and in consequence, the sulci appear to

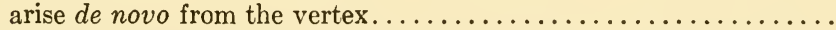

Vertex with the sulci and vertexal foveae well differentiated, the foveae broader than the sulci, so that the latter are seen to leave the foveae

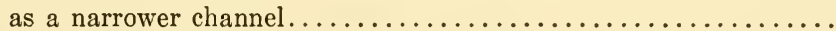

5. Antennal club distinct, composed of the last four segments, e.g. segments VIII, IX, $\mathrm{X}$ and XI......................

Antennal club indistinct............................

6. Antennal club distinct, composed of the last five segments, e.g. seg-

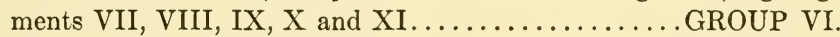
Antennal club indistinct.......................

\section{Jubus terranus new species}

Head $0.328 \times 0.335 \mathrm{~mm}$.; pronotum $0.369 \times 0.436 \mathrm{~mm}$.; elytra $0.469 \times 0.549$ mm.; abdomen $0.657 \times 0.643 \mathrm{~mm}$; t total length $1.84 \mathrm{~mm}$.

General body color light yellowish brown. Pubescence straw color, closely appressed; average length of body pubescence 0.0335 to $0.0536 \mathrm{~mm}$.

Head subtriangular, occiput strongly sinuate, broadly impressed at median posterior margin, this depression forming a broad basal notch. Eyes medium in size, composed of about 26 facets, not conspicuous. Vertexal foveae small, equidistant from the occipital margin and the anterior margin of antennal insertion on the front; the foveae close together, each fovea being much closer to its companion fovea than either is to its associated eye. A narrow sulcus proceeding anteriorly from each vertexal fovea, this sulcus being about the same diameter as the fovea, straight for the basal half of its length, then arcuate mesially to unite with the companion sulcus to form a common sulcus which ends at the center of the antennal tubercle. Front simple, almost vertical, greatly reduced between the antennal insertions to form a thick lamina. Antennae close together at base as typical for the genus, stout, eleven-segmented. Segment I very short from above and subquadrate, because of the expansion of its apical articular surface to the dorsal face; II not quite as wide as I, and from a certain point of view shaped like a parallelogram; III to VII gradually increasing in width; III obconic; IV to VII progressively more rhomboidal; VIII, IX, X and XI forming the club, and conspicuous because of their length, the four of about the same width; XI conical, truncate basally, subacute apically, the segment about two and a half times longer than X. Maxillary palpi small, first segment minute; 
second segment elongate, increasing in width to become clubbed at distal end; third segment wider than second, subtriangular; fourth and last segment largest in length and width, symmetrically fusiform, distal end acute, bearing a very short, blunt palpal cone. Lateral margins of head evenly rounded both anteriorly and posteriorly from the eyes. Ventral surface of head subglabrous. Mentum very wide, evenly concave. Cardo of maxilla produced into an elongate spinoid process to obscure base of maxillary palpi. Ventral surface of head with a long $\checkmark$ formed by two converging carinae, which unite medianly far behind the eyes and near the union of neck and gular-genal areas; this $V$ enclosing a triangular space which is raised from the rest of the ventral face, and enclosing two distinct foveae, a gular fovea at the posterior acute end of the triangle between the uniting carinae, and an apical fovea near the median posterior margin of the mentum.

Pronotum more or less heptagonal, broadest anterior to middle. Just posterior to middle, each lateral margin armed with a short but prominent acute tooth. Lateral margins sinuate anteriorly to this tooth to the antero-lateral angles of the pronotum, forming two sides of the heptagon. Apical pronotal margin, between these angles, in a broad, forwardly directed curve to form the two anterior angles of the heptagon. Posterior to the lateral tooth, each side abruptly narrower and sinuate to the rounded postero-external pronotal angles, forming two sides of the heptagon. Basal margin of pronotum straight, forming the seventh side of the heptagon. If the rounded anterior margin of the pronotum is considered as one side, then the pronotum dorsally may be spoken of as hexagonal. Disc of pronotum flat, with a well-developed sinuate transverse sulcus posterior to disc, this sulcus ending on each side at the base of the lateral tooth. Laterally, the transverse sulcus is expanded anteriorly, but lateral foveae are not apparent. No median fovea in transverse sulcus, but the anterior median margin of sulcus is differentiated into a slightly darker subtriangular area. From a purely lateral point of view, the base of the pronotum has an elongate, fusiform, obliquely-directed, well-defined depression.

Elytra with a transverse basal carina paralleling the basal margin. Sutural stria entire, ending basally in the sutural fovea. Lateral to this basal fovea, partially recessed beneath the transverse basal carina, are two more foveae, the discal and humeral. These two latter foveae are mutually more close to each other than are the discal and sutural foveae. No dorsal stria. Each elytron, therefore, with three nude basal foveae. Flank of elytron with a subhumeral fovea, from the edge of which arises a longitudinal carina; mesiad to this carina is a longitudinal sulcus which arises from the subhumeral fovea.

Abdomen with five visible tergites, decreasing in width to the subacute apex. Segments strongly margined. First tergite slightly longer than second, in the ratio of 3 to $2 \frac{1}{2}$; second tergite slightly longer than third; third and fourth subequally long; fifth shorter than fourth and triangular. Six sternites visible. First sternite forming an elongate triangle between posterior coxae, and visible shortly posterior to coxae and on each side of the coxae; second sternite longer than third in the ratio of $21 / 2$ to $1 \frac{1}{2}$; third almost twice as long as fourth; fourth 
slightly longer than fifth; sixth very large. Medianly the sternites are flattened, this flattening becoming more pronounced apically, and culminating on the fifth and sixth sternites. Fifth sternite short medianly, and deeply incised to contain the base of sixth; median posterior margin of fifth slightly produced, and with two transversely ovate foveoid depressions. Sixth sternite broadly and entirely concave, about four times as long as fifth.

Prosternum long before the coxae, obtusely longitudinally carinate in the anterior half. Anterior coxal cavities sharply defined. Mesosternum produced between middle coxae in a long spinoid process; middle coxae subcontiguous. Metasternum with a strong, longitudinal, median carina; the metasternum is long.

Anterior legs with the coxae prominently conical, the femora strongly inflated. Intermediate legs with the coxae much shorter, conico-ovoidal, femora less strongly inflated. Posterior legs with coxae conical, each trochanter armed with a very slender, translucent, aciculate spine which arises from the mesiobasal angle. Tarsi long, slender; segments of equal diameter; first tarsomere short, second and third tarsomeres very long, the third ending in two unequal claws. Above description of male holotype.

Female Allotype. Resembling the male holotype save for the following secondary sexual differences: Eyes much smaller than in the male, consisting of six coarse facets. These facets are arranged four in a ventral row and two in a dorsal row. Sternites unmodified, convex. Second sternite long, longer than first in the ratio of $2 \frac{1}{2}$ to $11 / 2$, and longer than the third in the ratio of $21 / 2$ to $11 / 2$. Third sternite longer than fourth in the ratio of 1 to 0.8 ; fifth and sixth sternites medianly of same length, simple; the sixth sternite sharply, semicircularly incised in median third of hind margin. Femora moderately inflated but the posterior trochanters are wholly simple and unarmed. Metasternum much shorter than in the male, in the ratio of $\mathbf{2 . 8}$ for holotype metasternal length to 2 for allotype metasternal length.

Described from six specimens, all collected by Dr. E. C. Williams, Jr. in the floor mold of the rain forest on Barro Colorado Island, Gatun Lake, Panama Canal Zone, as follows: Holotype male and paratype male in mold sample No. 1118 on July 17,1938 . Allotype female in mold sample No. 1034 on July 19, 1938. Paratype female in mold sample No. 34 on July 24, 1938. Paratype male in mold sample No. 103 on July 24, 1938. Paratype female in mold sample No. 345 on July $29,1938$.

Jubus terranus is a member of Group IV, since I interpret this group as having the vertexal foveae minute rather than absent, and hence the vertexal foveae in Group IV are small, of the same diameter as the vertexal sulci, whereas in Groups VI and VII they are conspicuously larger than the associated vertexal foveae. Such an interpretation of Raffray's group key (l.c.) is entirely consistent with the anatomy of the genus, and takes into account the less powerful and less illuminated equipment of earlier days. If such an interpretation is not made, then the suggestion arises that there are no vertexal foveae, or that such foveae are not in any way associated with their vertexal sulci, and this view is 
not at all consistent with the anatomy of the genus. Furthermore, if Jubus terranus is not assigned to Group IV, then it would go to a new group, since the presence of vertexal sulci, minute vertexal foveae, first two tergites subequal in length, and a distinct antennal club of only four segments, bars the species from Groups I, II, III, V, VI, and VII.

Much better data for its place in Group IV are obtained by checking its similarities with the other species in this group. Jubus terranus is similar to tetratomus (Reitter), caviventris Raffray, gracilicornis Raffray and related species; it is distinct from all these forms on the described anatomy, especially the male secondary sexual characters, antennal proportions and sternal features.

\section{Jubus chickeringi new species}

Total length $0.837 \mathrm{~mm}$. Greatest width $0.295 \mathrm{~mm}$.

Color light brown with the antennae, maxillary palpi and legs paler. Body pubescence yellowish cream, short, appressed. Average length of body pubescence 0.02 to $0.034 \mathrm{~mm}$.

Head rounded-triangular, eyes large and prominent. Eyes composed of about 36 small facets. Occiput sinuate with a clearly defined median notch. Temporal angles rounded, their length less than the longitudinal diameter of the eye from a dorsal view. Vertex evenly convex, conspicuously higher than the eyes; vertexal foveae minute, nude, not wider than their associated sulci, and situated on a line which passes through the middle of the eyes. Vertexal sulci as in terranus. Antennal insertions close together at base, narrowing the front as in the typical pattern for the genus. Front almost vertical, simple. Antennae eleven-segmented, segment I large, as wide as II; III, IV, V, VI, and VII narrower than II; III a little longer than IV, of equal width; V, VI, VII progressively transverse, subrhomboidal, with their lateral basal angles progressively reduced; VIII, IX, X, and XI forming a distinct club, these segments progressively slightly wider; VIII wider than II; XI narrowly truncate at base, broadening rapidly to basal third and then narrowing slowly to the subacute apex. Maxillary palpi four-segmented, first segment minute; second elongate, arcuate, slightly clubbed distally where it articulates with the third; third shorter, triangular, wider than second; fourth large relatively, wider than third segment, as long as other three segments, widest beyond base, then lengthily acute to apex which has a small palpal cone. Ventral surface of the head typical for the genus, with the wide mentum and produced cardo. Eyes prominent ventrally. Tempora long ventrally, their length distinctly greater than the longitudinal diameter of the eyes from a ventral view. V-shaped pattern very clear, the converging carinae fusing to form the apex of a triangle or $V$ at a point near the posterior limit of the eyes. Posterior to this fusion, the converged carinae continue to the base of the head, where they are lost in a semicircular sulcus which separates the neck from the head. Enclosed surface of the $V$ regularly arcuate in its longitudinal diameter, from a high point at the fusion of the 
carinae, to a low point just back of the mentum. Sides of the head subcarinate anterior of the eyes, and evenly rounded posterior of the eyes.

Pronotum wider than the head, with the transverse arcuate sulcus dividing the pronotum into two unequal portions; anterior portion is more than twice as long as the posterior portion, and a third wider. This anterior part is subrhomboidal, with the sides converging to the semicircular apical border on each side from a very small acute tooth, this tooth arising opposite the transverse sulcus on each side. Posterior to this lateral tooth, the basal portion of the pronotum is formed by the sides becoming abruptly narrower. Transverse sulcus curves posteriorly on each side and ends just below the marginal tooth.

Elytra with the base transversely carinate. Each elytron with three basal foveae recessed beneath the transverse carina. Sutural fovea gives rise to an entire sutural stria. There is no dorsal stria. The median and lateral foveae are mutually closer than is the median to the sutural. The humeri are not dentate. Flank of each elytron with a conspicuous longitudinal carina; this carina is abruptly arcuate basally to recess the rather large subhumeral fovea. Each elytron, then, with three basal foveae and a subhumeral fovea; an entire sutural and epipleural stria but no dorsal stria.

Abdomen with five visible tergites, narrowing to a subtruncate apex. First and second tergites subequal in length; third tergite shorter than second; third and fourth tergites subequal in length; fifth tergite rounded triangular, about as long as fourth. Six visible sternites; first sternite broadly triangular between posterior coxae; second sternite as long as first; third sternite long, as long as second; fourth sternite one-half as long as third; fifth very short medianly, a third as long as fourth, deeply, semicircularly incised to contain the sixth sternite; sixth large, medianly twice as long as the fourth sternite, and the median posterior margin deeply incised. The ventral surface of the abdomen is conspicuously, medianly concave; all of the sternites are involved, with their median halves flattened or concave and differentiated from the sloping sides. This concavity is notable on the second and third sternites, where the limits of the concavity are subcarinate. The sixth sternite has a secondary median concavity.

Prosternum prominent anterior of the coxae, and medianly gibbous but not carinate. Mesosternum laterally carinated. Metasternum very long, as long as first and second sternites united, but not carinated medianly; it is medianly concave. All coxae well-developed, the anterior coxae very prominently conical; middle coxae apparently contiguous and elongate-ovoid; posterior coxae also very prominent, conically produced mesially, and subcontiguous. The conical portion of each posterior coxa is carinate on the mesial face, and the mesialposterior angle is produced in a sharp point. Trochanters not armed. Femora slightly inflated, the anterior pair especially. Tarsi three-segmented, elongate, cylindrical in the jubine pattern, first tarsomere minute; second and third much longer, subequal in length, the third ending in two claws.

Described from one specimen, a male. This type was collected by the author on July 25, 1936, on Barro Colorado Island, Gatun Lake, Panama Canal Zone, from moist stage four log mold at Drayton 12. 
I take pleasure in naming this distinct species for my young friend, Donald Chickering, with whom I spent many happy hours in the Central American forest. This species belongs to Group IV, and can be readily separated from terranus on many characters, e.g. the posterior tronchanters are not spined, metasternum not carinate medianly, entirely different pronotal outline, shorter pubescence and much smaller size.

\section{Jubus turneri new species}

Total length $0.8 \mathrm{~mm}$. Greatest width $0.29 \mathrm{~mm}$. (Pl. VII.)

Unless stated otherwise, the following details are drawn from the holotype male; certain details were obtained from slide mounts of male paratypes, where magnifications of from 500 to 1000 diameters could be used. Such magnifications are indicated.

Color light yellowish-brown, with the antennae, maxillary palpi and legs paler. Body pubescence yellowish-cream, short, appressed. Average length of body pubescence 0.02 to $0.035 \mathrm{~mm}$.

Head rounded-triangular, eyes medium large, prominently semicircular from the dorsal view, composed of about 30 moderately coarse facets. Occiput is broadly sinuate but not medianly notched. Temporal angles rounded and prominent, their length equal to the longitudinal diameter of the eye from a dorsal view. Vertex evenly convex, conspicuously elevated above the eyes. Vertexal foveae minute, nude, of same diameter as the associated sulci, and placed on a line passing through the middle of the eyes; vertexal sulci straight in their basal half, then medianly arcuate to form a common sulcus; this common sulcus extends medianly between the antennal prominences, to medianly notch the abruptly vertical front between the antennae. Antennae eleven-segmented; close together at insertions, narrowing the front in the typical genus pattern; segment I and II large, equal in width; I quadrate; II oval; III and IV subequal in length and width, subspherical; V to VII narrower than II; V to VII progressively wider, V transversely ovate, VI transversely ovate and subrhomboidal, VII transversely rhomboidal; VII not as wide as VIII; VIII, IX, X and XI forming a club, these segments progressively slightly wider, the club distinct from a dorsal view and indistinct from a lateral view; XI slightly longer than VIII, IX and $\mathrm{X}$ united, narrowly truncate at base, broadest at basal third then lengthily narrowing to subacute apex.

Maxillary palpi out of the ordinary for the genus, the following taken from slide mounts of four male paratypes. Four-segmented. First segment unusually large, $0.013 \mathrm{~mm}$. long, cylindrical, slightly wider at apex, sharply angulated at middle so that the segment is bent nearly to a right angle. Second segment 0.018 $\mathrm{mm}$. long by $0.018 \mathrm{~mm}$. wide, strongly triangular, and very little longer than large first segment. Third segment $0.018 \mathrm{~mm}$. long by $0.018 \mathrm{~mm}$. wide, pyramidal, with the narrow face basal, and the broad face apical. Fourth segment $0.054 \mathrm{~mm}$. long by $0.027 \mathrm{~mm}$. wide, significantly larger than other segments, pedunculate-securiform, broadest medianly, tapering rapidly to base and slowly 
to apex, apex armed with a relatively long, very aciculate palpal cone. The palpi are unusual in that the first three segments, although differing in shape, are more or less equal in length.

Ventral surface of head typical for genus. Mentum conspicuously concave. Cardo produced from base and partially obscuring mouth-parts. Tempora with their length equal to the longitudinal diameter of the eye from a ventral view. Eyes prominently extended medianly from a ventral view, to narrow the genalgular field near the mentum. $V$-shaped pattern clear on lower face of head, the converging carinae fusing to form the apex of a long triangle or $V$, the fusion taking place at a line drawn through the posterior margins of the eyes; basal to this fusion, the carinae enclose a small, elongate gular fovea, and continue to the neck. Enclosed surface of the $V$ regularly arcuate in its longitudinal diameter, from a point distinctly anterior to the fusion of the carinae, to a low point just back of the wide mentum. Sides of head subcarinate anterior to the eye and evenly rounded posterior to the eye.

Pronotum in two lobes, an anterior subrhomboidal and a posterior transversely oblong lobe. These lobes separated by a clearly defined, arcuate, transverse sulcus. Anterior lobe nearly four times as long as basal lobe, with the sides evenly arcuate to the semicirculately produced apical margin, and obliquely narrowed from this widest level, to the transverse sulcus. No sign of a tooth or spine on the pronotal margins, in both triangle and slide-mounts. Basal or posterior lobe nearly one-half narrower than anterior lobe, sides evenly and slightly arcuate, from transverse sulcus to relatively straight basal margin.

Scutellum very minute, acute-triangular.

Elytra radically different from many species of genus: each elytron with only two basal foveae. These foveae are relatively large, nude, and lie just posterior to the biarcuate transverse basal carina. Sutural stria entire. No dorsal stria. Humeri sub-dentate, this condition being due to the structure of the elytral flank: each elytral flank has a longitudinal carina which is sharply bent, nearly at a right angle, near the humerus, so that the humerus appears in relief from rest of flank. Beneath this apical flexure of the carina is a large subhumeral fovea.

Abdomen with five visible tergites: first tergite very large, as long as the second and third tergites united; second tergite slightly longer than third; third one-fourth shorter than the fourth, so that both the second and fourth tergites are longer than the third; fifth is small, triangular and inconspicuous. Six sternites visible, first sternite broadly triangular between the coxae; second sternite very large, one-half longer than the first and medianly very gibbous or tumid, with a transverse fossa at its base. In slide-mounts, under high magnification, this transverse fossa is seen to have considerable depth, and to have carinate edges. Third sternite simply convex, one-third as long as second; fourth sternite as long as third; fifth very short medianly, one-half as long as fourth, medianly incised to hold the large, transversely ovate sixth sternite; sixth three times as long as fifth, concave in median basal half, medianly slightly produced at posterior margin. 
Slide-mounts show the penis to be large, $0.126 \mathrm{~mm}$., long; longer than the third, fourth, and fifth sternites united, in four male paratypes.

General punctation of the dorsal body surface very minute, the punctules each bearing a seta. In slide-mounts of four male paratypes, one female paratype and female allotype, the following averages obtain: pronotal disc with 4 to 5 punctures per 0.04 sq. mm.; elytral disc with 7 to 8 punctures per 0.04 sq. mm.; tergites with 3 to 4 punctures per 0.04 sq. mm.; these punctures small, very isolated, not recessed.

Prosternum medianly gibbous anterior to coxae, but not carinate.

Mesosternum laterally carinate each side, to form the usual ante-coxal plate between the middle coxae and prepectoid area.

Metasternum very large, twice as long as first sternite, or about one-fifth shorter than first and second sternites united; medianly with a longitudinal entire carina, this carina strong in basal two-thirds of its length.

In slide-mounts of both sexes, under high magnification, the following sternal foveae are demonstrable: lateral prosternal foveae, one anteriad of each of the anterior coxae in the basisternum; lateral mesosternal foveae well developed, in the prepectoidal wall just anteriad, and on each side of the mesosternal field or ante-coxal plate noted above; median mesosternal fovea, unpaired, at anterior end of ante-coxal plate. This mesosternal fovea can be seen in triangle mounts as well. Other foveae, e.g. vertexal, gular, etc. have been previously noted. The second sternite has a well-developed pair of foveae, long, cylindrical, whorled lumen. These are placed one just above each side of the transverse fossa at base of second sternite, and hence parallel to the fossa, with the orifice opening laterally, and the fovea ending medianly near the center of the fossa. These foveae are present in both sexes.

Coxae shorter than in chickeringi. Anterior coxae conical, longest. Middle coxae conico-ovoidal, in slightly confluent cavities, the mesosternal and metasternal processes not quite meeting, the coxae subcontiguous. Posterior coxae shortly conical, contiguous or very nearly so, with the metasternum just perceptibly visible between them as a microscopically acute point.

Femora moderately inflated. Tarsi three-segmented, cylindrical, first tarsomere minute, second and third very much longer, the second slightly longer than third; end of distal segment with two arcuate, equal claws.

Allotype female differs from the holotype male as follows: size, color, pubescence, maxillary palpi, pronotum, elytra are not different. Eyes vestigial, reduced to two facets on each side of the head, giving a long, evenly arcuate and convergent aspect to the tempora. This great reduction of eye is typical of the tribe, but in this species reaches a maximum expression.

Antennae like the male, save that the segments VIII, IX, and X are not so asymmetrical, XI shorter, not quite so long as VIII, IX, and X united, and the club is indistinctly formed as compared with the males.

Ventral surface of the head is different in that the converging carinae form a very long triangle or $V$-shaped pattern, these carinae fusing where head and neck meet, and enclosing a shorter gular fovea. 
Metasternum very much shorter than that of the male, $0.09 \mathrm{~mm}$. long, about as long as the first sternite between the posterior coxae. The metasternum is carinated longitudinally and medianly, however, as in the male.

Tergites with the first long, one-half longer than the second, but not so long as in the male.

Sternites differing. First as in the male; second long, two-sevenths longer than third, with a median transverse fossa at base. However, the fossa in the female is less deep and slide-mounts show no carinate edges, although the whorled ante-fossal foveae are well-developed. Third longer than fourth; fourth longer than fifth; sixth also longer than fifth.

Comparison of the two sexes of this species bring out the interesting point that while a concave ventral abdominal surface often designates a male, it is not a universal rule since the male venter in this species is not concave as it is in chickeringi. Secondly, the metasternum may be medianly carinate in the male sex only, or in both sexes. On the other hand, the males have relatively large eyes and a long metasternum, while the females have relatively small eyes and a short metasternum.

Described from seven specimens as follows: Holotype male collected by the author on July 25, 1936, from moist, stage four (wholly decayed) log mold at Drayton 17, on Barro Colorado Island, Gatun Lake, Panama Canal Zone. One male paratype with the same data.

Three male paratypes collected by the author, on the same island, July 29 , 1936, from beneath the loose bark of a log at Pearson 4 .

Allotype female and one paratype female collected by Dr. Eliot C. Williams, Jr., from the same island. The paratype on July 15, 1938 in mold sample No. 1148, and the allotype on July 21, 1938 in mold sample No. 716.

I take pleasure in naming this distinct species for my colleague, Prof. C. L. Turner, who spent part of a summer with me in the Canal Zone. This is another minute species of Jubus, about the same size as chickeringi, but wholly different in numerous particulars. Jubus turneri belongs in Group II by virtue of the elongate first tergite in both sexes. Its other peculiarities include the two basal elytral foveae, and differently constructed venter.

This is the first species to be recorded in Jubus between Mexico and South America in Group II. Other species of this group are known from Brazil, Bolivia, and Colombia on the south, and one from Acapulco, Mexico on the north. The Mexican Jubus punctatus (Sharp) is so vaguely described that only a single structural difference can be cited: Sharp notes that punctatus has the elytral punctation strong and cribrate, whereas turneri has the elytral punctation very slight, sparse, and minute; quantitatively, these two species are easily separable on size, punctatus being $2.33 \mathrm{~mm}$. long and turneri significantly less than a millimeter in length. Similarly turneri differs from others in the group by its small size and described anatomy. It is distinct from such large species as brevis Raffray of Bolivia, $1.7 \mathrm{~mm}$. long with dentate humeri, and is more closely allied to the small liliputanus Raffray of Brazil. 
Including the three new species of Jubus, this neotropical genus has fortynine known species: in the catalogue which follows, the Roman numeral designates the Raffrayian group, a key to which has been given previously.

\section{I}

laeviceps Raffray. 1893. Brazil.

brevis Raffray. 1903. Bolivia.

decipiens Raffray. 1893. Colombia.

liliputanus Raffray. 1893. Brazil.

punctatus (Sharp). 1887. Mexico. (Duciola)

spinicollis Schaufuss. 1872. Colombia. (schaufussi Raffray, 1883)

trouessarti Raffray. 1896. Brazil.

turneri new species. Panama Canal Zone.

vulpinus Raffray. 1893. Brazil.

\section{III}

argus Raffray. 1893. Brazil.

heterocerus Raffray. 1918. Paraguay.

lativentris Raffray. 1893. Brazil.

IV

alternans Raffray. 1918. Paraguay.

caviventris Raffray. 1890. Venezuela.

chickeringi new species. Panama Canal Zone.

gracilicornis Raffray. 1903. Mexico.

hetschkoi Raffray. 1893. Brazil.

inermis Schaufuss. 1887. Colombia.

insularis Raffray. 1908. Guadeloupe, Leeward Islands.

pallidus Raffray. 1893. Colombia.

laticollis Raffray. 1883. Venezuela.

longicornis Raffray. 1893. Brazil.

punctulatus Raffray. 1890. Venezuela.

semipunctatus Schaufuss. 1872. Colombia.

subopacus Schaufuss. 1872. Colombia.

terranus new species. Panama Canal Zone.

tetratomus (Reitter). 1882. Venezuela. (abbreviatus Raffray, 1890) (Duciola)

V

aberrans (Sharp). 1887. Guatemala. (Duciola) (Placed in fifth group with doubt) 
coeculus Raffray. 1896. Brazil. (Placed in sixth group in 1903, replaced in fifth group in 1908 by Raffray)

laetus Raffray. 1890. Venezuela.

longipennis Raffray. 1883. Colombia.

\section{VI}

clavatus Raffray. 1903. Grenada, Windward Islands.

grouvellei Raffray. 1893. Brazil.

intermedius Raffray. 1893. Brazil.

\section{VII}

bifossulatus Raffray. 1893. Brazil. brasiliensis Raffray. 1893. Brazil. crassipes Raffray. 1909. Brazil. convexiusculus Raffray. 1893. Brazil. (convexinscutus Raffray, 1908) dominulus Raffray. 1893. Brazil. gracilis Raffray. 1893. Brazil. microcephalus Raffray. 1893. Brazil. microphthalmus Raffray. 1893. Brazil. quadratus Raffray. 1893. Brazil. simoni (Reitter). 1882. Brazil. (Gasola) sinuatus Raffray. 1893. Brazil. subrectus Raffray. 1893. Brazil.

\section{Group UnKNown}

brucki (Schaufuss). 1872. New Granada (Colombia?) (Gamba) elongata (Schaufuss). 1872. Argentina. (Gamba) rugicollis (Schaufuss). 1872. Argentina. (Gamba)

\section{BARROJUBA new genus}

Jubinini having: (1) large eyes, composed of coarse facets, in the male sex; (2) vertexal foveae vestigial or absent; (3) eleven-segmented antennae with the last four segments long, subequal in width, to form a club, the antennae being close together at their insertion, narrowing the front; (4) typical carinated pattern of ventral surface of head being $Y$-shaped, with a glabrous, unifoveate enclosed area; (5) pronotum unidentate each side at basal third, and with no transverse sulcus; (6) elytra with a single basal fovea (sutural) on each elytron, no dorsal stria; well-developed subhumeral fovea and longitudinal carina on elytral flank; (7) abdomen with five visible tergites, and six visible sternites; (8) prosternum transverse, not medianly carinate anterior to coxae; (9) coxae conical; anterior coxae separated, very long; middle coxae long, contiguous; posterior coxae short, contiguous; (10) tarsi three-segmented, elongate, later- 
ally compressed, second tarsomere very much longer than third, third tarsomere ending in a pair of unequal claws.

Genotype: Barrojuba albertae new species

\section{Barrojuba albertae new species}

Measurements: Head $0.469 \times 0.469 \mathrm{~mm}$; eyes $0.201 \mathrm{~mm}$. long; antennae $0.904 \mathrm{~mm}$. (club $0.569 \mathrm{~mm}$.) long; cervicum $0.067 \mathrm{~mm}$.; pronotum $0.482 \times 0.603$ $\mathrm{mm}$.; elytra 0.683 at suture $\times 0.871 \mathrm{~mm}$. at posterior third; abdomen $0.75 \mathrm{~mm}$. x $0.8 \mathrm{~mm}$.; first tergite $0.24 \mathrm{~mm}$., second tergite $0.19 \mathrm{~mm}$., third tergite 0.16 $\mathrm{mm}$., fourth tergite $0.10 \mathrm{~mm}$., fifth tergite $0.05 \mathrm{~mm}$.; hind tibiae $0.67 \mathrm{~mm}$.; hind tarsi $0.45 \mathrm{~mm}$., first tarsomere $0.03 \mathrm{~mm}$., second tarsomere $0.3 \mathrm{~mm}$., third tarsomere $0.12 \mathrm{~mm}$., tarsal claws $0.04 \mathrm{~mm}$. long claw; total length $2.45 \mathrm{~mm}$. x 0.87 $\mathrm{mm}$. greatest width. (Pl. XVIII.)

Color reddish-brown with maxillary palpi, antennae and legs yellowishbrown. Pubescence abundant, long, golden; average length of body pubescence 0.067 to $0.12 \mathrm{~mm}$.

Head rounded-triangular. Eyes very large, hirsute, much longer from a dorsal view than sides of head either anterior or posterior of the eyes; composed of about 56 very large, coarse facets. Tempora converging slightly behind eyes, not prominent. Occiput medianly sinuate. Vertex simple, evenly convex, not appreciable higher than eyes. Vertexal foveae very far forward, on a line passing just posterior to posterior margin of first antennal segment, vestigial, small and difficult to locate, appearing as a pair of minute, oblique scars, without much depth, mutually close together (being separated by the width of two eye facets), as though they were the byproduct of the articulation of the first antennal segment with the mesio-dorsal wall of its acetabulum. These scars may not be true vertexal foveae, viz. they may not have a connection with the cephalic endoskeleton, in which case true vertexal foveae are lacking. Vertex and front densely, cribrately, coarsely punctate (about 24 to 32 punctures per $.01 \mathrm{sq} . \mathrm{mm}$.) ; front evenly and continuously declivous, simple, strongly narrowed by antennal acetabula.

Antennae eleven-segmented, I and II large; I longer and wider than II; I and II suboblong; III shorter and narrower than II, obconical; IV, V, VI, and VII gradually and progressively wider than III; IV obconic; V subquadrate; VI and VII progressively transverse and trapezoidal; VIII, IX, X and XI forming a long, distinct club, abruptly longer than VII, subequal in width, slightly wider than VII; VIII, IX, and X cylindrical; VIII twice as long as VII, and a little longer than IX, and subequal in length to $\mathrm{X}$; XI ovate-acuminate, twice as long as $\mathrm{X}$.

Maxillary palpi four-segmented; first segment minute, cylindrical; second segment long, slender, pedunculate at base, broadening apically; third segment broader and shorter than second, pyriform, broadening apically; fourth segment largest, broader than third and longer than second, ovate-acuminate, densely clothed with very short setae and bearing apically a small palpal cone. 
Ventral surface of the head typical of the tribe. Mentum large, transverse, concave. Cardo with the base notably produced, this produced portion is especially thick, forming a large, equilateral triangular piece on each side of the mentum. Two oblique, very sharp, high carinae fuse medianly at a point opposite the posterior third of the eyes, forming a thin, low common carina, to give a $Y$-shaped pattern. The neck and head ventrally are separated by a wellformed semicircular sulcus, and at the point where the common median carina approaches this sulcus, the carina sharply bifurcates to enclose the gular fovea. On both sides of the common carina the head is subopaque, clothed with shaggy setae, but the enclosed triangular field, between the forks of the $Y$, is glabrous, shining and concave, with a darkened, minute, pore-like fovea near base of mentum.

Pronotum campanulate, similar to many species of Jubus in its contour, but unique in the tribe by having no trace of a transverse basal sulcus. A strong short, triangular, acutely-pointed tooth situated on each side at basal third. Anterior to this tooth, each side is sinuate, then evenly arcuate to apex, to form a transverse anterior portion which includes two-thirds of the pronotal length. Posterior to this tooth, each side is immediately, semicircularly incised to form a short, narrower basal portion, with subacute basal angles. A large, foveoid depression on each side of the pronotum, mesiad of lateral tooth. Disc of pronotum covered largely by a conspicuous triangular glabrous area, which begins near the anterior margin, and broadens regularly to include most of the basal portion of the pronotum. The basal area of this triangular, glabrous region is sparsely granulate. The sides of the disc, about this glabrous region, are punctate and closed with long setae so that the shining area is very distinct. In the middle of this triangular, glabrous field is a weakly elevated, fusiform area which includes five large, raised punctures in the form of a $\mathrm{V}$, with the median basal puncture bearing a remarkably long, thick, spinoid seta. No trace of a transverse sulcus.

Scutellum visible, triangular.

Elytra clothed with long pubescence, and evenly punctate; humeri subdentate due to the strong transverse basal carina. Each elytron with an entire sutural stria and a single basal fovea, the sutural, which lies at the origin of the sutural stria, partially recessed by the transverse basal carina. No dorsal stria, but a vague depressed area mesiad of each humerus. Elytral flank with a strong, longitudinal carina which begins at the humerus, and a large, circular, nude subhumeral fovea.

Abdomen with very strong margins, long, evenly tapering to rounded apex. Five visible tergites, with proportions indicated by previous measurements, densely pubescent. Six visible sternites; first sternite short, obscure between the coxae; second sternite longest, slightly longer than third; third slightly longer than fourth; fourth slightly longer than fifth; fifth weakly incised to hold sixth; sixth sternite very transverse, shorter than fifth, and deeply concave in median apical half. All sternites more or less flattened medianly. Third, fourth and fifth sternites foveate on each side of median flattened area; these 
foveae appear to be complex, and to open into short, transverse sulcoid depressions. Second sternite with a pair of basal carinae on basal half, obscured by the posterior trochanters.

Prosternum broad, flat, transverse, pubescent, not medianly carinate anterior to the coxae. Mesosternum relatively very elongate for the tribe, and narrow and pubescent. Metasternum moderately elongate, medianly gibbous and medianly longitudinally carinate. Anterior coxae very prominent, conical, separated by a flat prosternal process which is medianly carinate. Middle coxae prominent, conical, contiguous. Posterior coxae short, medianly conical, contiguous. The legs are long, simple and unmodified, with long, compressed tarsi. Tarsomeres with proportions as noted previously, ending in two arcuate, unequal claws.

Described on one male type, collected by Dr. Eliot C. Williams, Jr., from Barro Colorado Island, Gatun Lake, Panama Canal Zone, in floor mold sample No. 1438. July 6, 1938. It gives me pleasure to name this species for my wife, who accompanied me on an expedition to the American tropics. The genus Barrojuba has no near allies as a consequence of its described anatomy. It is placed near Jubus, with which it has more affinities than with any other jubine aggregate.

\section{BALEGA (Reitter, 1881)}

dentata Raffray. 1904. Mexico.

elegans Reitter. 1883. St. Thomas, Virgin Islands. Genotype.

PHAMISUS (Aube, 1844)

reichenbachi Aube. 1844. Colombia. Genotype.

reitteri (Raffray). 1883. Colombia. (Jubus)

velutinus Raffray. 1904. Bolivia.

STRATUS (Schaufuss, 1872)

ursinus Schaufuss. 1872. Mexico. (Teapa); also New Orleans, Louisiana?

villosulus (Motschulsky). 1855. Panama. (Canthoderus) (generic place doubtful, based on a sketch by Motschulsky).

ENDYTOCERA (Sharp, 1887)

oognata Sharp. 1887. Panama.

vestita Sharp. 1887. Panama. Genotype. 


\section{Tribe 4. Euplectini, sensu latiore}

After considerable study of the American fauna I have combined the Euplectini, sensu strictiore, and the Trichonychini into a single tribe.

Apparently the only character separating these two aggregates concerns the tarsal claws. Thus Raffray $(1903,1908)$ says of Euplectini "tarsi with a single or principal claw, and at times also an accessory, claw-like hair" and of Trichonychini "two unequal claws on each tarsus, the small or accessory claw is curved, and not to be confused with a hair." Bowman (1934, p. 2) says of Euplectini "inner tarsal claw absent or exceedingly minute" and of Trichonychini "inner tarsal claw very small but distinct, at least one-fifth as long as the outer."

These differences are insufficient to separate two groups of genera which inhabit much the same zoögeographic range, the same ecological niches, and resemble each other in many basic morphological features. If the claw formula was rigid, with one group having one claw and the other group having two claws, the two aggregates could be separated for practical purposes; this still would not demonstrate a fundamental arrangement. Leng (1920) followed Raffray in using both tribes; such a course was proper, since Raffray's opinion held, will always hold, great authority, but as data accumulate such a course becomes less advisable. American students of the family have not found the employment of both tribes wholly profitable. Thus, early workers, such as Brendel and Wickham (1890) and the brilliant Casey (1893, p. 442 and 1897, p. 552) opposed such a course; recently Bowman (1934, p. 8) separated the two groups with apparent reluctance, since he felt that a still further break-up of the euplectines might be justifiable "especially if the Trichonychini be removed."

Casey bitterly opposed separation of these two groups of genera, and his remarks in one instance (1893) will bear quoting:

"The tribes or groups Euplectini and Trichonychini of Reitter and Raffray cannot be maintained as distinct and natural aggregates of genera, and should be united to form the single tribe Euplectini. The auxiliary (tarsal) claw varies by successive degrees in different genera and species otherwise closely related so that it is impossible to draw any line of demarcation between two groups founded upon this character or any other which it seems possible to discover.

The second tarsal claw is distinctly visible as a minute hair-like appendage in at least several species of European Euplectus, in Trimiopsis, and also in Actium, which was recently re-described by Mr. Raffray under the name Proplectus and placed in the "Trichonychini". I have seen the second rudimentary claw plainly in Bibloporus bicanalis and Euplectus californicus. Finally in (Ramecia crinita) the auxiliary claw becomes as large, conspicuous and fully formed as in Trichonyx itself, and yet in general habitus and details of structure crinita is unmistakably very closely allied to Euplectus, and should be not widely separated from that genus. 
The so-called second claw is always in the nature of an appendage, even in Trichonyx, Oropus and other typical trichonychide genera. That is to saythe large claw is in every case perfectly in the plane of the axis of the tarsus, the auxiliary claw projecting laterally from its base."

I have the same feeling concerning the evaluation of the tarsal claws as Casey, and consequently treat the two groups of genera as one tribe, Euplectini. Without going into lengthy detail here, since species descriptions can be studied by anyone interested in the problem, slide mounts of tarsi under high magnification show the truth of the inapplicability of the secondary tarsal claw as a prime character. Thus the North American specialized Rhinoscepsis bistriatus LeConte has a secondary claw over half as long and a third as thick as the primary claw. Again, although one of the new species from Central America, Panaramecia williamsi, has a secondary claw fully half as long as the primary claw, most of its anatomy indicates a position near such euplectine genera as Bibloplectus, Pteroplectus and Ramecia.

The Euplectini is a very large tribe, with an average size which is small, even for the family; they are very difficult to study. Of cosmopolitan distribution, the group has a combination of characters which almost always renders tribal designation simple. Few pselaphid genera of other tribes are confused with euplectines, although exceptions can be found; for example, Eupsenius of the Brachyglutini has many characteristic euplectine features.

Euplectines have the typical three-segmented pselaphid tarsus, with the first tarsomere very minute, and the second and third tarsomeres relatively very much larger than the basal segment. The articulation of the trochanters with the femora is typically brachysceline; that is, the trochanter is short and not clubbed apically but very obliquely articulated with the femur so that the latter closely approaches the coxa. The mentum is not greatly expanded transversely to cover the mouth-parts as in the Jubinini, but is normally small, and the cardo of each maxillary palpus is also normally small and not externally produced at the base in a long spinoid process. Finally, the posterior (metathoracic) coxae are very transverse, save at the mesial face where they articulate with the trochanter of the posterior legs; this mesial, articulating face is abruptly conical, or conically produced instead of being globular or broadly triangular.

The maxillary palpi are relatively primitive for the great majority of the species, being four-segmented with the first segment very minute; second segment elongate, slightly arcuate, narrow basally and slightly clubbed or inflated apically; third segment shorter than second, globular, triangular or pyriform; fourth segment largest, oval or fusiform, more or less rounded-truncate at base, acuminate at apex, the latter bearing a small, usually aciculate palpal cone.

The dorsal surface of the head (vertex, front), antennal insertions, form of the antennal segments, pronotum, abdomen and tarsal claws are diverse in the tribe. Such variation is specific, but in many instances sexual, and this diversity is demonstrated in the keys, descriptions and illustrations which follow. 
The abdomen is generally elongate, strongly margined, and of five to six visible tergites; ventrally there may be six visible sternites in both sexes, or six in the females and seven in the males. In the latter case, the seventh sternite may be in one piece, or longitudinally divided into a right and a left pygidial plate. The male sex often has the sternites secondarily modified.

Euplectini offer a promising field for evolutionary study. Such an investigation is not contemplated in the present paper, since the world fauna must be taken into such calculations. The American euplectines appear to culminate in the cluster of genera which includes Melba, Dalmosella, Basolum, Pseudotrimium, Trimiomelba, Actium, Actinoma, Trimiosella and their allies. In these genera there is a general summation of morphological features away from the staphylinid pattern. This is suggested by increasing glabrosity, consolidation of sternal sutures and foveae, increasing prominence of the distal antennal segment, and in many of these genera the signal development of specialized capitulate setae on the ventral surface of the head. These trimiforms or melbaforms appear to have affinities with some of the Brachyglutini, for example Eupsenius and Eupsenina.

If the assumption is made that pselaphids have evolved from staphylinoid ancestors, and morphological evidence has been presented for such a view, then development in the euplectines must be based on more and more remote organization from the staphylinid stem. For example, the following criteria may be taken into brief consideration:

1. General consolidation of the body, including head, thorax and abdomen, is considered a specialization of great weight, carrying the family from Staphylinidae, through Faronini, into Clavigerinae. Such consolidation leads to increasing abdominal immobility, loss of sutures, reduction of sternal foveae and finally loss of sternal foveae.

2. A general vestiture of simple setae is considered primitive, but either a glabrous condition, or highly modified setae such as capitulate or scales, or a combination of glabrosity with modified setae, is considered specialized.

3. Tarsi with two equal, simple claws are considered generalized. Bilaterally asymmetrical claws, reduction in the size of one claw, or presence of a single claw are considered progressively specialized.

4. Tendency towards filiform or moniliform antennae with a loose weakly developed club is considered primitive, but the development of a large antennal club and the progressively larger distal segment of the club, is considered specialized.

5. Simple four-segmented maxillary palpi are primitive, whereas increasing specialization of the palpi is viewed as more highly evolved.

6. A penial plate, increasing the number of visible sternites in the male sex to seven, is more primitive than six sternites visible. Where this plate is longitudinally divided into a right and left piece by the pygidial carina, the combination is more primitive than a single penial plate. This single penial plate may move asymmetrically to the right, or to the left.

7. The bilaterally symmetrical aedeagus, with lateral lobes, is more primitive than the asymmetrical aedeagus, with fewer parts. 
We must be very cautious in using those structural features which may be secondary adjustments, such as the reduction of mouth-parts for a specialized diet, as in the Clavigerinae; or the reduction or loss of eyes and wings in one or both sexes. It is quite possible that a genus may be primitive in its general anatomy, but will have certain parts highly specialized. Thus Rhinoscepsis is a primitive genus in many respects, but there is a reduction in eyes and wings. Species living habitually in deep soil, caves, or the nests of ants and termites are usually illustrations of this idea.

\section{Key to THe Genera}

Prosternum with a median longitudinal carina (lateral straight or oblique carinae may or may not be present separating the prosternum from the pronotum, but these are not involved; where the prosternum is medianly carinate, the carina extends from a point between the bases of the anterior coxae, across the sternum, ending

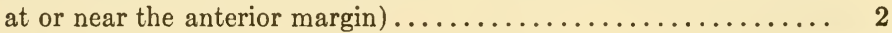

Prosternum with no median longitudinal carina............. 6

2 (1). Base of each elytron with four foveae (the basal foveae lie in a line between the suture and the humeral angle; these basal foveae do not include a subhumeral fovea which may or may not be present just posterior of the humerus and on the flank

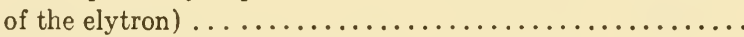

Base of each elytron with fewer than four foveae...........

3 (2). Ventral surface of head with a fine, median carina..........

Ventral surface of head with a median sulcus ............. PTEROPLECTUS

4 (2). Second tergite armed, a prominent tubercle on each side, in the male (female unknown) ...............FARONOMA Second tergite not armed or laterally tuberculate in either sex

5 (4). Disc of pronotum simple, with no central fovea or foveoid depression....................... BIBLOMIMUS

Disc of pronotum with a central depression which varies from a small fovea to an elongate, fusiform, longitudinal foveoid

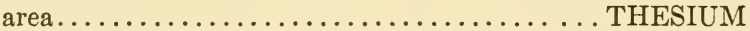

6 (1). Base of each elytron with four foveae............. 7

Base of each elytron with fewer than four foveae........ 10

7 (6). Sides of pronotum with one or more distinct teeth ${ }^{1} \ldots \ldots \ldots .8$

Sides of pronotum not dentate ${ }^{1} \ldots \ldots \ldots \ldots \ldots \ldots \ldots \ldots . \ldots \ldots$

${ }^{1}$ The presence or absence of teeth must be clearly understood. There are three basic types of lateral pronotal margins involved in the Euplectini: entire, in which the margin is a simple line; crenulate, in which the margin is thrown into a series of waves or undulations, the period of the wave varying with the species, but the waves being continuous, not discrete entities; dentate, in which the margin is periodically erected into discrete elevations. These elevations are nearly always prominent, acute teeth or spines, with sharp- 
8 ( 7 ). Pronotum with a small, subspherical to subcylindrical anterior lobe, and a very large posterior lobe, the small anterior lobe acting as a bearing for the equally small pedunculate neck

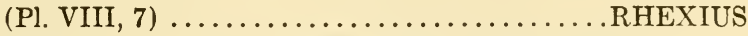

Pronotum without such a small anterior, pedunculate lobe....

9 ( 8 ). Lateral pronotal margins unidentate, each side bearing a single tooth at middle of subbasal area....................

Lateral pronotal margins pluridentate, each side bearing five to six teeth (Pl. VIII, 10) ........EURHEXIUS (in part)

10 (6). Base of each elytron with three foveae.............. 11

Base of each elytron with two foveae............... 21

11 (10). Eyes invisible from above..............MITRACEPHALA

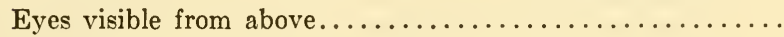

12 (11). Disc of pronotum simple, with no trace of a fovea or a longi-

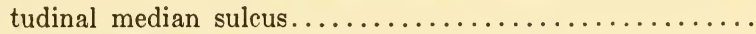

Disc of pronotum with either a median longitudinal sulcus, or a central fovea or foveoid depression.................

13 (12). Sternite IV very short, much shorter than II and III which are subequal in length.................LIOPLECTUS

Sternites II, III and IV subequal in length, or gradually de-

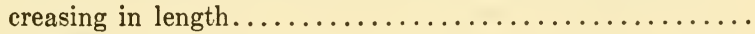

14 (13). Lateral pronotal margins entire; elytral base simply foveate, having a transverse basal carina........ACTIUM (in part)

Lateral pronotal margins with a small subbasal tooth, and crenulate anterior to this tooth; base of each elytron with a multiarcuate, transverse, basal carina, the basal foveae being vestigial, and appearing as pits, one under each arc of the transverse carina..........PANARAMECIA, new genus

15 (12). Dise of pronotum with either a central fovea, or a foveoid depression ............................. 16

Disc of pronotum with a long, median, longitudinal sulcus....

16 (15). Ventral surface of head with a few stout, strongly capitate, rather spiniform setae; basal tergites with no basal carinae

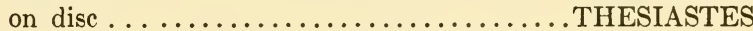

to-blunt ends; in several species the elevations are subdentate, minute and blunted denticles. Thus a tooth may be distinct, but require high magnification to discern its form, this latter condition is especially notable in the fifth group of Eurhexius with subdentate margins, as contrasted with Aporhexius and Rhexinia with crenulate margins.

In some cases there is a combination of these features. Thus Panaramecia has a basal tooth, and anterior to this tooth the margin is minutely crenulate. Again in Fletcherexius the margin is subentire, with the area opposite the lateral pronotal fovea slightly granular so that the line of the pronotal margin appears similar to our North American Rhexidius in part.

The above remarks refer to dry mounts on points. Microscope slides under high magnification may show a crenulated margin to be composed of asperate tubercles, as in some Thesium. 
Ventral surface of head with no capitate setae, the setae present being simple, acute, recurved; basal tergites with a pair of short basal carinae on disc of segment................

.EUPLECTUS (in part)

17 (15). Pronotum with both the transverse sulcus and the median longitudinal sulcus rudimentary and just discernible. RHEXINIA Pronotum with both transverse and longitudinal sulci strongly formed and clearly visible.................... 18

18 (17). Lateral pronotal margins entire................... 19

Lateral pronotal margins either crenulate or dentate...... 20

19 (18). Pronotum as wide as head; first tergite very large, much longer than second tergite.................ADROGASTER

Pronotum much wider than head; first tergite only a little longer than second tergite..............ANARMODIUS

20 (18). Lateral pronotal margins crenulate..........APORHEXIUS

Lateral pronotal margins with five to six teeth (PI. VIII, 10) .EURHEXIUS (in part)

21 (10). Front of head prolonged into either (a) an elongate rostrum, or (b) a median spinoid process, or (c) a dilated process extending far beyond antennal insertions................

Front of head not abnormally prolonged in any of these ways. .

22 (21). Restricted to termite nests; front irregular and abnormal, prolonged far beyond antennal insertions..... PHTEGNOMUS Not inhabiting termite nests; front prolonged into a conspicuous antennal rostrum, with antennae articulated at the distal end of this tubercle, nearly contiguous; vextex and genae with complex, tortuous sulci (Pl. IX, 2) ...RHINOSCEPSIS

23 (21). First three tergites highly abnormal in male sex (female unknown), the lateral margins of first two tergites being deeply concave and polished; sides of third sternite extending dorsally as an apically fimbriated, rounded lobe to clasp the posterior angle of the second tergite; a tuft of scales in a slight depression, above each lobe ( $e x$ Fletcher)....ALLOBROX

Tergites not so modified in either sex..................

24 (23). Pronotum with a median, obtuse but well developed, longitudinal carina passing over the disc........ NEODALMUS Pronotal disc simple and unmodified, or centrally foveate, or longitudinally sulcate, but never with a median longitudinal

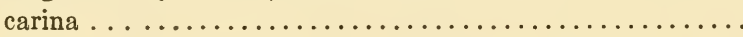

25 (24). Pronotal disc simple, with no trace of fovea or sulcus........ Pronotal disc either centrally foveate, or longitudinally medi-

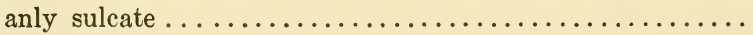

26 (25). Pronotal dise with a median longitudinal sulcus............ Pronotal disc centrally foveate or with a central foveoid depression .................................. 
27 (26). Pronotal disc slightly flattened, and from an oblique point of view there is a just discernible elongate depression TRIMIOPSIS (in part)

Pronotal disc with a well formed central fovea or foveoid de-

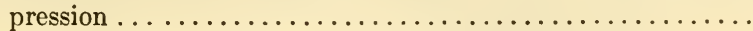

28 (27). Pronotum with a subbasal, transverse, arcuate sulcus........ .EUPLECTUS (in part)

Pronotum with two lateral foveae and a median foveoid depression at base, these three areas not connected by a transverse subbasal sulcus of any kind...................

..BARROEUPLECTOIDES, new genus

29 (25). Posterior coxae not contiguous, either slightly or widely

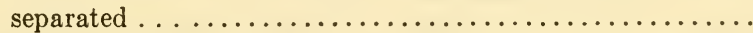

Posterior coxae contiguous, or so close that they are virtually so

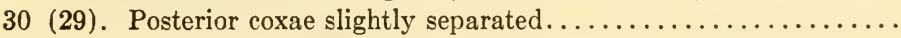

Posterior coxae widely separated, the first sternite appearing between them as a transverse plate EUPSENINA (this genus will key out here if the shape of the posterior coxae has not been correctly diagnosed. It belongs in Brachyglutini).

31 (29). Each elytron with a long, sharply defined, nearly entire dorsal stria on the disc, this stria extending for about three-fourths of elytral length.................. TOMOPLECTUS

Each elytron with either (a) a short dorsal stria, (b) a short fusiform dorsal depression from discal median fovea, or (c) no dorsal stria or depression.................... 32

32 (31). Elytral humeri dentate to denticulate or acutely prominent... Elytral humeri prominent or not, but never dentate or acute. .

33 (32). Base of elytra simply foveate, without a transverse basal carina............................. (in part)

Base of elytra with a transverse carina parallel to the basal elytral margin.

ACTINOMA

34 (32). Pronotum with lateral foveae invisible from a strictly dorsal

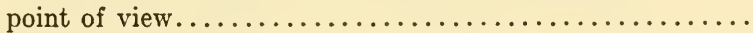

Pronotum with the lateral foveae wholly or partially visible from a strictly dorsal point of view..................

35 (34). Integument pubescent, punctate to punctulate; subbasal, transverse sulcus continuing down flank of prothorax to end laterally each side in a fovea; these fovea are not visible from above, and lie near or on the sides of the prosternum (Pl. XI, $7,8) \ldots \ldots \ldots \ldots \ldots \ldots \ldots \ldots \ldots \ldots \ldots \ldots \ldots \ldots \ldots \ldots \ldots \ldots \ldots$

Integument glabrous, without punctures or pubescence; the subbasal, transverse pronotal sulcus absent or represented by a just discernible linear impression which ends on the sides of the prothorax in a vague depression............ 
will key out here if the shape of the posterior coxae has not been correctly diagnosed. It belongs in the Brachyglutini). (Pl. XIV)

36 (34). Tenth antennal segment symmetrical and lenticular (biconvex

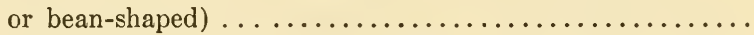

Tenth antennal segment asymmetrical and transversely tri-

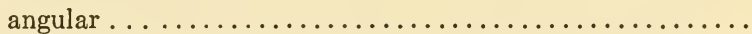

37 (36). Dorsal surface of head with a pair of deep, longitudinal sulci which are parallel to each other, and do not unite anteriorly .TRIMIODINA

Dorsal surface of head without sulci, or the sulci very vestigial, hardly perceptible ..........................

38 (36). Head small, triangular, distinctly narrower than pronotum .PSEUDOTRIMIUM

Head large, much wider than pronotum............... TRIMIOPSIS (in part)

39 ( 7 ). Pronotum with a median, longitudinal sulcus which is nearly entire and extends from near base to near apex, crossing the transverse subbasal sulcus at right angles (Pl. VIII, 11).................. FLETCHEREXIUS, new genus

Pronotum with disc either (a) wholly unmodified, or (b) with

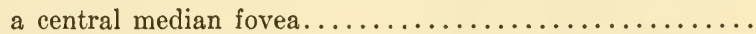

40 (39). Pronotal disc simple, not foveate; tenth and eleventh antennal segments bilaterally asymmetrical; tenth segment much wider and longer than the ninth, and of a rounded-triangular shape, very asymmetrically articulated on the antero-mesial face of the ninth, so that both ninth and eleventh segments are in contact laterally and widely separated mesially by the wedge of the tenth segment (Pl. VI, 10)...MELBAMIMA Pronotal dise with a median fovea; tenth and eleventh antennal segments bilaterally symmetrical; tenth segment normal, transversely pyramidal, and normally articulated......... .VERABAROLUS, new genus

41 (26). Head small, much longer than wide; first two tergites of equal length; tarsi with a single claw.............ACOTEBRA Head large, more or less transverse; first tergite longer than second; tarsi with two claws of nearly equal length, the inner claw much thinner and slightly shorter...............

ANARMODIUS (in part)

42 (9). Ventral surface of the head with a strong median sulcus; pronotal margins with a strong tooth near the middle, on each side; base of elytra with four foveae but no transverse basal

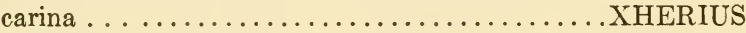

Ventral surface of the head with a basal, circular gular fovea but no median sulcus; each lateral pronotal margin with a 
small subbasal tooth and crenulate from the tooth to anterior third; base of elytra with four small, rudimentary foveae on each elytron, these foveae being apically margined by a triarcuate or quadriarcuate transverse basal carina........

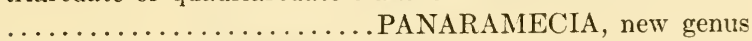

43 (30). Integument punctulate and pubescent.... DALMOPLECTUS Integument glabrous, without punctures or pubescence..... EUPSENIUS (this genus will key out here if the shape of the posterior coxae has been incorrectly diagnosed. It belongs in Brachyglutini).

44 (37). Head with two vertexal foveae; lateral margins of the pronotum sharply defined, with the lateral fovea on each side wholly within the margin, and wholly visible from a dorsal view (female known only).............. TRIMIOSELLA

Head with four strongly formed foveae, two vertexal foveae widely separated and on a line passing through the posterior half of the eyes, and an anterior pair of foveae, closer together and near the frontal margin, one slightly behind and mesiad of each antennal prominence; lateral pronotal margins smoothly rounded as in Melba, but the lateral subbasal fovea visible on each side from a dorsal point of view...... .RAMELBIDA, new genus

\section{FARONOMA (Raffray, 1894)}

cavangula (Reitter). 1894. Chile. Genotype. (Rybaxis)

The single species of this genus, originally described in Rybaxis of the Brachyglutini, transferred to Faronini in the genus Faronoma by Raffray, and subsequently (1903) placed by Raffray in the Trichonychini, is here placed in the enlarged Euplectini. It is one of two monotypic genera of trichonoforms in which the male sex is known only, and in this sex the tergites are remarkably modified. In this species the male has subequal tergites and the second tergite has each lateral margin strongly tuberculate and armed. Described from Valdivia, Chile, it has not been recorded since.

\section{ALLOBROX (Fletcher, 1928)}

dampfi Fletcher. 1928. Mexico. Genotype.

The author of this remarkable species has this to say regarding its affinities: "Allobrox is without doubt more closely allied to the Chilian Faronoma than to any other of the Trichonychini. These two genera are alone in the tribe in possessing modifications of the dorsal abdominal segments reminding one of Brachygluta." 


\section{ANARMODIUS (Raffray, 1890)}

Six visible sternites in male and female; male with femora more inflated, and the anterior femora tuberculate.

\section{KeY to the SPECIES}

Each elytron with three basal foveae................. gibbus

Each elytron with two basal foveae................ bifoveatus

gibbus (Schaufuss). 1872. Brazil. (Trichonyx) Genotype.

bifoveatus Raffray. 1891. Venezuela.

\section{FLETCHEREXIUS new genus}

This genus is erected primarily for Eurhexius macrodactylus Fletcher (1928). It appears to be more closely related to the eurhexiforms with edentate pronotal margins (Anarmodius, Aporhexius, Rhexinia) than to the genera having dentate margins (Xherius and Eurhexius as limited here), but warrants isolation on the remarkable tarsal claws, length of the eleventh antennal segment, pronotal outline and elytral foveae.

Macrodactylus was described on three doubtfully male specimens collected in 1925 from decaying log mold of Abies religiosa, between 3000 and 3200 meters near Mexico City.

Salient structural features are the shining punctate-granulate integument; transverse head, but slightly narrower than pronotum; very small, oval eyes; medianly placed vertexal foveae; a small, deep fovea behind each antennal tubercle; occiput with a median longitudinal sulcus which passes forward to just anteriad of the vertexal foveae; antennae eleven-segmented with segments III, IV and V small and moniliform, VI, VII and VIII slightly increasingly transverse, the XI slightly longer than VIII, IX and X combined. Ventral surface of head with capitate setae. Pronotum distinctive. I examined a paratype of macrodactylus in the National Museum (U.S.N.M. No. 44612) and found the lateral pronotal outline (PI. VIII, 11) to strongly suggest our North American Rhexidius (Pl. VIII, 1). These outlines are subentire, widest slightly posterior to the middle of the pronotum, strongly convex anterior of this point, ending in a rounded obtuse apex, and slightly sinuate posterior to this widest point to the subtruncate base with rounded posterior angles; the lateral margin in the basal third granulated so that, under high magnification the margin gives the impression of being composed of about five very minute, blunted denticles; median longitudinal sulcus deep and extending from basal margin to apical sixth; transverse pronotal sulcus in basal third, crossing longitudinal sulcus at right angles, the junction being broadened, and ending each side in an ovate pubescent lateral fovea. Each elytron with a subepipleural carina and subhumeral fovea on elytral flank, and four basal foveae. The first of these foveae, the sutural, is the most apical and gives rise to the sutural stria; the 
second, or discal fovea is the most basal of the foveae and gives rise to a discal stria; the third and fourth are close together and give a paired appearance since their striae arise laterally and unite along the basal rims of the foveae, as in Thesium. Abdomen with subequal tergites and six sternites, of which latter the first is very short, shorter than posterior coxae; second, third and fourth sternites subequally long, evenly convex; fifth broadly emarginate; sixth transverse. Metasternum convex, medio-posteriorly slightly impressed. Tarsal claws very unequal and distinctive. An accessory claw less than half as long as primary claw, and about one-half as wide, that is, very thick for its length. Primary claw large, over twice as long as the accessory claw, and instead of becoming narrower to an attenuated apex, holds its width to the distal fifth where it is abruptly and ventrally acute, thus being apically inflated. macrodactylus (Fletcher). 1928. Mexico. Genotype. (Eurhexius)

The remarks about to be made on Eurhexius are also pertinent to Fletcherexius and any wholesale consolidation of the eurhexoid aggregates will involve the above genus as well.

\section{APORHEXIUS (Raffray, 1903)}

Pronotum with the lateral margins distinctly crenulated, as in the North American Rhexidius Casey. This character serves to separate Aporhexius from Fletcherexius where the lateral pronotal margins are subentire save for a crenulate-granulate area opposite the lateral pronotal foveae.

Pronotum with the median longitudinal and transverse subbasal sulci strongly formed, as in Fletcherexius and Eurhexius. This character separates Aporhexius from Rhexinia, the only other neotropical eurhexiform genus with distinctly crenulated pronotal margins.

Male metasternum slightly sulcate medianly and this sex with the last sternite impressed and medianly glabrous.

Pubescence unusually dense.

pubescens Raffray, 1903. Bolivia. Genotype.

\section{RHEXINIA (Raffray, 1890)}

Pronotal margins laterally crenulate, and with the longitudinal and transverse sulci virtually absent or so poorly developed as to be just perceptible. Head and pronotum confluently punctate and granular. Six visible sternites.

angulata Raffray. 1890. New Grenada (Colombia?). Genotype. versicolor Raffray. 1908. Guadeloupe, Leeward Islands.

\section{XHERIUS (Raffray, 1890)}

cordicollis Raffray. 1890. Venezuela. Genotype. 


\section{EURHEXIUS (Sharp, 1887)}

This is the largest of American eurhexiform genera (Raffray's second group of Trichonychini, 1908), containing about 25 species. Its central taxonomic position (analogous to Jubus in Jubinini) in the eurhexiforms, numerous species and wide distribution (Uruguay to Guatemala) make its examination necessary. The species all have a homogeneous habitus. Size range is large, from one to nearly four millimeters, with a thick body and integument more or less granulate and pubescent. The head is very transverse, subreniform, with prominent tempora. Maxillary palpi typically four-segmented, first segment small, short; second longer than wide, slender basally, inflated apically, sinuate; third small, much shorter but slightly wider than second; fourth large, ovoid-acuminate to subsecuriform, heavily pubescent. Antennae elevensegmented as usual, slightly geniculate, first segment relatively long and cylindrical; second globular; third to seventh submoniliform, narrower than second, with some variation in the species as to length and width of segments; club formed of the last three segments which gradually increase in width and length as a rule, the last segment being much larger than the tenth as a rule, acute-pyriform to obtuse-conical. Ventral surface of the head with the sulciform fossa for reception of the maxillary palpus on each side, well developed as typical for the eurhexiform genera. Pronotum (Pl. VIII, 10) cordiform, conspicuously narrowed anterior of the middle, but not forming a small pedunculate lobe as in Rhexius; disc crossed by a narrow, deep, entire longitudinal median sulcus and a subbasal transverse sulcus; lateral margins always armed with teeth, usually six in number, these teeth varying in size from very large spine-like projections (sexpunctatus Raffray) to minute teeth (muticus Raffray), but always present and always discrete, not merging to form a crenulate margin as in the North American Rhexidius and the neotropical Rhexinia and Aporhexius. Elytra subquadrate, with rounded humeri; each elytron with three or four basal foveae (usually four). Abdomen large, usually longer than elytra, and strongly margined. Tergites subequal or slightly shorter in progression. Six relatively simple sternites in both sexes, making sexual differentiation difficult or very doubtful without dissection. Prosternum flat, transverse, laterally carinated on each side. Tarsi three-segmented, first tarsomere small, second and third much longer than the first, with the second usually slightly thicker and much longer than third; two unequal claws, the external claw large, over half as long as the inner claw.

With his usual acumen, Fletcher (1928) has observed that in setting up the genus Eurhexius, Sharp (1887) did not specify lateral pronotal teeth in vestitus, parviceps, ventralis, and trimiodes, nor show pronotal teeth in his figure of vestitus. Such negligence on the part of Sharp has left some doubt as to the composition of Eurhexius, and as Fletcher noted, if Sharp's species (of which I have not seen the types) do not have pronotal teeth, then Rhexidius Casey (August, 1887) of North America becomes a synonym of Eurhexius Sharp (April, 1887) of the American tropics. I doubt this very much, especially since Raffray $(1903,1908)$ definitely allocates Sharp's four species in Eur- 
hexius, along with many other species known to have well formed pronotal teeth. It is a pity that such an important genus should have been so vaguely described as to allow confusion in its composition. Raffray (1903) cited Sharp's four species and rugulosus (Reitter) as of doubtful status-a strange situation in which the great majority of the genus could be placed, but the genotype could not!

Raffray (1908), in his great generic treatment, defined Eurhexius as always having lateral pronotal teeth or tubercles, and incorporated rugulosus (Reitter) and the four species of Sharp without any query. Raffray made so few mistakes (an exception being application of the wrong priority with Thesium and Apothinus), that between 1903 and 1908 he must have seen the Sharp types; at least that is a strong inference which would account for the change in status of these doubtful species between these two dates.

There is another line of indirect evidence to substantiate the presence of pronotal teeth for Eurhexius, in these doubtful species. In 1882 Reitter described three species of Rhexius, namely simoni, rugulosus, and procerus. In the case of simoni and procerus his descriptions state definitely that the lateral pronotal margins are denticulate, whereas in rugulosus he states that the pronotum has the lateral margin without denticulations. This is a definite statement by a competent coleopterist. Sharp (1887), in erecting Eurhexius, has no doubt that "Rhexius simonis and R. procerus, Reitter, belong to it." Therefore Sharp included the two species of Reitter, known to have pronotal teeth, with his four species, and did not mention rugulosus of Reitter, which was described in the same paper and did not have pronotal teeth. The inference is that Sharp's four species, with vestitus as a probable genotype, have pronotal teeth. Other Eurhexius by Raffray follow this position.

This consolidates the limits of Eurhexius, with the exception of Rhexius rugulosus Reitter, which I am unable to place. This latter species may belong in Anarmodius or Fletcherexius if the pronotal margins are not dentate, or in Aporhexius if these margins are crenulate; or if Reitter did not correctly describe his specimen, and subsequent examination of the type by Raffray showed pronotal teeth, it belongs in Eurhexius. I doubt the last assumption on the basis of Reitter's reputation.

If Raffray (1908) is wrong as to Eurhexius, then at least seven related genera will have to be reëxamined comparatively from the types; for example, Eurhexius may be found to contain Sharp's four species with vestitus as genotype, rugulosus (Reitter) and macrodactylus Fletcher. In this case the species of Raffray, and others by Schaufuss, Reitter, and the author, probably belong in a new genus.

Until further research can clear up the obscurity, my position is that of the Raffray 1908 diagnosis. Raffray (1903) divided Eurhexius into five groups of species, which I have had to modify slightly:

Each elytron with three basal foveae...................... I

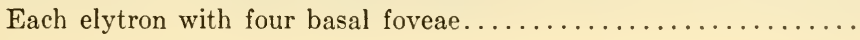


2. Lateral pronotal margins with about six sharply defined, acute teeth. .

Lateral pronotal margins with about six very minute, blunted but discrete denticles, of which one may be larger.........Group $\mathrm{V}$

3. Tempora with the posterior angles pointed, subdentate... . Group II Tempora with the posterior angles rounded, not subdentate........

4. Antennae with segments $\mathrm{IX}$ and $\mathrm{X}$ at least as long as wide, if not longer than wide................................ III Antennae with segments IX and $\mathrm{X}$ slightly or distinctly wider than

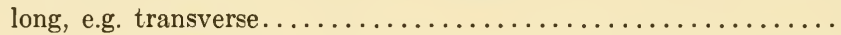

5. Antennae with segments III to VIII all transverse, wider than long Group IV, first section.

Antennae with segments III to VI having length and width equal, and segments VII and VIII slightly transverse..............

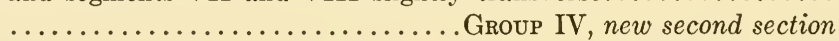

The following keys to the species of Eurhexius are offered tentatively with the exception of rugulosus Reitter, which appears to belong in some other aggregate (vide supra):

Key to the Group I Species

Species known from Central America................... 1

Species known from Brazil........................ 4

1. Basal antennal segment twice as long as second segment; first visible tergite twice as long as second.................. ventralis

(2.5 mm., 3000-4000 ft., Volcan de Chiriqui, Panama)

Basal antennal segment not twice the length of second; first two

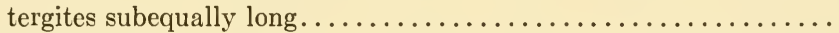

2. Antennal segments VII and VIII slightly broader and shorter than

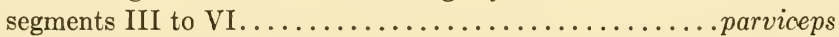

(2.12 mm., 8000 ft., Volcan de Chiriqui, Panama)

Antennal segments III to VIII of equal length and width, similar...

3. Integument polished, pubescence short...............trimiodes

(1.5 mm., 8500-10500 ft., Totonicapan, Guatemala)

Integument not shining, more or less opaque, pubescence dense and

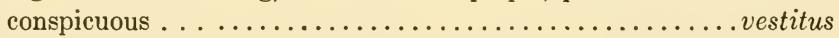

(2.12 mm., 2000-3000 ft., Volcan de Chiriqui, Panama)

4. Length $1 \mathrm{~mm}$; long, brown pubescence............. sexpunctatus

(Blumenau, Brazil)

Length $2 \mathrm{~mm}$.; shorter, sparse pubescence............ longicornis

(Blumenau, Brazil)

\section{Group II}

The second group contains but a single species, simoni (Reitter). In this species, described from Sao Paulo, Brazil, at 3000 feet altitude, the length is given at 3.0 millimeters and the pronotum is much more densely punctate than the head or elytra. The acute temporal angle separates it from the rest of the genus. 
Key to the Group III Species

Here belong six species, unusual for the length of the antennal segments. Species known from south of 32 south latitude..........putzeysi

(Montevideo, Uruguay)

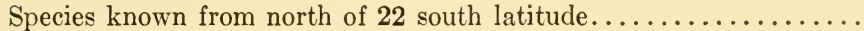

2. Third tergite with two short median spines near the apical margin, the margin slightly depressed and emarginate between these pro-

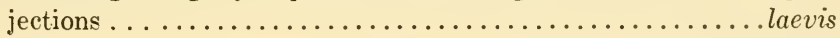

(2.0 mm.; Bahia, Brazil)

Third tergite not so modified.

3. Fourth tergite strongly, longitudinally carinate.......... procerus (3.0 mm.; $3000 \mathrm{ft}$; Sao Paulo, Brazil)

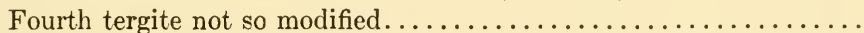

4. Head relatively less transverse, one-third narrower than the pro-

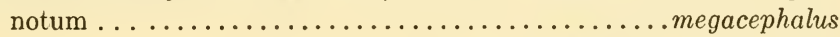

(2.0 mm.; Matto Grosso, Brazil)

Head relatively very transverse, subequal to the pronotum in

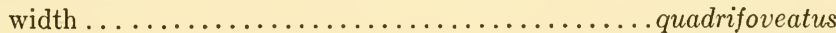

(2.4 mm.; Brazil)

This key does not include majorinus (Schaufuss), of the Amazon river system, Brazil.

\section{Group IV}

Key to Species of First Section

This key does not include two species, insignis (Schaufuss) and angustatus (Schaufuss), of the first section.

Second antennal segment quadrate....................... 3

Second antennal segment ovate....................... 2

2. Antennal segments IX and X slightly larger than VIII.subacuminatus (2.0 mm.; Blumenau, Brazil)

Antennal segments IX and $\mathrm{X}$ very abruptly larger than antennal segment VIII . . .........................topunctatus

(.1.8 mm.; Blumenau, Brazil)

3. Elytra red, rest of body nigropiceus.............. rubripennis

(2.2 mm.; Argentina)

Coloration of body uniform rufous or ferrugineous..............

4. Head unusually small, distinctly more than one-fifth narrower than the pronotal width.......................... reitteri

$(1.9 \mathrm{~mm}$.; Blumenau, Brazil. Male with anterior femora briefly

bicarinate; dorsal stria evanescent before middle of elytra)

Head very transverse, not more than one-fifth narrower than the

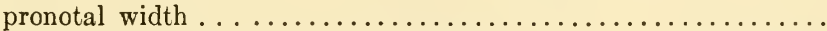

5. Lateral pronotal margins with six teeth.............crassicornis (1.95 mm.; San Esteban, Venezuela. Male with anterior femora briefly carinate; dorsal stria wholly absent) 
Lateral pronotal margins with five teeth; first antennal segment three times as long as second, or as long as III to VII inclusive, funicle minute, moniliform, abruptly narrower than IX; IX and X three times larger than VIII......................... bicolor

(1.8 mm.; Alpine Bolivia)

The two species crassicornis Raffray and rubripennis Raffray are said to closely resemble putzeysi (Schaufuss) of Uruguay, but differ from this species in antennal structure, much thicker and shorter antennae, and much stronger pronotal teeth.

\section{Second Section, new}

\section{Group IV}

This section of the genus has (a) each elytron with four basal foveae, (b) lateral pronotal margins with six strong teeth, (c) rounded tempora, (d) antennae with segments III to VI as long as wide and VII and VIII slightly transverse. At the present time it includes one species:

\section{Eurhexius zonalis new species}

Male Holotype. Measurements in millimeters:

Head 0.24 (median) or 0.3 (through tempora) x 0.44 wide, through eyes; cervicum $0.06 \times 0.21$; antennae 0.73 total; segment I 0.13 , II 0.06 , III to VIII inclusive 0.24 , club 0.28 , XI only 0.13 ; pronotum $0.5 \times 0.53$, the spines from 0.03 to 0.01 ; elytra 0.5 (at suture) $\times 0.67$; abdomen total 1.0 , first tergite $0.3 \times 0.77$, second 0.2 , third 0.2 , fourth 0.16 , fifth 0.13 ; sternites first 0.13 , second 0.2 , third 0.13 , fourth 0.11 , fifth 0.03 , sixth 0.16 . Total length $2.31 \times 0.77$ greatest width. (Pl. VIII.)

Reddish brown uniformly, integuments very shining; lightly but subasperately and diffusely punctate with the following exceptions: the anterior sixth of the pronotum and the basal marginal area are coarsely, deeply punctate and the antennal prominence on each side of the head is very coarsely and cribrately punctate while the cervicum is lightly alutaceous.

Head transverse, the eyes small but prominent and composed of about 28 small but prominent facets, the eyes not quite as long as tempora. Tempora prominent and rounded. Vertexal foveae two, large, circular, nude, on a line passing through the middle of eyes, widely separated, one being behind each antennal prominence, connected by an entire, broadly arcuate sulcus. Occiput medianly sulcate to just beyond vertexal foveae, with a short, conical, obtuse but prominent spine on each side of this longitudinal sulcus at the occipital margin of the head. Head dorso-ventrally flattened, the ventral surface very broad, flat, glabrous, densely pubescent with long, non-capitate setae. These setae are very long $(0.13$ to $0.18 \mathrm{~mm}$.) in contrast to the body pubescence (0.08 to $0.12 \mathrm{~mm}$.). Medianly, the glabrous ventral surface has a very large circular deep gular forea at base, and a strong median carina from this forea to 
mentum; laterally the ventral surface is sharply limited each side by a carina, from eye to basal margin posteriorly and from eye to base of mandible anteriorly. The cervicum is subcontinuous with the ventral surface of the head, but dorsally is separated from head by an abrupt, deep, arcuate sulcus.

Maxillary palpi four-segmented, first segment short; second long, sinuate, basally slender becoming strongly inflated apically; third short, ovate-triangular, as wide as apex of second; fourth longer than second and wider than third, fusiform, with mesial face inflated, and bearing a short palpal cone.

Antennae eleven-segmented, proportions as given above, I elongatecylindrical, II obconical, III to VIII submoniliform, III to VI with length and width equal, VII and VIII slightly transverse, narrower than II; club (IX, $\mathrm{X}, \mathrm{XI}$ ) large and conspicuous, $\mathrm{IX}$ trapezoidal, $\mathrm{X}$ transversely trapezoidal, $\mathrm{XI}$ basally truncate, conical.

Pronotum (PI. VIII, 10) anteriorly narrowing and then suddenly obliquely dilated to form a very short collar at the extreme anterior margin for the reception of the broad cervicum; disc crossed by a deep, subentire, longitudinal median sulcus and a deep, subentire transverse subbasal sulcus; a large circular fovea athwart the transverse sulcus, on each side, about midway between margin and median pronotal point; sides each with six teeth, the first basal, the second opposite the transverse sulcus, four more between transverse sulcus and anterior fourth, decreasing in length and thickness from the third spine on each side, sixth small, denticulate; basal margin thin, slightly raised, with a median longitudinal carina for a short distance, this carina merging with the longitudinal sulcus.

Each elytron with an entire sutural stria, the sutural angle being slightly produced into an acute tooth; shorter along suture than along flank; base with four large foveae, decreasing in diameter from sutural to lateral; two vague, short dorsal depressions, not reaching middle of elytron; humeral angle prominent, obliquely elevated but rounded, not dentate; a long carina parallel to elytral margin, far down on the flank, but no subhumeral fovea.

Abdomen strongly margined, proportions of tergites and sternites as given in measured lengths above. First tergite with a small but stout tuberele on each side of the disc, well within the margin, near the base. First sternite strongly produced and elevated between the posterior coxae, as a narrow, elongate-triangular platform.

Prosternum flat, glabrous, separated from pronotum on each side by an obtuse, arcuate carina; no median longitudinal carina; a pair of large, deep, circular lateral prosternal foveae at base, between coxae. Mesosternum simple. Metasternum medianly and weakly sulcate.

Anterior coxae long, conical, prominent, not contiguous; middle coxae short, contiguous; posterior coxae short, massively conical, slightly separated. Anterior femora strongly inflated, and with a high, thin, lamina-like carina on the anterior-ventral face in the distal third; middle and posterior femora not as strongly inflated. Tarsi three-segmented, with the first segment small and other two tarsomeres much larger, the second being longer than the third. 
Tarsal claws euplectine, very unequal; a very large, rapidly very acute primary claw, and an accessory bristle-like claw one-sixth as thick and less than half as long as primary claw.

Penis very large, bilaterally asymmetrical. Slide mount gives the length as $0.126 \mathrm{~mm}$., and $0.0504 \mathrm{~mm}$. wide through the posterior muscular bulb.

Female Allotype: As for the holotype with the following exceptions:

Length $2.0 \mathrm{~mm}$. $\times 0.85 \mathrm{~mm}$. wide, that is shorter and broader. The eyes are composed of 28 facets like the male, but the facets are very much smaller so that the eyes are less prominent, and the tempora are twice the eye length. Metasternum not medianly sulcate, but simply convex.

First sternite not elevated as a prominent triangular platform between the posterior coxae. First, third, and fourth sternites equal in length, fifth sternite one-third shorter than fourth, sixth sternite one-fourth longer than fourth or twice as long as fifth; second sternite the longest, $0.16 \mathrm{~mm}$., twofifths longer than first or third.

Tergites regularly decreasing in length, from first $(0.26 \mathrm{~mm}$.) to fifth $(0.1 \mathrm{~mm}$.$) .$

Described on four specimens, all collected by Dr. E. C. Williams, Jr., on Barro Colorado Island, Gatun Lake, Panama Canal Zone as follows: Holotype male July 9, 1938 in floor mold sample No. 1342; Allotype female July 29, 1938 in floor mold sample No. 345; Paratype male July 26, 1938 in floor mold sample No. 285; Paratype male July 31, 1938 in floor mold sample No. 1440.

It is notable that both male and female have the anterior femora carinate. The less prominent eyes and evenly convex metasternum serve to quickly differentiate the female. Eurhexius zonalis is quite distinct from all others of the genus on the described anatomy. The antennal differences between the two sections of the fourth group are not so important as might be imagined, but serve to differentiate certain groups from each other; on the other hand the many structural differences are notable.

\section{Key to the Group V Species}

These three species make a definite approach to Aporhexius, but the pronotal margins are not simply crenulate, but instead have very minute, discrete blunted denticules evenly spaced on the lateral pronotal margins. They are quickly separable from the first four groups of the genus on the same character. It is possible that this group also includes Rhexius rugulosus Reitter.

Size very large, in excess of four millimeters long; each lateral pronotal margin with a minute tooth nearly opposite the transverse sulcus, and five much smaller, blunted denticles evenly spaced between this minute tooth and the apex; four elytral foveae arranged in two basal pairs ............................muticus

(Largest species of genus, $4.25 \mathrm{~mm}$., and one of the largest of the entire family; Bogota, Colombia) 
Size less than four millimeters in length; lateral pronotal margins with minute blunted denticles of equal size and shape; four basal elytral

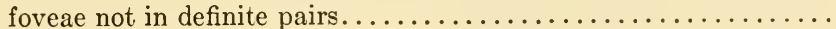

2. Antennae with segment III small, subobconic; IV to VIII transverse, laterally crescentric; IX and X quadrate; XI subcylindrical, very

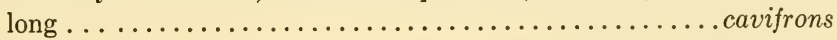

(2.6 mm.; Sao Paulo, Brazil)

Antennae with segments III to VIII moniliform, equal, much smaller than IX or X; IX and X abruptly larger, subquadrate; XI ovate. .

3. Metasternum medianly impressed; sternites with second medianly, triangularly impressed; third sternite broadly transversely impressed; fourth sternite deeply medianly exacavated, the excavation with carinated lateral margins; fifth triangularly elevated each side; sixth entirely concave and apically sinuate.... MALE abdominalis

(3.7 mm.; Blumenau, Brazil)

Metasternum convex; sternites convex, with distal sternite apically emarginate . . ................... FemaLe abdominalis

( $2.9 \mathrm{~mm}$. ; Blumenau, Brazil. Note great size range!)

The excellent secondary sexual differences in abdominalis form a notable exception for the genus.

One species of the genus, Eurhexius putzeysi has been taken with ants (Bruch, 1929) in Argentina.

The species may be listed as follows:

longicornis Raffray. 1904. Brazil. parviceps Sharp. 1887. Panama.

sexpunctatus Raffray. 1904. Brazil.

trimiodes Sharp. 1887. Guatemala. (nec trimioides)

ventralis Sharp. 1887. Panama.

vestitus Sharp. 1887. Panama. Genotype?

II

simoni (Reitter). 1882. Brazil. (Rhexius) (nec simonis)

\section{III}

laevis Raffray. 1904. Brazil.

majorinus (Schaufuss). 1872. Brazil?

megacephalus Raffray. 1904. Brazil.

procerus (Reitter). 1882. Brazil. (Rhexius)

putzeysi (Schaufuss). 1879. Uruguay. (nec putzeisi, putzeitsi, etc.) and Buenos Aires, Argentina con Solenopsis richteri Forel (Bruch, 1929).

quadrifoveatus Raffray. 1904. Brazil. 
angustatus (Schaufuss). 1882. French Guiana.

bicolor Raffray. 1904. Bolivia.

crassicornis Raffray. 1891. Venezuela.

insignis (Schaufuss). 1879. New Grenada (Colombia?) (semihyalinus

(Schaufuss), 1882).

octopunctatus Raffray. 1904. Brazil.

reitteri Raffray. 1904. Brazil.

rubripennis Raffray. 1908. Argentina.

subacuminatus Raffray. 1904. Brazil.

zonalis new species. Panama Canal Zone.

\section{V}

abdominalis Raffray. 1904. Brazil. (see also Raffray, 1911)

cavifrons Raffray. 1912. Brazil.

muticus (Raffray). 1883. Colombia. (see also Raffray, 1904)

This census does not list rugulosus of Reitter, vide supra.

RHEXIUS (LeConte, 1850)

LeConte $(1850,1878)$

SHARP (1887)

Schaufuss (1872)

BRENDEL (1893)

RAFFRAY (1903, 1908)

CASEY (1908)

BOWMAN (1934)

This wholly American genus is better represented in North America (8 species) than in the neotropics (3 species), although the genotype insculptus LeConte and a few other species have an essentially subtropical distribution. Since all of the temperate species are distributed in the eastern part of the United States, the distribution of the genus in the Americas follows the forested areas, in a long curve from the drainage basin of the Amazon River, through the Isthmus of Panama and into Louisiana, Mississippi, Missouri, Illinois, Indiana, District of Columbia, Virginia, and Pennsylvania. The last complete treatment of the North American forms was by Casey (1908, p. 278); the neotropical forms have not been coördinated, and very probably will be found to include many new species.

The neotropical species all have four basal foreae on each elytron, but show considerable variation in the relative lengths of tergites, of the first antennal segment, and the structure of the pronotum. It is notable that the Panamanian optatus is very similar to the genotype insculptus in general aspect, while the Amazonian species depart radically from the more northern forms. 
All members of Rhexius have a common habitus (Pl. VIII, 6-9) which affects the antennae and articulation of the head to the pronotum. This is so striking that once seen it is seldom forgotten. The eleven-segmented antennae have the basal segment very elongate, varying from one-half of the total antennal length to as long as segments II to VI inclusive. The antennae are typically geniculate, the arc being between the first two segments.

The articulation of head and pronotum is especially diagnostic. The very transverse head narrows abruptly to a small subcylindrical neck. This peduncle is closely invested by the exceptionally small anterior lobe of the pronotum, in the manner of a bearing, and the large posterior lobe of the pronotum seems to constitute the pronotum as a whole, the anterior lobe appearing as a part of the head. Sharp (1887, pp. 40-41) describes the condition succinctly, "the structure of the prothorax is most remarkable, its anterior part being constricted so as to form a short tube in which the head is inserted by a very short neck; this thoracic tube has the appearance of being only a development, rather greater than usual, of the neck of the head...."

Six sternites in both sexes. The sixth sternite is usually medianly prominent and sinuate in the male; rounded in the female. The males usually have the anterior femora carinated on the internal face. Tarsi with two very unequal claws, of which the first is very large, arcuate and acute, and the accessory claw very thin, and not more than half as long.

\section{Key to the Species}

Antennae with first segment as long as II to $\mathrm{X}$ inclusive united.elegans (1.4 mm.; Sao Paulo, Brazil. Male metasternum with a minute median impression)

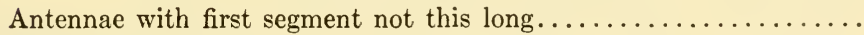

2. First visible tergite very long, longer than second and third tergites

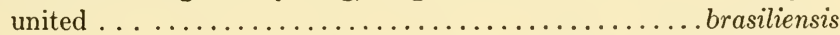

(Amazon basin, Brazil)

First visible tergite relatively short, about as long as the second

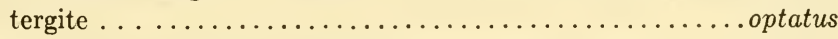

(1.5 mm.; 4000-6000 ft., Volcan de Chiriqui, Panama)

The species of Rhexius inhabiting the neotropics are:

brasiliensis Schaufuss. 1872. Brazil.

elegans Raffray. 1909. Brazil.

optatus Sharp. 1887. Panama.

\section{MITRACEPHALA (Raffray, 1890)}

\section{RafFray $(1890,1904)$}

This and the next genus are so specialized that they show little close affinity with others of the tribe. The present genus, founded on a single peculiar species, may be generally described as follows: 
The head is almost semicircular from a dorsal point of view, with an almost straight occiput, and a semicircularly produced front, the surface of the head being medianly, broadly concave. Although the eyes are large, they are wholly invisible from above, as a consequence of the expanded top of the head. The extended front covers the mouth-parts, labrum, and base of antennae. The antennae are inserted on the antero-lateral sides of the front, beneath the expanded dorsal wall, instead of at the extreme end of an elongate rostrum as in Rhinoscepsis, and these organs are relatively short, and the segments progressively thicker apically, so that the club is not apparent, although the distal segment is large, about three times the length of the tenth segment.

Pronotum transverse, wider than head, with a strong bisinuate transverse sulcus and a less developed longitudinal median sulcus.

Elytra with three basal foveae on each elytron.

Abdomen elongate-cylindrical, weakly margined; five tergites and six sternites. Tarsi with two very unequal claws.

Raffray (1908, p. 128) thinks that the species may be an inhabitant of the nests of social insects, either ants or termites.

longipennis Raffray. 1890. Brazil. Genotype.

\section{PHTEGNOMUS (Raffray, 1890)}

RAFFraY (1890, 1904)

This genus is also remarkable for the development of the head; in fact it may represent several genera and many undescribed species when it is more fully understood. It is notable in that it is one of the very few genera of pselaphids which are exclusively found in the nests of termites.

Head always greatly dilated laterally, but not obscuring the eyes from a dorsal viewpoint, and the front is always expanded to cover the mouthparts; the eleven-segmented antennae are inserted under the sides of the front, and not at the end of the expanded portion; these organs have a conspicuous threesegmented club. Vertex excavated. Eyes placed near the posterior margin of the head.

The front is variously formed; it may be expanded as an elongate tubercle, with parallel sides and a truncate apex (naso), or as a long median spur.

Pronotum not greatly wider than head, transversely ovate, with the longitudinal and transverse sulci more or less vestigial.

Elytra with the base transversely carinated, and each elytron with two foveoid depressions.

Abdomen with a wide, strong margin; five visible tergites, with the first tergite hidden beneath the elytral apices as usual, but appearing laterally, so that six tergites may be counted; six sternites.

inermis Wasmann. 1894. Venezuela. (con Eutermes meinerti Wasmann) naso Wasmann. 1894. Venezuela. (con Eutermes meinerti Wasmann) oberthuri Raffray. 1890. Brazil. Genotype. 


\title{
RHINOSCEPSIS (LeConte, 1878)
}

\author{
LeConte (1878) \\ Schaufuss (1888) (Rhinosceptis) \\ RAFFRAY (1898) (Rhynoscepsis) \\ RAFFrAY (1904, 1908) (Rhinoscepsis) \\ BowMAN (1934)
}

As in the case of Rhexius, this is a genus of pselaphids which is found in the subtropics of North America through the region of Florida, and again in the Amazon basin and as far south as Argentina. Its dispersal is more discontinuous, however, since no species is known from the whole of Central America.

The genus is primitive in its structure, but has several highly specialized characters, as has already been noted (PI. IX and X). The genotype (bistriatus LeConte) appears to be relatively abundant in the Steinhatchee river drainage of Florida, and differs in many particulars from the South American congeners. This species has been discussed, and its gross anatomy figured so that other species of the genus can be contrasted with it.

All Rhinoscepsis have the head attenuated anteriorly to form a long rostrum or antennal tubercle, with the antennae inserted subcontiguously at the apex of this extension; again the vertex, sides of the head, and genae are usually crossed by tortuous lateral sulci, as noted in the key to the tribe. The eyes are generally small, almost rudimentary, in both sexes. The eleven-segmented antennae have a moderately developed club, the distal segments of which are provided with antennal cones.

The cordiform pronotum usually has four foveae at basal margin, two large foveae or foveoid depressions connected by a transverse sulcus, and a longitudinal median sulcus more or less entire. Prosternum is not medianly carinate. Sternal foveae are well developed, usually including lateral prosternals, and meso-metasternal foveae II, III, IV, and V on each side.

Each elytron has two basal foveae, entire sutural stria, subhumeral fovea; subepipleural carina and sulcus more or less developed. There may be a rudimentary third basal fovea present. The dorsal stria is variable in extent. The humeri are prominent, usually subdentate.

Abdomen large and well developed. Six tergites visible, and both sexes have seven sternites. The male has the seventh sternite primitive, divided into a right and left pygidial plate, so that when these plates are appressed, their mesial margins form a straight or arcuate "pygidial carina", as in Euplectus and Acolonia, etc. The penis is large and bilaterally symmetrical in the genotype. The female has the seventh sternite transversely triangular and small, or ovaterhomboidal with two converging carinae. Some females, at least, have the third tergite prominently spined at apical margin.

Prothoracic coxae primitive, elongate-conical and prominent; mesothoracic and metathoracic coxae shorter, the former contiguous and the latter contiguous or virtually so.

Tarsi primitive for the euplectines, with a well-developed secondary tarsal claw. 
I have had to modify Raffray's early key to the genus (1898) in order to incorporate recently discovered species:

Pronotum nearly as long as wide...................... 2

Pronotum transverse, at least one-fourth wider than long (Pl. XVIII,

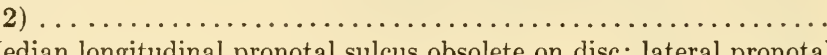

2. Median longitudinal pronotal sulcus obsolete on dise; lateral pronotal foveae not, or very slightly, incising lateral pronotal margins; 1.6 mm. long . ................................

Median longitudinal pronotal sulcus deep and entire; lateral pronotal foveae deeply incising lateral pronotal margins. .dybasi new species 3. Longitudinal, median pronotal sulcus very obsolete on the disc, forming a deep anterior and a deep posterior sulciform fossa... militaris

$(1.1 \mathrm{~mm}$.; "Amazones", Brazil; antennae short, thick, with fifth segment larger than either the fourth or sixth segments) Longitudinal, median pronotal sulcus deep and entire for the whole of its length (Pl. XVIII, 2) ....................... 4

4. Fifth antennal segment subequal in size to fourth and sixth segments

Fifth antennal segment one-half wider, and slightly longer than either fourth or sixth antennal segments; third tergite with a very long and prominent spine directed posteriorly from the median third of apical margin ............................ fall new species

5. Lateral pronotal margins incised or notched each side opposite the lateral pronotal fovea.......................pubescens

(1.2-1.3 mm.; "Amazones", Brazil)

Lateral pronotal margins not incised each side opposite the lateral pronotal fovea ................................

(1.5 mm.; Argentina)

Rhinoscepsis falli new species

Measurements: Head $0.27 \times 0.27$; antennae 0.47 total length, first segment 0.08 , second segment 0.04 , third to ninth united 0.16 , tenth segment $0.04 \times 0.05$, eleventh segment $0.13 \times 0.07$; pronotum $0.23 \times 0.3$; elytra $0.36 \times 0.45$; abdomen 0.45 including spine $\mathrm{x} 0.43$ through second tergite; first tergite 0.13 , second 0.13 , third 0.12 to base of spine, spine on third tergite 0.1 ; fourth 0.03 , fifth 0.1 . Total length $1.4 \times 0.45 \mathrm{~mm}$. (Pl. XVIII).

Dark yellowish-brown with paler legs and maxillary palpi; integument moderately shining; pubescence very short ( 0.02 to $0.03 \mathrm{~mm}$. long), sparse, pale.

Head with rounded temporal angles; the tempora nearly straight, longer than the eyes. Eyes small, composed of 24 small facets, set obliquely on the sloping anterior half of the head. Sides converging arcuately to form the long antennal rostrum; distal end of this rostrum spherically expanded, bearing apically the subcontiguously articulated antennae. Occiput medianly, longitudinally carinate from base to the spherically enlarged end of rostrum. Vertex and front granulate, two vertexal foveae on a line passing through the posterior 
margin of the eyes. Basal half of head with a sinuate sulcus on each side; this sulcus arising on the occipital margin, extends obliquely mesiad to a point behind the vertexal fovea, then turns sharply across the head behind the eye, to the ventral surface of the head, where it expands abruptly into a deep ovate fossa, half as large as eye and enclosing some of the ventral facets. Ventral surface of head tumid between fossae, with a median basal gular fovea.

Labial palpi relatively long, two-segmented. Mentum longer than wide. Cardo of maxilla prominently exposed. Maxillary palpi four-segmented, first segment relatively large, that is, distinctly wider than base of second; second segment about three times as long as first, slender basally and arcuate to inflated apex; third short, ovate-triangular, wider than second; fourth longer than second and wider than third, fusiform, with a very small palpal cone at apex. Mandibles long, arcuate and well developed, twice as long as the simple labrum. Labrum hidden dorsally by antennal rostrum, but mandibles clearly visible.

Antennae long, about one-third of body length, eleven-segmented. Segment I cylindrical, twice as long as II; II ovate; III to IX submoniliform; III, IV, VI equal in length and width; V half wider and slightly longer than either IV or VI; VII and VIII slightly larger than V, transversely moniliform; IX spherical, not as wide as VIII; X transverse, drum-shaped; XI ovate-acuminate.

Pronotum widest anterior of middle, apical margin nearly straight, the sides curving evenly each side to an incised notch opposite to and in part containing a large lateral fovea, the sides then abruptly expanding to an acute tooth, then narrowing obliquely to basal margin. Base with four foveae; disc crossed by a deep, entire median, longitudinal sulcus extending from base to apical seventh, and a transverse submedian sulcus, equally deep, connecting the lateral foveae; a median foveoid depression formed where these two sulci cross each other.

Elytra shorter than abdomen. Each elytron with two basal foveae, a sutural at base of an entire sutural stria, and a discal at base of a deep dorsal stria which extends to basal third of disc. Humeral angle prominent, with a subhumeral fovea on the elytral flank, recessed beneath a carina which extends longitudinally parallel to margin, and turns mesiad at base just behind humerus.

Abdomen with five visible tergites, but only three are visible from a dorsal view. Proportions as given above. Third tergite is notable, bearing a long, basally broad, apically acute spine from the middle of the apical margin. From a dorsal view the abdomen ends with this spine, giving a highly unique outline. Fourth tergite very short, set obliquely under the end of the third, and invisible from above. Fifth tergite wholly ventral in position, and invisible from above. Sternites seven: first small, hidden largely by posterior coxae save for a depressed triangle between them; second longest; third, fourth and fifth progressively shorter; sixth semicircular, enclosed by the fifth, as long as third; seventh sternite very small, transversely triangular, not carinated, and enclosed between the sixth sternite and fifth tergite. All sternites convex and simple.

Prosternum not medianly carinate; granulated; lateral prosternal foveae present. Anterior coxae long, conical. Middle coxae contiguous. Metasternum long, longer than second and third sternites combined, with a deep median 
sulcus; lateral mesocoxal foveae obvious; metasternal foveae fused and median. Posterior coxae shortly conical, subcontiguous.

Anterior femora and tibiae inflated; anterior tibiae basally sinuate, with a minutely serrated carina along the ventro-anterior face in basal half.

Tarsi three-segmented; first tarsomere small, second and third much larger; second longest and much thicker than third, this thickness being due to the dorso-ventral width, the segment being laterally compressed; third slightly arcuate and thick; tarsal claws primitive, very unequal, with a large, thick, arcuate, pointed primary claw and a very thin secondary claw which is half as long as the first.

Described on a single female specimen, from Matto Grosso, near Corumba, in Brazil. I dedicate this striking species to a lamented friend of long standing, Mr. H. C. Fall. ${ }^{1}$

\section{Rhinoscepsis dybasi new species}

Type Male: Measurements: head $0.27 \times 0.23 \mathrm{~mm}$.; pronotum $0.25 \times 0.28$ $\mathrm{mm}$.; elytra $0.30 \times 0.40 \mathrm{~mm}$; ; abdomen $0.50 \times 0.40$; antennae $0.43 \mathrm{~mm}$. long; total length $1.3 \mathrm{~mm}$; greatest width $0.4 \mathrm{~mm}$.

Yellowish brown, subopaque with flavous, abundant, short pubescence; the distal segment of maxillary palpi swollen and light yellow.

Head with prominent, rounded tempora which are slightly convergent anteriorly, three times longer than the eyes, and slightly longer than wide; eyes hardly visible from above, rudimentary, composed of 8 facets lying within the cephalic sulcus. Apical end of rostrum transversely ovate. Cephalic sulcus holding the eye and the ovate genal fossa relatively larger, being more than twice as large as eye. Head otherwise as in falli.

Maxillary palpi four-segmented, as in falli save for distal segment. This latter segment tumid, yellow, ovate with rounded base and subacute apex, ventral face fiattened; very large for the genus, being slightly more than three times as wide as third, and nearly four times as long. (In the male bistriatus of the United States the fourth segment is about twice as wide as third, and in falli the fourth is twice as wide as third.)

Antennae long, slightly more than one third the body length, eleven-segmented; segment I subconical with the ventral face strongly produced at base, twice as long as second (this is very distinctive when contrasted with the cylindrical first antennomere of males of bistriatus and falli); II ovate; III-VI moniliform; VII-VIII transversely moniliform, longer and wider than eighth; $\mathrm{X}$ transverse, drum-shaped; XI ovate-acuminate.

${ }^{1}$ I owe much to Mr. Fall, who encouraged my work on Pselaphidae through examination of specimens and long, instructive letters. My earliest taxonomic attempt was on two different families of Coleoptera, including a new genus of Cryptophagidae (Glyptophorus mycetoecus Park, 1929). Mr. Fall subsequently examined the types, pronounced the species valid, and found an undescribed specimen in his own collection which belonged to mycetoecus. Such aid to a young taxonomist, and long correspondence concerning Rybaxis and other pselaphids, were very stimulating, and I take this opportunity to express my gratitude. 
Pronotum as in falli with deep entire longitudinal and transverse sulci and deeply incised lateral margins.

Elytra as in falli save that dorsal stria is subentire, extending to apical ninth.

Abdomen with five visible tergites, first four subequally long, the fifth shorter with broadly rounded apex; tergites simple; margins strong.

Seven sternites, the first four subequal in length, evenly and minutely granulate; fifth half as long as fourth, medianly and transversely tumid with tumid region glabrous; sixth semicircular, enclosed by fifth, as long as fourth and transversely foveate for apical third, with basal margin of foveation elevated and densely pubescent, these setae recurved toward base of segment; seventh enclosed by sixth, obliquely divided into a right and left triangular plate.

Middle coxae contiguous; metasternum relatively short, as long as fourth and fifth sternites united, not sulcate but medianly depressed at apex; posterior coxae approximate. Femora simple; tibiae thick, especially the anterior pair which are medianly inflated, very slightly contorted near base and excavated apically; tarsi as in falli.

Described on one male collected by Mr. Dybas, for whom this important addition is named, on July 13, 1941, at San Juan, Vera Cruz, Mexico. The importance of $d y b a s i$ is zoögeographic. In structure dybasi shows definite affinities with the genotype bistriatus of the southern United States, as well as the South American species; it serves to bridge the gap which existed, no members of the genus having been reported previously between Brazil and the United States. Species are to be expected from Central America if northward spread from a postulated Brazilian center is tenable.

The species of Rhinoscepsis are as follows:

falli new species. Brazil.

gracilis (Schaufuss). 1872. Brazil. (Panaphantus)

militaris (Schaufuss). 1872. Brazil. (Panaphantus)

pubescens (Raffray). 1898. Brazil. (Rhynoscepsis)

richteri (Raffray). 1908. Argentina. (Rhynoscepsis)

dybasi new species. Vera Cruz, Mexico.

\section{THESIUM (Casey, 1884)}

Casey $(1884,1893,1908)$

SHARP (1887) (Apothinus)

BRENDEL and WICKHAM (1890)

RAFFraY (1898, 1903, 1908) (Apothinus)

LENG (1920)

Bowman (1934) (Thesium cavifrons (LeConte) genotype, p. 144)

Of the nine known species of this genus, two are found north of the Rio Grande river (including the genotype), one from Brazil, and six from what appears to be the center of distribution, Central America. The genus, then, is wholly American and extends from the Amazon basin through the Istlimus of 
Panama, Guatemala, Mexico, and up the Mississippi and Ohio river valleys. This genus is very well-marked. The eyes are well-formed, large and with coarse facets as a rule. The eleven-segmented antennae have a large two to three-segmented club, of which the distal segment is characteristic. This eleventh segment is formed in two portions, as in Eutyphlus, but not so sharply differentiated as the latter. The basal piece is large, more or less cylindrical, but the apical piece is pyramidal or conical and much smaller, being set within the circular distal face of the basal piece. The ninth and tenth obviously and increasingly transverse, the eleventh much longer than wide, longer than ninth and tenth combined, not much wider than tenth segment. Vertexal foveae large and pubescent. Pronotum with lateral margins crenulated; disc with a median, longitudinal ovate puncture of varying proportions and size among the species; base with a large pubescent lateral fovea each side, connected more or less indefinitely with a median, nude impression by a transverse sulcus; basal margin with a brief, longitudinal carina which does not reach the median impression. The elytra have three basal pubescent foveae each, a sutural, median, and lateral. The sutural and median foveae of each elytron are characteristically enclosed by the strong sutural stria which passes anteriorly, parallel with the mesial elytral margin, to a point anteriad of the sutural fovea, where it curves laterally to pass above and over the anterior margins of the sutural and median fovea, enclosing them, and then curving posteriorly, sharply, just lateral of the median fovea, and ending before the middle of the elytra. The lateral basal fovea is by itself and also more or less enclosed in a discal stria which ends posteriorly before the middle of the elytron. In addition, the humeri are well marked, set off by an oblique humeral line, and below this, on the subhumeral flank, is a large pubescent subhumeral fovea and long stria which extend posteriorly nearly to the apex of the flank. The prosternum is longitudinally and medianly carinate. The abdomen has no apparent basal carinae, and is sexually differentiated: males with seven sternites, the seventh being a circular, simple, one-piece, asymmetrically articulated pygidium; females with six sternites. The metathoracic coxae are broadly subconical, and consequently the first sternite is seen between them medianly as a triangular field, and laterally well shown where the coxae narrow markedly near the elytral flanks.

\section{Key to the Species}

Vertex with three foveae across middle, between the eyes; size relatively large, nearly two millimeters long........... impressifrons

(1.85 mm.; 4000-5000 ft., Cerro Zunil, Guatemala)

Vertex with two foveae on the middle of the vertex, between the eyes; size smaller, not longer than one and one-third millimeters.......

2. Head relatively large, as wide through the eyes as the pronotum.... Head relatively small, including the eyes, distinctly narrower than the pronotum; pronotum very transverse, about one-third wider than

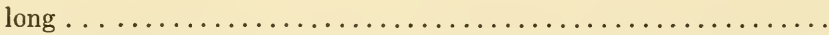

3. Eighth antennal segment strongly transverse, almost as wide as ninth

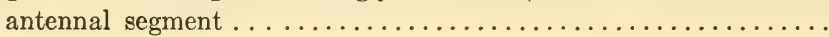


Eighth antennal segment not transverse, not wider than seventh, and distinctly narrower than ninth segment......................

(1.1-1.2 mm.; Mexico)

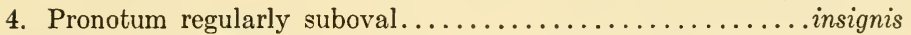

(1.1 mm.; Blumenau, Brazil)

Pronotum strongly cordiform, with the lateral margins angulated and subincised anterior to middle...........................

(1.3 mm.; Mexico)

5. Disc of pronotum with a small subapical fovea..........brevicollis

(1.1 mm.; Mexico)

Disc of pronotum with an elongate sulcoid or fusiform foveoid de-

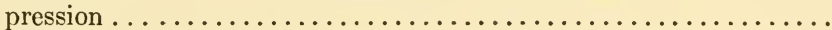

6. Depression on pronotal disc in the form of a deep, sulcoid, medianly longitudinal depression, with the apical end of this depression broadest and rounded; tempora long, longer than the eyes in both sexes, the eyes relatively small................. obscurus

(1.25 mm.; San Geronimo and Capetillo, Guatemala)

Depression on pronotal disc in the form of an elongate, fusiform depression, median, and with both ends tapered; tempora short, only half as long as the eyes in the male (female unknown), the eyes relatively very large, two-fifths the length of the head.........

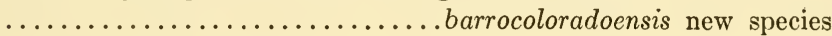

Thesium barrocoloradoensis new species

Measurements: Head $0.2 \times 0.25 \mathrm{~mm}$.; pronotum $0.2 \times 0.3 \mathrm{~mm}$. ; elytra 0.36 x $0.4 \mathrm{~mm}$.; abdomen $0.5 \times 0.4 \mathrm{~mm}$.; penis 0.18 x $0.1 \mathrm{~mm}$.; metasternum $0.2 \mathrm{~mm}$.; antennae $0.4 \mathrm{~mm}$. Total length $1.26 \mathrm{x}$ greatest width $0.4 \mathrm{~mm}$.

Yellowish-brown, with long sparse pubescence; head and pronotum asperate, the asperities each bearing a seta.

Head trapezoidal, occiput with a short, median, longitudinal carina which does not end on the vertex in a fovea; two vertexal foveae placed on a line passing through the middle of the eyes, their orifices slightly anteriorly directed, and with the floor of each fovea attached to an arm of the supratentorium. Supratentorium massive. Eyes large, two-fifths as long as head. Tempora very short, half as long as the eye. Front broad, with a short, blunt, median tubercle at the beginning of the declivity, between the antennae. Ventral surface with a small gular fovea, the floor of which is attached to the supratentorium.

Antennae eleven-segmented, rather widely separated, segment I a little longer and half wider than second, oblong-obconic; II ovate; III obconic, half the width of second; IV transverse, submoniliform, as wide as third but shorter; V-VII slightly wider than fourth, about as long, transversely submoniliform; VIII asymmetrically transverse, as wide and as long as seventh; IX distinctly wider and longer than eighth, transversely trapezoidal; $\mathrm{X}$ gradually wider than ninth, longer, transversely trapezoidal; XI as wide as tenth, in two portions, a basal cylindrical portion almost twice as long as the tenth segment, and a much 
narrower pyramidal apical portion, about one-fourth as long as basal piece.

Maxillary palpi four-segmented, first segment short, thick, one-third as long as second, and articulating obliquely with second; second segment short, subconical with the basal width narrower than first segment; third segment slightly wider than the inflated apical end of the second, and half as long as second, subspherical; fourth three and a half times longer than third and twice as wide, ovate, with a truncate apex bearing a very long, blunt palpal cone.

Pronotum with simple apical and basal margins, the surface asperatetuberculate, especially the lateral margins which are strongly crenulate; broadest at middle; a short median carina extends from the basal margin to a large subbasal, transversely fusiform fossa; three minute foveae on each side of the basal carina, at basal margin; a deep lateral fovea on each side of this median depression, the three connected by a transverse subbasal sulcus; anterior half of disc with a median, longitudinal, fusiform foveoid depression.

Scutellum elongate-triangular, small.

Elytra lightly punctate; each elytron with prominent, oblique, subdentate humeral angle, three basal foveae arranged in the typical form for the genus, as noted previously; subhumeral fovea recessed beneath the humerus, and associated with a long subepipleural sulcus on the flank.

Abdomen with six tergites visible, first very short and exposed at base of elytra, one-fourth as long as second (normal first visible tergite for pselaphids); second one-third longer than third; third and fourth and fifth subequal in length; sixth very short, as long as first, and transversely triangular. Second tergite with a transverse depression in basal half, and half the segmental width. Seven sternites, of which the first is triangular between the coxae; second longest, with a short, deep and wide depression in basal third; third sternite one-third shorter than second; fourth slightly shorter than third; fifth medianly short, one-half as long as fourth, the apical margin broadly concave; sixth with basal margin broadly convex, fitting the fifth, but with apical margin medianly deeply incised to contain the small, circular seventh; seventh sternite articulating with the abdomen on its right side, and swinging to the right to permit. extrusion of the penis, measurements of which have been given.

Prosternum with anterior margin strongly dentate, and with a strong median, longitudinal carina from coxal cavity to apical margin, entire; lateral prosternal foveae well formed.

Mesosternum with a median, longitudinal carina; prepectoid alutaceous.

Metasternum very long and broad. Sternal foveae of the meso- and metasternal fields well developed and all paired to give a high (primitive) number, foveae II, III, IV and VI typical, and in addition a pair of foveae rarely found (Posterior Mesosternal Foveae) which penetrate between the posterior-lateral angle of the mesosternum and the mesocoxal cavity on each side. Thus barrocoloradoensis has two prosternal, and ten meso-metasternal foveae.

Middle coxae distinctly separated by the union of a truncate process from the inesosternum and metasternum. Posterior coxae very short, triangularly conical, almost contiguous. Femora only moderately inflated. Tarsi relatively short 
and thick, with a first segment two-fifths as long as second; second inflated; a single very long, arcuate claw.

Described on a single male, the type. Collected by the author on July 27, 1936, on Barro Colorado Island, Gatun Lake, Panama Canal Zone, from beneath the bark of a log at Zetek 23. The type is a slide mount.

The genus may be listed as follows:

barrocoloradoensis new species. Panama Canal Zone.

brevicollis (Raffray). 1898. Mexico. (Apothinus)

clavatus (Raffray). 1898. Mexico. (Apothinus)

impressifrons (Sharp). 1887. Guatemala. (Apothinus)

insignis (Raffray). 1898. Brazil. (Apothinus)

obscurus (Sharp). 1887. Guatemala. (Apothinus)

sharpi (Raffray). 1898. Mexico. (Apothinus)

\section{BIBLOMIMUS (Raffray, 1903)}

\section{RAFFRAY (1903) (Biblomimus)}

RAFFrAY (1908a,b) (Ramecia)

Raffray erected this genus (p. 545, 1903) on a single species, minutus; later he described a second species, impressa (1908a, p. 36), and placed both of these in the North American genus Ramecia (Casey, 1893, p. 450). This synonymy was followed in the Genera Insectorum (1908b, p. 101). After giving the matter some study, I feel that the two species of Raffray do not belong in Ramecia, and reinstate Biblomimus for them.

These two genera, Biblomimus and Ramecia, are structurally similar save that the former has the prosternum with a median, longitudinal carina, whereas the latter has the prosternum simple and not carinate. The presence or absence of the median prosternal carina is considered too fundamental to allow such an association. Possibly Biblomimus should be placed as a neotropical subgenus of Ramecia, but generic isolation is considered preferable at this time. Both genera are believed to be more primitive than their relative positions given by Raffray (1908), and Casey (1893, p. 450-453 and 1897, p. 552) has discussed the affinity of his genus with the trichonychide genera.

The species of Biblomimus may be separated as follows:

Tenth antennal segment strongly transverse, twice as wide as the ninth segment; head and pronotum about equally wide........minutus

(1.0 mm.; female sex known only)

Tenth antennal segment twice as long as ninth segment, but not appreciably wider; head narrower than pronotum...............

2. Six sternites present; sternites second to fifth subequal in length; sixth sternite large, triangular............... impressa FEMALE

(1.1 mm.)

Seven sternites present; sternites second to fourth progressively shorter; fifth minute; sixth much larger, arcuate, deeply emarginate; seventh large, briefly ovate............... impressa MALE 
Two species known:

impressa (Raffray). 1908. Guadeloupe, Leeward Islands. (Ramecia) minutus Raffray. 1903. St. Vincent, Windward Islands. Genotype.

It will be noted that Biblomimus is restricted so far to the Lesser Antilles, no species having been recorded from North, Central or South America; on the other hand, Ramecia is unknown from Central or South America. This wide geographic separation is additional evidence that the two genera are not identical.

\section{PANARAMECIA new genus}

Euplectini having (1) vertex trifoveate; (2) eleven-segmented antennae which are widely separated, and with a three-segmented club; (3) maxillary palpi four-segmented, first minute, second long and apically inflated, third subtriangular, fourth wider than third and longer than second, bearing apically a small palpal cone; (4) pronotum cordiform, disc simple and unmodified, lateral margins each with a small subbasal tooth and crenulate anterior to tooth, a median fovea connected each side with a smaller lateral fovea by a biarcuate transverse subbasal sulcus; (5) elytra with a transverse multiarcuate basal carina, each arc sheltering a small vestigial basal fovea, the foveae usually three with a vestigial fourth sometimes present, no subhumeral fovea but a well developed longitudinal carina on elytral flank; no dorsal stria or dorsal depression; (6) five visible tergites in both sexes, first four subequal; (7) six visible sternites in both sexes, second, third and fourth subequal; (8) middle coxae contiguous; (9) tarsi with a large primary claw and a very thin accessory claw which is half as long as large claw and difficult to see on dry mounts, but readily seen on cleared slide mounts; (10) prosternum simple, with no median, longitudinal carina.

Genotype: Panaramecia williamsi new species.

Panaramecia williamsi new species

Male Holotype. Measurements: head $0.22 \times 0.29 \mathrm{~mm}$; antennae $0.38 \mathrm{~mm}$; pronotum $0.24 \times 0.3 \mathrm{~mm}$.; elytra $0.33 \times 0.45 \mathrm{~mm}$.; abdomen $0.5 \times 0.4 \mathrm{~mm}$.; total length $1.29 \mathrm{~mm}$.; greatest width $0.45 \mathrm{~mm}$. (Pl. XV)

Reddish-brown, integument moderately shining; pubescence opaque, dense, conspicuous (average length of body setae 0.03 to $0.05 \mathrm{~mm}$.), and in addition about twenty-five very much longer setae dispersed on the tergites, these setae from 0.1 to $0.15 \mathrm{~mm}$. long.

Head with tempora straight, and temporal angles broadly rounded, the tempora longer than the eyes. Eyes relatively small, composed of about 26 to 28 very minute facets. Head dorso-ventrally flattened, the vertex only slightly convex, the sides above the eyes carinated each side from the antennal insertion to a point opposite the posterior eye margin. Occiput medianly with a very 
strong longitudinal carina which arises on the cervicum, crosses occiput and ends just posterior, and between the vertexal foveae, this median carina ending in a median vertexal foveae. Vertex, therefore, triforeate including the paired vertexal foveae which are on a line passing through middle of eyes. A long, slightly oblique sulcus arises at each vertexal fovea and ends just mesiad of each antennal insertion, not actually joining its fellow, but seeming to, as a consequence of the raised frontal margin between antennae. Head between lateral carina and sulcus moderately flat, slightly raised and slightly granulated; head between sulci slightly depressed and less punctate, not granulated. Ventral surface of head coarsely, sparsely punctate, with a median basal gular fovea; pubescence short, not capitate but is finely pointed and subprostrate; laterally carinated each side from base of mandible to posterior eye margin.

Maxillary palpi four-segmented, first minute; second four times as long as first, equal to first in width at base, and inflated to width of third apically; third short, subtriangular; fourth widest and longest, obliquely truncate at base, subacute at apex, bearing a small palpal cone.

Antennae eleven-segmented, widely separated at bases, segments I and II subequal in length, subquadrate, second narrower than first; III to VII narrower than second, subequal in length and width; III obconic; IV, V, VI, VII, and VIII submoniliform; club gradual, of IX, $\mathrm{X}$, and $\mathrm{XI}$, these segments progressively wider than eighth; IX and $\mathrm{X}$ transversely trapezoidal; $\mathrm{X}$ shorter but much wider than second; XI as long as from eighth to tenth united, but not forming the entire club.

Pronotum with a large, transversely expanded median foveoid depression between disc and basal margin, and a smaller lateral fovea each side slightly more anterior and well within margin, these three foveae connected by a weakly developed biarcuate transverse subbasal sulcus. Disc not medianly foveate or modified. Lateral margins narrowing obliquely to apex, and more sinuately to base, lateral margin with a short acute tooth opposite each lateral fovea, and anterior to this tooth the margin is very finely and irregularly crenulated.

Elytra with each elytron having a subbasal, transverse carina, this carina being medianly briefly interrupted, the mesial half biarcuate and the lateral half uniarcuate, so that the carina is triarcuate as a whole. Within each arc is a shallow, rudimentary fovea, that is, a sutural, a discal, and a lateral fovea. The lateral fovea under high magnification is seen to be in reality two vestigial foveae, but this is difficult to discern. Flank with a strong longitudinal carina which parallels the margin for apical three-fourths then turns mesiad abruptly to end behind the humeral angle. No trace of a subhumeral fovea. Humeri oblique and moderately prominent but not dentate. No dorsal stria of any kind.

Abdomen distinctly margined. Five visible tergites, first four are subequal and very gradually and progressively shorter; fifth very small and triangular. Six visible sternites, first triangular between coxae, slightly longer than coxae or subequal in length; second one-fourth than first medianly; third slightly shorter than second; fourth slightly shorter than third; fifth medianly half as long as fourth, posterior margin concave to enclose sixth; sixth transversely fusi- 
form, as long as second, slightly impressed medianly and the posterior margin nearly straight; all sternites little modified. Abdomen from a lateral view ventrally concave in the antero-posterior axis.

Prosternum simple, with no longitudinal median carina. Metasternum long, longer than second and third sternites united, with the basal half medianly slightly sulcate. Middle coxae contiguous. Posterior coxae obliquely conical, very short, and just perceptibly separated by the metasternum.

Femora slightly, equally inflated. Middle trochanters with the ventral face shortly produced into a thin subcarinated crest. Middle tibiae with a prominent rounded tubercle or uncus on the internal face at apical three-fourths. Tarsi with two unequal claws, the first claw large and prominent, the second claw half as long as first but very much thinner and not discernible at low magnifications since it is closely appressed to the first, the tarsi appearing to be singleclawed.

Female Allotype. As in the male holotype, save that (a) the abdomen when seen from a lateral view is not ventrally concave, but straight in the anteroposterior axis, (b) sixth sternite strongly bisinuate at the posterior margin, the median third extending as a short rounded lobe, (c) middle trochanters normally rounded on ventral face, (d) middle tibiae normal, without prominent uncus of male.

Described on six specimens all collected by Dr. E. C. Williams, Jr., on Barro Colorado Island, Gatun Lake, Panama Canal Zone, as follows: Holotype male, Paratype male and two Paratype females on July 25, 1938, from floormold sample No. 164; Allotype female and Paratype male on July 25, 1938, from floor-mold sample No. 134.

I am pleased to name this isolated species for my friend, Dr. Williams, who spent a summer with me at the Institute for Research in Tropical America at Barro Colorado Island. The series of specimens shows some variation in several structural features: the median vertexal fovea varies in the paratypes from a deep to a shallow fovea; the transverse carina at elytral base varies from a triarcuate carina with three small foveal pits, to quadriarcuate with four small foveal pits; the pronotal disc is perfectly simple, evenly convex in five of the specimens, but in one male paratype the disc has a faint, vestigial, median, longitudinal, depression rather like a stria. With more material, this variant may prove to be a distinct variety. Otherwise the series is perfectly homogeneous. The secondary sexual characters of the males are few but distinctive, the short laminoid tubercle of the middle tibiae being obvious and constant.

In a slide mount of a paratype female certain additional features may be noted: (a) the gular fovea resolves into two minute foveae, each with its floor attached to the supratentorium, (b) the apical prosternal margin is dentate, (c) the lateral prosternal foveae are present, and close to each other, and between them there is a very short, median, longitudinal earina for the basal fifth of the prosternum, (d) the foveae of the meso- and metasternum are well formed; II present on each side at union of prepectoid, mesoepisternum and 
mesosternum, each fovea having two whorled lumens opening at a common orifice; III median and fused; IV and V paired, giving a total nine foveae for the three sternal areas or seven foveae for the mesosternal and metasternal areas. This is a relatively high number and places the species (Table I) in a more primitive group.

Pararamecia shows certain structural affinities with several genera, for example Pteroplectus, Bibloplectus, Ramecia, and Adalmus. It appears to be most related to Pteroplectus of Chile, but the latter genus has the prosternum entirely carinated medianly and longitudinally, and the females have seven sternites. Ramecia in North America, Panaramecia of the Canal Zone, and Biblomimus of the Lesser Antilles have many things in common, and structurally there is an interesting gradation in the prosternal carina, which is entire in the latter, microscopically discoverable as a minute fold between the prosternal foveae in Panaramecia, and absent in Ramecia. Panaramecia and Ramecia are related through the development of the secondary tarsal claws, but Ramecia and Biblomimus have seven sternites. Such comments are given to reëmphasize the lack of a complete tabulation of comparative structural details. Until more is known the phylogenetic relationships will be poorly understood.

\section{PTEROPLECTUS (Raffray, 1898)}

grandicornis (Schaufuss). 1879. Chile. (Euplectus). Genotype.

\section{THESIASTES (Casey, 1893)}

Casey had the following to say regarding his genus (pp. 457-8):

"In general organization the species of this genus resemble Euplectus, but have the body much more minute, the head smaller and especially shorter, the frontal truncature narrower, the eyes relatively larger and more prominent, the tempora shorter and the abdomen completely devoid of dorsal carinae, although deeply impressed at the base of the first two or three segments. In spite of these differences I should have probably regarded them as one of the subgeneric groups of Euplectus, had it not been for the fact that the male sexual modifications at the apex of the venter were found to be of a completely different type. The large, rhomboidal, tumid and carinate seventh ventral in the male Euplectus is here replaced by the oval, flat, laterally enclosed pygidium so characteristic of Ramecia, Actium, and other more or less widely separated genera; this indicates a real divergence from Euplectus far more pronounced than might be inferred from the general organization. The male sexual organs must indeed be remarkably different in structure."

I am in entire agreement with Casey that Euplectus may not logically contain males with the seventh sternite in two valves, and with a single valve. Thesiastes has many structural features shared by Euplectus, but is not to be included in the latter genus. Thesiastes now holds some fourteen species, distributed over the world, including South America, Antilles, North America, and Asia, and the East Indies. The species have a general resemblance to Ramecia in habitus and pubescence, are similar to Euplectus in many ways, and there is an odd resemblance to Thesium in outline. The tarsi have a large 
primary claw and the accessory is little more than a bristle, visible under high magnification. The eleventh antennal segment often has a distinct sensory patch on the apico-lateral face. The ventral surface of the head bears a few spiniform, strongly capitate setae, quite different from the simple aciculates of Euplectus, or the simple capitulates of the melbaforms.

The neotropics have but two species:

argus (Reitter). 1883. Chile. (Euplectus)

liliputanus Raffray. 1904. Grenada, Windward Islands.

Both of these belong in Group I of Raffray (1904, p. 543), having the head as long as wide, relatively small, strongly narrowed apically; the antennal club large with the ninth and tenth segments transverse; the first two tergites transversely impressed at base. It is of interest to point out that this first generic group also includes the North American species (atratus Casey, debilis (LeConte), fossulatus (Brendel), and pumilus (LeConte), indicating that the American species as a whole have a common ancestry, with the neotropical forms having migrated southward.

PTERACMES (Raffray, 1890)

schaufussi Raffray. 1890. Chile. Genotype.

\section{LIOPLECTUS (Raffray, 1898)}

This strange genus is confined to Argentina and since all of the species have been described by Raffray, his 1908 key is given with slight modification:

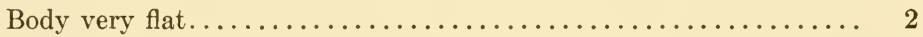

Body more or less convex........................... 4

2. Abdomen much longer than elytra; head much larger than wide; antennal segments IV to VIII moniliform, IX transverse...nitidus Abdomen slightly longer than elytra; head not longer than wide.....

3. Antennal segments IV to VII moniliform, VIII not much wider but slightly transverse, IX similar to eighth but a little wider, $\mathrm{X}$ strongly transverse and nearly concave, close to the eleventh; $1.8 \mathrm{~mm}$. long

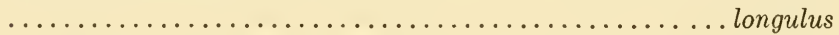

Antennal segments IV to VII moniliform but progressively more transverse, IX and $\mathrm{X}$ very transverse and nearly lenticular; 1.9

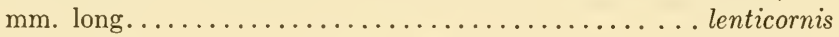

4. Body elongate and parallel but slightly convex; length $1.8 \mathrm{~mm}$.

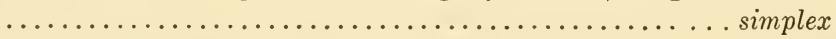

Body less elongate, less parallel and much more convex...........

5. Head normal with a simple parabolic sulcus and the front not excavated; length $1.75 \mathrm{~mm} . . . \ldots \ldots \ldots \ldots \ldots \ldots$.................. Head very flat, occiput transversely impressed and the front of the head (anterior of middle of vertex) slightly excavated; length 2.2

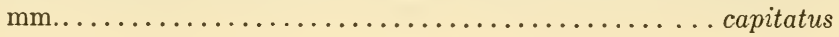


This key does not take into account myrmecophilus, $2 \mathrm{~mm}$. long, erected on the male sex and said by Raffray to be near nitidus but to have a shorter, more anteriorly narrowed head and rounder tempora.

The species of the genus may be listed as follows:

bicolor Raffray. 1909. Argentina.

capitatus Raffray. 1909. Argentina.

lenticornis Raffray. 1909. Argentina.

longulus Raffray. 1909. Argentina.

myrmecophilus Raffray. 1912. Argentina. (con Atta hystrix)

nitidus Raffray. 1898. Argentina. Genotype.

simplex Raffray. 1909. Argentina.

\section{EUPLECTUS (Leach, 1817)}

Like Jubus and Eurhexius, this is an important genus in the grasping of a generalized conception of the family (Pl. XII, 5, 6; XIII, 8; V, 3). Not only is it one of the older genera in the taxonomic literature, but it is one of the largest genera in the family. It contains some 102 described species, and is practically cosmopolitan in distribution. The taxonomy of the genus is in a highly confused state, and much research needs to be done on the fauna, from a world viewpoint, before subgeneric division can be thoroughly attacked, and certain constituents placed in new genera to give a homogeneous assemblage. Virtually all students of the family have had the genus under study and have contributed to our sum of information.

The faunal area under discussion here, namely the American neotropics, is much more easily handled, since Euplectus is relatively very poorly represented. This is oddly similar to the situation in Thesiastes, suggesting again that Euplectus has had its center of dispersal elsewhere, and has spread slowly from North America into the neotropics.

In this vast region being examined there are certainly five, possibly seven, species of Euplectus, as contrasted with some twenty-three to twenty-seven species known in North America north of the Rio Grande river. Despite this small number of neotropical species, it is difficult to key out the species without direct examination of the types, since descriptions of several are generic rather than specific; the species are based on a specimen of unknown sex in some cases, in one case on a single female, and the males of only four species are known.

Sex in Euplectus is quickly diagnosed. The females have six visible sternites; the males have seven visible sternites, of which the seventh is longitudinally carinate. This carina may be median or slightly asymmetrically placed; it may be straight or oblique; it may be convex to the right or convex to the left. These variations of the carina of the seventh sternite are species specific, and should form the basis for a reëxamination of the genus. The carina of the seventh sternite, as noted previously, is not in reality a true carina, but marks the median union of a right and left pygidial plate or valve of the 
seventh sternite, these valves swinging ventro-laterally to allow extrusion of the male copulatory organ. The male sternites are variously secondarily modified by trichomoid setae, fossae, carinae, foveae, et cetera, and are rarely perfectly simple and convex. The male legs may be variously modified.

The number of basal elytral foveae, the shape and extent of the pronotal discal fovea, and whether or not the vertexal foveae are nude or pubescent, are important characters, so that the genus does not lack taxonomic scope.

\section{Key to the Known Males (incomplete)}

Fourth sternite with a transverse fossa or foveoid depression.......

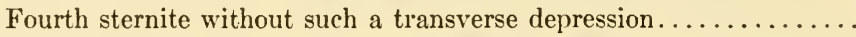

2. Head slightly wider than pronotum............... inhonestus

(1.4-1.5 mm.; each elytron with three basal foveae; Colombia) Pronotum slightly wider than head.................. illepidus

(1.4 mm.; Grenada, Windward Islands)

3. First antennal segment cylindrical; second antennal segment ovate; pronotal discal impression free and ovate............ insularis

(1.4 mm.; Guadeloupe, Leeward Islands)

First and second antennal segments quadrate; pronotal discal impression elongate-oblong, sulcoid...................exiguus

(1.0 mm.; St. Vincent, Windward Islands)

\section{Tentative Key to the Seven Species Ascribed}

Lateral pronotal margins not sinuate toward base, and not having a tubercle or a tooth at the level of the lateral fovea on each side....

Lateral pronotal margins slightly sinuate toward base, and each side with a small tubercle or tooth at the level of the lateral pronotal

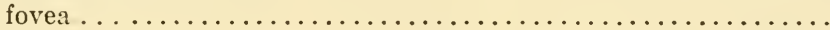

2. Known from the female sex only, and only from Venezuela. . signifera (Size?; each elytron with three basal foveae) Known from the male sex only, and only from the Lesser Antilles exiguus

(See male key)

3. Impression of pronotal dise in the form of an elongate sulcoid depression which extends to the median subbasal fovea of the pronotum. . Impression of pronotal disc variously shaped (sulcoid, foveoid or ovate) but free, that is, not joining the median subbasal fovea of

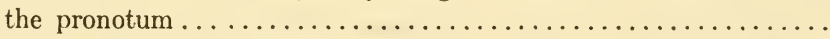


Head with the anterior union of the longitudinal vertexal sulci obsolete, rudimentary...............................

(1.2-1.4 mm.; both sexes known; Guadeloupe, Leeward Islands)

6. Base of each elytron with no foveae (?!) ; known only from Guate-

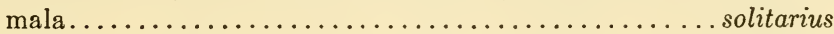

(1.25 mm.; sex of unique type unknown) (Cerro Zunil, Guatemala)

Base of each elytron with three foveae; known only from Colombia inhonestus

(See male key)

Raffray $(1903,1908)$ does not list guatemalenus Sharp, and thinks that solitarius Sharp is probably not Euplectus. However Sharp (1887, p. 37) compares his guatemalenus with Euplectus signatus Reichenbach of Europe, a well known species. If Sharp's two doubtful species be included, the neotropical forms may be listed:

exiguus Raffray. 1904. Grenada, Windward Islands. (VIII) guatemalenus Sharp. 1887. Guatemala. (Euplectus?) (X?) illepidus Raffray. 1904. St. Vincent, Windward Islands. (X) inhonestus Raffray. 1898. Colombia. (X) insularis Raffray. 1908. Guadeloupe, Leeward Islands. signifera Reitter. 1882. Venezuela. (nec signifer) (VII) solitarius Sharp. 1887. Guatemala. (Euplectus?) (X?)

The Roman numerals denote the Raffray group number (1904), and it is notable that the tenth group is wholly neotropical, and secondly that the Antilles have the greatest number of species.

\section{BARROEUPLECTOIDES new genus}

Euplectini having (1) vertex 4 -foveate; (2) eleven-segmented antennae which are widely separated, and with a two-segmented club; (3) maxillary palpi very small, four-segmented, first minute, second subtriangular; third subspherical, nearly as long as second and of about same width; fourth segment as long as second and third united, ovate; (4) pronotum subquadrate, lateral margin denticulate at basal third; lateral fovea each side at level of marginal denticule; median fovea at basal third; no trace of transverse subbasal sulcus connecting the three subbasal foveae; disk with a median fovea; (5) each elytron with two basal foveae; no subhumeral fovea but a welldeveloped longitudinal subepipleural carina and sulcus; (6) abdomen five visible tergites, of which the first three are subequal in length and the fourth much longer than the preceding; six sternites in the female sex (male unknown), second, third, fourth and fifth subequal; tergites with no basal carinae; (7) middle coxae contiguous; (8) posterior coxae contiguous; (9) prosternum not medianly, longitudinally carinate; (10) tarsi three-segmented, small, euplectine, with last tarsomere bearing a large claw.

Genotype: Barroeuplectoides zeteki new species 
Barroeuplectoides zeteki new species

Female Type. Measurements: head $0.17 \times 0.24 \mathrm{~mm}$.; pronotum $0.21 \times 0.23$ mm.; elytra $0.25 \times 0.33 \mathrm{~mm}$.; abdomen $0.34 \times 0.33 \mathrm{~mm}$.; antennae $0.25 \mathrm{~mm}$.; total length $0.97 \mathrm{~mm}$.; greatest width $0.33 \mathrm{~mm}$. (Pl. XV).

Reddish-brown, moderately shining; pubescence uniform in length $(0.03$ $\mathrm{mm}$. long), sparse on head, pronotum and elytra, but moderately abundant on tergites.

Head transversely trapezoidal, widest through eyes; tempora slightly convergent, long, almost twice as long as eyes. Eyes small, not prominent, composed of about 24 very minute facets; the eye almost circular from a lateral view, and each facet being about the size of one of the coarse head punctures. Occiput medianly, slightly sinuate, and with a feeble median notch. Vertex with two small, circular, nude foveae on a line through the middle of the eyes, each vertexal fovea being about twice as wide as one of the coarse head punctures. From each vertexal fovea is a deep, slightly convergent longitudinal sulcus which extends anteriorly to end in an anterior fovea as large as the vertexal fovea. This anterior pair of foveae not united to each other by a transverse arcuate sulcus. Surface of vertex between the longitudinal sulci strongly vaulted into a subtriangular area which is not punctate, and this impunctate condition continues anteriorly of the anterior pair of foveae to the nearly straight, slightly elevated frontal line. Sides of vertex lateral to the longitudinal sulci, from occiput to antennal prominences, coarsely and subcribrately punctured. Therefore the vertex has four foveae, the normal posterior pair and an anterior pair near the antennal prominences. Ventral surface of head coarsely but sparsely punctate, convex; laterally limited by a strong, short carina which extends each side from base of mandible to a point opposite the posterior margin of the eye, the lateral carina being parallel to, but not diverging toward, the eye; a small basal circular nude gular fovea. Ventral face of head without capitate setae; ventral surface of cervicum polished, impunctate, with a well-defined median longitudinal stria extending from the gular fovea to prosternal margin. Front nearly vertical.

Maxillary palpi very minute, slightly longer than the eye, presumably four-segmented; second segment subtriangular; third subspherical, almost as long and about the same width as second; fourth wider than third and as long as second and third united, ovate, medianly inflated, apically subacute.

Antennae short and thick, eleven-segmented, rather widely separated at base by the front, the separation equaling nearly one-half the width of the head; segment I and II subquadrate, of same width and length; III to VIII narrower than second, shorter than second, subquadrate, very closely articulated; of approximate same length and width; IX subquadrate, very slightly wider than eighth and about as long as eighth; club strongly formed of the last two segments; $\mathrm{X}$ twice as wide and twice as long as ninth, nearly twice as wide as long, transversely trapezoidal, with the apical half narrower so that the eleventh segment is conspicuously articulated in distinction to the appressed articulation of the rest of the segments; XI peculiar in that it is as 
wide as long, almost spherical, being slightly more acute in apical fifth.

Pronotum subquadrate, slightly transverse, the lateral margins only slightly convergent to base. Each lateral margin with a slight sinuation at basal third, and at the bottom (most mesial point) of the sinuation is a small but distinct tooth or denticule. Each side with a lateral nude fovea near but wholly within the margin, and at the level of the denticule, as in certain neotropical Euplectus. Pronotal disc with a very small, deep, polished fovea near the base of the disc. This circular discal fovea is about one-half the length of a discal seta. Posteriorly this discal fovea is connected with the larger subbasal fovea by a narrow, short canal or sulcus. The subbasal median fovea is also deep and polished, but is not connected with the lateral subbasal foveae in any way, viz. there is no transverse subbasal sulcus. The integument around the subbasal median fovea, and the basal third of the pronotum is in general coarsely and conspicuously punctate, whereas the anterior half of the pronotum is less coarsely and more sparsely punctate.

Elytra with integument shining, only very finely punctulate. Each elytron with two basal foveae. These basal foveae are very large, much larger than the fovea of the pronotal disc. An entire deep sutural stria from the sutural basal fovea, and a dorsal depression from the discal fovea extending to basal third. Flank with a well-formed longitudinal carina paralleling elytral margin, and a subepipleural sulcus immediately mesiad of this carina, this sulcus ends below the humerus, but there is no subhumeral fovea. Because of the strongly formed, arched apical end of the longitudinal carina, the humeral angle is slightly oblique and denticulate.

Abdomen strongly margined, with five visible tergites; first three tergites subequal in length; fourth tergite distinctly longer than the first three as in Euplectus; fifth tergite vertical, transversely fusiform, strongly convex and shorter than the preceding segments. No basal carinae on disc of the basal tergites. Six sternites visible, first very short; second, third, fourth, and fifth sternites subequal in length with the second and fifth being slightly longer, but this difference is difficult to discern; sixth sternite short, half as long as fifth. All sternites convex and unmodified.

Prosternum, simple, not medianly, longitudinally carinate. Lateral prosternal foveae present, one anteriad of each anterior coxa. Anterior coxae short, conical.

Metasternum long, as long as second and third sternites united, with a very short, median, longitudinal carina between the middle coxae, this carina only extending through basal seventh of metasternum. Middle coxae are contiguous. Posterior coxae contiguous and shortly conical. Legs short with simple femora, the tibiae similarly unmodified. Tarsi short, three-segmented, the first tarsomere very minute, last two tarsomeres much longer, with the second distinctly longer than third; third tarsomere bearing a large claw.

Described on a single female specimen, the type, collected by the author on July 27, 1936, by sifting leaf mold on the forest floor of Barro Colorado Island, Gatun Lake, Panama Canal Zone, near Zetek 23. 
I take pleasure in naming this interesting species for my friend $\mathrm{Mr}$. James Zetek, resident custodian of the Barro Colorado Island Laboratory, whose interest and aid made my trips to the Zone profitable and pleasant. This species runs to the neighborhood of Acolonia Casey in the 1908 key to genera of Raffray's great treatise. It is obviously not at all near to this genus. On the other hand it is allied to Euplectus in many features, in general habitus, pronotal outline, and tergite proportions, while differing from Euplectus in having no transverse pronotal sulcus of any kind, lack of basal abdominal carinae and other characteristics. Known so far by a single species, this genus is very distinct:

zeteki new species. Panama Canal Zone.

\section{VERABAROLUS new genus}

Euplectini having (1) vertex bifoveate; (2) eleven-segmented antennae which are widely separated at base, and with a three-segmented club; (3) maxillary palpi well-formed, four-segmented, first short and cylindrical; second arcuate, elongate, narrow at base and apically inflated; third short, transversely triangular; fourth long, nearly twice as long as eye, subsecuriform; (4) pronotum obcordate, lateral margins not dentate; lateral fovea each side at basal third, and a median subbasal fovea connected by a biarcuate, transverse, subbasal sulcus; disc with an elongate median fovea or linear groove, not reaching apical margin or subbasal transverse sulcus; (5) each elytron with four basal foveae, non-denticulate humeral angle; flank with subhumeral fovea and a subepipleural carina which is parallel to elytral margin; no dorsal stria, but an entire sutural stria; (6) abdomen of five visible tergites, these with no basal discal carinae, and subequal in length, being slightly progressively shorter; six visible sternites in the female sex (male unknown), second to fifth sternite progressively shorter; (7) middle coxae subcontiguous, allowing the mesosternal and metasternal processes to be discerned between them; (8) posterior coxae contiguous; (9) prosternum not medianly longitudinally carinate, but medianly gibbous, this gibbous area being posteriorly prolonged to form a short carinoid line in basal third, between lateral prosternal foveae; (10) tarsi three-segmented, first minute, second and third much larger, second longer and thicker than third, third with a single claw.

Genotype: Verabarolus subdendrus new species.

\section{Verabarolus subdendrus new species}

Female Type. Measurements: Head $0.18 \times 0.23 \mathrm{~mm}$.; antennae $0.33 \mathrm{~mm}$; pronotum $0.23 \times 0.24 \mathrm{~mm}$. ; elytra $0.26 \times 0.33 \mathrm{~mm}$; ; abdomen $0.39 \times 0.30$; total length $1.06 \mathrm{~mm} . \mathrm{x}$ greatest width $0.33 \mathrm{~mm}$.

Reddish-brown, the elytra slightly darker; pubescence abundant, rather short $(0.015 \mathrm{~mm}$.) to longer $(0.03 \mathrm{~mm}$.) ; integument punctulate, moderately shining. 
Head trapezoidal with rounded temporal angles; tempora rather long, longer than eye; eyes small $(0.04 \mathrm{~mm}$. long), moderately prominent, composed of about 22 small facets, the eye circular from a lateral view. Occiput broadly arcuate with a median longitudinal carina extending from cervicum, across occiput, to a point posterior to a line passing through posterior margins of eyes. Vertex with sides above eyes subgranulated; two vertexal foveae which are small, nude, circular, on a line through the posterior third of the eyes; vertexal sulci beginning at a point lateral to and posterior of each vertexal fovea, and converging in an arc to a point mesiad of each antennal prominence, thence being connected by a common transverse sulcus which passes posteriad of the almost vertically declivous front. Head dorso-ventrally flattened from a lateral point of view. Ventral surface of head nearly flat, subgranulated, with a large nude circular gular fovea at middle of basal margin. Ventral surface with no capitulate setae. Cervicum ventrally polished and simple.

Maxillary palpi well developed, four-segmented, first segment short and cylindrical; second about three times longer than first, distinctly more narrow than first at base and inflated in apical half, slightly arcuate; third short, wider than second, transversely triangular; fourth long $(0.07 \mathrm{~mm}$.), almost twice as long as eye, oblique at base, minutely truncate at apex, subsecuriform, with a small apical, palpal cone.

Antennae eleven-segmented, widely separated at base by about one half of the width of the head; segment I subquadrate; II ovate, as wide and as long as first, first and second segments distinctly wider than third; second as long as third and fourth united; III obconic; IV to VII subspherical, with the sixth segment slightly smaller than either the fifth or seventh segment; VIII subpyramidal; club well-formed of last three segments as follows, IX pyramidal, transverse, slightly wider than eighth; $\mathrm{X}$ pyramidal, transverse, slightly wider than ninth; XI relatively large, as long as eighth, ninth, and tenth united, cylindrico-globose, apically not acute, but rounded slightly.

Pronotum obcordate, widest through middle, with the lateral margins broadly rounded to apex and more angulated to base; each side with a large subbasal fovea, and at middle a small rounded median subbasal fovea, these three foveae connected by a transverse biarcuate subbasal sulcus; disk with a free, deep, short, polished subcuneiform fovea.

Elytra with the humeri not denticulate; each elytron with an entire sutural stria, no dorsal stria, four basal foveae; a well-formed subhumeral fovea which lies apical to a subepipleural carina on each flank, this carina being parallel to the elytral lateral margin.

Abdomen with five visible tergites, but no basal discal carinae, the tergites simple, subequal and very slightly diminishing in length, with the fifth slightly shorter, and of a rounded-triangular form from a dorsal view. Six visible sternites, the first short, triangular between the coxae, relatively heavily pubescent; second to fifth progressively decreasing in length, with the fifth less than one-half as long as the second; sixth sternite longer than fifth, subequal in length to third, slightly flattened in median apical half, and sinuate to form 
a rounded median lobe which fits into a ventral incisure of the posterior margin of the fifth tergite. Fifth sternite with a minute tubercle at middle of apical margin.

Prosternum with the apical margin serrato-dentate; medianly gibbous, with the posterior portion of the gibbous area forming a short carinated elevation between the lateral prosternal foveae which are well-developed anteriad of each coxa. No entire median longitudinal carina.

Mesosternum not carinated medianly, flat and shining.

Metasternum medianly tumid, with a short sulcoid area at extreme posterior fifth; long, as long as third and fourth sternites united.

Anterior coxae short, conical; middle coxae subcontiguous, the meso- and metasternum discernible between them as narrow, flat, acute extensions; posterior coxae contiguous, shortly conical. Legs simple, with short threesegmented, euplectine tarsi, the first tarsomere very small, the next two much larger; second tarsomere very much larger than the third, the third bearing a single claw.

The paratypes agree with the type, save that the median discal fovea of the pronotum is more linear and longer; in one paratype the elytra have the fourth (most lateral) basal fovea much smaller than the other three. From a slide mount of a paratype the following morphological additions can be added: (1) the sternal foveae are very well developed; in addition to the lateral prosternal foveae noted previously, the meso- and metasternum have foveae II, III, IV, and V paired and present. II are large, with a bifurcated whorled lumen, one arm of which penetrates the prepectoid and one arm the mesosternum proper. III are small, with a single whorled lumen, one on each side of a median longitudinal carina of the prepectoid. IV are relatively as large as any I have encountered, and typically located, that is, at the lateral angle of each middle coxal cavity, at the union of five sclerotic areas (mesosternum, mesoepisternum, mesoepimeron, and metasternum). VI are small, one in the center of the posterior margin of each middle coxal cavity. (2) Each of the elytra has three asetose pores. These appear as very clear, perfectly circular areas in strong relief against the yellow integument. They appear to be sensory, and, although they have no relation to the setal punctures, are of almost the same size. Two of these pores lie on the disc at the apical fourth. The third lies in the basal third, posterior to a line drawn between the fourth and third basal foveae. (3) There appears to be a peculiar mechanism between the inner face of the elytra and the sides of the invisible first tergite. In life this tergite, which is membranous, is tucked beneath the elytra. In the cleared specimen, there are about twelve short oblique striae on the lateral face (pleurite?) of this membranous segment. In apposition are about eight transverse carinae on the internal face of the elytron, near its apical external angle. Such a mechanism suggests the possibility of a stridulatory mechanism, but no further data concerning the possible function of this area are at hand.

Described on four females, collected by the author, beneath the bark of logs on Barro Colorado Island, Gatun Lake, Panama Canal Zone, as follows: July 
26, 1936, at Armour 8; July 28, 1936, at Zetek 3; July 29, 1936, at Pearson 4; July 30, 1936, at Armour 10.

This distinct species appears to be rather generally distributed in the center of the island. It is near Euplectus, from which it is readily separable by the subequal tergites, lack of basal tergite carinae, and other features. In Raffray's $1908 \mathrm{key}$, it runs to the neighborhood of the Chilean Pteroplectus, but cannot be confused with this genus as the latter has a strong, entire prosternal carina and seven sternites in the female. The genus as now constituted has but the one species:

subdendrus new species. Panama Canal Zone.

ADROGASTER (Raffray, 1890)

longipennis Raffray. 1890. Brazil. Genotype.

ACOTEBRA (Reitter, 1881)

simoni Reitter. 1893. Chile. Genotype.

TOMOPLECTUS (Raffray, 1898)

cordicollis Raffray. 1898. Mexico. Genotype.

ACTIUM (Casey, 1886)

Casey (1886, 1887, 1893, 1897, 1908)

Brendel and WickhaM (1890)

RAFFraY (1898, 1904, 1908)

Bowman (1934) (genotype Actium pallidum Casey)

Proplectus Raffray, 1890 (Trichonychini) a synonym of Actium.

This is a large genus of some seventeen species, of which only three are found south of the Rio Grande river. The center of distribution therefore appears to be in the United States, especially California, where some nine or ten species are known. Raffray (1908) thinks that this genus replaces Trimium (Aubé, 1833) in the western hemisphere, the latter genus being abundant and typical in the European palaearctic fauna. Actium seems to be rather centrally located in the tribe, in general much more specialized than the Euplectoid genera, and not so specialized as the Melboid genera. The three neotropical species are neither known from the eastern regions of South America nor from the Antilles, and hence it would seem probable that the species of Actium have spread eastward from California into the eastern United States, and secondly southward down the Rocky Mountain-Andean chain as far as Chile.

In general the eyes are well formed in both sexes. Vertexal foveae are always present and may be nude or pubescent. Antennae are eleven-segmented, with the club composed chiefly of the eleventh segment, although the length of this segment varies in the subgenera from as long as the eighth to tenth combined, to as long as the sixth to tenth combined. The maxillary palpi are 
four-segmented, with the distal segment elongate-oval, rather thick and acuminate. Ventral surface of the head with capitulate setae (a melbaform trend). Pronotum with the disc simple, not foveate or sulcate; the base with a transverse sulcus, usually arcuate or biarcuate, posteriorly angulated at middle, extending to a lateral fovea each side; these lateral foveae are usually pubescent. Prosternum not medianly longitudinally carinate. Elytra with two to three basal foveae on each elytron, plus a subhumeral fovea and a longitudinal subepipleural carina and sulcus. Abdomen with six sternites in the female, and seven sternites in the male; male seventh sternite in the form of the simple, asymmetrically articulated, one-plate pygidium found in Melba. First tergite usually provided with a pair of short, basal, discal carinae.

Raffray (1904) divided the then known species of this genus into four groups, and since a neotropical species is known from each of the first three only, this group key will serve to isolate the neotropical forms known at this time:

First tergite with a pair of basal discal carinae, second tergite with

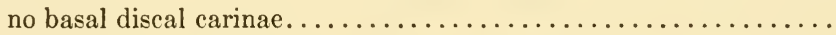

First and second tergites each with a pair of basal discal carinae; each elytron with three basal foveae.....trimiiforme (Reitter) Group I (Valdivia, Chile)

2. Each elytron with three basal foveae..... gracili Raffray, Group II (Chile) Each elytron with two basal foveae.....caviceps Raffray, Group III

(Mexico)

The three species of the region under examination may be listed as follows: caviceps Raffray. 1898. Mexico. gracili Raffray. 1898. Chile. trimïforme (Reitter). 1885. Chile. (Pseudoplectus)

ACTINOMA (Raffray, 1898)

obesum Raffray. 1898. Mexico. Genotype.

PSEUDOTRIMIUM (Raffray, 1898)

microcephalum Raffray. 1898. Probably Mexico. Genotype.

TRIMIODINA (Raffray, 1898)

concolor (Sharp). 1887. Guatemala. (Trimium). Genotype.

TRIMIOPSIS (Reitter, 1882)

This wholly neotropical genus has been strictly limited by Raffray (1908), and now includes two species from Guatemala so inadequately described that 
their inclusion is doubtful, the genotype from Colombia and a new species from the Panama Canal Zone.

These four species may be separated as follows:

Head not wider than pronotum; clypeal margin "strongly raised and connected on either side by a small process to the anterior acuminate part of the convex vertex, so that the depressed space is (distinctly) divided into a lateral portion on each side and a median portion placed more anteriorly" (ex Sharp)........... femoralis Sharp

(1.25 mm.; male?; El Tumbador, Guatemala)

Head wider than pronotum; clypeal margin not so connected each side with the vaulted vertex $(\mathrm{Pl}$. XIX, 7$) \ldots \ldots \ldots \ldots \ldots \ldots$

2. Vaulted median portion of the vertex extending anteriorly as a triangular angle into the post-clypeal depression..............

Vaulted median portion of the vertex transversely divided into a basal triangular portion which is separated by a transverse sulcus from an anterior acute tubercle (Pl. XIX, 7) ....... furcalis new species

3. Known from Guatemala; $1.4 \mathrm{~mm}$. long; rufocastaneus........... clavicornis Sharp

Known from Colombia; $1.3-1.4 \mathrm{~mm}$. long; testaceus............. .claviceps Reitter

Trimiopsis has a characteristic habitus, which includes the broad head, strongly vaulted vertex, and the distinctly asymmetrically triangular tenth antennal segment. The following species is new:

\section{Trimiopsis furcalis new species}

Holotype Male. Measurements: Head 0.20 x $0.24 \mathrm{~mm}$; pronotum $0.21 \mathrm{x}$ $0.20 \mathrm{~mm}$; ; elytra $0.28 \times 0.32 \mathrm{~mm}$; abdomen $0.40 \times 0.30 \mathrm{~mm}$.; total length 1.1 $\mathrm{mm}$; greatest width $0.32 \mathrm{~mm}$. (Pl. XIX, 7).

Reddish-brown, with the head and pronotum slightly darker; integument moderately shining, pubescence short and inconspicuous.

Head with the tempora parallel, as long as eye; eyes prominent; temporal angles prominent and squarely rounded; vertex with sides above each eye flattened and granulated, medianly the vertex is conspicuously vaulted and not granulated; vertexal foveae minute and punctiform (in contrast to the large vertexal foveae of the genotype), situated on a line passing through middle of eyes. Vertexal sulci complex: from each vertexal fovea there extends a short longitudinal sulcus, which bifurcates near a point opposite the anterior margin of the eye, into two arcuate sulci; these arcuate sulci are medianly confluent with their homologous sulci from the other side, so that there are two arcuate transverse sulci. This sulcation of the head divides the vaulted median part of the vertex into a larger, posterior, subtriangular portion which begins between the vertexal foveae and is limited anteriorly by the median transverse sulcus, and a smaller, acute subpyramidal tubercle which lies between the two 
transverse sulci. The posterior transverse sulcus lies at about the anterior margin of the eyes, the anterior transverse sulcus extends semicircularly behind the raised frontal margin. Front between the antennal bases arcuate. Ventral surface of the head coarsely and conspicuously punctate, without capitulate setae.

Maxillary palpi four-segmented, first segment minute and cylindrical; second slender, arcuate, apically inflated; third asymmetrically subspherical; fourth widest and longest, oblique at base, acute at apex, subconico-ovate, with an apical palpal cone.

Antennae short, not longer than the head, separated by half the width of the head, eleven-segmented, segment I and II relatively large, first inconspicuous because of the deep articulation beneath the front, and shorter and narrower than second segment; second ovate; III to VIII very closely articulated, of about same length and width, subequal, distinctly smaller than second; third obconical; fourth to eighth are transversely moniliform; IX wider than eighth, short and inconspicuously articulated to tenth; $\mathrm{X}$ much larger, as wide as eleventh and strongly, asymmetrically triangular, the mesial face being longer and tumified; XI truncate at base, closely appressed to tenth, as long as fifth to tenth segments united, asymmetrically subacute. With minor differences this is a typical Trimiopsis antennal pattern.

Pronotum trimiform, obcordate, each side with a small lateral fovea within the margin at basal third, and a medial subbasal fovea connected by an entire, biarcuate, transverse, subbasal sulcus; disc simple, slightly flattened (with an oblique light and high magnification, a just discernible ovate depression can be seen).

Elytra widest medianly, with rounded humeri; each elytron with two conspicuously large basal foveae, the sutural fovea giving rise to a sutural stria which is not entire, that is, it ends a short distance from the apical margin at about apical seventh; the discal fovea gives rise to a short, triangular dorsal depression in basal fourth; neither a subhumeral fovea nor a subepipleural sulcus on the elytral flank.

Abdomen with a relatively narrow margin and five visible tergites. First tergite with a pair of short, blunt, straight, parallel discal carinae separated by about one-half of segmental width. First three tergites subequal in length, fourth longer, fifth subequal to third and rounded-triangular from a dorsal view. Seven sternites visible, first sternite shorter than second, and triangular between the coxae; second slightly longer than third; third and fourth subequally long; fifth shorter, with a small median tubercle at basal margin; sixth as long as second, medianly flattened; seventh rounded-triangular, as long as sixth.

Prosternum medianly, transversely gibbous, not medianly longitudinally carinate. Middle coxae subcontiguous under high magnification. Posterior coxae shortly conical and contiguous. Metasternum long, nearly as long as first three sternites united, flattened and gently, medianly depressed. Sternal foveae IV very large and conspicous at the lateral angle of each middle coxa. 
Legs with the femora distinctly inflated; middle femora ventrally strongly sinuate, with a conspicuous blunt triangular tooth at base as a consequence of this sinuosity; tarsi three-segmented, euplectine, first minute, second and third much larger than first, second longer and thicker than third; third tarsomere bearing a single, large, arcuate claw.

Allotype Female is similar throughout save that (1) the fourth tergite is not much longer than the third, the five tergites being subequal in length; (2) only six sternites, with the first very short, second longer than first and third; third and fourth subequal; fifth one-half as long as fourth; sixth large, as long as second and third united, subtriangular, with lateral margins sinuate and apex rounded to fit into a deep ventral incisure of the ventral margin of the fifth tergite; (3) femora not inflated, and middle femora simple.

Note that the female has the vaulted vertex and bifurcated sulcal pattern present in the male.

Described upon a male and a female specimen, both collected at the same time and niche, beneath the bark of a $\log$ at Armour 8, July 26, 1936, on Barro Colorado Island, Gatun Lake, Panama Canal Zone, by the author. The species of the genus are as follows:

claviceps Reitter. 1882. Colombia. Genotype. (nec caviceps auct.)

clavicornis Sharp. 1887. Guatemala.

femoralis Sharp. 1887. Guatemala.

furcalis new species. Panama Canal Zone.

\section{NEODALMUS (Raffray, 1890)}

This is a melbaform, monotypic genus which is isolated by the pronotal structure: the disc of the pronotum is crossed longitudinally by a median carina, analogously to the brachyglutine Bunoderus. There is a single species:

carinatus Raffray. 1890. Venezuela. Genotype.

\section{DALMOPLECTUS (Raffray, 1890)}

This genus was created by Raffray to contain a melbaform species, known only from the female sex, originally placed in the Tychini. The fact that the posterior coxae are distinctly, although slightly, separated serves to differentiate the genus from Melba.

batrisoides (Reitter). 1882. Brazil. (Dalmodes).

\section{MELBAMIMA (Raffray, 1909)}

This genus contains a single melbaform species, separated from Melba chiefly on the structure of the antennae (Pl. VI). These organs are elevensegmented, with the first two segments relatively very large and subquadrate and nearly three times as wide as segments III to VIII; the third segment is obconical; fourth to eighth transverse and compactly articulated; IX of the 
same general form, but slightly wider than the eighth segment; club formed of the tenth and eleventh segments, of which the eleventh is conspicuously large: segment $\mathrm{X}$ bilaterally very asymmetrical, much longer and wider than ninth, of a rounded-triangular shape, and very asymmetrically articulated on the antero-mesial face of the ninth segment. Because of this asymmetrical articulation, the ninth and eleventh segments are in contact laterally, but widely separated mesially because of the wedge of the tenth segment; segment $\mathrm{XI}$ as long as the second to the seventh inclusive, asymmetrically subconical, with the apex acute, lateral face slightly and sinuately concave and the mesial face convex.

Melbamima clavicornis represents a divergent, specialized trend from Melba, since most species of the latter genus have only slightly asymmetrical tenth antennal segments, but certain species such as Melba clavata have this segment much more asymmetrically formed. One species represents the genus so far:

clavicornis Raffray. 1909. Brazil. Genotype.

\section{TRIMIOSELLA (Raffray, 1898)}

This also is a monotypic, melbaform genus, erected to contain a species formally placed in the then expanded Trimiopsis. Such a course was necessary following the restriction of Melba to contain only those species in which the lateral pronotal foveae were placed far down on the sides of the prothorax and hence invisible from above. In Trimiosella the lateral pronotal foveae are within the lateral pronotal margins and hence fully visible from above. Tenth antennal segment lenticular, and not asymmetrical. Males with seven sternites, females with six sternites, the seventh male sternite being the one-plate, noncarinated type of pygidium common to the melbaforms as a group.

anguina (Reitter). 1883. St. Thomas, Virgin Islands. Genotype.

\section{RAMELBIDA new genus}

This new genus is erected for Melba quadrifoveata Raffray (1904, p. 537). Raffray $(1898,1904,1908)$ restricted Melba to those species having the lateral pronotal margins rounded, and the transverse subbasal sulcus continuing down the sides of the prothorax, ending each side in a lateral fovea. Consequently these lateral foveae lie in or near the prosternum, and are not visible from a dorsal point of view. In 1898 Raffray erected Trimiosella for Trimiopsis anguina Reitter, since the latter, although closely related to Melba, had lateral pronotal foveae visible from above. Later, Raffray (1904) described quadrifoveata as a species of Melba. This was a mistake, since the latter species has the lateral pronotal foveae also visible from above, and in fact, is so shown in a figure (fig. 8, p. 537, Raffray, 1904).

Melba quadrifoveata may be a Trimiosella, but at present the described structure scems to be too divergent for this genus, and Ramelbida is erected to contain the melbaforms having: (1) eleven-segmented antennae, the sec- 
ond segment of which is large and ovate; third to eighth moniliform and slightly transverse; ninth and tenth segments progressively more transverse, lenticular and symmetrical; eleventh segment ovate and as long as sixth to tenth inclusive; (2) head wider than long, nearly as wide as pronotum; with the vertex holding four foveae, one pair on a line through the posterior half of the eyes, each nearer an eye than their mutual intrafoveal separation; a second pair of foveae placed near the subtruncate frontal margin, one on each side at the base of the small first antennal segment; no vertexal sulci; (3) pronotum with the biarcuate transverse subbasal sulcus terminating in a lateral fovea each side, these foveae being visible from a dorsal point of view; (4) elytra with obtuse humeri and each elytron having two large deep basal foveae.

Ramelbida has but two genera with which it may be confused, Melba and Trimiosella. From both of these it may be readily separated by the complete absence of vertexal sulci (these sulci being obsolete in Trimiosella), four welldeveloped vertexal foveae (approached in this only by Melba (?) temporalis), and the visible pronotal foveae (which takes it from Melba). Many of the species described in Melba may prove to belong in Ramelbida, but this may not be ascertained until types are examined. At present there is but one:

quadrifoveata (Raffray). 1904. St. Thomas, Virgin Islands. (Melba). Genotype.

MELBA (Casey, 1897)

CASEY (1897)

RafFray (1898, 1904, 1908, 1908a, 1909, 1912, 1912a)

LENG (1920)

Bowman (1934) (Melba thoracioa (Brendel), p. 144, genotype)

Brendel and Wickham (1890) (Trimium in part)

CaSey (1897) (Zolium)

ReITTER (1883) (Trimiopsis in part)

SHARP (1887) (Trimiopsis in part)

Like Jubus, Eurhexius, and Euplectus, this is a large and important genus; unlike Euplectus, it is wholly American, and appears to be one of the most highly specialized in the euplectine tribe. There are about eleven described species north of the Rio Grande river, distributed from Arizona eastward to the Atlantic coast, and from Louisiana and Florida to New York and Illinois. The genus does not appear to have any species spreading into Canada. South of the Rio Grande, there are about eighteen species, eleven of which are endemic in the Antilles, and the other seven species are recorded from Mexico, through Guatemala, French Guiana, Brazil, and Argentina. Such a distribution appears to indicate a neotropical origin for the genus, especially since related melbaforms (Ramelbida, Trimiosella) are antillean also, and the Lesser Antilles are the present center of taxonomic diversity in the genus.

The habitus of Melba is fairly consistent (Pl. XI, 7, 8). The species are small $(0.7$ to $1.1 \mathrm{~mm}$.), with a conspicuously large distal antennal segment, 
and the cordiform pronotum has rounded lateral margins, with the lateral foveae on each side not visible from a dorsal view.

Certain special features of their anatomy should be noted, and are figured for the genotype and related North American species in the plates (PI. IV, XI, XII). The head varies in outline from subtriangular, in which the sides are oblique, to the attenuated anterior end with a subtruncate front, to subquadrate. In the subquadrate head the males have the sides more or less suddenly dilated anteriorly (parmata, ventricosa). Although the front is usually not prolonged, in some species (clypeata and fleutiauxi) the front is prolonged above the epistomal region, strongly in males and less strongly in females. The eyes are large and prominent. Two vertexal foveae are present between the eyes, these foveae being nude, circular, and connected by an arcuate sulcus which is usually well formed but may be partially interrupted. The ventral surface of the head is provided with distinct capitulate setae. Maxillary palpi four-segmented; first minute; second arcuate, slender basally and inflated apically; third short, transverse, subtriangular, as wide as or wider than second; fourth longest and widest, elongate-oval to subsecuriform. Antennae eleven-segmented, with the first two segments larger than the third to seventh, the second larger than the first; third to tenth inclusive small, with some variation in shape and relative size among the species; tenth segment usually transverse, lenticular and bilaterally symmetrical but may be transversely tr1angular and asymmetrical (clavata); eleventh segment quite large, conoidal or ovoid, acuminate, provided with antennal cones which can be discerned only in slide mounts at high magnification.

Pronotum obcordate to cordiform, with rounded lateral margins, and the basal third crossed transversely by an arcuate to biarcuate variably developed sulcus; this sulcus continues down each pronotal flank to end in a lateral fovea near or on the flanks of the prosternum, making the foveae invisible from above; disc of pronotum simple.

Elytra with the humeri never dentate, usually rounded, but in some species nearly square (parmata, ventricosa, eggersi) ; there is no subhumeral fovea and no subepipleural sulcus on the elytral flank; on each elytral flank, however, there is an important generic feature in the presence of a fine oblique line which extends from near the middle of the lateral margin obliquely to the elytral apex. (In the North American Dalmosella and Trimiomelba, this cariniform line is not oblique, but is parallel to the elytral margin from its origin at basal third to apex, and forms a good criterion for separation; this feature was known to Casey in the erection of his melbaform genera.) Each elytron with two basal foveae; the sutural gives rise to a sutural stria, and the discal gives rise to a short variable dorsal depression. The abdomen has five subequal tergites, the first tergite not narrowed at base; the sternites show sexual differentiation, there being six sternites in the female and seven sternites in the male. The male seventh sternite is a circular, simple, uncarinated one-piece pygidium which is asymmetrically articulated.

Prosternum simple, with no median longitudinal carina. The mesosternum 
and metasternum have seven foveae developed (about parallel with the sternal development of Bibloplectus), foveae II, IV, and V are paired and III is median and fused in the genotype and closely related forms. The metasternum is usually simply convex in the female, and often sulcate or concave in the male sex.

The legs are usually secondarily modified in the males. This is diverse in the genus. The femora of the males are generally inflated. In dentipes the mesothoracic tibiae are medially spined; in others these tibiae are obtusely prominent and pubescent medially, angulate, swollen and bearing a copulatory pad on the mesial face at apical third (thoracica, sulcatula). This pad, when examined on slide mounts at high magnification, is seen to consist of minute semispherical transparent padules, the number of padules varying in some cases with the species. The swollen male middle femora may bear large punctures, or sensory pores, and these pores may be present on the anterior femora as well. The tarsi are euplectine, with a minute first and a relatively large second and third tarsomere; second slightly longer, and much thicker than the third; third bearing a large curved claw.

Although this present study is primarily concerned with the neotropical Pselaphidae, I should like to take this opportunity to make up a brief for Dalmosella of North America. Dalmosella (PI. IV, XII) was erected by Casey (1897, p. 570) for a new species, tenuis, which I designate as the genotype, and two doubtful inclusions, Trimium simplex LeConte and Trimium americanum LeConte. Leng (1920) placed Dalmosella in Melba, and this course was followed by Bowman (1934). I do not know simplex and americanum, but tenuis is very distant from our present conception of Melba. Casey's original description of tenuis was based on a female, and the remarkable male characters (Pl. XII, 15, 16) were unknown to him. I have taken tenuis in copulation in Illinois, and the male features have not been reported to my knowledge. The following tabular comparison (Table II) between two genotypes will set forth the striking differences between the two genera in question.

The genus Melba shows numerous radiating trends into other melbaform and some brachyglutine genera. Thus the general habitus and contiguous posterior coxae are similar to the glabrous Eupsenius with subcontiguous posterior coxae and an even larger distal antennal segment. The subglabrous Eupsenina with very distant posterior coxae seems much more remote, but the capitate setae of the ventral surface of the head are melboid. Melba frontalis suggests certain outlines of Dalmosella and Ramelbida. Melba clavata approaches Melbamima. Melba parmata suggests Dalmoplectus. It is evident that this genus has been an active evolutionary center in the past, and there are probably many new species awaiting discovery.

Raffray (1904, p. 535) divided the genus Melba into four groups of species. This grouping can no longer be maintained, since Group I of Raffray is Dalmosella, and the addition of many new species since this time, with increased structural and zoögeographic information, makes a revision necessary. The following key to subgenera is offered to bring our knowledge of this difficult group up to date. 
COMPARISON OF DALMOSELLA AND MELBA

\section{Dalmosella tenuis Casey}

Capitulate setae on ventral face of head.

Tenth antennal segment transversely triangular and bilaterally asymmetrical.

Vertexal foveae large and pubescent.

Arcuate vertexal sulcus wide, coarse, distinctive.

Pronotum with a strong, biarcuate transverse sulcus which cuts the lateral wall near base each side, the resulting constriction being distinctive. The anterior margin at the lateral end of the sulcus is distinctly tufted with setae.

Lateral pronotal foveae not visible from above, but pubescent.

Basal elytral foveae pubescent.

Elytral flank with a cariniform line which is parallel to the margin from origin at basal third to apex.

First tergite slightly constricted at base.

Males with seven, females with six sternites. Seventh male sternite a simple oval, asymmetrically articulated pygidium.

Male mesothoracic femora simple.

Male tibiae simple.

Male second sternite very greatly modified: integument extended into a broadly triangular lobe which extends posteriorly from basal two-thirds for the median fifth of width; this lobe is heavily pubescent and overhangs an equal depression posteriorly. In lateral view this pubescent lobe is distinctive. On each side of the apical depression is a small, erect, obtuse spine. (See plates).
Melba thoracica (Brendel) and Melba sulcatula Casey

Capitulate setae on ventral face of head.

Tenth antennal segment lenticular and practically bilaterally symmetrical.

Vertexal foveae smaller and nude.

Arcuate vertexal sulcus simple, only moderately developed.

Pronotum with the biarcuate transverse sulcus near basal third, narrowing the pronotal outline but not cutting the lateral margin in this manner, but passing simply down each pronotal flank. The sulcus not tufted laterally with setae.

Lateral pronotal foveae not visible from above, and nude.

Basal elytral foveae nude.

Elytral flank with an oblique line which arises near middle of flank and extends obliquely to apex. A striking structural difference.

First tergite not constricted at base.

Males with seven, females with six sternites. Seventh male sternite a simple, oval to suboval, asymmetrical articulated pygidium.

Male mesothoracic femora inflated and with sensory pores, under high magnification.

Male mesothoracic tibiae with a copulatory pad on mesial face at apical third, the pad being made up of a differential number of padules, at high magnification. 
Key to the Subgenera

Tenth (penultimate) antennal segment transversely triangular and bilaterally asymmetrical (approaching Dalmosella and Melbamima) known from Brazil and possibly Argentina............

ASYMMELBA, new subgenus

Tenth antennal segment transverse, lenticular or practically bilater-

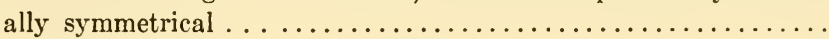

2. Vertex with four free foveae arranged in an anterior pair near antennal bases and a posterior pair between the eyes; no vertexal sulci connecting the foveae (approaching Ramelbida) known from

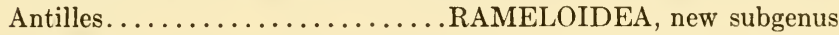

Vertex with a pair of vertexal foveae between the eyes, these foveae more or less connected by an arcuate vertexal sulcus............

3. Vertex with a large, deep, transverse excavation between the eyes, this depression medianly tuberculate; known from French Guiana

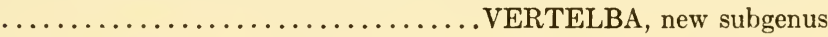

Vertex simply convex or flattened between the eyes.............

4. Head quadrate in outline, and in the males (seven sternites) anteriorly dilated; known from the Antilles (Raffray, Group IV) ..................................... new subgenus

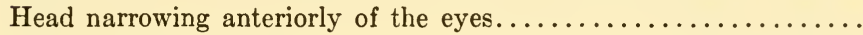

5. Front prolonged anteriorly above the epistomal area, this extension more pronounced in the males (seven sternites) than in females (six sternites), but distinct in both sexes; known from the Antilles and

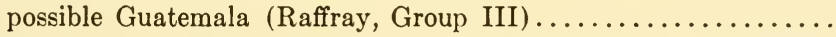

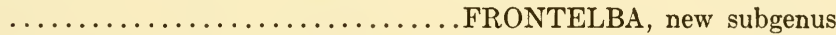

Front normally subtruncate to gently arcuate between bases of antennae; includes all North American species and the Antilles (Raffray, Group II, and original Melba of Casey) ...........MELBA, s.s.

\section{Key to Asymmelba}

Front transversely sulcate; tenth antennal segment strongly dilated on mesial face and very asymmetrical; eleventh antennal segment

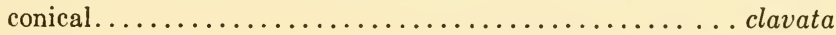

$$
\text { (0.9 mm.; Sao Paulo, Brazil) }
$$

Front rectilinear, and with two deep transverse sulci; tenth antennal segment slightly asymmetrical; eleventh antennal segment ovate .. impressifrons

(0.9 mm.; Sao Paulo, Brazil)

Melba impressifrons has affinities with both caviceps and temporalis. Melba longicollis (Raffray, 1912), from Argentina may also belong in this group, but the tenth antennomere is described as merely large and transverse. 


\section{Rameloidea}

Only one species appears to belong here, Melba temporalis Raffray, from Martinique (region of St. Pierre). By the four free vertexal foveae this species approaches Ramelbida, but the lateral foveae are not visible from a dorsal view; the species also shows a relationship to impressifrons, but the tenth antennal segment is simply transverse and symmetrical.

\section{Vertelba}

Here also belongs a single species, Melba caviceps Raffray, from French Guiana. Described on a male, the tibiae are simple, and the length is given as $1.00 \mathrm{~mm}$. long. The deep excavation of the head is approached only by Melba impressifrons Raffray, but the tenth antennal segment is not asymmetrical, although described as strongly transverse.

\section{Key to Quadrelba}

Head simply expanded on each side anterior of the eye; 0.8-0.9 mm. long; St. Thomas and Puerto Rico, Antilles...........ventricosa Head slightly expanded on each side anterior of the eye, and subdentate; 0.8-0.9 mm. long; St. Thomas and Puerto Rico, Antilles

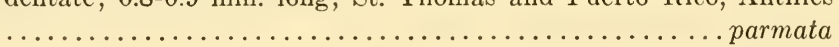

\section{Key to Frontelba}

The following key does not include Melba (Frontelba) fleutiauxi Raffray. The inclusion of David Sharp's two Guatemalan species is questionable in view of the inadequate descriptions and the geographic isolation of the two groups of species. It is wholly possible that these two species belong in Melba s.s. Sharp $(1887$, p. 38 ) says that mimula is closely related to clypeata; with respect to his other species, minuta is said to have the head transversequadrate (an approach to Quadrelba) but the figure of this species does not show the quadrate head outline expanded anterior of the eyes, and does show the anterior portion of the head expanded between the antennae. Examination of types will have to resolve these questions.

Species known from Guatemala..................... 2

Species known from the Lesser Antilles................... 3

2. Head distinctly longer than wide; $1.0 \mathrm{~mm}$. long.........mimula

Head as wide or slightly wider than long; $0.8 \mathrm{~mm}$. long...... minuta

3. Front produced between the antennae as a semicircular, flat extension;

$0.75 \mathrm{~mm}$. long; St. Thomas...............................

Front produced between the antennae, this extension with three tubercles arranged in a triangular pattern; $0.9 \mathrm{~mm}$. long; Gua-

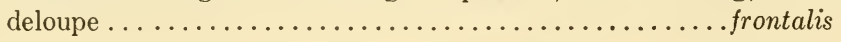




\section{Key to Melba s.s. Males}

The following unsatisfactory key is based on the male sex only. The females have only six sternites, whereas the males have seven sternites, the seventh being in the form of a small oval subcircular, or more rarely subrhomboidal plate. This plate (operculum, pygidium) is uncarinated medianly, asymmetrically articulated, and enclosed by the incised sixth sternite and fifth tergite. It should be noted that one species (longicollis Raffray) is a guest of ants.

Third, fourth, and fifth sternites presumably simple, without tubercles, foveae or conspicuous depressions (Raffray in describing these two species discusses the male characters but makes no mention of such

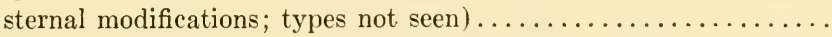

Third, fourth, and fifth sternites with at least one segment secondarily modified, often two segments modified by foveae, tubercles or depressions . . . . . . . . . . . . . . . . . . . . . .

Metasternum longitudinally sulcate; sternites II to $\mathrm{V}$ subequal in length; sternite VI medianly flattened; 0.9-1.0 mm. in length....

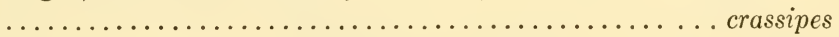

Metasternum flattened; sternites II to $\mathrm{V}$ progressively shorter; sternite VI transversely impressed; $0.9-1.0 \mathrm{~mm}$. in length......grenadensis

3. Third sternite with a median transverse impression; fifth sternite with two approximate transverse foveae; $0.6-0.7 \mathrm{~mm}$. in length.......

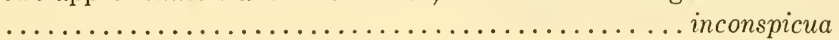

Third sternite otherwise modified...................

4. Third sternite with a tubercle on each side; $0.75 \mathrm{~mm}$. in length.....

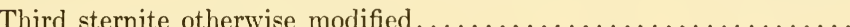

Third sternite with an impression on each side, this depression subtuberculate; metasternum not strongly impressed; $1.0 \mathrm{~mm}$. in length gibbula

Third sternite with an oblong, arcuate foveoid depression on each side; metasternum longitudinally impressed; length $1.0 \mathrm{~mm}$...... eggersi

This key does not take into account a remarkable myrmecocolous species, Melba longicollis Raffray from a nest of Atta lundi in Argentina. This species is $1.10 \mathrm{~mm}$. long and the male has the anterior and the intermediate femora inflated and the intermediate tibiae dentate. It is said to be near dentipes Raffray of Pennsylvania but to have a more elongate-oval pronotal outline.

It is possible that both Sharp's species, which are placed in Frontelba, belong in Melba s.s.

The species of the genus Melba may be listed as follows:

\section{Melba s.s.}

Tenth antennal segment not bilaterally asymmetrical; vertex of head with the vertexal foveae connected by an arcuate, more or less defined sulcus; vertex 
of head not modified between the eyes, usually simple, convex or flattened; front of head simple between the bases of the antennae and truncate to gently arcuate; head not dilated anteriad of the eyes, but narrowing from eye to antennal insertion.

Melba of Casey (1897), and Group II of Raffray (1904).

crassipes Raffray. 1908. Guadeloupe, Leeward Islands.

eggersi (Reitter). 1883. Puerto Rico; St. Thomas, Virgin Islands.

(Trimiopsis)

gibbula (Reitter). 1883. St. Thomas, Virgin Islands. (Trimiopsis)

grenadensis Raffray. 1904. Grenada, Windward Islands.

inconspicua (Reitter). 1883. St. Thomas, Virgin Islands. (Trimiopsis)

specularis (Reitter). 1883. St. Thomas and Water Island, Virgin

Islands; Dominica, Leeward Islands. (Trimiopsis)

longicollis Raffray. 1912. Argentina. (con Atta lundi Guer.) cf.

Bruch, 1929.

\section{Frontelba new subgenus}

As for Melba, save that the front of the head is prolonged between the antennal bases, above the epistomal area, as a flat or a multi-tuberculate, triangular piece, more pronounced in the male sex.

Group III of Raffray (1904).

clypeata (Reitter). 1883. St. Thomas, Virgin Islands. (Trimiopsis)

fleutiauxi (Raffray). 1890. Guadeloupe, Leeward Islands. (Trimiopsis)

frontalis Raffray. 1908. Guadeloupe, Leeward Islands.

?mimula (Sharp). 1887. Guatemala. (Trimiopsis)

?minuta (Sharp). 1887. Guatemala. (Trimiopsis)

\section{Vertelba new subgenus}

Tenth antennal segment bilaterally symmetrical; vertex of head with vertexal foveae between the eyes connected by an arcuate sulcus; vertex of head with a large, deep, transverse excavation, the excavation being medianly tuberculate. Otherwise similar to Melba.

caviceps Raffray. 1909. French Guiana.

\section{Quadrelba new subgenus}

Tenth antennal segment bilaterally symmetrical; vertex of head with vertexal foveae between the eyes connected by an arcuate sulcus; head quadrate or square in outline, the sides being tumid, dilated or subdentate between the eye and antennal base, this dilation being more pronounced in the male sex.

Group IV of Raffray (1904). 
parmata (Reitter). 1883. Puerto Rico; St. Thomas, Virgin Islands.

(Trimiopsis)

ventricosa (Reitter). 1883. Puerto Rico; St. Thomas, Virgin Islands.

(Trimiopsis)

Rameloidea new subgenus

Tenth antennal segment bilaterally symmetrical; vertex of head with four completely free vertexal foveae, an anterior pair between antennal bases, and a posterior pair between eyes; no trace of connecting, arcuate vertexal sulcus or sulci.

temporalis Raffray. 1909. Martinique, Windward Islands.

Asymmelba new subgenus

Tenth antennal segment transversely triangular and bilaterally asymmetrical.

clavata Raffray. 1909. Brazil.

impressifrons Raffray. 1911. Brazil. 


\section{Tribe 5. Brachyglutini}

The Brachyglutini is well represented in tropical America by twenty-eight genera out of sixty odd for the world. As with the preceding tribe, following a key to genera, these twenty-eight groups are arranged in linear form, although few phylogenetic relationships can be demonstrated in this way. The arrangement of these genera is almost the reverse of the order used by Raffray (1908). This eminent specialist placed the brachyglutines after the batrisines and metopiines. From what has been said previously on the derivation of the pselaphids from a staphylinoid stock, it appears that the batrisine genera are much less staphylinoid than the Brachyglutini. This is especially obvious when the tendency in Batrisini for the reduction or complete absence of the abdominal margins is contrasted with the generally better developed margins of the Brachyglutini.

On the other hand, the single tarsal claw of Brachyglutini is less staphylinoid than the two unequally developed claws of the Batrisini, although the Euplectini have both tarsal claw patterns frequently developed. Again, the first visible sternite in both brachyglutine and batrisine tribes is poorly developed, but less invisible in the latter. Thus, although there are many exceptions in both tribes, we feel that the batrisines are structurally more specialized than brachyglutines. The twenty-eight genera alluded to are arranged here in a series in which the species have progressively less contiguous posterior coxae, the middle coxae are progressively less contiguous, and the abdominal margins are progressively less developed. It should be noted that this is a tendency in the arrangement, and not a complete application since, in many cases, other structural features have altered the relative position of genera in the series. For example Drasinus and Decarthron are placed near each other, a course which I adopted after examination of my material in both genera, and later discovered that Fletcher (1928) had previously reached the same conclusion. Barada, Eupsenius and Eupsenina begin the series as a consequence of their melbaform affinities, and the approximate posterior coxae in the first two genera is common in the Euplectini but very rare in the Brachyglutini. The remarkable glabrosity of Eupsenius and Eupsenina however precludes considering them as very primitive, but it is thought that these genera are more euplectine than many other subglabrous genera and have arisen from euplectoid ancestors which have evolved highly specialized species which exist today. The case for each genus is more or less different, and involves summation of many values, thus the almost marginless, subglobose body of Eupsenina is accompanied by capitate setae on the ventral surface of the head, and many other instances could be cited.

The chief structural features which combine to distinguish this large tribe are (1) oblique articulation of trochanter and femur of the middle legs, (2) three-segmented tarsi, the first segment of which is relatively minute in con- 
trast to the much larger last two segments, (3) third tarsal segment with only a single claw, (4) generally globular posterior coxae, (5) abdomen with five visible tergites and usually but five visible sternites. The first sternite is nearly invisible between the posterior coxae with a few exceptions as in Eupsenius and Eupsenina.

At present the Brachyglutini is the largest tribe in the family, is world wide in distribution, and presents radiating lines of genera which appear to approach Euplectini in some cases, Batrisini in others, and Tychini in still other cases. Its central taxonomic position renders its study especially profitable for a conceptual view of the family as a whole.

\section{Key to the Genera}

Posterior coxae contiguous or subcontiguous $(\mathrm{Pl}$. XIV) $\ldots \ldots \ldots \ldots .2$

Posterior coxae distant ........................ 3

2 (1). Ventral surface of head with a median, longitudinal carina; maxillary palpi minute, with the first segment invisible; posterior coxae absolutely contiguous; integument with brownish pubescence; known only from Venezuela........BARADA Ventral surface of head without any trace of a median, longitudinal carina; maxillary palpi normally developed; posterior coxae subcontiguous, with the first sternite visible between them as a minute piece which is longer than wide; integument glabrous, without punctures or pubescence (Pl. XIV) .....

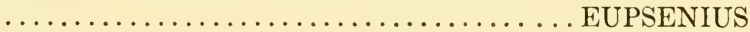

3 ( 1 ). Ventral surface of head with either a median, longitudinal

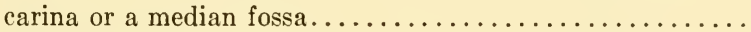

Ventral surface of head without a median longitudinal carina or fossa; habitus of Eupsenius, having the integument glabrous, with few punctures or pubescence, but posterior coxae are widely separated, the first sternite beneath the metasternal margin being a narrow, oblong piece, much wider than long; each side of head from the ventral face is angulated in the posterior half, the anterior portion being rounded and the posterior half with the margin carinated.....EUPSENINA

4 (3). Ventral surface of head with a large, median, oval fossa or fovea, the borders of which are more or less carinated; anten-

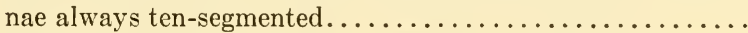

Ventral surface of head with a median, longitudinal carina; antennae either ten-segmented or eleven-segmented...... Third (penultimate) segment of maxillary palpi much longer

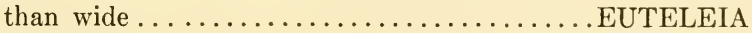

Third (penultimate) segment of maxillary palpi transverse, slightly or greatly wider than long, subtriangular, with the external face rounded and the internal face angulated or sub-

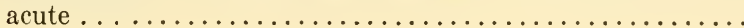


6 ( 5 ). Base of each elytron with two foveae (Pl. XVIII, 3)

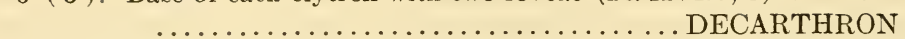

Base of each elytron with three foveae........... ITAMUS

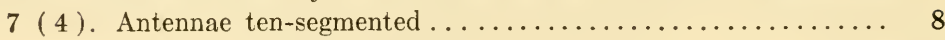

Antennae eleven-segmented . . . . . . . . . . . . . . 9

8 ( 7 ). Fourth (last) segment of maxillary palpi regularly ovoidal with subacute apex ................ECTOPOCERUS Fourth (last) segment of maxillary palpi with the internal face either slightly concave or straight, and the external face con-

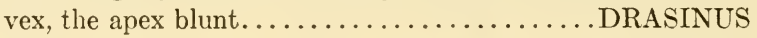

9 ( 7 ). Maxillary palpi with the third (penultimate) segment lenticular, with the long axis vertical, the external face concave and bearing spongy pubescence..........BYTHINOGASTER

Maxillary palpi with the third segment not so formed........

10 (9). Abdomen with at least the first two tergites margined, the margin may be narrow or wide, but is present...........

Abdomen with the tergites laterally limited by a single, simple

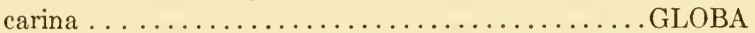

11 (10). Fourth (last) segment of maxillary palpi with a tooth or tubercle on the external face, this tooth may be acute or blunt, and may be at apical third or basal third (Pl. VII) ...........

BERDURA

Fourth segment of maxillary palpi not so formed...........

12 (11). Middle coxae contiguous, the mesosternal and metasternal processes not visible between them..................

Middle coxae either subcontiguous (in which case the mesosternum is visible between them as an acutely pointed, narrow lamina), or distant (in which case the mesosternum is visible between them as a more or less flattened plate with usually a truncate end which is in contact with a flattened plate extending anteriorly from the metasternum) $\ldots \ldots \ldots \ldots \ldots$

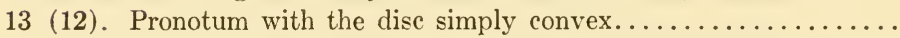

Pronotum with the disc distinctly longitudinally gibbous or with a median longitudinal carina, or with the disc deeply and

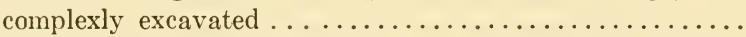

14 (13). Lateral pronotal foveae relatively much larger than the median

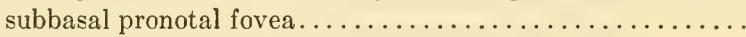

Lateral pronotal foveae absent or vestigial, never larger than the punctiform median subbasal fovea if present........

PHOBERUS

15 (14). Elytra with a discal stria of variable length, but distinct.... Elytra with no dorsal stria or striaform depression on disc...

EREMOMUS

16 (15). Epistomal region simple, or slightly expanded............ 
Epistomal region remarkably dilated into a transverse plate which extends apically beneath the antennae as far as the second antennal segment, and laterally is almost as wide as the head including the prominent eyes; known only from

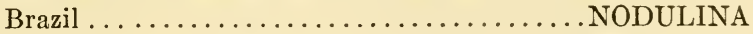

17 (13). Dise of prontum either with a strong, median, longitudinal carina, or the disc is medianly, longitudinally gibbous.....

BUNODERUS

Disc of pronotum with a very large and deep excavation which is trilobed, the large median lobe lies on the center of the disc and is confluent with a smaller oblique lobe on each apicolateral angle of the disc, each of these oblique lobes being more or less bilobed in themselves, giving a complex discal picture; this discal depression is in addition to the very large, deep lateral fovea each side of pronotum in the anterior half, and a small, circular subbasal fovea at middle; known only from Panama ............... PANABACHIA, new genus

18 (12). Middle coxae distant as previously described..............

Middle coxae subcontiguous as previously described..........

19 (18). Each elytron with either basal foveae, or with fine points re-

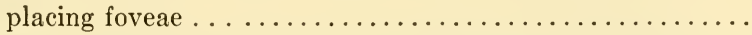

Elytra with no basal foveae, or replacing points of any kind; no pronotal foveae, neither lateral nor median, but with the pronotal base wrinkled at margin............PSELAPTUS

20 (19). Pronotum with no distinct foveae, neither lateral foveae nor a median basal fovea; base of each elytron with four minute points replacing the basal foveae..... SCALENARTHRUS

Pronotum with foveae, either two laterals and a median, or two minute laterals and no median, or no laterals and a median

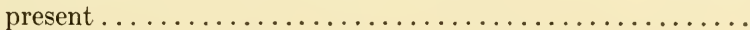

21 (20). Pronotum with a lateral fovea on each side and a median subbasal fovea present; base of each elytron with either two or or four foveae...................... XYBARIS

Pronotum with either the median fovea present and the lateral foveae absent, or the median fovea absent and the lateral

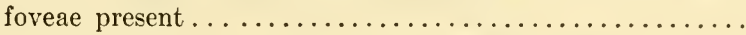

22 (21). Base of each elytron with four foveae; pronotum with the median fovea present, and the lateral foveae absent; pronotal base transversely impressed .................MITONA

Base of each elytron with two foveae; pronotum with the median fovea absent, and a minute lateral fovea present on

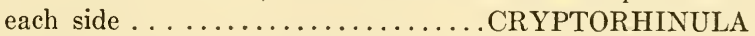

23 (18). Pronotum with three subbasal foveae present, consisting of a lateral fovea on each side and a median fovea, these foveae

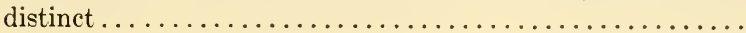


Pronotum with lateral foveae lacking entirely, and the median fovea may or may not be present, when present it is minute

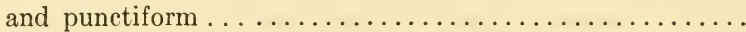

24 (23). Fourth (last) segment of maxillary palpi briefly and regularly

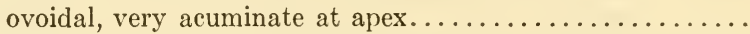

Fourth (last) segment of maxillary palpi ovoidal, but distinctly sinuate near apex on external face..................

25 (24). Body short, subglobular with the habitus of Xybaris and Scalenarthrus; each elytron with three basal foveae; abdomen with the lateral margin very narrow; known only from Brazil ................... STROMBOPSIS

Body elongate, subparallel and flattened; each elytron with either two or three basal foveae; abdomen with the lateral margins normally developed; known only from Chile and

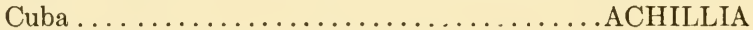

26 (24). Each elytron with two basal foveae............RAXYBIS Each elytron with either three or four basal foveae.........

BRYAXINA

27 (23). Each elytron with either four minute basal foveae, or four replacing points; median pronotal fovea may be absent or present........................ XYBARIDA

Each elytron with two basal foveae; median pronotal fovea minute and punctiform but always present; habitus of

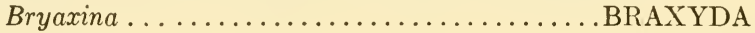

\section{BARADA (Raffray, 1891)}

The exceptionally small maxillary palpi, and absolutely contiguous posterior coxae separate this genus from the rest of the tribe. The male sex has sixth visible (seventh normal) sternite in the form of a small knob articulated at the apical margin of the fifth visible sternite. A single species known, erected on a single male $(1.45 \mathrm{~mm}$.), and to my knowledge the female has not been discovered.

mucronata Raffray. 1891. Venezuela.

\section{EUPSENIUS (LeConte, 1850)}

LeConte $(1850,1863)$

LeConte and Horn (1883)

REITTER (1883)

Brendel and Wickham (1890)

BRENDEL (1893)

Schaufuss (1887)

RAFFraY $(1896,1904,1908,1909,1911)$

LENG (1920)

Bowman (1934) 
The phylogenetic position of this genus is uncertain and many students have had something to say regarding the species. Raffray (1896, p. 262) said "The lack of sufficient materials renders the characteristics of the genus erroneous up to the present", and now, some forty-five years later, the position is still unsatisfactory. In 1850 LeConte erected the genus, based on Eupsenius glaber, the genotype (Pl. XIV) ; later this distinguished biologist described another species rufus (1863). Since then seven species have been described from the neotropics. Eupsenius appears to be very isolated in the northern part of its range, has no near relatives in the morphological sense, and both its zoögeographic affinities and morphological affinities lie in the neotropics.

If Brachyglutini are limited by distant metathoracic coxae in part, and Euplectini in part by contiguous to approximate coxae, then Eupsenius belongs in the latter tribe. If, on the other hand, the Brachyglutini are chiefly limited by triangular coxae and Euplectini by conical coxae, then Eupsenius belongs in the former tribe. If Brachyglutini are said to have globular coxae, then it becomes of interest to determine whether the triangular coxa is a globe or a cone. Final emphasis on coxal shape is of value where one has worked in a group, but is confusing and hardly practical otherwise since (a) exact coxal shape varies between species, (b) a cone is more or less triangular while triangular coxae are more or less conical if they have any length and thickness; moreover this descriptive term applies to the produced mesial end of each coxa and not to the morphological whole which extends laterally nearly to the margin of the metathorax.

The separation of the coxae has not been understood generally. Brendel and Wickham (1890, Vol. I, p. 1) describe the coxae of Eupsenius as widely separated. This is not correct, as pointed out by Raffray (1896, p. 262), and Raffray $(1904,1908)$ keyed out the genus as having the posterior coxae subcontiguous, but placed it at the end of the tribe with Barada. However in the recent treatment by Bowman (1934, p. 2) Eupsenius will not key out since it is assigned to the section of the tribal key having the coxae "very widely separated". In his generic key, however, Eupsenius will key out perfectly (Bowman, 1934, p. 76) on the Raffrayian characters affecting the ventral surface of the head.

In later years Raffray $(1904,1908)$ apparently had decided that this genus was definitely Brachyglutine, but in his last discussion of the genus (1909, p. 36) felt that Eupsenius and Eupsenina were very aberrant types of brachyglutine stock which established a transition between the Brachyglutini and the Tychini. It is readily seen that his earlier remarks (1896) are still available for adoption now. It is even possible that this genus should form a new tribe or subtribe.

Regarding the antennae of glaber, LeConte originally stated that the eleventh antennal segment was "wider in the middle than the tenth and one half longer". He must have meant something else since the eleventh antennal segment is much larger than the tenth segment, being longer than the third to the tenth segments combined in glaber.

The two species of the United States are predominantly subtropical in their distribution, having been recorded from South Carolina, Florida, and 
Louisiana (glaber) and Alabama and Florida (rufus). It would be of interest to study the types of all the species to see if glaber were more nearly related to the Mexican species and rufus more nearly related to the Antillean species, or if both arose from one or the other stem. Such data might throw light on the possible migration route northward.

Apparently glaber is penetrating northward up the Mississippi valley, since I have collected it near New Columbia, Illinois, the most northern record of the genus to my knowledge.

\section{Tentative Key to Neotropical Species}

Posterior coxae slightly oblique mesially, the metasternum appearing between them as a truncate edge, the coxae slightly separated.....

Posterior coxae not mesially oblique, the metasternum appearing between them as a minute, obtuse point, the coxae practically con-

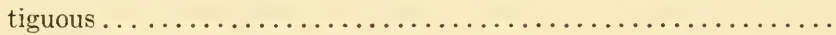

2. Ninth antennal segment as long as tenth antennal segment.........

(1.3-1.5 mm.; Mexico)

Ninth antennal segment shorter than tenth antennal segment.......

3. Tenth antennal segment two times as long as ninth segment.gibbicollis

(1.6-1.7 mm.; Mexico; eleventh antennal segment as long as second to tenth inclusive combined) Tenth antennal segment three times as long as ninth segment...... longicollis

(Bogota, Colombia; $1.8 \mathrm{~mm}$.)

4. Known only from Mexico...................... grouvellei

(1.2-1.4 mm. long; Mexico; segments of antennae IX and X lenticular, XI ovate, acuminate, shorter than in mexicanus; male last sternite lightly, longitudinally sulcate)

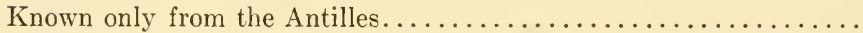

5. The last three described species are not separable with any certainty without recourse to the types:

a. politus Reitter. St. Thomas, Virgin Islands.

Ninth and tenth antennal segments less lenticular than in grouvellei; eleventh segment longer and less ovate than in grouvellei.

b. dominicanus Schaufuss. Hispaniola (probably Haiti as the citation is Saint-Domingue)

Said to be similar to grouvellei and politus but the antennae are lost from the type (only known specimen) according to Raffray, 1896.

c. gracilis Raffray. Grenada, Windward Islands. $1.0-1.1 \mathrm{~mm}$. long.

Near politus, but the ninth and tenth segments of antennae are 
more transverse than in politus, and the eleventh segment thicker than politus, and cited as being less than half the length of the antenna. Antennal segment IX lenticular, $\mathrm{X}$ transverse and twice as large as ninth, XI large and conical.

The general habitus and structural detail of the genotype, glaber, is depicted in the plates. Raffray $(1908,1909)$ has already remarked on the tychine character of the fourth segment of the maxillary palpi, this segment being slightly securiform.

The shining, glabrous, short and thick body, general lack of punctures and setae on the integument, the yellowish to reddish-yellow color, the subcontiguous posterior coxae, slightly securiform and large distal segment of the maxillary palpi, and the exceptionally large and melbaform eleventh antennal segment give a constant habitus to the genus.

The species may be listed as follows:

dominicanus Schaufuss. 1887. Hispaniola.

gibbicollis (Raffray). 1896. Mexico. (Euprenius Raffray nec LeConte)

gracilis Raffray. 1904. Grenada, Windward Islands.

grouvellei (Raffray). 1896. (Euprenius) Mexico.

longicollis (Raffray). 1896. (Euprenius) Colombia.

mexicanus (Raffray). 1896. (Euprenius) Mexico.

politus Reitter. 1883. St. Thomas, Virgin Islands and Guadeloupe,

Leeward Islands.

\section{EUPSENINA (Raffray, 1909)}

Eyes large, set in a trapezoidal head, the ventral surface of which is devoid of longitudinal median carina or large median fossa. The maxillary palpi are minute, the first segment very minute, second slender at base and swelling apically where it is abruptly clavate, third small and globose, fourth subsecuriform, subovate. Eleven-segmented antennae with the first segment elongate and cylindrical, the antennae subgeniculate between the long first and the shorter second segment, which varies in shape between the species from globose to triangular, third to eighth small, moniliform, ninth and tenth lenticular, crescentric, the eleventh segment relatively enormous. Pronotum subcordate. Elytra relatively very wide. Abdomen with tergites subequal, and with six sternites. Other differences are notable but are discussed in the description of a new species.

The genus is not discussed in the Genera Insectorum, so a rather free translation of Raffrey's remarks is not out of order:

"This genus is very aberrant and extremely near Eupsenius, which it resembles in habitus, and hardly differing at first sight with its geniculate antennae; but differing from Eupsenius by the smaller palpi, of which the last segment is more acuminate; ventral surface of the head does not have the lateral carina 
of Eupsenius, the eyes are smaller, the posterior coxae are widely separated, with the metasternum squarely truncate between them, uncovering the first sternite which is short, not extending beyond the coxae, but really visible. Among certain species of Eupsenius the first sternite is equally a little visible, especially when the posterior coxae are more or less separated. The visibility of the first sternite, coupled with the lack of a median longitudinal carina on the ventral face of the head, renders the addition of this new genus very embarrassing, and there is but little logic in placing Eupsenina in Tychini on the basis of the visibility of the first sternite, but on the other hand, Eupsenina resembles Eupsenius, where the latter's invisible first sternite (or nearly so) places it in the Brachyglutini. It is impossible to isolate Eupsenius from Eupsenina, each in a separate tribe since they resemble each other so much."

There are three species in the genus Eupsenina at present; they may be rapidly separated as follows:

Second segment of the antennae spherical to ovate and simple.......

Second segment of the antennae conspicuously, transversely triangular,

the mesial or internal face being produced and subacute, the lateral or external face simply convex.............patricia new species

2. Second antennal segment ovate; vertexal sulci arising from the vertexal foveae short, not uniting with the frontal depression anteriorly between the bases of antennae................. fracticornis

(1.1 mm.; described on female; metasternum large and simply convex)

Second antennal segment spherical; vertexal sulci arising from the vertexal foveae long, uniting with the frontal depression anteriorly between the bases of antennae................. sulcifrons

(1.2 mm.; described on male; metasternum medianly foveate)

Eupsenina patricia new species

Type Male. Measurements: head $0.2 \times 0.3 \mathrm{~mm}$. through eyes; pronotum $0.28 \times 0.26 \mathrm{~mm}$.; elytra $0.43 \times 0.49 \mathrm{~mm}$.; abdomen $0.15 \times 0.5 \mathrm{~mm}$; t total length $1.06 \times$ greatest width $0.5 \mathrm{~mm}$.

Uniform yellowish-brown, the integument highly polished and subglabrous. Under high magnification the integument is minutely punctulate, with very sparse, just perceptible setae $(0.01 \mathrm{~mm}$. long), these setae being about five per one-tenth square millimeter. At lower magnification the integument appears to be glabrous.

Head subtriangular from a dorsal view if the eyes are not included. Eyes large and prominent, being $0.087 \mathrm{~mm}$. long, and composed of about 50 distinct facets, subcircular from a lateral view, set in the anterior half of the head and slightly longer than the tempora. Tempora $0.08 \mathrm{~mm}$. subparallel, with rounded posterior angles forming the subtruncate, inconspicuous occipital margin. Vertex evenly, broadly convex with each side converging above the eye to form a subacute, triangular extension between the bases of the antennae, and extend- 
ing slightly beyond this line. This triangular extension simple with its apex continuous with simple, strongly declivous front. Vertexal foveae minute, placed on a line passing through the posterior margins of the eyes, and each fovea directly posterior of the antennal base; this pair of vertexal foveae connected by a pair of distinct, fine sulci which converge to unite near the anterior fourth of the eyes, i.e. the vertexal sulci are short, and enclose a triangular area of the vertex which is a smaller, more posterior replica of the frontal extension alluded to above, the lateral margin of the vertex being paralleled by the nearest vertexal sulcus. The ventral surface of the head is peculiar: it is flat, glabrous and medianly simple without median fossa or carina, and even the characteristic basal gular fovea is absent. There is a transversely oblique, short depression each side near the cephalic-cervical constriction; this depression on each side is moderately deep and from an oblique view the apical wall of the depression is strongly carinated so that the ventral surface of the head is deceptively flat from a direct view, but strongly angulate-carinate in reality. Thus the carina forming the wall of the short depression each side forms the transversely-oblique carina so typical of the genus Eupsenina; anteriorly, this carina becomes obsolete, and is represented by a small tumulus near the postero-ventral angle of each eye. The two transverse depressions noted above probably have their floors attached to the base of the supratentorium, and if so, they are collectively homologous to the gular fovea of other pselaphids. On each side of the ventral surface of the head are three distinct, capitate setae, reminiscent of melbaform euplectines. Anteriorly, the setae are on a line with a conspicuous, arcuate, narrow process which arises near the base of each maxilla, between the eye and the mentum; this slender process extends anteriorly in a divergent arc nearly to the level of the mandibles in repose, and each process bears six capitate setae. At first sight these arcuate extensions appear to arise from the maxilla, and so lend an allusion to the maxillary extension of the Jubinini.

Maxillae well-developed, the cardo and stipes large, the galea with a welldeveloped brush of setae. Maxillary palpi four-segmented, first segment minute; second elongate, very slender basally, suddenly inflated apically; third subtriangular, short. not quite as wide as second, mesial face acute, lateral face convex; fourth longer than second and twice as wide, obliquely truncate at base, subacute at apex, bearing a palpal cone, the mesial face is much more convex than the lateral face.

Antennae eleven-segmented, equal to the elytra in length $(0.43 \mathrm{~mm}$.$) , con-$ spicuous; segment I elongate-cylindrical $(0.08 \mathrm{~mm}$. long x $0.04 \mathrm{~mm}$. wide) ; II conspicuously triangular $(0.06 \mathrm{~mm}$. long $\mathrm{x} 0.06 \mathrm{~mm}$. wide), with lateral face convex and mesial face acutely produced; III briefly obconical; IV-VII subequal, as wide as third, closely articulated, submoniliform, conspicuously narrower and shorter than second segment; VIII submoniliform, slightly larger than seventh; IX transverse, larger than eighth; $\mathrm{X}$ very transverse, much wider than ninth and nearly as wide as eleventh, but very short and not much longer than ninth, rather disc-shaped from a direct dorsal view; XI exceptionally large (0.2 mm. long x $0.067 \mathrm{~mm}$. wide), about as wide as second segment and clothed 
with long setae $(0.067 \mathrm{~mm}$. long) which are distinctive since the rest of the body is subglabrous save for the ventral capitates of the head, and the hirsute metasternum noted later; this last segment is about one-half as long as the total antennal length; simply truncate at base, slightly sinuate apically, the segment being subsecuriform in outline with a straight lateral face becoming concave or sinuate apically, and the mesial face straight in basal half and strongly convex in apical half. The antennae are subgeniculate, as a consequence of the elongate first segment; moderately distant at base, being separated by the triangular front, their separation being equal to the width of the elerenth segment.

Pronotum melbaform, simple, obcordate, with unmodified disc, and rounded lateral margins; no median basal fovea, but an indistinct transverse, subbasal sulcus which is entire laterally but interrupted medianly; this sulcus or sulciform stria continues down each lateral flank of pronotum to end in a lateral fovea on each side; this fovea is glabrous, shallow and distinct laterally but not dorsally. Pronotal-prosternal coalescence demarcated by a carina which is anteriorly continuous with the apical pronotal margin.

Scutellum distinct and sharply triangular.

Elytra with the humeri obliquely tumid; each elytron with the sutural stria turning obliquely near the scutellum and parallel to the basal margin, forming a transverse basal carina reminiscent of Sebaga; two small, glabrous basal foveae on each elytron, just posteriad of the transverse basal carina (which separates this species from the unifoveate elytron of the other species of the genus). No subhumeral fovea or subepipleural sulcus on elytral flank.

Abdomen exceptionally short, specialized, convex. Five visible tergites, first tergite about twice as long as second medianly, and very closely fitted to the elytra, with no basal discal carinae; second one-third longer than third; fourth long, longer than second; fifth subtriangular, not visible from above, ventrodeclivous, long being about one-half longer than fourth tergite. Six sternites clearly visible; first forming a short, very transverse plate, about four times wider than long, closely fitted between posterior coxae and metasternum, and also visible laterally as a gradually lengthening plate, ending beneath the elytra; second sternite not quite twice as long as first, and with a prominent, short, longitudinal, slightly arcuate carina from the basal margin on each side between coxa and elytra, so that this carina must be looked for from an oblique view; third sternite very short, half as long as second; fourth still shorter; fifth longer, as long as third; sixth very large, transversely semilunar, with strongly convex basal outline and slightly bisinuate apical outline, investing the apical margin of the fifth tergite; this sixth sternite as long as fifth tergite, or as long as the first to fifth sternites combined. The abdomen has a distinct Globa aspect. Only a small portion of the fourth tergite and none of the fifth visible from above. The abdomen has no margin at all, and consequently the abdomen is formed of a series of unbroken rings; the first tergite-second sternite forms the first ring; second tergite-third sternite the second ring; third tergite-fourth sternite the third ring. For these three rings the terms "tergite" and "sternite" are used in a functional sense only. The fourth tergite and fifth sternite are 
morphologically separated by an oblique suture. The fifth tergite and sixth sternite are free to allow separation distally for the extrusion of the penis.

Prosternum very short before the anterior coxae, simple.

Mesosternum tumid, with carinoid margins, and medianly elevated into a longitudinal carina. Middle coxae approximate but not contiguous.

Metasternum large and complex; glabrous laterally and pubescent medianly. This sparsely pubescent area extends from the posterior coxae to an acute angle posterior of the median metasternal process which enters between the bases of the middle coxae, and the edges of this pubescent space are sharply raised or carinoid. The arcuate lateral carinoid margins of the area bifurcate anteriorly to send out an oblique carina posterior of each middle coxa, which passes externally of the coxa and ends just above sternal fovea IV on each side. Sternal foveae IV and V well-developed. Pubescent metasternal area depressed and thin in the posterior, median third between the posterior coxae. Posterior coxae very widely separated.

Anterior femora inflated; flattened on the ventral face in the apical half, this flattened area oblique and glabrous and bearing at its basal external angle a distinct foveoid scar. Tarsi very long and slender, first tarsomere minute, second and third very much longer, the last tarsomere being shorter and thinner than second. This third tarsomere bears a single claw. Under high magnification on a slide mount this claw is seen to be distinctly bifid at apex!

Described on a single male specimen, collected by the author from decayed log mold at Drayton 15 on Barro Colorado Island, Gatun Lake, Panama Canal Zone.

This minute, distinctive species is easily separable from its congeners by the triangular second antennal segment, sexual characters, and single fovea of each elytron. Its anatomy is so divergent that it may warrant subgeneric isolation with further accumulation of data.

fracticornis Raffray. 1909. Brazil. Genotype.

patricia new species. Panama Canal Zone.

sulcifrons Raffray. 1917. Paraguay.

\section{EREMOMUS (Raffray, 1904)}

This genus contains two South American species, closely allied to Reichenbachia. The head in both species has the vertex trifoveate, the foveae being large and equal in size, a pair of vertexal foveae lie on the head between the eyes, and a third fovea is on the anterior region of the head between the antennal bases, just behind the nearly truncate front. The four-segmented maxillary palpi have the usual minute first segment; second segment elongate, very slender at base and suddenly globose in distal third of its length; third segment transversely triangular, with the mesial face acute and lateral face rounded convex; fourth segment very much wider than third, ovate, base truncate, apex acute, 
bearing a short palpal cone. Ventral surface of head with a single, median, longitudinal carina. Pronotum with simple disc, and three foveae of unequal size, a lateral fovea each side at basal third which are larger than the median, subbasal fovea. Elytra with no dorsal stria, and each elytron with two basal foveae (Raffray, 1904), not trifoveate as stated by Raffray (1908); elytra triangular. Abdomen with first tergite with a pair of discal carinae, and much longer than second. Female sex known; male unknown.

\section{Key to THE Species}

Antennae with segments IV-VII cylindrical, VIII much shorter than either seventh or ninth and quadrate; $2.3 \mathrm{~mm}$. long; known only

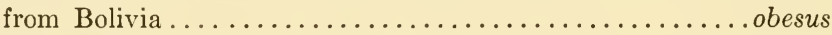

Antennae with segments IV and V ovate; VI-VIII progressively shorter and progressively wider; $2.0 \mathrm{~mm}$. long; known only from

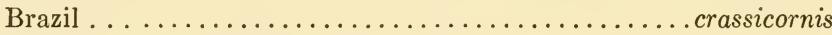

crassicornis Raffray. 1904. Brazil.

obesus Raffray. 1904. Bolivia. Genotype.

PHOBERUS (Raffray, 1904)

This is a monotypic genus known only from Bolivia. Ventral surface of the head tricarinate, a median, and a lateral longitudinal carina each side of head (in the male the lateral carinae are very strong, and are obsolete in the female). Maxillary palpi four-segmented, first minute; second elongate cylindrical, very gradually widening toward apex; third segment briefly obconical (or vertically triangular and as long as wide, with the base acute and apex broadly truncate); fourth elongate, regularly fusiform, subacute at base and apex bearing a slender palpal cone. Pronotum subhexagonal, with a median subbasal punctiform fovea, but no lateral foveae. Elytra with no dorsal stria; each elytron with three slightly elongated basal foveae; humeri prominent, nearly square in the male and rounded and obtuse in the female. First tergite longer than second, and with a pair of divergent basal discal carinae. Abdominal margin very strong, wide on the first two tergites.

Male with second antennal segment longer than first, cylindrical, with the mesial-apical face produced internally into a tooth; ninth antennal segment transverse, with the mesial-apical face triangularly produced into a large tooth; tenth segment distinctly shorter than ninth and drum-shaped. Head deeply excavated medianly, between eyes and antennal bases, this excavation complexly armed; epistome spinoid.

Female with antennae with segments II and IX not toothed; the frontal excavation of the head smaller, simpler. $2.0 \mathrm{~mm}$. long.

armatus Raffray. 1904. Bolivia. Genotype. 
REICHENBACHIA (Leach, 1826)

\author{
LECONTE and Horn (1883) (Bryaxis) \\ SHARP (1887) (Bryaxis in part) \\ BRENDEL and WickhaM (1890) (Bryaxis in part) \\ CASEY (1897)
}

RAFFraY (1904, 1908, 1908a, 1908b, 1909, 1911, 1917)

Fletcher $(1928,1928$ a)

Bowman (1934)

Reichenbachia juncorum (Leach) of Europe and Algeria is the genotype. Reichenbachia is the largest genus of the Pselaphidae, holding approximately 313 described species. Of this great number possibly twenty-one may belong to other genera, but have been so briefly described that they may not be verified without recourse to the types. These species are distributed over the world, the genus being cosmopolitan with the exception of Australia and New Zeland. The Americas have over a third of the species of the genus, there being sixty species north of Mexico and seventy-eight species south of the Rio Grande river. The North American species have not received original treatment since 1897 when Casey keyed out these species; the neotropical species have never been treated as a faunal unit. Both North and South American faunae need revision badly; many new species remain to be described, types must be examined to resolve several complex taxonomic situations, synonyms need to be studied and a new key developed; especially desirable is the formulation of a complete key on characters common to both sexes. Such treatment can not be offered at this time.

Reichenbachia occupies an important taxonomic position for the Brachyglutini, and is structurally much more average than the genus Pselaphus which has given the name to the family as a whole. The neotropical species have in common the following characters: (1) distant posterior coxae, (2) ventral surface of the head with a median, longitudinal carina or carinoid swelling, (3) eleven-segmented antennae, the segments of which are nearly infinitely varied, especially in the male sex (Pl. XVI, XVII), (4) four-segmented maxillary palpi, of relatively simple and generalized pattern as described later, (5) abdomen with a distinct lateral margin, (6) middle coxae contiguous, (7) pronotum with the disc simple, evenly convex and not sulcate, foveate or carinate, (8) pronotum with three subbasal foveae, the lateral foveae relatively much larger than the median fovea, these three foveae never connected by a transverse subbasal sulcus, (9) each elytron with a distinct dorsal or discal stria, varying in length among the species, and either two or three basal foveae, (10) the epistomal region generally simple and normal, sometimes slightly expanded laterally or vertically elevated but never swollen to the width of the head.

Certain species are at least facultative synoeketes; the majority of the species pass the day in floor mold of forests, becoming active at night. The large, coarsely faceted eyes and well-developed metathoracic wings coincide with their commonly observed reaction of flying to night lights. Both sexes come to lights at night, in about equal proportions for most species observed. Their powers of 
flight may have had a definite dispersal value, especially when their cosmopolitan distribution is noted. Poor flght for one sex, as in the case of many Jubus, would prove to be a restrictive factor in species dispersal as much as poor flight for both sexes, and it is of interest to again point out the parallel development of large eyes and wings in so many instances, or the converse of rudimentary eyes and wings in one or both sexes within the family. A few of the neotropical species have a moderately wide distribution, sallaei being reported from Mexico, Guatemala, and Panama, parviceps with the same general range, celata from Mexico, Guatemala and Nicaragua, reichei from Guatemala and Colombia. With wide geographic ranges known for certain species of the genus, structural characters become of great importance in separating new species, since similar specimens from relatively distant localities may represent either the same species, or variations within the same species population.

The genus as a whole was separated into at least seven valid divisions and sixty species groups by Raffray in 1904 . The addition of new species since that time has increased the number of groups holding neotropical species. Probably a new group will have to be formed to hold femoralis Fletcher, and one species has been placed in a new genus (vide infra). Three of Raffray's seven divisions, and eighteen out of sixty species groups, contain neotropical representatives of Reichenbachia. The following arrangement is based upon Raffray's 1904 treatment, and deals only with these neotropical species groups. Unfortunately, such keys place emphasis upon the male sex, and in most instances the females of this genus must be assigned by association rather than by exact structural detail. Among the neotropical species there are seven groups in which both sexes have the head, mandibles, antennae, pronotum and legs simple and unmodified. In these groups the males and females are difficult to separate. In such cases direct dissection to expose the copulatory organs, or cleared slide mounts to examine the latter, will settle the question of the sex of specimens; where a series is available this method of direct examination of one or two specimens is necessary to correlate minute structural differences with sex. These methods have been fully discussed in the section on preparation of material for study. The fifth visible (most distal) sternite is large in the genus, and subject to some variation. Such variation is especially found in the males and consequently proves helpful in separation of sexes in the seven groups noted above; the male fifth sternite is often laterally sinuate, or concave medianly, this concavity varying from a simple, even depression to a longitudinal impression. The males of the other groups are strikingly marked, with abnormal antennae, or front, or legs in various combinations, often grotesque and frequently very similar in allied species. In the following tentative key I have relied chiefly on structural characters of the male sex; the Roman numerals refer to the 1904 Raffrayan group number.

\section{Key to the Neotropical Species Groups}

Species in which both sexes are essentially normal in most particulars, and agree in the following essential items: (1) the vertex has three 
foveae, these are subequal in size and have a relatively constant position, namely two placed between the eyes, and median fovea between the antennal bases; (2) vertex normally convex or flattened between the eyes; (3) antennae with the segments normal; (4)

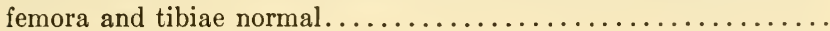

Species in which both sexes, or the male sex only, have at least one, frequently two or more, of the following essentially abnormal items: (1) anterior fovea of head normal in position between the antennal bases, but minute in size as compared with the two foveae between the eyes; (2) anterior fovea abnormally placed, incising the frontal margin, or lodged entirely on the steeply declivous front; (3) anterior or frontal fovea wholly absent, in which case the head has but two vertexal foveae; (4) vertex abnormal, either medianly vaulted and swollen, or with a median longitudinal carina or obtuse elevation; (5) antennae with one or more segments very abnormal in shape, size or bearing accessory foveae, spines or other deformities; (6) femora or tibiae or both, on one or more pair of legs, abnormally

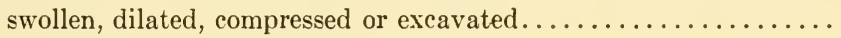

2. Each elytron with three basal foveae................... 3

Each elytron with two basal foveae................... 5

3. Lateral pronotal foveae circular to subcircular............. 4

Lateral pronotal foveae transversely oval, or distinctly wider than

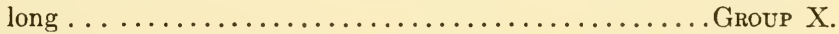

4. Basal discal carinae of first tergite relatively very long, at least onehalf of the segmental length....................

Basal discal carinae of first tergite relatively very short, not more than one-fifth of the segmental length................ IX.

5. Pronotum glossy and polished, very lightly punctulate; elytra dis-

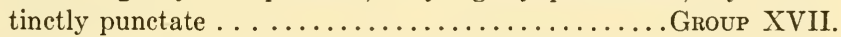

Body glossy and polished, very lightly punctulate.............

6. Dorsal or discal stria of each elytron well-developed, long, extending beyond the middle of the elytral length........... Group XX.

Dorsal or discal stria of each elytron shorter, not extending beyond the middle of the elytral length................... XXI.

7. Dorsal surface of head with three subequal, normally placed foveae, e.g. two between the eyes, and one between the bases of the antennae

Dorsal surface of head abnormal in one of the following ways: (1) vertex medianly, longitudinally carinate or obtusely elevated; (2) vertex vaulated and swollen medianly; (3) the anterior or frontal fovea minute but normally placed between antennal bases; $(4)$ anterior fovea incising the frontal margin or wholly on the declivous front; (5) the anterior or frontal fovea wholly absent..........

8. Posterior tibiae normal, neither dilated, nor flattened nor excavated. .

Males with the posterior tibiae abnormal, either dilated with a long 
median depression on ventral face, or strongly swollen at apex.... Group XLVII.

9. Antennal segment $X$ abnormally large in both sexes, being as wide or distinctly wider than the eleventh segment which is also very large. (Pl. XVII, 10) ..............................

Antennae with the tenth and eleventh segments normal, but one or more of the intermediate segments (fourth to ninth) abnormal....

10. Antennal segment $V$ abnormally large, distinctly larger than the fourth or sixth segments, the sixth segment not abnormal. (Pl. XVII, $11-15) \ldots \ldots \ldots \ldots \ldots \ldots \ldots \ldots \ldots$. . . . . . . . . . . . .

Antennal segments $\mathrm{V}$ and VI simple in the females and very abnormal in the males (PI. XVII, 16) ................... Group XLI.

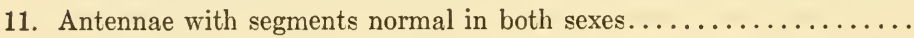
Antennae with one or more segments abnormal in the males, and

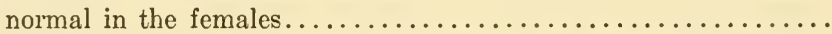

12. Head with the anterior, median fovea present and incising the frontal margin so that it is abnormal in position............ Group LI. Head with the anterior, median fovea wholly absent.... Group LIV.

13. Antennal segment $\mathrm{V}$ of the male (female unknown) slightly longer than either fourth or sixth segments; anterior, median fovea of head present between antennal bases, but minute; middle tibiae armed with a small spine near apex; posterior femora strongly dilated, with the dilation broadly and entirely excavated on the posterior face; known only from Peru............. Group LXIV, new group. Anterior, median fovea of the head wholly absent, or if present abnormal in position or subequal in size to the two foveae between the eyes, not minute as described above; legs in the male not so formed

14. Head with the vertex either (1) medianly swollen or vaulted between the two inter-ocular foveae, or (2) medianly and longitudinally

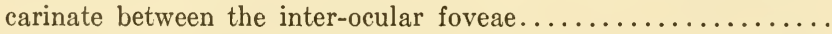

Head with the vertex normally convex to flattened between the inter-

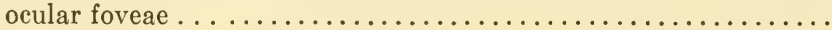

15. Head with the vertex simply but prominently swollen between the two vertexal foveae in both sexes, this swelling does extend towards the front, but does not reach the frontal margin; males with metasternum distinctly, medianly impressed and females with metasternum flattened . . . . . . . . . . . . . . . . Group LIX.

Head with the vertex sharply, medianly, longitudinally carinated between the inter-ocular foveae, this carina especially well formed posteriorly to occipital crest (male), or vertex with the carina not sharp, but in the form of an obtuse elevation between the interocular foveae........................

16. Anterior median fovea of the head present but abnormally placed, either incising the frontal margin, or wholly on the declivous front 
Anterior median fovea wholly absent, the head, therefore, having only

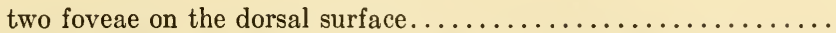

17. Antennal segments V and VI very large and more or less abnormal beneath ....................................

Antennae with segments VI to X inclusive abnormal... GrouP LIII.

18. Antennal segment $\mathrm{V}$ abnormal, being very long, often armed or otherwise unusual; VI normal................. Group LV (in part).

Antennal segments V and VI abnormal; epistome may or may not be prominently produced into a median, dorsal spine.... Group LVI.

\section{Group VI}

Only a single neotropical species belongs to this group, the other representatives being Asiatic. This neotropical species is unique in having very long basal discal carinae on the first tergite, these being subparallel, separated by one-third of segmental width, and two-thirds the segmental length, extending to apical third of the first tergite. Described on a male specimen; the trochanters of the middle legs are armed with a sharp spine at middle of posterior margin. Length $1.8 \mathrm{~mm}$.

limpida Fletcher. 1928. Peru.

\section{Group IX}

Antennal segment $\mathrm{V}$ distinctly longer than the fourth or sixth seg-

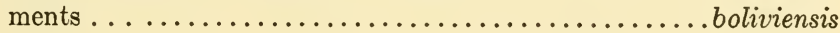

(2.0 mm.; known only from female)

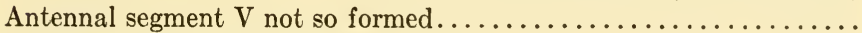

2. Antennae relatively shorter and thicker; $1.8 \mathrm{~mm}$.; known only from the female ............................ grouvellei

Antennae relatively longer and more slender; known only from the

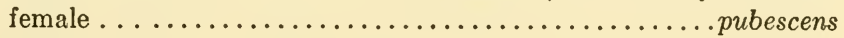

boliviensis Raffray. Bolivia. 1904

grouvellei Raffray. Mexico. 1904

pubescens Schaufuss. Mexico. 1879

\section{Group X}

Antennal segment IX subquadrate-obconical, only slightly larger than eighth segment; segment $\mathrm{X}$ similar to the ninth segment in form and somewhat larger; $2.15 \mathrm{~mm}$. long.............aubeana Antennal segment IX trapezoidal, slightly transverse, slightly larger than eighth segment; segment $\mathrm{X}$ very much larger than ninth segment, truncate-obconical; $1.9 \mathrm{~mm}$. long............ gounellei

aubeana (Raffray). 1890. Venezuela. (Bryaxis)

gounellei Raffray. 1909. Brazil. 


\section{Group XVII}

There is but one species in this group. Antennae slender, with a twosegmented club, segment VII subquadrate; VIII subquadrate, slightly transverse; IX quadrate; $\mathrm{X}$ large, twice the size of ninth, subovate; XI moderate in size in comparison to the eleventh segment of many other species, briefly fusiform. Basal discal carinae of first tergite including one-third of segmental width. Metasternum obsoletely, medianly carinate. Last sternite slightly impressed, with apical margin medianly obtusely, triangularly produced, with a slight sinuation on each side. $1.6 \mathrm{~mm}$. The elytra are distinctive, being cribrately, rugosely punctate. Known only from the male sex.

curvipes Raffray. 1904. Brazil.

\section{Group XX}

Antennal segments I and II elongate, cylindrical; III obconical; male with metasternum widely impressed and last sternite large, strongly oblique laterally, medianly truncate and with a subovate, distinctive and large impression; the middle trochanters each with a small, obtuse tooth $; 1.8 \mathrm{~mm}$. long..................... irrita

Antennal segments I and II not elongate-cylindrical; male secondary

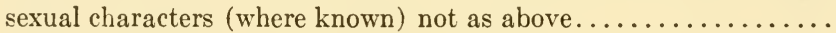

2. Antennal segment I quadrate; II ovate; III minute and briefly obconical; IV twice as long as third; V cylindrical, slightly wider than fourth and much longer; VI much larger than fifth; VIII strongly quadrate; IX large, truncate, obconical; $\mathrm{X}$ similar to ninth but larger; XI moderate in size, ovate, truncate at base and acuminate at apex; basal carinae of first tergite only including one-fourth of the discal width. Known only from the female; $1.6 \mathrm{~mm} . . . . .$. luteola

(When the male is found it may prove to have abnormal antennae especially since the third segment of the female is rather exceptional; if this proves to be the case this species will go to another group of the genus)

Antennal segment I large; II narrower and subcylindrical; III-VII small and oblong; VIII quadrate; IX obconical; $\mathrm{X}$ subquadrate;

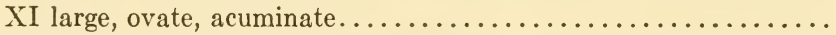

3. Metasternum unmodified, hardly depressed; last sternite widely excavated, and ogival in shape (in the form of a pointed arch); 1.6

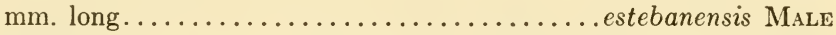

Metasternum similarly unmodified; last sternite transverse, medianly with an obsolete fovea, apex sinuate; $1.6 \mathrm{~mm}$. long........... estebanensis Female

estebanensis (Raffray). 1890. Venezuela and Brazil. (Bryaxis) irrita Raffray. 1904. Mexico. luteola Raffray. 1904. Mexico. 


\section{Group XXI}

This large group is not understood well enough at present to give a workable key.

goryi Aube. 1833. Colombia.

chevrolati Raffray. 1904. Brazil.

illepida Raffray. 1904. Brazil.

obesa Raffray. 1909. Brazil.

parviceps (Sharp). 1887. Mexico, Guatemala, Panama. (Bryaxis)

pilosa Raffray. 1904. Venezuela. (pilosella of Raffray, 1890, not the pilosella of Schaufuss.)

pilosella Schaufuss. 1872. Venezuela.

rubra Aube. 1844. Brazil.

semisanguinea Schaufuss. 1887. Brazil. (minassanae Schaufuss,

female) 1887.

subfoveolata Schaufuss. 1872. Colombia. (However, see Group LIV) subnitida Schaufuss. 1887. Brazil.

tenuicornis Schaufuss. 1887. Brazil.

\section{Group XXXV}

Antennal segments VII and VIII slightly transverse; IX very transverse, being only slightly longer than eighth but twice as wide as eighth; $1.9 \mathrm{~mm}$. long; not known north of Paraguay..tubericornis Antennae with segment IX transverse, but not twice as wide as the eighth segment; not known south of the equator..............

2. Antennal segment $X$ large, but not wider than eleventh segment; segments VII, VIII and IX strongly transverse; known only from Colombia and Venezuela......................... lebasi

(middle trochanters spined in MALE and simple in Female)

Antennal segment $\mathrm{X}$ large, slightly to distinctly wider than eleventh

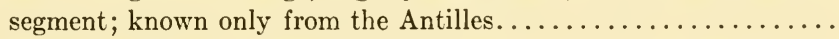

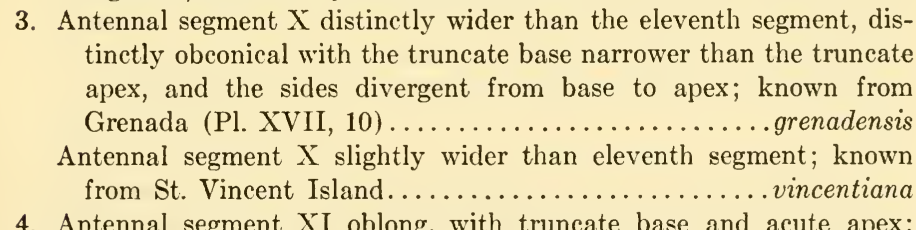

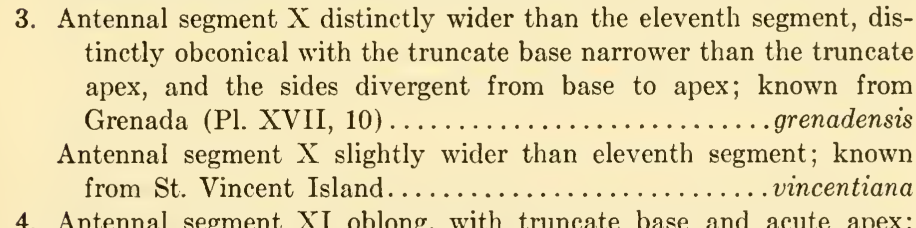

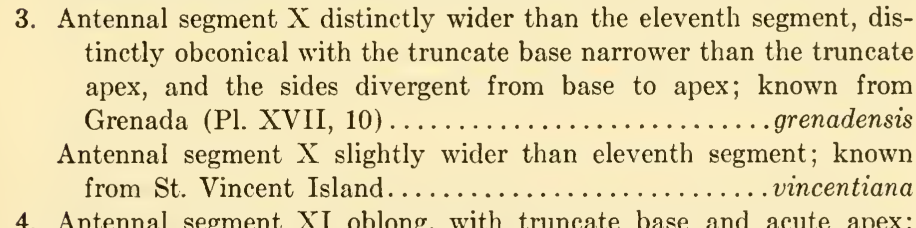

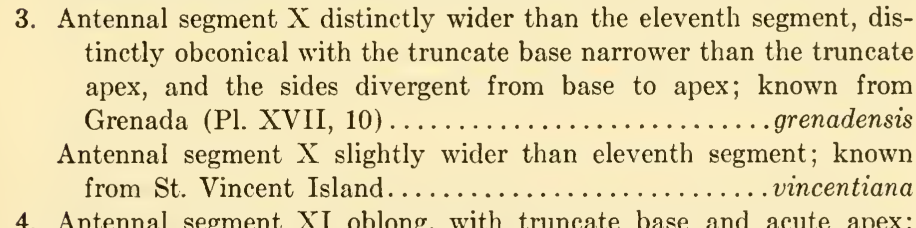

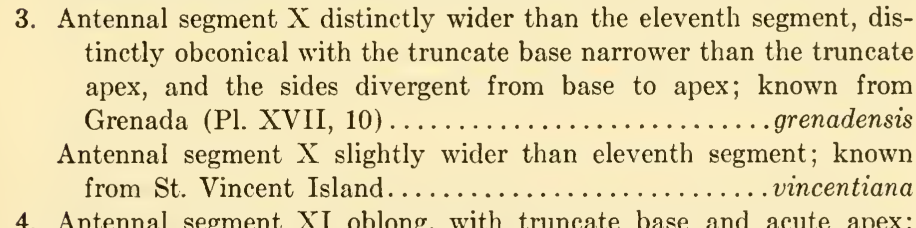

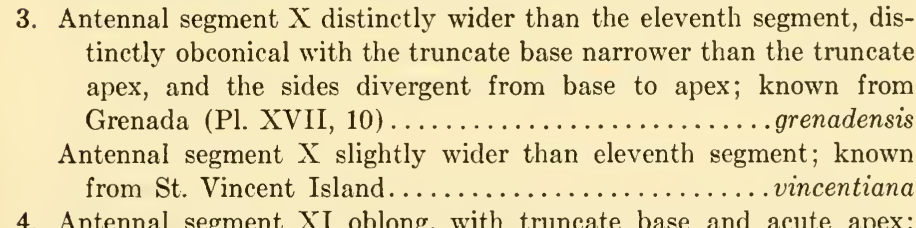
segments VII, VIII and IX very transverse, from one-third to onehalf wider than long; $2.0 \mathrm{~mm}$. long...........MALE (Pl. XVII, 10) Antennal segment XI ovate, with a much narrower base; segments VII, VIII and IX much less transverse.............. Female

5. Antennal segment $\mathrm{X}$ square, with the internal or mesial face rounded . MALE

Antennal segment $\mathrm{X}$ nearly two times longer than ninth segment, and

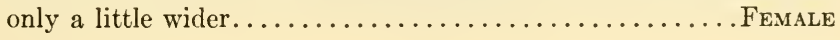


grenadensis Raffray. 1904. Grenada, Windward Islands.

lebasi Aube. 1844. Colombia and Venezuela.

tubericornis Raffray. 1917. Paraguay.

vincentiana Raffray. 1904. St. Vincent, Windward Islands.

\section{Group XL}

The following key is unsatisfactory since it does not take into account two of the species assigned to this group, pentachiroides (Schaufuss) of Brazil and intacta (Sharp) of Guatemala. As to the latter species, I can make nothing of the description which would effectually separate it from its congeners. Sharp says that the fifth antennal segment is greatly enlarged and foveolateimpressed in front. The large fifth segment is a group characteristic, and I do not know what face of the segment is meant by the "front". This, like many other species, must await examination of the types before proper allocation can be made. Intacta has, according to Sharp, a length of two millimeters, is known only from a male specimen which has the middle tibiae supplied with an acute spine or mucro near tlie apex.

Antennal segment $\mathrm{V}$ transversely triangular, the lateral or external face straight, the mesial or internal face prolonged into an obtuse ogival dilation; known only from the male, the metasternum being laterally convex, and medianly entirely concave, with subcarinated margins; $1.9 \mathrm{~mm}$. long...............globulosa (Pl. XVII, 15)

Antennal segment $\mathrm{V}$ ovate, not mesially produced...............

2. Antennal segment $\mathrm{V}$ with the dorsal face distinctly and densely punctate, and the ventral face with three irregular impressions; $1.9 \mathrm{~mm}$. long; known from the male sex, with the metasternum and last sternite flattened.................falsa (Pl. XVII, 14)

Antennal segment $\mathrm{V}$ with the dorsal face glabrous, polished and the ventral face with a large foveoid impression.................

3. Ventral face of fifth antennal segment with a large, median foveoid excavation, half-oval in shape with the basal margin of the excavation truncate, and the lateral margins converging apically to a very rounded apex; $1.65 \mathrm{~mm}$. long; known only from the male sex.... .callosa (PI. XVII, 13)

Ventral face of the fifth antennal segment with an elongate, sulciform excavation, this excavation being ovate medianly, with a much narrower apical and basal continuance of the ovate portion, so that the lateral margins present a subdentate appearance seen on looking directly into the excavation..........sarcinaria (PI. XVII, 11, 12)

callosa (Raffray). 1890. Venezuela. (Bryaxis)

falsa Raffray. 1904. Mexico.

globulosa Raffray. 1904. Brazil.

intacta (Sharp). 1887. Guatemala. (Bryaxis)

pentachiroides (Schaufuss). 1887. Brazil.

sarcinaria (Schaufuss). 1887. Mexico. 


\section{Group XLI}

In this group the females have the fifth and sixth antennal segments simple and normal, while the males have these segments very irregular or abnormally formed, being diversely expanded, foveate or spinose.

\section{Key to the Males}

Antennal segment $\mathrm{V}$ not excavated or foveate, but with one of its faces produced, either as an oblique rounded process, or an acute spine,

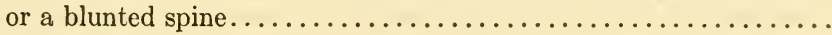

Antennal segment $\mathrm{V}$ with the ventral, mesial, or ventro-mesial face foveate or irregularly excavated; spines may or may not be present

2. Antennal segment $\mathrm{V}$ obliquely subpyriform with the apical-mesial angle produced into a rounded process; segment VI transverse, with the mesial face produced into a more slender, more acute, spinoid process; ventral faces of both fifth and sixth segments excavated; VII much smaller than sixth, wider than eighth, subquadrate but with the mesial face produced into a short, blunt process; basal discal carinae of first tergite separated by one-third of the discal width; metasternum slightly, obsoletely impressed at middle; last sternite simple, hardly impressed; legs simple; $1.8 \mathrm{~mm}$. long...... ..........................mexicana (PI. XVII, 16)

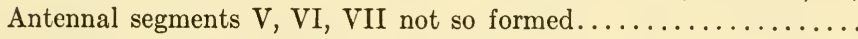

3. Antennal segment $\mathrm{V}$ subcircular, excavated on the ventral face in the apical-internal half, and with two minute spines; VI subquadrate, obconical; basal discal carinae of first tergite separated by more than one-third of the segmental width; $1.8 \mathrm{~mm}$. long..... biclavata

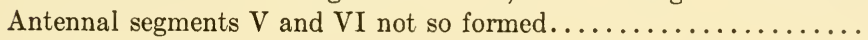

4. Antennal segment $\mathrm{V}$ elongate, about twice as long as wide, with the ventral face polished and foveate; VI also large, but about half as long as fifth, the length and width subequal; VII transverse, much smaller than sixth, with the internal-apical angle acute; metasternum medianly concave with the lateral boundaries prominent and tuberculate;

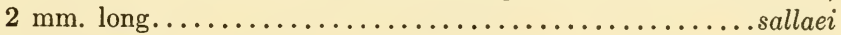
Antennal segment large, but differently formed, not elongate as de-

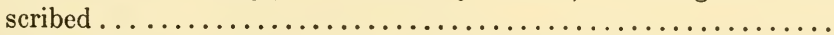

5. Antennal segment $\mathrm{V}$ in the form of an irregular triangle, and with the ventral face excavated; VI transverse; 2.0 to $2.33 \mathrm{~mm}$. long...... diversicornis (In this species the discal stria of each elytron is said to be wholly absent!)

Antennal segment $\mathrm{V}$ very large, transversely quadrate, with the ventral face bearing a transverse, irregularly biarcuate excavation; VI transverse, with the ventral face obliquely flat and this flattened, opaque surface studded with small asperities in sharp contrast to 
the glabrous dorsal face; VII elongate-cylindrical, slightly longer than sixth, much narrower, and distinctly longer than eighth segment but of the same width; middle coxae each with a broad, triangular laminoid spine......... fovearthra new species (Pl. XVI, 13, 14)

*6. Antennal segment $\mathrm{V}$ irregularly semilunar, with a sharp spine on the internal face; VI a little smaller than fifth, nearly ovoidal, with a small tooth on the internal face..................eucera Antennal segment $\mathrm{V}$ with lateral face strongly convex, and mesial face greatly produced, this production being arcuate so that the extension is an acute production of the internal apical angle which bears several short setae; VI with a very narrow base, and an irregularly pyriform, swollen apical two-thirds, the lateral face being very rounded, the mesial face being nearly straight, with this latter face bearing a short, blunt spine which is also equipped with several setae; $1.8 \mathrm{~mm}$. long................... guadalupensis

\section{Reichenbachia fovearthra new species}

Holotype Male. Measurements: head $0.29 \times 0.37 \mathrm{~mm}$; antennae $0.84 \mathrm{~mm}$.; pronotum $0.37 \times 0.40 \mathrm{~mm}$.; elytra $0.62 \times 0.73 \mathrm{~mm}$.; abdomen $0.47 \times 0.71 \mathrm{~mm}$.; total length $1.8 \mathrm{~mm}$; greatest width $0.73 \mathrm{~mm}$. (Pl. XVI, 13, 14).

Yellowish-brown, the integument shining, punctulate; pubescence moderately abundant, longer $(0.03 \mathrm{~mm}$. long $)$ on abdomen than on the elytra, pronotum and head $(0.02 \mathrm{~mm}$. long). Head with the prominent eyes (34 large facets) longer $(0.107 \mathrm{~mm}$.) than tempora $(0.07 \mathrm{~mm}$.). Vertex evenly convex, with three large, subequal, pubescent foveae, each lying in a depression, two being on a line through the middle of the eyes, mutually more distant than each to the nearest eye, and a third median anterior fovea between the antennal insertions. Front regularly declivous but not vertical; epistome simple; labrum simple. Ventral surface of head flattened, with the usual longitudinal, median, carinoid elevation typical of genus.

Maxillary palpi typical of genus, as for stroheckeri save that the fourth segment is slightly obliquely truncate at apex.

Antennae abnormal, eleven-segmented, separated by a distance equal to the mutual separation of the inter-ocular foveae; segment I irregularly elongatecylindrical, dorsal surface concave; II subspherical, as wide as first but shorter; III much narrower and shorter than second, transversely obconical; IV shorter and wider than third, transversely ovate, the mesial face subacute; $\mathrm{V}$ very large and complex, transversely subquadrate, dorsal face strongly convex longitudinally; laterally this curvature gives a semilunar outline to the segment, ventral face with a very large, densely setose, irregularly biarcuate excavation occupying apical half from side to side; VI abnormal, much smaller than fifth, excentrically articulated, transversely subovate dorsal face, ventral face

* These two species, eucera and guadalupensis, are the only two of this forty-first group known to inhabit the Antilles, and are very closely related. 
with an oblique, flat, oval, sharply-limited surface which is asperate and setose; VII-XI inclusive longer than wide; VII-X inclusive narrower than sixth; VIII distinctly shorter than either seventh or ninth; IX, X, and XI progressively wider; IX and $\mathrm{X}$ subequal in length; XI slightly wider than sixth and as long as ninth and tenth united, basally truncate and apically subacute.

Pronotum with disc simple; a large pubescent lateral subbasal fovea each side, and a minute median nude, punctiform fovea nearer base.

Scutellum acute--triangular, glabrous, distinct.

Each elytron with three circular nude, basal foveae-a sutural fovea at origin of entire sutural stria, a median, and a lateral at origin of a wellformed, arcuate discal stria which extends from fovea to far beyond middle to apical fifth. Wings well-developed.

Abdomen with the usual large first tergite and strongly defined margins; first tergite with a pair of strong, slightly divergent, straight, basal carinae one-third as long as segment, and separated by nearly one-half of segmental width. Last sternite medianly flattened, the apical margin bisinuate and consequently medianly slightly lobed, relatively long.

Sternal foveae II, III, IV, and VI well-developed and pubescent.

Metasternum laterally glabrous, medianly broadly concave and densely pubescent.

Femora moderately inflated, especially the intermediate and posterior pair; intermediate coxae each bearing a thin, triangular laminoid spine at mesial angle; this spine is indistinct due to the surrounding pubescence, but is quite large when dissected out; intermediate tibiae subtruncate apically, this truncature with a minute internal tooth; posterior tibiae thickened for apical half of length, the mesial face of the thickened area bearing a brush of short, dense, stiff, equal setae.

Allotype Female. As for holotype save that the antennae are simpler: segment I elongate-cylindrical, dorsally concave; II narrower, ovate; III distinctly narrower and shorter than second, obconical; IV as wide as, and slightly longer than third, subobconical; V and VII distinctly longer than VI and VIII, these last four subequal in width, as wide as fourth; IX-XI progressively wider and longer, forming the club. Secondly, the intermediate coxae are not armed. Thirdly, the last sternite is very different from the male, being simple, very transverse, relatively short, about as long as the two preceding sternites united, with a simple, convex apical margin.

Described on seven specimens collected by the author at light at night (9:00-10:30 p.m.), on Barro Colorado Island, Gatun Lake, Panama Canal Zone; holotype, allotype, and one paratype male July 7, 1936; one paratype female July 17, 1936; two paratype females July 28, 1936 and one paratype female July 29, 1936.

This species is not closely related to any member of this group, but is more allied with diversicornis (Sharp) from Guatemala than to the other species.

biclavata (Reitter). 1882. Colombia. (Bryaxis)

diversicornis (Sharp). 1887. Guatemala. (Bryaxis) 
eucera (Aube). 1844. Puerto Rico. (Bryaxis)

fovearthra new species. Panama Canal Zone.

guadalupensis Raffray. 1908. Guadeloupe, Leeward Islands.

mexicana Raffray. 1904. Mexico.

sallaei (Sharp). 1887. Mexico, Guatemala, Panama. (Bryaxis)

(sallei Raffray, 1908, nec Sharp)

\section{Group XLVII}

The neotropical representatives of this group have been contributed by Fletcher, and have few affinities with the rest of the group, the outstanding parallel being the possession of swollen tibiae of the posterior legs. These two neotropical species have the male sex characterized by (1) swollen hind tibiae, and (2) mandibles with a tooth on the external face; the females have simple hind tibiae and normal mandibles.

Mandibles each with a small tooth on the external face; posterior

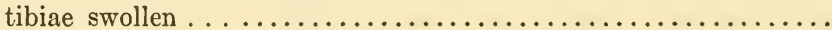

Mandibles and tibiae simple..................... Females

2. External mandibular tooth forming an acute angle with the mandibular curvature; posterior tibiae strongly dilated externally with an elongate median depression beneath; length $1.6 \mathrm{~mm} . . . . . .$.

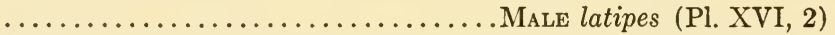

External mandibular tooth forming an obtuse angle with the mandibular curvature; posterior tibiae strongly dilated but lacking an elongate median depression beneath; length $1.4 \mathrm{~mm}$. (Pl. XVI, 1) ........................................ guatemalensis

guatemalensis Fletcher. 1928. Guatemala.

latipes Fletcher. 1928. Mexico.

\section{Group LI}

The fifty-first group contains but one species:

nasalis (Reitter). 1900. Brazil. (Bryaxis). (nasuta Reitter, 1882).

\section{Group LII}

The fifty-second group contains two species, but the remarks anent the fifty-sixth group should be considered for a more complete picture. The representatives of this group are specialized with respect to the vertexal foveae: the two foveae between the eyes are normal, but the third fovea, (which is generally of the same size and located on the top of the head, between the antennal bases, near the front), is here much smaller and placed on the abruptly declivous front, so that it occupies a plane at nearly right angles to the two vertexal foveae. This foveal arrangement is common to both sexes, where the female sex is known, and forms a transition to those species where this frontal fovea is wholly absent. 
Antennal segment VI elongate-cylindrical, three times as long as wide; intermediate legs with the coxae and trochanters simple, not spinose or acutely produced............................. oberthüri

Antennal segment VI abnormal and V also abnormal; either the coxae or trochanters of the intermediate legs spined or acutely produced. .

2. Antennal segment $V$ twice the size of the fourth segment, circular in form, with the dorsal face slightly convex and the ventral face gibbous; VI large, oblong-ovate, with dorsal face convex and ventral face depressed and granulated; intermediate coxae with the internal angle produced into a long, triangular, acute and posteriorly directed process $; 1.6 \mathrm{~mm}$. long.............................. oberthüri Antennal segment $\mathrm{V}$ oblong, the dorsal face reniform in outline, the ventral face concave, and bearing a strong, acute, median appendage; VI with the dorsal face elongate-oval in outline, but the ventral face very complex and abnormal; biappendiculate, the first appendage being near the base, elongate and slender, angulated at its basal third so that its expanded apical end extends ventrally beyond the second appendage; second appendage arises in the basal half of the ventral face as an acute tooth more or less covered by the basal appendage; anterior half of the ventral face not appendiculate but quadrately produced, with the apical area narrowing to form an angulated, subgeniculate articulation with the seventh segment; VII and VIII with ventral faces narrowed and produced; fifth and sixth segments articulated in an arc, to give the antennae a distinctive appearance; intermediate trochanters armed at base with a small spine; $1.8 \mathrm{~mm}$. long (Pl. XVI, 10, 11)......... ............................ appendiculata (female not known)

appendiculata Raffray. 1904. Mexico. (may be a variation of diversula Raffray, vide infra)

oberthüri Raffray. 1904. Colombia.

\section{Group LIII}

This fifty-third group contains but a single species:

reichei (Schaufuss). 1872. Colombia. (Bryaxis). (reicheiana Schaufuss) Guatemala (cf. Sharp, 1887, p. 27)

\section{Group LIV}

I am insufficiently acquainted with this group to attempt a key to the species:

bifoveata Fletcher. 1928. Mexico.

binodula (Schaufuss). 1872. Colombia. (Bryaxis)

celata (Sharp). 1887. Mexico, Guatemala, Nicaragua. (Bryaxis)

immodica Raffray. 1904. Colombia. 
obnubila Raffray. 1904. Mexico.

stussineri (Reitter). 1882. Brazil. (Bryaxis)

subfoveolata (Schaufuss). 1872. Colombia. (Bryaxis). It should be pointed out that this same species is also placed in Group XXI by Raffray (1904). I have followed this since I am unfamiliar with subfoveolata.

\section{Group LV}

This group is probably composite. It includes a species from Madagascar, a species from Sumatra, and two neotropical species. One of these latter probably should be placed in a new group, since the vertex is sharply carinate medianly in the male, and obtusely carinate in the female sex. This heterogeneous assemblage agrees in having the two vertexal foveae normally placed between the eyes, but the median frontal fovea is wholly absent, in both males and females. Males have the fifth antennal segment large, of relatively abnormal size. The two neotropical species may be separated as follows:

Vertex of the head normally convex................nominata

( $2.0 \mathrm{~mm}$. long; known from the female only)

Vertex of the head with a median, longitudinal carina or an obtuse

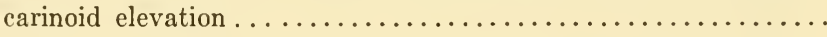

2. Vertex with a strong, sharp, median longitudinal carina which anteriorly becomes an obtuse ridge; basal part of vertex and adjacent occiput with a transverse, densely but finely granulated area covered with long, yellow, anteriorly directed setae; antennal segment $\mathrm{V}$ very large, about three times longer than second segment, arcuate externally, armed internally near apex with a strong, apically enlarged spicule; $1.4 \mathrm{~mm}$. long; metasternum medianly depressed... ........................... carinifer Male (Pl. XVII, 17)

Vertex with an obtuse carina between the vertexal foveae; antennal segment $\mathrm{V}$ elongate-cylindrical, as long as third and fourth segments united, not spiculate on internal-apical face............ ................carinifer Female (metasternum not depressed)

carinifer Fletcher. 1928. Mexico.

nominata (Sharp). 1887. Guatemala. (Bryaxis)

\section{Group LVI}

So far as known this group is purely American, and at present holds two neotropical species. They are allied to the fifty-fifth group in having no trace of a frontal fovea, and one of the species at least, has the epistomal area prominently elevated. It is also possible that the taxonomy of this section of the genus is very involved, and some changes may have to be made when more information has accumulated.

This group is separated from the fifty-fifth group in that the males have the fifth and sixth antennal segments abnormal, while the previous group had 
the fifth segment only abnormally formed. The females have the antennae normal. The two species may be separated as follows:

Each elytron with three basal foveae............. diversula

Each elytron with two basal foveae........stroheckeri new species

\section{Reichenbachia stroheckeri new species}

Holotype Male. Measurements: head 0.22 x $0.36 \mathrm{~mm}$.; antennae $0.87 \mathrm{~mm}$.; pronotum 0.31 x $0.38 \mathrm{~mm}$.; elytra 0.53 x $0.7 \mathrm{~mm}$.; abdomen 0.46 x $0.6 \mathrm{~mm}$.; first visible tergite 0.26 x $0.6 \mathrm{~mm}$; total length $1.52 \mathrm{~mm}$; greatest width $0.7 \mathrm{~mm}$. (Pl. XVI, 8, 9)

Integument yellowish-brown, shining, lightly punctulate with short $(0.016$ to $0.033 \mathrm{~mm}$.), moderately abundant pubescence. Eyes prominent, three times as long as tempora, with about 30 coarse facets. Tempora short, convergent, with subtruncate posterior angles. Vertex with two foveae between the eyes, these foveae being pubescent and large, e.g. a diameter equal to two eye facets united, free with no intrafoveal sulcus. Front almost vertically declivous between the antennal bases, the declivity glabrous, slightly concave. Absolutely no trace of a frontal fovea, pit, or foveoid depression between frontal margin and epistome. This total lack of a frontal fovea separates this species from appendiculata Raffray and allies. Epistome erected into a prominent, obtuse, glabrous, slightly recurved horn, forming a transverse sulcus or cleft between the declivous front and the epistome. This epistomal structure effectually separates this species from diversula Raffray and appendiculata Raffray as described. The epistomal tubercle is probably a male secondary sex character. Labrum small, transverse, tumid, the anterior margin medianly concave. Mandibles normal, not dilated and without external teeth or tubercles, bases exposed each side of labrum. Ventral surface of head triangular, subglabrous, with a median, longitudinal, poorly-defined carina. A minute gular fovea on each side of this carina, at its extreme base.

Maxillary palpi normal for genus, four-segmented; first segment minute, cylindrical; second elongate-pyriform, arcuate, basally slender and gradually expanded in apical half to apex; third short, subtriangular, mesial face subacute, lateral face strongly convex, wider than second segment; fourth segment largest, longer than second and wider than third, obliquely truncate at base, subacute at apex, bearing a short pelpal cone, mesial face nearly straight, lateral face convex, cylindrico-conical in outline.

Antennae abnormal, eleven-segmented, longer than pronotum and elytra united, rather widely separated by a distance equal to that from the center of one vertexal fovea to the center of the other $(0.134 \mathrm{~mm}$. $)$; segment I oblong, dorsally concave; II longer than wide, narrower than first, subobconical; III short, transversely obconical; IV as long as third but much wider, twice as wide as long, slightly asymmetrical; V large, distinctly wider than fourth and four times as long, the dorsal surface strongly biconvex or dumb-bell shaped, the ventral face constricted in apical third, and bearing a 
prominent, transverse, truncate lamina at center, just behind the constriction; VI as large as fifth, articulated at an angle with fifth to give antennae a subgeniculate appearance, the dorsal face simple, elongate, the ventral face with a long, slender, very capitate appendage extending from basal margin and seeming to arise from the fifth segment unless observed with care, also a short, acute, arcuate cusp arising from the ventral face just anterior to the capitate appendage noted, and partially covered by the latter; anterior to this cusp the ventral face is expanded ventrally and bears a median, arcuate, longitudinal lamina; VII-X excentrically articulated; VII strongly and VIII weakly narrowed mesially, of nearly equal length and width; IX slightly longer than eighth, of same width, with the non-articular portion drum-shaped; $\mathrm{X}$ subclindrical, as long as eighth and ninth united and slightly wider than ninth; XI as long as ninth and tenth united, basally truncate, apically subsinuate to bluntly narrower apex. The dorsal faces of the fifth and sixth segments are similar to those of diversula Raffray and appendiculata Raffray, and the remarkable anatomy of the ventral faces of the fifth and sixth segments is strikingly like the condition in appendiculata Raffray.

Pronotum with form typical of genus; a large pubescent, subbasal fovea on each side, and a minute, nude, punctiform median basal fovea, these foveae wholly free and unconnected by transverse sulcus; disc simple and unmodified.

Elytral form typical of genus; each elytron with but two basal foveae, these foveae circular, large; the sutural fovea at base of the well-formed sutural stria; the discal fovea at base of the long, arcuate discal stria which extends to apical fifth. Scutellum distinct. Wings long and well-formed.

Sternal foveae II, III, IV, and VI well-formed and with their orifices covered by long setae, foveae IV especially large and transverse. The metasternum medianly concave and pubescent, with the margins of the concave area moderately prominent; lateral areas of metasternum are glabrous.

Abdomen with the first visible tergite bearing at base two straight, divergent carinae; these basal carinae are short, being only one-fifth as long as segment, and separated by one-third of the width of the segment. Last sternite medianly slightly depressed.

Legs simple with exception of the intermediate coxae. Each of these coxae bears a short, acute spine at its mesial-posterior angle.

Described on two male specimens, both collected by the author at light on Barro Colorado Island, Gatun Lake, Panama Canal Zone. The holotype male at 10:00 p.m., July 17, 1936, and the paratype male at 10:00 p.m., July 28, 1936. Named for my friend, Dr. Strohecker.

There is either a striking case of genetic parallelism of the antennal abnormalities of the male sex, or a taxonomic imbroglio involving groups $\mathbf{5 2}$ and 56. After considerable thought I have decided the former condition exists, at least to the extent that appendiculata Raffray and stroheckeri are distinct. However, certain remarks must be set down to aid future students. David Sharp (1887, p. 29 and Pl. I, fig. 14) described Bryaxis diversa from Panama, based on seven examples taken from the sandy banks of streams 
near San Feliz and Tole. This description is dated March, 1887. Raffray described Bryaxis diversa from Cape Town, South Africa in January, 1887. These "Bryaxis" are Reichenbachia and Sharp's name was preoccupied; Raffray consequently named Sharp's species Reichenbachia diversula (1904, p. $363)$.

In the next place the original description of diversula is so poor that only a few items can be elicited: (1) pronotum with a minute median fovea, (2) frontal fovea of head present on the anteriorly declivous front, this condition being stated by Sharp and also shown in his figure; (3) each elytron with three basal foveae; (4) dorsal faces of the fifth and sixth antennal segments are well shown. This set of features, taken with other general characters, would place diversula in Group 52 in which the frontal fovea is present but on the declivous front, and the males have the fifth and sixth antennal segments abnormal. However, Raffray (1904) put diversula in Group 56 which is characterized by having no frontal fovea. Now it is obvious that either Raffray incorrectly placed diversula, or examined Sharp's types and discovered that Sharp incorrectly diagnosed the presence of the frontal fovea. Both assumptions are difficult to entertain and yet are mutually untenable. The matter is further complicated in that Raffray (1904, p. 295) described from Mexico Reichenbachia appendiculata. This latter species has a frontal fovea on the strongly declivous front, and abnormal fifth and sixth antennal segments in the male, and so belongs in Group 52. This appears to be a definite and correct allocation. However, if diversula belongs in group 52 (and Sharp's words and figure would seem to demonstrate this position), then we have appendiculata and diversula in the same group, and the dorsal faces of the male fifth and sixth antennal segments are slightly similar in form. The ventral faces of these segments are not even hinted at by Sharp, and are well described in all their abnormality by Raffray. However, appendiculata has each elytron with two basal foveae and diversula has three basal foveae as near as I can determine. This would definitely separate diversula from appendiculata.

In the next place, the new species, stroheckeri has the dorsal face outline similar to diversula and appendiculata, similar abnormal features on the ventral faces of the fifth and sixth antennal segments of appendiculata, agrees with this latter species in having only two basal foveae on each elytron; differs radically from appendiculata in having no frontal fovea at all and from both in having the epistome erected into a horn-like tubercle. Raffray has nothing to say on the epistome of appendiculata, and if this were abnormal in this species he would have been sure to describe it; Sharp figures a normal epistome in his diversa. It seems clear, then, that stroheckeri and appendiculata are not even closely related, and equally clear that stroheckeri and diversula are even more distantly separated.

diversula Raffray. Panama. (Bryaxis diversa Sharp, 1887, preoccupied, cf. Raffray, 1904). (Group 52, vide supra?)

stroheckeri new species. Panama Canal Zone. 


\section{Group LIX}

This fifty-ninth group holds a single species in the neotropical area, designata (Sharp), based on seven specimens from Las Mercedes, Guatemala. The median frontal fovea is absent; both sexes have the fifth and sixth antennal segments abnormal; male with a concave, and female with flattened, metasternum; the vertex is medianly swollen or prominent between the interocular foveae, this extending anteriorly as an elevated area, but not reaching the front. This prominent vertex is uncommon in the genus, and approached in the neotropics only by carinifer Fletcher of Group 55 .

designata (Sharp). 1887. Guatemala. (Bryaxis)

\section{Group LXIV new group}

This new group is erected for a single neotropical species, femoralis Fletcher. Since the sixty-third group of Raffray has been elevated to a new genus, femoralis could have been placed in this vacated spot, but the subsequent confusion would have been too great, and so Raffray's groupings have been left intact, there being no sixty-third group in the genus at present. The essential features may be summated as follows: head with the vertex, front, epistome, and mandibles normal for genus; the vertexal foveae not normal, there being the usual two inter-ocular foveae, and the median anterior fovea is very small on the depressed front between antennal bases, instead of being subequal in size to the posterior pair; antennae normal; pronotum normal, with a large, lateral, pubescent fovea each side and a smaller, nude fovea at middle nearer base; each elytron with two basal foveae, and a discal stria not reaching the middle; abdomen normal, first tergite with a pair of slightly divergent basal carinae not reaching middle of segment and separated by onehalf the segmental width at base; metasternum flattened in male (only sex known); legs not normal, intermediate tibiae armed with a strong spur on the ventral face near apex, posterior femora greatly dilated, the dilation being broadly and entirely excavated on the posterior face. As Fletcher pointed out (1928) this species falls in Division V of Raffray (Groups 29-32) but does not fit any of these on the character of the anterior cephalic fovea coupled with the abnormality of the posterior femora.

femoralis Fletcher. 1928. Peru.

In addition to the species enumerated in the above groups, the following species of Reichenbachia, known from the neotropics, are included without group allocation:

argentina Raffray. 1909. Argentina.

biocellata (Schaufuss). 1887. Mexico. (Bryaxis)

bisinuata (Schaufuss). 1887. Cuba. (Bryaxis)

bythinoides (Sharp). 1887. Panama (Bryaxis). Group LIV?

crassipalpis (Sharp). 1887. Guatemala. (Bryaxis) 
dorsopunctata (Schaufuss). 1887. Brazil. (Bryaxis)

festina Raffray. 1909. Argentina.

fluviatilis (Schaufuss). 1887. Brazil. (Bryaxis)

griseopubescens Raffray. 1909. Argentina.

hippopotamus (Schaufuss). 1887. Brazil. (Bryaxis)

impressicollis (Sharp). 1887. Guatemala. (Bryaxis). (Reichenbachia?)

impubis (Sharp). 1887. Guatemala. (Bryaxis). (Reichenbachia?)

impunctata (Schaufuss). 1887. Mexico. (Bryaxis)

lutea Raffray. 1909. Argentina.

penita (Schaufuss). 1887. Brazil. (Bryaxis)

pygmaea (Schaufuss). 1887. Brazil. (Bryaxis)

rubecula (Sharp). 1887. Panama. (Bryaxis)

spuria (Schaufuss). 1887. Brazil. (Bryaxis)

triangulifera (Schaufuss). 1887. Brazil. (Bryaxis). (Reichenbachia?)

truncata (Schaufuss). 1887. Cuba. (Bryaxis)

\section{PANABACHIA new genus}

This genus is erected for Bryaxis vulnerata Sharp. Sharp (1887, p. 31) has the following to say:

"Antennae short and slender, with rather large club; joints 4-8 minute, subequal, the terminal three gradually forming a club. Head short, moderately broad, the front of the clypeus a little raised and with a slight antennary tubercle; bifoveate between the eyes, the extreme vertex in the middle slightly notched or depressed. Thorax broad and short, much narrowed behind; with a very large and deep depression formed as it were of three depressions united, the larger on the disc, the smaller one a little nearer the front on each side. Elytra with a distinct sutural stria and a well-marked intrahumeral depression." $1.25 \mathrm{~mm}$.

This species is figured by Sharp, showing the remarkable discal excavation of the pronotum. Such pronotal structure is absent in the qualitative sense from Reichenbachia, and Raffray (1904, p. 156) placed this species with doubt in Reichenbachia as a new division, and felt that it warranted at least a new subgenus.

I feel that the structure of the pronotum is sufficient for a generic divergence. Based on a unique, it has not been reported since.

vulnerata (Sharp). 1887. Panama. Genotype.

\section{NODULINA (Raffray, 1904)}

This monotypic genus is allied closely to Reichenbachia, differing in the anatomy of the head. The head is very wide, including the prominent eyes, more than one-half wider than the length between the occipital margin and frontal margin; both occipital margin and the frontal margin between the antennal bases are truncate, with the angles rounded abruptly to give a transversely-squared appearance. Beyond the frontal margin the epistome is greatly 
expanded into a dilated plate extending apically beneath the antennae as far as the second segment, and laterally nearly to the eye margin to give a width subequal to the total head width through the eyes. This dilated epistomal area is simple in the female and bears a median, apically setose, triangular horn or tubercle in the male sex.

convexa (Schaufuss). 1879. (Bryaxis). Brazil; Dutch Guiana.

\section{BUNODERUS (Raffray, 1904)}

This genus, allied to Brachygluta and Reichenbachia, is distinct in the neotropical part of the tribe by having the pronotum with the disc crossed longitudinally by a median carina or carinoid gibbosity. In this it occupies an analogous position to the Brachyglutini, that Neodalmus occupies in the Euplectini.

\section{KeY to the Species}

Disc of pronotum with a strong, entire, median longitudinal carina ................... carinicollis $(1.6 \mathrm{~mm}$. Based on Female)

Disc of pronotum with the median longitudinal carina obsolete, replaced by a carinoid, longitudinally gibbous swelling...........

2. Metasternum with a wide, entire longitudinal, median impression the sides of which are carinated................ longipilis MALE

Metasternum widely, less deeply sulcate, the sides not thrown into carinae........... longipilis Female (species 1.5-1.7 mm. long)

carinicollis Raffray. 1904. Mexico.

longipilis Raffray. 1904. Brazil.

\section{STROMBOPSIS (Raffray, 1904)}

A monotypic genus allied to Xybaris, Xybarida, and Cryptorhinula on the one hand but considered more primitive than this group of genera on general anatomy as described.

breviventris Raffray. 1904. Brazil.

\section{ACHILLIA (Reitter, 1890)}

This large genus, named for Raffray by Reitter in 1890 , has an odd distribution. Out of twenty-five known species, twenty-four are found in Chile and one in Cuba! In its concentration in Chile, this pattern reminds one of the concentration of Lioplectus in the Euplectini with seven species known, all from Argentina.

The elytron has either two or three basal foveae (not two foveae as stated by Raffray, 1908). The body is elongate, subparallel and flattened. The subquadrate head has the front transversely sulcate and diversely impressed and armed, especially in the male sex. In elfridae the vertexal foveae are on a level with the anterior margin of the eyes, while in clavata the foveae are far 
forward, one near each antennal base. Ventral face of the head with the usual median, longitudinal carina. Antennae eleven-segmented, often irregular in the male sex. Maxillary palpi four-segmented, first minute; second gradually, strongly swollen apically; third transversely, often irregularly, triangular; fourth irregularly ovoidal. Pronotum subcordiform, disc simple, three subbasal foveae. Elytra with each elytron with two or three (possibly four foveae in valdiviensis?) basal foveae, dorsal stria present but shortened. Abdomen normally margined, not abnormally formed. Middle coxae subcontiguous; posterior coxae distant. Second tarsomere longer and thicker than the third, and bearing beneath a brush of setae in the male anterior tarsus.

The synonymy in many of the species is complicated. Being quite unfamiliar with the genus, I have used the group key of Raffray (1904) to partially separate the many species:

Antennae simple............................. 2

Antennae different in the two sexes.................... 11

2. Abdomen simple ............................ 3

Abdomen with first tergite modified (rare in genus as noted previously), with a strong, acute tubercle, set in a depression on each side of segment; head with a fine, transverse frontal sulcus, and between the eyes a large depression................. Group $\mathrm{X}$

3. Head with no transverse frontal sulcus, but the head diversely sculp-

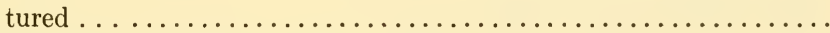

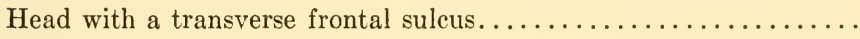

4. Head with a large frontal fovea and also a short longitudinal short

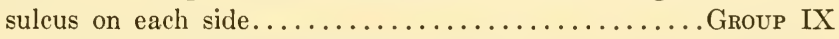

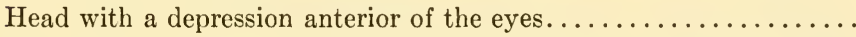

5. Head with a strong, transverse depression anteriad of eyes; vertex more or less prominent and produced above the eyes.... Group VII

Head with a sinuate depression anteriad of the eyes, the front prolonged anteriorly and head distinctate punctate......GRoup VIII

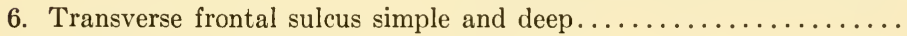

Transverse frontal sulcus present, and in addition, a very deep, wide, transverse depression anterior of eyes................ GRoup VI

7. Head much longer than wide, with a very large triangular anterior depression; last segment of antennae very large......... Group V

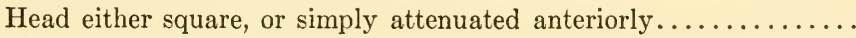

8. Head attenuated anteriorly and simple................ Group I Head square ................................ 9

9. Club of antennae with eleventh segment conspicuously large...... Club of antennae with the tenth segment large and transverse, eleventh segment not wholly forming the club.............. Group II

10. Eleventh antennal segment very large, club practically one-segmented 
11. First segments of the antennae abnormal; head armed; epistomal area

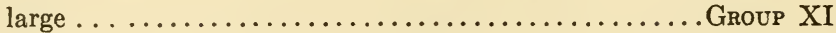

Last segments of the antennae abnormal..................

12. Segments VIII, IX, and $X$ very abnormal; occiput gibbous; vertex prominent and deeply excavated each side in the male; antennae simple, but sinuate, head wide, flattened triangularly on front and vertex and squamous in the female............... Group XII

Segments IX and X very large, abnormal, but not armed; head deeply excavated each side of vertex..................Group XIII

The species may be listed as follows, the roman numerals denoting the Raffrayian species groups:

I

approximatus (Reitter). 1885. Chile. convexiceps Raffray. 1904. Chile.

\section{II}

cordicollis Raffray. 1904. Chile.

III

clavata Raffray. 1904. Chile.

kindermanni (Reitter). 1883. Chile.

IV

blanchardi Raffray. 1904. Chile. (valdiviensis Reitter) 1883.

elfridae Raffray. 1904. Chile. (Reitter in. litt.)

latifrons Raffray. 1904. Chile.

picea Raffray. 1904. Chile.

quadriceps Raffray. 1904. Chile.

tripunctata (Reitter). 1885. Chile.

\section{V}

simulans (Reitter). 1885. Chile.

\section{VI}

brevicornis Raffray. 1904. Chile.

bifossifrons (Reitter). 1883. Chile.

humidula (Reitter). 1885. Chile.

VII

cosmoptera (Blanchard). 1852. Chile. (Pselaphus) (Aplodea, Reitter)

(Tyropsis, Raffray). See Raffray, 1904. (chilensis, Reitter, 1883) larvata (Reitter). 1885. Chile. 


\section{VIII}

longiceps (Reitter). 1885. Chile.

\section{IX}

praeclara (Reitter). 1885. Chile.

\section{X}

bituberculata (Reitter). 1885. Chile.

\section{$\mathrm{XI}$}

monstrata (Reitter). 1885. Chile.

valdiviensis (Blanchard). 1852. Chile. (Pselaphus) (Aplodea, Reitter) (Tyropsis, Raffray). See Raffray, 1904. (anas Reitter, 1885)

(nasuta Reitter, 1885; nasina Reitter, 1893)

\section{XII}

puncticeps (Reitter). 1883. Chile.

\section{XIII}

excisa (Schaufuss). 1879. Cuba.

validicornis (Reitter). 1885. Chile.

\section{RAXYBIS (Raffray, 1908)}

This is an Argentine genus closely related to Braxyda and Bryaxina, differentiated from them by the key characters. There is also a slight but constant difference. Raxybis males have the second segment of the anterior tarsi thicker than the third, but not dilated nor flattened, and the ventral surface is clothed with long, dense setae; this tarsal condition is also found in the females. On the other hand the males of Braxyda, Bryaxina, Xybaris, Achillia have the second tarsomere dilated, flattened and with a pad of setae beneath.

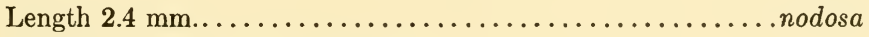

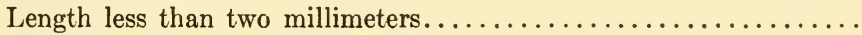

2. Front flat, obtusely angulated; epistome uncarinated

frontalis Female

Front medianly truncate, fasciculated and with a triangular tubercle; epistome strongly carinated...............frontalis MALE frontalis Raffray. 1908a. Buenos Aires, Argentina. (Male and female known.)

nodosa Raffray. 1908a. Buenos Aires, Argentina. Genotype. (Male known only.) 
This is a genus of moderate size, closely related to Achillia, and restricted to Brazil. The males have the second tarsomere of the anterior tarsi greatly expanded laterally, flattened, with the ventral surface setose. The maxillary palpi are four-segmented with the fourth segment irregularly pyriform or irregularly pyramidal, the base being rounded, widening rapidly to basal third, then lengthily narrowing to an acute apex, which bears a palpal cone, however, this narrowing is accompanied by a distinct sinuation on the external face, so that the external-apical outline is concave and the internal-apical outline is convex.

There are ten species known, and I have used Raffray's key (1904, pp. 262-263) for their separation since no new forms have been described.

Each elytron with three basal foveae................... 2

Each elytron with four basal foveae.................... 4

2. Basal discal carinae of first tergite one-third of the segmental

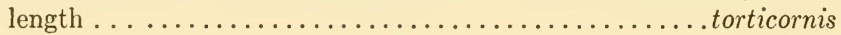

Basal discal carinae of first tergite one-fourth of the segmental length

3. Antennae thick, with eighth segment strongly transverse, ninth less transverse than eighth, tenth nearly square, eleventh elongate-oval; head armed and excavated in the male sex............armiceps Antennae thicker, with segment eight slightly and nine and ten strongly transverse, eleven briefly obconical; head simple in the female sex (male unknown?).......................fraudatrix

4. Antennal segments all longer than wide, or most of the segments longer than wide.

Antennal segments as wide as long (subequal), or fourth, eighth,

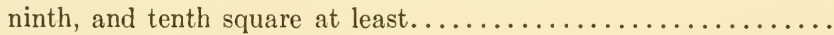

5. Basal discal carinae of first tergite one-fourth of segmental length; antennal segments four and eight square..............lucida

Basal discal carinae of first tergite one-third of segmental length; antennal segments four and eight slightly longer than wide. .clavata

6. Antennae with segments five, six, seven much longer than wide, and

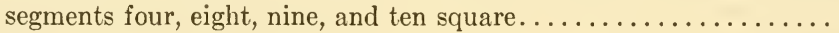
Antennae thick, with the segments not much longer than wide......

7. Basal discal carinae of first tergite one-third of segmental length

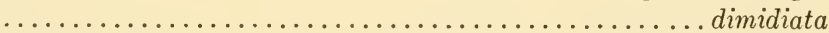

Basal discal carinae of first tergite one-fourth of segmental length schaufussi

8. Antennae with segment eight square, nine and ten transverse; basal discal carinae of first tergite one-fourth of the segmental length cavifrons

Antennae with segments eight, nine, and ten transverse; basal discal carinae of first tergite one-third of segmental length............

9. Antennae with segments eight and nine very transverse, not much 
larger than seventh, tenth less transverse; basal discal carinae of first tergite one-third of segmental length........... foveifrons Antennae with segments eight, nine, and ten less transverse, much larger than seventh, forming a marked club; basal discal carinae of first tergite one-third of the segmental length and divergent crassicornis

The species are listed as follows:

armiceps Raffray. 1904. Brazil. cavifrons (Schaufuss). 1879. (Bryaxis) Brazil. clavata Raffray. 1904. Brazil. crassicornis Raffray. 1904. Brazil. dimidiata Raffray. 1904. Brazil. foveifrons Raffray. 1904. Brazil. fraudatrix (Schaufuss). 1879. (Bryaxis) Brazil. Genotype. lucida Raffray. 1904. Brazil. schaufussi Raffray. 1904. Brazil. torticornis Raffray. 1904. Brazil.

\section{BRAXYDA (Raffray, 1904)}

This is a small genus of two Bolivian species, related to Bryaxina, and separated by the key characters noted previously. The males have the second tarsomere of the anterior tarsi expanded and supplied below with a brush of setae. Pronotum with a minute, punctiform median fovea near base and no lateral foveae. Elytra with a strong discal stria extending to the middle of elytral length; each elytron with two basal foveae, the sutural and discal. First tergite much longer than second, with a pair of basal discal carinae one-fourth of the segmental length and enclosing one-third of the segmental width. Male pygidium very large, subhexagonal, curved ventrally. Fourth segment of maxillary palpi truncate at base, regularly fusiform as in the genus Reichenbachia; third segment small, triangular. Middle coxae subcontiguous, allowing the mesosternum to be seen between them as a thin lamina.

The two species may be separated as follows:

\section{Key to the Species}

Male with segments of antennae III, IV, and VI short; V three times wider than long; VII two times wider than long; VIII quadrate; IX and $\mathrm{X}$ obconical-truncate, wide, slightly crescentric, tenth two times wider than long; XI fusiform; metasternum broadly concave; middle legs with trochanters lunate, produced mesially into a thick, acute tooth; middle femora inflated, with the ventral face obliquely notched to produce an apically directed tooth; middle tibiae with a large, strongly curved spine at internal-apical angle. Female with antennal segments VIII, IX and X quadrate; metasternum not concave; middle legs simple. $2.6 \mathrm{~mm} . . . \ldots \ldots \ldots \ldots \ldots$............... 
Male with segments of antennae III, IV, and VI two times longer than wide; V and VII three times longer than wide; VIII one-half longer than wide; IX slightly longer than eighth; $\mathrm{X}$ two times longer than ninth; XI fusiform, slightly sinuate, truncate at base; middle legs with trochanters more strongly lunate and mesially toothed; middle femora gibbous but not ventrally toothed at middle; middle tibiae slightly notched apically but not having the large, recurved spine at apex. $2.6 \mathrm{~mm}$. Female unknown................crassipes

crassipes Raffray. 1904. Bolivia.

hamata Raffray. 1904. Bolivia. Genotype.

XYBARIDA (Raffray, 1896)

RAFFraY (1896, 1904, 1908)

This small brachyglutine genus of only four species is widely distributed from southern Brazil, the Panama Canal Zone, into Yucatan. The species agree in having a short, globiform body and one species at least may be a facultative synoekete of a species of termite. The genus is structurally related to Scalenarthrus, Xybaris and their allies. The four known species may be isolated by the following key:

Antennal segment IX wider than long.................. 2

Antennal segment IX longer than wide........nasicola new species

2. Pronotum with a very minute, punctiform, median fovea at base....

Pronotum with no median pronotal fovea............ punctulum

3. Known only from southern Brazil..................clavata

Known only from Yucatan....................... pusilla

\section{Xybarida nasicola new species}

Holotype Male. Measurements: head 0.23 x $0.30 \mathrm{~mm}$; antennae 0.67 $\mathrm{mm}$.; pronotum $0.30 \times 0.35 \mathrm{~mm}$.; elytra $0.53 \times 0.53 \mathrm{~mm}$; abdomen $0.33 \times 0.50$ $\mathrm{mm}$.; total length $1.4 \mathrm{~mm}$.; greatest width $0.53 \mathrm{~mm}$. (Pl. VII)

Body subglobular, light reddish-brown, moderately shining, and punctulate with vertex and occiput more strongly punctate; pubescence short $(0.02 \mathrm{~mm}$. long), sparse, golden. Eyes prominent, consisting of about 34 small facets each, and $0.067 \mathrm{~mm}$. long. Tempora one-half longer than eye, and convergent to subtruncate occiput. Occiput, vertex, and epistome punctate and pubescent, semi-shining and in strong contrast to the glabrous, shining cervicum. Vertex convex between the vertexal foveae, which are small, about equal to an eye facet in diameter, and nearer the eyes than to each other. No circumambient interocular sulcus, but front between the antennal bases, and behind the rounded frontal margin, broadly, shallowly concave. Front simple, gradually declivous to epistome. Epistome elongate, roughly punctate and with longer pubescence, its apical margin strongly rounded and convex. Labrum prominent as a semilunar, subdetached plate. Mandibles conspicuous, left crossed over 
right, in an arc the length of the labrum removed from the head. Ventral surface of the head flattened, subglabrous, flask-shaped in outline and strongly marked by: (1) a high, thin, median, longitudinal carina; (2) a strong lateral carina, each side, which is straight and internally directed from base of mandible to base of maxilla, then arcuate externally to a point beneath occiput and finally internally arcuate to base of head; (3) a posteriorly arcuate, ocular carina from near the anterior margin of each eye to the median part of the lateral carina (Pl. VII, 10).

Maxillary palpi relatively long and slender, four-segmented; first segment minute; second strongly arcuate, basally slender, and apically inflated, slightly compressed laterally; third short, subtriangular, with the lateral face very convex; fourth very long and slender, wider than third and longer than second, obliquely truncate at base, narrowing gradually to acute apex, the apex bearing a long, obtuse, obliquely placed palpal cone, and of especial note: this fourth segment has an oblique, short, median scar or carniform line on the exteral face.

Antennae eleven-segmented, widely separated at base by almost the width of the head, not including eyes; segment I subquadrate, obonical, wider and slightly shorter than second; II elongate-cylindrical; III narrower and as long as second, obconical; IV, VI and VIII shorter than V or VII but subequal in width, obconical to conical; IX elongate-obconical, distinctly longer than wide, and longer than either seventh or tenth; $\mathrm{X}$ cylindrical, distinctly shorter than ninth; XI forming the club, relatively large $(0.17 \times 0.08 \mathrm{~mm}$.) and as long as eighth, ninth, and tenth united, subasperate.

Pronotum simple, with neither lateral nor median foveae.

Elytra with obtusely elevated humeri; each elytron with four, very minute, shallow points replacing the foveae, and an obliquely transverse basal carina just anteriad of these discrete foveal points, a faint sutural stria but no dorsal stria. Elytral flank simple.

Abdomen with a distinct, but very narrow margin. Five visible tergites of which the first is elongate $(0.17 \mathrm{~mm}$. long), as long as second and third united, with two very small, inconspicuous, straight, parallel carinae at base which are one-eighth as long as segment and separated by a little more than one-fourth of the segmental width. Second tergite very slightly longer than third. Fourth tergite about as long as third, vertical and not fully visible from above. Fifth tergite obliquely ventral, wholly invisible from above, distinctly longer than fourth, but not quite twice as long as fourth tergite, apical margin slightly sinuate laterally and subtruncate at median fifth of width.

Five sternites visible medianly and six sternites visible laterally, the first of these being invisible beneath the metasternum medianly between the distant posterior coxae, but visible laterally near each elytron, as an elongate-acute triangle. Second sternite very long laterally, becoming shorter medianly and concave where it is as long as the third and fourth united, and bearing each side at lateral third a longitudinally arcuate carina which arises on the basal half of the first sternite and extends through apical half of second. Third sternite medianly tumid, a little longer than fourth. Fourth sternite flattened and sub- 
truncate medianly. Fifth sternite as long as fourth and modified: excavated in median third and laterally the side of the excavation is erected into a prominent, triangular, setose cusp. Sixth sternite as long as fourth and fifth sternites united, granular, with the median third triangularly excavated and almost vertical, that is, this excavation is at right angles to the excavation of the fifth sternite, and covered with very short, dense setae forming a setose pad.

Metasternum glabrous laterally and pubescent medianly; medianly broadly concave with tumid margins.

Anterior femora inflated, flattened on ventral face, with a longitudinal sulcus partially developed on this flattened surface; intermediate femora less inflated, simply flattened ventrally; posterior femora normal.

Anterior legs with each trochanter bearing a thin, arcuate spine about as long as the trochanter.

Tarsi three-segmented; first tarsomere very short; second and third much longer, with the second very long on the intermediate and posterior legs, where it is twice as long as third tarsomere; third bearing distally a claw one-third as long as tarsomere. The anterior tarsi are secondarily modified: the second tarsomere is relatively shorter, and much thicker than this segment in the other legs, and the ventral face is flattened and bears stiff setae. This thickened condition is not to be confused with the wider second tarsomere of males of related genera. In the latter the segment is wide and thin; here it is thick and not much wider than the third, and the setae of the ventral face do not form a dense, short, setose pad.

Allotype Female. As for holotype with the following differences:

Integument uniformly lightly punctulate.

Eye relatively a little larger, about equal to the tempora in length, but of the same number of facets, the facets a little coarser. Mandibles smaller. Ventral surface of head and maxillary palpi as in holotype.

Antennae a little shorter and thicker, segments III to VIII subequal in width; IV slightly shorter than third or fifth; V, VI, and VII subequal in length; IX elongate-obconical, longer than eighth or tenth; $\mathrm{X}$ distinctly shorter than ninth, obconical; XI relatively large, as long as eighth, ninth, and tenth united, subasperate.

Pronotum and elytra as in holotype.

Fifth tergite relatively shorter, about one-third longer than fourth and subtriangular in outline.

Second sternite (first visible medianly) relatively longer, longer than the next three united, these latter simple, convex, very short. Last sternite (fifth visible medianly) long, almost as long as first visible, transversely semilunar, with basal margin convex and apical margin concave, investing the convex apical margin of fifth tergite, more coarsely punctate than other sternites and medianly tumid.

Legs with femora not inflated, and trochanters simple, not armed. Second tarsomere of anterior tarsi not thickened and not ventrally setose.

Metasternum not medianly concave, but distinctly tumid medianly. 
Described on two specimens, collected by the author on Barro Colorado Island, Gatun Lake, Panama Canal Zone. Holotype male on July 5, 1936, in the gallery of the termite, Nasutitermes ephratae (Holmgren) in a log at Armour 8. Allotype female on June 30, 1936, at a light at 10:00 p.m.

I associate the female with the male on the very close agreement in numerous structural details, including the peculiar modification of the distal segment of the maxillary palpi. The two sexes are readily told apart by the antennae, last sternite and male armature of the trochanters, anterior tarsi, metasternum and numerous other points.

Since the male was taken within the darkness of the termite nest $14: 00$ p.m.), while the female was taken at night, there is indirect evidence that (1) the species may be a facultative synoekete, and (2) the species follows the family rule of nocturnality. With respect to the former, the beetle was not seen to be molested by the termites in any way. Regarding this species, Professor Emerson, who identified all host termites in this study, has the following communication on the possible host:

\begin{abstract}
"Nasutitermes ephratae (Holmgren) and Nasutitermes corniger (Motschulsky) are the two most commonly collected termites on Barro Colorado Island, not because they are the most abundant, although they are actually numerous, but because they also build conspicuous nests and covered tunnels, so they stand out a little more in the general landscape than some other species which are actually more numerous, but live in relatively concealed places.

Two other species of the same genus also occur on the island, Nasutitermes columbicus and Nasutitermes nigriceps. $N$. ephratae was originally described from Surinam and is common throughout South and Central America from the Amazon region north. N.corniger was originally described from Panama and is common on the Pacific coast of South America, and Central America on both coasts. It has a very closely related species, N.costalis in the West Indies and northern South America, east of the Andes and from the Amazon valley north."
\end{abstract}

Xybarida nasicola does not appear to have the behavior, or the peculiar morphological extravagances of symphilic beetles, but on the other hand appears to be perfectly at home, and tolerated by the termites so that we may assign it the role of a synoekete pending further information.

This species does not appear to be even closely related to other species of the genus. The genus may be listed as follows:

clavata Raffray. 1896. Brazil. Genotype.

nasicola new species. Panama Canal Zone.

punctulum Raffray. 1904. Brazil.

pusilla (Schaufuss). 1879. Mexico. (Bryaxis)

\title{
BERDURA (Reitter, 1881)
}

This is a small genus with abnormal maxillary palpi, found in the Antilles and the Panama Canal Zone. It has affinities with Scalenarthrus of the neotropical fauna on the one hand, and also with the monotypic Berlara crassipalpis Reitter of Java. The combination of distant posterior coxae, ventral 
surface of head with a median longitudinal carina, eleven-segmented antennae, first two tergites distinctly margined, and the distal segment of maxillary palpi provided with a tooth on the external face separate the two species from other neotropical genera in this tribe.

The two species may be quickly separated as follows (Pl. VII, 4, 5):

Distal (fourth) segment of maxillary palpi with a minute, acute tooth on external face at apical third...................excisula

Distal (fourth) segment of maxillary palpi with a minute, rounded tubercle on external face at basal third.... dentipalpa new species

\section{Berdura dentipalpa new species}

Type. Measurements: head $0.20 \times 0.26 \mathrm{~mm}$; antennae $0.335 \mathrm{~mm}$.; pronotum $0.23 \times 0.30 \mathrm{~mm}$.; elytra $0.40 \times 0.44 \mathrm{~mm}$.; abdomen $0.15 \times 0.43 \mathrm{~mm}$.; total length $1.0 \mathrm{~mm}$.; greatest width $0.44 \mathrm{~mm}$. (Pl. VII)

Body subglobular, shining, reddish-brown; integument lightly punctulate, with short pubescence $(0.017$ to $0.022 \mathrm{~mm}$.). Eyes below level of vertex, subcircular from lateral view, of twenty-eight coarse facets, $0.067 \mathrm{~mm}$. through long diameter, longer than tempora; tempora slightly convergent to occiput; occiput truncate and slightly swollen to level of vertex; vertex slightly, evenly convex, with two foveae on a line through middle of the eyes; vertexal foveae small but distinct, equal in diameter to an eye facet, not connected by any sulcus; front angularly produced but declivous between antennal bases, no elevated frontal rim or margin; epistome unmodified, pubescent. Ventral surface of head and ventral surface of cervicum finely alutaceous. Dorsal surface of cervicum glabrous. Ventral surface of head medianly concave, and with stout carinae as follows: (1) a median, longitudinal, laminoid carina; (2) a strong, biarcuate lateral carina each side from base of maxilla to posterior area of head; (3) a short, strong, obliquely vertical carina which arises at the middle of the ventral margin of each eye (Pl. VII, 12) and drops in a straight line to join the lateral carina at its most external arc, quite different to the homologous carina of Xybarida nasicola in its course.

Maxillary palpi four-segmented; first segment minute and obconical; second elongate, arcuate, basally slender and only moderately inflated apically; third short, subtriangular; fourth longer than second and wider than third, conical-ovate in outline, with the base rounded and apex very rapidly acute and bearing a long, obtuse, obliquely inserted palpal cone. The external face of this distal segment bears a small, rounded tubercle as basal third (Pl. VII, 4).

Antennae eleven-segmented, rather short, widely separated at bases; segment I arcuate cylindrical; II ovate, as long and as wide as first from dorsal view, but shorter from lateral view due to the overhang of the antennal acetabulum; III obconical, much smaller than second; IV to VIII subequal in size, submoniliform, small and closely articulated; IX transverse, as long as eighth but wider; $\mathrm{X}$ wider than ninth and slightly longer; XI relatively large, twice as wide as tenth and nearly as long as fifth to tenth segments inclusive united, very 
hirsute, flattened dorso-ventrally when seen from the side, and with a distinct sinuation on the internal face at apical third.

Pronotum with neither subbasal lateral, nor basal median foveae.

Each elytron with an obtusely elevated humerus, an entire sutural stria, no trace of a dorsal stria, flank simple, base transversely carinate with four minute basal foveal points just posteriad of the basal transverse carina.

Abdomen with five visible tergites, only the first two being fully visible from above, the next two more or less vertical and the last ventral in position. Lateral margins narrow, but well-developed on the first three segments. First tergite twice as long as second, with a pair of straight, parallel basal carinae almost half as long as the segment and separated by one-fourth the segmental width. Second a little longer than third; third and fourth subequal in length. Fifth tergite twice as long as fourth, nearly semicircular, tumid, rather coarsely punctate.

Abdomen with five sternites visible medianly; first long, one-fourth longer than the next three united, the latter short, subequal in length. First visible with a lateral fovea on each side immediately posterior to the mesial angle of the posterior coxae, and with its orifice directed toward the lateral margin. Fifth visible (last) sternite one-half the length of the first visible sternite, transversely tumid, rather coarsely punctate and closely in contact with the apical margin of the fifth tergite.

Mesosternum very transversely elevated at middle into an angulated carinoid wing above each middle coxa; mesosternum broadly introduced between the middle coxae as a truncate plate; middle coxae distant.

Metasternum slightly longer than first visible ventral, simple, not concave; produced medianly into a broad, truncate plate between the very distant posterior coxae.

Legs simple.

Described from a single female specimen, the type, collected by the author on Barro Colorado Island, Gatun Lake, Panama Canal Zone, at a light at night, on July 7, 1936.

excisula Reitter. 1883. St. Thomas, Virgin Islands. Genotype.

dentipalpa new species. Panama Canal Zone.

SCALENARTHRUS (LeConte, 1880)

LeConte (1880)

LeConte and Horn (1883)

Brendel and Wickham (1890)

RAFFrAY $(1904,1908,1911,1912)$

Fletcher (1928)

BowMan (1934)

Schaufuss (1887) (Cylindrembolus; Bryaxis in part)

Schaufuss (1879) (Bryaxis)

RAFFraY (1890) (Abryxis)

RAFFRAY (1896) (Eupines) 
From the above references it will be seen that this genus has been given considerable attention, and second, that between the original description of the genus by LeConte in 1880 and the final congeneric elucidation by Raffray in 1904, the genus in its modern sense was not understood, the neotropical species being known under some four different names; as late as 1896, Raffray placed a Mexican species, clavicornis, in the purely Australo-Asiatic Eupines.

At the present time this important genus includes American species only, having in common: (1) short, globular to subglobular body, (2) ventral surface of head with a median, longitudinal carina, (3) maxillary palpi not abnormally formed, but simple and regular, (4) antennae eleven-segmented, often abnormal, (5) pronotum with neither lateral nor median foveae, in rare cases a minute, indistinct punctiform basal impression (inflatus), (6) each elytron with four punctiform foveal points replacing the basal foveae, and with no trace of a dorsal stria, (7) abdomen with a relatively long first tergite, and the first two to three tergites distinctly, but narrowly margined, (8) first sternite invisible medianly, and wholly covered at this point by the metasternum, (9) intermediate coxae distant, the mesosternum advanced between them as a flat, truncate plate, (10) posterior coxae very distant.

The males generally have the epistome diversely elevated and armed, but this is not an absolute criterion since some species have the epistome simple in the male, and in other species only the male sex is known. The antennae are usually abnormal in the male sex, but again this is not an absolute criterion. In one group the males have the second segment of the anterior tarsi expanded. Sex, then, is best determined by either direct dissection, or by examination of the genital structures in cleared microscope slide-mounts. On triangle-mounts specimens having the epistome or antennae abnormal, or both, are probably males. The metasternum may be either concave or convex in the males.

The genus is of interest to the zoögeographer. At present there are eighteen known species. The genotype, horni LeConte, is North American, distributed from southern California to Arizona, and is presumably derived from the Mexican fauna. Of the remaining seventeen species, three inhabit the Lesser Antilles, three inhabit South America from the Amazon drainage basin to high elevations in Bolivia, one at the cross-roads in the Panama Canal Zone, and the remaining ten are found from Guatemala and British Honduras to Vera Cruz, Mexico. If these species are all really congeneric, then Mexico, especially Yucatan with at least four species, would seem to be the center of distribution, with one migration route to the north-west into the arid southwestern United States, a second through the Canal Zone into South America, and a third over a now submerged connection with the Antilles. Much expeditionary work needs to be done before a clear picture can be presented. It should be noted that the related Berdura, as well as the Hybocephaline Ephimia among others, have species found in the Lesser Antilles and the Canal Zone. In Scalenarthrus the genus in general is Central American, with Antillean as well as South American and North American exponents. 
Raffray (1904) divided the genus into four groups, and his key to these groups has been followed, save that its expansion by the addition of a new group for a remarkable new species, necessitated some alteration:

\section{Key to the Groups, Based on males}

Eleventh antennal segment simple, ovate to elongate-ovate in form, or at most slightly sinuate on interal face near apex, often as long as

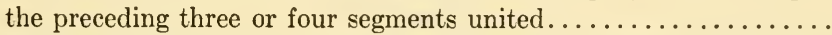

Eleventh, tenth, and ninth antennal segments abnormal in shape or

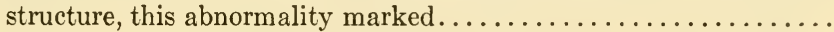

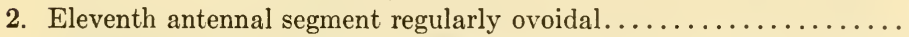

Eleventh antennal segment irregularly ovoidal, and very obliquely truncate at base.............................. III

3. First visible tergite with two thin, short basal carinae separated by one-fourth the segmental width....................... I

First visible tergite with no basal carinae visible........ Group II

4. Ninth antennal segment not as large as tenth........... Group IV Ninth antennal segment much larger than tenth. GRoup V, new group

\section{Alternative GROUP KEY BASED ON MALES}

Eleventh antennal segment simple, ovate to elongate-ovate in form, and never abnormal in either sex save a slight sinuation on internal face near apex (concavus) or a very slightly oblique base (simplex)

Ninth, Tenth, and Eleventh antennal segments distinctly abnormal

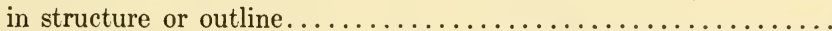

2. First visible tergite with two thin, short basal carinae separated by one-fourth the segmental width........................ I

First visible tergite with no basal carinae............ Group II

3. Eleventh antennal segment very obliquely and arcuately truncate at base, this obliquity paralleling the convex, arcuate apical margin of the tenth segment, and the eleventh segment, therefore, having an acutely produced basal external angle, with the external face of the segment being longer than the internal face; known only from Mexico; female with regularly ovate distal antennal segment........

Abnormality of the antennal club very pronounced, but not identical

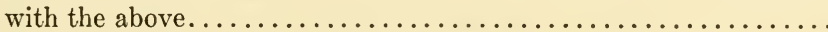

4. Ninth antennal segment not as large as tenth segment.... Group IV Ninth antennal segment very much larger than tenth antennal segment; known from the Panama Canal Zone... Group V, new group

\section{Group I}

Known only from Brazil......................marginalis

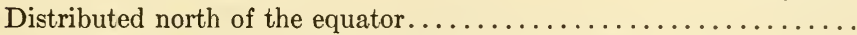


2. Antennal segment III subconical, IV-VIII quadrate, IX transverse, $\mathrm{X}$ trapezoidal, less transverse than ninth, XI short, ovate; known only from Yucatan........................ subcarinatus

Antennal segment III-VIII moniliform, IX quadrate, $\mathrm{X}$ transversely oblique and triangular and wider internally, XI large, ovate; known only from the Lesser Antilles.................guadelupensis

\section{Group II}

First visible sternite between the posterior coxae minutely carinate; frontal sulcus obsolete or quite shallow medianly.............

First visible sternite between the posterior coxae not at all carinate, but broadly concave; the transverse frontal sulcus equally deep for

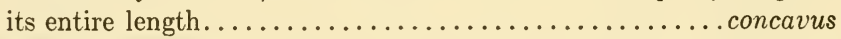

2. Antennal segment IX briefly obconical, IX ovate-elongate, as long as the preceding four segments united.................schaufussi Antennal segment IX transverse, IX large, ovate, the base very slightly subobliquely truncate (showing an affinity for Group III in this feature), and as long as the five preceding segments united.... simplex

\section{Group III}

Known only from a single species, obliquus, from Guanajuato, Mexico, but fortunately both sexes have been described. Length 1.2-1.25 $\mathrm{mm}$. The female has the eleventh antennal segment relatively small, as long as the four preceding segments united, and regularly ovate in shape. The male has the last three segments abnormal in shape, and appears to the author to be misplaced in Raffray's key, since the abnormalities of the antennal club would seem to place the group under step " 4 " of our key, rather than step " 2 "; however the degree of abnormality is much less than in the fourth and fifth groups. The male obliquus has the ninth antennal segment broadly transverse, with the mesial face simply convex and the lateral face narrowly acute at the distal angle; tenth segment very much more transverse and shorter than ninth, with the mesial face convex and the lateral face very narrowly produced and acute; eleventh antennal segment as long as the preceding five segments united, with a very obliquely truncate base, this obliquity following the arc of the distal margin of the tenth segment, and with the external basal angle of the segment very acute, thus the lateral face of the segment is distinctly longer than the subsinuate mesial face. Because of this abnormal club an alternative key to the groups of Scalenarthrus is given which departs still further from the Raffrayan pattern, but may serve to check one's group allocations.

\section{Group IV}

This the largest group in the genus and holds many remarkable antennal modifications. The following key to males, unless otherwise stated, does not 
take into account two species, separabilis (Schaufuss) and adparatus (Schaufuss), both from Yucatan.

Known only from the Lesser Antilles, and separable from the other species by remarkable male antennae described below...........

Not known from the Antilles, and male antennal modifications of a much different character, as described below................

2. Eleventh antennal segment longer than segments $\mathrm{I}$ to $\mathrm{X}$ inclusive united, and over twice as wide as first segment; this eleventh segment with an oblique, ovate fovea at basal third, and of a unique shape, obliquely truncate at base, obtusely rounded at apex, strongly sinuate medianly, with the internal face broadly concave and the external face angulate-convex; $1.0 \mathrm{~mm}$. long; known from Grenada

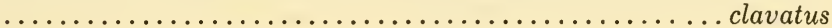

Eleventh antennal segment ovate, slightly sinuate, base roundedtruncate, apex acute, as long as the four preceding segments united; segment $\mathrm{X}$ as wide as eleventh, very transverse with the external face straight and the internal face obliquely produced to form an acute apical internal angle; IX much smaller than either tenth or eighth, with the internal face acute; VII and VIII subspherical, each with a long appendage or spine arising from the internal face; 1.25 mm. long; known from Grenada.................pectinicornis

3. The vertexal foveae free, not connected in any way with the transverse

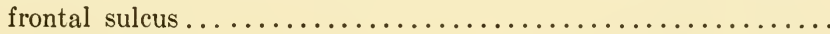

The vertexal foveae connected with the transverse frontal sulcus or impression by a fine, shallow arcuate inter-foveal sulcus.........

4. Antennal segment III obconic; IV to VII more transverse; VIII-XI abruptly wider to form the antennal club; $\mathrm{X}$ with a distinct blunt tooth which arises from the internal apical angle of segment and extends distally, almost reaching the excavation of the eleventh segment; XI longer than the four preceding segments united, lateral face straight for basal two-thirds and then very oblique to the obtuse apex, the internal face irregularly convex, surface with a deep transverse excavation which lies in a part of the basal half, this excavation with a small acute tooth on the inner basal edge provided with a dense brush of setae; length $1.0 \mathrm{~mm}$.; known from Guatemala and British Honduras ............................ globosus

Antennal segment III-VII moniliform, not transverse; VIII slightly transverse; IX slightly wider, lenticular; $\mathrm{X}$ strongly transverse and slightly oblique, not toothed; XI very large, almost as long as the third to tenth segments inclusive united, wide, with lateral face convex to internally oblique, subacute apex and mesial face distinctly sinuate at apical third, the entire basal half of the dorsal surface of the segment deeply excavated; length $1.2 \mathrm{~mm}$.; known from Mexico

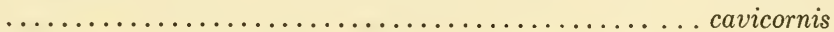

5. Antennal segment XI almost as long as the six preceding segments 
united, with outer basal angle forming a tooth which projects posteriorly to slightly overlap the tenth segment; this eleventh segment remarkable for the extent of excavation, the entire surface is excavated save for an elongate area at mesial apical face; $1.2 \mathrm{~mm}$. long; Vera Cruz, Ver., Mexico....................... inflatus Antennal segment XI with a transverse excavation which occupies

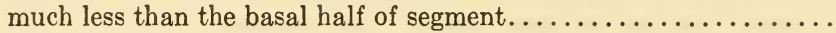

6. Antennal segment XI with a distinct subbasal tooth; known from

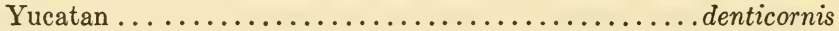
Antennal segment XI with no tooth, but with the basal margin of excavation sharply defined and provided with a long, dense tuft of inwardly directed setae on the inner basal angle; $1.0 \mathrm{~mm}$. long; known from British Honduras ................ ventricosus

\section{Group V New Group}

This new group has been erected for a remarkable new species of the Panama Canal Zone. The key character given for the separation of this species, undecimtympus, is simply a convenient structural feature for rapid separation from the other species in Group IV, and does not by any means indicate the divergence between these two groups. This Panamanian species has the male second tarsomere of the anterior tarsi swollen, flattened below, and provided with a brush of setae, as in the males of Xybaris, Achillia, Bryaxina, Braxyda. This secondary sexual character is not common to Scalenarthrus, and it is possible that the new species belongs in a separate subgenus or even a new genus. It is of interest in this precise connection to point out the parallel in another subglobose, related genus Cryptorhinula, where the anterior tarsi of the males are not dilated save in oedipus (Sharp), where the second tarsomere is peculiarly swollen.

In the essential key characters undecimtypus is Scalenarthrus, with affinities with Pselaptus and Xybaris. Numerous peculiarities will be found in the description which follows, especially the male antennal club and the remarkable air-filled tube on each side of the head.

\section{Scalenarthrus undecimtympus new species}

Holotype Male. Measurements: Head 0.20 x $0.26 \mathrm{~mm}$.; antennae 0.335 $\mathrm{mm}$.; pronotum $0.23 \times 0.30 \mathrm{~mm}$.; elytra $0.40 \times 0.47 \mathrm{~mm}$.; abdomen $0.13 \times 0.40$ $\mathrm{mm}$.; total length $1.00 \mathrm{~mm}$; greatest width $0.47 \mathrm{~mm}$. (Pl. VII, 2, 3, 12)

Body subglobular, light yellowish-brown, moderately shining, very lightly punctulate; pubescence rather short $(0.01 \mathrm{~mm}$. on pronotum and $0.022 \mathrm{~mm}$. on elytra), inconspicuous save under high magnification but rather abundant. Head subquadrate from a dorsal view, with prominent eyes. Eyes with about twentyfour coarse facets, relatively long $(0.09 \mathrm{~mm}$.), more than twice as long as the convergent tempora which are short $(0.04 \mathrm{~mm}$.). Vertex flattened, higher than 
eyes, with a pair of small, distinct vertexal foveae, each nearer an eye than to each other and distinctly less in diameter than an eye facet. No circumambient sulcus connecting the vertexal foveae. Front between antennal bases indistinctly impressed, and anterior to antennal bases triangularly declivous to the simple, nearly vertical, hirsute epistome. Labrum rather small and simple. Mandibles conspicuous, each with a distinct, obliquely truncate tooth or boss at base on the external face. Ventral face of head with a median, longitudinal carina, a biarcuate lateral carina on each side, and a short, straight carina from middle of ventral margin of each eye to lateral carina, joining the latter at a right angle. (Pl. VII, 12)

Maxillary palpi four-segmented, normal, first segment minute and cylindrical; second elongate, arcuate, basally slender and inflated in distal third; third short, one-third as long as second and slightly wider than second, subtriangular; fourth longer than second and wider than third, elongate-ovate, obliquely truncate at base, apex subtruncate slightly, with a palpal cone at apex.

Antennae widely separated at base, eleven-segmented, abnormal, segments I and II subovate, relatively large, subequal from dorsal view; III obconical, shorter and narrower than second; IV to VII subequal in width, transverse, shorter than third, closely articulated; VIII subtrapezoidal, a little wider than seventh; IX transverse, asymmetrically triangular from a dorsal view and quadrate from a posterior view, distinctly wider and longer than tenth, the quadrate posterior face with a broad, shallow fovea; $\mathrm{X}$ small and inconspicuous, very transverse, much narrower and shorter than ninth, asymmetrically trapezoidal; XI one-half wider than ninth and as long as fourth to ninth inclusive united, $0.107 \mathrm{~mm}$. long, truncate at base, subovate with a short, blunt apex, nearly as wide as long. This eleventh segment is excavated on the internal face at apical third and on the dorsal face near the base is a conspicuous, circular, raised table or drum-shaped tubercle.

Pronotum slightly wider than long; basal margin slightly medianly produced or sinuate; base of pronotum with no foveae, neither lateral nor basal. The positions usually occupied by lateral and median foveae are indicated by darkened areas of the integument.

Elytra with humeri obliquely elevated; each elytron with an entire sutural stria, no trace of a dorsal stria, flank simple, the base with four small basal foveae.

Abdomen with five visible tergites, only the first two of which are to be seen from a dorsal view; first three tergites narrowly but distinctly margined. First tergite as long as second and third united, with a pair of straight, parallel basal carinae separated by one-fourth of the segmental width and almost onehalf as long as segment. Second tergite and fourth subequal in length, longer than third. Fifth as long as the third and fourth united, apical margin roundedtriangular in outline.

Five sternites visible medianly, the first of these as long as the second to the fifth inclusive united; second, third, and fourth very short and inconspicuous; fifth relatively large, three-fourths the length of the first visible sternite, 
slightly tumid with a deep, subtriangular excavation in basal half occupying one-sixth of the segmental width.

Mesosternum advanced between the distant intermediate coxae as a subtruncate plate, this plate densely pubescent.

Metasternum slightly longer than first visible sternite, evenly and simply convex, posteriorly truncate between the very widely separated posterior coxae. Sternal foveae IV well developed, one at each lateral angle of an intermediate coxal cavity, the mesial wall of the fovea recessed by a longitudinally arcuate carina which extends from this point posteriorly for almost one-half the metasternal length. The metasternum medianly advanced between the intermediate coxae, meeting the mesosternal process, and like the latter pubescent in this restricted area. This pubescent intercoxal region is elevated above the plane of the metasternum and the paired sternal foveae VI lie just posterior to the elevation. The posterior walls of the intermediate coxal cavities are strongly beaded, this bead forming the anterior margin of the metasternum at this point and continuous with the intercoxal extension mesially and continuous with the longitudinal metasternal carina laterally.

Anterior femora strongly inflated; intermediate and posterior femora not inflated. Anterior and intermediate tibiae normal; posterior tibiae thickened in apical half and strongly arcuate internally. Trochanters and coxae not armed. Anterior tarsi with second tarsomere dilated and flattened, the ventral face provided with a brush of short oblique setae; intermediate and posterior tarsi normally developed and slender.

Examination of a male paratype, cleared and mounted in balsam, reveals additional structural details not appreciable in a triangle mount: (1) The labrum is seen to have two minute acute teeth which arise from the ventral surface and extend anteriorly slightly beyond the distal margin; (2) The obliquely truncate tooth at external base of each mandible has several convergent pore canals which extend into the integument as fine invaginations. These canals suggest a sensory function for this mandibular boss; (3) On each side of the head, between the antennal base and the eye, the integument is invaginated obliquely to form a long subpyramidal tube. This air-filled tube courses beneath the vertexal integument to end blindly near each vertexal fovea. As far as I know, this tubular extension is unique. It does not have any discernible connection with the vertexal fovea, nor with the arm of the supratentorium which connects the floor of the vertexal fovea with the floor of the gular fovea of each side; (4) The gular foveae are two in number and widely separated, one on each side of the extreme base of the longitudinal median carina of the ventral surface of the head, and clearly connected with the vertexal foveae by the supratentorium; (5) The circular, flat-topped, drum-shaped boss of the eleventh antennal segment is seen to have thin walls and apparently extends deeply into the substance of this segment; (6) The four basal elytral foveae are seen as minute, deep cylindrical foveae penetrating the elytral integument; (7) The true first sternite of other tribes is visible as a narrow, wide membranous sclerite between the posterior coxae, and wholly covered by the metasternum; (8) The penis is 
relatively large, bilaterally asymmetrical and in repose lies with its base at the base of the abdomen and its long axis parallel with the long axis of the body. The penis is as long as visible sternites I to V inclusive united. In actual size it is $0.25 \mathrm{~mm}$. long by $0.06 \mathrm{~mm}$. wide through the rounded basal bulb; (9) The tarsal pad consists of eight rows of oblique setae, with fourteen setae per row or one hundred and twelve setae in all.

Described from two male specimens collected by the author at light at night, on Barro Colorado Island, Gatun Lake, Panama Canal Zone as follows: holotype July 17,1936 , and paratype July 7,1936 . The many novel structural features readily separate this new species from others of the genus. The species of the genus may be listed as follows:

\section{Group I}

guadelupensis Raffray. 1912. Guadeloupe, Leeward Islands. marginalis (Schaufuss). 1887. Brazil. (Bryaxis)

subcarinatus Raffray. 1904. Mexico.

\section{Group II}

concavus Fletcher. 1928. British Honduras and Guatemala. schaufussi Raffray. 1904. Brazil. simplex Raffray. 1904. Bolivia.

\section{Group III}

obliquus Raffray. 1904. Mexico.

\section{Group IV}

adparatus (Schaufuss). 1887. Mexico. cavicornis (Raffray). 1896. Mexico. (Eupines) (clavicornis of Raffray, 1904, 1908)

clavatus Raffray. 1904. Grenada, Windward Islands. denticornis (Schaufuss). Mexico. (Bryaxis, 1879) (Abryxis of Raffray) globosus Fletcher. 1928. British Honduras and Guatemala. inflatus Fletcher. 1928. Mexico.

Pectinicornis Raffray. 1904. St. Vincent, Windward Islands. separabilis (Schaufuss). 1887. Mexico. (Bryaxis) (Abryxis of Raffray) ventricosus Fletcher. 1928. British Honduras.

\section{Group V new group}

undecimtympus new species. Panama Canal Zone.

\section{PSELAPTUS (LeConte, 1880)}

LeConte (1880)

Sharp (1887)

Brendel and Wick ham (1890) 


\section{CASEY (1897)}

RAFFrAY $(1891,1896,1900,1904,1908,1911,1912)$

LENG (1920)

Bowman (1934)

This is a genus of moderate size, holding eleven species. The group is wholly neotropical with the exception of the genotype, Pselaptus belfragei LeConte which is distributed sparingly from central Texas to southern California. This latter species has apparently evolved from the Central American group, as the center of the genus appears to be in northern South America, the species having radiated south into Brazil and Argentina, north-east via the Lesser Antilles into Cuba, westward into Venezuela and Columbia and from this point up the Isthmus into Guatemala and Mexico.

The genus is specialized and belongs to a section of the tribe (Xybarida, Berdura, Scalenarthrus, Pselaptus, Mitona, Xybaris, Cryptorhinula) holding species which have many features in common, and very difficult to separate effectually. Pselaptus has been isolated in the key by certain structural characters, from its allies. The size is small (1.0 to $1.4 \mathrm{~mm}$. in length), with smooth integuments which are usually glabrous and shining, but may be dull and unpolished in some species. The metasternum is large and usually concave in the male sex, variously formed. Thus the male politissimus has the metasternum elevated and triangular; in the male sternalis and cristatus the metasternum is concave, and in sternalis at least this concavity is wide, squamous. The females have the metasternum flattened (grouvellei).

The key is both tentative and incomplete, although it will serve to isolate the majority of the known species. I have found that the group of genera clustering about Scalenarthrus is one of the more difficult taxonomic areas in the family, generic limits not being too well drawn and many new species undoubtedly awaiting discovery.

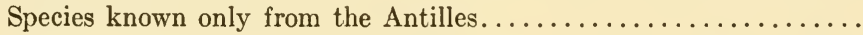

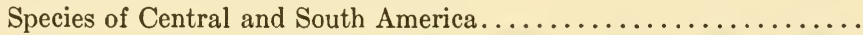

2. Male metasternum large, entirely and deeply concave, with carinoid lateral margins, the concavity provided with squamous pubescence; $1.4 \mathrm{~mm}$. long; known only from the southeastern end of the Antilles

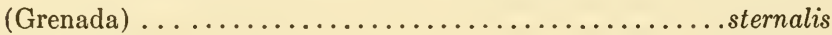

Metasternum not of this character; known only from Cuba. .longiclava

3. Base of pronotum with a fine crest anteriad of scutellum; area of pronotum occupied by lateral subbasal foveae of other genera here occupied by confluent punctures; $1.25 \mathrm{~mm}$. long; known from Mexico and said by Raffray (1904, p. 250) to resemble the Grenadine

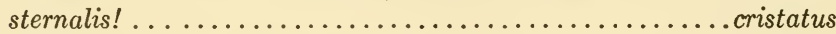

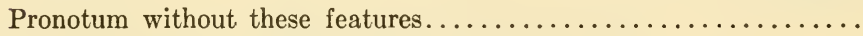

4. Species known only from Guatemala.................. 5

Species known south of the Isthmus of Panama............ 6

5. Antennal segments III-VIII small; IX slightly wider than eighth, quadrate, as long as wide; $\mathrm{X}$ similarly quadrate but larger than 
ninth; known from a single specimen of unspecified sex, probably female; $1.5 \mathrm{~mm}$. long; El Reposo, Guatemala.......... batrisoides Antennal segments III-X small, similar; $1.33 \mathrm{~mm}$. long; based on a male with concave metasternum............... simulatrix ${ }^{1}$

6. Antennae with segments III-VIII slightly progressively shorter; IX and $\mathrm{X}$ subtransverse, slightly larger than eighth and crescentric in form; metasternum slightly flattened; $1.7 \mathrm{~mm}$. long; known from a female from Bahia, Brazil.................... grouvellei

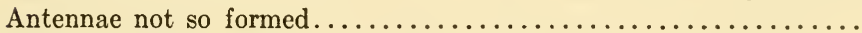

7. Antennal segment $I$ with the dorso-internal angle produced into a tuberculate tooth in the male sex................tuberculifer

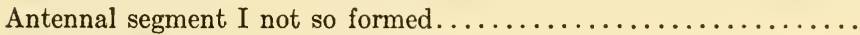

8. Antennal segments III obconical; IV-VIII subelongate-quadrate; IX obconical, twice as long as eighth; $\mathrm{X}$ slightly quadrate; male from San Esteban, Venezuela; $1.5 \mathrm{~mm}$. long..............caloaratus Antennal segments III-VIII longer than wide; IX elongate-obconical;

$\mathrm{X}$ slightly transverse; metasternum elevated and triangular in form; male from Blumenau, Brazil; $1.4 \mathrm{~mm}$. long......... politissimus This key does not take into account formicarius of Colombia. The species may be listed as follows:

batrisoides Sharp. 1887. Guatemala.

calcaratus Raffray. 1891. Venezuela.

cristatus (Schaufuss). 1897. Mexico. (Bryaxis) (Eutrichites by Raffray

in error, cf. 1904, p. 209).

formicarius Raffray. 1900. Colombia.

grouvellei Raffray. 1896. Brazil.

longiclava (Schaufuss). 1887. Cuba. (Bryaxis)

politissimus Raffray. 1904. Brazil.

simulatrix (Sharp). 1887. (Bryaxis). Guatemala.

sternalis Raffray. 1904. Grenada, Windward Islands.

tuberculifer Raffray. 1912. Argentina. (con Atta lundi Guer.)

Buenos Aires, Argentina (Bruch, 1929)

\section{MITONA (Raffray, 1904)}

This genus, allied to the North American Anchylarthron, as well as Xybaris, Pselaptus, and allies, is found in northern and northwestern South America. The mesosternum is bicarinated, and advanced between the middle coxae as a short, flat plate, these coxae distant. Metasternum wide and flattened. The short, subquadrate, slightly convex body, and narrow, slightly elevated abdominal margin is similar to Pselaptus. The complete lack of lateral pronotal foveae separate it from $X y b a r i s$.

The species may be separated as follows:

${ }^{1}$ This species, described by Sharp from Paraiso, Guatemala, may not be Pselaptus at all. Raffray (1908) places it in Pselaptus and states of the genus that there are no pronotal foveae of any kind. Sharp (1887, p. 31) says that the pronotal base is produced in front of scutellum and has a very minute fovea in middle close to the base! 
Antennae with segments V and VI subcylindrical, distinctly longer

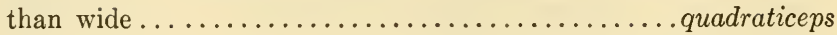

(1.1 mm.; antennal segments I short, quadrate; II elongate-ovate; III-VII subcylindrical; VIII quadrate; IX larger and quadrate; $\mathrm{X}$ twice as large as ninth; XI briefly ovate)

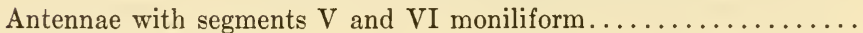

2. First tergite with the two basal, discal carinae divergent, approximate, their apical ends separated by about the distance between the two sutural striae of the elytra, these striae of the first tergite distinct, about one-third of tergite length................ bisulciceps

(1.1 mm.; close to quadraticeps)

First tergite with the two basal, discal carinae very short and in-

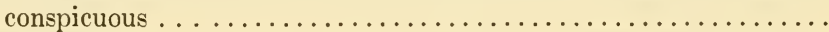

3. Antennae segments VII and VIII moniliform and of same size; IX transverse, slightly wider than eighth; $\mathrm{X}$ twice as large as ninth, subquadrate-transverse. Metasternum flattened.........mniszechi

(1.3 $\mathrm{mm}$. close to nigra)

Antennae with segment VII moniliform, VIII hardly larger than seventh, transverse; IX slightly larger, transverse, slightly acute internally; $\mathrm{X}$ twice as large as IX, slightly transverse. Metasternum posteriorly and widely, subtriangularly impressed........nigra

(1.4 mm. close to mniszechi)

quadraticeps Raffray. 1904. Bolivia. Genotype.

bisulciceps Raffray. 1904. Bolivia.

mniszechi Raffray. 1904. Colombia.

nigra Raffray. 1904. Venezuela.

\section{XYBARIS (Reitter, 1882)}

This is a genus of pselaphids confined to the neotropics. It contains seven species from Brazil and one from the Panama Canal Zone. These eight species all agree in the following: (1) normal maxillary palpi, (2) a median longitudinal carina on the ventral surface of the head, (3) base of pronotum with a lateral fovea each side and a median fovea, (4) two or four well formed foveae at the base of each elytron, (5) the dorsal elytral stria represented by a very faint intrahumeral impression, (6) a narrow abdominal margin, (7) mesosternum produced posteriorly between the mesothoracic coxae as a distinct and truncate plate, (8) metathoracic coxae not conical; and distant from each other, (9) five visible tergites and sternites, the true first sternite invisible between the posterior coxae. These characters separate the members of the genus from all other brachyglutine aggregates.

The sexes may be readily distinguished. The males have the second tarsomere of the anterior tarsi laterally dilated and slightly flattened dorsoventrally and with a conspicuous brush of setae on this flattened ventral sur- 
face; the females have this tarsomere normally formed and not brushy beneath. In addition most of the species have the males with special modifications of the head.

The following species is new. It is the first species of the genus known outside of Brazil, and may form the type of a new genus although I have not followed this latter course as both of the specimens at hand are females.

\section{$X y b a r i s$ funiculis new species}

Cotype Females. Measurements: Head 0.20 x $0.268 \mathrm{~mm}$; antennae 0.40 $\mathrm{mm}$.; pronotum $0.23 \times 0.288 \mathrm{~mm}$.; elytra $0.41 \times 0.536 \mathrm{~mm}$; abdomen from dorsal view only $0.134 \mathrm{~mm}$., in reality the first visible tergite, but the true total abdominal length $0.422 \mathrm{~mm}$; ; total length from strict dorsal view 0.974 $\mathrm{mm}$.; greatest width $0.536 \mathrm{~mm}$. (Pl. VII)

Body subglobose, yellowish-brown, moderately shining, uniformly punctulate. Pubescence long (setae $0.033 \mathrm{~mm}$.) on elytra and abdomen, stout and yellowish in color; setae slightly shorter on head and pronotum. Pubescence on the whole conspicuous when compared to Scalenarthrus, Berdura, Xybarida with very indistinct pubescence. Head in dorsal outline subtrapezoidal, with the eyes $0.087 \mathrm{~mm}$. long, $0.03 \mathrm{~mm}$. in diameter, and composed of about twentyfour very coarse facets. Tempora $0.033 \mathrm{~mm}$. long. Vertex evenly subconvex, with two large and deep vertexal foveae on a line through the anterior third of the eyes. Each vertexal fovea has the diameter of an eye facet, with nude, cylindrical walls, and separated from the adjacent eye by the foveal diameter. These foveae free, not connected to each other or to the front by a sulcus. A conspicuous transverse cleft arising just posterior to the anterior prominence of each antero-lateral corner of the vertex, and extending medianly to a point opposite each vertexal fovea. Front simple, steeply declivous to the simple, nude epistome. Labrum simple. Mandible simple, left crossed dorsal to right; no external basal tooth. Bases of maxillae relatively wide, and mentum relatively long and narrow. Ventral surface of the head with a high median, longitudinal carina; a biarcuate lateral carina each side; an ocular carina which arises at the anterior margin of the eye, and remains in contact with the eye, to join the lateral carina beneath the middle of each eye. (Pl. VII, 11)

Maxillary palpi normal, four-segmented; first segment minute; second elongate, arcuate, slender at base and inflated apically; third short, subtriangular; fourth longest and widest, obliquely truncate at base, subacute at apex, conico-ovate, bearing an apical palpal cone.

Antennae normal, eleven-segmented, widely separated at base; segments I and II subconical, relatively large; III obconical, smaller than second; IV to VIII closely articulated, subequal, shorter than third; IX transverse, wider than eighth, about as long as eighth; $\mathrm{X}$ wider and longer than ninth, subtrapezoidal; XI relatively large, subasperate, twice as wide as tenth and as long as fourth to tenth inclusive, subovate with a bluntly rounded apex.

Pronotum obcordate with a subbasal lateral fovea on each side and a 
median fovea nearer base, all three foveae distinct and subequal in size, with the median deeper than laterals; base with a row of about twenty coarse punctures just posterior to the median fovea.

Elytra with obliquely prominent humeri; each elytron with the flank simple, an entire sutural stria, and no dorsal stria; base of each elytron with four distinct foveae, each about the size of the median pronotal fovea. Metathoracic wings well developed, translucent, the membranous surface appearing minutely granular in dry specimens; each wing fringed with long setae, the setae being $0.047 \mathrm{~mm}$. in length.

Abdomen with five visible tergites and sternites medianly. Tergite one nearly four times as long as second; third as long as second; fourth about as long as third; fifth transversely, irregularly ovate and not visible from above, with a prominent median longitudinal tubercle on the basal half of length, and with the apical half of the tergite irregularly and medianly depressed near the junction with apical margin of last sternite, its surface more coarsely punctate.

First sternite wholly invisible between the posterior coxae; second sternite (first visible medianly) long, longer than the remaining sternites united; second, third, and fourth visible sternites very short, subequal; fifth visible sternite (true sixth) as long as the two preceding united, with its apical margin medianly produced or emarginate.

Metasternum with a very long, longitudinal carina on each side, arising at the lateral margin of the mesothoracic coxal cavity and extending posteriorly half the distance to the apical margin of the metasternum. This metasternal carina is a very conspicuous feature of the species. Legs simple, typical of genus and of the female sex, with the second tarsomere of the anterior tarsi not dilated and flattened and not bearing a setal brush beneath. The first tarsomere is minute, the second large, the third relatively large but not as long as the second, and bearing a single tarsal claw.

Described from two female specimens, cotypes, collected by the author at light at night, on Barro Colorado Island, Gatun Lake, Panama Canal Zone. One specimen collected the night of July 7, 1936 and one the night of July $17,1936$.

This is a very distinct species. At first these females were thought to be associated with the two males of Scalenarthrus undecimtympus. This association in the field was found to be purely fortuitous when they were analyzed as the conspicuous pubescence, radically different ocular carinae of the ventral surface of the head, and presence of well developed basal pronotal foveae of $X$ ybaris funiculis preclude such a point of view.

The genera clustering around Xybaris are both difficult to separate and not fully appreciated zoögeographically. The carinae of the ventral surface of the head offer excellent material for future study. Thus the lower face of the head, the region bounded by the mandibular bases and mentum apically, the posterior margin of the tempora, and laterally by the eyes is seen to be roughly trapezoidal in outline. On the field are five carinae: a median, longi- 
tudinal carina of varying height, marking the fusion of the mesial margins of the genal sclerites, the primitive gular sclerite not being in evidence; on each side of the median carina is a more or less biarcuate lateral carina which arises near the base of a mandible and extends to the posterior margin of the head; finally, there is a pair of ocular carinae. It is with these ocular carinae that we are especially concerned. They appear to be constant for a species, but show no discernible sexual modification and hence should serve in the separation of closely allied genera. For example (1) in Xybarida nasicola the ocular carina arises anterior to each eye, passes postero-ventrally, and unites with the lateral carina without touching the eye at any point (Pl. VII, $10)$; (2) in Xybaris funiculis the ocular carina arises at the anterior margin of the eye, passes postero-ventrally, and unites with the lateral carina; this ocular carina is in contact with the eye for most of its course (Pl. VII, 11) ; (3) In Berdura dentipalpa and Scalenarthrus undecimtympus the ocular carina arises from the median-ventral margin of the eye and passes ventrally to join the lateral carina at nearly a right angle (Pl. VII, 12).

The eight species of the genus Xybaris may be listed as follows:

spiniceps Reitter. 1882. Sao Paulo, Brazil. Genotype.

triangulifera (Schaufuss). 1887. Minas Geraes, Brazil. (Bryaxis)

sahlbergi Reitter. 1882. Petropolis, Brazil.

quadraticeps Raffray. 1904. Brazil.

atomaria Raffray. 1904. Blumenau, Brazil.

troglocera Reitter. 1882. Brazil.

excisa Raffray. 1909. Sao Paulo, Brazil.

funiculis new species. Panama Canal Zone.

\section{CRYPTORHINULA (Schaufuss, 1887)}

This specialized, wholly neotropical genus is closely allied to Xybaris. The center appears to be in Brazil, the species also being found in Venezuela and as far north as Guatemala.

The head is relatively large, subquadrate, with vertex simple and flattened to slightly vaulted; vertex separated from the front by a transverse, entire sulcus; front usually simple, truncate, and usually transversely elevated between the antennal bases (in some males the front has a median setose tubercle); the two vertexal foveae vary from minute to small and are free; ventral surface of the head with a median, and on each side a lateral, longitudinal carina. Maxillary palpi as in Xybaris. Antennae as in Xybaris save that (a) the second segment is not swollen in Cryptorhinula males and is often swollen or dilated in Xybaris males, and (b) the eleventh antennal segment in the males of some Cryptorhinula is of irregular form and may be toothed at base.

The tarsi are elongate, slender, with the second tarsomere slightly longer than the third, and a little thicker (in oedipus, which may not belong in this genus, the anterior tarsi of the male (?) sex is said to be peculiarly swollen). This condition is normal for the male Xybaris, among other genera, but not typical for Cryptorhinula. 
Other characters, of generic import, are stated in the key to genera.

The species of this genus (with the exception of longiclava) may be tentatively separated as follows:

\section{KeY tO THE SPECIES}

Head with the front having a setose tubercle between the bases of

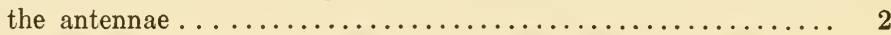

Head with no median setose frontal tubercle................ 3

2. Discal stria of each elytron distinct; head not distinctly and closely punctate.....................nodifera Schaufuss, MALE

(Antennae lacking from the unique type)

Discal stria of each elytron obsolete and very short; head not distinctly punctate................... longiceps Raffray, MALE

(Antennal segment XI large and oval; $1.2 \mathrm{~mm}$. long)

3. Antennae with the last segment (XI) oblong, apex obtuse, base compressed and minutely toothed; head distinctly and densely punctate .schaufussi Raffray, MALE

(1.4 mm. long)

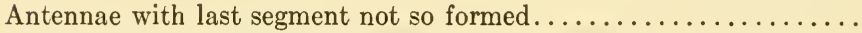

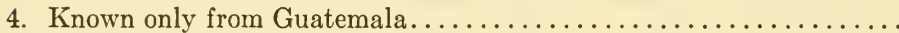

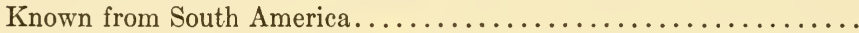

5. First tergite slightly longer than second; $1.3 \mathrm{~mm}$. long; eleventh antennal segment subacuminate and about as long as sixth to tenth segments combined....................trimioides (Sharp)

First tergite nearly twice as long as second; $1.5 \mathrm{~mm}$. long; eleventh antennal segment "very large and acuminate"... oedipus (Sharp)

6. Antennae with segment III obconical, IV-VII moniliform, VIII transverse, IX and $\mathrm{X}$ transversely subquadrate; first tergite with the basal discal carinae slender, slightly divergent, separated by onefourth of the discal width; $1.2 \mathrm{~mm}$. long.

.longiceps Raffray, FeMale

Antennae with segments hardly crescentric (III-VIII); segment III slightly wider than long, VIII slightly transverse, IX and X slightly transverse, larger than eighth and crescentric; first tergite with the basal discal carinae short, parallel, including slightly less than onethird of discal width; $1.2 \mathrm{~mm}$. long........xybaridoides Raffray

The species may be listed as follows:

longiceps Raffray. 1890. Venezuela.

longiclava Raffray. 1890. Brazil.

nodifera Schaufuss. 1887. Brazil. Genotype.

?oedipus (Sharp). 1887. Guatemala. (Bryaxis)

schaufussi Raffray. 1896. Brazil.

?trimioides (Sharp). 1887. Guatemala. (Bryaxis)

xybaridoides Raffray. 1904. Brazil. (nec xybaroides Raffray, 1904, 1908) 


\section{DRASINUS (Raffray, 1904)}

RAFFRAY (1904) (Drasinus, p. 148 and Euteleia in part, p. 183)

RAFFray (1908) (Drasinus)

Fletcher (1928) (Drasinus)

This genus is restricted to the neotropics. It contains at present four species which may be characterized as follows: (1) ventral surface of the head with a strong median, longitudinal carina; (2) antennae with ten segments; (3) maxillary palpi with four segments, of which the last has the external face convex, the internal face slightly concave to straight, and the apex bluntly rounded; (4) mesothoracic coxae slightly but distinctly separated, the mesosternum extending between them as a truncate plate; (5) metathoracic coxae distant from each other; (6) abdomen with the first tergite having a narrow but strongly formed margin; (7) first sternite hidden beneath the coxae and metasternum so that the first visible sternite is morphologically the second.

Raffray (1904, p. 148) in erecting Drasinus states that the intermediate (mesothoracic) coxae are slightly distant; in his generic key (1908, p. 196) Raffray places Drasinus in a group having contiguous intermediate coxae, and later in the same paper $(1908$, p. 226) in discussing the genus notes that the intermediate coxae are slightly distant. The 1908 generic key of Raffray is incorrect and the generic diagnosis of 1904 and 1908 must be followed.

I have placed Drasinus and Decarthron much nearer together than the relative positions given them by Raffray, despite the difference in the ventral surface of the head. This opinion was reached after a study of my own material in both genera and it was a source of satisfaction to discover that Fletcher $(1928$, p. 211) independently had reached the same conclusion.

\section{Key to the Species}

Bluntly rounded apex of fourth segment of maxillary palpus meeting the slightly concave internal face of the segment in an acute angle, the segment being widest near apex (apical fifth) ............

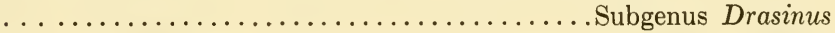

Bluntly rounded apex of fourth segment of maxillary palpus meeting the straight to slightly convex face of the segment in a perfectly rounded, non-angulate contour, the segment being widest nearer the middle (apical four-sevenths of total length) and externally rounded in apical fourth; this segment with a distinct terminal palpal cone............. Subgenus Paradrasinus, new subgenus

2. Known only from Mexico; 1.3-1.4 mm. long; antennal segments III to VII decreasing in length with the seventh quadrate....binodulus Known only from Brazil; $1.2 \mathrm{~mm}$. long; antennal segments IV to IX quadrate . . ........................................

3. Known only from Mexico; $1.5 \mathrm{~mm}$. long; male with the third visible sternite (morphological fourth) medianly tumid, the small tumulus very transverse and simple, provided with a sparse fringe of setae 
(U.S.N.M. paratype, No. 44604) ................... hirsutus

Known only from Panama Canal Zone; 1.2-1.3 mm. long; male with the third visible sternite (morphological fourth) highly modified: four protuberances, two lateral which are relatively low and broad and lightly pubescent, and two median which are relatively high and narrow and each heavily tufted with setae.............. cisinsularis new species

\section{Subgenus Drasinus}

I have given some thought to the composition of Drasinus and am still very dissatisfied. This is largely the result of mistakes and lack of fullness of species descriptions rather than with the original generic concept. As at present organized, all four species would appear to agree well in general habitus, in being closely related to Decarthron, and in having both sexes (as far as described) having the metasternum modified and the posterior tibiae inflated and slightly arcuate in posterior half or third of their length.

In addition to the confusion arising from the incorrect generic key of Raffray (1908) previously alluded to, the chief difficulty appears to lie in the shape of the distal segment of the maxillary palpi. When Raffray described the genus Drasinus $(1904$, p. 148) he gave a clear figure of the maxillary palpus of the genotype binodulus and I have used this as the shape of the palpus in the key to subgenera given above. However, in the same paper (1904, p. 183) Raffray described Euteleia and gave an equally clear figure of the palpus of recens (Schaufuss) the Brazilian genotype. In this second genus Raffray described three new species, Euteleia lewisi, trifoveata and nodosa. In 1908 Raffray took his Euteleia lewisi from this genus and placed it in his Drasinus. Now the cited figure of the fourth segment of the palpus of Euteleia recens (Schaufuss) is radically different from that of Drasinus binodulus Raffray and hence the distinguished French author must have subsequently discovered this error and reassigned lewisi to Drasinus. But the original description of lewisi (1904, pp. 183-184) cites the fourth segment of the palpus as fusiform, which agrees perfectly with that of recens and does not agree with binodulus at all.

I have not seen the genotypes of either of these Raffrayan genera and hence place lewisi Raffray in Drasinus on the assumption that the 1908 position is the true one and that both binodulus and lewisi have similar maxillary palpi.

\section{Subgenus Paradrasinus new subgenus}

I am perfectly satisfied with the composition of this section of Drasinus. I have had the opportunity to study a paratype (U.S.N.M. No. 44604) of the well-described hirsutus Fletcher and this species is wholy congeneric with cisinsularis. Both have similar terminal segments of the maxillary palpi, as described in erecting this new subgenus; both have the male sex with modified sternites. The many differences are of specific, rather than subgeneric rank. 
Drasinus cisinsularis new species

Holotype Male. Measurements: Head 0.189 x 0.308 through the eyes; antennae $0.569 \mathrm{~mm}$.; pronotum $0.276 \times 0.335 \mathrm{~mm}$.; elytra 0.469 v $0.57 \mathrm{~mm}$; abdomen from a dorsal view $0.268 \times 0.53 \mathrm{~mm}$.; first tergite $0.201 \times 0.53 \mathrm{~mm}$.; total length $1.2 \mathrm{~mm}$.; greatest width $0.57 \mathrm{~mm}$.

Body yellowish-brown, moderately shining, clothed with long, flavous, subdecumbent pubescence, very indistinctly punctulate. Head with prominent, large eyes $(0.1 \times .053 \mathrm{~mm}$. $)$ of about 32 very coarse facets. Occipital portion of the vertex simply and transversely gibbous, not medianly carinate. Occipitocervical field transversely sulcate with a sharp but minute longitudinal median carina which does not extend to vertex. Center of vertex very slightly depressed. Two vertexal foveae in a line with the second transverse row of ocular facets; each fovea nude, sharply defined and of the diameter of an ocular facet, neither connected with each other nor with the front by sulci. Sides of head sharply incised by a short, slightly oblique, subpubescent cut just anterior to each eye and hence near the lateral base of each antennal prominence. At the mesial base of each antennal prominence is a small, nude, foveaform pit. These pits, then, form a second, more anterior pair of vertexal foveae and presumably are consequences of the antennal articulation. Front between antennal bases simple and declivous to the clypeus. Clypeus simple, not rugose. Labrum simple, its apical margin slightly concave. Ventral surface of the head subtriangular, with the lateral margins carinated and with a strong median, longitudinal carina, the latter enclosing at its anterior tenth a small subcircular fovea.

Maxillary palpi four-segmented. First segment minute and cylindrical; second long, arcuate, swollen distally; third rounded-triangular with the outer face evenly convex and inner face angulate-convex, short, only about a third as long as second, and as wide as distal portion of second; fourth slightly longer than second, wider than other segments, obliquely truncate at base, outer face convex, inner face nearly straight, apex rounded and obtuse, bearing a small palpal cone.

Antennae ten-segmented; segment I subcylindrical; II subcylindrical with rounded, tapered ends, narrower and shorter than first; III-VII subcylindrical to submoniliform, gradually shorter and gradually slightly narrower; VIII-X forming the club, eighth and ninth of the same subtrapezoidal form with truncate base, oblique divergent sides and subtriangular apex, the eighth larger than seventh and smaller than ninth; distal (tenth) segment about as long as preceding two united and wider than ninth, base truncate, sides convex, apex gradually rounded.

Pronotum wider than head, similar in shape to hirsutus, with three circular subbasal, free, nude foveae, a lateral on each side and a median. Basal margin with a row of coarse punctures.

Elytra with two deep, circular, nude, subbasal foveae on each elytron, the sutural fovea at the origin of the well-marked, entire sutural stria and the discal fovea at the origin of the well-marked discal stria which reaches slightly 
beyond middle of elytral length. Humeri prominent and rounded. Elytral flanks with no subhumeral fovea and no longitudinal carina or stria.

Abdomen with five tergites visible, first with a narrow but strong lateral margin. First tergite as long as other four united, with a pair of slightly divergent discal carinae two-thirds as long as segment and separated by onehalf the segmental width. Five sternites medianly visible, the true first being hidden by the posterior coxae and the metasternum. First visible sternite twice as long as the remaining sternites united; second visible laterally but not medianly; third visible sternite (morphologically the fourth) strongly modified as follows: the segment has four elevations, a lateral pair which are relatively low and broad and lightly pubescent, and a median pair of elevated protuberances which are relatively high and narrow, each of these median elevations bearing a tuft of long setae; fourth visible sternite very short and medianly flattened; fifth visible (last sternite) with the apical margin medianly produced into a rounded lobe and medianly flattened, save at the middle of the basal margin which bears a minute, rounded tubercle.

Mesosternum extended between the intermediate coxae as a subtruncate plate, these coxae therefore clearly separated. Metasternum large, extending between the intermediate coxae as a subtruncate plate to reach the mesosternal extension. Sternal foveae IV and V large and pubescent. Metasternum between pair V slightly tumid and in the shape of a spear-head, with the apex of the spear continuing posteriorly as a median longitudinal striaform depression. The area just anteriad and mesiad of the articulation of the posterior legs also slightly tumid. Metaepisternal-metasternal sutures and metaepisternal sclerites well-formed. Posterior coxae distant.

Anterior and intermediate legs simple; posterior tibiae slightly swollen and slightly arcuate in apical third, with the ventral surface flattened and bearing a patch of dense pubescence at apical sixth.

Allotype Female. Similar to holotype male save that the sternites are simply convex and not modified in any way, consequently it is much easier to count the five visible ventral segments.

Described on seven specimens collected by the author at light at night on Barro Colorado Island, Gatun Lake, Panama Canal Zone. The holotype male, allotype female, one male and one female paratype on July 7,1936 , at 10:30 p.m.; one female paratype on July 8, 1936; one male paratype on July 17, 1936; one male paratype on July 28,1936 . All were taken near the island laboratory save the female of July 8 which was taken at the south-eastern end of the island, near Bangs Casa.

This distinct species is allied only to hirsutus, from which it may be distinguished by the non-rugose clypeus and wholly different modifications of the male sternites.

The species may be listed as follows:

Subgenus Drasinus s.s. (Raffray, 1904)

binodulus Raffray. 1904. Mexico. Genotype. (nodicornis Fletcher, 1928, nec Raffray)

lewisi (Raffray). 1904. Brazil. (Euteleia) 
Subgenus Paradrasinus new subgenus

cisinsularis new species. Panama Canal Zone.

hirsutus Fletcher. 1928. Vera Cruz, Vera Cruz, Mexico; Rio Azul,

British Honduras.

\section{ECTOPOCERUS (Raffray, 1904)}

This is a monotypic genus, known by the male sex only, limited to Chile, and allied to Drasinus and Decarthron in having antennae of but ten segments. The antennae are irregular: segment I ovate, large, as long as second and third united; II also large, but short, the segment being very transverse, evenly convex in the lateral face and produced on the mesial face into an elongate, subacute, apically flexed point, this mesial extension being half the width of the segment; III to VIII transverse, with the third about one-half as wide as the second segment and fourth to eighth progressively narrower, so that the eighth is just barely transverse, small and inconspicuous; IX very peculiar, very long but the articulation to the eighth segment is far forward, near the fourth of the segment, and consequently two-thirds to three-fourths of the ninth segment lies posteriorly, over the dorsal faces of the eighth, seventh, sixth, and fifth segments; the lateral face of the ninth segment is elongate-semicircular in outline, while the mesial face is bisinuate; $\mathrm{X}$ large and conspicuous in size, being wider than the ninth, and as long as first to seventh segments united, but simple in outline, elongate-oval, with both ends rounded.

Maxillary palpi four-segmented, first, minute; second elongate, basally slender and suddenly thicker apically; third, short, transversely subtriangular, acute mesially, convex laterally; fourth, largest, almost fusiform, slightly, obliquely truncate at base, very pointed apically, with a small palpal cone.

Ventral face of head convex, with a median, longitudinal carina.

Easily separated from Drasinus on the fourth segment of the maxillary palpi, and separated from Decarthron by the lack of the median oval fossa on the ventral surface of the head. This genus, then, is intermediate between these two genera just mentioned. One species:

verticicornis (Reitter). 1885. Chile. (Decarthron). Genotype.

\section{DECARTHRON (Brendel, 1865)}

BRENdeL (1865)

Brendel and Wickham (1890)

Schaufuss $(1879,1882)$ (Bryaxis in part)

LeConte and Horn (1883)

RAFFraY (1904, 1908 a, b, 1909 a, b, 1911)

Fletcher (1928 a, b)

Bowman (1934)

The genus Decarthron is limited to those species having the following characters: (1) Ventral surface of the head with a median, oval fossa or fovea of large size, the borders of which are well-defined or carinated; (2) Antennae 
of ten segments; (3) Third segment of the maxillary palpi transverse, subtriangular, with the external face rounded-convex and the internal face subacute-convex or angulated; (4) Base of each elytron with two foveae; (5) Distant metathoracic coxae.

As at present constituted, the genus holds 71 species of which 13 are known from the United States and Canada and 58 from the neotropics. Decarthron formiceti (LeConte), distributed from Pennsylvania and New Jersey south into the States bordering the Gulf of Mexico, has been designated as the genotype by Bowman (1934, p. 144).

The genus is essentially a neotropical aggregate: Mexico (18) from the coastal extension of the tropical rain forest in southern Tamaulipas southward; Mexico and Guatemala (2); Guatemala (2) ; Panama Canal Zone (4); Venezuela and Colombia (1); Colombia (2); Dutch Guiana (2); Brazil (13); Peru (1) ; Bolivia (1); Paraguay (1); Chile (1); Argentina (8); Grenada, Windward Islands (2) and Cuba (1).

The species in general have well-developed eyes and wings and fly well, coming to lights at night. This dusk flight may extend well into the night but I have not found the insects active by day. Many are synoeketes within the society of ants, one of the new species being adjusted to life with the rapacious army ants to cite but one example.

This is a very specialized genus of pselaphids and belongs near the limits of the Brachyglutini. It has few relatives. The secondary sexual modifications affect the male sex and may be partially outlined as follows. The front of the head may be prolonged beyond the bases of the antennae into a short truncated plate or into a long, conical, spiniform horn. The epistome or clypeal region may be variously armed. The antennae, from the third to the tenth segment, may be highly abnormal. The anterior tibiae may be dilated and bear a ventral sulcus and the anterior femora may be dorsally excavated. The intermediate femora are generally variously flattened and granulated or excavated dorsally, the excavation being of diverse shapes and bearing spines, tubercles, or contorted carinae. The posterior tibiae may be strongly inflated. In contrast, the females are usually much less variable among the species, the body and appendages being simple in form. For this reason the keys have employed the male sex in large part and females are difficult to determine in most cases.

The following key has been modified from Raffray's group key of 1904 and is prepared for the male sex unless otherwise stated:

\section{Key to Neotropical Groups of Decarthron, Based Chiefly on Males}

Front of head prolonged anteriorly between antennal bases........ 2

Front of head simply declivous or truncate between the antennal bases, never prolonged anteriorly.................... 3

2. Frontal extension in the form of a short, anteriorly truncated process 
Frontal extension in the form of a long, conical, subacute spine or

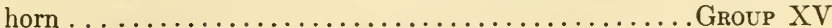

3. Pronotum with three subbasal foveae, a median and a lateral each side Pronotum with a single subbasal fovea, the median.............

4. Front more or less truncate; epistome armed........... Group I

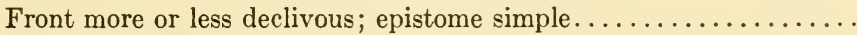

5. Anterior tibiae simple......................... Group II Anterior tibiae dilated apically and ventrally sulcate..... Group III

6. Base of pronotum with a row of small but sharply cut and well de-

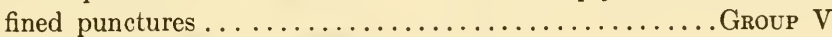

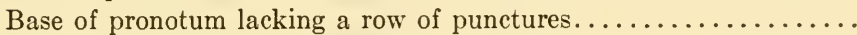

7. Antennae abnormal ............................... VI Antennae normal in both sexes..................... 8

8. All antennal segments much longer than wide.........Group XIII Antennal segments not all longer than wide............... 9

9. Intermediate antennal segments cylindrical to obconic.......... 10 Intermediate antennal segments ovoidal, globular or moniliform.... 11

10. Antennal segments III, IV, and V much longer than wide... Group $\mathrm{X}$ Antennal segments III, IV, V, and VI much longer than wide..... Group XI

11. Posterior tibiae strongly inflated; anterior and intermediate femora of males simple..........................Roup VII Posterior tibiae at most slightly thickened in apical half; intermediate femora of males always inflated, excavated, and more or

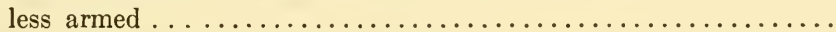

12. Intermediate antennal segments globular............Group VIII Intermediate antennal segments ovoidal, a little longer than wide . Group IX

It will be noted that there are no neotropical species known at present from Groups IV and XII of the genus.

The above key follows Raffray (1904) in separating Decarthron into fifteen groups of species. This is only a convenient way of separating the species, without any necessarily implied evolutionary order. To my mind the separation of, for example, groups X and XI does not rank with the separation of group XV. From the viewpoint of structural development it appears necessary to divide the genus into two subgenera, Decarthron s.s. holding the first fourteen Raffrayan groups, and a new subgenus Decarfuss holding the fifteenth group. This latter group is very isolated, not only in the remarkable frontal horn, but in swollen maxillary palpi, and is as unrelated to the general concept of Decarthron as Drasinus or Euteleia. The fourteenth group, holding Decarthron frontale Raffray alone, is not an annectant link between the rest of the genus and the fifteenth group, viz: frontale is typical Decarthron s.s. with excavated middle femora in the male sex, and the frontal prolongation in this species is simply a quantitatively more pronounced development of the front such as may seen in chichion at a much lower level of integration. 
On the other hand the swollen maxillary palpi and long conical, spiniform horn of euspinifrons appear to separate the fifteenth group of the genus in a qualitative sense. In the following treatment of the species, therefore, the reliable grouping of Raffray is divided into two subgeneric aggregates:

\section{Subgenus Decarthron s.s. (Brendel, 1865)}

Groups I to XIV inclusive of Raffray, 1904. Characterized by a simple front, either declivous from interantennal baseline to apical clypeal margin, or truncate and declivous, or produced as a truncated triangle between interantennal baseline and then declivous. Front never produced into an anteriorlydirected, long, cylindrical, spiniform horn between antennae.

Although some of the species of this subgenus have simple intermediate femora, the insignia of the majority are found in the abnormal intermediate femora. The femur may be considered as a subfusiform segment of the leg, having four faces and two ends: dorsal face, ventral face, anterior face, posterior face, basal end (articulating with the trochanter) and apical or distal end (articulating with the tibia). The apical end is usually subtruncate and may be gradually narrowed or abruptly narrowed and pedunculate. The basal end is almost always simply and acutely narrowed. The dorsal face of the male femur, when modified, is greatly swollen (inflated or tumid) and presents many different outlines but is usually triangular with the highest point of the tumidity forming the apex of an obtuse angle near the middle third of the femoral length. This swelling is usually excavated and the excavation almost infinitely varies between species and within the species population. Usually the excavation is a deep, broad fossa with glabrous floor but it may be a very narrow sinuate or arcuate sulcus involving the posterior face as well. The excavation often has the floor secondarily modified by thin lamellae or carinae or teeth or spines. The outline of the excavation has two ends, an apical and a basal end. The basal end often has the edge ornamented by a single spine or tooth which points apically; this spine may point dorsally or there may be two basal spines. The apical end very seldom carries a spine or tooth, but it may do so and the tooth may point basally and be straight or recurved.

In this first subgenus, keys to the species are given in those groups holding hitherto undescribed species (VI and VIII). Before passing to these matters, I should like to give a brief note in regard to Decarthron tropicum Fletcher (Group XI). This species was described on nineteen specimens collected at light at night on December 19, 1926, at Vera Cruz, Vera Cruz, Mexico. I have four males of this species collected on August 24, 1936, at light at night by Dr. Charles Seevers at Villa Juarez, Tamaulipas, Mexico. My specimens extend the northward range of tropicum to near the northward end of the coastal extension of the tropical rain forest. I have compared my males with a male paratype of tropicum (USNM No. 44599) and am satisfied that they are conspecific. They may represent a more northern race of tropicum since the oval impression of the anterior femora is lightly punctulate-granulate in comparison with the same area of the paratype and the depression of the intermediate femora is a 
little smaller and more truncate-ovoidal in outline in contrast to the larger, irregularly ovoidal depression of the paratype. These differences do not seem to warrant specific rank.

\section{Key to Males of Group VI}

Fourth antennal segment very swollen on mesial face and much wider

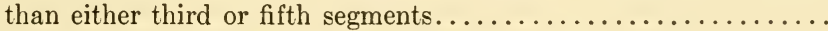

Fourth antennal segment not conspicuously wider than the third and

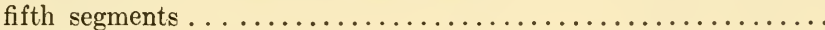

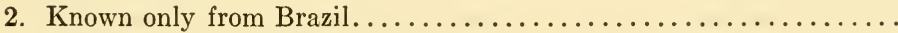

Known only from Panama Canal Zone........chichion new species

3. Intermediate femora greatly dilated dorsally, with the dilation bearing an apically directed tooth and abruptly excavated, this excavation having two strong, parallel carinae, apical to the excavation the femora are suddenly obconically pedunculate; antennal segments VII and VIII short and transverse, slightly produced on mesial

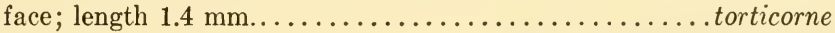

Intermediate femora differently modified; antennal segments VII and VIII more transverse; not as long.................nanum

4. Fourth antennal segment with the mesial face produced suddenly at middle into a truncated process.................rugulosum

Fourth antennal segment not produced mesially or if so, the mesial

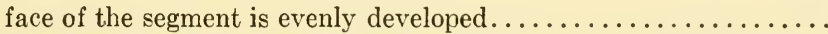

5. Known only from Grenada, Windward Islands.......... insulare

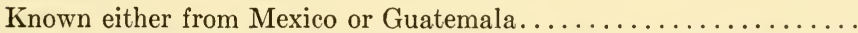

6. Third antennal segment relatively very large, longer than any antennal segment save the tenth, obtusely prominent mesially..... .punctatum

Third antennal segment never longer than ninth segment.........

7. Seventh antennal segment quadrate to transverse, lateral face never

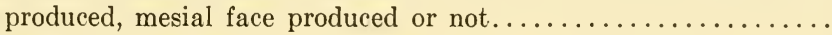
Seventh antennal segment transverse, very obliquely truncate at apex, lateral face produced, much larger than mesial face....squamosum

8. Seventh antennal segment with the mesial face produced.........

Seventh antennal segment with mesial face not produced.........

9. Intermediate femora swollen, but the swelling evenly developed on the dorsal face, this face slightly emarginate with the edge of the emargination bidentate and a recurved, narrow sulcus below the emarginated edge $; 1.6 \mathrm{~mm}$. long............... quadraticeps

Intermediate femora otherwise modified..................

10. Intermediate femora triangularly swollen in the middle of the dorsal face, this dilation bearing at dorsal apex an apically directed spine and the swelling bearing a broadly semilunar excavation; the apical fourth of femur set apart from basal three-fourths by a sudden 
annular constriction at base of swelling; length $1.5 \mathrm{~mm} . . . . .$. arthriticum

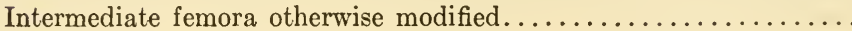

11. Intermediate femora greatly swollen, deeply emarginate and impressed; basal edge of emargination prolonged into a tooth in the same plane, apical margin continued within the emargination on the outer edge by a transparent lamella; bottom of emargination provided with an oblique lamella not connected with the sides;

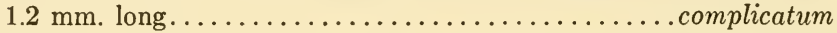

This key covers the species of the sixth group with the exception of curticorne (Schaufuss) from Yucatan, Mexico. This species, unknown to me, is said by Raffray $(1904$, p. 189$)$ to be close to arthriticum Raffray, but differs from Raffray's species in an entirely different structure of the male intermediate femora and much larger third, fourth and fifth antennal segments.

\section{Decarthron chichion new species}

Holotype Male. Measurements: Head $0.2 \times 0.3 \mathrm{~mm}$. through eyes; pronotum $0.268 \times 0.3 \mathrm{~mm}$.; elytra $0.4 \times 0.57 \mathrm{~mm}$.; abdomen $0.28 \times 0.56 \mathrm{~mm}$. from a strictly vertical view; total length $1.3 \mathrm{~mm}$.; greatest width $0.57 \mathrm{~mm}$. (Pl. VI, XVI)

Light reddish-brown, shining, integument clothed with moderately long, orange, subdecumbent pubescence; head, pronotum and abdomen lightly punctulate, elytra more heavily punctate (the elytral integument is thrown into semitransverse subscabroid wrinkles in one of the paratypes, probably a consequence of preservation too soon after pupation).

Head with large, prominent eyes $(0.107$ long $\times 0.067 \mathrm{~mm}$. wide from a vertical view) composed of about 32 very convex, coarse facets; the eye is sharply reniform from a lateral view. Vertex not medianly carinate but transversely swollen posteriorly and flattened anteriorly; with two free, nude, minute vertexal foveae, each smaller than an ocular facet but set in the bottom of a gently sloping depression so that they appear superficially larger, each fovea nearer an eye than to each other and on a line with the third transverse row of ocular facets; each side of vertex with a short, subarcuate incision at base of antennal area. Front medianly and triangularly truncate between antennal bases and then dropping abruptly in an anteriorly oblique plane as a narrow, suboblong with nearly parallel sides, to the anterior margin of the epistome. This declivous surface roughly punctate or subscabroid. Apical margin of labrum concave. Left mandible crossed dorsal to right mandible. Ventral surface of head with a large, sharply-defined, deep ovoid fossa (described from male paratype).

Antennae ten-segmented, distantly inserted beneath antero-lateral angles of head. The fourth, seventh, and eighth segments very abnormally formed 
and fourth to eighth segments inclusive articulated to form an arc. These striking abnormalities and the segmental proportions as illustrated.

Maxillary palpi four-segmented. First segment minute, longitudinally ovoid; second arcuate, with a cylindrical basal peduncle which is narrower than first segment but which gradually at first and then rapidly widens to from a swollen apical third; third segment short, transversely triangular with an evenly convex external face and a short subacute internal face; fourth segment obliquely truncate at base, both external and internal faces evenly converging to subacute apex, this segment longer than second and wider than third, with an apical palpal cone.

Pronotum rounded-hexagonal, wider than long. No lateral foveae but with a median, free, small, circular, nude fovea at basal third. Basal pronotal margin simple.

Elytra each with two small, perforate, circular, nude basal foveae. The sutural fovea at origin of deep, entire sutural stria. Discal fovea at origin of deep discal stria which extends four-sevenths of elytral length (length of elytra measured from the acute-triangular scutellum). Elytral flank with no subhumeral fovea, no carina and no stria.

Wings long (nearly three times as long as elytra when fully extended), strong, finely pubescent with margins having much longer setae (in dry specimens the membranous surface granular and iridescent).

Abdomen with first tergite nearly twice as long as remainder of abdomen from a strictly dorsal view, with a pair of strong, slightly arcuate apically and therefore slightly divergent, discal striae which are separated by one-half total tergite width and one-half as long as the segment (discal striae measured from a male paratype). Abdominal margin narrow but well-developed. Five visible tergites. Five visible sternites but these made out with difficulty because of their construction: first visible very long, medianly more than three times as long as the remaining four sternites combined, the apical margin of this first sternite gradually produced so as to vault over the second and third visible sternites; second, third, and fourth very narrow medianly; fifth (terminal) sternite also medianly produced posteriorly to fit into concave apical margin of terminal tergite.

Intermediate coxae separated by an oblong, truncate extension of the mesosternum. Posterior coxae distant. Sternal foveae IV and V, metaepisterna and associated sutures as in Drasinus cisinsularis. Metasternum tumid above the articulation of each posterior leg and medianly concave.

Posterior tarsi elongate, slender, subcylindrical; two-thirds as long as tibiae; first tarsomere minute, one-sixth as long as second; second tarsomere elongate-subcylindrical, longer than third; third tarsomere elongate-cylindrical, bearing apically a single long, arcuate, sharp claw one-third as long as tarsomere. Anterior and posterior tibiae bearing an apical pubescent process. Intermediate (mesothoracic) femora very complexly modified, the dilation, armature and excavation as illustrated. Tibiae of all legs, anterior and posterior 
femora not abnormally swollen. All tibiae pubescent in apical fifth at ventral face.

Allotype Female. Similar to holotype and paratypes save that (1) the declivous frontal area is slightly tumid and not scabroid; (2) antennae not abnormally formed; (3) intermediate femora simple; (4) first visible sternite not quite so produced and fourth sternite relatively longer.

Described on six specimens all collected by the author at lights between 9 and 11 p.m., on Barro Colorado Island, Gatun Lake, Panama Canal Zone, in July, 1936. Male paratype (July 14), male paratype (July 16), male holotype and female allotype (July 17 ) at island laboratory; two male paratypes (July 8) at Burrunga Point.

This is a clearly defined species. In antennal abnormality it approaches torticorne Raffray and nanum (Schaufuss) of Brazil. In complexity of male intermediate femora it approaches complicatum Fletcher of Guatemala. This large sixth group of the genus would seem to have a Brazilian and a Mexican focus, with the two rather satisfactorily united by complicatum and chichion of Central America.

\section{Key to the Males of Group VIII}

Head strongly narrowed anteriorly; vertexal foveae united by oblique sulci which unite near the frontal margin; intermediate femora with inflated dorsal area ending in an unspined obtuse angle, a long and narrow sinuate sulcus arising on posterior face from just below this angle and extending ventro-apically to apical eighth, the sulcus holding at its dorso-basal end a spine; length 1.3-1.4 mm.; known only from Grenada, Windward Islands................ spinosum

Head slightly narrowed anteriorly to square; males with the intermediate femora otherwise modified; not known from the Antilles..

2. Head square with a flattened vertex; known from Brazil and Argen-

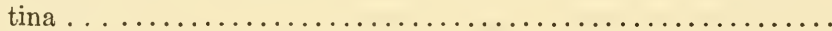

Head with occipito-vertexal area convex to tumid; known from neo-

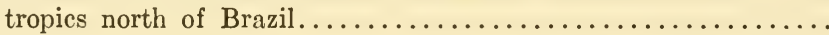

3. Intermediate tibiae with a small, apically directed spine at four-fifths; antennal segments II-V subquadrate and subequal, VI-VII slightly smaller, VIII larger and transverse, IX much larger and slightly transverse; anterior femora with dorso-posterior face with a transversely oval, lightly punctulate, well-defined area; intermediate femora with dorsal excavation in apical half, with a very large, slightly recurved and blunted spine at basal end of excavation, floor of excavation deeply notched on posterior face near apical end of excavation; $1.7 \mathrm{~mm}$. long; known only from Argentina. .rubripenne Intermediate tibiae without tibial spine on ventral face at apical fourfifths; spine at basal end of excavation of intermediate femora much smaller; vertexal foveae very shallow and superficial; known only from Brazil .........................externedens 
4. Excavation of intermediate femora with the apical edge erected into a blunt recurved tooth; $1.4 \mathrm{~mm}$. long; Mexico........ denticulatum Excavation of intermediate femora without an apical tooth.........

5. Apical end of intermediate femora with a deep, narrow notch or constriction on the dorsal face just distal to the apical end of the excavation; $1.6 \mathrm{~mm}$. long........................... plans Apical end of intermediate femora with no notch on dorsal face distal

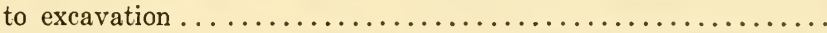

6. Excavation of intermediate femora with the spine of the basal edge arcuate and aciculate, excavation deep on dorsal face beneath the spine and narrowing and becoming shallow on posterior face; 1.7 mm. long; known from Cuernavaca, Morelos, Mexico.....schmitti Excavation of intermediate femora with the spine of the basal edge straight and bluntly truncate, excavation very broad and deep, semilunar in shape and extending broadly over the posterior face; 1.35 mm. long; known from Panama Canal Zone................ noctiphoton new species

Decarthron noctiphoton new species

Holotype Male. Measurements: Head $0.221 \times 0.335 \mathrm{~mm}$. through the eyes; pronotum $0.30 \times 0.335 \mathrm{~mm}$.; elytra $0.469 \times 0.67 \mathrm{~mm}$; abdomen from a dorsal view $0.368 \times 0.58 \mathrm{~mm}$. (first tergite $0.30 \times 0.58 \mathrm{~mm}$.) ; total length $1.35 \mathrm{~mm}$; greatest width $0.67 \mathrm{~mm}$. (Pl. XVI)

Color, pubescence and punctation as in chichion.

Head as in chichion save that the eyes are larger $(0.11 \times 0.067 \mathrm{~mm}$. from a dorsal view) and composed of about 40 coarse facets, the eyes more conical and less reniform. Vertex less flattened anteriorly, more tumid between vertexal foveae; vertexal foveae larger, of the diameter of an ocular facet, otherwise similar. Front evenly truncate between antennal bases and dropping vertically, obliquely to anterior margin of epistome; fronto-clypeal slope nearly glabrous, not scabroid. Labrum as in chichion. Ventral surface of head as in chichion.

Antennae ten-segmented, distantly inserted as in chichion, but "normal", of the form and proportions as illustrated. The only structural feature to be noted in addition is a finely pubescent, sharply-defined depression occupying the apical third of the ventral face of the distal (tenth) segment.

Maxillary palpi as in chichion save that the second segment is quite different: thicker in peduncle, more gradually enlarged apically to the apical third where it is then more suddenly and subacutely dilated; fourth segment thicker than in chichion.

Pronotum as in chichion.

Elytra as in chichion save that discal stria is half as long as elytra.

Wings long and well-developed. 
Abdomen with five tergites visible, the first very long as usual and with discal striae as in chichion. Five visible sternites clearly visible (combined median length $0.381 \mathrm{~mm}$.) ; first sternite long $(0.268 \mathrm{~mm}$.), apical margin produced in median third of width to partially cover second; second, short; third, produced into a sharp cusp at middle of apical margin, this tooth partially covering the fourth; fourth, short and simple; fifth (terminal) longer than the preceding three united, punctulated, apical margin broadly produced to fit concave apical margin of fifth tergite.

Mesosternum, intermediate coxae, posterior coxae, sternal foveae, metaepisternal and associated sutures and the metasternum as in chichion.

All tibiae normally slender at base, slightly thickened apically, bearing the usual setose area apically at ventral face; posterior tibiae slightly arcuate distally as usual. Anterior femora swollen dorsally, the swelling bearing a transversely oval depression on the dorso-posterior part of swelling, this depression punctulate-granulate and its dorsal edge strongly carinated as illustrated. Intermediate femora complexly excavated and armed as illustrated. Posterior femora simple.

Allotype Female. As for holotype and paratypes save that (1) the distal margin of labrum is less concave, (2) third visible sternite not medianly cusped, (3) apical margin of fourth and basal margin of fifth sternites involved in a small but distinct median depression, (4) fifth sternite with apical margin less convex, nearly straight but more definitely punctate than in the male.

Described on thirteen specimens all collected on Barro Colorado Island, Gatun Lake, Panama Canal Zone, at lights at night. Paratype female May 19, 1935, by Alfred Emerson. Paratype male August 31, 1935, by Alfred Emerson. Paratype males on July 6 , July 7 , July 14 , July 15 , 1936, by author. Holotype male and allotype female on July 7,1936 , by author.

\section{Subgenus Decarfuss new subgenus}

Group XV of Raffray, 1904. Characterized by the front between the antennae being produced into a long, conical and spiniform horn, directed anteriorly.

Key to the Males of Group XV

Antennae simple .........................monoceros

Antennae very abnormally formed as described............... .euspinifrons new species

Decarthron euspinifrons new species

Holotype Male. Measurements: Head 0.234 x $0.361 \mathrm{~mm}$. through the eyes; pronotum $0.321 \times 0.375 \mathrm{~mm}$.; elytra $0.53 \times 0.602 \mathrm{~mm}$; abdomen $0.335 \times 0.556$ $\mathrm{mm}$. from a dorsal view; total length $1.48 \mathrm{~mm}$; greatest width $0.602 \mathrm{~mm}$. (Pl. XVIII) 
Integument light reddish-brown clothed in subdecumbent rufoflavous pubescence; occipito-vertexal area very lightly punctulate, vertex anteriorly distinctly punctate, pronotum very lightly punctulate, elytra and abdomen more distinctly punctate.

Head with prominent eyes $(0.120 \times .046 \mathrm{~mm}$. from a dorsal view) of about 36 coarse facets, the eye rounded from a dorsal view, nearly circular from a lateral view with only a small triangular genal wedge incising the posterior margin, occupying the area of three facets.

Entire vertex convex save for a faint triangular flattened space between and behind the vertexal foveae. Vertexal foveae each separated from an adjacent eye by the space of three facets, free with no suggestion of sulci, nude, deep, a diameter slightly more than an ocular facet. Vertex not medianly carinated. Each side of the head between eye and antenna entirely involved in a large, pubescent, pyriform fovea which is not wholly visible from above. This fovea appears to be a specialized homologue of the subarcuate pubescent incision of the same area in other species of the genus (chichion, noctiphoton for example), and is another argument for subgeneric isolation of euspinifrons. Front produced between antennal bases into a horn $(0.10 \mathrm{~mm}$. long from interantennal base to apex), extending beyond the labrum. This horn, from a dorsal view, narrowing to an acute angle at apex, the apex bluntly rounded. From a lateral view this horn is seen to have a wide base, arising from the middle of the clypeus up to the interantennal line; narrowing rapidly from this base; near the apex the horn is suddenly and angulately constricted so that from this lateral view the apex is in two steps and sharp-pointed. The horn is provided at the apex with two laterally divergent, dorsally upcurved and prominent setae. Labrum tumid, with a concave distal margin. Left mandible crossed dorsal to right; base of each mandible notably tumid on dorsal face.

Antennae ten-segmented, distantly articulated. Segment I very long (as long as next two united) and with the middle of the ventral face bearing a conspicuous, rounded, flat-topped tubercle or drum-shaped tumulus; II long (as long as next two united) subcylindrical; III strongly obconic; IV-VI inclusive subequal, subquadrate, slightly narrower than third and much shorter; VII and VIII subtrapezoidal, gradually wider than sixth; IX and X distinctly more pubescent, the ninth larger than eighth, obtrapezoidal with a much narrower articular peduncle at center of anterior face; tenth segment only slightly wider than ninth, squarely truncate at base, rounded at apex. Ventral face of tenth sharply and deeply incised in apical third, the basal rim of this excavation densely set with a fringe of whitish setae.

Maxillary palpi in comparison with chichion and noctiphoton conspicuously swollen; four-segmented. First segment small but clearly visible; second arcuate and pyriform with a rapidly expanding width to the broad apex; third transversely triangular, outer face convex, inner face acute, this segment swollen; fourth longer and wider than other segments, obliquely truncate at base, swollen, the sides rapidly converging to subacute apex which bears a terminal cone. 
Ventral surface of head with a deep, ovate fossa with carinated edges typical of the genus.

Pronotum with basal margin strongly beaded, the bead continuous, flat and expanded anteriorly at middle into a blunt, triangular cusp. Median fovea free, nude, sharply cut. A deep, pubescent lateral fovea each side at bottom of an ovate depression.

Elytra each with the usual two basal, nude foveae, entire sutural stria and discal stria. The discal stria extends slightly beyond the middle of elytral length $(0.288 \mathrm{~mm}$.). No subhumeral fovea and flanks lacking stria or carina.

Wings well-developed.

Abdomen with five tergites. First tergite long, strongly and narrowly margined, with two strong, slightly divergent, straight discal striae; these striae separated by one-half the segmental width, and one-half the segmental length. Five visible sternites. First morphological sternite invisible, covered by metasternum and coxae but can be seen by dissection to be a narrow, very transverse plate medianly, this plate punctate. First visible sternite (second morphological) recessed each side to hold a posterior coxa, each coxal depression densely pubescent, the segment very long (four times as long as other sternites united, e.g. $0.268 \mathrm{~mm}$.) with apical margin medianly produced to cover the second and most of the third visible sternites; fourth sternite narrow; fifth (terminal) sternite twice as long as fourth, distinctly punctate, apical margin strongly produced to fit the subacutely concave apical margin of fifth (terminal) tergite. First visible sternite flattened medianly and last sternite tumid medianly.

Intermediate and posterior coxae, mesosternum, sternal foveae, metaepisterna and associated sutures as in chichion.

Metasternum medianly clothed with appressed, posteriorly-directed setae; medianly tumid and this raised area flattened and the center of the flattened area longitudinally sulcate. This sulcation is not deep but is clearly defined as the consequence of two striaform sulci. Each sulcus arises near one of the fifth sternal foveae, courses in an arc medianly, then laterally to end near each sternal-metacoxal border.

Anterior and intermediate trochanters with posterior face strongly flattened to form an ovate table; this tabular surface has a ctenoid appearance because of a single row of equally long, closely set, stiff setae.

Femora normal, neither swollen, excavated nor armed.

Anterior tibiae with the distal half of ventral face flattened and bearing a pad of short setae. Pubescence of the distal fourth to sixth of the ventral tibial face is typical for Decarthron but in euspinifrons the anterior tibial pubescence is quantitatively exaggerated.

Intermediate tibiae with a strong, lamelliform tooth, one-fourth as long as tibia, arising from the ventral face at apical three-fourths.

Allotype Female. Similar to holotype save that (1) front is simply declivous and simply formed, (2) first antennal segment simple, (3) second and third visible sternites clearly discernible because the first visible is not so produced 
medianly, (4) first visible sternite evenly convex, not flattened, (5) anterior and intermediate trochanters simple, (6) tibiae simple.

Described on eight specimens, all collected on Barro Colorado Island, Gatun Lake, Panama Canal Zone. Female paratype collected at light at night on August 2, 1935, by Alfred Emerson; holotype male, allotype female and two paratype females (July 7, 1936), paratype female (July 15, 1936), paratype female (July 17, 1936) collected at night at light by the author; paratype male collected July 29, 1936, at night from overnight nest of Eciton burchelli Westw. by the author.

With reference to this last paratype, the host ants were very kindly identified by Dr. Neal Weber. Regarding the host, I quote from my field notes: Wednesday, July 29, 1936

\begin{abstract}
"At about Snyder-Molino trail 4, Dr. Chickering and I saw a column of army ants moving along a log late in afternoon-the column was about ten ants wide. We followed column to large tree on trail fifty feet away and there, between two plank-buttresses the ants were forming nest of their own bodies, hanging in festoons 6 to 12 inches long, and the trunk and ground covered with them. We estimated that the nest was eight square feet and two inches deep (2305 cubic inches). Allowing 173 ants to a cubic inch and a conservative army ant volume of 90 cubic millimeters each, the population worked out at about 388,000 army ants. Collected quart of ants . . . . returned at 9:30 P.M. to find ants on the march, with pupae and larvae, the soldiers guarding column of ten ants wide as before. Nest about gone ..... Thursday, July 30, 1936. By 9:30 A.M. ants had entirely disappeared."
\end{abstract}

The rapacious habits of these ants are well known and their autecology has been reported recently (Schneirla, 1940) from this island. With this particular colony of Eciton burchelli Westw. there also occurred the limuloids Cephaloplectus mus Mann and Limulodes brachyscelis Seevers and Dybas.

With respect to Decarthron euspinifrons, I am inclined to place this pselaphid as a synoekete of burchelli, as the male collected was in the midst of a long festoon of ants and certainly would be quickly destroyed unless it was a tolerated guest. Since other specimens were collected at light at night, the pselaphid is probably a facultative synoekete enjoying its nocturnal pselaphoid heritage.

Euspinifrons is structurally very isolated in the genus, having its nearest relative in monoceros (Schaufuss) of Dutch Guiana, and its zoögeographic affinities seem to be South American rather than Central American.

Two species are worthy of additional note.

Bryaxis denticornis Schaufuss $(1880$, p. 15) of Yucatan, Mexico, was placed by Sharp (1887, p. 24) as Decarthron denticorne (Schaufuss), and in this allocation was doubtful, since Schaufuss did not describe the thorax of the species. Not listed by Raffray $(1904,1908)$ in genus.

Batrisus monoceros Sharp (1887, p. 14), based on one male from 7000 to 9000 feet in the Quiche Mountains of Guatemala, but not figured, is not listed by Raffray $(1904,1908)$ in Batrisini. I am struck with the similarity of Sharp's 
inadequate description and my Decarthron euspinifrons. If monoceros Sharp turns out to be a Decarthron, then it will have to have another name due to monoceros (Schaufuss), 1882, of Dutch Guiana. Sharp's species is undoubtedly valid and monoceros (Sharp), monoceros (Schaufuss), and euspinifrons new species are quite obviously all distinct on many structural features. The question turns on whether Sharp's species is Decarthron or not. The question can not be settled without recourse to the type but I am inclined to place monoceros Sharp as non-brachyglutine on the strength of his reputation since, in order to make the mistake he would have to: (1) count eleven antennal segments for ten, (2) find a transverse pronotal sulcus (his species was in the subgenus Arthmius of "Batrisus" and Decarthron has no such sulcus, a fact which was known to Sharp), (3) fail to see the abdominal margin, and many other obvious features, involving tarsal claws, ventral surface of head, et cetera.

Just what monoceros Sharp is I do not know. It is certainly not Batrisus as now limited; probably not Decarthron for reasons just stated. If in the Batrisini it may form the type of a new neotropical genus. For the present we must leave it unplaced.

The species of Decarthron may be listed as follows:

\section{Subgenus Decarthron}

I

bicolor Raffray. 1904. Chile.

binodosum Raffray. 1908. Argentina.

corpulentum (Schaufuss). 1887. Minas Geraes, Brazil. (Bryaxis)

fractifrons Fletcher. 1928. Vera Cruz, Vera Cruz, Mexico.

hetschkoi Raffray. 1904. Blumenau, Brazil.

?macrocephalum (Schaufuss). 1887. Brazil. (Bryaxis)

simplex Raffray. 1908. Argentina.

II

cochlearifer (Schaufuss). 1879. Mexico. (Bryaxis). Also Guatemala teste Sharp, 1887.

dimissionis (Schaufuss). 1887. Brazil. (Bryaxis)

hirsutum Raffray. 1908. Argentina.

soror (Schaufuss). 1887. Mexico.

III

sulcipes Raffray. 1904. Yuracaris, Bolivia.

$\mathrm{V}$

tritomum Raffray. 1904. Blumenau, Brazil.

VI

arthriticum Raffray. 1904. Sierra de Durango, Mexico.

chichion new species. Panama Canal Zone. 
complicatum Fletcher. 1928. San Miguil, Guatemala. curticorne (Schaufuss). 1872. Yucatan, Mexico. (Bryaxis) insulare Raffray. 1904. Grenada, Windward Islands. nanum (Schaufuss). 1887. Amazonas, Brazil. (Bryaxis) punctatum Fletcher. 1928. Vera Cruz, Vera Cruz, Mexico. quadraticeps Raffray. 1904. Cuantla, Mexico. quadrifoveatum Fletcher. 1928. Vera Cruz, Vera Cruz, Mexico. rugulosum Fletcher. 1928. Vera Cruz, Vera Cruz, Mexico. squamosum Fletcher. 1928. Vera Cruz, Vera Cruz, Mexico. torticorne Raffray. 1909. Sao Paulo, Brazil.

\section{VII}

laevicolle (Aube). 1844. Male: Venezuela and Colombia. (Bryaxis)

(Female: bipunctatum Reitter, teste Raffray, 1904)

\section{VIII}

denticulatum Fletcher. 1928. Vera Cruz, Vera Cruz, Mexico. externedens Reitter. 1882. Petropolis, Brazil. noctiphoton new species. Panama Canal Zone. planiceps Raffray. 1904. Colombia. rubripenne Raffray. 1908. Argentina. schmitti Raffray. 1904. Cuernavaca, Morelos, Mexico. spinosum Raffray. 1904. Grenada, Windward Islands. (spinosus Raffray, 1904, p. 186)

\section{IX}

brasilianum Raffray. 1904. Matto Grosso, Brazil. cearae (Schaufuss). 1879. Matto Grosso, Brazil. minutum Raffray. 1904. Matto Grosso, Brazil. nigricans Raffray. 1911. Sao Pallo, Brazil. unifoveolatum (Schaufuss). 1887. Cuba. (Bryaxis) vulneratum Raffray. 1904. Mexico.

X

restitutum Sharp. 1887. Guatemala (Rio Naranjo, Rio Maria Linda,

Torola, San Geronimo) ; Cordova, Mexico?; Nicaragua?; Amazonas, Brazil?

similare Sharp. 1887. Champerico, Guatemala. tomentosum Raffray. 1904. Colombia.

\section{$\mathrm{XI}$}

bruchi Raffray. 1911. Argentina.

fallaciosum Sharp. 1887. Cordova, Mexico and Cahabon, Guatemala. lamellipes Fletcher. 1928. Rio Pichis, Peru. planifrons Raffray. 1904. Yucatan, Mexico. 
schaufussi Raffray. 1904. Santarem, Amazonas, Brazil. suturale (Schaufuss). 1879. Mexico.

tropicum Fletcher. 1928. Vera Cruz, Vera Cruz, Mexico, and Tamaulipas, Mexico.

\section{XIII}

gracilicorne Fletcher. 1928. Vera Cruz, Vera Cruz, Mexico. longicorne Raffray. 1904. Amazonas, Brazil.

\section{XIV}

frontale Raffray. 1904. Colombia.

Subgenus Decafuss new subgenus

euspinifrons new species. Panama Canal Zone. con Eciton burchelli Westw.

monoceros (Schaufuss). 1882. Paramaribo, Dutch Guiana. (Bryaxis)

\section{UNPLACED}

aurivillii (Schaufuss). 1882. Dutch Guiana. (Bryaxis)

?denticorne (Schaufuss). 1880. Yucatan, Mexico. (Bryaxis denticornis) saucium Raffray. 1908. Paraguay.

Before taking up the few remaining brachyglutine genera, I have drawn up a key to the three new species of Decarthron and the new species of Drasinus. This is done since they are the only brachyglutines with ten-segmented antennae reported from Barro Colorado Island and form a group with superficially similar facies:

Key to both sexes of Barro Colorado Decarthron and Drasinus

Ventral surface of head with median longitudinal carina......... 2

Ventral surface of head with median ovate fossa............. 3

2. Third visible sternite with four elevations, a lateral pair relatively low, broad and lightiy pubescent and a median pair relatively high, narrow and densely tufted.......... Drasinus cisinsularis MALE

Third visible sternite simply convex.... Drasinus cisinsularis Female

3. Front produced into an anteriorly directed horn between antennal bases....................... Decarthron euspinifrons MALE

Front not produced into a horn...................... 4

4. Maxillary palpi swollen; pronotum with three subbasal foveae..... Decarthron euspinifrons FEMALE

Maxillary palpi normal; pronotum with a single median fovea, no lateral foveae .............................. 5

5. Intermediate femora swollen, excavated on dorsal and posterior faces 


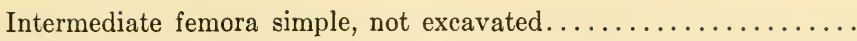

6. Antennal segments IV, V, VI, VII, VIII forming an are; IV very swollen and much larger than third or fifth; VII and VIII transverse, mesially produced.............Decarthron chichion MaLE Antennae simple, not as above....... Decarthron noctiphoton MALE

7. Apical margin of fourth and basal margin of fifth visible sternites involved in a small, distinct median depression................

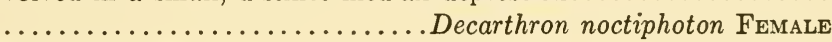
Apical margin of fourth visible sternite simple............... .Decarthron chichion Female

\section{EUTELEIA (Raffray, 1904)}

This is a small genus of three known species, two known from Brazil and one from Mexico, allied to Decarthron by having on the ventral face of the head a large, oval fossa with sharply defined or carinate borders, and in having antennae of only ten segments. It is easly separated from Decarthron on the third segment of the maxillary palpi. In Euteleia this third segment of the maxillary palpi is subconical to ovoidal, much longer than wide, subacute apically and almost pedunculate to acute at base; the second segment is similarly very long, slender basally, gradually widening apically to form a rounded apex which is as wide to slightly wider than the third segment; fourth segment longer than third segment, shorter than second segment, similarly stream-lined with rounded apex and subpedunculate, subacute base, and bearing a long, slender palpal cone at apex. This distinctive palpus quickly separates this genus from Decarthron, Drasinus and Ectopocerus.

\section{KeY to THE SPECIES}

Third segment of the maxillary palpi relatively very long, distinctly more than half the length of the fourth (last) segment)..... recens

Third segment of the maxillary palpi shorter, not more than half the

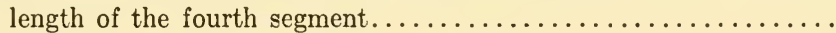
(However, see Raffray, 1904, pp. 304-306)

2. Antennae with the segments longer than wide; $1.6 \mathrm{~mm}$.; metasternum sulcate, with two setose bundles between the middle coxae at their

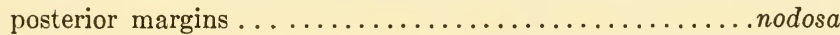
Antennae with segments III-VII moniliform, VIII a little larger, and nearly square, IX much larger and square; $1.2 \mathrm{~mm}$....... trifoveata nodosa Raffray. 1904. Mexico. recens (Schaufuss). 1879. Brazil. (Bryaxis). Genotype. trifoveata Raffray. 1904. Brazil.

\section{ITAMUS (Raffray, 1904)}

This is a monotypic genus, limited to Brazil, and closely related to Decarthron in the ten-segmented antennae, ventral surface of the head with a median 
oval fossa with sharply defined edges, and general shape of the segments of the maxillary palpi. It differs from Decarthron in the anatomy of the head. The head is transversely square from a dorsal view, with the front abruptly truncate between the bases of the antennae; the front is separated from the epistomal region by a deep, transverse sulcus (this sulcus is about as deep as half of the eye length, and therefore conspicuous) on the anterior end of the head below the level of the basal antennal segments; laterally this frontal sulcus continues along each side of the head, incorporating the antennal acetabulum, and extending posteriorly over each gena to end near the occipital margin beneath the posterior margin of the eye; this posterior portion of the circumcephalic sulcus is filled with pubescence which by its appearance suggests some secretory or sensory function.

Antennae with segment I as wide as tenth, subquadrate, medianly and transversely creased or impressed; II narrower than first, cylindrical, three times as long as wide; III obconic; IV-VI ovate; VII-VIII transverse, slightly produced or subacuminate on mesial face; IX subquadrate, transverse, subequal to width of eighth; $\mathrm{X}$ (last) ovate with a very truncate base.

laticeps Raffray. 1904. Brazil.

\section{GLOBA (Raffray, 1887)}

This genus is restricted so far to South America. It is highly specialized in that the abdomen is exceptionally short, convex, declivous, rounded apically, with the abdominal "margin" formed by a single thin carina. In this character Globa departs from the majority of Staphylinidae, from the Euplectini and on the other hand, approaches the Batrisini.

Antennae eleven-segmented, stout, generally simple in construction, with a three-segmented club.

Maxillary palpi four-segmented, first segment minute; second elongate, slender save for the usual apical inflation; third very small, transversely triangular as usual; fourth largest, oval, slightly flattened, acuminate with a palpal cone.

Ventral surface of the head tricarinate, a median straight carina and a sinuous lateral carina each side, all three longitudinal.

Pronotum cordiform, simple.

Elytra subglobular, without basal foveae, and neither a sutural nor a dorsal stria on either elytron.

Abdomen previously noted, the first tergite much longer than second or third; fourth and fifth longer than third, and diversely armed or irregular in the male sex; fifth tergite not visible from above. Six sternites, of which the first is visible beneath the metasternum, and the sixth is semicircular to invest the ventral margin of the fifth tergite.

Middle coxae distant; posterior coxae distant.

The three species may be separated as follows: 
Antennae with ninth segment large, obconical, the length of the segment equalling its apical width at least...............laevis

(1.4 mm.; known only from Bolivia)

Antennae with the ninth segment strongly transverse............

2. Known only from Venezuela; male with the fourth tergite transversely and obliquely foveate on each side, and with a median tubercle; $1.0 \mathrm{~mm} . . . \ldots \ldots \ldots \ldots \ldots \ldots \ldots \ldots \ldots$ brevicornis

Known only from Colombia; male fourth tergite not armed in this

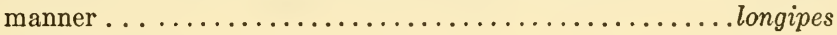

brevicornis Raffray. 1890. Venezuela.

laevis Raffray. 1904. Bolivia.

longipes Raffray. 1887. Colombia. Genotype.

\section{BYTHINOGASTER (Schaufuss, 1887)}

This is a highly specialized monotypic genus, known so far only from Hispaniola (probably Haiti as the citation is "Saint-Domingue").

The abdomen is short, convex with an exceptionally narrow margin for the Brachyglutini, and like Globa, presents certain batrisine features. The maxillary palpi, however, are very different from those of Globa, the first segment is minute; second segment elongate, arcuate, apically swollen; third segment peculiar, lenticular with the long axis of the segment vertical, that is longer than wide, the external (lateral as opposed to mesial) face is concave and this concavity is supplied with spongy pubescence; fourth large, oval, acuminate, bearing a palpal cone. Ventral surface of the head, flat and unsculptured (Raffray, 1908, p. 203) with exception of a median, longitudinal carina (Raffray, 1908, key, p. 192). Middle coxae slightly separated. This odd genus is said by Raffray to resemble the Australo-Asiatic genus Eupines. I am unfamiliar with either of these genera.

simplex Schaufuss. 1887. Hispaniola. Genotype. 


\section{Tribe 6. Metopiini}

This tribe was isolated by Raffray (1904, p. 106) to contain pselaphids having the following combination of characters: (1) head with antennae contiguous or subcontiguous, articulated on a prominent median antennal tubercle, the head constricted behind the tubercle and then expanded posteriorly; (2) eleven-segmented, long, slender antennae which are always conspicuously geniculate (Pl. XVIII) as a consequence of the inordinately long first segment; (3) mentum normal, not expanded to cover the mouth and mouth-parts; (4) first sternite small but visible between the posterior coxae as a plate which is not longer than these coxae; (5) medial faces of posterior coxae, articulating with the trochanters, subtriangular to subglobular; (6) intermediate trochanters short, very obliquely articulated with the femora so that the latter are near their respective coxae; (7) three-segmented tarsi having the first segment short and the last two long, the last segment bearing two very unequal tarsal claws.

Few tribes have such a characteristic facies. Their long, slender legs, long and geniculate antennae, and contiguous antennal insertion make a picture seldom forgotten. Within the neotropics the only pselaphids they remotely resemble are Goniacerini, also with a strong antennal tubercle and geniculated antennae (Bibrax), but with the first sternite very long, clearly visible from side to side and longer than the posterior coxae.

Sex in Metopiini can be quickly and infallibly diagnosed: the females have six sternites; the males have seven sternites, of which the seventh is in two plates, a right and a left as in the males of some euplectine genera. As in these latter, these two subtriangular valves move laterally at copulation, to allow extrusion of the penis; in repose, these plates meet medianly to form a median, longitudinal carina or sulcus with carinated edges.

The Metopiini are exclusively neotropical, centering in the rain forest of the Amazon River basin. From here the species extend with decreasing frequency south into Argentina and north to Panama. They are apparently nocturnal, spending the day beneath bark of fallen logs or leaf mold of forest floors, and flying at dusk. Some come to lights at night. Many species live with ants. One of the new species has been found with termites.

The following key to genera has been modified from Raffray, 1908.

\section{Key to the Genera}

Each side of pronotum bearing a long spine (Pl. XVIII) .........

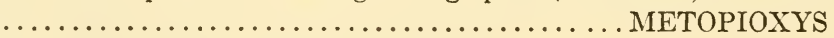

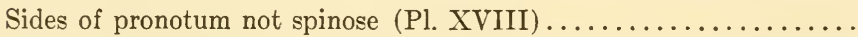

2. Third antennal segment subequal to the second segment in length, or very much longer................................. 
Third antennal segment always very much shorter than the second. .

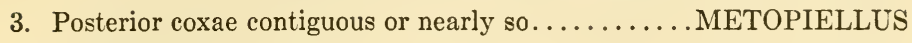

Posterior coxae distant......................... 4

4. Elytra with no sutural striae..................

Elytra each with a well-defined sutural stria (Pl. XVIII)........ .BARROMETOPIA new genus

\section{METOPIAS (Gory, 1832)}

GORY (1832)

Aube (1833)

Schaufuss (1872)

SHARP (1887)

RAFFrAY (1904, 1908)

This is the type genus of the tribe, and one of the first strictly neotropical genera to be delineated. As now restricted it holds the following species:

carinipes Raffray. 1904. Yuracaris, Bolivia.

curculionoides Gory. 1832. Cayenne, French Guiana. Genotype.

elegans Sharp. 1887. Volcan de Chiriqui, Panama.

elongatus Schaufuss. 1872. Amazonas, Brazil; Yuracaris, Bolivia.

\section{METOPIELLUS (Raffray, 1908)}

aglenus (Reitter). 1895. Blumenau, Brazil. con Tetratomium reitteri Mayr.

hirtus (Reitter). 1895. Sao Paulo, Brazil. Genotype. (Metopias)

silvaticus Bruch. 1933. Loreto, Misiones, Argentina. con ants.

\section{METOPIOSOMA (Raffray, 1908)}

pacificus (Westwood). 1856. Santarem, Brazil. (Metopias) Genotype. barretoi Bruch. 1924. Sante Fe, Argentina. con Solenopsis richteri Forel. cf. Bruch, 1929.

\section{METOPIOXYS (Reitter, 1885)}

The following key has been drawn up to separate the more numerous species of this genus, two of which are new. The genus is unique in the tribe in having the lateral pronotal margins spinose. Of the twelve known species, ten are from Brazil, one from Argentina and one as far north as Colombia. The genus is unknown from Central America or the Antilles.

Key to the SPECies

Large species, 2.3 to $3.3 \mathrm{~mm}$. long................... 5

Small species, 1.9 to $1.5 \mathrm{~mm}$. long.................... 2 
2. Elytra humeri spined........................... 3

Elytra may have prominent humeri, but humeri never spined..... 4

3. Antennal segment IX spherical, $\mathrm{X}$ spherical; known only from Brazil;

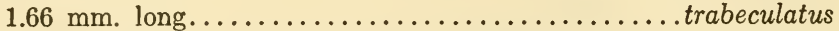
Antennal segment IX elongate-oval, $\mathrm{X}$ trapezoidal from a dorsal view, asymmetrically transverse from a lateral view with the dorsal face produced dorso-anteriorly; known only from Colombia; $1.7 \mathrm{~mm}$. long................................

4. Integument shining; elytral humeri not prominent; $1.87 \mathrm{~mm}$. long; antennal segment IX spherical, $\mathrm{X}$ quadrate.......... subcarinatus Integument strongly granulate between the eyes; elytral humeri prominently oblong; $1.5 \mathrm{~mm}$. long (smallest species known).. spiculatus

5. Pronotum trispinose, a large straight spine on each side anterior of the middle, and a single smaller spine at middle of the apical margin; $2.6 \mathrm{~mm}$. long; integument lightly punctulate and polished; humeri of elytra obtusely prominent but not spined; antennal segment VIII briefly ovate, IX transversely trapezoidal, XI conical; male metasternum slightly transverse and depressed; male last sternite obtuse and depressed................tricuspidatus

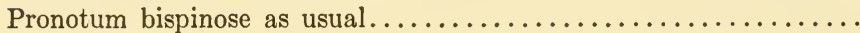

6. Very large, in excess of three millimeters long; integument entirely and cribrately punctate (largest species of the genus)........bellicosus Smaller, not longer than 2.7 millimeters; integuments variously shining, lightly granulate to locally strongly alutaceous............

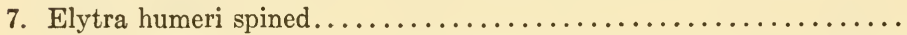

Elytra may or may not have prominent humeri but these never spined

8. Integument entirely granulated, the granules small but abundant, semishining; $2.3 \mathrm{~mm}$. long; antennal segment VIII obconical, IX subovate, $\mathrm{X}$ subglobular and slightly transverse........ gallardoi

Integument of elytra and abdomen semishining to strongly shining; integument of head and pronotum either weakly or locally strongly

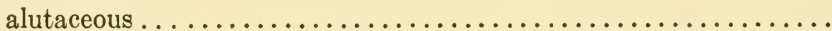

9. Male with metasternum simply tumid on either side of a median impression...................mattogrossoensis new species Male with the metasternum on each side of a median impression either subcarinately tumid or tuberculate with the tubercular swelling

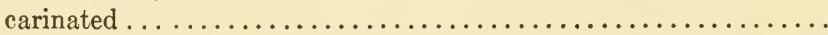

10. Alutaceous punctation of head and pronotum very strong; antennal segment VIII and IX oblong, X transverse; male metasternum with a strongly compressed, sharply carinated tubercle on each side; male with sixth sternite entirely and circularly excavated with the apical angles extended as the approximate arms of a forceps; 2.5 to 2.7

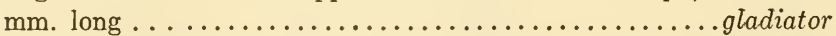
Alutaceous punctation of head and pronotum much weaker, with elytra and abdomen shining; antennal segment VIII oblong, IX ovate, 
$\mathrm{X}$ quadrate; male metasternum strongly concave, with each side rounded into an obtuse but subcarinated swelling; male with sixth sternite depressed, transversely emarginate apically, the apical angles being prolonged as divaricate spines; 2.5 to $2.6 \mathrm{~mm}$. long hamatus

11. Elytral humeri not strong; integument shining; antennae with segment VIII small, IX larger and spherical, X quadrate; $2.5 \mathrm{~mm}$.

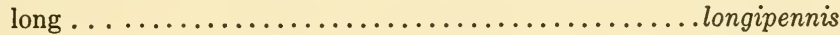

Elytral humeri strongly formed, prominently and oblongly elevated; integument shining also; antennal segments VIII and IX subspehrical, X quadrate; $2.33 \mathrm{~mm}$. long................ reichei

\section{Metopioxys seeversi new species}

Type. Measurements: Head 0.368 from apex of antennal tubercle to cervicum x $0.30 \mathrm{~mm}$. through tempora; cervicum $0.067 \mathrm{~mm}$.; pronotum 0.30 x $0.335 \mathrm{~mm}$.; elytra $0.53 \times 0.60 \mathrm{~mm}$.; abdomen $0.40 \times 0.53 \mathrm{~mm}$.; total length $1.7 \mathrm{~mm}$.; greatest width $0.60 \mathrm{~mm}$.

Yellowish-brown; head and pronotum subgranular; elytra semishining and sparsely but distinctly granulate, each granule bearing an erect seta; abdomen semishining. Pubescence very sparse.

Head pyriform; tempora long $(0.13 \mathrm{~mm}$.), nearly twice as long as the eyes, rounded. Eyes $0.08 \times 0.067 \mathrm{~mm}$. from a dorsal view, composed of 20 coarse facets, circular from a lateral view. Head widest through tempora, narrowing rapidly before eyes to a prominent, slightly upturned antennal tubercle; vertex deeply and broadly sulcate between the eyes; two vertexal foveae placed very near the posterior margin of the head, each fovea in line with the first longitudinal row of ocular facets and each fovea less than the diameter of an ocular facet. Cervicum finely, transversely alutaceous. Ventral surface of the head tumid laterally, with a median longitudinal depression in anterior half and a large, deep, circular median fossa in posterior half. Mentum minutely granulate.

Antennae eleven-segmented, contiguous on the prominent antennal tubercle; segment I very long $(0.70 \mathrm{~mm}$.), nearly as long as rest of antennae (second to eleventh segments inclusive $0.90 \mathrm{~mm}$.), the antennae strongly geniculate and nearly as long as body; the first segment swollen in basal fourth, minutely granular, with a double row of erect setae on ventral face; II elongate $(0.12 \mathrm{~mm}$.), slenderly obconical; III elongate-cylindrical $(0.23$ $\mathrm{mm}$.), almost twice as long as second; IV, VI and VIII elongate-oval and distinctly shorter than V and VII which are elongate-subcylindrical; third to eighth inclusive subequal in width; club formed of last three segments, IX regularly oval; $\mathrm{X}$ trapezoidal from a dorsal view but in reality asymmetrically transverse in the dorso-ventral axis, the ventral face evenly rounded and the dorsal face longer than the ventral face and produced dorso-anteriorly; XI slightly excentrically articulated toward the ventral face, as long as the pre- 
ceding two united, about as wide as tenth, subacute apex, rounded base, dorsal face sinuate, ventral face evenly convex.

Maxillary palpi small, four-segmented, first segment minute; second elongate, arcuate, basally slender, widest at distal three-fourths, narrowing at distal fourth; third elongate, shorter than second, pedunculate at base, swelling from distal three-fourths to apex, and about as wide as second; fourth much wider than third but shorter than second, external face slightly, evenly convex, internal face strongly arcuate-convex to blunted apex. No palpal cone discernible.

Pronotum with a sharp, obliquely dorsal spine $(0.1 \mathrm{~mm}$. long) arising from a swelling at middle of each lateral margin; a broad, rather poorly defined longitudinal sulcus mesial to each spine, from the anterior fourth to the basal bead; disc with a still broader and less well-defined median longitudinal sulcus from apical third to basal bead; a narrower, more clearly defined biarcuate transverse subbasal sulcus from side to side; the longitudinal median sulcus and the transverse sulcus divide the disc into four tumidities, a suboblong apical pair and a subquadrate basal pair.

Elytra with sloping humeri, each humerus armed with a sharp, erect spine; each elytron obliquely subplicate from base of humeral spine; each elytron with two vestigial foveae beneath a strong transverse basal bead and a poorly-defined sutural stria which is not entire, extending to apical sixsevenths where it ends abruptly in a foveaform depression.

Abdomen with five visible tergites of which the first is nearly as long as second and third united, these latter subequal; fourth longer than third; fifth longer than fourth, as long as first, longitudinally slightly tumid in middle. Lateral abdominal margins carinoid. Six visible sternites of which the first is seen as an oblong, depressed plate between the mesial ends of the posterior coxae, about half as long as the latter; second longest; third, fourth, and fifth subequal; sixth (last) longer than fifth. Sternites simple and convex.

Metasternum medianly tumid, this tumid area flattened.

Anterior coxae subcontiguous, narrowly separated by a prosternal lamina. Intermediate coxae approximate, their cavities confluent at the level of the sterna. Posterior coxae very widely separated.

Femora long and slender. Anterior femora gradually swollen at middle; intermediate more definitely swollen at apical three-fourths; posterior still more abruptly swollen at apical three-fourths.

Anterior tibiae thick, slightly contorted, with a long glabrous sulcoid scar on antero-ventral face for basal half, the upper margin of the scar strongly carinated. Intermediate and posterior tibiae long and slender.

Tarsi of usual pattern with two very unequal tarsal claws.

Described from a single female specimen, collected from a log on July 25, 1938, at Villavicencio, Meta, Colombia by Dr. Charles H. Seevers for whom the species is named.

This species has no close relatives. It is the only species of the genus known north of Brazil and structurally is best contrasted with trabeculatus of about the same size from Amazonas. 
Metopioxys mattogrossoensis new species

Type. Measurements: Head 0.522 from apex of antennal tubercle to cervicum x $0.40 \mathrm{~mm}$. through tempora; cervicum $0.08 \mathrm{~mm}$; pronotum $0.435 \mathrm{x}$ $0.50 \mathrm{~mm}$.; elytra $0.70 \times 0.737 \mathrm{~mm}$.; abdomen $0.563 \times 0.70 \mathrm{~mm}$.; total length $2.3 \mathrm{~mm}$.; greatest width $0.737 \mathrm{~mm}$. (Pl. XVIII).

Reddish-brown. Head, including long antennal tubercle, entirely minutely granulate save for two glabrous oblong areas, one obliquely antero-median of each eye. Cervicum transversely alutaceous. Pronotum entirely, minutely granulate save for the lateral spines and their associated basal prominence. Elytra and abdomen strongly shining. Pubescence very sparse.

Head pyriform; tempora long $(0.167 \mathrm{~mm}$.) but relatively shorter than in seeversi, not being much longer than the eyes. Eyes $0.134 \times 0.08 \mathrm{~mm}$. from a dorsal view, composed of about 24 coarse facets, circular from a lateral view. Head widest through tempora, narrowing rapidly anterior of eyes to a prominent, upturned antennal tubercle, this tubercle relatively longer than in seeversi. Vertex deeply, broadly, ovately sulcate between the eyes. Vertexal foveae as in seeversi save that (1) they are more median, each fovea placed mesiad of the mesial edge of the eye, and (2) larger, each fovea twice the diameter of an ocular facet. Ventral surface of head and mentum as in seeversi.

Antennae eleven-segmented, contiguous; segment I very long (1.07 mm.) nearly as long as rest of antennae (second to eleventh inclusive $1.34 \mathrm{~mm}$.), the antennae strongly geniculate and longer than body; first segment as in seeversi; II elongate-obconical $(0.167 \mathrm{~mm}$.) ; III elongate-cylindrical $(0.335$ $\mathrm{mm}$.) twice as long as second; IV, VI, and VIII distinctly shorter than V and VII, fourth and eighth elongate-oval; fifth, sixth, and seventh elongatecylindrical; third to eighth subequal in width. Club of last three segments, IX regularly oval, $\mathrm{X}$ circular from ventral view, transverse from dorsal view, very asymmetrically transverse from lateral view, the dorsal face being strongly produced; XI as in seeversi.

Maxillary palpi as in seeversi save that the fourth segment is slightly longer than second.

Pronotum with a sharp, obliquely dorsal spine $(0.187 \mathrm{~mm}$. long), otherwise as in seeversi save that (1) lateral longitudinal sulci and transverse sulcus are more sharply defined and (2) the basal bead is vestigial and (3) the transverse sulcus deepens medianly to form a distinct, glabrous fovea.

Elytra as in seeversi save that (1) humeral spine is shorter and more inclined, (2) basal elytral foveae relatively larger and deeper, (3) sutural stria ends simply at apical nine-tenths.

Abdomen with five visible tergites of which the first is as long as next two united, these last two subequally long; fourth as long as first; fifth slightly longer than first, rounded subtriangular.

Seven sternites clearly visible. First as in seeversi; second longer than third; third and fourth subequally long; fifth shortest; sixth and seventh subequal medianly and both longer than second. The third, fourth and fifth are 
medianly strongly and minutely granulate; second and seventh not granulate. Third and fourth slightly medianly depressed. Sixth deeply excavated medianly to form a large circular glabrous fossa with sloping sides, the sternite is strongly minutely granulate about this fossa and has each lateral-posterior angle produced into a wide, arcuate, truncate horn. Seventh composed of two separate plates, a right and a left piece which meet medianly to give the sternite an elongate-triangular outline with rounded apex.

Metasternum medianly tumid, this tumid area slightly depressed, the depression gradually deepening posteriorly to broadly separate each side into two simple swellings which are neither tuberculate-compressed (as in gladiator), nor subcarinated (as in hamatus).

Coxae as in seeversi. Femora swollen, but not as abruptly as in seeversi. Tibiae as in seeversi save that the scar of anterior tibiae is longer, occupying nearly two-thirds of tibial length. Tarsi as in seeversi.

Described from a single male specimen from Corumba, Matto Grosso, Brazil. The only close relatives would seem to be two Brazilian species, gladiator and hamatus from both of which it differs in male metasternum, antennae and other morphological features.

The species of Metopioxys may be listed as follows:

gladiator Reitter. 1885. Blumenau, Brazil. Genotype.

bellicosus (Westwood). 1856. Brazil. (Metopias)

gallardoi Bruch. 1917. Buenos Aires, Argentina. con Solenopsis rich-

teri Forel. cf. Bruch, 1929.

hamatus Raffray. 1896. Cavallo Cocho, Amazonas, Brazil.

longipennis (Schaufuss). 1872. Santarem, Brazil. (Metopias)

mattogrossoensis new species. Matto Grosso, Brazil.

reichei (Schaufuss). 1872. Iquitos, Brazil. (Metopias)

seeversi new species. Villavicencio, Meta, Colombia.

spiculatus (Schaufuss). 1886. Amazonas, Brazil.

subcarinatus (Schaufuss). 1872. Santarem, Brazil.

trabeculatus (Schaufuss). 1872. Amazonas, Brazil.

tricuspidatus Raffray. 1896. Iquitos, Amazonas, Brazil.

\section{BARROMETOPIA new genus}

Metopiini having (1) long, bristling, erect pubescence recurved distally; (2) eyes reduced in size and number of facets; (3) tempora long, four times the eye length; (4) vertex trisulcate between the eyes and the prominent, Tshaped antennal tubercle, and with two nude, posteriorly-placed vertexal foveae; (5) eleven-segmented, subcontiguous, strongly geniculated antennae in which the first segment is nearly as long as the other ten segments united, the second segment about twice the length of the third segment and a club formed of the last three segments; (6) short maxillary palpi of four segments; (7) pronotum with a median longitudinal sulcus but no lateral longitudinal sulci and no transverse sulcus; lateral margins not spinose; (8) elytra with humeri 
not spinose, each elytron with a single basal fovea, no dorsal stria but with a subentire, well-formed sutural stria; (9) five tergites with lateral margins carinoid; (10) males with seven sternites and females with six sternites; (11) posterior coxae widely separated.

Genotype: Barrometopia quasimoda new species.

\section{Barrometopia quasimoda new species}

Holotype Male. Measurements: Head 0.3 (from distal margin of antennal tubercle to occipito-cervical sulcus) $\mathrm{x} 0.3$ through tempora; cervicum 0.053 $\mathrm{mm}$.; pronotum $0.27 \times 0.28 \mathrm{~mm}$.; elytra $0.502 \times 0.53 \mathrm{~mm}$.; abdomen $0.23 \times 0.47$ $\mathrm{mm}$.; length $1.4 \mathrm{~mm}$.; width $0.53 \mathrm{~mm}$. (Pl. XVIII).

Uniform light reddish-brown with yellow palpi; integument very lightly, very sparesly and minutely granulate, strongly shining; the pubescence conspicuous, consisting of moderately long, moderately dense, flavous setae which are bristling and erect, with their ends sharply recurved on head, pronotum and elytra but more subdecumbent on abdomen.

Head subpyriform, widest through tempora, narrowing rapidly anterior of the eyes to form the prominent antennal tubercle which is $\mathrm{T}$-shaped in outline; tempora long $(0.16 \mathrm{~mm}$.) about half the head length and four times the eye length; eyes small $(0.04 \times 0.04 \mathrm{~mm}$.), circular, composed of 10 facets. Vertex with a narrow moderately deep, longitudinal sulcus from the base of the antennal tubercle to just posterior of the posterior eye margins; between the eyes, and on either side of the posterior part of this longitudinal sulcus, are two flavous, slightly elevated, quadrate, glabrous areas; each of these quadrate areas is extended anteriorly to the base of the antennal tubercle in a less elevated acute-triangular extension, and each of these triangular areas is bounded mesially by a sharply limited, narrow sulcus so that the head anterior of the eyes is trisulcate; two vertexal foveae placed on the posterior third of vertex, each fovea nude, conspicuous and obliquely oval in shape, larger than an ocular facet and in line with the lateral margin of the quadrate areas noted above.

Transverse occipito-cervical sulcus minutely, longitudinally sculptured; rest of cervicum lightly alutaceous to glabrous.

Mentum glabrous. Ventral surface of head tumid, with a weakly formed, subquadrate depression at middle of base. Ventral surface of cervicum granulated.

Antennae eleven-segmented, subcontiguous, strongly geniculated; segment I long $(0.8 \mathrm{~mm}$.$) , nearly as long as rest of antennae (1.0 \mathrm{~mm}$.), the total antennal length longer than body length, the first segment slightly contorted, granulate, broader in basal third, narrowing to apex where it is dilated, with a foveaform depression on the ventral face of this expanded apex; II, III obconical (second $0.2 \mathrm{~mm}$. long, third $0.1 \mathrm{~mm}$. long); IV subobconical, shorter than third; $\mathrm{V}$ as long as fourth, wider than fourth or sixth; VII as wide as 
fifth; VIII distinctly shorter and narrower than seventh. Club of last three segments, jointly forming an arc so that they have a secondary geniculation; IX longer than seventh and eighth united, asymmetrically suboblong with obliquely truncate base and rounded apex; $\mathrm{X}$ from a lateral view strongly triangular, with the ventral face narrow and acute and the dorsal face long, strongly produced in an arcuate, truncated tooth from the antero-dorsal angle of segment; XI subconical with subsinuate dorsal face and subacute apex.

Maxillary palpi short and four-segmented, the fourth segment carried in a forward arc, strikingly similar to the way in which the antennal club is carried; first segment minute; second elongate-arcuate, gradually thicker in distal three-fourths; third short and obconical, half as long as second and about as wide; fourth only slightly longer than second and about three times as wide, apex rapidly formed and briefly acute, with no discernible palpal cone.

Pronotum relatively simple, not spinose; disc with a deep, narrow but well-defined median longitudinal sulcus from apical six-sevenths to basal twosevenths, each side evenly tumid lateral to this sulcus. No lateral longitudinal sulci and no transverse basal sulcus. Basal two-sevenths constricted and more densely granulate with about six feeble impressions.

Elytra relatively simple with unarmed humeri, no dorsal sulcus or stria; each elytron with a well-formed, subentire sutural stria and a single basal fovea.

Wings well-developed, three times as long as elytra when fully extended, closely and minutely setose.

Abdomen with five tergites; first as long as next two united, these last two subequal; fourth nearly as long as first; fifth rounded subtriangular, about twice as long as first. Lateral margins of the abdomen very narrow and carinoid save at base of first tergite.

Seven sternites; first a subtrapezoidal, depressed plate between posterior coxae and nearly as long as these coxae medianly, clearly visible laterally; second slightly longer than first; third, fourth, and fifth progressively shorter; sixth long, as long as second to fifth inclusive united, flattened medianly with a deep V-shaped incision for apical half of length; seventh, three-fourths as long as sixth, obliquely and longitudinally divided into a right and a left triangular plate.

Metasternum broadly flattened and depressed medianly, with each side elevated into a well-defined, obtuse tubercular swelling; the posterior margin of metasternum medianly truncate and laterally near each posterior coxa extended posteriorly into an obtuse projection.

Posterior coxae widely separated. Femora simply inflated. Anterior trochanters each armed with a long, lamellate, narrow and truncate spine on the ventral face; other trochanters simple. Anterior tibiae with an elongate sulcoid scar with carinated margins extending from base to apical two-thirds on antero-ventral face; other tibiae simple. Tarsi of regular metopiine proportions with two very unequal tarsal claws.

Allotype Female. Similar to holotype save (1) integuments are very light 
flavous, the specimen having apparently just pupated, (2) six sternites only, (3) fifth sternite short and subequal to fourth; sixth sternite long, as long as second to fifth inclusive united and evenly convex, transversely acute-ovate, (4) metasternum simple and evenly tumid, (5) anterior trochanters simple, not armed.

Described from two specimens collected from Barro Colorado Island, Gatun Lake, Panama Canal Zone. Holotype male collected by the author in the morning of July 25, 1936, from stage four log mold at Drayton 12. Allotype female collected by Alfred Emerson on May 4, 1935, from a cell in the nest of the termite Termes panamaensis (Snyder).

This is the only metopiine recorded with Isoptera. Its peculiar appearance is largely that shared by the tribe as a whole but it may well prove to be a synoekete of the termite noted above and the reduced eyes and complicated cephalic sulci lend some credence to this view. The well-developed wings and sharp, typically pselaphoid mandibles mitigate against a symphilic role in the termite society.

Taxonomically it is only related to Metopiosoma of Brazil and Argentina.

Superficially it has the aspect of the goniacerine Bibrax of Barro Colorado Island, but is readily separable as Bibrax bradleyi Fletcher has six sternites in both sexes, strong and broad abdominal margins, eye composed of only a single facet, no median pronotal sulcus and the first sternite long and clearly visible from side to side, being longer than the posterior coxae. This similarity in habitus between Goniacerini and Metopiini has been alluded to by students previously (Fletcher, 1927) but the two tribes are basically very unrelated as will be seen later. 


\section{Tribe 7. Batrisini}

The Batrisini, in contrast with the neotropical Brachyglutini, are generically impoverished. The tribe at present contains eight neotropical genera which have in common (1) antennae distantly inserted on the head, never subcontiguously articulated on a common, median antennal tubercle. (2) Mentum normal, never expanded to cover the mouth and mouth-parts. (3) First sternite very small, nearly hidden between the posterior coxae and median apical margin of metasternum but not invisible as in the Brachyglutini. (4) Lateral abdominal margins absent or represented by one, or at most two, carinae; never wide and strongly formed. (5) Trochanters of intermediate legs always obliquely articulated on the femora so that each femur and coxa are close together. (6) Posterior coxae with their mesial ends forming a subtriangular articulating area for the posterior legs. (7) Tarsi threesegmented, with the first segment minute and the last two segments relatively much longer and elongate-cylindrical to elongate-obconical, the distal segment bearing apically two very unequally developed tarsal claws.

The Batrisini are in reality a very highly specialized tribe. Subfamily status could be advocated for them without too much difficulty. Numerically the tribe is only exceeded by the Brachyglutini in species from the viewpoint of the world fauna. Raffray (1908) finds the batrisines to be best developed in the Indo-Malayan region, poorly represented in Africa, New Zealand, Australia, and Madagascar. From an Indo-Malayan center they appear to have spread chiefly north into the Palarctic and Nearctic areas, chiefly by means of the great genus Batrisodes and its allies, and from these two northern realms to have penetrated into the African region and into the Neotropical region.

The Batrisini are approached in their carinoid abdominal margin by a few genera of Brachyglutini and some Metopiini, and by the Metopiini in the construction of the first sternite and tarsal claws.

Many batrisines are synoeketes of the ant society, especially within the genus Batrisodes, where they eat the eggs and larvae of the host while more or less tolerated by the host workers. The palarctic synoeketes have been discussed by Donisthorpe (1927) and the nearctic synoeketes in Batrisodes have been cited with their host ants by Blatchley (1910), Fall (1912), Holmquist (1928), Mann (1911), Park (1929, 1932, 1935a, 1935b), Schwarz (1890, 1896), and by Wickham $(1894,1896,1898,1900)$. Food, habits, and ecological relations within the ant nest have been reported less abundantly (Park, 1929, $1932,1935 \mathrm{~b})$. Virtually nothing is known of the neotropical inquilines among the Batrisini.

In general the majority of the Batrisini is free-living, inhabiting the floor stratum of forests, in moist leaf and log mold. Here they are strictly predaceous, feeding on mold mites (Oribatidae) or even attacking larger injured 
animals (earthworms) and some species may be facultative myrmecophiles, living freely in floor mold and the nest of ants (Park, 1932, 1935b). Many species of neotropical areas eome to lights at night, as will be noted later.

\section{Key to the Neotropical Genera}

Body short, thick and globular (Pl. XVIII) ............... 2

Body elongate-cylindrical (PI. XVIII) .................. 3

2. Humerus of elytron produced into a distinct callus; metasternum never medianly carinated.........EUPHALEPSUS (Pl. XV, XVIII)

Humerus of elytron without a callus or swelling; metasternum always medianly carinated .................... PHALEPSOIDES

3. Lateral margins of first tergite with both an external and an internal carina as the margin of the segment; other tergites with only a single lateral carina or no carina $(\mathrm{Pl} . \mathrm{XIX}, 1) \ldots \ldots \ldots \ldots \ldots \ldots \ldots \ldots$

Lateral margins of the first three or four tergites with both an external and an internal carina (Pl. XVIII)........BATOCTENUS

4. Elytron with a well marked dorsal stria.............. ITETICUS Elytron with no dorsal stria or replacing dorsal depression.........

5. Pronotum with a subbasal transverse sulcus, and without antebasal

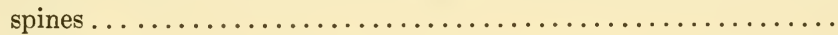

Pronotum with no subbasal transverse sulcus, but with two large antebasal spines, and at times with a smaller spine on each side of the pronotum anterior of middle................XXARTHRIUS

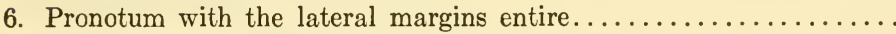

Pronotum with each lateral margin distinctly incised or gashed.... SYRMOCERUS (Pl. XIX)

7. Pronotum with a lateral longitudinal sulcus on each side. . SYRBATUS Pronotum without lateral longitudinal sulci..........ARTHMIUS

\section{ARTHMIUS (LeConte, 1850)}

LeConte (1850) (Arthmius)

LeConte and Horn (1883) (Batrisus)

Schaufuss (1872, 1879) (Batrisus, Bryaxis)

RAFFRAY (1890) (Batrisus)

RafFRAY (1897, 1904, 1908, 1911) (Arthmius)

Sharp (1887) (Batrisus)

Fletcher $(1928,1930)$ (Arthmius)

In 1850, John L. LeConte erected the genus Arthmius and the genotype, Arthmius globicollis LeConte, for a small batrisine whose range is now known to cover the eastern third of the United States (Florida and Georgia northwards into Pennsylvania). Few genera were destined to be more important taxonomically. Thirty-three years later LeConte and Horn placed globicollis into Batrisus, since the species had been described as having a single tarsal claw but later study "with a powerful microscope" demonstrated two unequal 
tarsal claws. Sharp (1887) and Raffray (1890) followed this lead, describing their new species in subgenus Arthmius of Batrisus.

In 1897 Raffray, in an important paper, reaffirmed his earlier belief of 1894, that Arthmius of LeConte was sufficiently distinct to warrant generaic status, and divided the genus into three subgenera: Syrbatus Reitter, Arthmius ss. of LeConte, and Syrmocerus Raffray. These three subgenera are now recognized as distinct genera, and as such are treated separately in this paper as I have been unable to find species which intergrade in their pronotal anatomy to allow bridging the gap between one genus and another, although all three show an arthmioid habitus.

The neotropical batrisines become numerically important by virtue of Arthmius. Although the genotype is nearctic, the genus as a whole is overwhelmingly neotropical. At present there are five species known north of Mexico, of which four are distributed east of the Rocky Mountains and one from Oak Creek Canyon, Arizona, at 6000 feet (morsus Fletcher, 1932). In contrast the neotropics have at present 94 species distributed: Mexico (12), Guatemala (3), Panama (2), Canal Zone (1), Colombia (5), Venezuela (2), Bolivia (10), Peru (5), Chili (1), Paraguay (2) and Brazil (51). Brazil, especially the drainage basin of the Amazon river, would seem to be the center of taxonomic diversity, and many new species remain to be discovered before our information can be considered complete enough for any generalized statement. At present I am inclined to view Arthmius as a typical neotropical genus of the rain forest, spreading with difficulty into drier or cooler areas. I should be surprised if species of the genus were found north of the deciduous forest biome or above the deciduous forest montane zone.

Their sharp mandibles presuppose an adherence to the predaceous family habit, and they do not appear to have adjusted to a life with ants and termites. Their natural habitat is the forest floor mold. New evidence presented later seems to prove that they inhabit this stratum by day and fly by night. Their large eyes and long wings support this view.

Sex is readily ascertained. The males have six sternites fully visible (not counting the morphological first sternite), of which the last is quite minute as a rule, placed as an ovate-transverse plate between the very large last tergite and next to the last sternite. This fifth visible sternite is usually large and variously ornamented or formed. The antennae, legs, and especially the dorsal surface of the head may be highly abnormal.

The females have simple legs, antennae, and head as a rule and always only five sternites fully visible (not counting the morphological first sternite), of which the last is large.

I have attempted to key out the species of Arthmius. This would have been impossible but for the work of Raffray since the types are not at hand in most instances. In 1897 Raffray keyed out the species of the genus then known, and this was especially good since he had direct access to most of the types of the early species of Schaufuss, Sharp, and Reitter. In the following keys this 1897 background is integrated with the more recent work. 
Key to Groups of Arthmius, Based on the Male Sex

(After Raffray, 1904)

Pronotum laterally flattened, and the disk medianly elevated into a definite but obtuse longitudinal median carina or strongly longitudinally gibbous ............................. 2

Pronotum with sides and disk normally convex.............. 3

2. Fourth antennal segment distinctly larger than either the third or fifth segments, or antennae thick or otherwise abnormal...... I

Antennae long, slender, simple....................... II

3. Antennae abnormal ............................. 4

Antennae normal . . .............................. 5

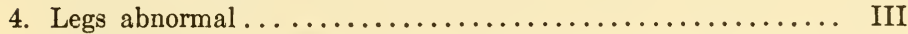

Legs normal ................................ IV

5. Legs abnormal .......................... V

Legs normal . . . . . . . . . . . 6

6. Dorsal surface of head abnormally excavated or armed......... 7

Dorsal surface of head normal..................... VIII

7. Clypeus (epistome) normal..................... VI

Clypeus (epistome) abnormally excavated, tuberculated or otherwise armed ................................ VII

\section{Key to Species of Group I}

Six sternites fully visible (MaLES) $\ldots \ldots \ldots \ldots \ldots \ldots \ldots \ldots \ldots \ldots, 2$

Five sternites fully visible (Females) $\ldots \ldots \ldots \ldots \ldots \ldots \ldots \ldots, 4$

2. Distal margin of clypeus truncate, with rounded apical angle, and dorsal surface strongly elevated into a wide median longitudinal biconcave carina; antennal segment IV three times as long as third, cylindrical but much wider than either third or fifth with the mesial face uniformly produced; $2.1 \mathrm{~mm}$. long.............plicicollis

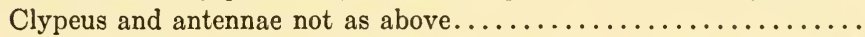

3. Distal margin of clypeus medianly produced into a long horn with its subacuate apex tufted with setae; antennal segment IV ovate; 1.5

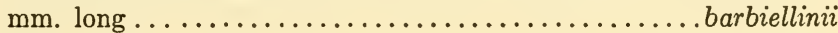

Distal margin of clypeus strongly, evenly rounded and with the dorsal surface tumid to end basally in a small pubescent horn; antennal segment IV twice as long as third, with the mesial face strongly produced medianly, much wider than third or fifth; $2 \mathrm{~mm} . . . .$.

4. Vertex with a strong median fossa $; 2 \mathrm{~mm}$. long............ prassicornis

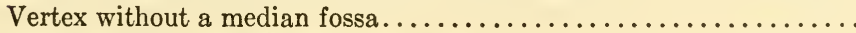

5. Known only from Mexico.......................plicicollis

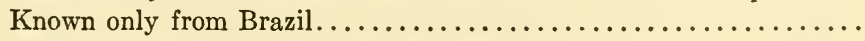

6. North of Tropic of Capricorn.....................barbiellinii South of Tropic of Capricorn...................primarius 


\section{Group II}

This second group holds a single species, dichrous, known from a single male from Blumenau, Brazil.

\section{Key to the Species of Group III}

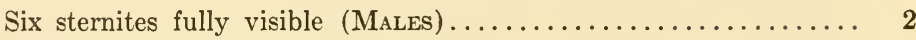

Five sternites fully visible (Females) $\ldots \ldots \ldots \ldots \ldots \ldots \ldots \ldots \ldots \ldots \ldots$

2. Antennal segment I very abnormal with the mesio-apical angle

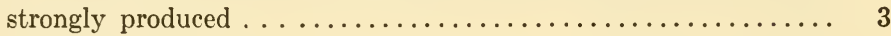

Antennal segment I simple, not as above................. 4

3. Antennal segment I with the mesio-apical angle produced into a long, flattened tooth with obtuse summit; dorsal surface of head simple, square, slightly convex through vertex with two pair of foveae, an anterior oblong pair and a posterior punctiform pair; $1.7 \mathrm{~mm}$.

Antennal segment I obtrapezoidal, wider than the eleventh segment, longer than second and third united, with the mesio-apical angle produced into a short, subconical, subacute extension; dorsal surface of head strongly transversely excavated and toothed as described below; $1.6 \mathrm{~mm}$. long............. sabomba new species

4. Antennae with the intermediate segments articulated to form an arc.. Antennae with the intermediate segments not forming an arc.......

5. Arc confined to antennal segments III, IV, and V, with the fifth segment with the ventro-apical face produced and projecting ventroapically $; 1.8 \mathrm{~mm} . . . \ldots \ldots \ldots \ldots \ldots \ldots \ldots . . \ldots \ldots$ truncaticeps

Arc confined to antennal segments distal to III................

6. Arc confined to antennal segments IV, V, VI, VII and VIII; VI and VII slightly longer than wide with squamous pubescence on ventral faces; VIII slightly transverse with the apical angle acute; 1.7

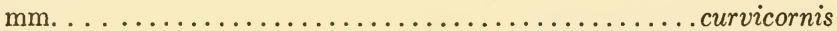

7. Arc beginning with segment V and ending with VII or VIII......... Arc extending from segment $\mathrm{V}$ to segment IX, all of these segments of normal shape; posterior trochanters enlarged with the posterior face concave, the concavity densely pubescent; $1.6 \mathrm{~mm}$....... scaphiger

8. Antennal segment $\mathrm{V}$ not much larger than IV; $1.8 \mathrm{~mm}$..... simplicior

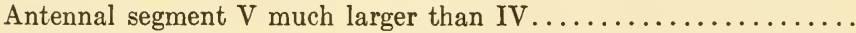

9. Segment V cylindrical-ovate, much wider than IV or VI; VI elongate, very slender, slightly arcuate; VII arcuate-triangular with apical face wide, truncate and the latero-apical angle produced; $1.9 \mathrm{~mm}$. . pedestrianus

Segment V strongly dilated toward the base; VI and VII thick and less than twice as long as wide, the seventh segment not arcuatetriangular and the apical-external angle not produced; $1.6 \mathrm{~mm}$. 
10. Antennal segment IV very transverse, dilated, one-half wider than II, the inner surface somewhat concave and notably pubescent; $V$ of same general form but wider and slightly produced on external face, surface also pubescent; VI greatly expanded on external face, auriculate, twice as broad as II, the edge fringed with dense white setae; VII subquadrate, narrower and not wider than II; $1.6 \mathrm{~mm}$.

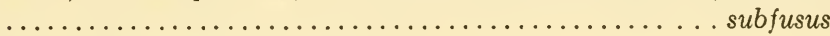

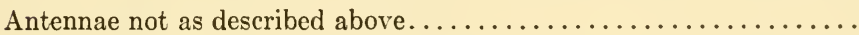

11. Antennal segment III much larger than I or II and swollen; II square;

IV to VIII oval $; 2.2 \mathrm{~mm} . . \ldots \ldots \ldots \ldots \ldots \ldots \ldots \ldots \ldots$ inflatipes

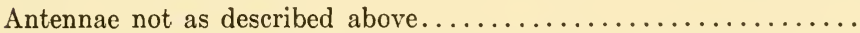

12. First four antennal segments simple, III and IV obconical; V to $\mathrm{X}$ progressively larger, slightly flattened and lightly, squamosely pubescent; V obconical, VI subglobular, VII square, VIII slightly transverse $; 1.7 \mathrm{~mm} . . \ldots \ldots \ldots \ldots \ldots \ldots \ldots$. . . . . . . . . . . . Antennal segment $\mathrm{V}$ at least twice as long as III; VI slightly shorter than VIII; VII nearly as long as V, slightly clubbed in form;

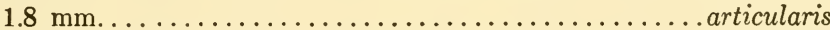

13. Head and pronotum black; elytra and abdomen chestnut red. .bicolor Body uniform reddish-brown....................... 14

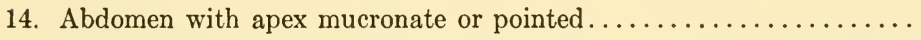
15

Abdomen with apex rounded, not mucronate... sabomba new species

15. Median depressions at base of first tergite very transverse, nearly confluent medianly; intermediate tibiae notched on the external face beyond the middle of their length................. singularis Median depressions at base of first tergite simply ovate and very distant from each other; intermediate tibiae not notched or grooved on the external face......................... articularis

In this key singularis and bicolor have been described on the female sex only, each from a single specimen. It is possible that bicolor belongs in Group I and the discovery of the males in both species may change their positions.

Arthmius sabomba new species

Holotype Male. Measurements: Head 0.368 including apex of clypeus to occiput $\times 0.469 \mathrm{~mm}$. through eyes; pronotum $0.368 \times 0.368$; elytra $0.55 \mathrm{x}$ $0.76 \mathrm{~mm}$.; abdomen $0.335 \times 0.67 \mathrm{~mm}$; t total length $1.6 \mathrm{~mm}$.; greatest width $0.76 \mathrm{~mm}$. (Pl. VI).

Reddish-brown, semishining with conspicuous semierect pubescence. Head with very short, right-angled tempora about the length of an ocular facet. Eyes large $(0.12 \times 0.067 \mathrm{~mm}$. from dorsal view), composed of about 24 very coarse facets; subreniform from a lateral view. Occiput with a short median longitudinal carina. Vertex with two foveae; each fovea nude, separated from an eye by the length of three ocular facets, deep and with a diameter of an ocular facet. Vertex very transverse, with square corners, the sides slightly 
divergent to the antero-lateral angles which are coarsely punctate; anterior half of vertex medianly excavated to form a deep glabrous fossa. Frontal margin evenly concave between antennal bases with two short, contiguous, triangular teeth at middle; front densely pubescent and declivous between antennae, the median portion of this declivity produced into an obconical, glabrous tubercle from the base of which arises on each side a tuft of conspicuous setae. Clypeus greatly elongated and strongly tumid; the apical margin is a black bead strongly produced in an obtuse angle; surface with erect pubescence and granulate-punctate, the tumidity ascending dorsoposteriorly in an obtuse angle. Considering the clypeus as a whole, therefore, the angulate apical and basal margins give it a symmetrical parallelogram outline. The median angle of elevated basal margin is strongly carinated and elevated to partially obscure the obconical appressed tubercle of the front.

Maxillary palpi four-segmented and simple; first segment minute; second sharply arcuate at base, elongate, slender for basal three-fourths and expanded in apical fourth; third short, rounded triangular with the usual convex external, and short subangulate internal, faces; fourth longer than second, twice as wide as third, base lengthily oblique, apex subacute, convex external face, sinuate-convex internal face; palpal cone short, thick, conical.

Antennae eleven-segmented, coarsely punctate, distant, abnormal; segment I obtrapezoidal, wider than the eleventh segment, longer than second and third united, with the mesio-apical angle strongly produced; II and III subequally wide, second moniliform, third slightly shorter and transversely asymmetrical; IV large, longer than any other segment save the eleventh, and wider than any other segment save the first and last three, asymmetrically elongate with the basal end much wider than apical end and the mesio-basal angle produced; V, VI, VII, VIII subcylindrical, fifth longest of these four, next two subequal, eighth shortest; IX elongate hexagonal; $\mathrm{X}$ transverse hexagonal; XI as long as preceding two united, with truncate base and subacute apex.

Pronotum rounded hexagonal in outline, widest in anterior third, with evenly convex disk; basal third with an arcuate-transverse glabrous sulcus, the median posterior margin of which is produced anteriorly into a short, acute cusp; sulcus ends on each side in an obscure fovea.

Elytra with prominent, obliquely elevated humeri; each elytron with three large nude basal foveae and an entire sutural stria.

Wings long and well-formed.

Abdomen with five tergites; first with a strong lateral margin for the basal two-thirds as a consequence of an external and an internal carina, apical third of segment not margined and not carinated; this first segment two and a half times longer than next two united; second and third subequal and without lateral margins; fourth half the length of first; fifth shorter than fourth, rounded subtriangular.

Abdomen with six sternites fully visible. Fifth (next to last) large, glabrous, as long as first four united, with a conspicuous median depression 
which is very broad and deepens apically, the apical margin abruptly erected to form a posterior wall of the depression and this apical margin medianly slightly concave; basal-external angles of depression subserrately elevated into three or four minute blackened obtuse denticles, each denticle bearing a long coarse, flavous, decumbent seta which is directed medio-posteriorly for one-third or more of the depression. Sixth (last) sternite minute, transversely fusiform, granulate-punctate, and lies between the median apical margins of the last tergite and next to last sternite.

Intermediate trochanters conspicuously abnormal, with the ventral face flat and ovate, this surface crowded with short, uniform setae and in addition a single, very long seta which arises from the anterior margin of the pad (examination of the numerous male paratypes, both dry and microscope slidemounts, attests to the complete constancy of this single erect seta set in the pad of short setae). Anterior and posterior trochanters, all femora and anterior tibiae simple. Intermediate and posterior tibiae with a strong uncus near apex. Tarsi normal for tribe.

Allotype Female. Similar to holotype save that (1) eyes are slightly smaller and tempora slightly longer; (2) occipital carina not as strongly formed; (3) vertex simple, semicircularly impressed between antennal tubercles, with an evenly declivous front which lacks teeth and tubercle; (4) clypeus simple, declivous, evenly convex; (5) antennae simple; (6) first tergite relatively shorter; (7) only five fully visible sternites, of which the last is large, distinctly longer than preceding three united, semilunar in outline with a concave apical margin; (8) intermediate trochanters simple; (9) tibiae not apically armed.

Described on 15 specimens, all collected on Barro Colorado Island, Gatun Lake, Panama Canal Zone. Male paratype (July 7, 1936); three male paratypes (July 15, 1936); male paratype (July 16, 1936); male holotype (July 22, 1936); three male paratypes (July 24, 1936); male paratype (July 29, 1936) all collected at light at night after 9 P.M. and before midnight, and all collected by the author. Two male paratypes (July 17, 1938), one male and one female paratype (July 19,1938) and allotype female (July 23, 1938) all collected from leaf mold of the rain forest floor by Dr. Eliot Williams.

From these data it should be noted that although ten were taken at light at night, only five were collected during the day. Of these taken at light all were males, but the diurnal catch was of nearly equal sex ratio ( 3 males, 2 females). This is either coincidence or an indication that the males fly to light more than females.

Second, it seems clear that the species is nocturnal. This is a general rule for the family but heretofore has lacked definite substantiation. Thus careful, quantitative quadrat samples of the forest leaf mold discovered sabomba in the floor by day and not by night; the same species, in the same locality, was taken on the wing only after dusk. For a full statement of the analysis the work of Williams (1941) should be examined.

Third, a male (July 17, 1938) and a female (July 19, 1938) had evidently 
only recently pupated. This checks with similar data on other species so that there seems to be a general period of pselaphid pupation in the rain forest floor in the rainy season, during the first half of July. Other periods are to be expected (May 4, 1935 for Barrometopia quasimoda in the nest of its host termite at the end of the dry season is of interest as the dark, humid nest environment is in contrast with the dry season) and it is quite possible that life cycles are begun and completed for the duration of the protracted wet period in the tropics.

Arthmius sabomba is unrelated to other groups in the genus save the third, and within this group is distantly associated with bubalus. Both sexes promptly diverge from Raffray's 1897 key to males and females, and the recent species of Raffray and Fletcher are equally different.

In this connection a word should be said as to the identity of unique specimens in the genus. Since many species are known only from one sex, the keys to Arthmius in the present paper will serve to identify males or species represented by both sexes but students with an isolated female will have to take the specimen through each group key, and then consult Raffray's notes of 1897. Even then there is an element of doubt since early descriptions are not complete.

\section{Key to the Species of Group IV}

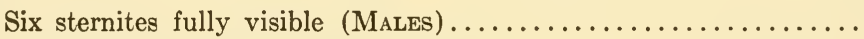

Five sternites fully visible (Females) $\ldots \ldots \ldots \ldots \ldots \ldots \ldots \ldots \ldots \ldots$

2. Antennal segment I very large, inflated on the ventral face, other antennal segments simple; $2.1 \mathrm{~mm} . . \ldots \ldots \ldots \ldots \ldots$................

Antennal segment I simple, not conspicuously large and ventrally

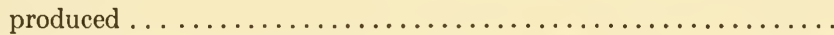

3. Antennal segment II abnormally large................. 4

Antennal segment II not abnormally large................ 6

4. Antennal segment II with the dorsal face dilated and with the internal

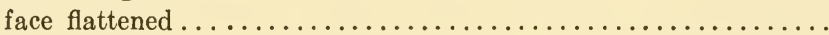

Antennal segment II not armed or dilated but more than three times longer than segment III, with the internal face rounded, and dorsal face depressed and squamously pubescent; $2.5 \mathrm{~mm}$.......... orion

5. Antennal segments III, IV, and VI not much longer than wide; V and VII much longer; VIII square; IX and $\mathrm{X}$ much larger and

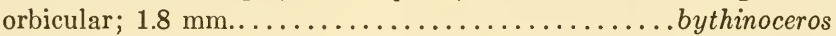

Antennal segments IV, V, and VI nearly three times longer than wide; VII much longer than wide; IX and $\mathrm{X}$ oval; $2.2-2.4 \mathrm{~mm}$..... reitteri

6. Antennal segments V, VI, VII with internal faces slightly rounded, slightly larger than IV or VIII; IV and VI square; VIII trans-

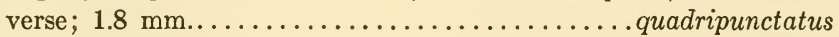

Antennal segment $\mathrm{V}$ much larger than IV or VI; VII cylindrical;

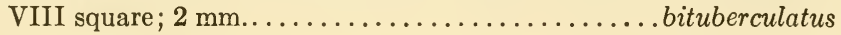


7. Abdomen mucronate or apically pointed; intermediate tibiae simple; antennal segments $\mathrm{V}$ and VII much longer and thicker than IV, VI, and VIII....................... quadripunctatus

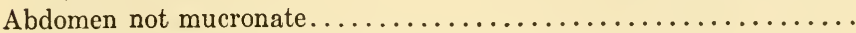

8. Head with a small longitudinal carina at middle of the front; antennal segment II much larger than I or III............... orion Head without a median longitudinal frontal carina but with a small longitudinal median carina on occiput............bythinoceros

\section{Key to the Species of Group V}

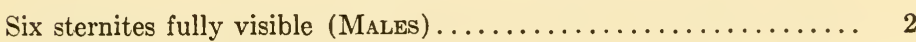

Five sternites fully visible (Females) $\ldots \ldots \ldots \ldots \ldots \ldots \ldots \ldots \ldots \ldots \ldots \ldots$

2. Anterior femora abnormal......................... 3

Anterior femora simple........................ 10

3. Anterior femora with a deep transverse sulcus on the dorsal face, this sulcus limited anteriorly by a strong transversely flattened and obtuse tubercle, and limited posteriorly by a much smaller, obtuse tubercle; intermediate trochanters with a small sharp median spine;

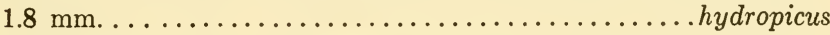
Anterior femora with different modifications................

4. Antennal tubercles very rugosely punctate and swollen; $1.6 \mathrm{~mm} . .$. manifestus

Antennal tubercles smooth and either flat or only slightly elevated...

5. Anterior femora with a median deep transverse sulcus on the dorsal face, the borders of the sulcus carinated and densely pubescent, and posterior (basal) to this sulcus a wide impression, and anterior (apical) to the sulcus a flattened squamous area; $1.9 \mathrm{~mm} . . . .$. femoratus

Anterior femora with different modifications.................

6. Anterior femora with a shallow median depression on the dorsal face, the anterior margin of this depression is slightly pubescent and lightly carinated; apical to this carinated margin is a minute transverse sulcus; $2 \mathrm{~mm} . . \ldots \ldots \ldots \ldots \ldots \ldots \ldots \ldots \ldots \ldots$.

Anterior femora with different modifications..................

7. Anterior femora with a deep oval fovea at apical third of dorsal face, the margins of this fovea lacking a pubescent carina; external to the apical fovea the femora are incised by a transverse notch;

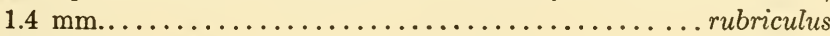
Anterior femora with different modifications............... 8

8. Fovea of dorsal surface of anterior femora oblong............ 9 Anterior femora with a perfectly circular fovea and a high crenulated

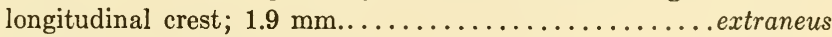

9. Intermediate trochanters with a light brush of setae; $1.9 \mathrm{~mm} . .$. 
Intermediate trochanters absolutely devoid of a pubescent brush;

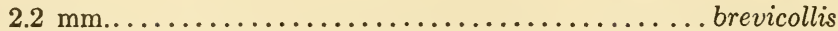

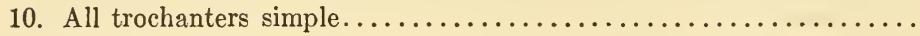

Anterior trochanters with a short apical spine; intermediate trochanters with a slender, sharp pointed, erect, very long median spine;

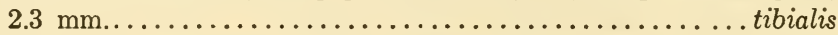

11. Anterior tibiae absolutely simple; metasternum with a deep median oblong fovea; first fully visible sternite with a thin, posteriorly-

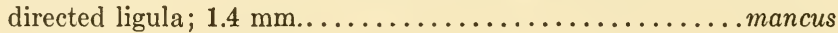

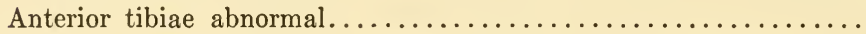

12. Anterior tibiae not dilated on external face, but short and thick, with the internal face thicker and rounded at middle, these tibiae not

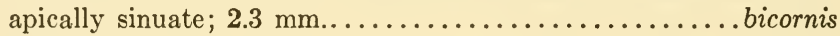
Anterior tibiae with different modifications..................

13. Anterior tibiae with an abrupt, pointed dilation near the middle of the dorso-external face $; 2 \mathrm{~mm} . . . \ldots \ldots \ldots \ldots$.......... simplicicornis Anterior tibiae nearly entirely dilated on the external face, this dilation slightly rounded and flattened; $1.4-1.5 \mathrm{~mm}$....... latipes

14. First apparent sternite (second morphological) with a median longitudinal carina near base.....................hydropicus First apparent sternite (second morphological) with no median longitudinal carina ..........................manifestus

Key to the Species of Group VI

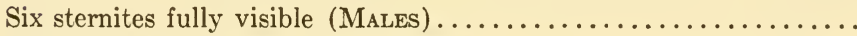

Five sternites fully visible (Females) $\ldots \ldots \ldots \ldots \ldots \ldots \ldots \ldots \ldots \ldots \ldots \ldots$

2. Head not excavated.............................. 3

Head variously excavated.......................... 4

3. Margin of front between antennal bases simply concave or posteriorly arcuate, with a pair of short conical approximate and anteriorly inclined truncated tubercles; $2.8 \mathrm{~mm} . . . \ldots \ldots \ldots \ldots$......... rhoceros

Margin of front between antennal bases biarcuate with the median area, joining the arcuations, produced anteriorly into a subacute,

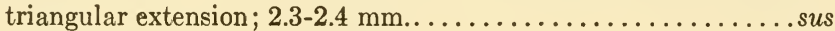

4. Species unknown south of Panama.................... 5

Species unknown north of Brazil.................... 6

5. Lateral margin of the vertex above each eye erected into a strong but obtuse, slightly arcuate carina; $2.0-2.2 \mathrm{~mm} . \ldots \ldots \ldots \ldots$........ vidus

Lateral margin of the vertex above each eye not at all carinated;

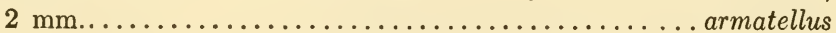

6. Head much longer than wide not including the eyes, or as long as wide including the eyes; lateral margins of the vertex concave or sinuate, the head widening to the prominent laterally everted antennal tubercles; vertex broadly excavated from eyes to frontal margin, this depression bearing an elongate carina in the shape of a narrow 
staple with abruptly everted ends (this odd structure may also be likened to a single heavy carina which is medianly and longitudinally sulcate, with this narrow sulcus closed apically and expanded basally) $; 2$ mm....................................

Head with different modifications..................... 7

7. Vertex and occiput more or less distinctly excavated, the excavation simple or complexly spined, tuberculated, sulcate or carinate.... Head between the eyes to the occiput simply convex or slightly tumid,

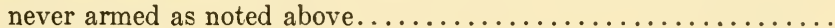

8. Metasternum with the apical margin medianly erected between the posterior coxae into a transverse lamella which is inclined anteriorly

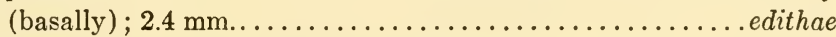

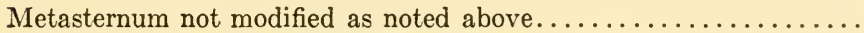

9. Vertex simply convex between the eyes and the occiput, anteriorly there are three obsolete impressions, an apical transverse and two subcircular $1.9 \mathrm{~mm} . . \ldots \ldots \ldots \ldots \ldots \ldots \ldots$. . . . . . . . . . . .

Vertex from the eyes to the occiput simple, slightly transversely gibbous; anterior half of vertex simply and deeply depressed, this excavation strongly rounded posteriorly, occupying the median third of the head width and extending in an arc for median third of the inter-antennal margin $; 1.6 \mathrm{~mm} . . . \ldots \ldots \ldots \ldots$. cinnamomeus

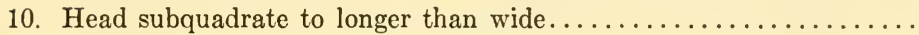

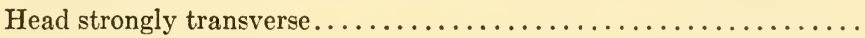

11. Head with a slightly arcuate, deep, entire sulcus which extends from just above and behind each eye transversely over the vertex, this conspicuous excavation extended posteriorly at middle in a secondary subtriangular excavation; in the center of this transverse sulcus is a small tubercle; metasternum sulcate; $1.25 \mathrm{~mm}$.... transversalis Head more strongly transverse; vertex with a suboval depression at middle between the eyes, with an elongate oval tubercle at center of this depression; just apical to this median depression is an arcuate, transverse sulcus occupying median third of the vertex; metasternum sulcate with a strong compressed tubercle on each side; $2.3-2.4 \mathrm{~mm}$. vulneratus

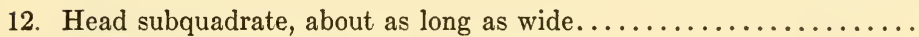
Head much longer than wide; $2.1 \mathrm{~mm} . \ldots \ldots \ldots \ldots \ldots$.................

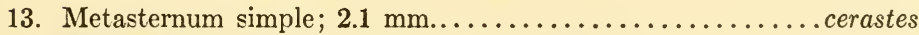

Metasternum broadly concave, with a deep and narrow sulcus in the concavity, armed on each side behind the middle by a sharp spine;

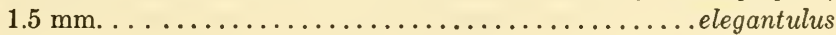

14. Head with either a small tubercle near middle of the front, or a slender

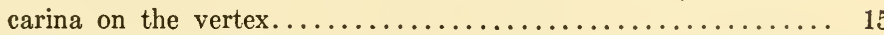

Head without a frontal tubercle and without a vertexal carina...... 17

15. Head with a small tubercle....................... 16 
Head with a slender carina on the anterior part of the vertex; front with two circular, sharply delimited foveae...............sus

16. Posterior frontal area with a small, median tubercle; antennal tubercles rounded, not prominent..................edithae

Anterior frontal area with a small, median tubercle; anterior tubercles strongly formed and more pointed; $2 \mathrm{~mm} . . \ldots \ldots \ldots$...... patruelis

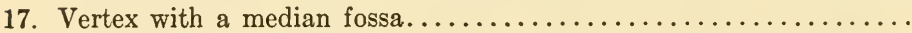

Vertex without a median fossa; front lacking a transverse frontal impression; head with four foveae, the posterior pair being placed between the eyes; a small rugose and squamously pubescent patch on each antennal tubercle....................... vividus

18. Head very strongly transverse................... vulneratus

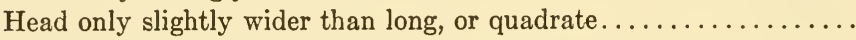

19. Vertexal fossa round, and either very shallow or deep............ Vertexal fossa oblong, very deep...................... cornutus

20. Vertexal fossa deep and well-formed................. armatellus Vertexal fossa wide but very superficial, being in reality a shallow depression . . .....................................

Key to the Species of Group VII

Six sternites fully visible (MaLes) $\ldots \ldots \ldots \ldots \ldots \ldots \ldots \ldots \ldots \ldots, 2$

Five sternites fully visible (Females) $\ldots \ldots \ldots \ldots \ldots \ldots \ldots \ldots, 16$

2. Clypeus (epistoma) abnormal....................... 3

Clypeus (epistoma) normally formed but the front having a median tubercle; this frontal tubercle separated from the inter-antennal frontal margin by a transverse depression so that the obtusely pointed and slightly suberect tubercle appears to be a part of the

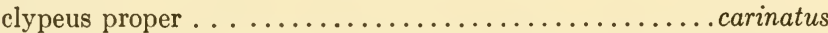

3. Head very transverse, with dilated and externally auriculated antennal tubercles, these tubercles expanded laterally beyond the eyes so that the head is widest through the antennal bases; vertex with a deep, sharply formed and regularly trapezoidal excavation between the eyes; intermediate trochanters simple but intermediate tibiae with a very strong spine; metasternum flat, with a nearly entire sulcus; $2.4 \mathrm{~mm} . \ldots \ldots \ldots \ldots \ldots \ldots \ldots \ldots \ldots \ldots \ldots \ldots$ auriculatus Head only slightly wider than long, or quadrate........... 4

4. Vertex concave ................................ 5

Vertex either simply convex or prominently elevated but not concave 6

5. Head between the eyes concave for nearly the entire head width, with a small tubercle each side between the eyes; intermediate trochanters armed medianly with a small tubercle; intermediate tibiae with a long spine $; 2.2-2.5 \mathrm{~mm} . \ldots \ldots \ldots \ldots \ldots \ldots \ldots \ldots \ldots \ldots$ boliviensis

Head with a median elongate-triangular shallow concavity; trochanters simple; intermediate tibiae with a strong spine......germaini 
6. Vertex prominently elevated..................... 7

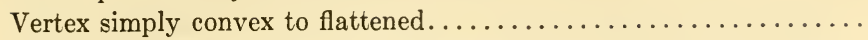

7. Vertex becoming prominently triangularly elevated apically, this elevation with an apical ciliated border and apical to this a very small median fovea; anterior and intermediate trochanters armed each with a small, pointed tubercle $; 1.9 \mathrm{~mm} . . . \ldots \ldots . .$. triangularis

Vertex becoming prominently triangularly elevated apically, the summit of this elevation acutely incised or notched, with a large oblique fovea on each side entering on the front; intermediate trochanters sparsely pubescent; $1.55 \mathrm{~mm} . . \ldots \ldots \ldots \ldots \ldots$. elevatus

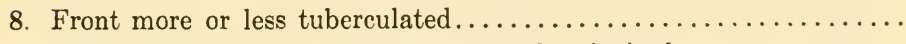

Front without a tubercle, but excavated or incised..............

9. Front with a very short, median, wide, strongly truncated tubercle, with the truncated face of the tubercle rugose; antennal tubercles flattened and rounded; the trochanters simple; $1.9 \mathrm{~mm} . . . . . .$. circumscriptus

Front with a median tubercle which is more or less sharp-pointed; antennal tubercle strongly formed, especially prominent laterally; therefore the frontal margin of head appears trituberculate......

10. Head some longer than wide, with a strong, thick, median triangular spinoid tubercle on the front and very prominent antennal tubercles; trochanters simple; metasternum deeply sulcate; $2.1 \mathrm{~mm} . . . . .$. . peniculus

Head slightly transverse, with a frontal tubercle in the form of a medianly-placed, erect, straight horn; intermediate and posterior trochanters with a small brush of setae; $1.9 \mathrm{~mm} . . . . .$. . erectus

11. Front simply depressed and broadly bifoveate; metasternum broadly sulcate; intermediate trochanters slightly pubescent; $1.7 \mathrm{~mm} . .$. labiatus

Front diversely notched, incised or excavated...............

12. Frontal incisure large and quadrangular; trochanters simple; metasternum with an entire but shallow median sulcus; $1.4-1.6 \mathrm{~mm} . .$. honestus

Frontal incisure deep to very shallow, and of various shapes but not quadrangular . . . . . . . . . . . . . . . . . . . . . . . . . . . .

13. Frontal incisure triangular, deep, with an excavated area within the

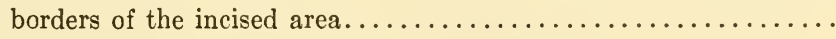

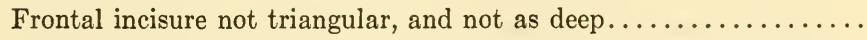

14. Deep triangular notch of the front regular in outline, with a transverse carina placed near the bottom of the incisure and apically; clypeus with a conspicuously large, basally compressed, transverse horn, this horn being dorsally swollen, rugose and slightly pointed posteriorly; trochanters simple; metasternum with a broad, entire sulcus more or less carinated apically; $2 \mathrm{~mm} . . \ldots \ldots \ldots \ldots \ldots \ldots$. elephas 
Frontal incisure less deep, less wide, more ogival-triangular, prolonged posteriorly in a sulcus which disappears on the vertex; clypeus triangularly gibbous; trochanters simple; metasternum with short

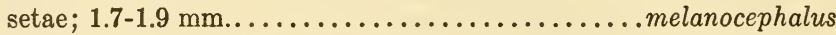

15. Frontal incisure transverse, medianly angulate, with long setae, and a slender carina disappearing posteriorly on the vertex; epistome (clypeus) with a strong, erect, triangular, pointed horn which is densely pubescent; trochanters simple; $2.5 \mathrm{~mm}$............ciliatus

Frontal incisure very wide, medianly circular and in the center of this incisure is a rudimentary tubercle or swelling; front and clypeus separated by a deep, slightly transverse excavation; clypeus with a strong, thick, triangular, flattened and slightly recurved horn; tro-

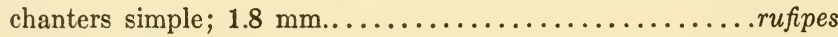

16. Anterior part of vertex with a slender median carina; antennae elongate, slender with segments at least twice as long as wide; front with two transverse, vaguely limited foveae...............carinatus

Vertex without carina, either medianly excavated or simply convex. .

17. Vertex with a median fovea, and lateral margins of head each with a small tooth or cusp.......................... germaini

Vertex with or without a median fovea or impression but the sides of

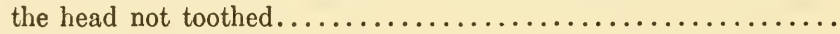

18. Vertex with a median foveaform depression; head slightly transverse with antennal tubercles slightly prominent laterally, large, flattened, obliquely cut and subcarinated at summit...........auriculatus

Vertex with neither a median carina nor fovea................

19. Front with an entire, transverse impression just posterior of a hypothetical line passing through the antennal tubercles. .circumscriptus Front without a transverse post-tubercular impression; head with four free foveae, of which the posterior pair lie between the eyes and are punctiform, relatively small and shallow, while the anterior pair are slightly oblong and obliquely placed between the antennal tubercles elevatus

\section{Key to the Species of Group VIII}

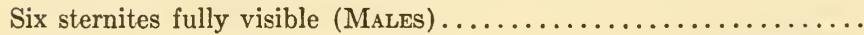

Five sternites fully visible (Females) $\ldots \ldots \ldots \ldots \ldots \ldots \ldots \ldots \ldots \ldots$

2. Head quadrate (that is, the width of the head not including the eyes, is equal to the head length), with tempora more rounded than the antennal tubercles; vertex perfectly simple from occiput to eyes with the usual pair of vertexal foveae; anterior of the eyes the vertex is transversely, narrowly impressed in an entire striaform line which broadens and deepens at middle, this median depression in reality formed by a pair of foveae $2.4 \mathrm{~mm} . . . \ldots \ldots \ldots \ldots \ldots$ fauveli

Head more or less transverse (that is, the width of the head not including the eyes, is greater than the head length) $\ldots \ldots \ldots \ldots \ldots$. 


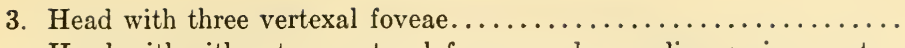

Head with either two vertexal foveae and a median carina, or two vertexal foveae only; vertex never with three foveae...........

4. Head with three vertexal foveae, two between the eyes as usual and a smaller median fovea which is circular in outline; intermediate trochanters with a small setaform spine; $1.8 \mathrm{~mm}$.........planifrons

Head with the usual pair of inter-ocular vertexal foveae and a median oblong fovea; anterior and intermediate trochanters angularly di-

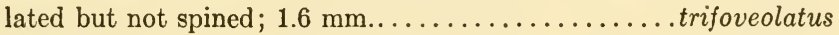

5. Vertex with a median longitudinal carina between the vertexal foveae Vertex simple, with the normal pair of vertexal foveae but no median longitudinal carina; trochanters simple; $1.7 \mathrm{~mm} . . . \ldots$... resectus

6. Vertexal carina long; intermediate trochanters slightly pubescent;

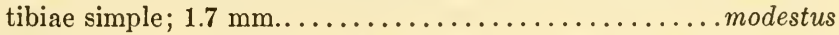

Vertexal carina very short; intermediate trochanters not pubescent; intermediate tibiae with a strong spine; $2 \mathrm{~mm} . \ldots \ldots \ldots$.....edmundi

7. Abdomen mucronate apically (this acute to subacute contour is caused by the last tergite being either obtusely prominent or having a blunt, obtusely prominent apical tubercle which may or may not be visible

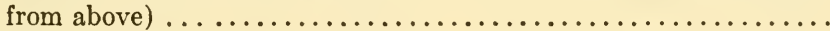

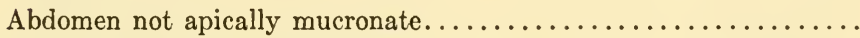

8. Vertex without a median fovea or depression of any kind; $2.2 \mathrm{~mm} . .$.

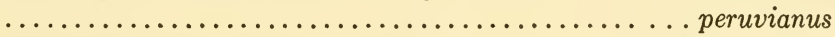

Vertex with an obsolete median depression placed posterior to the vertexal foveae............................productus

Vertex with a large transverse depression which extends from the antennal tubercles to behind the eyes, with the vertexal foveae within this depressed area $; 2.6$ mm...................magnus

9. First fully visible sternite (second morphological) with a median

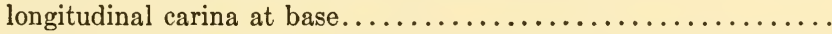

First fully visible sternite (second morphological) not medianly cari-

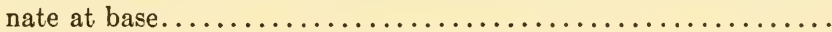

10. Head very transverse, nearly twice as wide as long........ breviceps Head only slightly wider than long or quadrate to elongate........

11. Front evenly declivous and without foveae or paired depressions.... Front with a pair of obsolete depressions or a pair of deep oblique

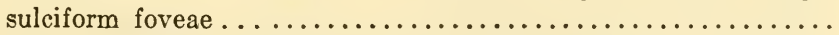

12. Known only from Argentina; vertex evenly convex and without a

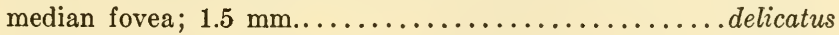

Known only from Peru; vertex trifoveate, with a large deep median fovea in addition to the usual pair of inter-ocular foveae; $1.8 \mathrm{~mm}$. laevipennis

13. Front broadly flattened with a pair of obsolete foveaform depressions . planifrons 
Front medianly slightly elevated with a deep, oblique and sulciform fovea on each side.......................trifoveolatus

14. Vertex with a median carina......................... 15

Vertex without a median carina....................... 17

15. Vertex with the median carina very short............... 16

Vertex with the median carina long, extending over the vertex; front with a transverse impression which is widely interrupted at middle

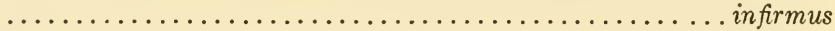

16. Front with a transverse impression which is wide, shallow and does not reach margins......................... modestus Front with a transverse impression which extends from side to side of front and is deep and sulciform..................humilior

17. Vertex with a median fovea or foveaform depression........... 18

Vertex without any median depression................... 19

18. Median vertexal fovea very small and punctiform..........adulator Median vertexal fovea not of this form; body very much more elongate and cylindrical, with parallel sides; $2.6 \mathrm{~mm} . . . \ldots \ldots$..... parallelus

19. Abdomen and posterior portion of elytra punctate to punctulated;

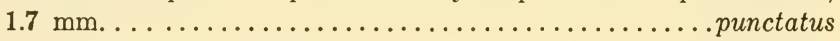

Body absolutely impunctate.................... fauveli

The species of Arthmius known to inhabit the neotropics are listed by groups as follows:

barbiellinii Raffray. 1909. Sao Paulo, Brazil. crassicornis Raffray. 1897. Mexico.

plicicollis Reitter. 1882. Mexico.

primarius Reitter. 1888. Blumenau, Brazil. (rostellatus Reitter)

\section{II}

dichrous Reitter. 1888. Blumenau, Brazil.

\section{III}

articularis Raffray. 1897. Yuracaris, Bolivia.

bicolor Ritter. 1882. Sao Paulo, Brazil. (or in Group I?)

bubalus Raffray. 1897. Mexico.

curvicornis (Schaufuss). 1872. Yucatan, Mexico. (Batrisus)

geniculatus (Sharp). 1887. Jalapa, Mexico. (Batrisus)

inflatipes Raffray. 1897. Brazil.

pedestrianus Raffray. 1904. Sierra de Durango, Mexico.

platycerus Reitter. 1888. Blumenau, Brazil.

sabomba new species. Panama Canal Zone.

scaphiger (Sharp). 1887. Jalapa, Mexico. (Batrisus). (Fletcher, 1930)

simplicior Raffray. 1897. Yucatan, Mexico. 
singularis (Schaufuss). 1879. Chile? (Bryaxis)

subfusus Fletcher. 1930. Jalapa, Mexico.

truncaticeps (Sharp). 1887. Guatemala. (Batrisus)

\section{IV}

bison Raffray. 1897. Brazil.

bituberculatus Reitter. 1888. Blumenau, Brazil.

bythinoceros Reitter. 1888. Blumenau, Brazil. (quinquefoveolatus

Reitter, nec Schaufuss teste Raffray, 1904)

lamellatus Raffray. 1890. San Esteban, Venezuela.

orion (Schaufuss). 1872. New Friburg, Brazil. (Batrisus) (carinatus

Schaufuss)

quadripunctatus (Schaufuss). 1872. Yucatan, Mexico. (Batrisus)

reitteri Raffray. 1897. Blumenau, Brazil.

bicornis Raffray. 1897. Brazil.

brevicollis Raffray. 1897. Brazil.

castaneus (Sharp). 1887. San Juan, Vera Paz, Guatemala. (Batrisus)

cicatricosus Raffray. 1897. Paraguay.

cristulatus Reitter. 1889. Brazil.

cruralis Raffray. 1897. Matto Grosso, Brazil.

extraneus Fletcher. 1930. Corumba, Matto Grosso, Brazil.

femoratus Raffray. 1897. Brazil.

hydropicus Raffray. 1897. Brazil.

latipes Raffray. 1897. Mexico.

mancus Fletcher. 1930. Corumba, Matto Grosso, Brazil.

manifestus Reitter. 1888. Blumenau, Brazil. (lubricus Reitter)

rubriculus Fletcher. 1930. Corumba, Matto Grosso, Brazil.

simplicicornis (Sharp). 1887. Guatemala. (Batrisus)

tibialis Raffray. Yuracaris, Bolivia.

areolatus Raffray. 1897. Brazil.

armatellus (Sharp). 1887. Volcan de Chiriqui, Panama at from 2000

to 4000 feet. (Batrisus)

aubei (Schaufuss). 1872. Rio de Janeiro, Petropolis, New Friburg,

Minas Geraes, Brazil. (quinquefoveatus Schaufuss). (Batrisus)

cerastes Raffray. 1897. Petropolis, Brazil. (cornutus Reitter nec

Schaufuss teste Raffray 1904).

cinnamomeus (Schaufuss). 1887. Minas Geraes, Brazil. (Batrisus) cornutus (Schaufuss). 1872. Minas Geraes, Brazil. (Batrisus) (stultor

Schaufuss)

edithae Reitter. 1888. Blumenau, Brazil. (minax Reitter) 
elegantulus Fletcher. 1928. Perene, Peru.

patruelis Reitter. 1888. Blumenau, Brazil.

rhinoceros (Schaufuss). 1872. Macahe, Brazil. (Batrisus)

sus (Schaufuss). 1872. Petropolis, Minas Geraes, Brazil. (Batrisus)

transversalis Raffray. 1904. Petropolis, Brazil.

vividus (Schaufuss). 1872. Panama. (Batrisus)

vulneratus Raffray. 1897. Yuracaris, Bolivia.

wasmanni Raffray. 1898. Rio Grande del Sol, Brazil.

\section{VII}

auriculatus Raffray. 1897. Yuracaris, Bolivia.

boliviensis Raffray. 1897. Yuracaris, Bolivia.

carinatus (Schaufuss). 1872. Theresopolis, Petropolis, Rio de Janeiro,

New Friburg, Minas Geraes, Brazil. (Batrisus)

ciliatus Raffray. 1897. Brazil.

circumscriptus Raffray. 1897. Blumenau, Brazil.

cristatifrons Reitter. 1889. Brazil.

elephas Raffray. 1897. Brazil.

elevatus Raffray. 1890. Tovar Colony, Venezuela.

erectus Raffray. 1897. Brazil.

germaini Raffray. 1897. Yuracaris, Bolivia.

honestus (Schaufuss). 1872. Petropolis, New Friburg, Brazil. (Batrisus)

labiatus Raffray. 1904. Theresopolis, Brazil.

melanocephalus Reitter. 1888. Blumenau, Rio Grande, Brazil.

peniculus (Schaufuss). 1872. New Friburg, Brazil. (Batrisus)

rufipes Raffray. 1897. Theresopolis, Brazil.

triangularis Raffray. 1897. Bogota, Colombia.

VIII

adulator Reitter. 1888. Sao Paulo, Brazil.

breviceps Raffray. 1897. Yuracaris, Bolivia.

delicatus Fletcher. 1928. Tucuman, Argentina.

edmundi Raffray. 1904. Petropolis, Brazil. (carinatus Reitter, 1888,

nec Schaufuss; reitteri Raffray, 1897)

fauveli Raffray. 1897. Yuracaris, Bolivia.

humilior Reitter. 1888. Blumenau, Brazil.

infirmus Raffray. 1897. Brazil.

laevipennis Fletcher. 1928. Iquitos, Peru.

luzerae Reitter. 1882. Colombia.

macrocephalus (Schaufuss). 1872. New Friburg, Brazil. (Batrisus)

magnus Fletcher. 1928. Iquitos, Peru.

modestus Raffray. 1897. Theresopolis, Brazil.

parallelus Raffray. 1897. Yuracaris, Bolivia.

peruvianus Raffray. 1882. Peru. (Batrisus) 
planifrons (Schaufuss). 1872. Bogota, Colombia. (Batrisus) (tripunctatus Reitter, 1882)

productus Raffray. 1897. Yuracaris, Bolivia.

punctatus Raffray. 1897. Mexico.

resectus Raffray. 1897. Brazil.

trifoveolatus (Schaufuss). 1872. Bogota, Colombia. (Batrisus)

\section{Unplaced}

coronatus (Westwood). 1870. Brazil. (Bryaxis)

concolor Raffray. 1908. Paraguay

rugiceps (Schaufuss). 1872. Bogota, Colombia. (Batrisus)

\section{SYRBATUS (Reitter, 1881)}

ReITTER (1881, 1882, 1885, 1888) (Syrbatus, Arthmius)

RAFFray (1897, 1904, 1908, 1908a) (Arthmius)

RAFFRAY (1917) (Syrbatus)

This genus was treated as a subgenus of Arthmius until recent years. It is undoubtedly closely related to Arthmius but generically distinct on pronotal structure. All Syrbatus have a longitudinal sulcus on each side of the pronotum, and these sulci are absent in Arthmius; the present genus may be regarded as intermediate between Arthmius and Syrmocerus.

With one questionable exception, it is a South American genus: Brazil (25); Paraguay (3); Argentina (2). In addition to these thirty species Raffray (1897a) described mashona from Salisbury, Southern Rhodesia, Africa as belonging to the genus!

I have reorganized the key to males (1897) and key to groups (1904) of Raffray to include recent work:

\section{Key to the Groups of Syrbatus Males}

Sides of head (genal-temporal area) simple, neither ridged nor carinated ................................... 2

Sides of head (genal-temporal area) longitudinally carinated...... 5

2. Antennae more or less abnormal in the male sex......... Group I Antennae simple, similar to the female................. 3

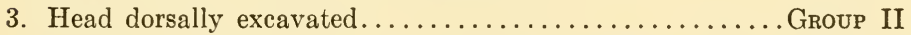
Head not excavated or infossate on dorsal surface..............

4. Epistome (clypeus) armed or abnormal............. Group III Epistome (clypeus) simple.......................... IV

5. Antennae abnormal . . . . . . . . . . . . . . . . Group $V$ Antennae simple ............................. VI

\section{Group I}

Represented by a single species, antennator, in which the male has the third antennal segment much longer than wide and the latero-apical angle 
swollen, fourth segment irregularly transversely flattened at base on dorsal face and the external face angulate-produced at middle; clypeus extended apically in an acute-pyriform outline with sharp apex; interantennal line medianly concave, with a small cusp just posterior to the concave area, a pair of small median tubercles in a depression between the eyes.

\section{Group II}

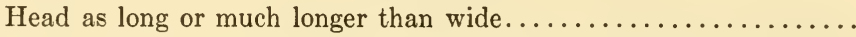

Head distinctly much wider than long, and distinctly wider than pronotum ................................. 6

2. Clypeus with a posteriorly curved, pointed horn............ 3

Clypeus with either a simple tubercle or a carina............ 5

3. Interocular excavation not limited apically by a carina $; 2.4 \mathrm{~mm} . .$. hiatusus

Interocular excavation sharply limited apically by an elevated carina

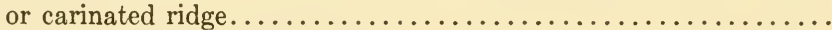

4. The limiting carina entire and simple between the antennal bases;

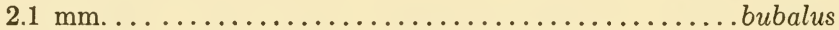
(Not to be confused with Arthmius bubalus, s.s.)

The limiting carina between antennal bases strongly ciliated and medianly interrupted; $2.4 \mathrm{~mm} . . \ldots \ldots \ldots \ldots \ldots \ldots$. grouvellei

5. Clypeus with a simple tubercle; $2.3 \mathrm{~mm} . . . \ldots \ldots \ldots \ldots$. centralis Clypeus with an obtuse carina.................. brevispinus

6. Head, including eyes, one-fourth longer than head from occiput to apex of clypeus, and because the antennal tubercles are externally produced, the head through the tubercles is distinctly wider than total head length; vertex with a deep, transverse excavation in the shape of a dumbbell, with a small acute median horn at center of excavation which opens apically as the deeply arcuate interantennal line; $1.8 \mathrm{~mm}$. intermediate trochanters simple. .hetschkoi

Intermediate trochanters provided with a dense brush of short setae;

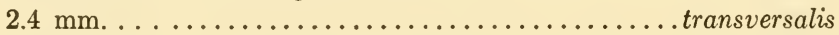

Transversalis and hetschkoi are separable on a number of points in addition to the intermediate trochanters. The former has obtuse but well developed apical pronotal angles, sides of pronotum nearly straight posterior to the abruptly formed apex and deep lateral pronotal sulci. The latter has a cordiform pronotum with insensibly formed apical angles, rounded sides and poorly formed lateral sulci.

The ambiguously isolated mashona Raffray of Southern Rhodesia is placed by Raffray (1897) next to hetschkoi.

There is another species which is placed in this group. Raffray (1908a) described Arthmius bruchi as belonging to the subgenus Syrbatus, but stated that it was near Arthmius sus (Schaufuss) and Arthmius carinatus (Schaufuss). Both of the latter are true Arthmius without lateral pronotal sulci, the former 
in Group VI and the latter in Group VII. The male bruchi is described as having the vertex deeply and transversely impressed, and this feature with the simple, uncarinated tempora and normal antennae would place bruchi in Syrbatus Group II if the pronotum is Syrbatus.

\section{Group III}

Vertex with a semicircular patch of squamous pubescence just above (mesiad) of each eye, these areas sharply defined and conspicuous so as to give the impression of a double eye each side; $2.1 \mathrm{~mm}$.... quadrioculatus

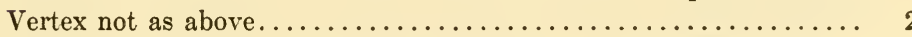

2. Clypeus with either a strong obtuse carina or an elevated tubercle... 3

Clypeus not carinate or tuberculate................... 4

3. Clypeus with a strongly developed obtuse median, longitudinal carina; clypeus excavated on each side and apically in the form of a pointed

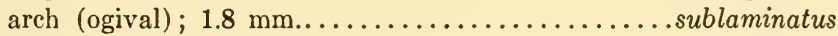

Clypeus excavated each side near base and medianly an elongate tubercle which is flattened on top and may be described as an "elevated plaque", squamous; $2 \mathrm{~mm} . . \ldots \ldots \ldots \ldots \ldots \ldots$.............. scitus

4. Clypeus prominent, wholly concave with a ciliated margin; 1.7-1.8

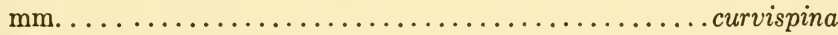

Clypeus prominent, flattened and ogival in form (that is acutepyriform or in the form of an apically pointed arch) $; 1.7 \mathrm{~mm} . .$.

phantasma

\section{Group IV}

Intermediate trochanters dilated and truncate, with a brush of short setae; $1.6-1.7 \mathrm{~mm} . \ldots \ldots \ldots \ldots \ldots \ldots \ldots \ldots \ldots \ldots \ldots$. calcarifer

Intermediate trochanters each with a strong tooth or spur at apex; $2.3 \mathrm{~mm} . \ldots \ldots \ldots \ldots \ldots \ldots \ldots \ldots \ldots \ldots \ldots \ldots$ simplicifrons

Also in this group belongs marthae Reitter, but described on the female sex only; $1.7 \mathrm{~mm}$. long, and said by Raffray to closely resemble calcarifer Reitter.

\section{Group V}

First antennal segment simple, not abnormally large or irregularly

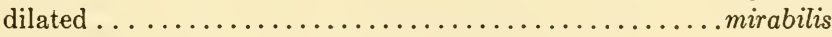

First antennal abnormal, large, irregularly dilated.............

2. Pronotum abruptly narrowed apically so that the apical angles are accentuated, and the sides only slightly rounded in contour to nearly

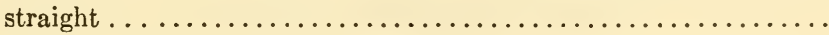

Pronotum gradually narrowed apically so that the apical angles are obsolete and the sides arcuate...................... 8

3. Clypeus with apical margin square and truncate............. 4 


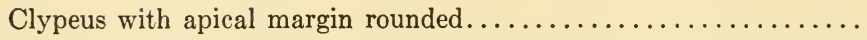

4. Antennae short and thick, segments not twice as long as wide, VIII and IX quadrate, $\mathrm{X}$ slightly transverse; $2.05 \mathrm{~mm}$..... spathulatus Antennae elongate and slender, segments III to VII at least three times as long as wide, VIII twice as long as wide, IX and X ovoidal......

5. First antennal segment strongly dilated, subcircular in dorsal outline and deeply concave in mesio-apical half ...................

First antennal segment with mesio-apical angle obliquely prolonged, with the prolonged point recurved.............. bidenticulatus

6. Second antennal segment strongly globose; $1.4-1.7 \mathrm{~mm}$.....caudatus Second antennal segment elongate-cylindrical; $2.3 \mathrm{~mm} . .$. divergens

7. Antennal segments III-VII elongate but less than twice as long as wide, VIII quadrate, IX briefly oval $; 2 \mathrm{~mm}$............clypeatus Antennal segments III quadrate; IV slightly smaller and transverse,

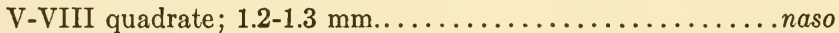

8. Clypeus bifid at apex; $2.2 \mathrm{~mm} . \ldots \ldots \ldots \ldots \ldots \ldots$................. Clypeus subtruncate at apex, not bifid; $2.15 \mathrm{~mm}$..........nasutus

To this relatively large fifth group must be added sublyratus Reitter, described on both male and female. This species is easily recognized by the cephalic architecture. Sublyratus has a more triangular outline of the head than any other species. The head is as long, from clypeal apex to occiput, as wide if the eyes are not included; or two-fifths wider than long if the eyes are included. The clypeo-frontal area is in the form of a rounded-triangular plate which is longer from apex to interantennal line than the rest of the head from interantennal line to occiput. In addition the first antennal segment is as abnormal as the same segment of many males in the genus, being cordate in dorsal outline, as wide apically as half the clypeal width, with the subcylindrical second segment articulated in a slight median notch of its apical margin. I am unable to place the species in the key as I am ignorant of the shape of the thorax.

\section{Group VI}

There is only one species at present in this group, demoniacus Raffray, based on a single male specimen, $1.5 \mathrm{~mm}$. long, with unique cephalic architecture. The sides of the head are evenly, strongly arcuate, with the eyes placed at the lowest part of the arc and not projecting much beyond a line drawn through the antennal tubercle and tempora on each side; this outline is approached in other species but the tempora are everted and sharply, obliquely truncate behind each eye so that the apical corner of each tempora is in the form of a cusp; between the eyes the vertex is broadly excavated, limited laterally by a double carina.

The species of Syrbatus may be listed as follows: 
II

brevispina (Reitter). 1882. Sao Paulo, Brazil. (brevispinus) (Genotype?)

bruchi (Raffray). 1908. Argentina. (Arthmius)

bubalus (Raffray). 1897. Bahia, Brazil. (Arthmius)

centralis (Raffray). 1897. Blumenau, Brazil. (Arthmius)

grouvellei (Raffray). 1897. Bahia, Brazil. (Arthmius)

hetschkoi (Reitter). 1888. Blumenau, Brazil.

hiatusus (Reitter). 1888. Blumenau, Brazil.

transversalis (Raffray). 1897. Sao Antonio, Brazil. (Arthmius) (nec

Group III of Raffray, 1904)

\section{III}

auritulus (Westwood). 1870. Brazil. (Bryaxis)

curvispina (Reitter). 1888. Blumenau, Brazil.

phantasma (Reitter). 1882. Sao Paulo, Brazil. (soror Reitter)

quadrioculatus (Reitter). 1888. Blumenau, Brazil. (atricapillus Reitter)

scitus (Reitter). 1888. Blumenau, Brazil. (solivagus Reitter)

sublaminatus (Reitter). 1888. Sao Paulo, Brazil.

IV

calcarifer (Reitter). 1882. Blumenau, Sao Paulo, Brazil.

marthae (Reitter). 1882. Blumenau, Colonia Alpina, Brazil. (martha)

simplicifrons (Reitter). 1882. Blumenau, Colonia Alpina, Brazil.

V

bidenticulatus Raffray. 1917. Asuncion, Paraguay.

bifurcatus (Raffray). 1908. Argentina. (Arthmius)

caudatus Raffray. 1917. Asuncion, Paraguay.

clypeatus (Reitter). 1882. Brazil.

divergens (Reitter). 1888. Blumenau, Brazil.

mirabilis (Reitter). 1885. Blumenau, Brazil.

naso Raffray. 1917. Asuncion, Paraguay.

nasutus (Reitter). 1888. Blumenau, Brazil.

spathulatus (Raffray). 1897. Brazil. (Arthmius)

sublyratus (Reitter). 1882. Sao Paulo, Brazil.

VI

demoniacus (Raffray). 1897. Bahia, Brazil. (Arthmius)

\section{Unplaced}

trinodulus (Schaufuss). 1887. Minas Geraes, Brazil. (vide Raffray, 1904) 


\section{SYRMOCERUS (Raffray, 1897)}

RAFFraY (1897) (Arthmius) (1904, 1908, 1911)

This is a Brazilian genus of five species having many structural affinities with Arthmius. It was originally erected as a subgenus of the latter but has been recognized as distinct since 1904. The genus is quite disparate from its nearest ally, Syrbatus, by the key character. The three genera, Arthmius, Syrbatus and Syrmocerus form one evolutional line within the neotropical batrisines, in which Arthmius with many species and a wide range has entire pronotal margins and no longitudinal sulci, Syrbatus with about one third as many species and the lateral pronotal depressions expanded apically into longitudinally developed sulci, and Syrmocerus with sharply incised lateral pronotal margins, the incisure caused by the development of a shorter, more arcuate, heavily pubescent sulcoid fovea. The last two genera are entirely South American, and Syrbatus with a range which includes Brazil, Paraguay, and Argentina, seems less highly specialized than Syrmocerus with five species limited as far as known to the Brazilian rain forest.

The following key, based on the male sex, will separate the known species:

\section{Key to the MaLes of Syrmocerus}

Antennal segment I normally developed, subobconical to subcylindrical, with the apical angles mutually developed and regularly acute Antennal segment I very abnormally developed, with the mesio-apical or internal angle formed as a long spine or greatly expanded...... 2. Dorsal surface of head with an entire, broad, obtuse, median longitudinal carina and the surface entirely and roughly granulated; $\mathbf{2 . 8}$

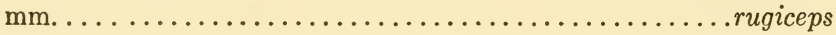

Dorsal surface of head with a short median longitudinal carina which crosses occiput and extends apically for a short distance on the posterior part of the vertex; dorsal surface of head not roughly granulated but the area of the antennal tubercles is coarsely punctate...

3. Antennal segment III quadrate; V longer than IV, VI, or VII; antennal tubercles flattened; head tuberculated posterior and ventral to the eyes; vertex with a median, transverse, arcuate tubercle;

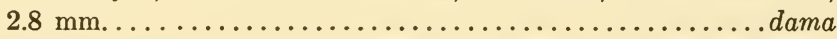

Antennal segment III elongate-obconical; III, V, and VII longer than IV or VI; antennal tubercles tumid; head not tuberculated on lateral or ventral surface; vertex with a median, subconical, erect tubercle;

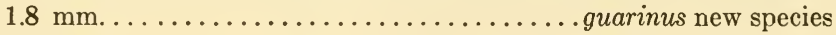

4. Antennal segment I with the mesio-apical angle extended apically into a conspicuous, flattened, sinuo-arcuate tooth which reaches the apex of the third antennal segment; $3 \mathrm{~mm} . . . \ldots \ldots \ldots \ldots \ldots$............

Antennal segment I with the mesio-apical angle extended mesio-posteriorly in an abrupt, apically rounded, lamellate plate, the axis of the plate being at right angles to the segmental axis; $2.9 \mathrm{~mm} . .$. . 
Syrmocerus guarinus new species

Type Male. $1.8 \mathrm{~mm}$. long x $0.7 \mathrm{~mm}$. wide through elytra. Chestnut brown, semishining with coarse flavous sparse long semibristling pubescence. (Pl. XIX)

Head, including eyes, subtriangular with short tempora half as long as eyes; eyes large, composed of about 24 coarse facets. Occiput and posterior part of vertex with a median, longitudinal carina. Vertex and occiput subglabrous to the antennal tubercles, with a pair of deep, circular, nude vertexal foveae between the eyes. These foveae connected by an arcuate sulcus which widens and deepens apically to form a large, median depression between the antennal tubercles. Antennal tubercles large, tumid, subtriangular and very coarsely punctate, sparsely pubescent. Between and just anterior to the vertexal foveae is a median vertexal tubercle; this tubercle is subconical, coarsely punctate dorsally and with its width, length, and height equal and obliquely truncate at apex. Front entirely concerned with the excavation noted above, the inter-antennal line being entirely concave. Clypeus triangular with a sharp apical angle; medianly strongly elevated into a high laminoid longitudinal crest, the crest being dorsally flat and pubescent and abruptly cut off posteriorly at the frontal excavation; a very small tubercle each side of crest. Therefore from a dorsal view the head appears quadrituberculate, with the vertexo-frontal excavation being bounded anteriorly by the clypeal crest, laterally by the antennal tubercles and posteriorly by the vertexal tubercle. Ventral surface of the head transversely tumid in apical third; very coarsely punctate, without tubercles, and with the punctures becoming more sparse and strigose medianly.

Maxillary palpi as in Arthmius.

Antennae eleven-segmented, distant, coarsely punctate; segment I simple, elongate obconical; II elongate, narrower than first; III elongate-obconical; III, V, and VII longer than IV, VI, and VIII; III to VI subequal in width; VII obtrapezoidal; VIII smaller than either VII or IX.

Pronotum characteristic of genus; widest through apical three-fourths, with prominent apical and nearly rectangular basal angles. Disc strongly medianly elevated in the form of an obsolete carinoid crest as in Group I Arthmius. An entire transverse sulcus at basal fourth, with the discal tumidity abruptly falling to base basal to sulcus; posterior wall of sulcus beaded, the bead expanded and angulated laterally into a tumid area to lateral margin. Each lateral margin sharply incised, the incisure continued apico-medianly as a large, oval, pubescent fovea typical of genus, and the incisure abruptly limited posteriorly by the bead of the transverse sulcus, Pronotal integument subglabrous.

Each elytron with an entire sutural stria, no dorsal stria or impression, the humeral angle obliquely well-defined, and with three deep, nude, circular foveae. Integument sparsely punctulate.

Five tergites, the first large, the last subtriangular with rounded, nontuberculate apical profile; margins as in Arthmius.

Six clearly visible sternites (morphologically II to VII), of which the first four are progressively shorter; fourth medianly, transverely creased or narrowly 
sulcate and with the apical margin medianly minutely tuberculate; fifth large, sparsely but distinctly punctate, transversely semilunar in shape, two-thirds as long as first four united, basal third tumid, apical two-thirds semilunarly impressed, apex with the margin raised and medianly sharply, triangularly incised; sixth (last) sternite minute, tumid, coarsely punctate, transversely subfusiform in shape, lying between the concave median apex of the last tergite and the incised margin of the fifth sternite.

Metasternum subglabrous, with a deep median, longitudinal sulcus; this sulcus is sharply defined but with rounded lateral margins, and is not entire, being abruptly limited at apical third.

Tarsi as in Arthmius. Anterior femora compressed at apical fourth on ventral face to give a subcarinoid appearance at this point; other femora simple. Anterior tibiae with a highly specialized spur, this spur being nearly half tibial length, inserted just beneath base of first tarsomere, flat, angulate medianly, and with a spatulate tip; intermediate tibiae with a strong, acute, simple spur of regular length; posterior tibiae simple. Intermediate trochanters with the posterior face flattened and bearing a pad of short, dense setae; other trochanters simple.

Described on one male, the type, from Corumba, Matto Grosso, Brazil. Most closely related to dama, from which it is distinct on antennal proportions, vertexal tubercle, genal structure and sternite structure.

In the original diagnosis of Syrmocerus (Raffray, 1897, p. 459) it is clearly stated that a transverse pronotal sulcus is present. Raffray (1904, p. 125 and 1908 , p. 134) in his keys states that the transverse pronotal sulcus is present; in the 1908 discussion of the genus, Raffray states (p. 153) that the transverse pronotal sulcus is absent. I have followed the original diagnosis in order not to create a new genus.

The species of this genus follow:

cervus (Raffray). 1897. Minas Geraes, Brazil. (Arthmius)

dama (Raffray). 1897. Brazil. (Arthmius) (Genotype)

gazella (Raffray). 1897. Brazil. (Arthmius)

guarinus new species. Corumba, Matto Grosso, Brazil.

rugiceps (Raffray). 1897. Brazil. (Arthmius)

OXARTHRIUS (Reitter, 1882)

REITTER (1882)

Sharp (1887) (Batrisus)

Raffray (1897) (Batrisus) (1904) (Oxarthrius) (1908, 1911, 1917)

FLETCHER (1928)

BRUCH (1933)

This is an entirely neotropical genus of twelve species: Guatemala (1), Panama (1), Panama Canal Zone (2), Brazil (2), Peru and Bolivia (4), Paraguay (1) and Argentina (1). It is not known north of Guatemala and the species appear to be rather thinly distributed over a great area and uniformly uncommon. 
Structurally the species have a common habitus. The truncated cordate pronotum, lacking sulci, and provided with a pair of large conspicuous antebasal spines is typical of the genus. In addition some species have a pair of smaller spines, one on each lateral margin of the pronotum between the middle and apical third. The body is usually large, always elongate-cylindrical. In common with the arthmioid genera, the abdominal margin of the first tergite is strongly formed by both an external and an oblique internal carina, and the following tergites have the "margin" formed by a very short basal external carina on each side. The elytra are simple with a single large basal fovea and sutural stria on each elytron in the majority of the species, while in a new subgenus there are no basal foveae.

The males have the antennae, metasternum, and intermediate legs abnormally modified in most of the species; where both sexes are known the females have relatively unmodified antennae, metasternum and intermediate legs.

Oxarthrius was considered a subgenus of Batrisus until 1904. The genus is more allied to Iteticus than to other neotropical aggregates, from which it is distinct in lacking any dorsal elytral stria and the possession of antebasal pronotal spines.

The following arrangement of the genus is necessitated by the accumulation of novel data:

\section{Key to Subgenera (both sexes)}

Each elytron with a single basal fovea; distal segment of maxillary palpi with simple, unscarred external face................ .SUBGENUS OXARTHRIUS, s.s.

Elytra without basal foveae; distal segment of maxillary palpi with a distinctive scar on the external face near middle............ .SUBGENUS BAROXARTHRIUS, new subgenus Subgenus Oxarthrius, s.s.

\section{KEY TO SPEcies (both sexes)}

(Modified from Raffray, 1897) Bruch.

The following key is complete with the exception of Oxarthrius attaphilus

Pronotum, in addition to the large antebasal spines, with a small spine or tooth on each lateral margin between middle and apex........

Pronotum with lateral margins not armed............... 7

2. Pronotum conspicuously rugose and granular.............. 3

Pronotum nearly glabrous, at least shining and lightly punctulate... 5

3. Antebasal spines of pronotum long, compressed, sharp-pointed; lateral spines relatively large $; 1.76 \mathrm{~mm} . . \ldots \ldots \ldots$.......... Antebasal spines of pronotum relatively shorter, less pointed, and directed posteriorly; lateral spines relatively small; $2.8 \mathrm{~mm} . . . \ldots$.

4. Intermediate femur with a small pubescent tubercle near base; intermediate tibia with an apical spur.............rugosus MALE 
Intermediate legs not armed as described..........rugosus Female

5. Intermediate and posterior tibiae mucronate or spined at apex; vertexal foveae small and obscure; supraocular carina indistinct; lateral pronotal spines relatively large and triangular; $2.25 \mathrm{~mm} . . . . .$.

hamaticollis MALE

Intermediate and posterior tibiae not mucronate or spined at apex, the apex simply pubescent; vertexal foveae deep, large and distinct; supraocular carina strong and distinct; lateral pronotal spines small;

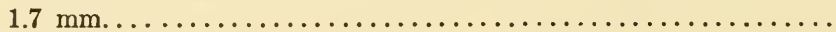

6. Antennal segments VIII, IX, and X abnormally produced on the ventral face; metasternum with a large, erect spine at middle of apical margin; intermediate femur with a lamellate spine at basal third and a sharp conical spine at center of ventral face; intermediate tibia contorted and with a large tooth at apical three-fourths.......... sternadens MALE, new species Antennae, metasternum and intermediate legs simple............ .sternadens Female, new species

7. Pronotum rugose and granular; $2.7 \mathrm{~mm}$........ anthicoides Female Pronotum varying from shining and lightly punctulate to slightly

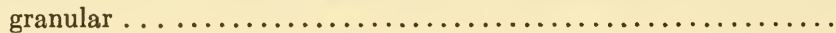

8. Antennal segments VIII, IX, and X progressively transverse; $2 \mathrm{~mm}$. rivularis Female

Antennal segments VIII and IX either much longer than wide or quadrate .

9. Lateral pronotal fovea large, elongate, nearly sulciform; vertex tumid, with sharply defined fovea and sulci; $2.5-2.7 \mathrm{~mm} . . \ldots \ldots \ldots \ldots .$.

Lateral pronotal fovea small, circular, never sulciform; vertex flattened, with punctiform vertexal foveae and obsolete sulci........

10. Intermediate femur with a small spine at base; intermediate tibia with a strong triangular tooth beyond middle on ventro-posterior face.. bispinosus MALE

Intermediate legs not as described............ bispinosus Female

11. Head much longer than wide...................... 12

Head either quadrate or much wider than long............... 13

12. Intermediate trochanters with a very long, biarcuate spine......... ........................... armatus MALE 2.4. mm.

Intermediate trochanters not armed....... armatus Female 2.6.mm.

13. Pubescence fine in quality and very short; vertexal sulci almost invisible $; 2$ mm........................ simplex Female

Pubescence long and coarse; vertexal sulci relatively developed; 2.8 mm........................... forticornis Female

Oxarthrius sternadens new species

Holotype Male. Measurements: head $0.268 \times 0.435$ through eyes; cervicum $0.033 \mathrm{~mm}$.; pronotum $0.4 \times 0.4 \mathrm{~mm}$.; elytra $0.53 \times 0.67 \mathrm{~mm}$.; abdomen from a 
dorsal view $0.469 \times 0.55 \mathrm{~mm}$. (in reality the abdomen is $0.737 \mathrm{~mm}$. long but this length is not visible from above; the tergites are I $(0.335)$, II $(0.067)$, III $(0.067)$, IV $(0.201)$ and $\mathrm{V}(0.067 \mathrm{~mm}$.) long, or in a ratio of $5 / 1 / 1 / 3 / 1$. Total length $1.7 \mathrm{~mm}$. Greatest width $0.67 \mathrm{~mm}$.

Rich chestnut brown with palpi, antennae, and legs paler; the integument polished and shining; sparsely but distinctly punctulate, each puncture raised and bearing a long seta.

Head transverse with long, rounded tempora so that the head has a semicircular occipito-genal contour; eyes prominent, medianly placed, each composed of about 72 very minute facets. Head abruptly narrowed apical of eyes, the sides slightly convergent, with obliquely truncate antennal tubercles, thus the head has a transversely oblong vertexo-frontal contour. Front concave between antennae, declivous, apically subtuberculate. Vertex medianly vaulted and surmounted by a prominent median, longitudinal carina extending from occiput to a line drawn through bases of antennal tubercles. Vertex lightly punctulate posteriorly, coarsely punctate on antennal tubercles, glabrous at anterior center. A deep, circular, nude vertexal fovea each side on a line through middle of eyes and mesiad of antennal tubercle, mutually connected by a $\mathrm{U}$ shaped sulcus with obsolete inner and strong outer wall, the sulcus communicating broadly with the frontal depression. Therefore the vertex has an inverted $\mathrm{Y}$ sulcus with the long vertexal carina entering between the foveal arms. Each side of head with a prominent oblique carina from tempora, above eye, to lateral margin of antennal tubercle; from a lateral view there is a second angulated carina which arises at middle of anterior margin of eye and extends apically to form the bead of the clypeal margin. Genae furnished with a beard of bristling setae. Labrum remarkably transverse, short, deeply, and entirely concave along margin, with each lateral angle produced sharply as a sharp cusp. Ventral surface of head anteriorly densely set with small, crowded punctures.

Maxillary palpi four-segmented; first segment minute; second elongateconical, apically three times wider than base; third short, in the shape of an elongate triangle, longer than wide, apically twice as wide as base, wider than second; fourth longest and widest, obliquely narrowed at base, lengthily narrowed to apex, subsinuate ventrally.

Antennae eleven-segmented, distant, elongate, subgeniculate because of the strong four-segmented club; segment I oblong; II subcylindrical, much narrowed; III-VII elongate-obconical; last four segments as long as second to seventh inclusive, distinctly wider and the eighth, ninth, and tenth abnormal: VIII with the ventral face produced apicolaterally, IX and $\mathrm{X}$ with ventral faces strongly produced to form a triangular crest, this crest foveate on mesial face of IX and foveate on lateral face of $\mathrm{X}$.

Pronotum typical of genus, truncate-cordate. A pair of strong, conicopyramidal, sharp-pointed antebasal spines; disk simple; no sulci; a large triangular foveaform depression lateral to each antebasal spine, a smaller foveaform depression far down on pronotal flank and lateral to the lateral fovea, 
not visible from above; base with a pair of small foveae on each side; a second pair of small horns or teeth on lateral margins, one of these small cusps being near middle of each side.

Elytra typical of genus with very oblique humeri; each elytron with a single, large, circular, deep, nude basal fovea and an entire sutural stria.

Abdomen elongate with five tergites having proportions as noted above; first tergite with a straight external and an oblique internal carina each side; second and third with a very short, straight carina each side at base; last tergite distinctly, transversely impressed at base. Five clearly visible sternites (morphological II-VI) without abnormalities, and of normal proportions.

Metasternum with a very prominent spine at middle of apical margin, this spine nearly as large as antebasal pronotal spines, laterally compressed, with a sharp, slightly recurved apex.

Intermediate trochanter with apex sharpened into a prostrate, acute tooth; intermediate femur excavated in basal half of ventral face and with two conspicuous spines: a long, narrow, aciculate, erect spine at middle, and a lamellate, subtruncate spine at basal third; intermediate tibia contorted, apically slightly inflated, basally flattened, with a short, strong tooth at apical threefourths of length, this tooth appressed and apically directed.

Allotype Female. Similar to holotype male save that (1) antennae are simple, (2) the tooth at pronotal margin each side is larger than in the male, (3) metasternum not spined, and (4) intermediate legs not armed or abnormal.

Described on a male and a female, collected by the author on Barro Colorado Island, Gatun Lake, Panama Canal Zone. Holotype male on July 25,1936 , in stage $4 \log$ mold at Drayton 12; allotype female on July 27, 1936, beneath bark of a $\log$ at Zetek 23 .

Oddly enough this new species has little in common with rivularis of Panama, and is more nearly allied with hamaticollis of Guatemala; from the latter it differs in numerous structural details noted in the key. Among other differences between the latter two species is a qualitative difference in the armature of the intermediate legs of the males: hamaticollis has a single spine on the femur, while sternadens has the femur strongly bispinose, and the former has apparently simple tibiae which are apically cusped while the latter has contorted tibiae with a strong appressed tooth at apical three-fourths.

\section{Subgenus Baroxarthrius new subgenus}

This new subgenus is erected for the new species which follows, and is characterized by (1) the distal segment of the maxillary palpi having a foveoid scar on the external face; (2) elytra without a trace of basal foveae; (3) the male sex having the lateral wings of the pronotum and the prosternum secondarily modified.

Oxarthrius escharus new species

Holotype Male. Measurements: Size and general proportions as in sternadens, being slightly larger; total length $1.8 \mathrm{~mm}$. Uniform reddish-brown with palpi paler. Pubescence abundant, long, bristling, and rufous. 
Head with occiput, vertex and front with the punctures elevated so that the integument is minutely but distinctly granulate; clypeus subrugose. A very long, median longitudinal carina extending from the occiput across the vertex to a line drawn through the bases of the antennal tubercles; this carina abruptly limited apically by the interfoveal sulcus. Interfoveal sulcus is entire, connecting the vertexal foveae, and does not extend down the front as in sternadens; floor of the sulcus glabrous; external wall of sulcus more sharply defined than internal wall in the region of the eyes, and less sharply defined than internal wall anteriorly; sulcus transversely ovoid between antennal tubercles, very sharply definedi basally so that the long vertexal carina has its apical end bifurcated. Supraocular lateral carina as in sternadens. Ocular-clypeal carina not angulate as in sternadens but broadly arcuate. Eyes with about 64 facets, the facets being fewer and larger than in sternadens. Fronto-clypeal area declivous, the front between antennae in the form of a triangular field with laterally carinated edges. Ventral surface of head sparsely granulated. Labrum as in sternadens save that the produced apical corners are more obtuse.

Maxillary palpi with first three segments typical of the genus, the distal (fourth) segment with a small, oblique, foveoid scar at the middle of the external face. This distinctive feature is equally well-developed in the allotype female, and in the paratypes of both sexes.

Antennae eleven-segmented, distant, integument granular; segments all simple, all longer than wide, without foveae, dilations or other abnormalities.

Pronotum truncate-cordate, integument with sparse, elevated punctures which are smaller than those of the head. Disc simple. Lateral margins not spined. Two strong conical, sharp, antebasal spines at basal two-fifths, with an elongate-oval, subsulcoid median fovea between these spines, and a deep, circular lateral fovea between each spine and the lateral margin. Base of pronotum with a pair of small foveae each side, that is, a fovea basal to each spine and a fovea basal to each lateral fovea.

Ventral surface of prothorax highly abnormal. In the first place, the flank of the pronotum is a glabrous, triangular plate with carinated edges which extends ventrally on each side as a free process. This is best appreciated from a lateral view. From a ventral view each of the pronotal wings is seen to give rise to an oblong lamella on its mesial face, this lamella extending obliquely mesio-posteriorly. Between these oblique lamellae the prosternum is erected into two abnormal processes: (1) an acutely arcuate, subtruncate lamella at center, and (2) a fusiform spinoid process between the anterior coxae, this process strongly arcuate anteriorly, with its sides fringed with stiff setae. This pronotal-prosternal modification equally well developed in the male paratype.

Elytra with sparse elongated punctures and prominent oblique humeri; each elytron with a sutural stria, the interstrial space elevated and the punctures subtuberculate. No dorsal stria and no trace of basal foveae.

Abdomen with five tergites with proportions as in sternadens; lateral margins weaker than in sternadens, and last tergite not transversely impressed at base, but simple convex with a strongly concave apical margin. Five fully 
visible sternites (morphological II-VI), with the last entirely, circularly impressed for median third of segmental width.

Metasternum simply, slightly, longitudinally impressed in apical half.

Coxae, trochanters, femora, tibiae and tarsi normal, save for the intermediate femora. Each of the latter with a spine at base of the ventral face. This mesofemoral spine is long (one-fourth as long as femur), apically inclined instead of erect, and very conspicuous.

Allotype Female. Similar to holotype, save that (1) pronotum laterally is normal, lightly punctulate, and closely invests the anterior coxae and prosternum; (2) prosternum simple; (3) last tergite and last sternite simply tumid and punctate; (4) legs not armed.

Described on five specimens collected on Barro Colorado Island, Gatun Lake, Panama Canal Zone. Holotype male (July 25, 1936) collected by the author from decayed log mold at Drayton 15; one male paratype and two female paratypes (May 2,1935) collected by Alfred Emerson from the galleries of a termite nest, probably Coptotermes niger Snyder, in a fallen tree; allotype female (August 15, 1935) collected by Alfred Emerson from decaying log mold.

The species of Oxarthrius may be listed as follows:

Subgenus Oxarthrius, s.s.

anthicoides (Schaufuss). 1887. Brazil. (Batrisus) armatus (Raffray). 1897. Yuracaris, Bolivia. (Batrisus)

attaphilus Bruch. 1933. Loreto, Misiones, Argentina. con Atta sexdens $\mathrm{L}$.

bispinosus Reitter. 1882. Blumenau, Santa Rita, Brazil. (Genotype) forticornis (Raffray). 1897. Yuracaris, Bolivia. (Batrisus) hamaticollis (Sharp). 1887. Las Mercedes, Guatemala (3000 feet).

(Batrisus) nec hamatus of Raffray key, p. 437, 1897. rivularis (Schaufuss). 1872. Panama. (Batrisus) rugosicollis Raffray. 1917. Asuncion, Paraguay. rugosus (Raffray). 1897. Yuracaris, Bolivia. (Batrisus) simplex (Raffray). 1897. Yuracaris, Bolivia. (Batrisus); and from Perene Colony, El Campamiento, Peru at 2000 feet (Fletcher, 1928). sternadens new species. Panama Canal Zone.

Subgenus Baroxarthrius new subgenus escharus new species. Panama Canal Zone.

\section{ITETICUS (Raffray, 1904)}

RAFFRAY (1897) (Batrisus)

RAFFray (1904, 1908, 1909, 1911)

This is a purely South American genus of eight species found so far only in Brazil and Bolivia. It was erected in 1904 (p. 140) for seven species described 
under the old generic name of Batrisus, a genus unknown in the western hemisphere and, as at present restricted, limited to four species. This is of interest since the great genus Batrisodes, although abundant in the United States, is unknown from Mexico southwards and Raffray, in erecting Iteticus, states that the latter replaces Batrisodes in the neotropics. If this is true, and the morphological differences between these two genera are not great, then there is a gap between Batrisodes and Iteticus of over 4000 miles. Iteticus is quite isolated in the neotropical batrisines by the key characters, especially the well developed dorsal stria on each elytron. This latter structural feature separates the genus at once from the three arthmioid genera and the peculiar Oxarthrius. Iteticus is quickly distinguished from Batrisodes by having the last segment of the maxillary palpi regularly ovoidal, only slightly elongated and slightly subacute at apex, and not much wider near middle than at base, and in having lateral margins as described in the generic key; whereas Batrisodes and the specialized Batoctenus have the lateral margins of the first several tergites clearly formed by both an internal and an external carina, and the last segment of the maxillary palpi is wider at base and with a much more acute apex.

The following key to species has been based on the 1897 key of Raffray with recent work integrated to bring our knowledge up to date:

\section{Key to the Males of Iteticus}

Head and pronotum cribrate, the punctures coarse and very crowded;

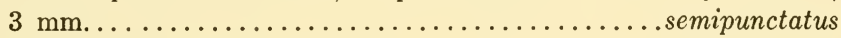

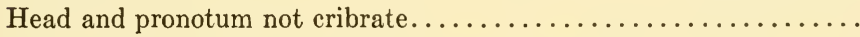

2. Vertex with a median longitudinal carina, this carina may be strong

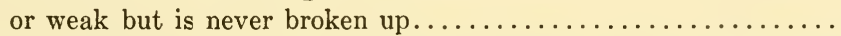

Vertex with no median longitudinal carina, but in some species there are several, more or less irregularly separated points or cusps which

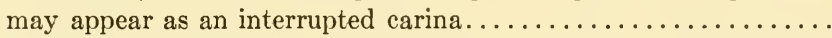

3. Intermediate trochanters armed near the middle with a short, blunted spinoid tubercle; posterior trochanters armed at middle with a tubercle shaped like a toad-stool fungus, being basally columnar and apically flattened and expanded................princeps

Intermediate trochanters armed at middle with a long, strong, erect, pointed spine; posterior trochanters armed near base by a thick,

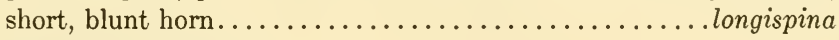

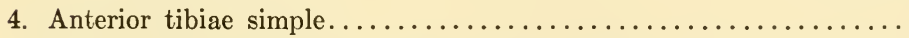

Anterior tibiae inflated at middle of internal face, and notched apically, this incisure being pubescent and terminating in a minute spur just

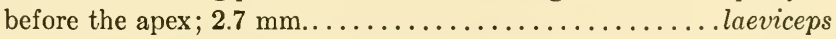

5. Intermediate trochanters simple; posterior trochanters apically extended, with a very long, obtuse tooth; $3.6 \mathrm{~mm} . \ldots . .$. imperialis Intermediate trochanters armed with a tooth, spine or tubercle..... 
6. Intermediate trochanters bearing at middle a tubercle which in turn bears a trichome of long setae; posterior trochanters bearing at middle a short tubercle which bears in turn a trichome of long setae, and apically these trochanters are recurved with the apex in the form of a small hook with a very sharp point; $3.2 \mathrm{~mm}$....... biarmatus

Intermediate trochanters bearing at middle a small tooth........

7. Posterior trochanters with the apex extended in a long, strong, compressed spine which is recurved and truncate...........germari

Posterior trochanters bearing at apical third a hook-shaped spine, this spine is broad, flattened, slightly spiral with a truncate apex and bearing near base a trichome..................... regius

Species of Iteticus may be listed as follows:

biarmatus (Raffray). 1897. Bahia, Brazil. (Batrisus) germari (Aube). 1844. New Friburg, Brazil. (Batrisus) imperialis (Raffray). 1897. Yuracaris, Bolivia. (Batrisus) laeviceps (Raffray). 1897. Yuracaris, Bolivia. (Batrisus) longispina (Raffray). 1897. Minas Geraes, Brazil. (Batrisus) princeps (Reitter). 1882. Petropolis, New Friburg, Constancia, and Theresopolis, Brazil. (Syrbatus) (Genotype) regius (Raffray). 1896. Caraca, Minas Geraes, Brazil. (Batrisus) semipunctatus Raffray. 1908 and 1909. Serra de Baturite, Ceara, Brazil. (First species described as Iteticus)

At this place in the tribe Batrisini a few words may be said regarding three very puzzling species:

Schaufuss described Batrisus asteriscus from Bogota, Colombia in 1887. Raffray (1897) examined and reported on the type of this insect, placing it with doubt in the neotropical species of Batrisus. In this paper he felt that asteriscus was quite apart from other neotropical members of the genus since it had three cephalic sulci and five pronotal sulci, placing it near Batrisus quinquesulcatus Raffray of Singapore. In 1904 Raffray erected Iteticus for all of the neotropical Batrisus listed in his 1897 paper, save asteriscus. The type of asteriscus was imperfect, but Raffray concluded that it could not be Iteticus as this genus, among other things, lacks any trace of a median longitudinal sulcus. In the structure of the abdominal margins asteriscus is Batrisodes, unknown in the neotropics. If asteriscus turns out to be in the latter genus, it becomes very important as a link with Iteticus, for reasons given above, but since the species has not been recorded since 1887, little more can be said now save to point out its affinities with Group 40 of Batrisodes holding quinquesulcatus Raffray of Singapore and Sumatra, and spinicollis Motschulsky of Ceylon! This highly doubtful assignment is doubly questioned by Raffray (1908) and I feel that there is insufficient data to cita Batrisodes as present in the neotropical region on the assumption that asteriscus might belong to the genus. 
David Sharp described two similarly unplaced species in 1887, Batrisus crassipes and Batrisus lamellipes from Bugaba, Panama. Without recourse to the types I am unable to place either in a genus: (1) their body shapes take them from Phalepsoides and Euphalepsus, and Sharp was familiar with the latter genus; (2) they are not Batoctenus on the integumental punctation, and Sharp erected this genus in 1887 so that this preclusion is assured; (3) they are not Iteticus as both of Sharp's species lack spines, longitudinal and transverse pronotal sulci; (4) they are not Arthmius, Syrbatus or Syrmocerus as they lack a transverse pronotal sulcus and do have a short dorsal striaform depression. Therefore they are not members of any neotropical genus known. Raffray left them unplaced in his revision (1897), left them without definite generic assignment (1904) and in 1908 left them as unplaced but near Iteticus.

\section{BATOCTENUS (Sharp, 1887)}

\section{SHARP (1887)}

RAFFray (1904, 1908)

This is a neotropical genus of five species, two from Panama and three from South America (Bolivia 1 and Brazil 2).

Morphologically it is very isolated from the other neotropical genera, and the species of the genus have an unusually striking similarity in habitus. The body is very elongate-cylindrical, with an elongate head which is always coarsely, rugosely punctate, with a relatively simple vertex, indistinct vertexal foveae, very large eyes and flat antennal tubercles. The pronotum is similarly rugosely punctate with the exception of the genotype, and lacks longitudinal and transverse sulci. Elytra elongate, with prominent, usually subcarinoid humeri; each elytron with four basal foveae and a well-formed sutural and dorsal stria. Abdomen with five tergites, of which the first is laterally margined by an external and an internal carina and the next two tergites have the margins less distinctly formed by two carinae which tend to form between them a minute longitudinal fold of the integument near tergite base. Seven sternites in the male and six sternites in the female sex, the first five subequally long, sixth relatively very large; seventh sternite of the male small, indistinctly lodged between the last tergite and sixth sternite. The males have the distal (eleventh) antennal segment, metasternum, legs and prosternum variously ornamented, modified or armed.

Maxillary palpi four-segmented, relatively short in comparison to Oxarthrius, Iteticus and the arthmioid genera, but not minute as in Euphalepsus; first segment minute; second elongate-arcuate, distally wider; third short, subtriangular, nearly as wide as long; fourth longer than the preceding two segments but relatively short when contrasted with Oxarthrius, ovate to subconical, with a very acute apex and a minute palpal cone.

The cribrate, elongate vertex; large eyes; depressed antennal tubercles; relatively short distal palpomere and better devloped abdominal margins readily isolate the genus. 


\section{Key to the Species}

Pronotum nearly impunctate; $2.12 \mathrm{~mm} . . \ldots \ldots \ldots \ldots \ldots \ldots \ldots .2$

Pronotum rugosely and cribrately punctate............... 3

2. Antennal segment VIII oblong, much larger than VII; X shorter than

IX; intermediate tibiae with an apical spur........ simplex MALE Antennal segment VIII only slightly larger than VII; X larger than

IX; intermediate tibiae simple.............. simplex Female

3. Known only from northern Panama; $2 \mathrm{~mm} . \ldots \ldots \ldots \ldots \ldots \ldots . \ldots . \ldots . \ldots$

Known only from South America south of the Equator.......... 5

4. Anterior tibiae slightly dilated on internal face for median third of length, tapering towards both base and apex; intermediate tibiae with an apical spur.....................puncticollis MaLE Anterior and intermediate tibiae simple.........puncticollis Female

5. Antennal segments II-VIII longer than wide............... barberi new species, MaLe

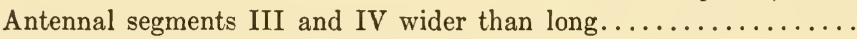

6. Antennal segment V quadrate, VI quadrate; $2.2 \mathrm{~mm}$. known only from Brazil........................... incertus Female Antennal segment $\mathrm{V}$ slightly transverse, VI quadrate; $2.5 \mathrm{~mm}$. known

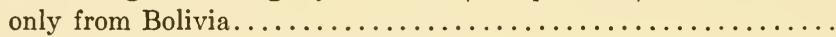

Antennal segment XI with internal (mesial) face incised or notched at base and toothed at middle...............dimidiatus MALE Antennal segment XI simple, ovate with a truncate base........ dimidiatus Female

\section{Batoctenus barberi new species}

Type Male. Measurements: Head 0.40 x $0.40 \mathrm{~mm}$. including eyes, or 0.167 mm. wide not including eyes; cervicum $0.134 \mathrm{~mm}$.; pronotum $0.43 \times 0.40 \mathrm{~mm}$.; elytra $0.67 \times 0.72 \mathrm{~mm}$; abdomen $0.60 \times 0.53 \mathrm{~mm}$; t tergites in the following proportional length: I (4), II (2), III (11/2), IV (2), V (1); total length $2.2 \mathrm{~mm}$.; greatest width is through elytra, $0.72 \mathrm{~mm}$. (Pl. XVIII).

Body very elongate-cylindrical, reddish-brown; head both above and below completely, rugosely, cribrately punctate, the punctures becoming elongate-oval to substrigose between eyes; pronotum both above and laterally, and prosternum completely, rugosely and cribrately punctate save for apical eighth of pronotal disc; elytra subglabrous and shining; abdomen subimpunctate and shining. Pubescence short, sparse and subappressed on head and pronotum; shorter and sparser on elytra; relatively abundant, longer and appressed on abdomen.

Head much longer than wide if the eyes are not included, with an arcuate, abruptly vertical and glabrous occipital wall; tempora short, oblique and sharp-angled; vertex long, longitudinally convex, simple, extending as a subquadrate area apical to eyes. Eyes very large $(0.18 \mathrm{~mm}$. long $\mathrm{x} 0.12 \mathrm{~mm}$. wide 
from a dorsal view) composed of 32 enormous facets, each $0.02 \mathrm{~mm}$. in diameter, which are high and conical. The head outline reminds one of a large-eyed Fustiger. The long cervicum is in sharp contrast to the cribrate head and pronotum as it is subglabrous, evenly arcuate and has a strong median, longitudinal carina. Occiput abruptly higher than cervicum and medianly slightly notched. Vertex with a pair of foveae on a line through posterior third of eyes, these vertexal foveae absolutely free, circular, nude, and as wide as an ocular facet but difficult to discern because of the cribrated integument. Anterior sixth of vertex medianly, longitudinally sulcate, the sulcoid area apically incising the inter-antennal line broadly. Front and clypeus narrow, directed obliquely ventrad so that the labrum is beneath the antennal tubercles. These latter flattened, rounded in outline and being merely the areas of antennal articulation. Ventral surface of head tumid medianly and strongly depressed and narrowed each side of base.

Maxillary palpi four-segmented; first segment small, of same diameter as base of second, obconical; second elongated arcuate-conical as usual with inflated apical end; third subtriangular, wider than second, less than half as long as second, with a short subtruncate internal face and a long convex external face, nearly as wide as long; fourth longer than preceding two palpomeres but relatively shorter than in Oxarthrius, one-third wider than third, obliquely truncate base and an acute apex bearing apically an excessively minute, truncated palpal cone.

Antennae eleven-segmented, distant; segment I arcuate-cylindrical from a dorsal view, as wide as tenth; II-VIII subequal in width, all longer than, wide, obconical to cylindrical (this character separates barberi from all other known species of the genus of both sexes); IX slightly wider than eighth, subcylindrical in dorsal outline; $\mathrm{X}$ distinctly shorter than ninth, subtrapezoidal; XI large, as long as preceding three segments united and much wider. Club formed chiefly of this distal segment. Ventrally the eighth and ninths segments are abnormal, having their ventral faces produced strongly; the ventral face of the eleventh segment is very abnormal: longitudinally biconcave or bifossate with the two excavations separated medianly by an oblique, transverse elevation, the basal excavation shallow, devoid of coarse antennal setae, the apical excavation asymmetrically deepened into a pyramidal fovea.

Pronotum cribrate as described, with no other markings save an elongatetriangular lateral fovea each side just behind the middle, the apex of the triangle sulcoid; pronotum longer than wide, sides parallel in basal half and slightly convergent in apical half.

Elytra complex; each elytron elongate, with (1) a subhumeral fovea at apical end of a long, strong, subepipleural carina on elytral flank; (2) humerus tumid, with apex transversely carinated above the subhumeral fovea, this carina turning abruptly apically as a long entire carina on the edge of elytral disc (this gives to the humeral angle the carinated callus aspect of Group I Euphalepsus); (3) base with four deep circular nude foveae, the integument arched over the orifices of the foveae; (4) a long entire discal carina arising 
between the orifices of the second and third basal foveae; (5) sutural stria entire, arising from the most mesial basal fovea. The elytron, therefore, has three entire carinae in addition to the sutural stria.

Abdomen with five tergites with proportions as given above; first narrowed at base, with a strong lateral margin formed of an external and an internal carinae which converge apically but do not join; second and third tergites with the two carinae very short; fourth tergite with a short, conspicuous horn arising each side near base and partially covered by the lateral margin of the corresponding sternite. First tergite deeply, transversely depressed at base, this depression primarily divided into three subequal chambers by a pair of long, parallel basal carinae which extend to apical third; second and third tergites also with a pair of long basal carinae.

Abdomen with seven sternites, with complex modifications: first sternite clearly visible laterad of coxal-trochantal articulation, and between coxae as a short, longitudinally carinated and glabrous area. Second not longer than first, but visible from side to side. Third as long as second, medianly glabrous and bearing medianly a very large, erect, subcylindrical spine; this spine is obliquely truncate and holds a small tube, the orifice being seen on the posterior portion of the truncate apex. Fourth sternite as long as third, medianly glabrous and bearing a tubercle in apical third. Fifth sternite medianly as long as fourth, but with the apical margin semicircular; medianly glabrous. Sixth sternite semicircular, fitting into the apical outline of the fifth, wholly glabrous, medianly tumid and as long as the preceding three sternites united, and with two projections: first a strong tubercle at center of tumid disc, this tubercle bearing apically two strongly divergent tufts of setae so that the tubercle appears bifurcated; second, a strongly recurved or rolled, lamelloid, truncate plate from center of apical margin. Seventh sternite is a small, medianly tuberculated plate between the last tergite and the sixth sternite.

Tarsi normal for the tribe.

Anterior trochanters with a short spine at base of ventral face.

Anterior tibiae highly modified: middle third of length dorso-ventrally flattened and widened; apical fourth of length laterally flattened; entire tibiae dorsally concave so that the wide middle portion is at a lower level than both ends; anterior edge with two strongly formed and broadly triangular teeth, one tooth at middle and one tooth near apical fourth just basal to laterally flattened apical area, both teeth in the plane of the dorso-ventral flattened portion; a small conical tooth projecting ventrally from ventral face, just apical of first triangular tooth.

Intermediate femora inflated, with the ventral face flattened and arcuate.

Intermediate tibiae inflated medianly, with the ventral face flattened and sinuate.

Metasternum medianly glabrous and tumid, with a subentire median longitudinal sulcus which deepens apically to terminate in a subapical fovea.

Described on two males (type and paratype) from Corumba, Matto Grosso, Brazil. Named for my friend, H. S. Barber. 
This is a bizarre representative of a fauna notable for its morphological diversity. It is very distinct from other members of the genus in many details. Of the five species, three (dimidiatus, puncticollis and simplex) have both sexes known, and the proportions of the third to sixth antennal segments are similar for both sexes of a species. The fourth species (incertus) is known only from the female sex, and barberi only from the male sex but barberi is the only one of the five having segments II to VIII longer than wide and I assume that the female, when discovered, will have elongate antennal segments. The genotype, simplex, unfortunately does not represent the genus morphologically, it being the only species without a cribrate pronotum.

The species may be listed as follows:

simplex Sharp. 1887. Volcan de Chiriqui (2000-4000 feet), Panama.

Genotype.

puncticollis Sharp. 1887. As for genotype.

dimidiatus Raffray. 1904. Yuracaris, Bolivia.

incertus Raffray. 1904. Amazonas, Brazil.

barberi new species. Corumba, Matto Grosso, Brazil.

\section{EUPHALEPSUS (Reitter, 1883)}

Reitter $(1883,1885,1888)$

SHARP (1887)

RAFFraY $(1887,1890,1904,1908,1909,1911,1917)$

FLETCHER (1927)

PARK (1933)

This is an exclusively neotropical genus with the exception of a single doubtful record, namely Euphalepsus dentipes Raffray (1904, p. 184) questionably cited from Louisiana. With this exception there are 24 species: Mexico (2), Guatemala (1), Costa Rica (1), Panama Canal Zone (1), Panama (1), Colombia (1), Venezuela (2), Brazil (13) and Paraguay (2). As in so many neotropical aggregates Brazil appears to be the center of speciation.

This is a genus of large, highly specialized species. The species are easily recognized, their size, globular form, uncarinated metasternum and especially the callus at each elytral humerus differentiate them from other pselaphids. As yet nothing is known concerning their ecology.

Raffray (1904) has divided the genus into groups and this plan is followed here:

\section{Key to Neotropical Groups}

Humeral callus very pronounced, abruptly formed and extending on the elytra beyond the humeral margin (PI. XVIII) ...........

Humeral callus much less pronounced, apically narrowed, less abruptly formed and restricted to the humeral margin.......... Group V

2. Humeral callus apically extended on the elytra as an acute triangular wedge or a carina..................... Group I (Pl. XV). 
Humeral callus simple, abruptly and bluntly terminated (PI. XVIII)

3. Pronotum gibbous (by gibbous in this genus is meant a pronounced swelling of the pronotal disc, so that at least 50 per cent of the dorsoventral height of the pronotum proper is dorsal to a line drawn through the basal and apical pronotal margins at their median points; some species (globipennis) have the pronotum gibbosity very pronounced, approaching the carinoid disc of Group I of Arthmius and some Syrmocerus; other species (liljebladi and panamensis) have a simple gibbous condition as described) .........

Pronotum not gibbous, the disc simply and evenly convex... Group IV

4. Pronotum as long as wide or very slightly longer than wide. . Group II

Pronotum much longer than wide.................... III

In the following keys to species the male sex only is used. The majority of species of Euphalepsus is known from this sex, few females having been recorded. The secondary sex characteristics of females are correspondingly poorly known. The female of centralis Sharp is described as having a conical projection on the dorsal surface of the last tergite. The male secondary sex characteristics are much better known, and in this sex the intermediate and the posterior femora and tibiae are generally modified. A common pattern is a spine or tooth on the ventral face of the intermediate femur and a spine or tooth on the ventral face of the intermediate tibia, these spines varying specifically in size, shape and exact position between closely related species.

\section{Partial Key to Group I}

Antennae with segments I to VIII inclusive forming one-half the total antennal length, with IX, X, and XI forming a very elongate club, these last three segments being very cylindrical; head and pronotum densely punctate, the punctures being subconfluent; 2.24-2.44 mm.

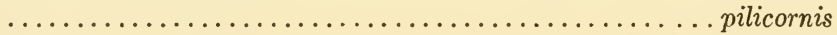

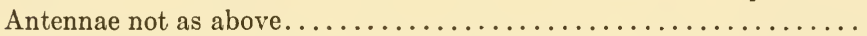

2. Base of pronotum with three longitudinal carinae which extend from the basal margin to the transverse sulcus, one median and a submedian carina each side between the median carina and the lateral

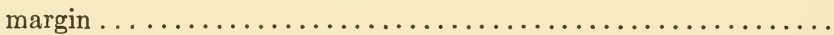

Base of pronotum not as described..............................

3. Antennal segments IX and $\mathrm{X}$ slightly transverse; $2.4 \mathrm{~mm}$... gounellei

Antennal segments IX and $\mathrm{X}$ elongate-oval, distinctly longer than wide $; 2 \mathrm{~mm} . \ldots \ldots \ldots \ldots \ldots \ldots \ldots \ldots \ldots \ldots \ldots \ldots \ldots \ldots \ldots \ldots$ tricarinatus

4. Here belong three Brazilian species. .bilineatus, bistriatus, longicornis

\section{Key to Group II, After Park (1933)}

Vertex strongly canaliculated; a deep interantennal sulcus, communicating laterally with a pair of anterior sulci which curve between median frontal process and the antennal tubercle each side, and 
communicating laterally with a pair of posterior sulci which curve between occiput and antennal tubercles, each posterior sulcus terminating basally in a deep glabrous fovea $; 2.88 \mathrm{~mm} . . . \ldots$. liljebladi

Vertex not canaliculated as described.................... 2

2. Antennal segments IX and X oblong, longer than wide; no small pore-like foveae on sides of head behind eyes................ Antennal segments IX and X transverse; each side of head with two approximate, minute, pore-like foveae behind each eye; $1.6 \mathrm{~mm}$.

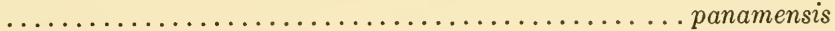

3. Base of each elytron trifoveate; $2 \mathrm{~mm} . \ldots \ldots \ldots \ldots$......... glpennis

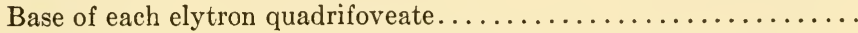

4. Antennal segments II to VIII subquadrate to quadrate; $2 \mathrm{~mm} . .$.

Antennal segments elongate $; 2.25 \mathrm{~mm} . \ldots \ldots \ldots \ldots \ldots \ldots$.

\section{Group III}

Only one species known in this group, fasciculatus Raffray $1.6 \mathrm{~mm}$. long from Bahia, Brazil, described on a male specimen with each elytron trifoveate, simply convex pronotal disc and the pronotum distinctly longer than wide.

\section{Group IV}

This is the largest, least understood group of the genus, containing ten species. It is possible that centralis Sharp and reitteri Sharp belong in Group II. Raffray $(1904$, p. 63) stated that he was unfamiliar with centralis and (p. 104) placed Sharp's species in Group IV with simply convex pronotal disc. I have followed Raffray in this designation although Sharp's figure of reitteri might be construed as gibbous, in which case both Sharp's species would have to be placed in Group II. A second suggestion for this transfer is the parallel development of vertexal sulci between reitteri and liljebladi; although the two species differ in numerous details one cannot help feeling that Sharp's species are out of place with such forms as cavifrons, dentipes and tibialis. Until Sharp's types can be examined I have left the original Raffray list unchanged save for integration of new work.

The following partial key to the species of this group follows:

Anterior part of vertex and front abruptly depressed, this depression holding three large foveaform impressions arranged so that each impression forms one angle of a triangle; $1.5 \mathrm{~mm}$..........cavifrons Anterior part of vertex and front not as described............ 2

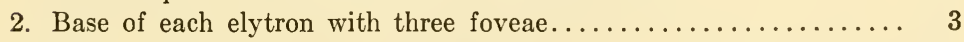

Base of each elytron with four foveae.................. 4

3. Intermediate femur not spined; $1.4 \mathrm{~mm} . \ldots \ldots \ldots \ldots \ldots$ tibialis

Intermediate femur with a curved spine near base on ventral face; $1.5 \mathrm{~mm} . . \ldots \ldots \ldots \ldots \ldots \ldots \ldots \ldots \ldots \ldots \ldots \ldots \ldots$ ovipennis 
4. Intermediate femur with ventral face lacking spines, serrations or

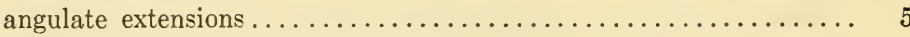

Intermediate femur not as described.................. 6

5. Intermediate femur with a minute pubescent patch near base of ventral face; intermediate tibia with a very small tooth near middle of ventral face $; 2 \mathrm{~mm} . . \ldots \ldots \ldots \ldots \ldots \ldots \ldots \ldots \ldots \ldots \ldots \ldots$ centralis

Intermediate femur lacking pubescent patch; intermediate tibia with a very small tooth near apex $; 2.5 \mathrm{~mm} . . \ldots \ldots \ldots \ldots \ldots$. reitteri

6. Intermediate femur very strongly arcuate, with the ventral face excavated, very thick near trochanter where ventral face is extended in a pronounced acute, aciculate angle; $1.8 \mathrm{~mm} . . . \ldots . .$. cruralis

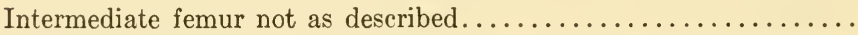

7. Intermediate femur with a serrate line of small teeth or spines on

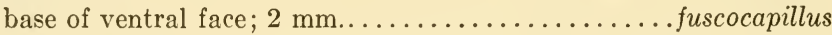

Intermediate femur with very long spine before the middle of ventral

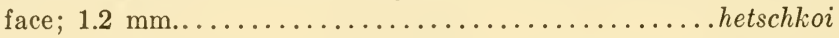

Of the eight species assigned to this group in the neotropics, the female of but one (centralis) has been described. Second, of these eight species only one is known north of Panama (centralis from Guatemala). The following species, based on four females, is very distinct from the female centralis and has been found with ants. This is the first myrmecocolous record of the genus, although it was previously suggested (Park, 1933) that at least some species of the genus might be myrmecophilous. The description of this new species follows:

\section{Euphalepsus myrmecocolus new species}

Type Female. Measurements: Head $0.30 \times 0.40 \mathrm{~mm}$.; pronotum $0.43 \times 0.43$ $\mathrm{mm}$.; elytra $0.80 \times 0.87 \mathrm{~mm}$.; abdomen $0.47 \times 0.80 \mathrm{~mm}$.; total length $2.0 \mathrm{~mm}$.; greatest width $0.87 \mathrm{~mm}$. (Pl. XVIII).

Body, femora, and first eight antennomeres dark red; tarsi, both ends of tibiae and palpi tan; antennal club coal black. The pubescence dark brown, abundant, recurved to subappressed. Integument moderately shining and lightly punctate.

Head with rounded tempora not quite as long as eyes but distinctly longer than wide; eyes very large and prominent, composed of about 80 small facets, ovate in lateral view, placed obliquely on sides nearer to ventral than dorsal surface. Head in dorsal outline regularly trapezoidal, converging simply to antennal tubercle at each antero-lateral angle; vertex simple, rather flattened, with a pair of large, deep, nude vertexal foveae. Front and clypeus simply declivous between antennal tubercles. Labrum simple. Ventral surface of head with a conical tubercle each side, between eye and cardo of maxilla, this tubercle surmounted by a very long, thick, translucent spiniform process. Genal-gular area bearing about 16 long, bristling, strongly capitate setae, reminiscent of certain euplectine genera. 
Maxillary palpi four-segmented and quite small in keeping with genus; first segment minute, elongate-cylindrical; second three times as long, arcuate, pedunculate for basal third then expanded in apical two-thirds; third as wide as second, one-half as long, triangular from ventral view, broadly obconical from lateral view; fourth as long as preceding two united, wider than third, subfusiform, with a minute apical truncature bearing a palpal cone. Fourth segment $0.10 \mathrm{~mm}$. long $\times 0.03 \mathrm{~mm}$. wide.

Antennae $0.93 \mathrm{~mm}$. long, eleven-segmented, distant, simple; first segment rounded-oblong; II similar but smaller; III smaller, obconical; IV-VIII moniliform; club large $(0.40 \mathrm{~mm}$. long), composed of last three segments, integument rugose, black, the last segment as long as ninth and tenth united (0.20 mm.).

Pronotum with length equal to width, widest near middle; disc strongly and simply convex but not gibbous (33 per cent elevated above the critical line given in Group key); transverse antebasal sulcus connecting a lateral fovea each side; longitudinal sulcus extending apically from each lateral fovea, between disc and margin, and becoming evanescent at middle; basal bead extended medianly in a short, narrow carina for half the distance between bead and transverse sulcus.

Scutellum large for pselaphids, equilaterally triangular.

Each elytron with a prominent humeral callus; a subhumeral fovea; an entire longitudinal carina on flank, from subhumeral fovea to apical margin; four large, deep, nude basal foveae of which the sutural is set apart; sutural stria strong and entire.

Wings present.

Abdomen with five visible tergites in a length ratio of $3 / 1.3 / 1.3 / 2.5 / 3$, with margins as follows: first each side with a strong, entire external and internal carina; second and third each side with a single, entire carina. First four tergites with a pubescent fovea in each latero-basal corner (by microdissection these foveae were found to extend deeply into the abdominal cavity as conical invaginations. They appear to be spiracular, and if so then the setae at orifice may be guard hairs.) Base of first tergite with a pair of minute, distant, blunt cusps separated by one-third the discal width of segment. Last tergite simple, flattened, vertical, and transversely fusiform.

Six sternites in a length ratio of $1 / 1.5 / 1 / .5 / .5 / 3$ at middle. First in the form of a circular platform with concave, rugulose upper surface, between posterior coxae. Second with a longitudinal median carina. Sixth transversely semilunar, with a broad, black apical bead.

Metasternum simple, convex, medianly foveate at apex.

Legs neither toothed nor inflated. In addition to the usual patch of setae at apex of ventral face, each intermediate tibia has a sharply defined, longitudinally ovate, densely pubescent fovea or depression on the antero-dorsal face for apical third of length. Tarsi long, slender, three-segmented; first tarsomere short and triangular; next two much longer, third longer than sec- 
ond and bearing a very long, slender primary and a much shorter, slender secondary claw, typical of genus.

Erected on one type and three paratype females, collected with ants at 5500 feet, on June 30, 1941, at Las Vigas, Vera Cruz, Mexico, by Mr. Dybas. The host ants have been sent away for identification. The sex was determined by dissection. ${ }^{1}$

The female of centralis and of myrmecocolus are rapidly differentiated. Sharp $(1887$, p. 20$)$ states that the female centralis "is remarkable on account of the existence of a conical projection of the dorsal surface of the hind body at the extremity." As seen from the description of myrmecocolus there is nothing analogous to this condition.

\section{Group V}

I am unfamiliar with this group of three Brazilian species, all described by Reitter.

The species may be listed as follows:

\section{I}

bilineatus Reitter. 1888. Blumenau, Brazil.

bistriatus Reitter. 1883. Brazil.

gounellei Raffray. 1917. Pernambuco, Brazil. (Male known only)

longicornis Reitter. 1885. Blumenau, Brazil.

pilicornis Raffray. 1917. Asuncion, Paraguay. (Male known only)

tricarinatus Raffray. 1904. Bahia, Brazil. (Male known only)

\section{II}

humeralis Raffray. 1887. Bogota, Colombia.

globipennis Reitter. 1883. San Marcos, Mexico. (Genotype)

liljebladi Park. 1933. Turrialba, Costa Rica. (Male known only)

panamensis Fletcher. 1927. Barro Colorado Island, Gatun Lake,

Panama Canal Zone. (Female known only)

rugipes Raffray. 1890. Tovar Colony, Venezuela. (Female known only)

III

fasciculatus Raffray. 1904. Bahia, Brazil. (Male known only)

\section{IV}

cavifrons Raffray. 1909. Sao Paulo, Brazil. (Male known only)

centralis Sharp. 1887. San Geronimo and Quiche Mountains (7000

to 9000 feet) Guatemala. (Both sexes known)

${ }^{1}$ This dissection is easily performed on Euphalepsus. The abdomen is large and conical and can be cut off without injury to legs. Then the abdomen is held firmly, lumen up, by the spread hairs of a small brush. If this is done in 95 per cent alcohol, under a binocular dissecting microscope, the penis can be picked out with a fine micro-hook if a male, or the absence of penis confirmed if a female. 
cruralis Raffray. 1890. Tover Colony, Venezuela. (Male known only) fuscocapillus Reitter. 1888. Blumenau, Brazil. (Male)

hetschkoi Reitter. 1888. Blumenau, Brazil. (Male)

ovipennis Reitter. 1883. Brazil. (Male)

reitteri Sharp. 1887. Volcan de Chiriqui (2500 to 4000 feet), Panama.

(Male known only)

tibialis Raffray. 1904. Amazonas, Brazil. (Male known only)

myrmecocolus new species. Vera Cruz, Mexico. (Female known only)

V

laevicollis Reitter. 1888. Blumenau, Brazil.

lothari Reitter. 1888. Blumenau, Brazil.

puncticollis Reitter. 1888. Blumenau, Brazil.

PHALEPSOIDES (Raffray, 1890)

ReITter (1888) (Euphalepsus)

RAFFrAY $(1890,1904,1908,1909)$

This is small genus of four species known to inhabit Brazil. Three of the species were described as Euphalepsus, and Raffray two years later emended this genus, erecting the present genus to hold those neotropical batrisines having (1) no humeral callus and (2) the metasternum as strongly, medianly, longitudinally carinated. It should be noted that Group V of Euphalepsus forms a transition to Phalepsoides with respect to the humeral callus.

The species may be listed as follows:

punctatissimus (Reitter). 1888. Blumenau, Brazil. (Genotype)

(Euphalepsus)

laevissimus (Reitter). 1888. Blumenau, Brazil. (Euphalepsus)

longiceps (Reitter). 1888. Blumenau, Brazil. (Euphalepsus)

vagepunctatus Raffray. 1909. Sao Paulo, Brazil. 


\section{Tribe 8. Tychini}

The Tychini are delineated by the following combination of characters: (1) the neotropical species have eleven-segmented antennae which are never geniculate, and are always widely separated at their bases. This particular character tends to make neotropical tychines unfamiliar in habitus to the student of nearctic Tychini, since such genera as Tychus, Cylindrarctus and their North American and European allies have the antennae approximate at base, the head correspondingly narrowed into more or less of an antennal tubercle, and therefore imparting to the whole animal a distinctive facies. The neotropical tychines, on the other hand, never have the antennae close together upon a common median antennal tubercle and hence the head has a broad, unfamiliar outline approaching Batrisini in many genera; (2) Mentum normal, never expanded to cover the mouth and mouth-parts; (3) Abdomen with five visible tergites. The first tergite is margined each side by an external and an internal carina and the second and third tergites are also usually margined each side by at least a single, short carina. This pattern holds for all neotropical genera with the exception of one genus, Dalmophysis, which has no marginal carinae on the first tergite or any succeeding tergites and is wholly marginless. Some genera have the lateral margins well-developed (Iniocyphus, Dalmodes, Dalmomima, Batriphysis) although narrow and variously formed. Other genera (Buris) have the margin indistinct, limited to the base of the first tergite; (4) Abdomen with the first sternite as long or much longer than the posterior coxae and always continuously visible from side to side. Females always with six sternites. Males with six sternites in all but three neotropical genera. These latter (Buris, Dalmoburis, Dalmophysis) have seven sternites in the male sex. Dalmophysis has a small, transversely triangular seventh sternite; Buris and Dalmoburis have the seventh sternite relatively large and longitudinally divided into a right and a left plate. It should be added that in a few genera only a single sex is known, thus Iniocyphus and Batriphysis are known only from males, and Bythinophysis from the female sex alone; (5) Posterior coxae have their mesial faces globular; (6) Femora obliquely articulated with their trochanters, so that coxa and femur, of the intermediate legs at least, are close together; (7) Three-segmented tarsi with the first tarsomere very small, and the last two relatively very long, the distal tarsomere bearing either a single large claw, or a large claw and an accessory bristle-like claw.

In contrast to Batrisini, neotropical Tychini are represented by a relatively large number of genera, but few species. Thus, there are fourteen genera and only thirty spcies. The neotropical genera may be artificially separated as follows: 
Key to the Neotropical Genera

Base of each elytron with at least three foveae...... DALMODES

Base of each elytron with at most two foveae.............. 2

2. Base of each elytron with two foveae.................. 3

Base of each elytron simple, without foveae, and at most with a vague impression ............................ 6

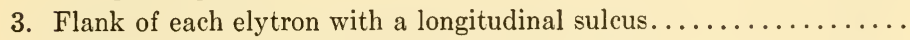

Flank of each elytron with no trace of a longitudinal sulcus, but with a strong longitudinal carina on the posterior (apical) half of elytral flank...................... DALMONEXUS, new genus

4. Pronotum with a longitudinal sulcus on each side...HARMOPHOLA

Pronotum without lateral longitudinal sulci.................

5. Pronotum with three free antebasal foveae but no trace of a trans-

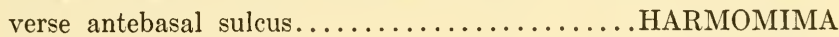

Pronotum with a lateral fovea each side connected by a transverse

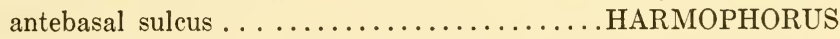

6. Flank of each elytron with a longitudinal sulcus...............

Flank of each elytron without any trace of a longitudinal sulcus; the elytral flank may be variously modified: (1) perfectly simple, (2) an entire longitudinal carina of varying thickness, which may or may not arise in a subhumeral fovea, or (3) a carina developed only on the posterior (apical) third of the elytral length........

7. Posterior coxae widely separated by the metasternum........... BYTHINOPHYSIS

Posterior coxae very slightly separated........... DALMOMIMA

8. Flank of each elytron with a subhumeral fovea.............BURIS

Flank of each elytron without a subhumeral fovea.............

9. Flank of each elytron with an entire longitudinal carina from near

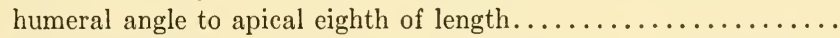

Flank of each elytron either perfectly simple and noncarinated, or with a longitudinal carina for the apical third of elytral length....

10. Occiput and vertex longitudinally, medianly carinate............ ..BATRIPHYSIS, new genus

Occiput and vertex not medianly, longitudinally carinate.......... .DALMOBURIS, new genus

11. Flank of each elytron with a fine longitudinal carina for the apical third, the basal two-thirds of length being perfectly simple....... ........................ PHYBYTHARSIS, new genus

Flank of elytra without any trace of longitudinal carinae..........

12. Abdomen absolutely immarginate, lacking even an external carina at base of first tergite on each side............. DALMOPHYSIS Abdomen with at least the first tergite narrowly but distinctly margined with an external and an internal carina each side......... 
13. Posterior coxae separated by appreciably more than half the median metasternal length, usually by as much as three-fourths this distance; sutural striae of elytra indistinct or rudimentary......... Posterior coxae separated by not more than half the median metasternal length, usually by as little as one-third this distance; sutural striae of elytra distinct and strongly formed..... BATRYBRAXIS

14. Head slightly longer than wide through eyes; vertex convex, uncarinated with vertexal foveae not apparent; front very long, ogival between antennal bases; each side of head with a narrow longitudinal sulcus extending from antennal insertion posteriorly above each eye; antennae simple, slender, much more than half as long as body; legs long and slender................INIOCYPHUS

Head much wider through eyes than long; vertex with a thick, short, median longitudinal carina at base; front sharply declivous beyond inter-antennal line; each side of head with an obliquely mesioposteriad incisure and vertexal fovea; antennae highly abnormal in the male sex, not more than half of body length; legs normally inflated; known only from nest of termites.................

ANOPLOBRAXIS, new genus

DALMODES (Reitter, 1882)

REITTER (1882)

Sharp (1887)

RAFFrAY $(1896,1904,1908,1908 a, 1911,1911 a)$

As limited here, Dalmodes is a neotropical genus of tychines, the species of which have the base of each elytron quadrifoveate with one exception, gracilipes, in which the elytron base has three foveae; the flank of the elytron has a longitudinal sulcus; the pronotum has a transverse subbasal sulcus but no lateral longitudinal sulci; the posterior coxae are widely separated; the abdomen has the first tergite narrowly but distinctly margined each side with an external and an internal carina, the second and third tergites much less sharply margined; six sternites in male and female, the sixth being relatively large and more or less rounded at apical margin.

This is a tentative restriction, placing several species in other genera. Early descriptions are vague and types usually not available for study so that the exact limits of the genus will remain unknown for some time to come. Five species are considered as belonging in Dalmodes, but of these one may be misplaced.

Key to THe Species

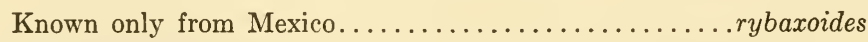

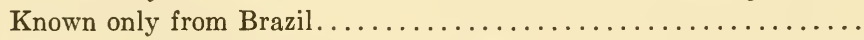

2. Base of each elytron with three foveae............. gracilipes

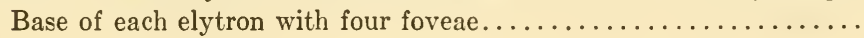


3. Total length more than two millimeters............. infossus

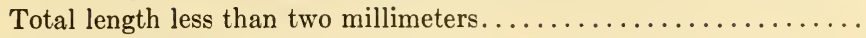

4. Antennal segments III-VIII regularly moniliform; head as long as

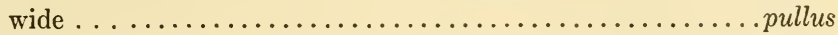

Antennal segments III-VIII not all moniliform; head shorter, not as

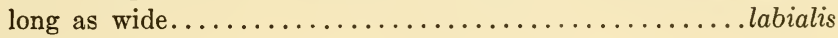

The species of Dalmodes may be listed as follows:

gracilipes Raffray. 1904. Blumenau, Brazil.

infossus Raffray. 1911. Sierra de Baturite, Brazil.

labialis (Schaufuss). 1887. Rio de Janeiro, Matto Grosso, Brazil.

(Batrisobryaxis). Genotype.

pullus Raffray. 1911. Matto Grosso, Brazil.

rybaxoides Reitter. 1882. Mexico. (Dalmodes as emended?)

\section{BYTHINOPHYSIS (Raffray, 1908)}

This genus was erected on a single species from French Guiana (punctipennis). Originally the genus was separated from Dalmodes by having the first tergite longer than the second, elytral margins slightly dilated, and distal palpomere sharply securiform, whereas Dalmodes has the first tergite subequal to second, elytral margins not dilated and distal palpomere only slightly securiform. These two genera agree in such basic features as widely separated posterior coxae and flank of each elytron with a longitudinal sulcus, so that they are quite close together. Bythinophysis has no basal elytral foveae and consequently I have placed several species, formerly in Dalmodes, in this genus as the qualitative character of no basal elytral foveae seems more fundamental than a quantitative length of the first tergite, amount of flair of elytra and degree of securiformity of the last maxillary palpal segment. In this I may be in error but more morphological research is indicated before the question may be laid aside arbitrarily. It is possible that the two genera will have to be combined under Dalmodes. In the present state of our knowledge the following key may help to separate the species with the exception of plicatulus.

First tergite distinctly longer than second tergite; antennal segments III obconical, IV-VI quadrate, VII-VIII slightly transverse, IX-X crescentric and transverse; $1.5 \mathrm{~mm}$.; known from female only....

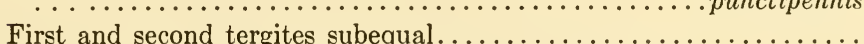

2. Pronotum with the transverse sulcus entire and connecting the lateral

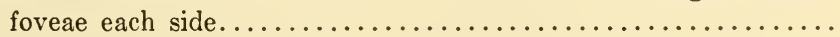

Pronotum with the transverse sulcus abbreviated so that the median fovea is transversely dilated; known from male only: sternites longitudinally excavated; fourth sternite strongly toothed on each side; intermediate trochanters compressed and toothed at base of ventral face; posterior tibiae bisinuate, with a small tooth at mid-

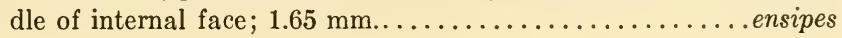


3. Antennal segments III-VII simple, similar, moniliform ........ 4

Antennal segments III-VII not mutually similar............. 6

4. Known only from Guadeloupe, and only from female sex; $1.3 \mathrm{~mm}$. .humilis

Known only from Guatemala; $1.66 \mathrm{~mm} . \ldots \ldots \ldots \ldots \ldots \ldots \ldots$.

5. Posterior tibiae with a very large, triangular, sharp tooth on internal face just above middle of length..............brevicollis MALE Posterior tibiae simple, not armed.............brevicollis Female

6. Antennal segment II quadrate, III moniliform, IV-V slightly transverse, VI-VII transverse and slightly crescentric with the internal face slightly serrate; VIII-IX very transverse and internal face produced; anterior femora broadly foveate; $1.5 \mathrm{~mm} . . . . . . .$.

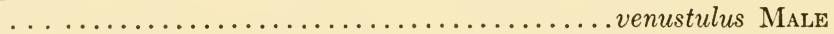

Antennal segment II briefly ovate, III-VII moniliform but progressively slightly decreasing in width; VIII-IX wider and lenticular;

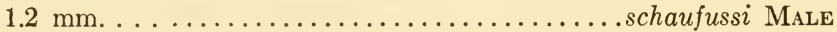

The species may be listed as follows:

${ }^{1}$ brevicollis (Sharp). 1887. Coatepeque, 1300 feet, Guatemala. (Dalmodes)

ensipes (Raffray). 1890. San Esteban, Venezuela. (Dalmodes) (May be the type of a new genus) humilis (Raffray). 1908. Guadeloupe, Leeward Islands. (Dalmodes) plicatulus (Schaufuss). 1882. Cayenne, French Guiana. (Trichonyx) punctipennis Raffray. 1908. Cayenne, French Guiana. Genotype. schaufussi (Raffray). 1896. Teapa, Mexico. (Dalmodes.) (Also recorded with doubt from New Orleans, Louisiana, and Yucatan, Mexico)

venustulus (Schaufuss). 1872. Teapa, Mexico. (Trichonyx)

\section{HARMOPHOLA (Raffray, 1896)}

This is a monotypic genus in which the elytral flank has a longitudinal sulcus and two basal elytral foveae and the pronotum has both a transverse subbasal sulcus and a lateral longitudinal sulcus on each side. The lateral pronotal sulci differentiate the genus from its allies.

clavata Raffray. 1896. Colonia Alpina, Brazil. Genotype.

\section{HARMOPHORUS (Schaufuss, 1886)}

This is a monotypic genus in which the elytra are similar to Harmophola, but the pronotum lacks the longitudinal lateral sulci and has a well-formed transverse subbasal sulcus. The eyes are very large but not visible from a dorsal viewpoint because the sides of the head are dilated. The integuments are strongly punctate.

manticoroides Schaufuss. 1886. Brazil. Genotype.

${ }^{1}$ However, see Dalmoburis. 
This neotropical genus holds two species of montane Bolivia. It is related to Harmophorus, having two basal foveae and a subepipleural sulcus on each elytron, but is readily distinguished from the allied genera by having the median pronotal fovea transversely dilated only, lacking a transverse subbasal sulcus and therefore the pronotal base has three free foveae. The two species may be separated as follows:

Antennal segment II briefly ovate, III-VIII moniliform, with the seventh slightly larger than sixth, and the eighth slight transverse, IX and X strongly transverse and with the lateral face slightly cres-

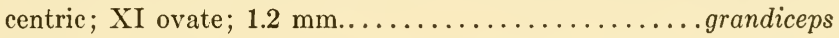

Antennal segment II globose, III-X moniliform with the third to eighth globose, ninth and tenth slightly transverse; XI oblong-ovate;

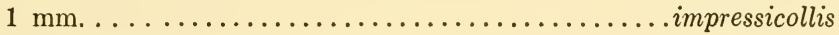

grandiceps Raffray. 1904. Yuracaris, Bolivia. Genotype. impressicollis Raffray. 1904. Yuracaris, Bolivia.

\section{DALMOMIMA (Raffray, 1908)}

This is a monotypic genus which has a habitus very similar to Batrybraxis but differs from this genus in having the flanks of the elytra longitudinally sulcate; Dalmomima is similar to the five preceding genera in having the elytral flanks longitudinally sulcate, but of these five only Dalmomima and Bythinophysis have no basal elytral foveae; it is distinct from Bythinophysis in that the latter genus has widely separated posterior coxae, whereas Dalmomima has the posterior coxae only slightly separated.

The male has the head with the dorsal surface excavated anteriorly and elevated and subauriculate laterally, while the female lacks this modification.

caviceps (Raffray). 1896. Colonia Alpina, Brazil. (Batrybraxis). Genotype.

This concludes the section of neotropical Tychini having the flank of each elytron longitudinally sulcate. The next section holds five neotropical genera in which the flank of each elytron has either (1) a subhumeral fovea and an entire longitudinal carina (Buris); (2) no subhumeral fovea but an entire longitudinal carina (Batriphysis, Dalmoburis) ; (3) no subhumeral fovea but the apical half of each elytron with a longitudinal carina, or (4) no subhumeral fovea, but with each elytron having a longitudinal carina for the apical third of its length. This is not a proposed evolutionary arrangement, and the differences between these genera are many and basic, as will be noted, but is given here as a convenient grouping in which neotropical tychines are divided into three sections, the sulcate group, the carinate group, and the unmodified group with respect to the flanks of the elytra. 
BURIS (Fletcher, 1928)

This is a monotypic genus which is unique among neotropical tychines in having each elytral flank with a subhumeral fovea from which extends an entire, broad, strong longitudinal carina. The base of the elytra have no foveae. The pronotum has a transverse subbasal sulcus connecting a small lateral fovea of each side. The males have seven sternites, of which the seventh is longitudinally divided into a right and left plate; females have six sternites. This sternite number is shared by only two other neotropical genera, Dalmoburis and Dalmophysis. The abdominal margin is limited to the base of the first tergite. Posterior coxae widely separated, the separation equal to the distance between the intermediate and the posterior coxae.

brunneus Fletcher. 1928. In rotten trunk of Coco palm, Vera Cruz, Vera Cruz, Mexico. Genotype.

I have a good series of Buris brunneus Fletcher as follows: four males Cordoba, Vera Cruz, collected in log mold July 20, 1936, by Dr. Charles Seevers; two males from Huichihuyan, San Louis Potosi, in log mold June 18, 1941; one male and two females from Tamazunchale, San Louis Potosi in log mold June 22, 1941, by Mr. Dybas.

These nine specimens check the ecological niche of the types and extend the Mexican range of the species.

\section{DALMOBURIS new genus}

This new genus is distinct from other Tychini on the following combination of characters: (1) Pronotum without lateral longitudinal sulci, but with a transverse subbasal sulcus connecting a small lateral fovea on each side; (2) Elytra with no basal foveae, but each elytron with a sutural stria and on the flank an entire, narrow, longitudinal carina; flank with no subhumeral fovea and no longitudinal sulcus; (3) Six sternites in the female sex; seven sternites in the male sex, the seventh sternite being longitudinally divided into a right and left triangular plate; (4) First tergite strongly margined each side by a short external carina half the segmental length, and a longer, arcuate internal carina three-fourths the segmental length; second and third tergites with a short basal carina each side at base; (5) Posterior coxae widely separated by a distance equal to the metasternal length; (6) Head transverse, with simple, eleven-segmented antennae widely separated at base on the antero-lateral corners of the front; (7) Maxillary palpi four-segmented, moderately long, slender and simple.

\section{Dalmoburis petrunkevitchii new species}

Holotype Male. 1.0-1.2 mm. long x 0.5.-0.55 mm. greatest width.

Shining, light reddish-brown when mature. Head subglabrous; pronotum lightly punctulate, with unusually short, sparse, appressed setae; elytra distinctly punctate, with long coarse subappressed setae; abdomen lightly punc- 
tulate, with pubescence intermediate in length between that of pronotum and elytra.

Head transverse, with long rounded tempora twice as long as eyes; eyes small $(0.05 \mathrm{~mm}$. long $\times 0.03 \mathrm{~mm}$. wide from a dorsal view), not prominent, composed of about 28 small facets, reniform in lateral view; the eye being $.073 \mathrm{~mm}$. in the dorso-ventral diameter. Occiput and associated portion of vertex strongly, medianly tuberculate; this tubercular elevation is evenly convex and not longitudinally carinate. Vertex tumid in posterior half to between the eyes, depressed in anterior half, with a pair of vertexal foveae distantly placed, one behind each antennal insertion on a line running through middle of eyes; vertexal foveae small, nude, about the diameter of an ocular facet, and connected by a wellformed circumambient sulcus. This sulcus apically reaching the arcuate, medianly concave, but entirely elevated frontal margin between antennal bases. No longitudinal median carina on vertex. Fronto-clypeal area short, simply declivous. Labrum relatively large, with a biarcuate apical margin. Ventral surface of head simple.

Maxillary palpi similar to Buris, relatively long and slender, four-segmented; first segment minute, subcylindrical; second, arcuate, elongate, as wide as first for basal half then gradually inflated to apex; third not quite half as long as second, obconical from a lateral view and triangular from a ventral view, slightly wider than second; fourth only slightly wider than third, but as long as preceding three segments, obliquely truncate at base, gradually narrowed to apex, apex narrowly truncate with a short, conical palpal cone occupying the apical truncature.

Antennae eleven-segmented, distant, simple; first segment dorso-ventrally compressed and arcuate, longer than second and as wide as ninth; II regularly elongate-oval, longer than third; III obconical; IV and V slightly shorter than third, elongate-oval; VI moniliform, shorter than fifth; V, VIII, and IX progressively wider and pyramidal, the ninth wider than long; $\mathrm{X}$ distinctly transverse, trapezoidal; XI as long as preceding four united, regularly truncate at base, sides subparallel and widest apart in basal two-fifths, narrowing to a conical, obtuse apex for apical three-fifths.

Pronotum with rounded apical corners; strongly evenly convex on disc; straight, convergent sides; a small lateral nude fovea each side near base connected by a nude, biarcuate, medianly expanded subbasal sulcus.

Elytra with evenly convex, nodular humeri; each elytron with an entire sutural stria; no basal foveae; no subhumeral fovea; flank with an entire longitudinal carina arising just ventrad of the nodular humerus and continuing to apex as a fine, but distinct carina.

Abdomen with five tergites with a length ratio of $1 / 1 / 1 / 1 / 2 / 11 / 2$; first tergite each side with a margin formed by a straight external carina half the segmental length, and a strongly arcuate internal carina which reaches apical three-fourths of segment; second and third tergites each with a very short, straight carina each side near base; last tergite broadly rounded-triangular in outline. 


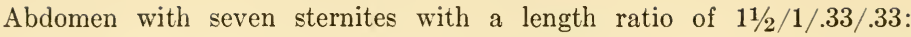
$.2 / 1.33 / 1.33$. First five simple and convex; sixth with an erect, transversely oblong lamina arising medianly at apical four-fifths. On using high magnification this peculiar plate is seen to consist of erect, slender, sharp teeth so that the plate in reality, is a comb; seventh as long as sixth, in two parts, a right and a left subtriangular plate. In the holotype and some paratypes, these plates are widely separated and the partially extruded penis protruded between them; in some paratypes the plates are closed, the line of junction forming a median, longitudinally arcuate carina.

Intermediate trochanters with a small, blunt tooth near base on ventral face. Femora simply inflated. Tibiae gradually thicker to apex and apically pubescent on ventral face; posterior tibiae with a short apical spur. Tarsi relatively short and thick, first segment small, triangular; second and third much longer, second twice as long as third; third with a long, thick primary claw and an accessory bristle. Posterior coxae widely separated, their separation equal to the metasternal length.

Metasternum medianly, simply and broadly concave.

Allotype Female. Similar to male save that (1) occiput is not medianly tuberculate, (2) six sternites only, all unmodified, (3) femora not inflated, (4) intermediate trochanters unarmed.

Described on nineteen specimens, all collected from soft, moist, decayed log mold or sifted from leaf mold of the rain forest floor at Barro Colorado Island, Gatun Lake, Panama Canal Zone, during the day. One female paratype and two males paratypes collected July 20, 1935, by Alfred Emerson. The rest collected by the author during the summer of 1936 by the author as follows: female paratype at Drayton 16 (July 25); holotype at Zetek 23 and allotype at Zetek 23 (July 27); two male paratypes at Zetek 3 (July 28); one male and two female paratypes at Zetek 17 (July 28); two female and two male paratypes at Pearson 2 (July 29); one male and three female paratypes at Armour 10 (July 30 ).

Because of its relatively wide insular distribution and abundance, I am inclined to consider this species as a characteristic constitutent of the rain forest $\log$ mold. It is strange that none were taken at night at lights. It is of interest also that of nineteen specimens, nine were males and ten females, attesting a normal sex ratio.

One male collected July 20, 1935 , had just pupated.

I take pleasure in naming this distinctive species for my friend, Professor Alexander Petrunkevitch, with whom I spent many a happy hour collecting in the rain forest.

At first glance Dalmoburis petrunkevitchii and Buris brunneus appear very similar. Both have the same indefinable habitus of close taxonomic relationship, and at first I had thought that petrunkevitchï could be placed in Buris. Mature consideration of paratypes of Buris brunneus in the U. S. National Museum and direct comparison of these with the present species, showed such a course to be both impracticable and unjustifiable. Both genera agree in such fundamentals 
as habitus, posterior coxal separation, antennal separation, sternite number and Iongitudinally divided seventh male sternite, in pronotal structure and other characters. Both genera disagree on such fundamentals as abdominal margination and elytral structure, so a new genus had to be erected in keeping with the separation of genera in Tychini.

As species, brunneus and petrunkevitchii are widely different on many characters, in addition to generic differences, such as the very abnormal and specialized male antennae of brunneus, radically different character of the male vertex and male sternite modification.

I have also included Dalmodes brevicollis Sharp in this genus. My series consists of five specimens as follows: three males from log mold on July 20, 1936, collected by Dr. Charles Seevers in Cordoba, Vera Cruz; one female on June 18, 1941, by Mr. Dybas from Huichihuyan, San Louis Potosi; one male on July 10, 1941, by Dr. Seevers from Penuela, Vera Cruz. These specimens were mounted on points or cleared and slide-mounts prepared. On careful study they appear to agree with Sharp's description and figure of brevicollis from Guatemala, in so far as these go. However, the males have seven sternites with the seventh sternite longitudinally divided; the females have six sternites and this is not Dalmodes where both sexes have six simple sternites. In the next place the males have the last tergite strongly produced into a sharp, conical spine whereas the female has a rudimentary spine. Sharp stated that the abdominal spine was strong in the female and rudimentary in the male, although his observation that the male hind tibiae are spined while the females have unarmed tibiae agrees with my series. Finally the elytral flanks are ornamented with a long, strong carina which Sharp might have interpreted as a sulcus.

The penis of the males of my material is very large $(0.45 \mathrm{~mm}$. long $\mathrm{x} 0.27$ $\mathrm{mm}$. wide) through the basal bulb, extending nearly to the second sternite, and of typical tychine pattern, so that the sex is not in question.

In the following key both sexes are included and Buris added since these three species, although very different, have the same habitus:

Seven sternites present, the seventh longitudinally divided into two

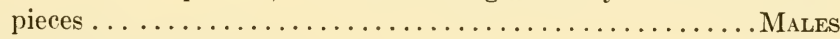

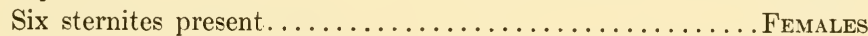

2. Elytral flank with a longitudinal carina ending near humeral angle in

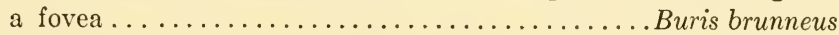

Elytral flank with a longitudinal carina ending near humeral angle but lacking a subhumeral fovea......................

3. Posterior tibiae with a large, triangular, acute spine on internal face

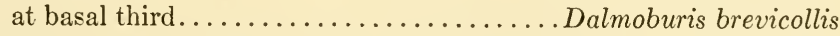

Posterior tibiae without tooth at basal third and with a minute spur

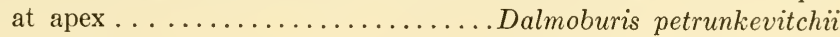

4. Elytral flank with a longitudinal carina and subhumeral fovea.....

Elytral flank with a longitudinal carina but without a subhumeral

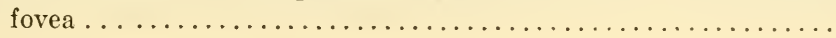


5. Last sternite ogival, very long, nearly as long as wide........... Dalmoburis brevicollis

Last sternite transversely fusiform with apical margin nearly straight, much wider than long.............Dalmoburis petrunkevitchii

I have keyed brevicollis Sharp in both Bythinophysis and Dalmoburis until the type can be studied, although the latter genus appears to be a more suitable vehicle. The species of Dalmoburis may be listed as follows:

brevicollis (Sharp). 1887. Coatepeque, 1300 feet, Guatemala; Cordoba,

Vera Cruz, Mexico; Penuela, Vera Cruz, Mexico; Huichihuyan, San

Louis Potosi, Mexico.

petrunkevitchii new species. Panama Canal Zone. Genotype.

\section{BATRIPHYSIS new genus}

This new genus is distinct from other Tychini on the following combination of characters: (1) Head subquadrate with simple, eleven-segmented antennae widely separated at base on the antero-lateral corners of the front; eyes reniform, not prominent, placed far below the convex, longitudinally medianly carinate vertex; (2) Vertexal foveae absent; (3) Maxillary palpi simple, foursegmented, moderately slender and elongate; (4) Integuments of dorsal and ventral surfaces roughtly punctate to granular; (5) Pronotum lacking lateral longitudinal sulci and lacking lateral foveae, but with a long transverse antebasal sulcus; (6) Elytra lacking basal foveae, sutural stria vestigial, but each elytron with an entire, longitudinal carina on the flank; (7) Six sternites in the male sex (female sex unknown); (8) Five visible tergites, the first three laterally margined each side; (9) Posterior coxae moderately separated by a distance equal to one-third the metasternal length; (10) Tarsi with a large, broad, acute primary claw and a much shorter, narrow accessory claw.

Batriphysis epicranis new species

Type Male. $1.6 \mathrm{~mm}$. long x $0.6 \mathrm{~mm}$. wide.

Light reddish-brown; punctation heavy as described below; the pubescence moderately abundant and subappressed; body elongate-cylindrical as in Dalmophysis, the habitus batrisoid.

Head subquadrate, slightly wider through the eyes than long; tempora short, one-fourth the head length, strongly arcuate, and only slightly longer than the eyes. Eyes appear very small from above $(0.05 \mathrm{~mm}$. long $\mathrm{x} 0.02 \mathrm{~mm}$. wide) but in reality elongate-reniform, with a dorso-ventral depth of $0.1 \mathrm{~mm}$. placed far below vertex, on the sides of head, and composed of about 32 small facets. Occipital margin subtruncate. Vertex high, convex, coarsely granulate, with an entire, high, median, longitudinal carina from occiput to a point just apical of anterior eye margin; here this median vertexal carina bifurcates and becomes vestigial and interrupted. Vertexal foveae absent, their homologues present as a pair of circular tumuli with blackened periphery, each elevation formed by 
the anchorage of one arm of the supratentorium, each tumulus just beyond an arm of the bifurcated median carina. A median triangular portion of the anterior vertex (bounded by the interantennal line and an oblique line from antennal insertion to bifurcated arm of median carina) subglabrous, with few scattered granules; this triangular area transversely depressed just posterior to interantennal line, and with a transversely suboblong tumulus with blackened periphery placed just posterior of this depression and just apical of median carinal bifurcation. Frontoclypeal surface long, nearly vertical, convex and simple save for a small median tuberculation on interantennal line. Labrum short but unusually wide, with a simple, truncate margin. Ventral surface of head transversely tumid, coarsely punctate, not medianly carinate.

Maxillary palpi distinctly paler, four-segmented; first segment very short, triangular, wider apically than base of second; second sharply arcuate at base, slender and cylindrical in basal half, gradually inflated in apical half, about five times longer than first; third globose-triangular in lateral outline, slightly wider than second but one-third as long as second; fourth relatively short, one-fourth longer than second, subsecuriform-conical in outline with blunted apex bearing a long, slender palpal cone.

Antennae eleven-segmented, widely separated, absolutely simple; segment I cylindrical, longer and wider than second; II subcylindrical, longer and wider than third; III subobconical; IV-VII moniliform; VIII transversely moniliform, slightly wider; IX transversely ovate-moniliform, wider than eighth; $\mathrm{X}$ subquadrate-submoniliform, much wider and longer than ninth; XI as in Dalmoburis.

Pronotum subquadrate, one-tenth wider than long, widest in apical twofifths, sides converging apical and basal of this point; disc evenly convex. Integument granulate. No lateral longitudinal sulci or lateral foveae. Subbasal transverse sulcus strongly angulate medianly, continuing laterally where sulcus is expanded, then narrowing and passing far down pronotal flanks.

Elytra simply punctate, with angulate humeri; each elytron with a vestigial sutural stria which is discernible only at apex, and lacking basal foveae; each elytral flank with a strong, entire longitudinal carina but lacking subhumeral fovea or longitudinal sulcus.

Abdomen with five visible tergites having a length ratio of 2.5/1.5/1/1.5/1. First tergite, in addition to its much greater length, is roughly punctate, the punctures very large, shallow, elongate-oval whereas the remaining tergites are simply punctate. Margins as follows: first tergite with an exceptionally high, entire external carina which continues the line of the elytral-flank carina, and a short oblique internal carina for basal third (the triangular area between carinae obliquely elevated with the orifice of a large fovea seen beneath this oblique elevation) ; second, third, and fourth tergites with a short, thick, straight carina each side at base.

Abdomen with six sternites; the first four rugosely punctate with large, oval, crowded punctures; sixth simply punctate; six sternites with a length ratio of 1.8/1.8/.7/.6/.5/2. First and second sternites subequal, the first much longer 
than posterior coxae. No abnormal modifications; sixth the longest, and transversely oval. In the type the large penis is partially extruded between apical sternite and tergite.

Prosternum simple, subglabrous, with a fovea apical of each coxa. Mesosternum rugose with a strong median longitudinal carina for apical half. Metasternum coarsely punctate, slightly medianly sulcate. Posterior coxae separated by a distance equal to about one-third the metasternal length. Legs simple and unarmed except that the anterior femora are slightly inflated with a flattened ventral face. Tarsi batrisine, thick; first segment short, triangular: second four times as long as first; third (distal) half as long as second, with two distinct claws, a large, acute primary claw and a much shorter, slender accessory claw.

Erected on a single type male, collected by the author on Barro Colorado Island, Gatun Lake, Panama Canal Zone, July 28, 1936, in log mold at Zetek 3.

This is a difficult species to analyse. It has the general cylindrical outline of Dalmophysis, from which it differs in many basic generic characters such as abdominal margin, relative tergite length, et cetera. In general epicranis appears like a heavily punctate batrisine, and the tarsal claw aids this illusion whereas the elongate first sternite precludes such association. Taxonomically the species is near Batrybraxis. It agrees with Batrybraxis in tergite and sternite lengths and separation of posterior coxae, but cannot be placed in this genus as (1) it lacks vertexal foveae, lateral pronotal foveae per se and has a vestigial sutural stria, and (2) has an entire longitudinal carina on elytral flank.

\section{DALMONEXUS new genus}

This new genus is distinct from other Tychini on the following combination of characters: (1) Head with vertex, front and clypeus highly modified in the male, but the occiput and vertex strongly, medianly, longitudinally carinate in both sexes; (2) Eleven-segmented, simple antennae widely separated on the antero-lateral angles of the front; (3) Maxillary palpi simple, four-segmented, elongate and moderate in size; (4) Pronotum wider than long, abruptly narrowed in basal third; subbasal sulcus connecting a lateral fovea each side; (5) Each elytron with entire sutural stria, but lacking basal foveae; flank with a strong, longitudinal carina for apical half of length; (6) Six sternites in both sexes; (7) Five visible tergites, the first three laterally margined each side; (8) Posterior coxae widely separated by a distance equaling three-fourths the metasternal length.

\section{Dalmonexus seeversi new species}

Holotype Male. $1.20 \mathrm{~mm}$. long x $0.60 \mathrm{~mm}$. wide.

Moderately shining dark red when mature, palpi and legs paler. Flavous pubescence moderately abundant, long and bristling on head, pronotum and elytra; pubescence sparse and subappressed on abdomen. Integuments lightly punctulate.

Head distinctly wider through eyes than long; tempora very short, very 
wide and rounded; eyes short and inconspicuous from above, but reniform and conspicuous from a lateral view, composed of about 32 medium-sized facets. Head with a strong median longitudinal carina bisecting cervicum, occiput and vertex to a point opposite the anterior margin of the eyes. This posterior half of the vertex evenly vaulted above the eye level. Anterior half of vertex rapidly, evenly declivous to front and also medianly longitudinally carinate. Therefore, only the median third of length is not carinated. Sides of head anterior of the eyes convergent and erected into a conspicuous, suboblong crest or marginal wing from anterior third of eye to apex of first antennal segment. This marginal crest deeply, obliquely incised just posterior to antennal articulation, with a small vertexal fovea just mesiad of the incisure. These vertexal foveae nude and entirely free. Interantennal line conspicuously bicornuate each side as a consequence of the extension of each lateral crest past the antennal articulation as a rounded horn; deeply arcuate between these frontal horns, with the median point of arcuation sharply, narrowly incised (this median incisure just apical to origin of anterior median carina), and with a coarsely setose, acute spine on each side of incisure. Front deeply and transversely recessed below these median spines. Clypeus complex: produced into a transversely obconical elevation which has its anterior face medianly elevated into a longitudinally lamelloid carina which continues dorsally to end in a short median tooth of dorsal margin, this tooth bearing a pair of divergent pencils of setae; a lateral tooth at each dorsal angle of the clypear elevation so that this obconical process is dorsally tridentate. Labrum simple, transverse, with concave apical margin. Ventral surface of head simple, evenly flattened, without median longitudinal carina.

Maxillary palpi four-segmented; first segment minute; second strongly arcuate near base, elongate, basally pedunculate, gradually expanding to apex; third short, one-third the length of second and slightly wider, subquadrate with evenly convex external and angulate internal face; fourth large, one-fourth longer than second, twice as wide as third, obliquely truncate at base, apically becoming subconical and subsinuate with the apex minutely truncate and bearing a small but distinct palpal cone.

Antennae eleven-segmented, simple; segment I subcylindrical, as wide as tenth; II ovoidal, shorter than first and as wide as ninth; III-VII small, moniliform; VIII transversely moniliform, slightly wider; IX and X trapezoidal, progresively transverse; XI slightly wider than tenth, as long as distal segment of maxillary palpus or slightly longer than preceding three segments united, basally truncate, convergent in apical half to blunt apex.

Pronotum one-fifth wider than long, widest through basal third, with a subsemicircular apical outline and then sides abruptly and angulately narrowed in basal third, the sides subparallel basal to the constriction; transverse subbasal sulcus in basal fourth connecting a lateral fovea each side, the foveae placed beneath the overhang of the lateral margins.

Each elytron with an entire sutural stria, two large basal foveae and the posterior (apical) half of flank decorated with a strong, longitudinal, blackened carina which continues the arc of the external carina of the first tergite. 
Abdomen with five visible tergites in the length ratio of $3 / 1.8 / 1 / 1 / 1$, simple. Margins as follows: first tergite each side with two parallel, subentire carinae with the internal carina strongly $Y$-shaped (a rounded cusp of elytral apex fitting into the bifurcation); second, third, and fourth tergites each side with a straight, short internal carina and second and third with a rudiment of an external carina at base.

Six sternites in the length ratio of 1.3/1.5/.6/.5/.5/1.2. First sternite visible side to side, separated from second by a deep pubescent trough; sixth sternite with a suberect, transvesely arcuate, lamelliform carina at middle and one-fifth the segmental length from apical margin.

Metasternum medianly, longitudinally sulcate.

Posterior coxae distant, separated by a distance equal to three-fourths the median metasternal length. Legs simple save posterior tibiae. Each posterior tibia thickened in apical half, the thickened portion sharply arcuate. A tuft of long setae at start of arcuation on internal face, and apex with a dense pad of short setae and a stout, arcuate tooth. Tarsi three-segmented; first tarsomere very short, last two relatively long, second longer than third; third with a long tarsal claw.

Allotype Female. Similar to holotype save that (1) longitudinal median carina of posterior half of head much longer, extending to a point opposite antennal bases; (2) anterior median longitudinal carina not present; (3) sides of head anterior to eye elevated, but in the form of a wide flattened margin, not produced apically as horns, but simply converging between and below antennae as a narrow continuous, carinoid arc; (4) front evenly declivous and entirely simple save for the union of the marginal elevation just noted; (5) clypeus simply declivous; (6) sixth sternite not modified; (7) posterior tibiae slightly arcuate through apical half, without basal tuft and lacking terminal tooth.

Described on twenty-three specimens, all collected on Barro Colorado Island, Gatun Lake, Panama Canal Zone. One female paratype collected August 15,1935 , by Alfred Emerson in nest of the termite, Cornitermes $(C$.$) acignathus$ walkeri Snyder. Rest collected by the author as follows: Two male and two female paratypes July 25, 1936, in rotten log mold at Drayton 15; holotype, allotype, seven male, and two female paratypes sifting floor mold at Zetek 23 on July 27, 1936, and three male and four female paratypes same place and date in $\log$ mold.

The record with the termite is probably accidental.

It should be noted that the sex ratio is nearly $1 / 1$ and that the August 15 specimen and five taken in floor debris had just pupated.

This isolated form is named for my friend, Dr. Charles H. Seevers. The genus is nearest Dalmodes and Bythinophysis in Raffray's 1908 arrangement, but is obviously distant from these genera on the absence of a longitudinal sulcus on elytral flank, and an entirely different pronotum among other basic features.

PHYBYTHARSIS new genus

This new genus is distinct from other Tychini on the following combination of characters: (1) Head with vertex, front and clypeus highly modified in the 
male, but occiput and vertex strongly, medianly and longitudinally carinate in both sexes; (2) Eleven-segmented, simple antennae widely separated on the antero-lateral angles of the front; (3) Maxillary palpi simple, four-segmented, elongate and moderate in size; (4) Pronotum wider than long, abruptly narrowed in basal fourth; no median and no lateral foveae; a transverse sulcus which receives an oblique accessory sulcus from basal margin each side; (5) Each elytron with entire sutural stria, but lacking basal foveae; flank with a longitudinal carina for apical third to apical half of elytral length; (6) Six sternites in both sexes; (7) Five visible tergites, the first three laterally margined each side; (8) Posterior coxae only moderately separated by a distance equaling one-half the metasternal length.

\section{Phybytharsis gambosis new species}

Holotype Male. $1.14 \mathrm{~mm}$. long x $0.60 \mathrm{~mm}$. wide.

Moderately shining, dark red when mature. Pubescence flavous, moderately abundant, long and bristling. Integument sparsely, lightly punctulate.

Head one-ninth wider than long with eyes included; tempora short, as long as eyes but very wide and gradually rounded. Eyes subreniform, central, of about 30 medium-sized facets. Cervicum not carinate. Occiput and vertex bisected by a thick, longitudinal median carina which extends to a point opposite anterior third of eyes. Vertex vaulted above eye level. Sides of head anterior of eyes with a deep, glabrous, rounded-triangular incisure. This incisure conspicuously developed in contrast to the narrow, oblique homologue of Dalmonexus. A pair of minute, shallow vertexal foveae, each fovea nude and placed mesioposteriad of lateral incisure. Anterior half of vertex, between vertexal foveae and interantennal line, glabrous, simple, declivous. Front very complex: the anterior glabrous vertexal area is entirely separated from the front by a prominent cylindrical antennal tubercle on each side, and by an interantennal crest which is abruptly elevated medianly into a high, thin, transverse lamella. Just anterior to this lamella the front is very deeply, transversely excavated, and this wide, deep, short excavation is in turn walled in by the clypeus. The clypeus is equally complex, elevated into a high thin lamella; this clypeal lamella extends from one antennal acetabulum to the other, and medianly is thickened into a triangular, apically setose column, while laterally the walls are very thin and translucent. Labrum simple. Ventral surface of the head uncarinated.

Maxillary palpi paler, pubescent, four-segmented, first two segments as in Dalmonexus; third quadrate with a slightly convex external, and a straight, shorter internal face, slightly wider than second and one-third as long; fourth one-half wider than third, four times as long, obliquely truncate at base, apically narrowed, with a small palpal cone.

Antennae eleven-segmented, widely separated at base, perfectly simple; segments as in Dalmonexus.

Pronotum transverse, apical three-fourths transversely ovate; basal fourth suddenly narrower; these two portions separated by a deep, arcuate, transverse sulcus. This antebasal sulcus becomes broader laterally where it is overhung 
with a brush of long setae, and then extends down each pronotal flank. Neither median nor lateral foveae discernible. A unique feature is a short accessory sulcus, each side near lateral margin, which arises from the basal margin and extends obliquely mesiad to enter the transverse sulcus.

Each elytron with an entire sutural stria; no basal foveae but with a faint intrahumeral impression; flank with a longitudinal carina extending from apical margin and continues as a strong feature to apical third of elytral length, gradually fading out between apical third and apical half; basal half of flank perfectly simple.

Metathoracic wings well developed.

Five visible tergites in a length ratio of $2 / 1 / 1 / 1 / 1$ with margins as follows: first three each side with a subentire, subparallel external and internal carina, these carinae well-formed, the external following the arc of the elytral carina. Internal carina of first basally bifurcated.

Six sternites in a length ratio of $1 / 1 / .4 / .3 / .3 / 1.5$. First visible from side to side, and with a large circular, pubescent fovea between posterior coxae. Sixth sternite with apical margin produced. Penis partially extruded in holotype.

Metasternum with a median longitudinal sulcus.

Intermediate coxae narrowly separated by an unusually long and narrow mesosternal process. Posterior coxae moderately separated by a distance equal to half the median metasternal length. Intermediate trochanters triangular, with a spine at center of ventral face. Posterior tibiae entirely arcuate. Tarsi thick, tarsomeres of usual length proportions, with a large tarsal claw.

Allotype Female. Similar to holotype save that (1) the head is simple, the lateral incisure narrow, oblique and pubescent; vertexal foveae simple connected by a narrow, anteriorly arcuate sulcus which is bounded apically by the arcuate, tumid interantennal line of the simple front; clypeus simply declivous; (2) tergite ratio $3 / 1 / 1 / 1 / 1$; (3) sternite ratio $1 / 1.2 / .5 / .3 / .5 / 1.2$; (4) intermediate trochanters unarmed.

Erected on three specimens (holotype, allotype, male paratype) from rotten $\log$ mold at Miller 3, by the author on July 29, 1936, on Barro Colorado Island, Gatun Lake, Panama Canal Zone. The allotype and paratype had recently pupated.

By the 1908 arrangement of Raffray, Phybytharsis is nearest Batrybraxis. It differs from Batrybraxis in numerous ways, among which may be noted: pronotum with accessory, oblique sulci between basal margin and transverse sulcus, and lacking lateral foveae; elytral flank with longitudinal carina in apical third; it is also related to Dalmonexus but is distinct in lacking basal elytral foveae and on posterior coxal separation.

The remaining four tychine genera are distantly related by the essential tribal characters and have little in common save the perfectly simple elytra.

\section{DALMOPHYSIS (Raffray, 1896)}

This is a monotypic Mexican genus with no nearly allied relatives, as demonstrated by the following combination of characters: (1) Vertexal foveae 
well-formed, on a line which passes through the posterior margin of the eyes, and placed on the simply convex, wholly unmodified head; (2) Antennae simple; (3) Pronotum ovoidal with the usual antebasal, transverse sulcus; (4) Elytra perfectly simple, lacking basal foveae, with wholly unmodified flanks and lacking a satural stria; (5) Abdomen without any traces of marginal carinae, which in itself is unique among neotropical genera; (6) Second tergite conspicuously longer than first or third; (7) Six sternites in the female sex; seven sternites in the male sex, this seventh sternite being very small, triangular, and not longitudinally divided.

\section{cylindrica Raffray. 1896. Mexico. Genotype.}

\section{INIOCYPHUS (Raffray, 1911)}

This is a monotypic Brasilian genus known only from the male sex, and equally unrelated to other Tychini as indicated by the characters set forth in the generic key. In addition to these it should be mentioned that the male sex has six sternites only; the abdomen is conical with the first three tergites narrowly, but distinctly margined.

iheringi Raffray. 1911. Sao Paulo, Brazil. Genotype.

\section{ANOPLOBRAXIS new genus}

This genus is distinct from other Tychini on the following combination of characters: (1) Head transverse, with prominent eyes placed at middle of head; (2) Ventral surface of head simple, lacking median longitudinal carina; (3) Antennae widely separated beneath distinct ovoidal tubercles, eleven-segmented, highly abnormal in the male sex; (4) Maxillary palpi simple, elongate, and slender, four-segmented, with distal segment bearing a palpal cone; (5) Pronotum nearly as long as wide, disc simple, with an antebasal, transverse sulcus connecting a large, deep, pubescent fovea each side; (6) Each elytron perfectly simple, lacking any modification of the flank, lacking basal foveae and with rudimentary sutural stria; (7) Abdomen with first three tergites distinctly margined each side and male with six sternites; (8) Posterior coxae distant, separated by a distance equal to three-fourths of the median metasternal length.

Its novelty is enhanced by living with termites.

\section{Anoplobraxis guianensis new species}

Type Male. Measurements: Head 0.26 x $0.361 \mathrm{~mm}$. through eyes; pronotum $0.335 \times 0.35 \mathrm{~mm}$.; elytra 0.56 x $0.737 \mathrm{~mm}$; abdomen 0.388 x $0.53 \mathrm{~mm}$. Total length $1.54 \mathrm{~mm}$. Greatest width $0.74 \mathrm{~mm}$. (Pl. XIX, 2).

Brownish-yellow with flavous, long shaggy pubescence; integument lightly punctulate.

Head transverse with rounded tempora which are as long as wide; eyes prominent, at middle of head, as long as tempora, with about 24 rather large facets; vertex evenly convex, bisected at base by a short, low, thick carina which 
is recessed in the integument. Sides of head sharply narrowed and angulated just anterior of eye, the angle continued mesio-obliquely as a deep, pubescent incisure, and then elevated into an ovoidal, distinct antennal tubercle each side. A small vertexal fovea lies as the end of each incisure. Front between antennal tubercles flat, with a drum-shaped platform or circular tumulus at middle of flattened inter-antennal line. Front below interantennal line, and clypeus declivous and perfectly simple; labrum simple; ventral surface of head simple. Temporal beard well-developed.

Maxillary palpi yellow, four-segmented, moderately elongate and slender; first segment short, slightly wider than base of second; second elongate, slender and arcuate in basal two-thirds, gradually broader in apical third; third onethird as long and subequal in width to second, elongate-triangular; fourth onefourth longer than second and distinctly wider than third, subtruncate at base, broadening to middle, thence narrowing to acute, minutely truncate apex which bears a distinct palpal cone.

Antennae half as long as body $(0.74 \mathrm{~mm}$.), distant, eleven-segmented, very abnormal; segment I large, elongate-cylindrical, as long as next three united $(0.134 \mathrm{~mm}$.) and as wide as sixth; II elongate-ovoidal; III-VI subequal in length, third briefly obconical, fourth moniliform, fifth transverse-moniliform, sixth slightly wider with mesial face narrowly, subacutely produced; VII longer and wider, transverse-pyramidal, with mesial face also strongly produced; club distinctly formed of next four segments; VIII, IX and X very irregularly but strongly transverse, with their ventral faces deeply and completely excavated, each excavated face at a different plane than the other two, and the eighth also with a pubescent, laminoid horn on its dorso-mesial face; XI much narrower than any of the preceding three but as long as preceding four united $(0.19 \mathrm{~mm}$.), base circular and regularly truncate, segment in two parts, a basal subcylindrical half and a conical half set within the circular distant rim of the wider basal portion reminiscent of the condition in Thesium.

Pronotum subquadrate with evenly convex disc and gradually diverging sides to basal fourth where the margins become obliquely narrowed; base crossed by an arcuate antebasal sulcus at this point, the sulcus deepening laterally to end in a large, very deep, pubescent fovea each side.

Scutellum small, acute-triangular.

Elytra entirely simple, lacking basal foveae and with unmodified flanks; sutural stria rudimentary.

Wings present and moderately well-developed.

Abdomen with five visible tergites in a length ratio of $2.5 / 1 / 1 / 1.5 / .8$ and margins well-formed as follows: first each side with a pair of strong, arcuate, parallel, subentire carinae; second and third with a single, straight carina for basal half on each side.

Six sternites in a length ratio of 1.2/1.2/.7/.5/.4/1.2 and all simple and convex; first visible from side to side, with a large circular, pubescent fovea between posterior coxae as in Phybytharsis; sixth with apical margin simply rounded. 
Posterior coxae widely separated by a distance equal to three-fourths the median metasternal length as in Dalmodes and Bythinophysis.

Intermediate trochanters each with a long, oblique, translucent spine on ventral face. Femora not inflated, but tibiae, especially the posterior pair, arcuate. Tarsi long (posterior pair nearly two-thirds as long as their tibiae), threesegmented; first tarsomere short, obconical-triangular; last two relatively very long as usual, with the second longest and the third bearing a long, acute tarsal claw.

Described on a single male specimen, collected April 20, 1924, at Kartabo, British Guiana, in the nest of a new species of Anoplotermes (Anoplotermes) by Alfred Emerson. Professor Emerson's field notes disclose that the beetle was collected unnoticed with termites of the colony and discovered later in the vial. There are no ecological data to show this species is a definite termitophile but the fact that it was collected with the termites indicates toleration by the host and hence we can suggest that guianensis is a synoekete. On the other hand, the well-formed eyes and wings as well as the normally formed mandibles and maxillae suggest a nonsymphilic role. These latter characteristics are to be treated with reserve since some true symphiles (Fustiger) have both eyes and wings, although the mouth-parts are reduced, while other pselaphids live a nonsymphilic, predaceous life, but are blind and wingless.

The new genus and species is a welcome addition since it adds a species to the few pselaphids associated with Isoptera, and is one of the very few pselaphids recorded from British Guiana. In the 1908 Raffrayan arrangement Anoplobraxis becomes associated with Dalmodes and Bythinophysis in the tribal key but is rapidly separated from these two aggregates since they have the elytral flanks longitudinally sulcate.

\section{BATRYBRAXIS (Reitter, 1882)}

This is an important genus of neotropical Tychini, organized on the following combination of characters: (1) The head is large, more or less transverse and the vertex, front and ventral surface of the head are often very complex, armed, excavated or fasciculated in the male sex whereas the females are generally conservative and appear very differently from males of the same species; (2) Antennae eleven-segmented, widely separated on the antero-lateral angles of the head, and often highly abnormal in the male sex, this range of abnormality varying greatly among the species; (3) Maxillary palpi four-segmented, moderately elongate and slender; first segment always very small, obconical to subcylindrical; second much longer, elongate, slender and arcuate in basal half and strongly inflated near apex; third obconical, about as wide as second, but from a third to a fourth as long, much longer than wide; fourth widest and longest, varying from cuneiform to securiform, with the apex bearing a palpal cone; (4) Pronotum transverse, with evenly convex, simple disc and transverse antebasal sulcus connecting a lateral fovea each side; at this level the pronotum is usually suddenly narrower, or the pronotal outline may be subcordiform; (5) Elytra are simple, they lack basal foveae, although faint dorsal depressions 
may be present, and the elytral flanks lack foveae, sulci or carinae; the sutural stria of each elytron, however, is strongly developed; (6) Abdomen with five visible tergites and six sternites in both sexes; first tergite conspicuously longer than second; first two sternites long, the second varying from slightly longer to much longer than the first; (7) The posterior coxae are only moderately separated by a distance which varies from one-third to nearly one-half the median metasternal length; (8) Three-segmented tarsi with the first tarsomere very short; next two relatively elongate, the second longest and elongate-obconical while the third is thinner, cylindrical and bears a large, acute claw and an accessory bristle.

The size is small and the body typically thick, convex, and more or less ovoidal. They appear to inhabit the forest floor mold by day and the species are probably much more numerous and widely spread than our meagre knowledge indicates.

The following species are new:

\section{Batrybraxis panamaensis new species}

Holotype Male. $0.93 \mathrm{~mm}$. long; $0.50 \mathrm{~mm}$. wide; antennae $0.4 \mathrm{~mm}$. long.

Light brown with legs, maxillary palpi, and swollen seventh antennal segment yellow; integument shining, uniformly but minutely punctulate; pubescence flavous, moderately long, abundant, and semierect on body save abdomen where it is subappressed. Temporal beard well-developed.

Head transverse and structurally very complex; tempora very short and wide, only half as long as eyes; eyes small, far down on sides of head but prominent, placed in basal third, and composed of about 32 small facets. Occiput medianly, longitudinally sulcate. Vertex high, transversely vaulted from occiput to opposite anterior eye margins, and at this point the vaulted area is abruptly and vertically declivous. This transverse declivity forms a crest which is modified as follows: the median third of the crest is lower than the lateral thirds and holds a pair of erect, oblong, truncate horns while each lateral third of the crest is in the form of a laminoid plate which becomes lower nearer each eye. The head is laterally excavated anterior to the eye as usual by a narrow, pubescent, deep and parallel-sided incisure. The vertexal foveae are not discernible as such. The vertex just anterior to the transverse crest (in line with the lateral incisures) is ornamented by a median, semi-circular crest whose posterior edge is roundly elevated into a subcornuate pubescent process which nestles against the median horns of the transverse crest. What I take to be the homologues of the vertexal foveae are two roughened depressions, one at each end of the just noted semicircular crest, these indentures probably mark the anchorage of the supratentorium to vertex. The inter-antennal line of the front is marginally tumid and semi-circular in outline, with a small foveoid indenture each side which marks the articulation of the first antennomere. Clypeus simply vertical. Ventral surface of the head perfectly simple.

Maxillary palpi as described for genus.

Antennae eleven-segmented, distant, abnormal; segment I elongate-cyl- 
indrical, only shorter than eleventh; II ovate, smaller than first but only shorter than first, tenth or eleventh; III minute, obconical; IV-VI gradually, slightly wider but subequal in length to third, transversely moniliform; VII abnormal, very transverse, wider than any segment save last two, with the mesial face produced, of a yellow color (glandular?) ; VIII and IX pyramidal; X trapezoidal; $\mathrm{XI}$ not much wider than tenth but almost as long as preceding four united, shaped as in Anoplobraxis.

Pronotum obviously transverse, formed as in Dalmonexus.

Elytra perfectly simple, as in Anoplobraxis save that the sutural striae are strongly developed.

Wings long, well-developed, iridescent, fringed with long setae.

Abdomen with five visible tergites in a length ratio of $2 / .6 / .5 / 1 / .6$ with margins well-formed on sides of first tergite, consisting of two high, parallel, straight, subentire carinae.

Six sternites in a length ratio of $.6 / 1.3 / .3 / .3 / .4 / 1$ and unmodified save that first sternite has a circular pubescent fovea between posterior coxae.

Posterior coxae not distant, separated by a distance equal to one-third of the median metasternal length. Intermediate and posterior trochanters each armed with a long translucent spine on the ventral face. Tarsi as described for genus.

Allotype Female. Similar to holotype save that (1) occiput is simply medianly indented instead of sulcate; (2) vaulted vertex simply declivous to a point opposite the lateral incisures and wholly unarmed. Despite this simplified field the vertexal foveae are not discernible as such; (3) Antennae perfectly simple, the seventh segment small and intermediate in size between the sixth and eighth and the distal segment much more ovoidal; (4) Trochanters unarmed.

Described on two specimens collected by the author on Barro Colorado Island, Gatun Lake, Panama Canal Zone, from beneath bark. The holotype on July 27, 1936, at Zetek 23 and the allotype on July 26, 1936, at Zetek O.

\section{Batrybraxis bowmani new species}

Type Male: $0.90 \mathrm{~mm}$. long; $0.47 \mathrm{~mm}$. wide; antennae $0.43 \mathrm{~mm}$.

Yellow with shining, sparsely punctulate integument; pubescence short and erect on head, long and semierect on pronotum and elytra, subappressed on abdomen; no temporal beard.

Head one-fourth wider than long; tempora prominent, longer than wide, nearly rectangular; eyes as long as tempora, median, much less convex and prominent than in panamaensis, reniform, composed of 28 facets. Occiput broadly, medianly indented but not sulcate. Vertex vaulted above eye-line, the tumidity being deeply, simply, medianly excavated with each side of the excavation erected into a strongly arcuate cornuate cusp, and the vaulted area sharply declivous each side at antennal base. At this latter point each lateral margin is obliquely, deeply, narrowly incised in the usual pubescent, paralle". 
sided furrow. Anterior to this line (which passes well beyond eyes, skirting the vertexal declivity and ending each side in the lateral incisure), the front is divided by two longitudinal depressions into three areas: a lateral tumidity above each antennal base, and a median elevation which posteriorly bifurcates into a pair of teeth. These median, sharp teeth lie just opposite the median vertexal excavation, and therefore are framed by the larger vertexal cusps. As in panamaensis, I could not discern vertexal foveae. The inter-antennal area just described is perfectly semicircular in outline, and ventrally merges with the clypeus in a simple vertical descent. Labrum simple. Ventral surface of the head perfectly simple and unmodified.

Maxillary palpi as described for genus.

Antennae eleven-segmented, distant, normal; segment I elongate-oval, half as long as eleventh but longer than any other segment; II nearly as wide and half as long as first, quadrate; III-VII small, third obconical, others moniliform; VIII and IX subpyramidal, increasingly transverse, the ninth about as wide as second; $\mathrm{X}$ is asymmetrically trapezoidal, wider than first; $\mathrm{XI}$ as in panamaensis.

\section{Pronotum as in Dalmonexus.}

Elytra as in panamaensis.

Wings present.

Abdomen with five visible tergites in a length ratio of 1.5/.6/.6/1/.6 and with margins as in panamaensis. Six sternites in a length ratio of .6/1.4/.3/ $.4 / .5 / 1$ with first sternite visible from side to side and with the usual pubescent fovea between posterior coxae.

Posterior coxae approximate, separated by a distance equal to one-fourth the median metasternal length. Intermediate and posterior coxae each armed with a long translucent spine on the ventral face. Tarsi as described for genus.

Described on a single male collected by the author on July 28, 1936, from log mold at Zetek 17 on Barro Colorado Island, Gatun Lake, Panama Canal Zone, and named in honor of Dr. John R. Bowman in recognition of the labor involved in bringing the descriptions of North American pselaphids between two covers.

Bowmani is congeneric with panamaensis but is quickly separated by the simple male antennae, wholly different head and more narrowly separated posterior coxae. It is possible that additional information will cause us to place these two species in a new genus because of the lack of vertexal foveae per se.

The species of Batrybraxis may be listed as follows:

bowmani new species. Panama Canal Zone.

curtula Reitter. 1882. Blumenau, Sao Paulo, Brazil. Genotype.

fortis Reitter. 1882. Sao Paulo, Brazil.

inflexa Schaufuss. 1887. Mexico.

longipennis (Raffray). 1890. Tovar Colony, Venezuela. (Batrisus:

Arthmius)

panamaensis new species. Panama Canal Zone.

punctipennis Reitter. 1882. Petropolis, Brazil. 


\section{Tribe 9. Goniacerini}

The Goniacerini are highly evolved brachysceline pselaphids, representing one of the apices of specialization in the family. The tribe has few genera and few species. Its zoögeographic penetration is limited to tropical Africa and tropical America, with the latter region being more abundantly represented in both genera and species.

Taxonomically, Goniacerini are differentiated from other pselaphids by the following combination of characters: (1) head narrowed anterior to the eyes to form a prominent, median frontal antennal tubercle; $(2)$ antennae subcontiguously articulated on this tubercle, with a long first segment and strongly geniculate (as in the Metopiini), and with the genera varying in number of antennal segments from five to eleven; (3) abdomen with five visible tergites, and six sternites in both sexes; first sternite longer than posterior coxae, clearly visible from side to side (as in the Tychini); abdomen with strongly formed, flattened abdominal margins; (4) trochanters short, with the femora obliquely articulated on them so that the corresponding coxa and femur are subcontiguous; (5) posterior coxae with their mesial articulating faces subtriangular, not conically produced; (6) tarsus three-segmented, strong, first segment small and triangular, second and third segments relatively much longer than first; third segment bearing a large tarsal claw and in some groups an accessory bristle-like claw; (7) maxillary palpi short, small, and always appear three-segmented. However, this will probably prove erroneous when all of the genera have been fully investigated. Fletcher (1927) found that the maxillary palpi of Bibrax bradleyi have four segments, but that the first was very minute and visible only after dissection; second strongly arcuate, apically inflated; third ovate-elongate; fourth ovate-elongate with an obtusely pointed apex, obliquely truncate at base, with a short thick palpal cone. Raffray (1890) found that the apparently three-segmented maxillary palpi of Goniacerus perforatus were in reality four-segmented on dissection, the first relatively large and sharply arcuate. Raffray $(1908$, p. 295) states that the maxillary palpi are three-segmented for the tribe, (p. 297) demonstrates only three segments for Ogmocerus giganteus of Abyssinia, and later (1908, pl. 8, fig. 55) figures only three segments for this species, although Fletcher (1927) thought that this Raffrayan figure showed four segments. From such data it appears that a great deal of morphological work, especially with prepared microscope slides, needs to be done on the goniacerine mouth-parts.

The individuals of this tribe seem to be very uncommon, and nothing is known of their ecology. The neotropical genera may be separated by the following key: 


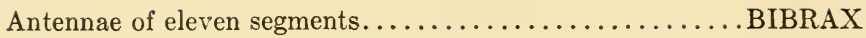

Antennae with less than eleven segments................. 2

2. Antennae of six segments.......................... 3

Antennae of five segments......................... 4

3. Antennal segment I convex on dorsal face, concave on ventral face, with the face margined for its entire length by a thin, denticulated

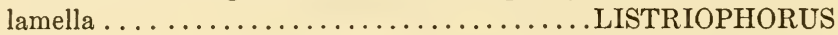

Antennal segment I cylindrical, gradually thickened and slightly

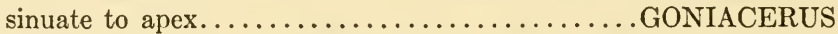

4. Antennal segment I strongly elongate, slightly sulcate mesially; II subquadrate; III oblong in females and obconical in males; IV quadrate; $\mathrm{V}$ oblong-cylindrical, with an acute apex; wide abdominal margins limited externally and internally by carinae; known only

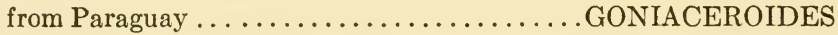

Antennae not as described; abdominal margins narrower, in the form of a flattened, narrow, sharply cut lamina; known only from Brazil

5. Antennal segment I elongate, deeply sulcate on dorsal face, with the internal face having a thin denticulated marginal lamina as in Listriophorus; II slightly transverse; III cylindrical; IV slightly longer than wide, cylindrical; $\mathrm{V}$ ovoidal-acuminate..GONIASTES Antennal segment I elongate, convex on dorsal face, concave on ventral face, slightly sinuate; II small, transversely triangular; III large, strongly obconical and with the ventral face excavated; IV transverse, slightly wider at apex than third; $\mathrm{V}$ slightly narrower than fourth, slightly longer than wide..............ADROCERUS

\section{BIBRAX (Fletcher, 1927)}

This monotypic genus has its nearest apparent ally in the Ethiopian Ogmocerus because of its eleven-segmented antennae and strong abdominal margins. Its aspect is similar to the Metopiini with non-spinose pronotum (Metopiellus, Metopiosoma, Barrometopia). Males have the fourth sternite medianly flattened and shining; fifth with a large transverse depression; sixth (last) sternite with a deep circular apical fovea. Females with sternites simply, evenly convex. Eyes composed of a single facet. Maxillary palpi four-segmented.

bradleyi Fletcher. 1927. Barro Colorado Island, Gatun Lake, Panama

Canal Zone. Genotype.

\section{LISTRIOPHORUS (Schaufuss, 1872)}

This is a monotypic genus with three-segmented maxillary palpi, and brilliantly shining integuments. The six-segmented antennae separate it from other neotropical aggregates with the exception of Goniacerus, from which it is quickly diagnosed by the remarkable first antennal segment and an entirely different integumental structure.

felix Schaufuss. 1872. Mexico. Genotype. 
GONIACERUS (Motschulsky, 1855)

This is the largest neotropical genus. The six-segmented antennae have an entirely different first segment than that of Listriophorus, as noted in the generic key. The palpi apparently three-segmented. The integument is distinctive, consisting usually of an anastomosing lattice of minute carinules to give a subopaque alutaceous surface. The six sternites are subequal but notable in that the first and second sternites are fused medianly, although laterally distinct. As Raffray (1908) has pointed out, this is an interesting approach to the Cyathigerini, a remarkably specialized tribe holding a single large genus (Cyathiger) of the Indo-Malayan rain-forest. It is possible that the Cyathigerini are ecological equivalents in the last-named tropical region, of the Goniacerini of the other two great tropical areas.

gibbus (Motschulsky). 1851. Obispo, Panama. Genotype.

setifer (Schaufuss). 1872. Brazil. (Metopioides)

anophthalmus Raffray. 1890. Blumenau, Brazil.

perforatus Raffray. 1890. Caracas and San Esteban, Venezuela. (nec

perforatue of Raffray, 1908)

GONIACEROIDES (Raffray, 1917)

umbilicatus Raffray. 1917. Asuncion, Paraguay, Genotype.

GONIASTES (Westwood, 1870)

sulcifrons Westwood. 1870. Brazil. Genotype.

westwoodi Raffray. 1890. Brazil.

ADROCERUS (Raffray, 1890)

cavicornis Raffray. 1890. Brazil. Genotype. 


\section{DIVISION II. MACROSCELIA (Raffray, 1890)}

The preceding nine tribes form the first division of the subfamily Pselaphinae, all having the coxae subcontiguous to their respective femora as a consequence of the short, obliquely articulated trochanter.

The Macroscelia have the intermediate trochanters elongate obconical to clubbed apically, with the articulation of the respective femur distinctly apical, and consequently the intermediate coxa and femur are relatively distant. This division holds fewer tribes, genera and species.

\section{Tribe 10. Pselaphini}

The Pselaphini are poorly represented in the neotropics by two genera and eight species. They may be differentiated from other macrosceline tribes by (1) fourth (distal) segment of the maxillary palpi is very long, slender and pedunculate at base, inflated and clubbed at apex, and (2) the tarsi are normally formed, with the second tarsomere never bilobed, the third (distal) tarsomere having only a single large claw. The two genera may be separated as follows:

Distal segment of the maxillary palpi without a sulcus on the external face, or if present it is very short and restricted to the apex; vertex with a deep, median, longitudinal sulcus from near anterior margin of eyes to apex of antennal tubercle; abdomen relatively long, nearly as long as elytra......................................

Distal segment of the maxillary palpi with an entire longitudinal sulcus on the external face from base to apex; vertex with no longitudinal sulcus, at most the apical margin of antennal tubercle incised; abdomen relatively short, much shorter than elytra......

PSELAPHUS (Herbst, 1792)

Herbst (1792)

DenNy (1825)

Aube (1833)

REITTER (1881)

RAFFray (1890, 1904, 1908, 1911)

Ganglbauer (1895)

LeConte (1850)

LEConte and Horn (1883)

BRENDEL and Wickham (1890) 
CASEY (1893)

Blatchley (1910)

BRAdLEy (1930)

BOWMAN (1934)

This genus was the first genus recognized as a pselaphid aggregate, and historically, therefore, is of great importance. Obviously it is highly specialized, and far from the norm of the family. Out of more than eighty species of Pselaphus, distributed over the entire world, the Western Hemisphere is poorly represented, with five species in the United States and a single species of the Amazon drainage basin in Brazil.

bizonatus Schaufuss. 1886. Brazil.

PSELAPHELLUS (Raffray, 1908)

RAFFray $(1908,1908 a, 1911)$

The remaining genus of neotropical Pselaphini is restricted to the area, extending from Guatemala to Argentina. It is closely allied to Pselaphus. No key is attempted as I am unfamiliar with the genus save for a single species.

bicolor Raffray. 1911. Buenos Aires, Argentina. convexus Raffray. 1908. Buenos Aires, Argentina. elegantissimus (Schaufuss). 1886. Brazil. (Pselaphus) longiceps (Sharp). 1887. Paso Antonio, Guatemala. (Pselaphus) (laeviceps Raffray, 1904; laviceps Raffray, 1908) opacus (Schaufuss). 1886. Brazil. (Pselaphus) pallipes Raffray. 1908. Buenos Aires, Argentina. vestitus Raffray. 1908. Buenos Aires, Argentina. 


\section{Tribe 11. Holozodini}

This is a small tribe of macroscelines holding two specialized genera, one of which (Holozodus) occurs in Madagascar, while the other is known from the neotropics. This tribe, then, has a parallel zoögeography to the Goniacerini, in that both are confined to two out of three of the world's great tropical and subtropical regions.

As in Pselaphini, the tarsi have a single tarsal claw and the second tarsomere is not bilobed; they differ from Pselaphini in that the ventral surface of the head is flattened, rather than gibbous, and the maxillary palpi are radically different. These palpi are very small. Sharp $(1887$, p. 22$)$ in erecting Caccoplectus stated that the maxillary palpi "are unusually minute, so that I can only with difficulty obtain a sight of the terminal joint." Raffray (1908, p. 316) describes these palpi as follows: segment I invisible, II slightly arcuate and slightly inflated apically, III very small and slightly triangular, IV hardly as long as the preceding two united, briefly ovoidal and apically obtuse.

\section{CACCOPLECTUS (Sharp, 1887)}

There are two species in this genus, the genotype, and a second species, spinipes Schaeffer (1906) known from Texas.

celatus Sharp. 1887. Zapote, Guatemala and Mexico. Genotype. 


\section{Tribe 12. Hybocephalini}

In a regional study such as the present paper, this tribe is difficult to integrate. There is a single hybocephaline genus in the neotropics (Ephimia), and this genus differs from other genera of the tribe in having two equal tarsal claws. This tribal abnormality taken together with the nonbilobed and simple second tarsal segment, and general habitus and pubescence runs an example either to the Ctenistini or Tyrini-never to the Hybocephalini!

The species are very uncommon and the distribution peculiar, so that a close comparison of a specimen with the generic characters will serve to isolate a member of this genus in the neotropics.

\section{EPHIMIA (Reitter, 1882)}

\section{REITTER (1882, 1883)}

\section{SHARP (1887)}

RAFFRAY $(1904,1908)$

One of the strangest facts concerning Ephimia is its distribution. It is entirely insular, with two species in the West Indies and the third species in the Pearl Islands. Thus both sides of Central America are inhabited, without any species yet described from the mainland.

Head longer than wide, with prominent eyes placed behind the middle, very short oblique tempora; narrowed anterior of the eyes to form a long truncate vertex terminating in an antennal tubercle. The antennae are subcontiguous, eleven-segmented, the segments closely articulated with the intermediate segments transverse and a three-segmented club. Maxillary palpi foursegmented: first small, visible, subglobular; second arcuate, slender at base, elongate and apically inflated; third obconical, about as wide as second; fourth much larger, ovoidal, apically acuminate, with stiff pubescence and a minute palpal cone.

Pronotum slightly longer than wide, convex, with three large, free, densely pubescent basal foveae of which the median is very visible from a dorsal view but the laterals far down on the sides.

Elytra each with a large basal pubescent fovea, and sutural stria but without definite humeral angle and no dorsal stria.

Abdomen with five visible tergites, the lateral margins very widely and strongly margined as in Tyrini; six sternites in both sexes. Intermediate, and posterior, coxae widely separated. Intermediate legs macrosceline, the legs thick and long; tarsi thick and short, three-segmented, with the first segment small, last two relatively larger, but the second is only about half as long as the third, the third bearing two short equal claws. 
The integument is shining where it is not densely pubescent; the pubescence complex. Thus the tempora, sides of head and the area anterior of the eyes have squamous setae; antennal segments densely pubescent, obscuring the articulation; distal segment of maxillary palpi has the apical half covered with short, spike-like setae; pronotal foveae have spongy pubescence; basal elytral fovea and apical area densely pubescent; general body pubescence dense and in the form of subappressed to appressed, thick-shafted setae.

To the author, this genus presents one of the most perplexing taxonomic problems in the neotropics, and it is possible that Ephimia will have to be taken from the Hybocephalini entirely, in which case the tribe will not be a neotropically represented group. The reader is requested to study the remarks made under the genus Juxtahamotopsis of the Tyrini for further discussion.

\section{Key to the Species}

Known only from the Antilles; length less than two millimeters.... 2 Known only from Pearl Islands; length two millimeters.......... crassicornis

2. Antennal segments III to VIII strongly transverse, only slightly lenticular; known only from the Windward Islands............ Antennal segments III to VIII strongly, transversely lenticular; known only from the Virgin Islands..................... simoni

3. Antennal segments $\mathrm{IX}$ and $\mathrm{X}$ of equal length; $1.6 \mathrm{~mm} . \ldots \ldots \ldots$ subnitida MALE Antennal segment $\mathrm{X}$ nearly twice as long as IX. subnitida Female crassicornis Sharp. 1887. San Miguel, Isla del Rey, Pearl Islands. simoni Reitter. 1882-1883. St. Thomas, Virgin Islands. Genotype. subnitida Raffray. 1904. Grenada, Windward Islands. 


\section{Tribe 13. Ctenistini}

In the neotropics this tribe is poorly represented by four genera and twelve species, one genus and species of which may be incorrectly assigned to the region.

These are clearly separated from other macrosceline tribes by the key characters: second tarsomere normal, not bilobed; tarsi with two large, equal to subequal claws; pubescence always in the form of scales. This scaley pubescence has a characteristic structure, as illustrated (Pl. IV, 6-11), and is never entirely absent; it is especially dense in the temporal areas, in sulci and foveae of the pronotum and elytra, and at articular surfaces of the abdominal segments. In addition, the Ctenistini are separable from the Tyrini by the form of the epistome. In Ctenistini the epistome is relatively very large and expanded or tumid between the labrum and the frontal tubercle, and this tumidity may be so pronounced that the lateral margins of the clypeus are auriculate; in Tyrini the epistome is large but is never laterally expanded or auriculate, never conspicuously tumid between labrum and frontal tubercle. The Ctenistini may be separated from the hybocephaline Ephimia with greater difficulty, although the latter genus never has the greatly expanded epistome.

The three-segmented tarsi have the last two tarsomeres much larger than the first, but the second is never as long as the third; tarsi have two large equal claws.

A number of Ctenistini inhabit the society of ants (Bruch, 1929; Casey, 1893; Mann, 1911, 1914, 1924; Wickham, 1889, 1892, 1900).

\section{Key to The Genera ${ }^{1}$}

Second (apparent first) segment of maxillary palpus with a lateral appendage on external face, this appendage may be long or short, and terminates in a bundle of setae (PI. IV, 22).............

Second (apparent first) segment with the external face without trace of tubercle or appendage..............ENOPTOSTOMUS

2. Third and fourth segments of maxillary palpus always wider than long, transversely ovoidal to transversely triangular...........

Third and fourth segments always longer than wide, elongate triangular to acuminate-fusiform............... CTENISIS

3. Fourth segment of maxillary palpus with the apical face rounded, and without a terminal palpal cone (not to be confused with an appendage of the external face) (Pl. IV, 22)........PILOPIUS

${ }^{1}$ If the specimen has run to Ctenistini in the tribal key (p. 31), and none of the segments of the maxillary palpi have conspicuous lateral appendages, it is either an unrecorded neotropical genus of Ctenistini or belongs to Ephimia of the Hybocephalini (p. 289). 
Fourth segment with apical face angulate and bearing at angulate apex a slender palpal cone, in addtion to the appendage of the

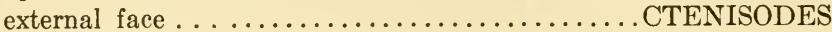

In the above generic key I have material in all four genera so that I am confident of the larger taxonomic aggregates but less so of the limits of many of the species. In two cases I have assigned my specimens to species previously described. These species were named many years ago and the structural detail is very incompletely set forth. The sympathetic reader will understand the risk taken in such cases, yet without the types for direct comparison I am unable to state positively that the material is new to science in these two particular instances.

\section{ENOPTOSTOMUS (Schaum, 1864)}

This fairly large genus is found in Africa, Asia Minor, and as far north as Portugal and Greece, and as far east as Sumatra. In addition a single species is placed here with doubt by Raffray from the neotropics. I share Raffray's apprehension that it may belong to some other genus but do not know the species. My material in the genus belongs to Enoptostomus aubei (Rosenhauer) collected by Simon at Algeciras, Cadiz, Spain, and identified by the illustrious Reitter. The maxillary palpi are so different from other genera that should another specimen of clandestinus be found the question of generic status can be quickly answered.

clandestinus Schaufuss. 1886. Brazil. (cf. Raffray, 1904, 1908)

\section{CTENISIS (Raffray, 1890)}

RAFFray (1890, 1896, 1904, 1908, 1908a)

Sharp (1874) (Tetracis), (1887) (Desimia)

CASEY (1893)

BOWMAN (1934)

In this genus, where both sexes are known for the same species, the sex can be diagnosed by the antennal proportions. The males have a prominent club formed by the last four segments (VIII-XI) which are generally elongatecylindrical; the eighth segment is conspicuously larger than the seventh, and segments IV-VII very small. The females have segments IV-VII relatively larger than the same segments of the male, the eighth segment is similar to the seventh, and the club is more or less composed of the last three segments.

\section{Key to the Males}

Segment VIII as long as the four preceding united............ 2

Segment VIII as long as the five preceding united............ 4

2. Not known south of Mexico....................... raffrayi

Not known north of the Amazon basin................. 3 
3. Head with a very long, recurved infraocular spine.......amazonica Head without an infraocular spine, but with a small pencil of setae below each eye.............................nasuta

4. Not known south of Guatemala................... dispar Not known north of Colombia.................... 5

5. Head with a very long, recurved infraocular spine..... aequinoctialis Head with a very thin, nearly straight infraocular spine... angustata

\section{Key to the Females}

Not known south of Guatemala................... dispar

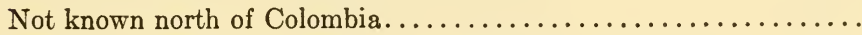

2. Apparently indistinguishable on the described characters:

aequinoctialis amazonica

Only three of the above six species have known females, and this key does not include fasciculata and gracilis. The species may be listed as follows:

aequinoctialis (Aube). 1844. Matto Grosso, Brazil and Valencia, Colombia. (Also recorded from Amazon basin)

amazonica Raffray. 1896. Amazon basin, Brazil. angustata Raffray. 1896. Argentina.

dispar (Sharp). 1887. Cordova, Mexico and Paraiso (300 feet), Guatemala. (brevicollis Raffray, 1896) Genotype. (Desimia).

I have a female of what I consider dispar from Sabinas Hidalgo, Nuevo Leon, Mexico, collected June 14, 1941, by Charles Seevers. This locality is in northern Mexico, is not rain forest, and extends the range of Sharp's species materially.

fasciculata Raffray. 1908. Buenos Aires, Argentina. con Solenopsis richteri Forel, ef. Bruch, 1929.

gracilis Raffray. 1908. Argentina.

nasuta Raffray. 1896. Amazon basin, Brazil.

raffrayi Casey. 1893. Tucson, Arizona, and Mexico. (dispar Raffray, 1896, nec Sharp.)

PILOPIUS (Casey, 1897)

CASEY (1897)

BowMAN (1934)

This genus is typical of the nearctic fauna. Out of sixteen species, thirteen are found within the United States, including the genotype Pilopius lacustris Casey; one species is reported from Japan (Pilopius discedens (Sharp), 1883; cf. Raffray, 1904, 1908); one species, Pilopius zimmermani (LeConte) has a remarkable range for a pselaphid if the species population is truly homogeneous; and one species is reported from the neotropics. 
This generic distribution pattern is exceptional in pselaphids, and indicates that the genus has dispersed southward from a nearctic center. A commoner pattern is the reverse situation, with species dispersing northward from a neotropical center. The scant representation of Ctenistini in the neotropics is additional indirect evidence that this tribe originated elsewhere.

major Mann. 1914. San Miguel, Mexico. con Prenolepis (Nylanderia) mexicana Forel.

zimmermani (LeConte). 1850. (Ctenistes auct. nec Reichenbach) United States (Indiana south to Florida, Georgia and Louisiana); Mexico; Colombia; Amazon basin, Brazil!?

\section{CTENISODES (Raffray, 1897)}

RAFFraY $(1897,1904,1908)$

Erected on a female specimen, $1.6 \mathrm{~mm}$. long, with unique maxillary palpi. The genus approaches Ctenisis. Unfortunately the male sex is unknown. It has not been recorded for forty-four years and I am happy to report another specimen of this genus and what I consider the same species. The new record indicates that the genus may be a synoekete in the ant society.

laticeps Raffray. 1897. Mexico. Genotype.

I have a single female from Montemorelos, Nuevo Leon, Mexico, taken June 16, 1941, by Charles Seevers with ants. The host is being determined. 


\section{Tribe 14. Tyrini}

This is an extensive tribe of elegant, large-sized pselaphids distributed over the world, and notable for the generic diversity of the maxillary palpi. The tribe reaches a peak in species and individuals in the tropical forests, and the neotropical forms may be characterized as follows: (1) Pubescence normally long, abundant, and setiform; never in the form of scales, but at times very sparse, short, and thick-shafted (this separates the tyrines from the ctenistines); (2) head generally with prominent, multi-faceted eyes placed medianly or postmedianly; the head generally longer than wide, usually narrowed anterior to eyes, then more or less widened to form a prominent, median, usually bilobed antennal tubercle. However, in Hamotocellus the head is squarely truncate anterior to the eyes, not narrowed, and the widely separated antennae are placed on the angles of the subrectangular front; (3) antennae eleven-segmented, approximate save for Hamotocellus, and do not show the startling specific and sexual abnormalities of Batrisini, Brachyglutini, and other assemblages previously covered although some exceptions to this will be encountered in the diagnoses which follow; (4) maxillary palpi four-segmented and generically of the utmost value, showing an almost infinite range of variation; (5) the pronotum usually cordiform to ovate, usually with three antebasal foveae which are highly variable in themselves and may or may not be connected by a sulcus; disc usually simply convex but may be strongly gibbous and medianly spinoid (Neotyrus); $(6)$ abdomen with a strong margin each side of the first three visible tergites as a rule; the tergite length ratio is of importance both generically and specifically; the neotropical genera have six sternites in both sexes, and show little sexual diversity as compared to many other tribes already studied; (7) the trochanters of the intermediate legs are typically macrosceline, elongate and distally enlarged to articulate the femora distally so that femur and coxa are not approximate; (8) tarsi three-segmented, large, the first tarsomere short, the next two relatively much longer of which the third is always the longest and bears two long, equal claws (save for Phalepsus, where the tarsal claws are very unequal).

Ephimia of the hybocephalines and Ctenistini are the only neotropical pselaphids liable to be confused with this tribe. Ephimia has the two equal tarsal claws very short, and Ctenistini are distinctive as a consequence of their scaly pubescence and the conformation of the epistomal area previously alluded to.

The general habitat of Tyrini is the leaf and log mold of the forest floor, although many species are exquisitely adjusted synoeketes of the ant society (Park, 1932), or are facultative synoeketes (Park, 1933) and numerous records are extant of their common occurrence with ants (Blatchley, 1910; Dury, 1898; Hamilton, 1886; McCook, 1877; Park, 1935; Raffray, 1908; Schwarz, 
1890,1896 , and Wickham, 1894, 1900). Several of the new species subsequently described have been discovered with termites.

The neotropical genera may be separated by the following key:

\section{Key to the Neotropical Genera (Pl. XX)}

Tarsi each with long equal to subequal claws.................

Tarsi each with two short and very unequal claws.... PHALEPSUS

2. Internal face of distal segment of maxillary palpi longitudinally sulcate (this sulcus may be broad or narrow; entire or only ex-

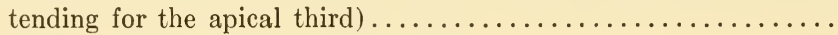

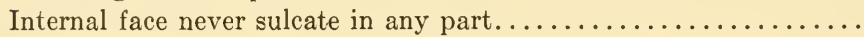

3. Distal segment of maxillary palpus widest near apex which is broadly convex; this segment has the internal face produced near the apex into a pointed and pubescent process at right angles to the long axis of the segment, and from this point the segment narrows rapidly

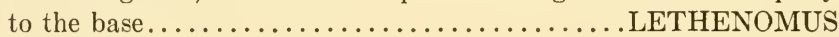

Distal segment not as above........................ 4

4. Distal segment of maxillary palpi covered with short, bristling, spike-like setae............JUXTAHAMOTOPSIS, new genus

Distal segment nude or with pubescence minute, appressed and in-

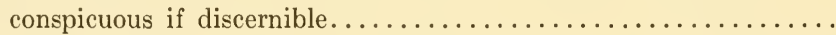

5. Distal segment of maxillary palpi with a broad and shallow longitudinal sulcus for the apical fourth of the dorsal face; pubescence very long and thin with the apical ends of the setae curving in various directions to intertwine or mat.................

TYROGATUNUS, new genus

Distal segment and pubescence not as above................

6. Pronotum with three free antebasal foveae; first tergite only slightly longer than second....................... TYROPSIS

Pronotum with antebasal foveae connected by an arcuate transverse antebasal sulcus; first tergite longer than next three united.....

NEOTYRUS

7. Pronotum with an entire transverse antebasal sulcus........... 8

Pronotum without a transverse antebasal sulcus............. 12

8. Distal segment of maxillary palpus less than half as wide as long.... 9

Distal segment nearly three-fourths as wide as long, semicircular in

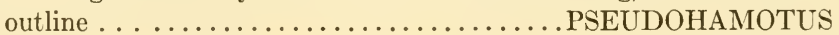

9. Third (next to last) segment of maxillary palpus perfectly globular APLODERINA

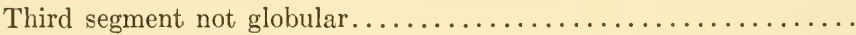

10. Head squarely truncate anterior of eyes, with no antennal tubercle and the antennae widely separated at the corners of the sub-

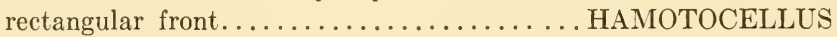

Head narrowed anterior of eyes, with antennae articulated upon a more or less bilobed and median frontal tubercle............. 
11. Tergites I, II, III subequal or decreasing in length............ ...HAMOTOIDES (subgenus of Hamotus)

Tergites I, II, III increasing in length............PHAMISULUS

12. Sulcus of distal segment of maxillary palpus confined to apical

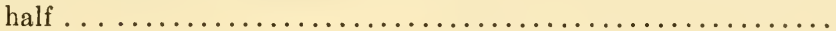

Sulcus of distal segment of maxillary palpus extending beyond apical

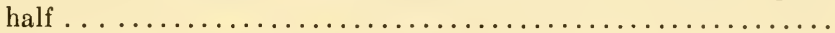

13. Distal segment of maxillary palpus ovate-cylindrical, obliquely truncate at base, with sulcus extending as an elongate fovea on apical half of internal face...............................

Distal segment gourd-shaped, narrowed basally, ovate in median twofifths, and very narrow and elongate-cylindrical in apical half, with a very narrow and striaform sulcus on apical half of internal

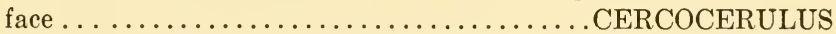

14. Apex of distal segment of maxillary palpus lengthily very acute to aciculate, with a palpal cone one-third the segmental length set in apex and continuing the long axis of the latter............

PSELAPHOCOMPSUS

Apex of segment obtuse, with a palpal cone set obliquely within the

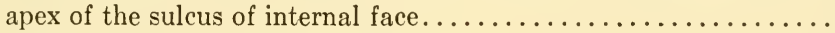

15. Distal segment of maxillary palpus very elongate-cylindrical, narrow and subfiliform, with the sulcus of internal face deep but very

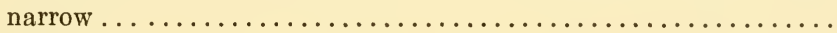

Distal segment ovate-fusiform to ovate-conical, obliquely truncate at base, with a broad sulcus of variable shape, length and depth HAMOTUS ss.

16. First tergite much longer than other tergites united.......... CERCOCEROPSIS

First tergite varying from slightly longer to distinctly longer than second tergite, but never as long as second and third united.... CERCOCEROIDES

\section{PHALEPSUS (Westwood, 1870)}

This is a moderately large genus of eight elegant species known from Brazil and Paraguay. They are of average size $(1.3$ to $2.0 \mathrm{~mm}$.) with an elongate-oval, strongly convex outline, very attenuated anteriorly and broadly rounded posteriorly. They bear somewhat the same relation to the other neotropical tyrines as Ephimia does to the other hybocephalines, that is they are aberrant in having the tarsal claws short and very unequal.

The genus, although highly specialized, clearly belongs to the first division of neotropical tyrines-those having the maxillary palpi nonsulcate. The maxillary palpi are four-segmented, long and slender; the first segment is very small and subcylindrical; second very long, subsinuate and pedunculate through the basal half, becoming inflated apically, with the apical internal face obtusely angulate; third similar in form to second, but much shorter, 
somewhat narrower, subtriangular, with the internal apical face obtusely angulate, segment slightly longer than wide; fourth as long or as much as one-third longer than second, subfusiform, wider than second, very narrow towards base and apex, the apex more or less lengthily aciculate, and without a discernible palpal cone. (PI. XX).

The species may be listed as follows:

ampliventris Schaufuss. 1879. Amazon basin, Brazil.

batesellus Westwood. 1870. Amazon basin, Brazil.

cavicornis Raffray. 1904. Matto Grosso, Brazil.

fluminicola Schaufuss. Amazon basin, Brazil.

marelloides Reitter. 1888. Blumenau, Brazil.

nanus Schaufuss. 1879. Amazon basin, Brazil.

subglobosus Westwood. 1870. Amazon basin, Brazil. Genotype.

vulgaris Raffray. 1904. Central Paraguay.

\section{TYROPSIS (Saulcy, cf. Raffray, 1908)}

This neotropical genus holds seven species from Chile and two from Brazil. Since I am unfamiliar with any of the species, I have followed the 1908 treatment of Raffray. It would appear that the taxonomy of the genus is involved and partially lost in the early records of the family. Blanchard described Pselaphus castanea (led no doubt to place it in this genus because of its large maxillary palpi). Reitter, recognizing castanea as not related to the Pselaphus of Herbst, included Blanchard's species in a new genus, Aplodea. Previously, however, Saulcy had erected the genus Tyropsis for a beetle in Chevrolet's collection, and which was supposed to belong to the Mediterranean fauna but in reality was identical with castanea. Some order was attained when Raffray was able to examine the Blanchard type in the Museum of Paris.

Structurally, Tyropsis is homogeneous and typically tyrine. The sexes are well marked. The males have the last three to five antennomeres variously excavated or spined as a rule, while the three-segmented antennal club is simple in the females. The sixth sternite is laterally sinuate and medianly lobed or produced in the males, and simply transverse in the females. The last (fifth visible) tergite is gibbous in the males and flat in the females.

Its closest relatives are to be found in Neotyrus, both genera having similar maxillary palpi and differing in pronotal and tergite structure as previously set forth in the tribal key.

The maxillary palpi are four-segmented, large and conspicuous; first segment very small; second and third similar in form, elongate with a slender base swelling in a rounded apical inflation, the third much shorter and as wide to slightly narrower than the second segment (the amount of apical inflation in both palpomeres subject to specific variation); fourth segment elongate-fusiform, slender at both base and apex, the apex is minutely truncate with a setiform palpal cone set within this truncature. (Pl. XX). 
Raffray (1904) divided the genus into three groups as follows:

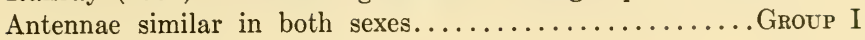

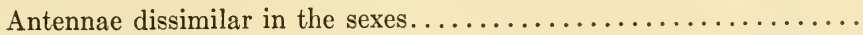

2. Head not excavated.............................. II

Head excavated . . . . . . . . . . . . . . . . Group III

The species of Tyropsis have not been increased since 1908 and may be listed as follows:

castanea (Blanchard). Chile. Genotype. (Pselaphus)

(chevrolati Saulcy; elsbethae Reitter; cosmoptera Schaufuss, nec Blanchard)

hirta Reitter. 1888. Blumenau, Brazil.

pilifera Reitter. 1888. Sao Paulo, Brazil.

valdiviensis Reitter. 1885. Chile.

\section{II}

adumbrata Reitter. 1885. Chile.

difformis Schaufuss. 1879. Chile.

palpalis Reitter. 1883. Chile. (praeses Schaufuss, female)

spinula Reitter. 1885. Chile.

\section{III}

cavifrons Raffray. 1895. Chile. (valdiviensis Schaufuss, 1886, nec Reitter)

\section{NEOTYRUS (Raffray, 1895)}

This is a small neotropical genus of four species, two of which are termitocolous, related to Tyropsis by the maxillary palpi, but distinct from this genus on pronotal and tergite differences, as indicated in the tribal key to genera.

Neotyrus coptocolus new species

Type Male. Measurements: Head $0.43 \times 0.47$ through eyes; pronotum $0.53 \times 0.49 \mathrm{~mm}$.; elytra $0.76 \times 1.00 \mathrm{~mm}$; abdomen $0.62 \times 0.87 \mathrm{~mm}$.; total length $2.4 \mathrm{~mm}$; greatest width $1.00 \mathrm{~mm}$. (Pl. XX).

Reddish-brown with very short, stiff, inconspicuous, and wholly appressed setae; integument subopaque and coarsely granulate-asperate on antennae, legs, head, pronotum, and elytral costae; slightly shining, with small and sparse asperities on abdomen; palpi, vertexal foveae, transverse pronotal sulcus and elytral intervals glabrous and shining.

Head with rounded tempora as long as eyes; eyes prominent, placed slightly behind middle and composed of about 76 very small facets. Vertex and occiput 
vaulted posteriorly with a pair of very small, nude vertexal foveae on a line through center of eyes, nearer each other than either from an eye, and on the highest part of the vertex; anteriorly from this point the vertex slopes to the front. Sides of head suddenly narrowed anterior of the eyes, then suddenly expand to form a conspicuous antennal tubercle on each side. These tubercles are deeply and widely separated by a trough-like sulcus which arises just anterior of the vertexal foveae and extends to the inter-antennal line of front. Front suddenly declivous at end of this sulcus. Clypeus simple, lower than front and longitudinally medianly elevated; clypeus hirsute with long, apically-directed setae in contrast to the general body pubescence. Labrum simple. Genae with a broad, triangular, infra-ocular spine. Maxillary palpi as described for Tyropsis save that the apex of the distal segment is thin, more acute, and with palpal cone set within a very small truncature.

Antennae eleven-segmented, $1.3 \mathrm{~mm}$. long; simple; segment I elongatecylindrical; II-VIII subequal in width, slightly narrower than first; second and third subquadrate, subequal; fourth to eighth submoniliform, slightly decreasing in length; club distinctly of last three segments; IX longer than eighth, transverse, trapezoidal; $\mathrm{X}$ very transverse, trapezoidal, much wider and shorter than ninth; XI very large and coarsely asperate, wider than tenth and nearly as long as preceding three segments united, truncate at base, broadly rounded at apex.

Pronotum hexagonal, with a straight apical margin and two short oblique sides which continue into two long, straight sides, which in turn abruptly unite to form the wide, straight basal margin. Disc strongly gibbous, the gibbosity culminating in an acute spinoid tubercle near base; antebasal transverse sulcus nearly semicircular, curving below the discal gibbosity apically each side to end in a circular, perforate lateral fovea; a minute median fovea lies just apical of transverse sulcus, at base of discal spine, and a longitudinal carina extends from basal bead, crossing sulcus, to median fovea.

Scutellum large, triangular, with apex sinuate-acute.

Elytra each with sloping humerus; five strong and asperate costae between lateral and sutural margins; five wide glabrous intervals; two perforate pubescent basal foveae, one at base of each of the two innermost intervals, with inner fovea smaller.

Abdomen large, of five visible tergites with a length ratio of $8 / 1 / .8 / 1.6 / 2$, only the first tergite visible from above and strongly margined. First tergite medianly, longitudinally elevated into a high carina, this bisecting carina also continued over the next three tergites; last tergite transversely suboval.

Six sternites in a length ratio of $1 / 2 / .5 / .5 / .8 / 1.5$, simple, save that the first is heavily pubescent.

Metasternum glabrous, conspicuously and triangularly elevated into a tubercle each side of a wide median sulcoid depression; a tremendous, pubescent fovea at base of median depression. Both intermediate and posterior coxae widely separated. Anterior legs with glabrous trochanters which are compressed and extend apically in a long, thin spine; femora inflated, with a large elongate- 
oval glabrous field on the basal half of ventral face, the posterior margin of this field carinoid, and the whole is sharp contrast to the asperate femoral integument. Intermediate legs with the trochanters glabrous, compressed and carinoid; femore inflated and asperate. Posterior legs wholly asperate. Tibiae simple. Tarsi as for tribe with two large, slightly unequal, tarsal claws.

Described on a single male specimen collected on Barro Colorado Island, Gatun Lake, Panama Canal Zone, by Dr. Laura Hare on May 13, 1935, from a nest of Coptotermes niger Snyder in a decaying log.

Although there are no data on the ecology of coptocolus, I unhesitatingly assign a role of synoekete to this pselaphid until definite observations between termite host and beetle prove otherwise. This seems justifiable on assaying its remarkable external anatomy. Coptocolus is geographically isolated from the other species of the genus, as well as by its habitat with termites.

The pubescence of coptocolus allies it with vestitus of Argentina rather than gibbicollis of central Brazil. From vestitus it is very distinct on tibiae, antennal club and numerous other points. It differs from both in the distal segment of the maxillary palpi: in vestitus and gibbicollis the apex of this palpomere is narrowly but distinctly truncate; in coptocolus the apical truncature is so small as to be nearly absent, hardly larger than the base of the palpal cone. I prefer to assign to Neotyrus a variably developed apical truncature of the distal palpomere, rather than erect a new genus at this time.

\section{Neotyrus harem new species}

Holotype Male. $2.4 \mathrm{~mm}$. long x $1.0 \mathrm{~mm}$. wide. Reddish-brown with moderately long, stiff, subappressed, and conspicuous setae of a bright golden color. Integument bright and shining throughout with sparse, subasperate punctation save for legs which are coarsely asperate-punctate.

Head with tempora as in coptocolus. Eyes large, prominent, median, each composed of about 120 small facets. Vertex rounded into convex occiput, and glabrous and flattened between the eyes; on each side of this elongate glabrous area is a vague, glabrous depression on a line with the posterior margins of the eyes. The bottom of this depression holds a minute vestigial vertexal fovea. The median glabrous area extends anteriorly, deepening to form a median, fusiform, inter-antennal sulcus which separates the poorly developed antennal tubercles, and then curves ventrally over the inter-antennal line of the front. At this point the sulcus has much higher and sharper walls which terminate at the clypeus. Clypeus granulate-punctate. Ventral surface of head flat, glabrous, with a large median basal fovea. Genae with a large, triangular, laminoid infra-ocular spine.

Maxillary palpi four-segmented, of Tyropsis-Neotyrus construction; first segment small; second elongate-arcuate, strongly pedunculate for basal half and expanding to form an obliquely truncate, pyriform apical half; third smaller but similar in form to second, with the basal peduncle for basal fourth and pyriform area extending for apical three-fourths, also obliquely truncate; fourth (distal) elongate-fusiform as in coptocolus, with apical end dorso-ventrally flattened and 
minutely truncate, this truncature scariform and oblique, bearing a small palpal cone.

Antennae with segment I elongate-cylindrical; II quadrate, smaller; III as long as second, longer than wide, obconical; IV-VIII submoniliform, slightly decreasing in length and slightly increasing in width; IX larger, quadrate-trapezoidal; $\mathrm{X}$ as long but wider than ninth, transverse-trapezoidal; XI as in coptocolus.

Pronotum with lateral contour, spinoid discal gibbosity, and arcuate basal sulcus as in coptocolus. The arcuate sulcus ends each side in a circular pubescent fovea, and in addition there also extends from each lateral fovea a straight, oblique sulcus to basal margin. That is, two sulci leave each lateral fovea: the arcuate interfoveal sulcus, and an oblique fovea-basal bead sulcus. Median basal fovea minute. Flanks of pronotum glabrous.

Scutellum large, elongate-triangular, alutaceous.

Elytra with obtuse humeri. Each elytron with two, equal, circular, pubescent foveae. From the inner fovea extends a strong, entire sutural stria. The outer fovea has a subentire discal stria. The inner wall of the discal stria is elevated to form a single, strong costa.

Abdomen with five visible tergites in a length ratio of $8 / 1.5 / 1 / 2.5 / 2$. First tergite strongly margined; last tergite truncate-triangular. All tergites evenly convex, lacking the median bisecting carina of coptocolus.

Six sternites in a length ratio of $2 / 3 / 1 / .5 / 1 / 1$. First sternite medianly elevated between posterior coxae into a large alutaceous rhomboidal tubercle; first two sternites deeply separated, with the trough densely pubescent; last sternite medianly deeply incised or notched. A discoid process of the male copulatory apparatus fits into this notch, when the penis is not exserted, so that the truncate apex of the last tergite is flush with the last sternite.

Metasternum glabrous laterally and sharply elevated into two longitudinally carinate tubercles which are separated by a sparsely pubescent and broadly concave median region.

Anterior legs: trochanter glabrous; femur with a glabrous ovoidal field occupying the basal four-fifths of femoral length, with the posterior margin of the field strongly carinated, this area on the antero-ventral face; tibia arcuate, apically setose on ventral face.

Intermediate legs: trochanter glabrous, ventrally carinate and extended at apex into a triangular tooth; femur with a much smaller, fusiform, glabrous field on antero-ventral face; tibia as above.

Posterior legs: simple, wholly granulate-puntate with straight tibiae.

Tarsi as for tribe, with two large, arcuate, slightly unequal tarsal claws, one claw being slightly shorter and thicker.

Allotype Female. As for holotype save that (1) last tergite transversely rhomboidal, with a longer subtruncate apical margin; (2) first sternite only normally elevated between coxae; (3) sixth (last) sternite with the apical margin simply rounded, lacking any median incisure or discoid process.

Described on two specimens collected from nests of the termite Coptotermes 
niger Snyder by Alfred Emerson on Barro Colorado Island, Gatun Lake, Panama Canal Zone. Holotype on April 30, 1935, and allotype on April 30, 1935.

The maxillary palpi and slightly unequal tarsal claws are intermediate between Phalepsus and Neotyrus s.s. on the one hand while the oblique scariform truncature of the dorsal apex of the distal palpomere tends towards Tyrogatunus. This distinctive species also approaches Tyrogatunus and the nearctic Tyrus in common trochantal and femoral modification of both sexes as well as sexual differences in the form of the last sternite. This genus may have to be broken up, but for the present the species of Neotyrus may be listed as follows:

coptocolus new species. Panama Canal Zone (con Coptotermes niger). gibbicollis (Schaufuss). 1886. Amazon basin, Brazil (Aplodea) Genotype.

harem new species. Panama Canal Zone (con Coptotermes niger). vestitus Raffray. 1908. Buenos Aires, Argentina.

\section{JUXTAHAMOTOPSIS new genus}

This new genus is distinct from other Tyrini on the following combination of characters: (1) head elongate-subtriangular with prominent post-median eyes, a pair of small vertexal foveae, and a long narrow, medianly sulcate vertexal-frontal field ending in a small bilobed antennal tubercle; (2) antennae nongeniculate, eleven-segmented, with an inconspicuous club composed of the last three segments which are very elongate-cylindrical and as long as the preceding eight segments united; (3) maxillary palpi (PI. XX) short, four-segmented, with the last segument non-sulcate but covered with short, spike-like setae; (4) pronotum with strongly convex disc, and lateral margins biconvex as a consequence of a large triangular fovea, large circular median basal fovea, no sulci; (5) elytra with two large basal foveae, a dorsal depression, and an entire sutural stria on each elytron; (6) abdomen with five visible tergites and six sternites, margins very strongly developed and broadened, tergites progressively shorter, second and third sternites longer than others; (7) intermediate legs strongly macrosceline; (8) pubescence thick-shafted, setiform, not scaly; (9) tarsi three-segmented, not bilobed, third tarsomere much longer than second, second much longer than first; two long, equal tarsal claws; (10) male sex with anterior legs greatly modified as described in genotype; female sex unknown.

\section{Juxtahamotopsis bardeni new species}

Type Male. Measurements: Head $0.44 \times 0.35 \mathrm{~mm}$.; pronotum $0.47 \times 0.47$ $\mathrm{mm}$.; elytra $0.53 \times 0.93 \mathrm{~mm}$.; abdomen $0.84 \times 0.97 \mathrm{~mm}$.; total length $2.3 \mathrm{~mm}$.; greatest width $0.97 \mathrm{~mm}$. (Pl. XX)

Body reddish-brown, shining, pyriform contour as a whole, being progressively wider to first visible tergite. Punctation diverse: antennal tubercle with a few very coarse punctures, and the rest of the head, pronotum, and abdomen nearly impunctate; elytra very sparsely asperate; antennal club and femora 
scabroid to asperate. Pubescence long, thick-shafted, appressed, and golden in color on the body; anterior femora, anterior tibiae, vertexal, pronotal, elytral and sternal foveae, sides of head anterior and posterior of eyes, sides of pronotum and apical elytral margin densely pubescent.

Head elongate-subtriangular, with simple rounded tempora as long as eyes; eyes prominent, composed of 50 large facets, placed just behind the middle of head and appearing to lie in a bed of pubescence. Vertex highest near occiput, simple, sloping evenly to inter-antennal line; a pair of small vertexal foveae on a line through posterior ocular margins; sides of head anterior of eyes gradually concave to form a median antennal tubercle, this latter medianly longitudinally sulcate, forming a bilobed front, to a point on a line through anterior ocular margins. Clypeus deeply recessed beneath overhanging frontal antennal tubercle, simple, and erected near apex into a semicircular carina. Labrum minutely granulose. Ventral surface of head simple.

Maxillary palpi four-segmented, as long as distal antennal segment; first segment short, oblong; second four times as long as first, as wide as first for basal half, then slightly wider and arcuate in apical half but not inflated, with a rounded apex; third distinctly wider and half as long as second, asymmetrically ovoidal; fourth as long as first three united, twice as wide as third, with the external face nearly straight, and the internal face broadly convex to narrow but rounded apex. This distal segment is conspicuous because it is clothed in short, stiff, apically-directed, spike-like setae.

Antennae closely articulated, approximate, eleven-segmented, long (1.6 $\mathrm{mm}$.), being two-thirds the body length, with the first eight antennomeres $(0.8 \mathrm{~mm}$.) as long united as the last three $(0.8 \mathrm{~mm}$.) united. Segment I elongatecylindrical; II as wide but shorter and obconical, with the articular surface between these two being obvious (as in Attapseniini) in contrast to the other articulations; III-VIII as wide as second; third very short and transverse, discshaped; fourth one-half longer, transverse and drum-shaped; fifth to eighth gradually longer, from quadrate to obconical; club of the last three segments, inconspicuous but in reality strongly formed; IX very elongate-cylindrical, not wider than eighth; $\mathrm{X}$ very elongate-subobconical; XI very elongate and slightly wider, apically rounded. The antennal club has a notable ornamentation: the integument is studded with small, separate asperities which are so arranged in lines that these segments appear to have the surface separated into oblong compartments.

Pronotum with strongly convex disc which is steeply declivous in basal fourth; sides biconvex; a large circular fovea at middle of basal fourth, on the discal declivity just noted; each side provided with an enormous triangular fovea which incises the side at basal third as noted above.

Each elytron with sloping humeri, two large basal foveae, an entire sutural stria and a broad but shallow dorsal depression to middle of length.

Abdomen large, with simple segments. Five visible tergites in a length ratio or 3.8/3.5/3.0/2.0/1.5 and the first three with broad, flat margins. Six sternites in a length ratio of $1 / 2.5 / 2.5 / 2 / 1 / 0.5$. 
Metasternum long, elevated into a flattened surface which is sulcate in apical half.

Intermediate coxae widely separated by a space equivalent to trochanter width at apex. Posterior coxae widely separated by a space one half the median metasternal length.

The intermediate and posterior legs simple.

Tarsi three-segmented, relatively short; first segment short and triangular; second twice as long as first; third nearly twice as long as second and obconical, bearing a pair of long, strong, equal claws.

The anterior legs are profoundly modified: they measure $1.8 \mathrm{~mm}$. in length, well over two-thirds the body length (femur 0.73 , tibia 0.8 and tarsus $0.27 \mathrm{~mm}$.) and are in an arc. The femur is greatly inflated dorso-ventrally and flattened laterally, with the narrow inner face densely setose. The tibia is longer than the femur, strongly arcuate and very thin in contrast to the large femur; it is carinated along the concave inner face, which also is densely pubescent. The relatively short tarsus articulates basal of the tibial apex so that the latter extends nearly to the apex of the second tarsal segment.

Described upon a single male specimen, collected by Dr. Williams in leaf mold (Sample 1118) of the rain forest of Barro Colorado Island, Gatun Lake, Panama Canal Zone, on July 17, 1938.

In its essential structural features this genus is tyrine, in the development of the antennal club it is allied to the ctenistine and hybocephaline stems; the maxillary palpi agree with Ephimia with respect to the stiff setae but not the shape of the distal palpomere. This is another instance which suggests that the hybocephaline Ephimia, unknown from the American mainland, belongs in the Tyrini near Juxtahamotopsis.

\section{LETHENOMUS (Raffray, 1895)}

This is a monotypic Chilean genus equally isolated as Juxtahamotopsis by virtue of its maxillary palpi. These latter organs are four segmented, with an extremely small first segment; second elongate, slender in basal half, gradually broader to apex where the segment is nearly four times as wide as base, with a rounded apex; third similar in form to the second, two-thirds as long, and as wide, with the internal apical face subangulate; fourth segment unique in the tribe, much longer than second and much wider, with a slender base and a swollen, perfectly rounded apex. This apex lacks a palpal cone and its contour is unbroken; however, the internal face near apex is produced into an acute tooth which is pubescent. ( $\mathrm{Pl}$. XX)

villosus (Schaufuss). 1886. (Aplodea) Chile. Genotype.

\section{APHARUS (Reitter, 1882)}

This genus holds four species, all of which are South American. The group is closely related to the subgenus Hamotus, differing in having a narrower abdominal margin, a very long first visible tergite, and in having the sulcus of the internal face of the distal palpomere limited to the apical half. All three of these 
features are approached by Hamotus: the abdominal margin, the relative lengths of the first two tergites, and the extent of the palpal sulcus vary among the species and, as will be seen, this variation is taken advantage of in the keys to species. The development of the palpal sulcus seems to be the best criterion: in Apharus this sulcus never extends for more than the apical half of the internal face, while in those Hamotus with a shortened sulcus, this latter extends into the basal third of the internal face.

The maxillary palpi of Apharus are four-segmented; first segment very small as usual among Tyrini; second elongate, basally slender and arcuate, gradually expanding to an oblique apex; third short, triangular; fourth much the longest and widest, elongate-ovoidal, obliquely truncate at base, rounded at apex, the internal face with an elongate-oval fovea or sulcus occupying the anterior half of the segment, with the palpal cone set within the apex of this palpal sulcus at an oblique angle ( $\mathrm{Pl}$. XX).

The males, where known, have the anterior trochanters each armed with a tooth. Both sexes have the metasternum variously sulcate, impressed and tuberculate. The posterior tibiae are without spurs in the male of mülleri and armipes, have the spurs well developed in the female of armipes and lacking in the female of colombiensis.

The following key to species does not account for clavicornis Raffray with which I am unfamiliar, and the reference to which I have been unable to check.

Anterior trochanters armed with a tooth.... MALES............ 2

Anterior trochanters unarmed.... Females................ 3

2. Metasternum simply impressed at apex; occiput gradually formed; pronotum with length and width subequal; length $2.0 \mathrm{~mm}$.. .mülleri Metasternum medianly sulcate, with a large tuberculate tooth each side; occiput abruptly and sharply formed; length $1.85 \mathrm{~mm} . . .$. .

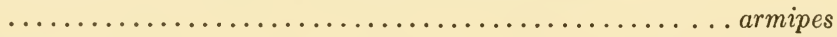

3. Posterior tibiae without spurs; occiput abruptly and sharply formed; pronotum transversely subglobose, being one-third wider than long; disc of elytron with a dorsal depression for basal third; metasternum medianly sulcate and tuberculate each side; length $1.20 \mathrm{~mm} . . .$. . ..................................mbiensis new species

Posterior tibiae each with a strong arcuate spur; pronotum subglobose; disc of elytron lacking a dorsal depression; occiput and metasternum as above; length $1.85 \mathrm{~mm} . . \ldots \ldots \ldots \ldots \ldots \ldots \ldots$. armipes

\section{Apharus colombiensis new species}

Type Female. $1.20 \mathrm{~mm}$. long x $0.60 \mathrm{~mm}$. wide through elytra. Shining reddish-brown, convex, 40 per cent smaller than the allied armipes, and with long, coarse, semierect, flavous pubescence. Head, pronotum and abdomen lightly punctulate; elytra with a few very large coarse punctures; femora and antennal club scabroid. 
Head as in armipes, with the occiput abruptly and vertically formed from the occipital-cervical sulcus, the occipital crest carinoid; however, in contrast to armipes, the front is distinctly narrowed anterior of the eyes and then expanded to form a larger antennal tubercle.

Maxillary palpi as for genus.

Antennae short, thick, eleven-segmented; I elongate-cylindrical; II shorter, slightly narrower, quadrate; III-VI subequal, very short and transverse; VII transversely triangular with the internal or median face acute, wider than sixth; VIII slightly wider and longer than seventh, transversely trapezoidal; IX-XI forming a club; ninth much larger than eighth, transverse, with median face subacute; tenth subequal to ninth, regularly trapezoidal; eleventh very large, truncate at base, asymmetrically narrowed at rounded apex, much wider than tenth and as long as preceding four segments united.

Pronotum transversely subglobose, one-third wider than long in contrast to mülleri; a very large lateral fovea each side at basal fifth and a small, punctiform median fovea at basal fourth.

Each elytron with two circular basal foveae; an entire sutural stria from inner fovea; a broad triangular dorsal impression from outer fovea to basal third of elytron, in contrast to armipes.

Abdomen with five visible tergites in a length ratio of 3.5/2/.6/1.5/1.2. From a dorsal view only the first two tergites can be entirely seen, and the first appears, therefore, much larger than the rest of the abdomen. First with a narrow but distinct margin, this marginal field being longitudinally triangular, and the disc of the segment is medianly tumid and strongly depressed at each latero-basal corner. Second tergite with a conspicuous transverse sulcus from side to side at base; lateral margins carinoid.

Six sternites in a length ratio of $1 / 2 / 1 / .5 / .2 / .5$, with the first deeply excavated and densely pubescent, and the second very tumid.

Intermediate coxae widely separated. Posterior coxae separated by no greater distance than the intermediate coxal separation. Legs all simple, unarmed, uninflated and not arcuate. Tibial spurs entirely absent in contrast to the female armipes. Tarsi of the usual tyrine proportions, with two long, arcuate, equal claws.

Metasternum broadly medianly sulcate, with a tubercular swelling each side.

Described on one female, collected by C. H. Seevers on August 1, 1938, from beneath bark, at Puerto Salgar, Cundinamarca, Colombia.

The species of the genus may be listed as follows:

armipes Raffray. 1891. Caracas, Venezuela. (both sexes known)

clavicornis Raffray. 1891? Ceara, Brazil.

colombiensis new species. Puerto Salgar, Cundinamarca, Colombia.

(female known only)

mülleri Reitter. 1882. Sao Paulo, Brazil. Genotype. (male known only)

Taken at 2600 feet. 
Aube (1844)

REITTER (1882)

SHARP (1887)

Schaufuss (1887)

RAFFraY (1904, 1908)

FLETCHER (1932)

PARK (1935)

Hamotus was erected by Aube on three species in 1844: the genotype lateritius (p. 92), bryaxoides (p. 93), and humeralis (p. 93). The last named species was misplaced by Aube, and was early assigned to Tyrus. Tyrus was a genus erected by Aube in 1833 and its genotype is mucronatus (Panzer). LeConte and Horn (1883, p. 87) correctly placed Tyrus humeralis (Aube) and this course has been uniformly followed by American students. Tyrus humeralis is widespread in the Nearctic Region, from Canada south into Florida, and west to the Mississippi drainage basin. I have satisfied myself that humeralis (Aube) is perfectly congeneric with mucronatus (Panzer) of Europe. My material in the latter species comes from Germany and has been identified by Edmund Reitter. Both species have the typical distal segment of the maxillary palpus, that is, pedunculate-ovoidal in outline, with no longitudinal sulcus and with the palpal cone set in the acuminate apex of the segment.

The other two species of Aube, lateritius and bryaxoides, are typical Hamotus. Both species have the distal segment of the maxillary palpus cylindrico-ovoidal in outline, with the base obliquely truncate and the internal face conspicuously longitudinally sulcate, with the palpal cone set obliquely within the apex of the sulcus.

Hamotus has received much attention from three distinguished students of the family, Reitter, Schaufuss, and Raffray. The substantial increase in information since 1904 has rendered a new treatment desirable. At the present time the genus contains eighty-nine species and as a homogeneous aggregate of large size ranks with Reichenbachia, Decarthron, Arthmius, and a few other genera in the region under examination.

Taxonomically it is one of the most important neotropical genera. It is distributed over the Neotropical Region from the tropic of Cancer to the tropic of Capricorn, and its restriction to this fauna is complete with one exception, Hamotus opimus Fletcher discovered in 1932 in peninsular Florida. Such a dispersal pattern is presumptive evidence of neotropical origin and, since there has been great speciation in the genus, its confinement to this area indicates physiological intolerance of extra-tropical environment rather than inability to disperse or to compete with nearctic species.

There is but one other species about which doubt can be entertained. Brendel described Tyrus elongatus (Brendel and Wickham, 1890, p. 239) from a male from Williams, Arizona. Leng (1920, p. 132) placed it doubtfully in Cercocerus. Bowman (1934, p. 136) placed it in Hamotus. I agree with Bowman that elongatus cannot be Cercocerus - a glance at Brendel's figure precludes such 
an association. As to whether elongatus is Hamotus or Tyrus cannot be ascertained from the original description, but a single glance at the palpi of the type will settle the question as the two genera are wholly distinct, with no overlap. Presumably this has been done by Bowman. The habitat is too arid for Hamotus but I do not know this species.

America north of the tropic of Cancer has but one ally of Hamotus. This relative is the myrmecophilous, monotypic Cercocerus batrisoides Leconte (1861, p. 57). This species is in entire agreement with the subgenus Hamotoides of Hamotus. In fact it could be placed in Hamotus with no great difficulty as the only differential between Cercocerus and Hamotus is the relative size of the eleventh antennomere. In Cercocerus this distal segment forms the antennal club and is about seven times longer than the tenth segment. In Hamotus the last three antennomeres form the club but there is great variation in the relative size of these segments, thus in some species the ninth and tenth segments are small and the eleventh is longer than the preceding five united.

Otherwise these two genera are congeneric, Cercocerus having the typical hamotine palpi. ${ }^{1}$ Cercocerus batrisoides is a remarkable pselaphid, with unusually strong secondary sexual characters as indicated in the plates. Its apparent rarity in collections is probably a consequence of its being represented by a stray specimen from log mold. It is an habitual synoekete of ants, being perfectly unmolested by its host. I have usually taken it from nests of Aphaenogaster tennesseensis Mayr. Leng (1920) lists it from Pennsylvania, Indiana, and Louisiana. My series comes from Cincinnati, Ohio; Smith, Indiana; Topeka, Kansas, all with the ant host noted (Park, 1935). From these few data it appears that the species does not occur south of New Orleans. It is a nearctic extension of Hamotus, distributed through the Mississippi basin from the subtropics, eastward to Pennsylvania and westward to Kansas. Thus this species and Hamotus opimus become of great zoögeographic importance. The distribution of batrisoides is linked with its formicid hosts and we await more collecting records as well as its detailed ecology.

Within the neotropical region Hamotus has also many specialized relatives. It is closely allied with Apharus through Hamotus alleei in a phylogenetic shortening of the palpal sulcus and lengthening of the first tergite; it is allied to Pseudohamotus with its semi-circularly swollen distal palpomere but typical palpal sulcus; it is allied to a long series of genera in which the distal palpomere becomes elongate-cylindrical and the palpal sulcus very narrow (Cercoceropsis, Cercoceroides); and more remotly allied to Pselaphocompsus and Cercocerulus.

In other words, Hamotus is a stem genus which has one close ally in the nearctic, and many allies in the neotropical region. Throughout its neotropical range, the species seem to be a part of the rain forest fauna. They are especially

${ }^{1}$ In Bowman's recent treatise (1934, p. 132) the genus Cercocerus will not key out. In this key to tyrine genera Hamotus is given an apical palpal cone along with Tyrus, while Cercocerus is given no palpal cone.

This was probably a typographical error, as Tyrus is the only one of the three with a terminal palpal cone while both Hamotus and Cercocerus have a distinct palpal cone set obliquely within the apex of the longitudinal palpal sulcus. 
typical of moist, well-decayed log mold and there are few records of their being taken at lights at night; some species have adjusted to the rapacious army ant society (ecitophilus), others live with termites as noted later.

The largest pselaphid known to the author belongs in this genus. This giant is Hamotus (Hamotoides) ecitophilus Raffray of Brazil which measures $5.5 \mathrm{~mm}$. in length and lives with Eciton.

The comparative anatomy of the genus is not given here as the numerous descriptions of new species which follow serve to give the range of structural diversity. It should be pointed out, nevertheless, that, although the diversity is extensive, the central habitus of Hamotus is unmistakable and the species vary in the quantitative development of such features as the length of the palpal sulcus, length ratio of tergites, color of pubescence, proportions of the antennomeres, development of the pronotal foveae, and sulcus.

Sex is poorly differentiated by secondary characters. Only rarely are the males distinctive from the females on clear cut modification of the antennae, tibiae, or metasternum. Much more commonly the secondary sexual differences are subtle differences in the proportions of the antennal club or abdominal contour. Therefore long series of a species are greatly to be desired in the genus, and direct dissection necessary.

On the other hand, what at first appear to be slight differences in antennomeres of insufficient value for species separation, prove to be relatively stable in a long series of specimens. Raffray (1904) stated that these slight antennal differences were quite reliable for species separation. I have been at some pains to check this view. Having at hand several species represented by both sexes in series of a dozen or more, I used an ocular micrometer at high magnification to measure the length and width of the last three antennal segments. A summary of these data are given later under the species concerned, but it should be said here that the reliance of Raffray, Reitter, and Schaufuss on antennal segments has been justified in my own work.

Finally, it is pleasing to find at least a tenth of the known species are known from several adjacent countries, that is, the genus is becoming sufficiently known to have the distribution of its components partially delineated. Some species have a great range. Thus monachus is known from Costa Rica to Mexico; tritomus from Colombia to Mexico; hirtus from Grenada, St. Vincent, and Guadeloupe; bryaxoides from Colombia, Venezuela, and Brazil. In time such information, it is to be hoped, will appear comparatively scanty; this calls for much expeditionary labor and taxonomic discrimination.

As late as 1908 Raffray recognized Hamotus of Aube and Hamotoides (Schaufuss, 1887) as subgenera, but between 1909 and 1917 Raffray treated them as genera. I feel that this latter treatment is a mistake. Hamotus and Hamotoides differ in several ways but the differences are gradual, lacking any precise break in a qualitative sense. The chief character for their separation is the presence or absence of the transverse pronotal sulcus. Now the transition between having or lacking this sulcus is fully bridged by lateritius, decipiens, longepilosus, micans, longiceps and alleei. In these species, which are placed 
in Hamotus s.s. but could just as easily be allocated to Hamotoides, we run the gamut from a transversely oval median fovea with a vestigial sulcus present for a short distance on each side, through an entire shallow depression not quite reaching the lateral foveae, to an entire but interrupted sulcus. Furthermore, the genotype, lateritius, is just such a midway species. It stands at about the center of the genus with respect to sulcus development, and if the subgenera were made separate entities then great confusion might arise. Finally, the clean break between Arthmius, Syrbatus, and Syrmocerus in the pronotal outline and associated foveae is a good example of how a genus may be fragmented at the hands of taxonomists, whereas the breaking up of Hamotus would not result in such a practical arrangement.

\section{Key to the Subgenera of Hamotus}

Pronotum with three perfectly free, circular antebasal foveae and with no trace of a connecting sulcus, or rarely with the median fovea transversely oval or with the foveae connected by an interrupted vestigial sulcus, or a broad, shallow vestigial depression. (Pl. XIX, 3) ......HAMOTUS s.s.

Pronotum with a deep, entire transverse antebasal sulcus connecting the lateral foveae. (Pl. XIX, 4) .............HAMOTOIDES

Key to the Subgeneric Groups of Hamotus, s.s.

Median pronotal fovea connected to the lateral foveae by an interrupted sulcus, or the sulcus represented by a wide, very superficial impression . . ..................................... XI

Median pronotal fovea lacking any connection with the lateral foveae

2. Median pronotal fovea transversely oval, with a short vestige of a transverse sulcus entering the foveal lumen on each side..Group $\mathrm{X}$ Median pronotal fovea large, circular and entirely free...........

3. Antennal segments IX and X much longer than wide....... Group I Antennal segments IX and $\mathrm{X}$ with width equal to length, or much

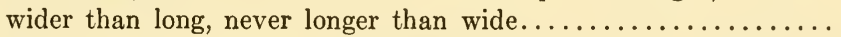

4. First visible tergite subequal in length to second, or the tergites very

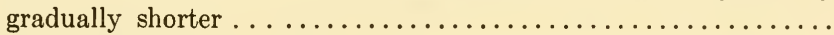

First visible tergite distinctly much longer than the second tergite....

5. Antennal segments IV-VIII quadrate............... Group II Antennal segments IV-VIII not all quadrate, some being transverse. .

6. Antennal segments IV and V quadrate............... Group III

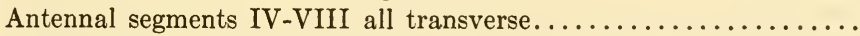

7. General body pubescence varying from a clear light yellow, through golden to a reddish-yellow..................... Group IV General body pubescence varying from a dark brown to nearly

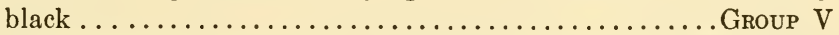

8. Antennal segment XI with a large, shallow foveiform depression on

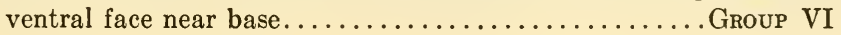


Antennal segment XI lacking such a foveiform depression..........

9. Elytra punctate, the flanks wrinkled and the punctures granulose on

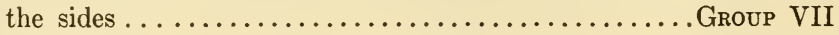

Elytra either lightly punctulate or impunctate............ 10

10. General body pubescence deep brown.................... VIII General body pubescence tawny to yellowish-brown....... Group IX

\section{Key to the Subgeneric Groups of Hamotoides}

Median pronotal fovea very large and strongly formed, with the transverse sulcus seen from each side of the foveal lumen as a sharply narrower groove. (Pl. XVII, 5) ..................... XII Median pronotal fovea either very small, or formed by a slight arcuation of the walls of the transverse sulcus or wholly absent.

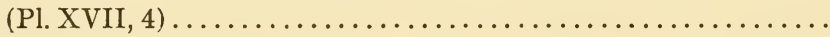

2. General body pubescence deep brown.............. Group XIII General body pubescence varying from yellow to yellowish-brown or tawny................................. XIV ${ }^{1}$

This organization is an extension of the 1904 arrangement of Raffray, and divides the genus into fourteen groups of species. In the following keys to species the term "palpal sulcus" refers to the longitudinal sulcus of the internal face of the distal segment of the maxillary palpus, and the Roman numerals refer to antennal segments.

\section{Key to Species of Group I}

$\mathrm{V}$, VI, VII three times longer than wide................. 2

V, VI, VII quadrate to transverse..................... 6

2. Metasternum tuberculate or spined.................... 3

Metasternum simple ........................... 5

3. Metasternum with a pair of long spinoid processes at base, these processes compressed and curved near apex; $3.4 \mathrm{~mm}$.; Bolivia

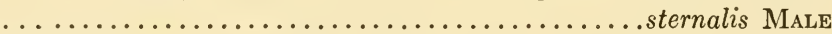

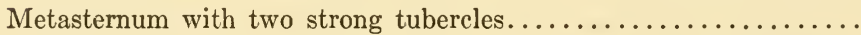

4. XI not twice as long as wide; $3.0 \mathrm{~mm}$.; Panama.... rostratus MaLe $\mathrm{XI}$ slightly more than twice as long as wide; $3.5 \mathrm{~mm}$.; Panama....

5. $3.4 \mathrm{~mm}$.; Bolivia..........................sternalis Female

6. First visible tergite distinctly longer than second........... 7

First and second tergites subequal in length............... 9

7. Known from Buenos Aires, Argentina; $3.3 \mathrm{~mm} . . . \ldots \ldots$ argentinus Known from Blumenau, Brazil northwards............... 8

8. XI regularly ovoidal, longer than the preceding two united; Brazil and Colombia ......................... gracilicornis XI elongate, longer than the three preceding united; Colombia. . badius

\footnotetext{
${ }^{1}$ Rarely the pubescence is a silvery gray.
} 
9. Median pronotal fovea much smaller than lateral pronotal foveae;

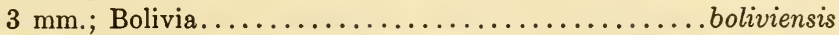
Three pronotal foveae subequal in size; $3.5 \mathrm{~mm}$.; Brazil..... iheringi

\section{Key to Species of Group II}

IX and $\mathrm{X}$ subequal in length and width; XI briefly ovoidal, slightly longer than preceding two united; Blumenau, Brazil....parviceps $\mathrm{X}$ about one-half longer than IX; XI as long as the three preceding united; Minas Geraes, Brazil..................... subtilis

Key to Species of Group III

Elytral flanks roughly punctate, disc nearly impunctate; Brazil..

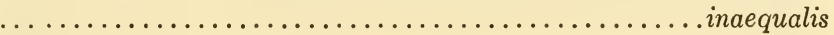

Elytra wholly impunctate.......................... 2

2. IX and $\mathrm{X}$ subequal in size, slightly transverse.............. 3

$\mathrm{X}$ one-half wider than IX, very transverse; $2.5 \mathrm{~mm}$.; Brazil. . globulifer

3. XI with parallel sides and rounded apex, as long as preceding four united; $2.6 \mathrm{~mm}$.; Brazil.......................ubeanus XI much wider in apical third, apex obtusely acuminate, not much longer than three preceding united; $2.1 \mathrm{~mm}$.; Brazil. . appendicularis

\section{Key to Species of Group IV}

This is a large group of nineteen species notable for their bright golden pubescence. The center of the group seems to be the northern rain forests of South Amrica, especially Venezuela and Colombia. This key does not include furcifer and claviger.

Body dorso-ventrally flattened; very attenuated anteriorly; elytra and abdomen with lateral outlines oblique to second tergite; I unusually elongate-cylindrical; $2 \mathrm{~mm}$.; Brazil..............deplanatus

Body of normal convexity and outline; I of normal proportions......

2. Male with posterior tibiae swollen and with the mesial face very abnormal, bearing either a large fovea or a prominent truncated

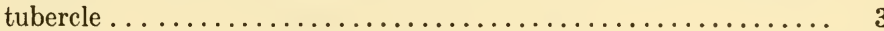

Males and females with tibiae not abnormal at middle of mesial face. . 4

3. Posterior tibiae with a large, elongate-oval, pubescent fovea at center of mesial face; $2.9 \mathrm{~mm}$.; Mexico. (PI. XVII, 8) ..........tibialis

Posterior tibiae with a conspicuous, drum-shaped tubercle at center of mesial face, the apex of the elevation pubescent; $2.6 \mathrm{~mm}$.; Costa Rica. (PI. XVII, 9) .........................turalbus

4. Antennae very slender, III-VIII transversely spheroidal; Colombia brunneus

Antennae short and thick........................... 5

5. VI, VII, VIII abruptly more transverse than III, IV, V........ 6

III-VIII all very transverse or very gradually more and more trans-

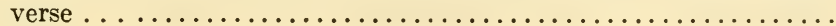


6. XI acuminate at apex; vertexal foveae as near to each other as either is to the adjacent eye; $2.1 \mathrm{~mm}$.; Venezuela............ frontalis XI obtusely rounded at apex; vertexal foveae mutually more distant

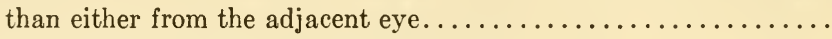

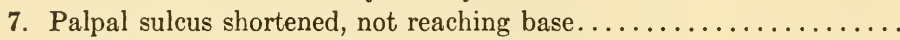
Palpal sulcus entire; $2.3 \mathrm{~mm}$; Venezuela.............vesiculifer

8. XI as long as four preceding united; Venezuela...........clavicornis $\mathrm{XI}$ as long as five preceding united; $2.3 \mathrm{~mm}$.; Colombia. . punctipennis

9. Posterior tibia with a distinct apical spur of setae (this is not a sexual character)

Posterior tibia without an apical spur; pubescence a rich yellow-gold color, long and appressed; $2.2 \mathrm{~mm}$.; Colombia......... bryaxoides

10. Posterior tibial spur short, thick and obtuse; $3.1 \mathrm{~mm}$; Venezuela .globifer

Posterior tibial spur fine, aciculate, usually sharply angulate or

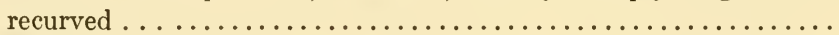

11. IX and $\mathrm{X}$ very short and so transverse that they appear as disks; head much wider than pronotum; Colombia............ barbatus IX and $\mathrm{X}$ of variable width but never in the form of thin disks......

12. Palpal sulcus entire; $2.5 \mathrm{~mm}$; Venezuela.............. auricapillus

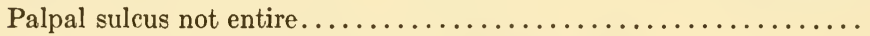

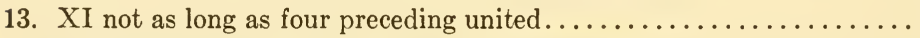

$\mathrm{XI}$ as long or longer than four preceding united................

14. XI short, thick, sides subparallel, rounded at apex; $2.2 \mathrm{~mm}$.; Venezuela and Colombia......................robustus XI very narrow at base, nearly globular; $2.25 \mathrm{~mm}$.; Venezuela..

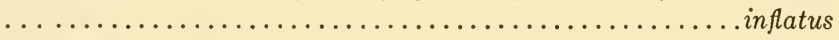

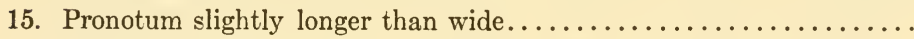
Pronotum distinctly wider than long........sandersoni new species

16. XI as long as four preceding united; $2.1 \mathrm{~mm}$.; Colombia.... bulbifer $\mathrm{XI}$ as long as five preceding united; $2.1 \mathrm{~mm}$.; Colombia.. transversalis

\section{Key to Species of Group V}

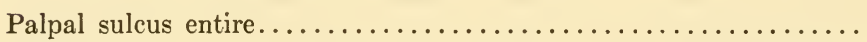

Palpal sulcus not entire; $2.7 \mathrm{~mm}$.; Ecuador........... fuscopilosus

2. Antennal club not well developed, IX and $\mathrm{X}$ only slightly transverse, subequal, and not much wider than VIII.............. Antennal club strong, very abruptly formed, IX at least twice as

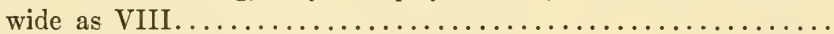

3. Pubescence long; Brazil..................... impunctatus Pubescence short; $2.4 \mathrm{~mm}$. Venezuela..............crassipalpus

4. XI very large, as long as six preceding united; $1.9 \mathrm{~mm}$.; Paraguay .laetus XI not much longer than four preceding; $2.2 \mathrm{~mm}$.; Brazil. .gracilipes 
Group VI contains a single remarkable species, cavicornis Raffray of Guatemala. The species has long, semierect, brown pubescence, is $2.4 \mathrm{~mm}$. long and owes its isolation to the foveoid eleventh antennomere. As stated earlier in the genus treatment, this latter character probably refers to the male sex only and is remarkable in Hamotus where few species have abnormal antennal modifications.

Group VII contains a single species, rugosus Raffray of Bolivia. This species also has long brown pubescence, is $2 \mathrm{~mm}$. long and owes its isolation to the elytral punctation. The elytral flanks have the integument strongly punctate-granular.

\section{Key to Species of Groups VIII and IX}

I have reorganized these two groups into one key since the color of pubescence, varying from tawny to deep brown, may prove confusing.

Palpal sulcus entire, reaching and dividing basal margin........ 9

Palpal sulcus not entire, not reaching base................ 2

2. Apical spur of posterior tibia long, fine and acuminate........ 3

Apical spur of posterior tibia blunt to truncate............. 4

3. XI equal to the five preceding segments united; $2.4 \mathrm{~mm}$; Brazil grouvellei

$\mathrm{XI}$ equal to only slightly longer than the three preceding united;

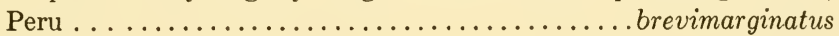

4. III distinctly longer than wide................... 5

III distinctly wider than long, or at most with width and length equal

5. Known only from Mexico; $2.3 \mathrm{~mm} . \ldots \ldots \ldots \ldots \ldots \ldots \ldots$. . . . . . . .

Known only from Brazil ; $2.3 \mathrm{~mm} . \ldots \ldots \ldots \ldots \ldots \ldots \ldots$ simplex

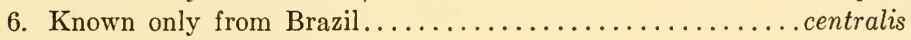

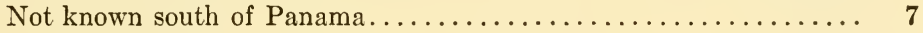

7. Pubescence fine in texture, long and abundant............. 8

Pubescence stiff, very short and sparse...... costaricensis new species

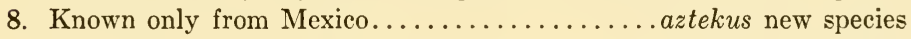
Known only from the Canal Zone................................... new species

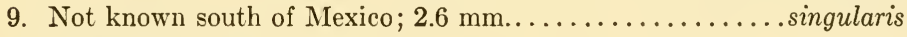
Not known north of Panama.................... 10

10. III much longer than wide to slightly longer. . . . . . . . . . 11

III very transverse to width equaling length .............. 13

11. Known only from Bolivia ...................... 12

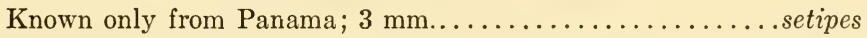

12. III, IV, $\mathrm{V}$, and VI much longer than wide $; 2.6 \mathrm{~mm} . \ldots \ldots \ldots$. . bicolor III slightly longer than wide, IV and V quadrate, VI transverse;

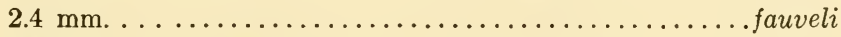

13. Posterior tibia without tibial spur (?) (Sharp states that his species is closely allied to singularis of Reitter. Raffray had difficulty in placing this Sharp species, described on two imperfect specimens without any detail given); $2.5 \mathrm{~mm}$; brown pubescence; Panama 
(If parvipalpis has III longer than wide it will run to setipes of Sharp which is better known: the latter has lighter pubescence and is larger)

Posterior tibia with an apical spur..................... 14

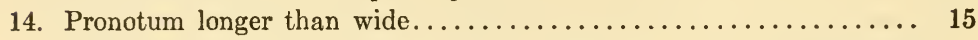

Pronotum wider than long; $2.4 \mathrm{~mm}$; Venezuela............. soror

15. III-X progressively more transverse; Brazil............vulpinus

III-VIII regularly transverse; not known from Brazil............

16. Body elongate; XI much longer than four preceding; posterior tibial spur long; $2.4 \mathrm{~mm}$; Venezuela...................cavipalpus Body short and thick; XI as long as or slightly longer than four preceding; posterior tibial spur much shorter; $2.1 \mathrm{~mm}$.; Bolivia.... .sulcipalpus

\section{Key to Species of Group X}

Intermediate trochanters each strongly spined; Venezuela and Colombia .................................teritius Male Intermediate trochanters not spined; $2.9 \mathrm{~mm}$.; Colombia......... decipiens MaLe

Apparently Raffray had access to the type of lateritius Aube, and since this species is the genotype, the following data have been translated from Raffray (1904) to give a rough word picture of this key form. The head has an antennal tubercle nearly as long as the rest of the head and the two vertexal foveae are separated by a distance nearly twice as great as that separating either from its adjacent eye. Distal palpomere is subcylindrical, with subacuminate apex, and an entire longitudinal sulcus on the internal face. The long antennae have III longer than wide, obconical; IV-VII square; VIII slightly transverse; IX and X large, gradually transverse; XI regularly oblongoval. The pronotum is longer than wide, subconical; the median fovea is free but transversely oval, with a short vestige of the transverse sulcus extending from each side. The male has each posterior tibia supplied with a short, straight, obtuse apical spur and the intermediate trochanters each prolonged into a strong, obtuse spine; metasternum flattened and medianly slightly impressed.

\section{Key to Species of Group XI}

III to VI longer than wide.......................... 2

III to VI quadrate, as wide as long.................... 3

2. II twice as long as wide, IX and $\mathrm{X}$ with length and width equal; pubescence subappressed, brown; $3.4 \mathrm{~mm}$. ; Bolivia.... longepilosus

II slightly longer than wide, IX and $\mathrm{X}$ much longer than wide; pubescence bristling, yellow; $3.6 \mathrm{~mm}$.; Brazil........... longiceps

3. IX and $\mathrm{X}$ very large, much larger than VIII; head slightly longer than wide; $2.3 \mathrm{~mm}$.; Venezuela and Colombia...........micans 
IX and X small; ninth with width and length equal, not much larger than VIII; tenth with width and length equal, not much larger than ninth; head very long, one-third longer than wide......... .alleei new species

\section{Key to Species of Group XII}

Lateral pronotal margins tuberculate and sinuate above the lateral pronotal foveae which incise the lateral contour; Mexico. .nodicollis

Lateral pronotal margins simple; lateral pronotal foveae not incising

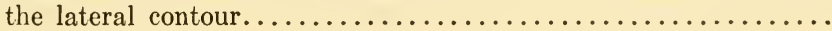

2. Distal palpomere of a peculiar form, being curved internally near apex which is acuminate; $3.5 \mathrm{~mm}$.; Nicaragua........ pubiventris

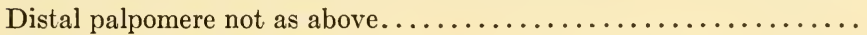

3. IX and X subglobular with all angles rounded; $2.5 \mathrm{~mm}$.; Brazil.. appendiculatus

IX and X not subglobular.......................... 4

4. X subquadrate, either as long as wide or slightly longer than wide... 5

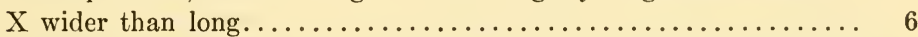

5. IX twice as large as VIII, $\mathrm{X}$ quadrate with length and width equal, twice the size of ninth but of nearly the same length; XI very large, oblique and ovoidal; $1.6 \mathrm{~mm}$.; French Guiana........ sanguinipes IX twice as large as VIII, as wide as long, trapezoidal; $\mathrm{X}$ slightly larger than ninth, trapezoidal, slightly longer than wide; XI of normal size, as long as the preceding two united; $2.3 \mathrm{~mm}$.; Mexico.. .electrae new species

6. Intrahumeral impression strioid, clearly defined and one-half the elytral length; 2.3-2.5 mm.; Mexico, Guatemala and Costa Rica..

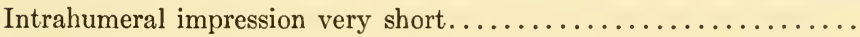

7. First two visible tergites of equal length; $2.33 \mathrm{~mm}$.; Guatemala... difficilis

First tergite shorter than second (!) ; $2.33 \mathrm{~mm}$.; Guatemala. .vicinus This key does not include emeryi Wasmann, of Brazil.

\section{Key to Species of Groups XIII and XIV}

These two groups have been reorganized to accommodate new material and the species incorporated into one key to avoid possible confusion in the color of pubescence which, with one exception, varies from yellowish-brown to brown.

Pubescence a silvery gray; body length in excess of five millimeters; known only from colonies of army ants; Brazil........ecitophilus

Pubescence tawny to deep brown; body length less than three milli-

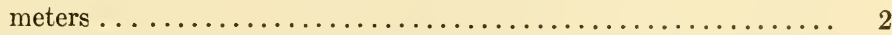

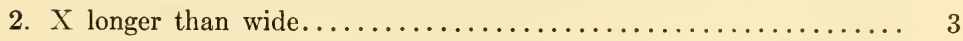

$\mathrm{X}$ with length and width equal, or much wider than long........ 6 
3. General body pubescence varying from deep brown to black..... General body pubescence varying from light yellow to reddish-gold. .

4. $\mathrm{X}$ very large and cylindrical, nearly twice as long as IX; Colombia to Mexico .............................tritomus

$\mathrm{X}$ trapezoidal, not nearly twice as long as IX; 2 mm.; Brazil.... nigropilosus

5. IX quadrate, length and width equal; $X$ obconical, much longer than wide; IX briefly and regularly ovoidal; Mexico.......... suturalis IX slightly longer than wide; $\mathrm{X}$ slightly longer than wide, with an arcuate tooth at center of ventro-external face; XI as long as preceding two united, with a porous tubercle at apico-internal face and a sharp spicular tooth at center of ventro-external face;

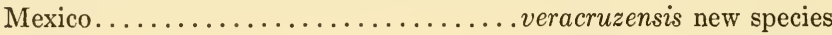

6. IX distinctly longer than wide.............thomasi new species IX with length and width equal or much wider than long..........

7. Large, at least $2.8 \mathrm{~mm}$. long; known only from Mexico; elytra with sparse, strong, rugose punctures...................mmodus Smaller; not known north of Panama or Lesser Antilles...........

8. X distinctly transverse; $2 \mathrm{~mm}$.; Windward and Leeward Islands.. hirtus

$\mathrm{X}$ very slightly transverse or with length and width equal; known only from the mainland.......................... 9

9. Known from Argentina, Paraguay and Brazil.............. 10

Known from Panama Canal Zone, Venezuela and Colombia........ 11

10. Pubescence inserted in minute granulations; male with anterior trochanter spined and anterior femur with an obtuse tooth at base; $2.3 \mathrm{~mm}$.; Argentina.....................punctulatus

Pubescence not inserted in minute granulations; male with anterior trochanter spined but the anterior femur simple, not toothed; 2.0-2.2 mm.; Brazil and Paraguay................... bellus

11. Elytra impunctate; $1.75 \mathrm{~mm}$; Colombia...............hilaris

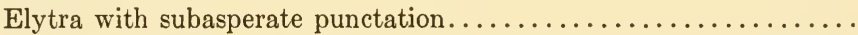

12. IV-VIII all subequal in size and all transverse; $2.5 \mathrm{~mm}$.; Venezuela . flavopilosus

IV and V quadrate-moniliform to slightly transverse, VI-VIII very

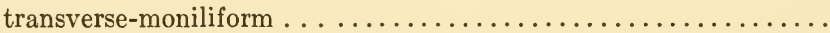

13. IV-VI transverse, VII and VIII lenticular; IX slightly transverse, $\mathrm{X}$ quadrate, much larger than ninth; XI briefly, regularly ovoidal, very large, obtuse at apex; pubescence short, appressed and flavous; $2.1 \mathrm{~mm}$.; Venezuela......................... reichei

IV and V quadrate-moniliform, VI-VIII gradually transverse-moniliform; IX and X quadrate, tenth with a tooth on the ventro-lateral face in the male sex; XI as long as preceding two united, also with a tooth at center of ventro-lateral face in male sex; male with anterior trochanters toothed; females with simple quadrate ninth and tenth 
segments, eleventh not toothed, anterior trochanters not toothed;

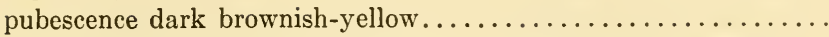
veracruzensis fletcheri new subspecies

This group key is complete with the exception of rossii described from Paraguay. Rossii measures $1.96 \mathrm{~mm}$. in length and is said to be near hirtus but has a larger head, more transverse antennal tubercles, antennal segments $\mathrm{V}$-VIII more transverse, IX more transverse and $\mathrm{X}$ much longer than hirtus. Rossii has the first two visible tergites subequal in length and a simple metasternum.

\section{Hamotus (Hamotus) costaricensis new species}

Type. Measurements: Head $0.45 \times 0.43 \mathrm{~mm}$; pronotum $0.47 \times 0.50 \mathrm{~mm}$; elytra $0.60 \times 0.87 \mathrm{~mm}$; abdomen $0.60 \times 0.90 \mathrm{~mm}$. Total length $2.12 \mathrm{~mm}$.

Shining brownish-yellow. Pubescence light tan color, sparse, very short and stiff. Integument lightly punctulate.

Head slightly elongate with long tempora, much longer than wide and longer than eyes. Eyes strongly reniform, composed of about 92 small facets. Vertex and occiput simply convex, with three foveae: a pair of small vertexal foveae, each about the size of an ocular facet, nude, punctiform, on a line through posterior third of eyes and equidistantly placed; a third fovea even smaller, punctiform, nude, on a line through anterior third of eyes in center of head. Front narrowed to form two small antennal tubercles separated medianly by a shallow sulcoid impression which extends posteriorly to median vertexal fovea; front very narrow and vertical from inter-antennal depression to clypeus. Clypeus simple, with a strong semi-circular carina just posterior of apical margin, extending from side to side as in Juxtahamotopsis. Labrum very transverse. Right mandible crossed dorsad to left; jaws strong with large teeth. Ventral surface of head broad and very flat, with a large circular, nude fovea at middle of base.

Maxillary palpi four-segmented; first minute, cylindrical; second elongate, base pedunculate and no wider than first, arcuate, becoming strongly inflated at apex; third short, triangular with angulate internal and convex external face, less than half as long as second, nearly twice as wide as second; fourth one-third longer than second, nearly twice as wide as third, elongate-oval with base obliquely truncate base and rounded apex, internal face nearly straight, external face convex; palpal sulcus of internal face elongate-oval, extending obliquely from apex to basal fourth, the basal fourth of the segment, therefore, not sulcate; palpal cone strong and blunt, set obliquely in the apical end of the sulcus.

Antennae eleven-segmented; I elongate-cylindrical; II shorter, slightly narrower and quadrate; III asymmetrically narrowed at base, but with length equal to apical width; IV-VIII moniliform, becoming very slightly transverse; IX slightly longer and wider, slightly transverse, subtrapezoidal; $\mathrm{X}$ similar, slightly larger; XI large, truncate at base, twice as wide as tenth, as long 
as the preceding four segments united, apex rounded, external face strongly convex, internal face slightly convex. Antennae $0.94 \mathrm{~mm}$. long.

Pronotum slightly transverse, with simple disc and sides which slightly diverge from base to near apex and then become broadly rounded to apical margin; base with three large, subequal, circular pubescent foveae.

Elytra with rounded humeri. Each elytron with two circular, pubescent basal foveae, a deep and entire sutural stria and a very short discal impression for basal fifth of length.

Abdomen with five visible tergites in a length ratio of $6 / 3.5 / 1 / .5 / 1.5$ with the first three strongly margined. Six simple sternites in a length ratio of $1 / 2.5 / 1.5 / .8 / .5 / 1.5$.

Metasternum medianly with a broad longitudinal depression and each side with a rounded tumidity. Legs simple save that the posterior tibiae are apically spurred. This spur is long, oblong, angulated at base, truncated at apex. Tarsi slightly more than one-half the tibial length; first tarsomere short and triangular; second three times as long as first; third longer than second, with a pair of long arcuate, aciculate tarsal claws.

One specimen from Turrialba, Costa Rica. Probably a female.

In Raffray's 1904 treatment costaricensis runs off the key near centralis Reitter with which it has little in common, and it would appear to have no close relatives.

\section{Hamotus (Hamotus) alleei new species}

Type. Measurements: Head $0.37 \times 0.23 \mathrm{~mm}$; pronotum 0.33 × $0.40 \mathrm{~mm}$; elytra $0.53 \times 0.74 \mathrm{~mm}$; abdomen $0.53 \times 0.74 \mathrm{~mm}$. Total length $1.8 \mathrm{~mm}$.

Shining reddish-brown when mature; pubescence long, silky and golden; integument strongly punctate with base of pronotum cribrate, the femora and tibiae scabroid, but the antennal club nearly smooth.

Head elongate, one-third longer than wide, with long converging tempora which are bearded. Eyes shorter than tempora, not prominent, medianly placed, semilunar in lateral view and each of 56 moderately sized facets. Occipital margin subretuse. Vertex elevated but dorsally flattened, with a pair of small punctiform nude vertexal foveae between the eyes. Each vertexal fovea lies in a pyramidal impression, and mutually closer than either to adjacent eye. Front with inconspicuous antennal tubercles which are separated by a short but deep longitudinal sulcus; this sulcus terminates posteriorly in a median punctiform fovea. Front and clypeus as in costaricensis. Ventral surface of head complex and nonhamotine: transversely tumid between eyes, the tumidity mounted by an arcuate carina; this transverse carina connected to oral cavity (submental boundary) by a longitudinal median carina; below each eye at its ventral angle, the transverse carina forms an infraocular tubercle and this tubercle is connected with posterior boundary of head by a longitudinal lateral carina; enclosed surface between these three carinae flattened, with a transversely oblong fovea at middle of base. 
Maxillary palpi large; first three segments as in costaricensis. Fourth (distal) palpomere obliquely truncate at base, internal face straight, external face convex to rounded apex to form the usual elongate-oval outline. Internal face with an entire, longitudinal sulcus and a large palpal cone inserted within apex of sulcus as usual. This distal segment $0.19 \mathrm{~mm}$. long by $0.09 \mathrm{~mm}$. wide. It is covered with a thin pearly secretion which became hardened after immersion in alcohol. This palpal secretion has been noted on many species of Hamotus and suggests a sensory function.

Antennae one-half the body length $(0.9 \mathrm{~mm}$.) and simple; I elongatecylindrical; II similar but smaller; III-VIII subequal, moniliform; IX and X as in key; XI much longer than wide, subconical, not quite as long as three preceding united.

Pronotum shorter and wider than head, slightly transverse, subglobose. Base with small distinct median fovea and large lateral fovea each side; foveae nude and connected by a rudimentary transverse sulcoid depression of varying breadth and depth, at no time cleanly cut and always difficult to follow.

Abdomen with five visible tergites in a length ratio of $6 / 1 / 1 / 1 / 1.5$ with first two with strong lateral margins. Base of first with a pair of strong, straight, slightly divergent basal carinae which are two-fifths as long as segment and separated by one-half the segmental width. Six simple sternites in a length ratio of $1 / 2.5 / 1 / 1 / 1 / .5$.

Metasternum elongate, tumid each side of a subglabrous broadly concave depression; apical margin finely incised at middle.

Posterior coxae and intermediate coxae separated by one-third the median metasternal length. Legs simple and the posterior tibiae are not spined or spurred. Tarsi of typical Hamotus proportions, with two large, equal claws.

Described on two specimens of doubtful sex, both collected by the author in decayed $\log$ mold in rain forest of Barro Colorado Island, Gatun Lake, Panama Canal Zone. Type July 25, 1936, at Drayton 13; paratype July 29, 1936, at Zetek 3. The paratype had recently pupated.

Alleei runs to Group XI but has little affinity with other species. With more time it may form the type of a new genus. The general habitus, pubescence, head from above, antennae, pronotum and elytra, and especially the maxillary palpi are Hamotus. The very long first tergite is Apharus. The vestigial pronotal sulcus places the species near the genotype lateritius rather than the extremes of Hamotus but lack of tibial spurs and nude foveae incline it to Hamotoides. The ventral surface of the head, punctation, and basal abdominal carinae are nonhamotine. It is a pleasure to name this distinctive pselaphid for my friend, Professor Warder Clyde Allee.

\section{Hamotus (Hamotus) sandersoni new species}

Type. Measurements: Head $0.37 \times 0.38 \mathrm{~mm}$.; pronotum $0.37 \times 0.43 \mathrm{~mm}$; elytra $0.47 \times 0.80 \mathrm{~mm}$.; abdomen $0.63 \times 0.80 \mathrm{~mm}$.; total length $1.84 \mathrm{~mm}$.

Uniform light brownish-yellow. Pubescence abundant, fine in texture, subappressed, dark golden in color. Integument lightly punctulate. 
Head with length and width subequal, of the usual form, with long convergent tempora. Eyes moderately prominent, median, reniform, with about 96 very minute facets. Vertex with three relatively large nude foveae arranged in a triangle: a pair placed on a line through eye centers and as near each other as either is to its adjacent eye-each of these foveae lies in the apical margin of a definite ovate depression, which gives a peculiarly double aspect to these interocular foveae; the third fovea is median and anterior, placed at the base of the narrow longitudinal sulcus separating the small antennal tubercles. Front, clypeus, and labrum as in costaricensis. Ventral surface of the head is flattened, with a longitudinal lateral carina each side below the eye-which is an approach to the condition in alleei-and a triangular gular fovea at middle of base.

Maxillary palpi of usual hamotine form; fourth palpomere with the longitudinal sulcus of the internal face not entire, reaching to three-fourths of length, slightly oblique, narrow with an expanded apical end in which is inserted the very oblique palpal cone.

Antennae short and thick; I elongate-cylindrical; II less elongate, but longer than wide, smaller than first; III-VIII all transverse; IX larger, asymmetrically trapezoidal, transverse, mesial face shorter than lateral face; $\mathrm{X}$ still larger and very transverse, also asymmetrically trapezoidal; XI as long as four preceding united, as wide as long, with very round apex.

Pronotum distinctly transverse; form as in costaricensis; three pubescent antebasal foveae of which the median is distinctly smaller than the lateral.

Elytra as in costaricensis.

Wings well developed.

Abdomen with five visible tergites in a length ratio of $3 / 3 / 2 / 2 / 1.5$ and the first three strongly margined. Six simple sternites in a length ratio of $1 / 3 / .8 / .5 / .4 / .4$.

Metasternum, posterior coxae, and intermediate coxae as in alleei. Posterior tibiae slightly arcuate in apical fourth, and bearing an apical spur of setae. This apical spur is moderately long, very slender, strongly angulate, aciculate. Tarsi as for genus.

Named on three specimens collected by the author on Barro Colorado Island, Panama Canal Zone, from decaying log mold of the forest floor. Sex not determined with certainty from external anatomy. Type on July 6, 1936, at Armour 7 and two paratypes on July 26, 1936, at Armour 8. Named for one of the younger students of Pselaphidae, Dr. Sanderson. This species is distinctive in its morphology. It is typical of Raffray's fourth group and appears to be closest to bulbifer of Colombia from which it is quickly separated on pronotal dimensions.

\section{Hamotus (Hamotus) castanalus new species}

Type. Measurements: Head $0.40 \times 0.43 \mathrm{~mm}$; pronotum $0.47 \times 0.49 \mathrm{~mm}$; elytra $0.60 \times 0.94 \mathrm{~mm}$; ; abdomen $0.74 \times 0.87 \mathrm{~mm}$; t total length $2.21 \mathrm{~mm}$.

Integument shining reddish-chestnut; almost impunctate save for legs 
and antennal club which are subscabroid. Pubescence long, silky, abundant, and yellowish-brown.

Head with width and length subequal with long oblique tempora. Eyes medianly placed, reniform in lateral view, moderately prominent and composed of about 58 moderately large facets. Vertex high, prominently and evenly vaulted into a dome between the eyes. A pair of very small, nude, punctiform, vertexal foveae on a line through anterior third of eyes, mutually separated by a distance greater than either from its adjacent eye. Antennal tubercles small and separated by a simple median depression, at the bottom of which is the small median fovea. Front, clypeus, labrum, ventral surface of head and maxillary palpi as in costaricensis.

Antennae short and thick; I subelongate-subcylindrical, being shorter than usual; II smaller and subquadrate; III-VIII transverse, moniliform to trapezoidal; IX and X gradually larger, transverse, trapezoidal; XI truncate at base, very rounded at apex, one-third longer than wide, as long as preceding four united.

Pronotum and elytra as in costaricensis.

Abdomen with five visible tergites in a length ratio of $5 / 3.5 / 2 / 2.5 / 2$ with the first three strongly margined as usual. Four tergite with a large circular, pubescent fovea in each latero-basal angle. Fifth tergite distinctive: transversely flattened in basal half and slightly tumid in apical half, with a short blunt dentoid tubercle at center of apical margin.

Six simple sternites in a length ratio of $2.5 / 3 / 1.8 / 1 / 1 / .8$ and since the last four are slightly flattened medianly the sex is probable male.

Metasternum as in alleei. Posterior coxae separated by one-half, and intermediate coxae separated by one-fourth the median metasternal length. Legs simple save that the posterior tibiae each bears an apical spur. These spurs consist of about six long, thick, truncate setae arranged in an angulated, truncate bundle. Tarsi as for genus.

Described on a single specimen collected by the author on Barro Colorado Island, Gatun Lake, Panama Canal Zone, from beneath the bark of a log at Armour 8 on July 26, 1936.

This species is readily separated from its allies. The domed vertex, long silky pubescence, conspicuously fewer ocular facets and the terminal tergite distinguish castanalus from costaricensis. The shorter terminal antennomere separates it from aztekus among other characters noted. The only other near relative is centralis of Brazil which has the pronotum distinctly longer than wide, while castanalus has the pronotum slightly transverse.

\section{Hamotus (Hamotus) aztekus new species}

Type Male. Measurements: Head 0.40 x $0.40 \mathrm{~mm}$; pronotum $0.40 \times 0.50$ mm.; elytra $0.50 \times 0.78 \mathrm{~mm}$; abdomen $0.70 \times 0.84 \mathrm{~mm}$; total length $2.00 \mathrm{~mm}$.

Shining reddish-brown; integument subimpunctate save for elytra which 
are lightly punctulate and antennal club which is subgranulate. Pubescence yellowish-brown, long, silky, and abundant.

Head as in castanalus save for the following: vertex not unusually vaulted but is medianly depressed; the small antennal tubercles are distinctly separated by a longitudinal sulcus instead of a median depression; eyes of about 88 facets. Front, clypeus, labrum, ventral surface of head, and maxillary palpi as in costaricensis.

Antennae $0.87 \mathrm{~mm}$. long; I to $\mathrm{X}$ as in castanalus; XI distinctive, being three-fourths as wide as long, and as long as the preceding five segments united.

Pronotum slightly transverse with the sides nearly parallel; three antebasal pubescent foveae, of which the median is slightly smaller and more circular.

Each elytron with two large, circular, pubescent basal foveae; an unusually broad, deep, sulcoid sutural stria; a relatively long dorsal sulcoid impression extending from outer fovea through basal third of elytral length.

Wings long and well-developed.

Abdomen with five visible tergites in a length ratio of $5 / 3.5 / 2 / 1.5 / 2$ having the first three margined as usual. The last tergite is sexually distinctive, being broadly subtriangular.

Six sternites in a length ratio of $1 / 3 / 2.5 / 1 / .8 / .8$ with the last four slightly flattened. The penis is exserted between the last sternite and tergite, establishing the sex of the type.

Metasternum as in alleei. Intermediate coxae separated by less than onethird, and posterior coxae separated by slightly more than one-half, the median metasternal length. Legs as for genus; posterior tibiae each with an apical spur. This spur is sharply angulate at base, thick, subtruncate, and composed of six very stout setae.

Described on nine specimens, all from Vera Cruz, Mexico, as follows: type male and four paratypes from Tezonapa, one paratype from Penuela; two paratypes from Tuxpango collected by Henry Dybas in July and August, 1941, and one male paratype from Cordoba on July 20, 1936, collected by C. H. Seevers.

The female sex has the eleventh antennal segment as long as the preceding four united; the sternites normally convex; the last tergite broadly trapezoidal with the apical margin concave. The form of the terminal tergite rapidly sexes the species, while the sexual variation in the distal antennomere is a good illustration of a quantitative differential, in contrast to the qualitative differences in the club of veracruzensis. There is some variation in the third antennal segment, some specimens having this segment as long as wide and others wider than long, but never longer than wide, which, therefore, quickly separates aztekus from ursulus, simplex and other species with a distinctive elongate third antennomere. From its nearest allies aztekus differs in the long distal antennal segment of the male. The relatively short second sternite and elytra are also diagnostic.

In the following descriptions of three new species of the subgenus Hamotoides I have given a tolerably full account of one species and contrasted 
the others with this and previously recognized species. Such a course not only saves space but it introduces the comparative method more strongly. This is valuable in itself since the subgenus as a whole has a deceptively common habitus, as demonstrated by Schaufuss, Reitter, and Raffray and therefore the several species populations must be separated with great care to avoid confusion.

Hamotus (Hamotoides) veracruzensis new species

Holotype Male. Measurements: Head 0.40 x $0.40 \mathrm{~mm}$; pronotum 0.38 x $0.43 \mathrm{~mm}$.; elytra 0.56 x $0.80 \mathrm{~mm}$; abdomen 0.70 x $0.77 \mathrm{~mm}$. Total length $2.04 \mathrm{~mm}$. (Pl. VI, XVII)

Elongate, graceful body of a shining reddish-brown color. Integument uniformly and distinctly punctate, with the elytra having the punctures asperate and the antennal club granulate. Pubescence an opaque reddish-yellow color, moderately short, subappressed, and not unusually sparse or abundant.

Head with oblique tempora slightly longer than the eyes. Eyes median, very large and prominent, convex and subreniform, each composed of about 48 large facets. Occiput and posterior half of vertex convex; a pair of very large, deep vertexal foveae placed on a line passing through eye-centers. Each vertexal fovea is close to an eye, separated from the eye by the united diameters of two ocular facets, and each with a diameter of three facets. Just anterior to each eye the side of the head is abruptly narrowed by an angulation which then expands to form an antennal tubercle. The antennal tubercles are separated by a deep longitudinal sulcus, the posterior end of which forms the median fovea. This pubescent circular fovea thus has its lumen directed apically instead of dorsally. Front narrow and vertical between antennae, descending to the simple clypeus. Clypeus and labrum as in costaricensis. Base of mandibles with abundant golden setae; left mandible crossed dorsal to right. Ventral surface of head simple and flattened.

Maxillary palpi large; first segment minute; second elongate, gently arcuate and slightly obconical, the base much thicker and the apex much less inflated than usual in the genus, apex not twice as wide as base and with the internal face longitudinally sulcoid (for repose of distal palpomere?) ; third segment as usual short and triangular, wider than second and about onethird as long, with an acute-angular internal and a longitudinally convex outer face. Fourth (distal) segment as long as eleventh antennal segment $(0.234$ $\mathrm{mm}$.), one-fourth longer than second, slightly more than twice as wide as second, elongate-oval, with a very obliquely truncate base and blunt apex. The internal face of this last segment is entirely sulcate; this palpal sulcus is narrow, apically its margin circles the apex, enclosing the unusually apical palpal cone, and basally the sulcus margins flair along the truncate base to form its basal margin and hence enclose the peduncle or articular neck of the segment. The palpal cone is exceptionally thick, blunt, translucent, slightly 
arcuate. This last segment is in reality covered with excessively fine, appressed pubescence which gives a micro-strigoid appearance. Over the surface is spread the flaky, dehydrated, pearly secretion noted previously.

Antennae $0.87 \mathrm{~mm}$. long; sexually modified in a qualitative sense; I elongate-cylindrical; II smaller, elongate-cylindrical; III obconical, longer than wide; IV and V shorter than third, quadrate-moniliform; VI-VIII gradually transverse-moniliform; last three segments forming a distinct club; IX slightly longer than wide, rounded-trapezoidal; X larger, also slightly longer than wide, obconical-trapezoidal, with an apically arcuate tooth at middle of latero-ventral face; XI subovate, as long as the preceding two united or as long as distal palpomere, having a straight sharp, apically directed spicule at center of latero-ventral face, and a porous tubercle at apico-mesial face. Club granular in addition to these sexual modifications.

Pronotum simple with evenly convex disc; sides subparallel in basal half, then converging to rounded apex; base with a strong arcuate transverse sulcus which connects a large lateral fovea each side with the poorly formed median fovea. This latter is small and deep and lies in a widening of the sulcus.

Elytra each with two circular basal foveae, an entire sutural stria and a broad discal impression extending for the basal half of elytral length.

Abdomen with five visible tergites in a length ratio of $4 / 3.5 / 2.3 / 1.6 / 1.5$ and the first three strongly margined. Last tergite tranversely trapezoidal, with a nearly straight apical margin.

Six sternites in a length ratio of $1.5 / 2.5 / 2.5 / 1.8 / 1 / .5$ these being distinctly concave medianly. The penis is exserted between terminal tergite and sternite, assuring the sex of the holotype.

Metasternum strongly tumid each side of a longitudinal sulcoid impression and the apical margin is deeply, narrowly incised to enclose a narrow, crossstriated tubercle of the first sternite.

Intermediate coxae separated by one-fifth, and posterior coxae separated by two-fifths the median metasternal length.

Anterior trochanters each apically prolonged into a short, black, triangular tooth; posterior tibiae not spurred. Tarsi as for genus.

Allotype Female. Substantially as for holotype save that (1) the tenth and eleventh antennomeres are not toothed; (2) right mandible crossed dorsal to left; (3) sternites more convex medianly; (5) anterior trochanters simple, not dentate.

Described on thirty specimens from Vera Cruz, Mexico, as follows: holotype, allotype, three male and two female paratypes from Cordoba (July 11, 1941, Henry Dybas); two male paratypes from Cordoba (July 20, 1936, C. H. Seevers) ; two female paratypes from San Juan, 20 miles east of Cordoba at 1750 feet elevation (July 18, 1941, Henry Dybas); nine male and eight female paratypes at Penuela (July 10, 1941, C. H. Seevers); one male and one female paratype at Tezonapa (August 8, 1941, Henry Dybas). 
This very distinctive species, with clear-cut qualitatively different sexual characters, is a member of Group XIV by virtue of its tawny pubescence.

\section{Hamotus (Hamotoides) veracruzensis fletcheri new subspecies (PI. XVII)}

I have set aside the following Panamanian population as a subspecies of veracruzensis, although it may prove to have full specific rank. It agrees with veracruzensis save for the following: (1) Pubescence a darker brownish-yellow; (2) ninth antennal segment as wide as long; (3) tenth antennal segment as wide as long; (4) eleventh antennal segment relatively longer; (5) antennal club of same length but distinctly less asperate; (6) terminal tergite of male transversely subfusiform; (7) terminal tergite of female transversely subtrapezoidal.

The secondary sexual characters are the same and this appears to be an excellent opportunity to study the male copulatory apparatus of veracruzensis s.s. and of fletcheri for information on the specific value of the penis between two widely separated populations geographically, but with so many structural features in common. Such a study, involving other neotropical pselaphids, is now in progress.

This subspecies described on eighteen specimens collected by the author on the rain forest floor of Barro Colorado Island, Gatun Lake, Panama Canal Zone, as follows: one female paratype (July 1, 1936) in a termite gallery of a decayed log at Bang's Casa; one male paratype (July 1, 1936) in log mold at Bang's Casa; one male and two female paratypes in log mold at Zetek 3 (July 28, 1936); five male and eight female paratypes beneath loose bark at Zetek 15 (July 28, 1936). Named in honor of Frank C. Fletcher.

\section{Hamotus (Hamotoides) electrae new species}

Type Male. $2.3 \mathrm{~mm}$. long x $0.87 \mathrm{~mm}$. wide. Shining reddish-brown with the integument distinctly subasperately punctate and the antennal club granulate. Pubescence bright yellow-gold, long, semibristling and abundant. Head as in veracruzensis save that the eyes have about 38 even coarser facets and the clypeus is roughly asperate. (Pl. XVII)

Antennae $0.94 \mathrm{~mm}$; I elongate-cylindrical; II subquadrate; III as long as second but narrower, obconical; IV and V subequal, quadrate-moniliform, as wide as third; VI and VII transverse-moniliform, as wide as fifth but shorter; VIII very slightly wider than seventh, of same length, subtrapezoidal; distinct club of last three segments; IX as wide as long, trapezoidal; $\mathrm{X}$ slightly longer than ninth, trapezoidal, slightly longer than wide; XI as long as preceding two united, granulo-asperate as usual, with the poroid tubercle of apicointernal area well-developed. Last two segments not toothed.

Pronotum as in veracruzensis save that the median pronotal fovea is very large, deep, cleanly cut and conspicuous, slightly larger than in monachus and about five times larger than in veracruzensis. 
Elytra as in veracruzensis.

Tergites margined as usual, in a length ratio of 3.5/3.5/2.5/2.5/2 with the last tergite rounded-triangular.

Sternites in a length ratio of $1.5 / 2.5 / 2 / 1.5 / 1 / 1.5$ with the last five much more concave medianly to form an elongate-oval depression. The sixth sternite is notably large, trapezoidal, coarsely punctate and deeply depressed medianly. The penis is partially extruded so that the sex of the type is verifiable.

Metasternum, coxal separation and legs as in veracruzensis save that the anterior trochanters are not toothed but instead the ventral face is compressed into a longitudinal blackened carina.

Described from a single male specimen from San Juan, Vera Cruz, Mexico, collected by C. H. Seevers on July 13, 1941.

In the Raffray 1904 key this species becomes associated with sanguinipes Raffray of French Guiana, with which it has little affinity save common position in Group XII.

\section{Hamotus (Hamotoides) thomasi new species}

Type. Measurements: $2.11 \mathrm{~mm}$. long x $0.80 \mathrm{~mm}$. wide. Shining reddishbrown; pubescence and punctation as in electrae. (Pl. VI, XVII)

Head as in electrae save that the eyes have about 34 facets each and are distinctly hirsute; median cephalic fovea more distinctly pubescent and with the lumen obliquely dorsal, rather than apical as in veracruzensis.

Antennae with segment I elongate-cylindrical; II subquadrate; III shorter and narrower, longer than wide, obconical; IV-VIII as in electrae; club wellformed: granulate-asperate as usual with IX trapezoidal, longer than wide; $\mathrm{X}$ trapezoidal, wider than ninth and wider than long; XI as long as the two preceding united, distinctly flattened so that the dorso-ventral diameter is much greater than the latero-mesial diameter, and with the poroid tubercle of its apico-mesial face well developed.

Pronotum as in veracruzensis with a very small median fovea not much larger than the transverse sulcus, but with the latter almost straight in the median third of its course instead of sharply arcuate as in veracruzensis.

Elytra as in veracruzensis.

Abdomen with five visible tergites in a length ratio of 4/4/2.8/2.2/2 of which the first three are margined as usual and the last tergite is transversely trapezoidal.

Six sternites in a length ratio of $1.5 / 2.5 / 2.5 / 1.8 / 1 / .5$ with the sternites deeply separated, convex antero-posteriorly and slightly flattened medianly. Metasternum as usual. Legs simple; trochanters simple, posterior tibiae not spurred.

The sex of the single specimen is unknown. It was collected from log mold by C. H. Seevers on August 1, 1938 near Puerto Salgar, Cundinamarca, Colombia. This species is a member of Group XIV, and within this assemblage 
is distinctive in having the combination of elongate ninth and transverse tenth antennomeres and golden pubescence. Named in honor of my brother.

The species of Hamotus may be listed as follows:

\section{Subgenus Hamotus s.s. (Aube, 1844)}

argentinus Raffray. 1908. Buenos Aires, Argentina.

badius Schaufuss. 1887. Colombia.

boliviensis Raffray. 1904. Yuracaris, Bolivia.

gracilicornis Reitter. 1882. Blumenau, Brazil; Colombia.

grandipalpis Sharp. 1887. Volcan de Chiriqui (2000-3000 feet), Panama.

iheringi Raffray. 1911. Sao Paulo, Brazil.

rostratus Sharp. 1887. Bugaba, Panama.

sternalis Raffray. 1904. Yuracaris, Bolivia.

\section{II}

parviceps Reitter. 1888. Blumenau, Brazil.

subtilis Schaufuss. 1887. Minas Geraes, Brazil.

\section{III}

appendicularis Schaufuss. 1887. Brazil.

aubeanus Reitter. 1882. Brazil.

globulifer Raffray. 1904. Brazil.

inaequalis Reitter. 1882. Petropolis and Blumenau, Brazil.

\section{IV}

auricapillus Reitter. 1882. Tovar Colony, Venezuela.

barbatus Schaufuss. 1887. Colombia; San Esteban, Venezuela.

brunneus Schaufuss. 1887. Colombia.

bryaxoides Aube. 1844. Caracas and San Esteban, Venezuela;

Colombia; Bahia, Brazil.

(subpunctatus Reitter, 1882)

bulbifer Raffray. 1904. Colombia.

clavicornis Reitter. 1882. Venezuela.

claviger Schaufuss. 1887. Colombia.

deplanatus Raffray. 1909. Serra de Baturite, Ceara, Brazil.

frontalis Reitter. 1882. Venezuela.

furcifer Schaufuss. 1887. Brazil.

globifer Reitter. 1882. Venezuela.

inflatus Raffray. 1891. San Esteban, Venezuela.

punctipennis Raffray. 1904. Colombia.

robustus Schaufuss. 1887. Caracas, Venezuela; Colombia.

(frater Schaufuss, 1887 and bryaxoides

Schaufuss, 1887 nec Aube, 1844) 
sandersoni new species. Panama Canal Zone.

tibialis Raffray. 1904. Mexico.

transversalis Reitter. 1882. Colombia.

turalbus Park. 1935. Turrialba, Costa Rica.

vesiculifer Raffray. 1891. Cumana, Venezuela.

crassipalpus Raffray. 1891. Tovar Colony, Venezuela.

fuscopilosus Reitter. 1888. Tambillo, Ecuador.

gracilipes Reitter. 1888. Blumenau, Brazil.

(brevicornis Reitter, 1888)

(or reversed synonomy?)

impunctatus Reitter. 1888. Blumenau, Brazil.

laetus Raffray. 1904. Paraguay (central area).

\section{VI}

cavicornis Raffray. 1904. Guatemala.

\section{VII}

rugosus Raffray. 1904. Yuracaris, Bolivia.

\section{VIII}

bicolor Raffray. 1904. Yuracaris, Bolivia. castanalus new species. Panama Canal Zone. cavipalpus Raffray. 1891. Caracas and San Esteban, Venezuela. fauveli Raffray. 1904. Yuracaris, Bolivia. grouvellei Raffray. 1904. Bahia, Brazil. parvipalpis Sharp. 1887. Bugaba and Volcan de Chiriqui (2500 to 4000 feet), Panama.

sulcipalpus Raffray. 1904. Yuracaris, Bolivia.

\section{IX}

aztekus new species. Vera Cruz, Mexico.

brevimarginatus Schaufuss. 1887. Pozuzu, Peru.

centralis Reitter. 1888. Blumenau, Brazil.

costaricensis new species. Turrialba, Costa Rica.

setipes Sharp. 1887. Bugaba ( 800 to 1500 feet), and Volcan de

Chiriqui (2000 to 4000 feet), Panama.

simplex Raffray. 1904. Theresopolis, Brazil.

singularis Reitter. 1882. Mexico. Sharp (1887): Cordoba, Vera

Cruz, Mexico; Guatemala; Panama.

soror Raffray. 1904. Caracas, Venezuela. 
ursulus Schaufuss. 1887. This was described from Mexico without a definite locality. I am glad to be able to extend the range. I have a series from Tezonapa and Penuela, Vera Cruz.

vulpinus Reitter. 1888. Blumenau, Brazil.

\section{$\mathrm{X}$}

decipiens Raffray. 1904. Colombia.

lateritius Aube. 1844. GENOTYPE. Venezuela; Colombia.

(tenuicornis Reitter, 1882 cf. Raffray, 1891)

XI

alleei new species. Panama Canal Zone.

longepilosus Raffray. 1904. Yuracaris, Bolivia. I have this species from Coroico, Bolivia.

longiceps Raffray. 1904. Minas Geraes, Brazil.

micans Reitter. 1882. Venezuela; Colombia.

Subgenus Hamotoides (Schaufuss, 1887)

XII

appendiculatus Reitter. 1888. Blumenau, Brazil.

difficilis Sharp. 1887. Zapote, Guatemala.

electrae new species. Vera Cruz, Mexico.

emeryi Wasmann. 1894. Joinville, Brazil.

monachus Reitter. 1882. One of the better known species.

Described from Yucatan, Mexico. Sharp (1887)

lists it from El Reposo and Zapote, Guatemala, and Park (1935) lists it from Turrialba, Costa Rica.

nodicollis Raffray. 1883. Mexico.

pubiventris Sharp. 1887. Chontales, Nicaragua.

sanguinipes Schaufuss. 1887. Cayenne, French Guiana. (sanguinifer of Raffray, 1904; sanguinipes in Raffray, 1908) vicinus Sharp. 1887. Capetillo, Guatemala.

\section{XIII}

nigropilosus Raffray. 1904. Para, Brazil.

tritomus Reitter. 1882. This is a widely distributed species. Described from Colombia; Sharp (1887) records it from Mexico (Jalapa?); El Reposo, Zapote, San Isidro, Cahabon, San Juan in Vera Paz, Teleman, Panzos and La Tinta, Guatemala; Granada and Chontales, Nicaragua; Bugaba, Volcan de Chiriqui, David, Panama. 


\section{XIV}

bellus (Shaufuss). 1886. (Phamisulus). Sao Paulo and Matto Grosso, Brazil; Paraguay (central area). Raffray (1908) lists it also from Pernambuco and Para, Brazil.

commodus Schaufuss. 1879. Yucatan, Mexico. Teapa, Tabasco, Mexico. ecitophilus Raffray. 1909. Largest pselaphid reported to my knowlledge. San Jose dos Campos, Brazil. con Eciton. favopilosus Raffray. 1891. San Esteban, Venezuela. hilaris Schaufuss. 1887. Colombia.

hirtus Raffray. 1904. Only Antillean member of the genus so far reported. Described on the female from Grenada, Windward Islands. Raffray (1908) described the male and reported the species from St. Vincent, Windward Islands and Guadeloupe, Leeward Islands.

punctulatus Raffray. 1912. Argentina. reichei Raffray. 1891. Cumana, Venezuela. rossii Raffray. 1917. Asuncion, Paraguay. thomasi new species. Puerto Salgar, Cundinamarca, Colombia. suturalis Schaufuss. 1879. Yucatan and Teapa, Tabasco, Mexico. veracruzensis new species. Vera Cruz, Mexico. veracruzensis fletcheri new subspecies. Panama Canal Zone.

\section{APLODERINA (Raffray, 1904)}

This is a monotypic Bolivian genus closely allied to Hamotoides. Its distinction lies in a perfectly globular third palpomere and a remarkably developed male antennal club. The illustrations serve to isolate this hamotine better than verbal description ( $\mathrm{Pl} . \mathrm{XX})$.

sulcicornis Raffray. 1904. Yuracaris, Bolivia. Genotype.

\section{PHAMISULUS (Reitter, 1888)}

This is a monotypic Brazilian genus, also closely allied to Hamotoides. The last (fourth) segment of the maxillary palpi is elongate-conical, very acuminate at apex, and with the internal face entirely sulcate. It is readily distinguished by the increasing length of the first three visible tergites.

The complex taxonomic history of this genus is cited by Raffray (1908, p. 401).

horroris (Schaufuss). 1886. Brazil. Genotype. (Phamisus Schaufuss, nec Aube). (Neophamisus hetschkoi Reitter, 1888). 
HAMOTOCELLUS (Raffray, 1911)

This is a monotypic Brazilian genus with no close allies in the Tyrini. Raffray in erecting the genus places it near Phamisulus, but there is little qualitative affinity. The maxillary palpi are four-segmented with the first segment minute; second elongate-sinuate and subcylindrical; third short, triangular; fourth very long, subfusiform with an acuminate apex and the internal face entirely sulcate ( $\mathrm{Pl}$. XX).

The head is unique among neotropical tyrines, being wholly devoid of a common antennal tubercle. The front is perfectly truncate and rectilinear, with an antenna distantly articulated at each apico-lateral angle.

Pronotum with disc moderately gibbous, laterally the contour is concave to give a modified cordate outline; there is no median antebasal fovea, and on each side is a sinuation in which lies the lateral fovea; lateral foveae connected by a transverse antebasal sulcus which is medianly expanded.

Each elytron is subtriangular, without any striae or foveae.

The abdomen is very similar to Phamisulus, broad, tapering rapidly, first three tergites however subequal to slightly decreasing in length, but with a strong, high and narrow margin on the first three visible tergites.

Cinnamon red with short, abundant, rigid, obtuse setae. Length given as four millimeters so that it ranks as one of our large pselaphids.

hirsutus Raffray. 1911. Sao Paulo, Brazil. Genotype.

\section{CERCOCEROPSIS (Raffray, 1904)}

At present there are only two species in this genus, occupying a relatively restricted area of the neotropical region-the Matto Grosso swamp of southwestern Brazil, southwards into the Paraguay river drainage to Asuncion, Paraguay.

In general organization the genus is a specialization of the hamotine plan, especially the antennae, head, pronotum, and elytra suggest Hamotus s.s. while the very elongate first visible tergite suggests Apharus as noted by Raffray (1904), this segment being longer than the other four tergites united. The maxillary palpi are well-developed and indicate parallelism or affinity with Cercoceroides.

The maxillary palpi have the first segment very small as usual in the tribe; second segment elongate, slender basally and apically gradually inflated to a rounded apex; third segment short, triangular, slightly longer than wide, the apex of this triangle inserting into the second, and the base of the triangle articulating with the fourth, segment; fourth (distal) segment very elongate, subfiliform or narrowly subfusiform, subcylindrical, with both base and apex subacuminate, and the internal face entirely but narrowly sulcate, with the usual oblique palpal cone set near apex within the sulcus (Pl. XX).

The species may be separated as follows:

Third palpomere regularly obconical, as long as wide; fourth palpomere regularly fusiform, slender; $1.6-1.8 \mathrm{~mm}$.; Brazil.... longipes 
Third palpomere much longer than wide, gradually wider to apex which is obliquely truncate; fourth palpomere not so regularly symmetrical, slightly cultriform or knife-shaped, with external face subrectilinear, internal face suboblique and slightly thicker at obtuse basal angle; $1.54 \mathrm{~mm}$. Paraguay.................rugicornis

longipes Raffray. 1904. Matto Grosso, Brazil. Genotype. rugicornis Raffray. 1917. Asuncion, Paraguay.

\section{CERCOCEROIDES (Raffray, 1896)}

This genus at present holds six species, all residents of the South American rain forest, with the swampy jungle of Matto Grosso appearing to be the center of dispersal with four species.

It is hamotine in form, allied to the subgenus Hamotus in major structural features of head, pronotum, elytra, and tergites. The maxillary palpi are remarkably similar to Cercoceropsis, while the metasternum is diversely tuberculate in the male sex and this latter character is fully utilized in the following key to species:

Metasternum with at least one pair of recurved or otherwise modified tubercles, and the metasternum always medianly and longitudinally

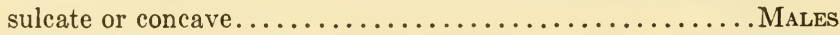

Metasternum not tuberculate.................... Females

2. Metasternum medianly, longitudinally impressed..............

Metasternum simple, slightly elevated and not longitudinally impressed; 2.4 mm........................ simplex Female

3. Known from Matto Grosso; $2.3 \mathrm{~mm} . . . \ldots \ldots \ldots$...... germaini Female

Known from Paraguay; $2.3 \mathrm{~mm}$; head larger and less narrowed anteriorly; eleventh antennomere of same length (as long as three preceding united in my material), but thicker and more rounded on external face; fourth palpomere longer and more slender.......... laticeps Female

4. III slightly obconical, slightly longer than wide; IV and V quadrate;

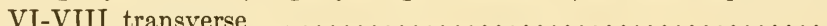

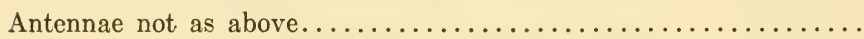

5. III, IV, V longer than wide; VI quadrate; VII and VIII transverse; metasternum very deeply and very broadly concave, with a very strong, acute, compressed and recurved tubercle adjacent to each posterior coxa; Venezuela; $2.6 \mathrm{~mm}$.............pectoralis MALE

Not known north of Paraguay river basin; III much longer than wide; IV-VII quadrate; VIII slightly transverse; metasternum broadly concave, with a microtubercle each side, this tubercle being acute, recurved or hook-shaped; $2.5 \mathrm{~mm} . . . . . . . .$. . tuberculatus MaLE

6. Metasternum medianly narrowly sulcate, with a strong hook-shaped process each side; sternites strongly impressed longitudinally; 2.3 mm. . . .............................maini MALE 
Metasternum broadly concave, with two pair of tubercles: one elongate, subcarinoid tubercle immediately anteromesiad of each posterior coxa and at the center of metasternal length a microtubercle which is sharply curved anteriorly; $2 \mathrm{~mm} . . . \ldots \ldots \ldots . . . . .$. sternalis MALE, new species

\section{Cercoceroides sternalis new species}

Type Male. $2.0 \mathrm{~mm}$. long x $0.94 \mathrm{~mm}$. wide. Dark reddish-brown with the elytra red and palpi and tarsi brownish-yellow. Integument shining, lightly punctulate. Pubescence long, thin, semi-bristling and shaggy (Pl. XX).

Generally hamotine in form with tempora shorter than the eyes; eyes large, convex, very prominent and each composed of about 46 facets which are coarse and convex. Occiput and posterior half of vertex strongly, evenly convex. A pair of large and deep vertexal foveae on a line through anterior third of eyes and each closer to an adjacent eye than to each other. Head subangulately narrowed anterior of eyes, then expanded to form the well-developed antennal tubercles. These latter separated by a deep longitudinal sulcus which arises on the interantennal line and ends in a median foveoid depression opposite posterior margins of antennal tubercles. Narrow front vertical to the subgranulate clypeus. Ventral surface of head in great contrast to rest of body-roughly granulate-punctate, with the usual gular fovea having alutaceous walls.

Maxillary palpi prominent; first segment short, obconic-cylindrical; second elongate-pedunculate for basal half, gradually inflated to rounded-oblique apex; third short, triangular, longer than wide, internal face acute, external face gently convex, with second and fourth segments articulating at each end of the external face; fourth very long $(0.3 \mathrm{~mm}$.), longer than second, very narrow (one-third wider than third), slightly wider at basal four-fifths, base and apex narrower, internal face entirely, narrowly sulcate, this sulcus bearing a palpal cone set obliquely below apex, and the sulcus basally sinuate.

Antennae I elongate-cylindrical; II smaller, slightly longer than wide; III slightly longer than wide, obconical; IV and V quadrate; VI-VIII progressively transverse; IX and X slightly transverse, trapezoidal, progressively larger; XI as long as the preceding three united but shorter than distal palpomere, subobconical with truncate base and rounded apex.

Pronotum with three large, free, pubescent, circular, antebasal foveae and simple convex disc.

Elytra each with two large pubescent, circular, basal foveae, the inner of which at base of a deep, entire, sutural stria and the outer at base of a welldeveloped dorsal impression half the elytral length.

Abdomen with five visible tergites in a length ratio of $5 / 4 / 2.5 / 2.5 / 2$ with first three margined as usual. Last tergite recessed beneath fourth, vertical, invisible from above, very convex or longitudinally tumid at middle.

Six sternites in a length ratio of $1 / 3 / 2 / .5 / .7 / 1$ with the second, third, and fourth attractively bicolored, their apical margins being bright yellow. These 
segments not longitudinally impressed as in germaini but very slightly flattened. Penis partially exserted to assure sex of type.

Metasternum $0.335 \mathrm{~mm}$. long, medianly broadly concave. Immediately antero-mesiad of each posterior coxa is an elongate subcarinoid tubercle, and in the exact center of the metasternal length, on each sloping wall of the concavity, is a minute hook-shaped process or an anteriorly directed microtubercle; apical margin medianly incised as usual to accommodate intercoxal tubercle of first sternite.

Legs simple save that the posterior tibiae are spurred. This spur arises quite basad of apex; for quite a distance the coarse setae emerge to give a straight, thick, very obliquely truncate bundle.

Described on a single male from Corumba, Matto Grosso, Brazil.

This new species has the antennae of germaini and the metasternal microtubercles of tuberculatus in addition to a pair of juxtacoxal tubercles. It is possible that the variation in antennomeres and male characters is great within the genus, in which case tuberculatus and sternalis may be varities of germaini, and simplex the female of one of these male variations. Such a condition is not probable. Study of antennomeres in Reichenbachia, Arthmius, and both subgenera of Hamotus suggest a genetic ratio between length and width of a segment in the same sex of a given species of pselaphid. That is, the third antennomere for example, if obconical will vary in length but is never wider than long; or if this segment is more or less transverse, it will vary in width but is never longer than wide. Such study requires long series of specimens. Since Cercoceroides is not common in collections, this approach must be delayed.

The species may be tabulated as follows:

germaini (Raffray). 1890. Matto Grosso, Brazil. Genotype. (Cercocerus)

laticeps Raffray. 1917. Asuncion, Paraguay. ${ }^{1}$

pectoralis Raffray. 1911. Merida, Los Andes, Venezuela.

simplex Raffray. 1904. Matto Grosso, Brazil.

sternalis new species. Corumba, Matto Grosso, Brazil.

tuberculatus Raffray. 1904. Matto Grosso, Brazil.

\section{PSEUDOHAMOTUS (Raffrey, 1890)}

This neotropical genus holds five species having many notable affinities with Hamotoides but distinctive in the form of the last segment of the maxillary palpi (Pl. XX).

This distal palpomere is more or less semicircular in outline, nearly as broad as long, with external face consequently very convex; the internal face is subrectilinear and bears an entire but very narrow sulcus; as usual in the hamotine stem, the palpal cone is obliquely inserted at the apex of this sulcus.

${ }^{1}$ I have recently received a female of this species from Horqueta, Paraguay, collected December, 1935, by A. Schulze. This checks with Raffray's description and has not since been reported. 
The species may be tentatively separated as follows:

First visible tergite shorter than second; $2.33 \mathrm{~mm}$.; known only from

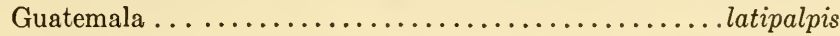

First two tergites subequal or first slightly longer than second; not

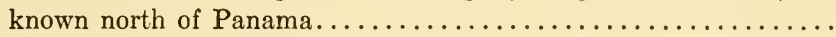

2. Known only from Panama; $2.33 \mathrm{~mm} . . \ldots \ldots \ldots \ldots \ldots$ curtipalpis

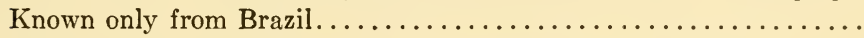

3. Antennomere VI quadrate, as long as wide; not more than $2.6 \mathrm{~mm}$. in

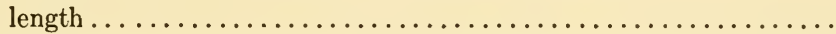

Antennomere VI regularly transverse, distinctly wider than long; 2.8

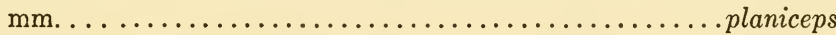

4. Antennomere III much longer than wide; antennal tubercles prominent, deeply separated and obviously constricted at base; $2.3-2.6$

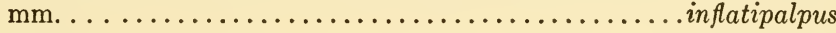

Antennomere III slightly longer than wide; antennal tubercles less

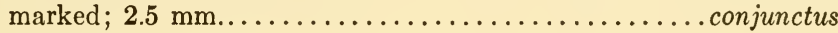

The species may be listed as follows:

conjunctus (Reitter). 1882. Petropolis, Rio de Janeiro, Brazil. (Hamotus) Genotype.

curtipalpis (Sharp). 1887. Bugaba, David, Panama. (Hamotus) inflatipalpus (Reitter). 1888. Blumenau, Brazil. (Hamotus) latipalpis (Sharp). 1887. Zapote, Guatemala. (Hamotus) planiceps Raffray. 1904. Brazil.

\section{PSELAPHOCOMPSUS (Raffray, 1908)}

This is an aberrant, monotypic Brazilian genus. Although erected in 1908 (p. 403), both genus and species were redescribed by Raffray in 1911 (pp. 447-449).

The maxillary palpi are unique among neotropical tyrines but are strikingly similar to these organs in Pseudophanias of the Indo-Malayan rain forest. The first segment is minute and inconspicuous as usual; second arcuate, very long and slender, becoming gradually wider to the rounded apex; third wider than long, slightly wider at apex than second, truncate at base and apex. Fourth onethird shorter than second, not much wider at base than third, then slightly broadening near base and then gradually narrowing to a long, acuminate apex; this gives a conical outline which is slightly sinuate internally near apex; the internal face bears a very slender, entire, slightly oblique palpal sulcus, with a very long apical palpal cone set within the sulcus. Raffray states that this palpal cone is one-third the segmental length ( $\mathrm{Pl}$. XX).

The infra-ocular spine is very strongly developed as a tubercle from the posterior genal angle to the middle of the eye, and suggests parallelism with some species of Neotyrus, Tyrogatunus, as well as non-neotropical genera as Tmesiphorus. The small size of the maxillary palpi and other features led 
Raffray to suggest some approach to Pseudotychus of South Africa and Eudranes of Australia. Finally the general form suggests the subgenus Hamotoides but the nonsulcate pronotum suggests Hamotus proper.

punctatus Raffray. 1908. Nouveau-Fribourg, Rio de Janeiro, Brazil. Genotype.

\section{CERCOCERULUS (Raffray, 1904)}

This is a monotypic Brazilian genus. Originally placed in Phalepsus, the genotype was removed by Raffray because of its large, equal tarsal claws. Structurally it shows many affinities with the subgenus Hamotus but is unique among neotropical tyrines on the basis of its maxillary palpi.

These organs are similar to those of the Australian Rytus. The large maxillary palpi have a minute first segment, which however, is slightly wider than the base of the second; second segment about three-fourths as long as fourth, slightly arcuate and very slender for basal two-thirds then inflated to the rounded apex; third obconical, longer than wide, less than one-third as long as fourth; fourth distinctively shaped, gourd-like, with a wide ovoidal basal half and a subulate spinoid apical half, with the internal face having a striaform longitudinal sulcus from near apex to middle of segment (Pl. XX).

hirsutus (Schaufuss). 1886. Amazon basin, Brazil. Genotype.

\section{TYROGATUNUS new genus}

This new genus is distinct from other Tyrini on the key characters previously given, but several morphological features necessitate further elaboration. The termitocolous members of Tyrogatunus have a novel eye structure, an unusual distal palpomere, and peculiar pubescence.

The eyes are slightly postmedian in position, reniform in lateral view as customary in the tribe, and are flanked with a strong infraocular spine; each eye is composed of about 62 facets. These facets are not uniform in size or shape. The dorsal third of each eye holds some 22 facets which are very flat, and significantly greater in diameter while the ventral two-thirds holds much smaller normally convex facets. This striking condition is found in both sexes (Pl. XVII, 1).

The pubescence is very long $(0.20 \mathrm{~mm}$.), moderately abundant (about 5 setae per 0.005 sq. mm.), bristling and golden. These setae are thin-shafted with the distal third to fourth excessively thin and tending to curl (Pl. III, 6) in various directions, so that from an optical view the setal tips present a variably developed mat.

The maxillary palpi ( $\mathrm{Pl} . \mathrm{XX})$ are large with the first three segments formed as in Tyropsis and Neotyrus in general and their detail can be seen in the illustrations. The fourth or distal palpomere is distinctive. It is long $(0.22 \mathrm{~mm}$.) and is a fusiform shape, with the base subpedunculate and the apex rounded. The unique feature is a longitudinal sulcus on the dorsal face, that is, when the specimen is seen from above the sulcus is in full view, the internal face being 
devoid of any trace of sulcation. Such a condition is nonhamotine on the one hand, and yet the presence of a sulcus is nonneotyrine so that this sulcus, alone, serves to isolate the genus. The sulcus is very broad and shallow, but the margins are sharply defined. The long, truncate palpal cone is set within the apex of the sulcus, which latter occupies the apical fourth of the segment. In a paratype the distal palpomere is coated with the pearly palpal secretion noted for other genera.

The males and females resemble each other in coxal spines, trochantal spines, and carinate anterior femora, reminding one of similar nonsexual leg abnormalities in Tyrus. Sex is quickly diagnosed by the shape of the terminal (sixth) sternite, which is a narrow, very short and simple segment in the female; in the male this sternite is deeply incised at the middle of the apical margin to accommodate a discoid penial plate, as in Tyrus. At first I thought that the female sex had the notched terminal sternite but subsequent dissection of a paratype demonstrated the sex and served to impress the author with the necessity for such direct methods.

\section{Tyrogatunus zeteki new species}

Holotype Male. Measurements: Head 0.47 x $0.43 \mathrm{~mm}$.; pronotum 0.50 x $0.50 \mathrm{~mm}$.; elytra $0.67 \times 0.94 \mathrm{~mm}$.; abdomen $0.63 \times 0.97 \mathrm{~mm}$. Total length (including cervicum) $2.4 \mathrm{~mm}$. (Pl. III, XVII, XX).

Dark reddish-brown, shining and lightly punctulate with the elytra slightly more punctate. Pubescence as described above.

Head with long oblique tempora which are longer than the eyes. Eyes as described above. Vertex smoothly rounded, with a pair of small, deep, nude fovea on a line through eye centers, and slightly closer to eyes than to each other. Each fovea lies in a depression and the latter is faintly connected with the frontal fovea by a rudimentary, oblique impression. Frontal fovea is larger, pubescent, and occupies the apex of a triangular interantennal sulcus. The antennal tubercles, therefore, are oblique. Below each eye is a broad, triangular infraocular spine. The ventral surface of the head is simply flattened, with the usual median gular fovea at middle of base.

Maxillary palpi as described above.

Antennae half the body length $(1.27 \mathrm{~mm}$.) slender: segment I elongatecylindrical; II smaller, similar; III-VIII obconical, third to sixth longer than wide, seventh and eighth as long as wide; club poorly differentiated and progressively asperate, with IX longer than wide, elongate-trapezoidal; $\mathrm{X}$ as long as wide, trapezoidal; XI not as long as preceding two united, with rounded apex and truncate base.

Pronotum with the hexagonal outline of Neotyrus coptocolus; disc evenly convex; a large pubescent lateral fovea each side and a smaller nude median fovea, these three foveae being connected by an arcuate antebasal sulcus; basal bead medianly extended as a longitudinal cuneiform carina which reaches lumen of median fovea. 
Elytra with obtuse humeri. Each elytron with two large, circular, pubescent basal foveae, an entire sutural stria and a long dorsal stria, at bottom of dorsal impression, which extends beyond the middle of elytral length.

Abdomen with five visible tergites in a length ratio of $7 / 2.5 / 1.5 / 1 / 2$ with first three margined as usual.

Six sternites with proportions and shape as illustrated. The sixth sternite is deeply incised at middle of apical margin to hold a discoid penial plate.

Metasternum deeply, broadly sulcate with each sulcal wall forming a prominent tumidity.

Anterior legs: trochanter with a short, stout triangular tooth at apex of ventral face; femur with a sharp, high longitudinal carina which occupies the median half of the ventral face; tibia arcuate.

Intermediate legs: coxa with a densely setose spinoid tubercle at ventroposterior face; trochanter with a very long, thin spine at apex of ventral face; tibia arcuate.

Legs otherwise simple and normal for tribe, with the tarsi having two large, arcuate, equal tarsal claws.

Allotype Female. Similar to holotype save that (1) the abdomen is slightly broader and shorter; (2) elytra more punctate; (3) sternite ratio differing, as illustrated, with the terminal (sixth) sternite short and simple.

Erected on three specimens collected from nest or galleries of the termite, Coptotermes niger Snyder, on Barro Colorado Island, Panama Canal Zone. Holotype and allotype collected by the author at Armour 7 (July 6, 1936) and paratype female collected by Alfred Emerson on September 6, 1935. Named for my friend James Zetek, resident custodian of the B.C.I. laboratory.

In closing this section on neotropical Tyrini the author is tempted to write a few words regarding the maxillary palpi as indicators of speciation. This is done in full recognition of the possibility that structural features of the oral and tarsal areas may not be the best regions for this purpose, and also that one structure is necessarily limited in its bearing. On the other hand these palpi offer such a range of generically limited characters that proper examination must have some value.

There appear to be two basic types of neotropical maxillary palpi in the Tyrini ( $\mathrm{Pl} . \mathrm{XX})$ : the tyrine type in which the second and third palpomeres are similar in shape, pedunculate, with the fourth or distal segment subfusiform and nonsulcate; and the hamotine type in which the third palpomere is short, triangular and the distal segment is obliquely truncate at base and with a longitudinal sulcus on the internal face. In the former case the palpal cone is more or less apical and inserted in a variably developed apical truncature. In the latter case the palpal cone is set very obliquely within the apex of the palpal sulcus. Virtually all palpomeres vary among the genera, and within generic limits there is considerable variation among the species. Few and minor are the sexual variations of the palpi, and within the species population there is no significant variation. 
In general the first two palpomeres are relatively stable, the first usually very short, cylindrical, and inconspicuous; the second very long, more or less arcuate, slender basally and more or less inflated apically. The third shows much more variation, being arcuate-pedunculate, obconical, triangular, or spherical. The fourth varies the most, being one of the most labile regions of the tyrine body, as may be seen in the illustrations. Thus we find that in both the tyrine and hamotine types, the degree of variation is in direct proportion to the distality of the palpomere.

Under the dissecting binoculars I have observed pselaphids feeding upon oribatid mites and small staphylinid larvae, as well as the larval and pupal brood of host ants, and in these cases the maxillary palpi were continually in use, being twirled about and especially the distal palpomere being used to rapidly, lightly touch the food in a continuous tapping. Such exploratory behavior suggests a sensory function, and the demonstrable secretion of the distal palpomere of many tyrines supports this view. Real progress would be achieved by making a study of serial sections of these organs.

I regard the tyrine type of palpus as primitive and the hamotine type as highly derived. Thus if we assume a fusiform distal palpomere with a simple, acute apex as a hypothetical basis for evolution, the neotropical genera may be arranged as follows:

\section{A. Development of the tyrine type.}

1. Phalepsus with a very primitive, fusiform distal palpomere.

2. Development of three tyrine modifications of the distal palpomere, but with the first three palpomeres primitive:

a. Lethenomus in which the fusiformity is lost and the segment becomes obconical-pyriform and the internal face, near the apex, becomes pointed and pubescent.

b. Tyropsis, Neotyrus, Tyrogatunus in which the apex becomes more or less truncate, with an apical palpal cone set within the truncature in the first two genera, and secondly this truncature moves basad over the dorsal face to form a sulcus in the last genus.

c. Juxtahamotopsis with the shortening of the third and fourth segments, and the development of many subpalpal cones.

These three lines are quite unrelated to each other.

\section{B. Development of the hamotine type.}

This appears most feasible from the lower end of $2 \mathrm{~b}$ (Neotyrus-Tyropsis stock), in which certain tendencies are assumed: the shortening of the long axis of the third palpomere from elongate-pedunculate to triangular; second, loss of fusiformity of the fourth palpomere which involves increasing width and increasing basal obliquity; third, the apical truncature of fourth palpomere moves basad over the internal face to form a longitudinal sulcus; fourth, as the sulcus 
develops, the terminal cone is pulled basad so that it becomes obliquely set within the apex of the sulcus.

Several lines of development are possible:

a. The main line would appear to include Apharus (with the sulcus limited to the apical half), Hamotus s.s. (with the sulcus gradually lengthening, but varying from short in which only the apical two-thirds of the segment are sulcate, through a sulcus four-fifths segmental length, to entire in which the sulcus divides the oblique basal margin and therefore radically alters the internal face since the basal margin is now continuous with the sulcal margin), Hamotoides (in which the tendency is for an entire sulcus of narrowing width). At this point there appears to be a basic divergence in length-width ratio of the segment:

b. The fourth palpomere becomes very wide in proportion to its length, as in Pseudohamotus with a very narrow, entire sulcus and a semicircular outline.

c. The fourth palpomere becomes very narrow in proportion to its length, also with a narrowing of the entire sulcus: Hamotocellus, Cercoceroides, Cercoceropsis.

d. An aberrant line shows the palpal sulcus narrowed to striaform proportions, and the distal palpomere becoming very narrow apically: Pselaphocompsus, Cercocerulus.

e. Another line would seem to diverge from $\mathrm{Ba}$, in which the third palpomere is spherical, and the simply ovoidal fourth palpomere is entirely sulcate. The base of this segment is simple, and the sulcus is broad and fusiform. Such a condition is approached by Aploderina.

This system is but one of many possible. It should be integrated with the tergite ratio, cephalic sutures, and sternal foveae as well as the pronotal sulcus and elytral striae-costae complex.

Of these structural criteria I should regard the sternal foveae, and especially the male copulatory apparatus as basic. These require prepared slides and are being studied at the present time. 


\section{Tribe 15. Arhytodini}

This is a monogeneric tribe of eleven species confined to South America. Structurally it is of great importance as the following points will demonstrate.

The body is elongate, ovoidal, with the abdomen broad, and the body dorsoventrally flattened. The pubescence is of two types: the general body setae are moderately elongate, arcuate, and more or less sparse and semierect; in addition foveae, sulci, many sutures and other areas, as described later, are filled with very short, appressed, matted scales which have a surgary appearance and make a direct approach to the Ctenistini.

Head elongate, flattened, with clearly marked antennal tubereles which are separated by a short frontal sulcus; the vertex bears a $Y$ or $V$-shaped sulcus; postmedian eyes of large facets. The antennae are eleven-segmented, with the last three antennomeres forming a poorly marked club. The shape and size of the antennomeres offers an excellent separation of the species.

The mouth-parts are peculiar. The large submentum-mentum is nearly vertical, almost wholly covering the oral aperture. The maxillary palpi are minute, apparently of one segment which is thin, pedunculate, basally arcuate, apically inflated to present a rounded apex holding a terminal seta. This latter may be the homologue of the palpal cone of other tribes. The mandibles are well-developed, elongate, with four or five teeth. The labrum is excessively transverse and short as a rule. Thus the rudimentary maxillary palpi and the occluding mentum form a direct approach to the rudimentary mouth-parts of Clavigerinae, while the long and narrow, but well-toothed mandibles, suggest the primitive predaceous habit of the family. Since at least one species is known to be myrmecophilous we may have here a group of species well on the road to social parasitism, in which case the obviously primitive (mandibles), and highly specialized (mentum, labium, maxillae, and associated palpi) mouth-parts are nicely balanced.

Pronotum usually wider than long, with the disc usually longitudinally gibbous and subcarinoid as in some Euplectini and Batrisini; antebasal, strongly biarcuate to $\mathrm{V}$-shaped sulcus present.

Elytra with two basal foveae, and several striae some of which vary in length among the species.

Abdomen with wide, flattened margins; five visible tergites and six sternites. Tergites often gibbous or diversely tuberculate.

Metasternum more or less longitudinally sulcate. Anterior femora with the antero-ventral face more or less carinoid and produced, especially in the male sex. The long, slender, typically macrosceline legs have tarsi which are unique in the Pselaphidae. The three-segmented tarsi have a short first tarsomere; second much longer, thick, arcuate-obconical, with the apical face very oblique, as is the first segment, and ventrally bilobed; third tarsomere short, conical, 
articulated deeply into the oblique apex of second, between the two lobes and bears a single, very large, arcuate and sharp claw.

From this resumé it will be seen that Arhytodini offer affinities with Ctenistini in pubescence, and Clavigerinae in oral structure, but have unique tarsi.

I have expanded and modified the 1909 key of Raffray to include later species:

\section{ARHYTODES (Reitter 1881)}

\section{REITter (1881)}

RAFFray $(1890,1891,1904,1909)$

The genus is sufficiently summarized above. The species may be separated as follows:

Dorsal striae of elytra entire; disc of pronotum more or less longitudi-

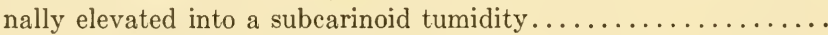

Dorsal elytral striae either absent, or if present not beyond the middle

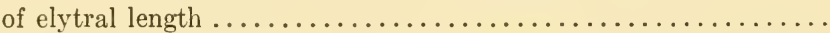

2. Antennomeres II, III, IV, V, and VII transverse; VI and VIII elongate; $2.7 \mathrm{~mm}$. long; Argentina...............myrmecophilus

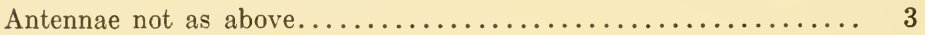

3. Antennomere III quadrate, as wide as long.............. 4

Antennomere III elongate, longer than wide............... 5

4. IV three times longer than wide; V quadrate; VI three times longer than wide; VII quadrate; VIII three times longer than wide; Brazil; $1.9 \mathrm{~mm}$. long. .............................. IV-XI all longer than wide.....................

5. IV transverse; V-XI elongate; Brazil...............brevicornis

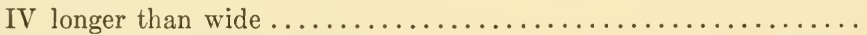

6. All antennomeres cylindrical; dorsal elytral stria geminate or paired only at base; Brazil; $2 \mathrm{~mm}$. long................. vestitus VIII, IX, and X obconical; dorsal elytral stria geminate for the entire

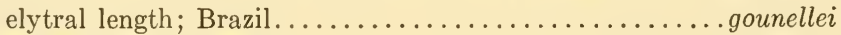

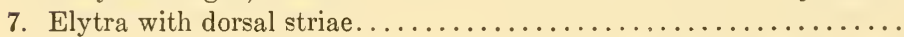

Elytra with no dorsal striae; pronotum with disc simply convex, not longitudinally gibbous; tergites not medianly gibbous; antennae very long, nearly as long as body: I large and cylindrical; II quadrate; III, IV, V, and VII slightly, VI and VIII twice as long, as wide; Argentina .............................. bruchi

8. Dorsal elytral stria geminate and extending for half the elytral length; antennomere II quadrate; III-VIII about twice as long as wide; IX and $\mathrm{X}$ three times as long as wide; tergites weakly gibbous medianly; pronotal disc strongly longitudinally carinoid; Brazil... semisulcatus

Dorsal elytral stria very short, not extending to middle of disc...... 
9. Known only from Bolivia; MALE with II quadrate, III-VIII gradually

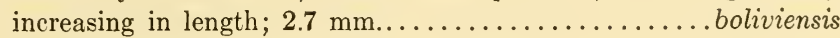

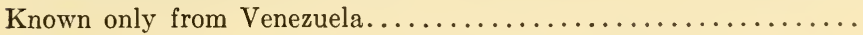

10. VI and VIII nearly two times longer than wide, IX and X nearly four times longer than wide in the MALE; antennomeres much shorter with IX and $\mathrm{X}$ only three times longer than wide in the Female;

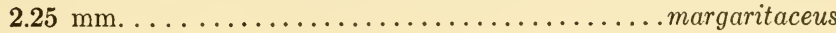

VI and VIII nearly two times longer than wide, IX and X about three times longer than wide in the MALE; VI and VIII slightly longer than wide, IX and $\mathrm{X}$ about two times longer than wide in the Female; 2.25 mm........................ rubripennis

\section{Arhytodes achillei new species}

Type. Measurements: head $0.49 \times 0.45 \mathrm{~mm}$.; pronotum $0.43 \times 0.52 \mathrm{~mm}$.; elytra $0.74 \times 0.94 \mathrm{~mm}$; abdomen $0.67 \times 1.07 \mathrm{~mm}$. Total length $2.33 \mathrm{~mm}$. (PI. VI, XIX)

Shining reddish-brown; antennae and legs densely granulate-punctate; vertex and front sparsely, coarsely granulate; pronotum sparsely asperate-punctate; elytra subglabrous; abdomen very sparsely asperate-punctate. Pubescence as described above, with body setae golden and squamose setae white.

Head with straight, oblique tempora nearly as long as eyes and meeting the occiput at nearly a right angle; occipital margin deeply, semi-circularly incised for median half of width. Vertex with sides subparallel and subcarinoid from posterior angles to middle of eyes; vertex flat, with a broad, squamose $V$-shaped sulcus, from occipital incisure one arm of this sulcus passes obliquely anteriad, filling the space between eye and antennal tubercle. Eyes postmedian, prominent, each composed of 26 very convex facets. The ovoidal eye does not have the facets in rows but irregularly placed and in the type before me, the facets are oddly bicolored, with the pigment sharply concentrated distad and the lower two-thirds of the facets a translucent amber. Antennal tubercles separated by a broad, short, squamose frontal sulcus, which does not extend posteriorly to join the V-shaped vertexal sulcus. Mouth-parts as described above. Ventral surface of head flattened, with a large triangular squamose patch each side. Cervicum alutaceous.

Antennae long $(1.87 \mathrm{~mm}$.) reaching well beyond posterior elytral margin; segment I elongate cylindrical, about three times longer than wide; II slightly longer than wide, narrower than first; III very short and quadrate; IV-VI elongate-cylindrical, fourth one-third longer than third segment, fourth to sixth progressively greatly increasing in length; VII elongate-cylindrical, subequal to fourth; VIII elongate-cylindrical, subequal to sixth. These first eight are all longer than wide, save for the quadrate third antennomere, and measure 1.07 $\mathrm{mm}$. united. Club of last three segments measures $0.80 \mathrm{~mm}$. united; IX elongatecylindrical, slightly longer than first, about as wide as first, two times longer than eighth; X subobconical, longer than ninth; XI as long as eighth, slightly 
wider than first, slightly longer than wide, with truncate base and rounded apex.

Pronotum with disc longitudinally gibbous and subcarinoid; base with a broad, squamose, biarcuate, V-shaped sulcus.

Elytra with oblique humeri. Each elytron with two squamose basal foveae, an entire sutural stria, two entire dorsal striae, and a short humeral stria; arising between the basal foveae is an entire, wide, flat costa which is limited each side by an entire dorsal stria so that the elytral disc has one costa and two intervals; the outer interval is incomplete externally since the short humeral stria is obsolete beyond the humeral elevation; the inner interval is complete being bounded by the inner of the two dorsal striae and the sutural stria.

Abdomen with five visible tergites in a length ratio of $3.5 / 3 / 2.5 / 1.5 / 2$ with the first three having wide, flat margins. The tergites are simple, not medianly gibbous and without tubercles. Base of first and elytral margin, as well as lateral articulations of first-second and second-third tergites, densely squamose.

Six sternites in a length ratio of $2 / 3 / 2 / 1.5 / .5 / 1$ with sternites well separated. First wholly, and lateral articulations of second-third and third-fourth sternites, densely squamose.

Metasternum $0.335 \mathrm{~mm}$. long, medianly sulcate, sulcal walls tumid. All sternal foveae, the prosternum, the mesosternum, and lateral sternal sclerites squamose. Intermediate coxae separated by one-fifth, and posterior coxae separated by two-fifths, of the median metasternal length.

Legs very long and slender, with the tarsi as described for tribe. The anterior femora are modified: each femur has the basal third of the anterior face semi-circularly produced into a carinoid and stiffly setose lamina.

Described from a single specimen from Corumba, Matto Grosso, Brazil. The sex is probably male. This distinctive species is named in honor of the great French expert, Achille Raffray.

Achille $i$ belongs in the first section of the genus by virtue of its entire dorsal elytral striae, but has few affinities with the species of the genus. The subcarinoid pronotal disc, strial elytral pattern, simple tergites and antennomere proportions at once separate it from others in the genus. To the author's mind it most closely approaches gounellei of Brazil but the antennae of these two species are very different, as well as the tergites. Thus gounellei has antennomere III, IV, and V only slightly longer than wide, and VI twice as long as wide; achillei has III quadrate, IV, V, and VI rapidly increasing in length. Gounellei has the tergites obtusely gibbous medianly, and provided with three bundles of scales; achillei has simple tergites.

The species may be listed as follows:

achillei new species. Corumba, Matto Grosso, Brazil.

boliviensis Raffray. 1904. Yuracaris, Bolivia.

brevicornis Raffray. 1904. Minas Geraes, Brazil.

bruchi Raffray. 1908. Argentina.

gounellei Raffray. 1909. Rio de Janeiro, Brazil.

margaritaceus Raffray. 1891. San Esteban, Venezuela 
myrmecophilus Bruch. 1918. Cordoba, Argentina. Con Wasmannia auropunctata australis Em.

oberthüri Raffray. 1891. Cavallo Cocho, Amazonas, Brazil.

rubripennis Raffray. 1891. Caracas and San Esteban, Venezuela.

semisulcatus Raffray. 1909. Ceara, Sierra de Baturite, Brazil.

vestitus (Westwood). 1870. Genotype. Brazil: Petropolis, Theresopolis, Blumenau, Nouveau-Fribourg (?Novo-Riborgo), and Rio de Janeiro. 


\section{Tribe 16. Attapseniini}

This is a recently recognized, monogeneric, wholly myrmecophilous tribe. At present it holds two species, one from Brazil and one from Argentina. Since both species are adjusted to the society of leaf-cutting ants (Atta sexdens L.) there is the possibility that the exact ecology of these species can be worked out, and also that additional species can be discovered with other kinds of leafcutting ants.

The chief structural points may be summarized as follows:

Head subhexagonal with short, oblique tempora; eyes large, reniform in lateral view, composed of large facets; vertex with the usual pair of vertexal foveae; a short antennal tubercle on each side of the narrowed front. In the genotype the front is sharply, longitudinally bicarinate from the vertexal foveae to the antennal tubercles, with the intervening space between the carinae sulcoid.

Mandibles with five to six teeth.

Maxillary palpi presumably only three-segmented; first segment elongatecylindrical (true second palpomere?), obliquely truncate; second slightly obconical and not much longer than wide, slightly longer and distinctly wider than first; third (distal segment) subovoidal, slightly more than one-fourth longer, and distinctly wider, than second, with a short, blunt, palpal cone at apex. The maxillary palpus is not as long as the maxillary cardo! Such reduced mouthparts are intermediate between the Arhytodini and Tyrini, and the myrmecophilous habitat suggests a parallel with Clavigerinae. In the latter case, however, the rudimentary clavigerine mandible suggests a much more complete adjustment to the society of the host ant, while the toothed attapsenine mandible suggests the primitive predatism of pselaphids. Such speculation, in the absence of direct ecological experiments, leads to the conclusion that this new tribe plays the rôle of the synoekete in the Atta society.

The antennae are eleven-segmented, with a compact funicle and poorly developed club. This condition is approached by Endytocera and Barrojuba in the Jubinini, and to a less extent by Ephimia of the Hybocephalini and Juxtahamotopsis of the Tyrini.

Pronotum lacking either basal foveae or sulci.

Elytra inclined towards the abdominal impression noted later; each elytron with a sutural stria but lacking basal foveae, discal striae, sulci, and impressions.

This total absence of pronotal and elytral foveae and sulci is a very specialized feature for pselaphids.

The abdomen is also specialized in the direction of the Clavigerinae. The abdomen, as a whole, forms a perfect oval with the elytra, and has a deep, subelliptical basal depression. An oblique carina limits the sides of this depression, giving a sharp and triangular wall; the basal fourth of the lateral carina, 
each side, is furnished with a row of ten to twelve long, trichomatous, setae which project into the depression and, therefore, appear to be analogous to the trichomes of Fustiger, Adranes, and other clavigerid aggregates. This basal depression occupies more or less of the first two tergites, and the remaining tergites are convex, short, and without lateral margins. Six sternites.

Mesosternum trapezoidal-subrectangular. Metasternum obconical in optical outline, medianly excavated, and with the posterior margin medianly and deeply incised. Anterior coxal cavities confluent, their coxae subtriangular. Intermediate coxal cavities confluent, their coxae large and globose; intermediate legs typically macrosceline. Posterior coxae subtriangular.

Femora and tibiae arcuate; the tibiae dilated and compressed for basal third to half of length. Tarsi three-segmented; first short; second and third very elongate (about three times longer than first tarsomere, with the third slightly longer than second); two long, subequal, tarsal claws.

\section{ATTAPSENIUS (Bruch, 1933)}

\section{BRUCH (1933)}

\section{Reichensperger (1936)}

This genus is described above, it being the only genus of the tribe.

The two species may be separated as follows:

Antennomere I straight, cylindrical, longer than next two united; II-X subquadrate, progressively slightly wider, very closely articulated; XI oblong-oval, as long as the preceding three or four segments united; $2.3 \mathrm{~mm}$. long.............chernosvitovi Antennomere I elongate-cylindrical; II-VI smaller, one and one-half times longer than wide; VII very short; VIII quadrate; IX and $\mathrm{X}$ broader and longer; XI elongate-cylindrical, longer than the three preceding segments united; $3.2 \mathrm{~mm}$. long (or $4 \mathrm{~mm}$. long if the curvature of the abdomen is taken into consideration)..eidmanni These two remarkable species may be listed:

chernosvitovi Bruch. 1933. Loreto, Misiones, Argentina. Genotype. eidmanni Reichensperger. 1936. Mendes, Est. Rio, Brazil. Both from the nests of the leaf-cutting ant, Atta sexdens L. 


\section{Subfamily Clavigerinae}

The Clavigerinae usually have the following combination of characters. The head is longer, much longer than wide, and subcylindrical; very rarely is the head subquadrate, or as wide as long. A median gular fovea is present; the pair of vertexal foveae is present, often small, but at times absent (Adranes). The eyes may be well-developed to rudimentary in the same genus (Fustiger), or absent (Adranes, Claviger). The mouth-parts are always rudimentary-in fact, this is one of the best characters in defining the subfamily. The mandibles are usually slender, terminating in a blunt point, and lacking teeth. The maxillae are vestigial, provided with a distinct brush of setae, used in scraping their specialized food. The maxillary palpi appear to be of a single segment, or at most two segments, with the distal piece usually pedunculate, and terminating in setae rather than a palpal cone. This palpomere is elongatetruncate (Claviger) or subspherical to ovoidal (Clavigerodes). Mentum very large. Labrum very large. Thus these small mouth-parts (mandibles, maxillae, labium) are only studied with precision from slide-mounts of dissected parts. In life these oral organs are relatively hidden by the mentum and labrum, the oral aperture being often a transversely oval, sharply delimited area with the mouth-parts somewhat recessed. This means that apprehension of living and struggling prey by toothed mandibles is impossible, rather the food must be passive, and nourishment obtained either by piercing with the mandibles, then sucking and licking the exuded liquids, or scraping, brushing, and licking a surface.

The antennae have but one feature in common, namely the distal antennomere is, as far as I know, more or less sharply truncate, with the circular to oval truncation provided with erect setae. This is not usual in the Pselaphinae. The number of antennomeres is highly variable. Thus the antennae have two segments (Mastiger, Articerus, Disarthricerus), three (Adranes, Fustiger, Apoderiger), four (Rhynchoclaviger, Radama, Diartiger), five (Clavigerodes, Paussiger, Microclaviger) or six (Claviger, Clavigeropsis, Pseudacerus) to mention but three genera in each type. This variation in antennomeres is an excellent character for separation of groups of genera within the subfamily, but is not valuable as a phylogenetic feature for separating Clavigerinae from Pselaphinae, since this variation is surpassed in Goniacerini. Thus clavigerines have a variation of from two to six segments, while Goniacerini has a variation of from five to eleven segments. The first clavigerine antennomere is invisible from above, deeply inserted into the acetabulum at each side of the front.

Elytra with the apical margins bearing a trichome of long, tortuous, golden setae near each external angle; only rarely are these trichomes absent-they are badges of the symphile. 
The large abdomen has six sternites, the typical Pselaphid number, but the tergites are specialized: the general tergite pattern is a tergum or dorsum of three fused tergites, and two terminal tergites. The fused dorsum shows its lineage along the lateral margins, where the component tergites have not been wholly fused; medianly the tergum presents a glabrous expanse which is usually deeply depressed at the base. The antero-lateral angles of the margin of the tergum also usually bears trichomes. Thus the elytral and abdominal trichomes ornament the base of the abdomen. This dorsum, with its trichomes, is paralleled in the less complicated but similar abdomen of the myrmecophilous Attaseniini, so that it is not purely clavigerine. The actual reduction in abdominal segments is not peculiar to Clavigerinae, in fact this reduction is surpassed in the Cyathigerini, where Cyathiger has the segments fused to give only two tergites and two sternites. Thus the abdominal features are not unique, and may not be used to separate the two subfamilies.

The legs are definitely macrosceline; the tarsi are three-segmented, with the first two tarsomeres small and the third tarsomere much larger, elongatecylindrical, subarcuate, and bearing a single tarsal claw.

Integumental modification is very diverse, glabrous, punctulate, punctate, granulate, cribrate, alutaceous, or striate. Pubescence is similarly diverse, the setae being elongate-aciculate, subsquamoid, bifurcated (Adranes), or apically plurifurcate (Claviger, in part).

Sex is best discovered by direct dissection. The aedeagus is of the tyrine type, with a narrowly oval basal bulb which is bifenestrated, and which terminates apically in a rapidly narrowing, arcuate, sperm-conducting apex. The males often have the sternites longitudinally concave, giving a distinctive lateral profile; the abdomen is more tapering from a dorsal view, the metasternum is often secondarily modified by tubercles or cusps, and the legs usually armed by spines or teeth, but not always. Thus males may bear prominent femoral spines, or femoral and tibial spines, or lack spines entirely, in the same genus. Females have the sternites longitudinally convex in profile, the abdomen much more rounded apically from a dorsal view, and the metasternum and legs are simple, or relatively so.

It is obvious that the clavigerines are, at most, of subfamily rank. The elevation of these species to family status in the Leng (1920, p. 132) catalogue is not tenable unless the Staphylinidae are broken into numerous families and the Pselaphidae are similarly separated into at least five families. Although my opinion is derived independently from the comparative morphology of the pselaphids, it should be noted that students of the family give the clavigerids subfamily rank (LeConte and Horn, 1883; Brendel and Wickham, 1890, p. 218; Ganglbauer, 1895; Raffray, 1904, 1908, 1911; Mann, 1921; Bruch, 1933; Bowman, 1934; Meixner, in Kükenthal, 1936).

The comparative ecology of Clavigerinae is in much need of study. They are an example of adaptive speciation within a particular niche, namely the society of ants. They are never free-living-indeed, their rudimentary mouthparts make it probable that they would be unable to compete with the predators 
of the floor mold described so well by Jacot (1935). Their ornamented integument, oily trichomes, unhurried walk, reduced oral equipment, and specialized antennae and dorsum are hall-marks of the true guest or symphile.

Their presence with ants has long been known (Mueller, 1818; Dury, 1884, 1898; Schwarz, 1890, 1896; Wickham, 1889, 1892, 1894, 1900, 1901; Hetschko, 1896; Raffray, 1908; Knaus, 1908; Krueger, 1910; Wheeler, 1910 [including much data on ant guests as a group and the early work of Wasmann] ; Blatchley, 1910; Mann, 1911, 1915, 1918; Crawley, 1916; Gallardo, 1916; Donisthorpe, 1927; Bruch, 1929, 1931; Park, 1932, 1935; Reichensperger, 1931, 1933). From this imposing array little more is known than that the clavigerines are always with ants, and are unmolested by their hosts.

Two species have been studied: Claviger testaceus of Europe by Mueller, Hetschko and Krueger; Adranes lecontei of North America by Park.

Summarizing what is known of these two species we arrive at the following generalities:

1. Lecontei and testaceus are wholly unmolested by their hosts. They stalk about the dark, moist galleries, haunting the brood chambers, and when approached by an ant do not hurry away but either pass on, stop and twirl the antennae, or crouch so that the worker must pass around or over the beetle.

2. The host ant workers assiduously suck the beetle's trichomes, lick their integuments, at all hours of the day and night in this arhythmic social medium (Park, 1941). I have seen lecontei licked for two minutes at a time, by several ants together.

3. The beetles ride about upon the gaster of the ant. This phorecy has been seen repeatedly in lecontei. The author has watched a lecontei riding on its host (Lasius aphidicola Walsh) for ninety consecutive minutes before the ant was relieved of its heavy burden.

4. The beetles are fed regurgitated liquid food by the host workers, in the same manner as one worker will feed her sisters.

5. When not being fed, or transported, by the workers, the beetles strike at the society by scraping, puncturing, and sucking, the eggs, larvae, and pupae of the host. Scavengerism is not their metier although they may scrape at a shred of cast pupal membrane-this work is carried out by the more primitive synoeketes and synechthrans of the nest, chiefly the former.

6. The juvenile mites (Antennophorus wasmanni) which balance upon the aphidicola workers also climb upon the lecontei.

These exquisite adjustments of the blind testaceus and lecontei suggest long association with their hosts, with selection pressures very different from free-living pselaphines and it is to be expected that the modern clavigerids exhibit many specializations of their pselaphid organization.

The forty-two genera of Clavigerinae have been eagerly sought by collectors and consequently the distribution has been fairly well outlined, as a by-product of the collection. It seems clear that the clavigerines have followed their hosts, and are known over all major faunal regions save New Zealand. 
According to the work of Raffray and Wasmann, these insects are most diversified and abundant in Madagascar, that anciently separated home of so many strange animals. Europe and the Western Hemisphere have an impoverished clavigerine fauna.

The neotropical region contains three genera. Unfortunately the author is entirely unfamiliar with either specimens or the original description of one of these genera (Neofustiger) and consequently the following key is incomplete.

\section{Key to Genera of Neotropical Clavigerinae}

Third (distal) antennal segment with a transverse suture near middle of length; known only from the Antilles..... PSEUDOFUSTIGER Third (distal) antennal segment entire, with no suture...FUSTIGER

NEOFUSTIGER (Bruch, 1929)

cochlearis Bruch. 1929. Misiones, Argentina. Genotype. con Paratrechina fulva fumata For.

\section{PSEUDOFUSTIGER (Reitter, 1884)}

This interesting monotypic genus is important in that it represents a stage in the consolidation of the clavigerine antenna from four to three segments.

stricticornis (Reitter). 1883. St. Thomas, Virgin Islands. Genotype.

(Articerus).

FUSTIGER (Brendel, 1866)

Brendel (1866) (Fustiger) (1889)

RAFFrAY (1882) (Commatocerus) (1904, 1908, 1909, 1911)

LeConte and Horn (1883)

Wiскнам $(1889,1892)$

Brendel and Wickham (1890) (Articerus Brendel, nec Dalman, 1825)

SCHWARZ (1896)

WaSManN (1897) (Commatocerinus)

SCHAEFFER (1906)

Knaus (1908)

Blatchley (1910)

MaNn $(1915,1918,1921)$

GallaRdo $(1916)$

BRUCH $(1929,1931)$

REICHENSPERGER $(1931,1933)$

BOWMAN (1934)

PARK (1935)

This is a very important genus and by its numerous species, centering in Brazil, signalizes neotropical clavigerines in somewhat the same way that Arthmius contributes to neotropical batrisines. 
The genotype, fuchsi Brendel, has been found with Cremastogaster lineolata and Cremastogaster leviuscula; other hosts are listed for the species later, but it should be noted that the species ecology has not been worked out, as it has for Adranes and Claviger. Gallardo is the only one to have written on the host-beetle relationship, finding the species elegans completely tolerated by its host.

The general construction of the genus may be understood from the following description of a new species:

\section{Fustiger veracruzensis new species}

Holotype Male. Measurements: Head 0.36 x $0.32 \mathrm{~mm}$.; pronotum 0.31 x $0.47 \mathrm{~mm}$.; elytra $0.60 \times 0.77 \mathrm{~mm}$.; abdomen $0.76 \times 0.79 \mathrm{~mm}$. Total length $2.03 \mathrm{~mm}$. Greatest width $0.79 \mathrm{~mm}$. (Pl. II, VI, VII, XVII, XIX).

Shining reddish-yellow brown. Integument of antennae asperate-strigose; legs lightly, sparsely subasperate; head and pronotum strongly sculptured with crowded, longitudinally ovate, glabrous cells having strong, common, carinate walls; elytra with sparse, uniformly distributed, subasperate punctures, and the posterior third medianly strigose; abdomen subglabrous. Pubescence long, monaxon, very fine and apically directed on antennae; short, strongly arcuate, subsquamoid on head and pronotum; elytra with more slender, subappressed setae more or less arranged in rows on flanks and disc, and in addition a very rudimentary trichome of about twelve very long setae at postero-apical angle; abdomen with fully formed trichome on the lateral margin of first visible tergite. This trichome is in two parts, a basal tubercle is surmounted by a brush of long golden setae which are directed posteriorly; second, an apical tubercle is surmounted by a brush of long golden setae which fan out mesio-basally. The dorsum of the fused first three visible tergites has about twenty-six very long, slender, erect setae in about three transverse rows, the apical half of each seta directed anteriorly towards basal depression. In addition, the dorsum and last two tergites are sparsely supplied with excessively minute, prostrate setae.

Head subquadrate, being only 12 per cent longer than wide through eyes. Tempora long, subparallel, nearly as long as eyes. Eyes median, subreniform, each of 30 prominent facets. Occiput and subrectangular temporal angles clearly set off from alutaceous cervicum. A pair of minute, poroid vertexal foveae on a line through posterior eye margins. Antennal acetabulum, each side, long, arcuate, and glabrous, extending from anterior eye margin to vertical, narrow, frontal lamina separating acetabulae. Clypeus subquadrate, extensively involved with front in acetabulae; transversely triangular when seen in optical apical view. Labrum very transverse and granular. Oral aperture, framed by clypeus, genae, and mentum, nearly as wide as head but very narrow, being elongate-elliptical, arcuate. Maxillary palpi with a minute subspherical basal segment or piece, and a much larger, strongly pedunculateobconical distal segment or portion-the palpi are minute and lie wholly 
within the frame of the oral aperture. Mandibles minute, simple, elongatetriangular, not toothed, also wholly within the oral frame. Ventral surface of head with a large, median gular fovea.

Antennae long $(0.64 \mathrm{~mm}$.), the visible portion three-fourths as long as head, cervicum and pronotum united; three-segmented; segment I invisible from above, as usual, subquadrate $(0.046 \mathrm{~mm}$. long); II very obconical but as wide as long $(0.046 \mathrm{~mm}$. long); III elongate-obconical ( $0.55 \mathrm{~mm}$. long), slightly arcuate, with circularly truncate and setose apex, this apical surface relatively narrow, being only slightly more than one-third the width of the head.

Pronotum transversely suboval with a large, shallow, glabrous, foveoid depression at middle of base.

Elytra with oblique humeri. Each elytron with an entire sutural stria; then a row of setae; then an entire juxtasutural stria; then a row of setae; then two discal striae which converge and do not extend beyond middle of disc, and which enclose one or two rows of setae; then about three poorly defined rows of setae; then a short, shallow, intrahumeral depression; then about ten rows of setae to lateral elytral margin.

Abdomen with first tergite partially membranous and hidden beneath elytra for the most part. Five visible tergites of which the first three are visible on the lateral margins by their sutures, but wholly fused between margins to form a prominent dorsum. Dorsum deeply depressed in basal half and tumidconvex in apical half. Fourth tergite with a small but prominent conical tubercle at each latero-basal angle. Fifth (distal) tergite is vertical, subtriangular. Length ratio: 12 (dorsum) $/ 2$ (fourth) $/ 2.5$ (fifth tergite).

Sixth sternites in a length ratio of $2 / 3 / 3 / .8 / .5 / 2$ with the first and last more pubescent and in lateral view the sternites form a slight arc, that is, they are longitudinally concave. Sixth transversely reniform to accommodate last tergite, medianly depressed near apex.

Abdomen from a dorsal view with broadly rounded apex, which is in contrast to many clavigerine males having a tapering apex.

Aedeagus dissected: $0.368 \mathrm{~mm}$. long $\mathrm{x} 0.107 \mathrm{~mm}$. wide, strongly sclerotized, yellowish-brown, stream-lined. The basal portion is oval, and this tapers rapidly to form the arcuate, elongate-triangular, apical portion. Dorsal surface of basal portion with the oval fenestra covered by a semi-membranous, expansible roof. Dorsal surface of apical portion with the triangular fenestra similarly covered, but medianly with a longitudinally shallow sulcus towards arcuate apex. This perfectly bilaterally symmetrical penis is entirely similar to the penis of Tyrini (Ceophyllus, Tmesiphorus) and is not similar to the ctenistine penis. It suggests either remarkable coincidence, or relationship despite the different tarsomere ratio.

Metasternum very large and strongly tumid, without any median modifications save that there is a pyriform patch of pubescence which projects over first sternite.

Legs all strongly macrosceline, with very long and subobconical trochanters; short, inflated femora; long, subarcuate tibiae; tarsi with two minute, 
subequal basal tarsomeres and the third (distal) tarsomere is very long, arcuate, cylindrical and bears a short, sharp tarsal claw. The legs are perfectly simple and unarmed.

Allotype Female. Similar to holotype save that: (1) the body is longer and broader $(2.31 \times 0.94 \mathrm{~mm}$.) ; $(2)$ abdomen from a dorsal view with a tapering apex; (3) sternite ratio entirely different, the six sternites having a length ratio of $1 / 6 / 5 / 1.5 / .5 / 1.3$. This is a notable differential when the two sexes are present. The male not only has a shorter, more blunt abdomen which is ventrally concave, but the subequal second and third sternites are only half as long as these sternites of the female. The female has the larger, more tapering abdomen ventrally convex.

Described on 60 specimens ( 56 males and 4 females). All were collected from the nests of a cremastogastrine ant which is now being identified. Further, this abundant material was taken in a single afternoon (June 30,1941) at 5500 feet elevation near Las Vigas, Vera Cruz, Mexico, by C. H. Seevers and Henry Dybas.

Fustiger veracruzensis is a very distinct species. In the first place, it is the first clavigerid from Mexico and serves to bridge the zoögeographic gap between the United States species, and the Costa Rican species which have been so well studied by Reichensperger.

In the second place, veracruzensis is isolated from all other species by the following combination of characters:

1. Eyes with 30 ocular facets. This separates all United States species, which never have more than 10 facets, and also clavipilis with 15 facets.

2. Head very brachycephalic, being only about one-tenth longer than wide. This separates the majority of the genus Fustiger which typically has the head much longer than wide. For example schmidti, clavipilis, haytiana, have head twice as long as wide and schwarzi has head three times as long as wide, etc.

3. Elytra uniformly punctate. This separates smithi with base of elytra rugosely punctate.

4. Males with unarmed legs. This separates many species. For example oglobini, gounellei, insignis, haytiana, henrici, etc. have the male sex with conspicuously spined or modified intermediate legs.

5. Head and pronotum coarsely sculptured. This separates elegans which has no integumental sculpture.

Fustiger veracruzensis is most closely related to cornicen Reichensperger, from the forest floor of Costa Rica. It differs from cornicen in many ways: cornicen is much smaller, being $1.5 \mathrm{~mm}$. long; the pronotum is as long as wide; the antennae are little longer than the head, but more arcuate, much broader distally, the last antennomere, in a photograph of the type, being half as wide as the head.

One thing of zoögeographic interest is that the host of this new species is definitely a cremastogastrine ant, and although the southern species of Fustiger 
have a variety of hosts, the species of the United States usually live with Cremastogaster.

The distribution of this genus of beetles is very broad, and the species may be listed as follows:

The following catalogue of the genus Fustiger is an exception to the usual plan of this paper in that it attempts to list the genus as a whole rather than the neotropical species.

\section{Africa and Madagascar}

1. elegantulus (Raffray). 1882. Massouah, Abyssinia (Ethiopia)

(Commatocerus)

2. ranavalonae (Wasmann). 1897. St. Marie, Madagascar.

(Commatocerinus)

3. laevis (Raffray). 1899. Suberbieville, Madagascar.

(Commatocerinus)

INDIA

4. indicus Wasmann. 1917. India.

\section{North America}

5. fuchsii Brendel. 1866. Genotype. United States: Tennessee; Mississippi (Cremastogaster leviuscula Mayr); Indiana; Arizona (Cremastogaster lineolata). See Blatchley, 1910; Park, 1935; Wickham, 1889, 1892.

6. californicus Brendel. 1889. United States: Los Angeles, California (Cremastogaster lineolata). See Schwarz, 1896.

7. knausii Schaeffer. 1906. United States: Cloudcroft, New Mexico. 9000 feet, in Sacramento Mountains. (Lasius americanus?). See Knaus, 1908.

8. veracruzensis new species. Vera Cruz, Mexico. (Host ants now being determined)

\section{Antilles}

9. smithi Raffray. 1904. St. Vincent, Windward Islands.

10. haytiana Mann. 1915. Diquini, Hayti. (Aphaenogaster relicta)

11. schwarzi Mann. 1918. Cayamas, Cuba. (Host unknown).

\section{Central America}

12. insignis Reichensperger. 1931. Vara Blanca, Costa Rica. At about 6000 feet, between Barba and Poas. (Pheidole).

13. schmidti Reichensperger. 1931. Vara Blanca, Costa Rica. At about 6000 feet, between Barba and Poas. (Pheidole). 
14. cornicen Reichensperger. 1933. Salvadora Farm, Parisminafluss, Costa Rica. (Ponera).

15. henrici Reichensperger. 1933. San Jose, Costa Rica. (Pheidole innupta Menozzi).

16. clavipilis Mann. 1921. Lombardia, Honduras. (Wasmannia auropunctata Roger).

\section{South AMerica}

17. brasiliensis (Westwood). 1856. New Friburg, Brazil.

18. amazonicus Westwood. 1869. Upper Amazon Basin, Brazil.

19. festivus Schaufuss. 1879. Amazon Basin, Brazil.

20. testudineus Schaufuss. 1882. Pozuzu, Peru.

21. hetschkoi Reitter. 1888. Blumenau, Brazil.

22. reitteri Wasmann. 1893. Blumenau, Brazil.

23. fauveli Raffray. 1898. Yuracaris, Bolivia.

24. elegans Raffray. 1908. Buenos Aires, Argentina.

Brazil.

(Solenopsis pylades Forel, Gallardo 1915, 1916). (Solenopsis richteri Forel, Bruch 1929).

25. gounellei Raffray. 1909. New Friburg, Brazil.

26. nitidus Bryant. 1915. Brazil.

27. oglobini Bruch. 1931. Loreto, Misiones, Argentina.

(Paratrechina silvestrii Em.)

\section{Fiji Islands}

28. cribratus Mann. 1920. Fiji.

29. levuanus Mann. 1920. Fiji.

30. raffrayi Mann. 1920. Fiji.

31. vitiensis Mann. 1920. Fiji.

32. wasmanni Mann. 1920. Fiji. 


\section{The Undescribed Species of Motschulsky}

The Russian entomologist, Victor de Motschulsky, published a letter in the Etudes entomologiques, pp. 8-25, in 1855. This letter was a description of a collecting trip he had made in the area about Obispo, Panama. In the several weeks of his stay he found about thirty kinds of Pselaphidae, practically all new since virtually nothing was known of the pselaphid fauna of the region. These "new species" were listed by Motschulsky, but save for a few words or a sketch, were not further treated, and Motschulsky never published their description.

Since the majority of these Motschulsky names have no description, they have no status at all. Even if these specimens could be located, and their authenticity proven (which is practically impossible now), subsequent description by some one else could not establish priority by Motschulsky. Therefore these names are of historical, but not of taxonomic, importance. David Sharp (1887, pp. 1-2) sums up the view of Reitter and himself in a cogent manner:

These names have no claim to be adopted, and I mention them only because they have been given as "published" in the list of Motschulsky's genera and species issued by the Entomological Society of Russia in 1868. In the case of three or four genera rude outline figures were given, and as these enable us to form an imperfect idea of what Motschulsky intended, their names have been adopted by Reitter and are also included in our list. It is certainly unfortunate that this letter of Motschulsky's should never have been followed by any proper description of the objects mentioned and named therein. It is quite clear that he could not have made a proper study of these minute creatures on board ship between Colon and New Orleans, where his letter was written; and, so far as we know, he never returned to their study except to sketch the rude outline figures I have alluded to. Although some of these insects have become disseminated to a small extent under Motschulsky's names, but little value can be attached to these "typical" examples. In the case of two of these names Reitter has had an opportunity of testing them, and finds they were incorrectly applied by Motschulsky; in short, Motschulsky not only failed to describe the species he gave names to, but actually did not even discriminate them. For these reasons I think the authors of the Munich Catalogue did right in refusing to recognize these names, and certainly Reitter has done all that courtesy and consideration demand when he treated those that were accompanied by figures as entitled to validity.

\section{I have listed the Motschulsky names of Panama pselaphids:}

Batrisus collaris

Batrisus cylindricus

Batrisus frontalis

Bryaxis consanguinea

Bryaxis cornigera

Bryaxis glabrella

Bryaxis macrura

Bryaxis nitida
Cercocerus perplexus

Ctenistes aequatorialis

Euplectus adustus

Euplectus antennatus

Euplectus cordicollis

Euplectus robustus

Euplectus tropicalis
Eupsenius aequatorialis

Metaxis robustus

Trichonyx aequinoctialis

Trichonyx canaliculatus

Trimicerus pacificus

Trimicerus rivalis

Tychus pilosus 


\section{Zoögeographic and Statistical Considerations}

A complete analysis of the distribution of Pselaphidae in the neotropics involves the Nearctic Region, and eventually all faunal regions since the analysis would be global in its many implications. Moreover, we should need some information on the palaeontology, ecology, and genetics of pselaphids as well as data on palaeogeography. Only a small portion of this is available.

Such an analysis is impossible in this paper for the reason that the neotropical pselaphid fauna is imperfectly known, and its distribution even less understood. Therefore my purpose here is to tabulate some suggestive data, and suggest some problems for future solution.

TABLE III

COMPARISON OF NEARCTIC AND NEOTROPICAL PSELAPHIDAE

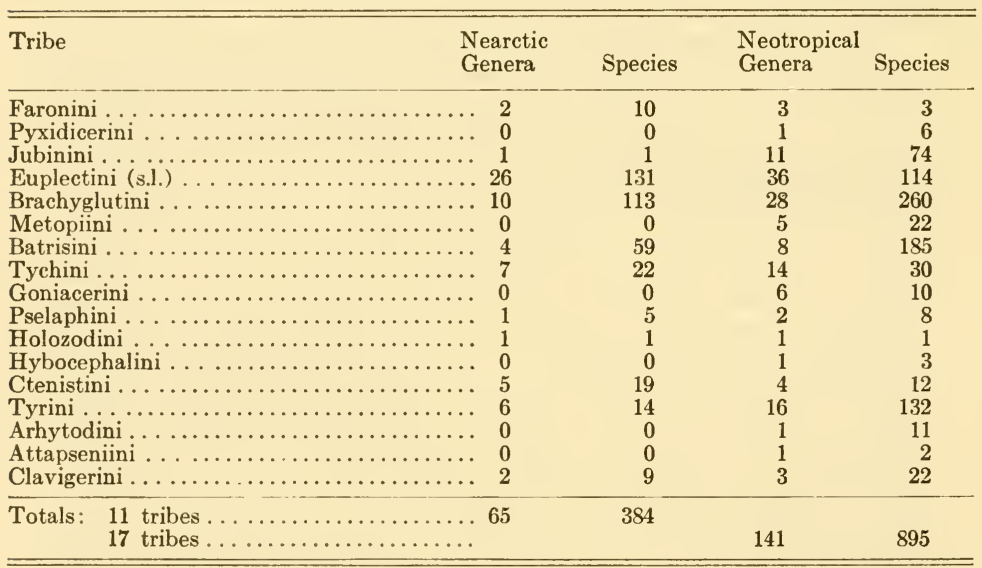

From this table it will be seen that the neotropics have all nearctic tribes plus six tribes not found in the nearctic, over twice as many genera and over twice as many species. Only the Faronini, Euplectini and Ctenistini are better represented in the nearctic areas. Of these three, the ctenistines are possibly truly better adjusted to the lower mean temperatures and lower annual rainfall, but the euplectine's slight superiority in nearctic species number is undoubtedly apparent rather than real. That is, the average minute size of euplectine units makes their collection difficult. While the United States has been very well collected relatively, floor sifting and Berlese sampling is just beginning in the neotropics. The vastness of the unexplored areas, their slow 
penetration, limited to coastal zones, river systems and populated places, has served to sample the neotropical fauna, rather than cover the territory.

TABLE IV

\begin{tabular}{ll}
\hline \multicolumn{1}{c}{$\begin{array}{c}\text { Genera common to } \\
\text { Nearctic and Neotropic Regions }\end{array}$} & $\begin{array}{c}\text { Genera common to Nearctic, Neotropic } \\
\text { Regions, and distributed outside the } \\
\text { Western Hemisphere }\end{array}$ \\
\hline Thesium & $\begin{array}{l}\text { Euplectus } \\
\text { Rhinoscepsis } \\
\text { Pseudotrimium (?) }\end{array}$ \\
Actium & $\begin{array}{l}\text { Reichenbachia } \\
\text { Melba }\end{array}$ \\
Euplaphus \\
Thesiastes & Fustiger \\
Rhexius & \\
Arthmius & \\
Euphalepsus (?) & \\
Scalenarthrus & \\
Pselaptus & \\
Reichenbachia & \\
Decarthron & \\
Pselaphus & \\
Pilopius & \\
Ctenisis & \\
Hamotus & \\
Fustiger & \\
\hline \hline
\end{tabular}

From this table we observe that there are 19 genera of pselaphids common to the two American faunal regions, and only five genera common to these two regions and having in addition species distributed outside of the Western Hemisphere. Of these 19 common genera, practically all have more neotropical than nearctic species. This gives a total of 17 tribes, 187 genera and 1279 species for the Western Hemisphere. Of these genera of American pselaphids, 46 are found only in the Nearctic, and 122 are found only in the Neotropic area. In terms of percentages, the Neotropical Region holds 64 per cent, and the Nearctic Region 36 per cent of all genera inhabiting the Americas. This shows that the former region is much more endemic, and suggests a much greater isolation. This conclusion is confirmed by the geological evidence available on separation of the Americas via the Panamanian Isthmus, and is also supported by the much greater resemblance between the Nearctic and Palaearctic Regions than between the Neotropical and Palaearctic Regions. In terms of species the neotropics are nearly, if not wholly, 100 per cent endemic. The nearctic pselaphid fauna is intermediate in composition, then, between the neotropical areas and the rest of the world. This suggests penetration from one or more northern connections between Asia or Europe, during favorable climate for terrestrial poikilotherms, dispersal southward into South America, either via the Central American or Antillean highway or both, and, under the relatively warm and moist tropical climate, evolution of a diverse and peculiar neotropical pselaphid fauna, with secondary dispersal northward of some faunal elements. 
Thus Euplectus, Reichenbachia, and Pselaphus would appear to have entered North America from the Palaearctic long ago. Reichenbachia, especially, seems to have great vagility. On the other hand Hamotus appears certainly to have evolved within the neotropics, and to have spread in all directions, reaching into the northern limit of the neotropics in Mexico and into peninsular Florida via the Antilles. In this connection a general hypothesis may be proposed regarding dispersal between the two American faunal areas. The change in climatic and associated biotic conditions is quite abrupt in the Mexican arm of the continent, between the arid southwestern United States and Mexico on the one hand, and the northern extension of the rain forest in Mexico. This faunal break appears to develop along the Tropic of Cancer. The eastern or Antillean arm, from Venezuela to Florida, offers much less change in climate and biotic conditions.

In other words, on the west the change is relatively abrupt from neotropical rain forest to nearctic semidesert; on the east the change is from neotropical rain forest to nearctic subtropical forest. The western highway offers continuous dispersal surface, with a good north-south highway in the Rocky MountainsAndes chain which allows vertical movements to compensate for changes in latitude; but the climatic-biotic change is marked. The eastern highway is subjected to frequent insular discontinuity, plus the vicissitudes of insular climate; but the climatic-biotic overall change is much more gradual. It would seem that these two dispersal paths have had to bear the north-south faunal interchange over a long period of time, and a careful analysis should demonstrate which path has been most successfully used. This requires a more complete knowledge of pselaphid distribution than we now possess.

The actual facts are meager. Separate cases can be made out for each highway, largely depending upon the genus involved, which must mean that, granting a sound taxonomy, both routes have been used by Pselaphidae. At present we have not enough data to espouse either the Mexican or the Antillean bridge as a major influence.

Thus the wholly American genus Melba has about twenty-nine species. Eleven species are nearctic, distributed north of the Rio Grande, from Arizona to the Atlantic coast, and from Florida to New York. The preponderant number of these, however, is east of the grassland biome. The neotropics have eighteen species, seven of which extend from central Mexico, through Guatemala, French Guiana, Brazil, and into northern Argentina; eleven Melba are endemic to the Antilles. The genus Melba then, appears to have used both routes, with a slight preponderance for the Antillean route.

On the other hand, the important genus Hamotus, with eighty-nine species, is distributed over the entire Neotropical Region and extends northwards to the limit of the rain forest in Vera Cruz. Here the genus breaks off short, with at least three species in Vera Cruz. The only non-neotropical species is Hamotus opimus of southern Florida, which suggests colonization from the Antilles. The difficulty here is lack of facts because the Antilles have but one species, Hamotus hirtus, of the Windward and Leeward Islands. This is a 
typically exasperating example-there is no doubt that other hamoti are living on the Antillean chain-we simply do not know enough.

Countless examples could be cited but many of these have been already stated in the preceding pages, and need not be restated here. There are numerous genera which appear to have moved up the Central American route (Eurhexius), others to have used the Antillean route, others both routes.

In the examples of genera using the Mexican route, they nearly always dwindle or stop at the northern limit of the rain forest and therefore aid in delimiting the Neotropical Region. My data show this limit to be just south of the Tropic of Cancer on the Atlantic side (southern Tamaulipas-northern Vera Cruz), as the description of new species attest. In so far as these data go, they confirm the work of Smith (1940) on the zoögeography of Mexico, especially with respect to the lizard genus, Sceloporus.

The northward extent on the Pacific side is unknown.

Thus, to sum up this first aspect, a major problem for the future is to ascertain the relative usage of the Antillean versus the Mexican highway between the Nearctic and Neotropical Regions. Emerging as subproblems are the (1) extent of neotropical species on the Pacific side of Mexico; (2) the ratio of nearctic to neotropical elements in the southern third of peninsular Florida; (3) the ratio of Central American to South American elements at several points through Central America, especially the shift between Panama and Guatemala. This requires much expeditionary work, followed by difficult taxonomic research. The regions in which materials are critically needed appear to be two: the Antilles as a whole; and the Pacific slope of Mexico, especially from Mazatlan to Manzanillo.

It must be pointed out that two influences may obscure the relationships present. These are chiefly intra-tropical. The first of these is altitude. Most of the vast neotropical area lies below 3000 feet, but the species may penetrate at different latitudes to different elevations, following the well known relationship between altitude, climate and biome from pole to equator. We have no information on this point either, at least nothing comparable to Schmidt's study of vertical distribution of the salamanders of the genus Oedipus in Guatemala (1936). We know that pselaphids can penetrate to moderately high altitudes:

TABLE V

SELECTED ALTITUDE RECORDS OF PSELAPHIDAE

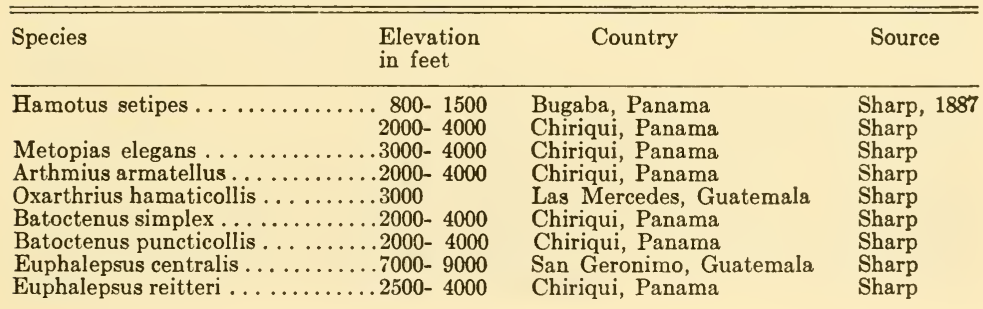


TABLE V (Continued)

SELECTED ALTITUDE RECORDS OF PSELAPHIDAE

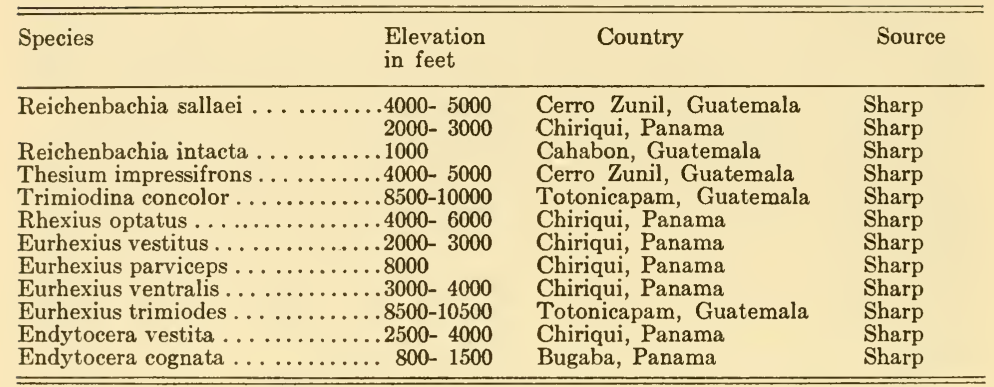

I have used here the records of Sharp's ancient work. Although his descriptions are not complete, his locality data are much better than the more recent work of Raffray. From this table we find the greatest elevation attained by neotropical pselaphids to be Totonicapam, Guatemala (Eurhexius trimiodes) at 10,500 feet, and the greatest known vertical range that of Hamotus setipes, from 800 to 4000 feet in Panama. The few data make prediction rather hazardous but the situation in Eurhexius is suggestive, with vestitus at 2000-3000 in northern Panama, ventralis at 3000-4000 in the same forest, parviceps at 8000 in the same forest extension, and northwards trimiodes at 8500-10500 in Guatemala. There are many species described from "HauteBolivie, Yuracaris" which suggest considerable altitudes, and a third critical area for study would be the Bolivian Andes from the northeastern corner up the Madeira drainage to tree-line. This should throw much light on altitude stratification from the Amazon floor to the limit of penetration; this compared with a similar transect in the Panamanian Chiriqui, Guatemala, and Central Mexico would be especially desirable. Of course these remarks refer to the free-living species. The symphiles, and to a less extent the synoeketes, live in the relatively stable, dark, humid nest of their host and their distribution becomes the host's distribution. In such cases the oxygen available and the barometric pressure would be the two influences varying with altitude, while food, shelter, lack of light and relative humidity would remain more or less constant; temperature, especially nocturnal temperatures, in and out of the ant and termite nest in a restricted altitude range have not been sufficiently studied in this respect. Some information is at hand on one genus of symphiles: Fustiger insignis and schmidti occur at 6000 feet in Costa Rica, while Fustiger veracruzensis occurs at 5500-5000 in Vera Cruz, Mexico.

Since pselaphids are poikilothermal this problem of vertical distribution probably has a profound effect upon their distribution and is taken into account later in the discussion of taxonomic density. At least four zones are recognized for the Andes (Chapman, 1933; Cutright, 1940): tropical (sea level to $3,500-5,000$ feet); subtropical (3,500-5,000 to $8,000-9,000$ feet); 
temperate $(8,000-9,000$ to $11,000-12,000$ feet) ; paramo or puna $(11,000-12,000$ to lower snow limit at $15,000-16,000$ feet). Chapman found relatively abrupt changes in bird species between zones and there is no reason to suppose that the pselaphids would not be even more limited. So far definite neotropical altitude records show pselaphids to be in the first three zones but no data are available to show increasing relationship with the nearctic fauna with increasing elevation. This should be interesting to work out since (Humboldt, 1850) from pole to equator mean temperature increases about one degree Fahrenheit with each degree latitude, and ascent of the Andes (Cutright, 1940) shows a decrease in the mean air temperature of about one degree Fahrenheit for each 300 feet-that is, 300 feet elevation in the Andes is equivalent to about 67 miles of latitude. The importance of mountains, both as barriers to dispersal and as dispersal highways, is summarized in general terms in Hesse, Allee and Schmidt (1937) and is too well known to prolong this discussion without specific information.

The second intra-tropical influence relates more especially to the Antillean area and is concerned with the possibility of dispersal of pselaphids by natural rafts or floating masses of vegetation (Wallace, 1880). Any such debris from the mouths of the Amazon, Essequibo, or Orinoco rivers might move northward on the arm of the South Equatorial Current that develops north of Pernambuco, passing between Trinidad and Martinique, and if it withstood the passage might secondarily colonize the Lesser Antilles. Again, drift would tend to move from the Lesser Antilles west by north to the Yucatan coast. Finally, drift from between Nicaragua to Yucatan would tend to eventually attain the Gulf Stream and pass through the Straits of Florida. These remote possibilities should be kept in mind since rafts have been sited far at sea, and a few minute oribatid mites in a handful of leaf mold could support a pselaphid population for a long time.

To continue the analysis, some remarks are desirable on the horizontal range of pselaphids. In the first place the great majority of the 895 neotropical species listed in this paper are valid, that is, contain few synonyms which might give a necessarily imperfect idea of species range. The sound condition of this taxonomy is due to two chief reasons. The majority of the species were described prior to 1904 by four Europeans, Sharp, Schaufuss, Reitter and Raffray; Raffray was able to examine practically all of the Reitter and Schaufuss types, and at least some of the Sharp types, and hence could discover synonyms of his own and others. This placed the pselaphids of the neotropics on a fairly firm, if limited foundation, upon which the modern school could build.

The debt we owe to these four workers is easily measured by their taxonomic activity. In the following table, it will be seen that eighteen men have described 897 species in the Americas south of the United States (this figure includes two northern Mexican species, not properly neotropical). Of these the first four, mentioned above, have described 751 species, while Raffray has described nearly half of the entire number! 
TABLE VI

\section{SPECIES OF NEOTROPICAL PSELAPHIDAE BY AUTHORS}

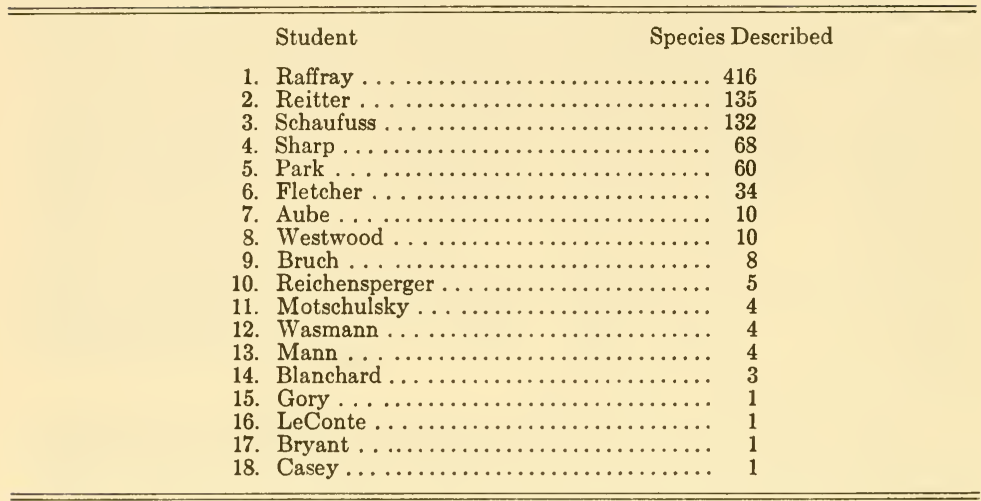

In the second place, the very vastness of the area already noted, has served to isolate the collecting localities. This has had an advantageous effect upon the validity of species but has not been beneficial to zoögeography. In the following table the several political portions of the neotropics are analyzed with respect to number of species.

The next table shows the Pselaphidae broken down into as many separate political areas as possible. The sum of the tribal totals ( 969 species) compared with the actual number of species present ( 895 species) indicates how few of the species have been reported from more than one country. The majority of species have been reported at the time of their description, and have not been heard of since that time. In the present paper a number are reported for the first time in fifty years. This simply means that until local lists are present, the range of species is too inadequately known for careful zoögeographic analysis. It also means that, in addition to species already described, hundreds of undescribed species await discovery if the long columns of zero in Table VII are to be properly changed.

On the other hand, some progress is being made through the years. About one out of eleven species is known from two countries. Some pselaphids are known to have an extensive geographic range. These cases lie especially in forms which fly readily to lights at night (Arthmius, Reichenbachia) or are large-sized and more or less abundant (Hamotus). The Tyrini especially have ranges better understood. For example Hamotus hirtus is known from both sexes and in three islands in the Antilles; Hamotus monachus from Mexico to Costa Rica; Hamotus tritomus from Mexico to Colombia; Reichenbachia celata from Mexico to Nicaragua; Reichenbachia sallaei from Mexico to Panama, and numerous additional examples could be added. 
TABLE VII

SPECIES OF PSELAPHIDAE IN NEOTROPICAL COUNTRIES

\begin{tabular}{|c|c|c|c|c|c|c|c|c|c|c|c|c|c|c|c|c|}
\hline \multirow[b]{2}{*}{ Countries } & \multicolumn{16}{|c|}{ Tribes } \\
\hline & & & $\dot{3}$ & $\dot{\vec{\Xi}}$ & 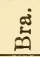 & 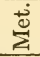 & $\ddot{\mu}$ & 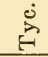 & & 乩 & $\stackrel{0}{0}$ & & ठّं & $\stackrel{\vec{c}}{\overrightarrow{5}}$ & & \\
\hline Argentina & 0 & 1 & 3 & 10 & 13 & 3 & 3 & 0 & 0 & 40 & 00 & & 3 & 3 & 2 & 13 \\
\hline Bolivia & 0 & 0 & 2 & 2 & 10 & 2 & 17 & 2 & 0 & $\begin{array}{ll}0 & 0 \\
\end{array}$ & 0 & & 0 & 8 & 1 & 0 \\
\hline Brazil & 0 & 2 & 26 & 28 & 73 & 14 & 128 & 11 & 5 & 30 & 0 & & 4 & 47 & 6 & 1 \\
\hline British Guiana & 0 & 0 & 0 & 0 & 0 & 0 & 0 & 1 & 0 & $\begin{array}{ll}0 & 0\end{array}$ & 0 & & 0 & 0 & 0 & 0 \\
\hline British Honduras & 0 & 0 & 0 & 0 & 4 & 0 & 0 & 0 & 0 & $0 \quad 0$ & 0 & & 0 & 0 & 0 & 0 \\
\hline Chile & 3 & 0 & 0 & 7 & 26 & 0 & 1 & 0 & 0 & 0 & 0 & & 0 & 8 & 0 & 0 \\
\hline Colombia & 0 & 0 & 11 & 5 & 17 & 1 & 6 & 0 & 0 & 0 & 0 & & 2 & 17 & 0 & 0 \\
\hline Costa Rica & 0 & 0 & 0 & 0 & 0 & 0 & 1 & 0 & 0 & 0 & 0 & & 0 & 3 & 0 & 0 \\
\hline Cuba & 0 & 0 & 0 & 0 & 5 & 0 & 0 & 0 & 0 & 0 & 0 & & 0 & 0 & 0 & 0 \\
\hline Dominic & & 0 & 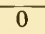 & & 0 & & & & & & & & & & & \\
\hline
\end{tabular}

Dominica

(Leeward Isl.)

\begin{tabular}{llllllllllllllllll}
\hline Dutch Guiana & 0 & 0 & 0 & 0 & 3 & 0 & 0 & 0 & 0 & 0 & 0 & 0 & 0 & 0 & 0 & 0 & 0
\end{tabular}

\begin{tabular}{llllllllllllllllll}
\hline Ecuador & 0 & 0 & 0 & 0 & 0 & 0 & 0 & 0 & 0 & 0 & 0 & 0 & 0 & 1 & 0 & 0 & 0
\end{tabular}

\begin{tabular}{llllllllllllllllll}
\hline French Guiana & 0 & 0 & 0 & 2 & 0 & 1 & 0 & 2 & 0 & 0 & 0 & 0 & 0 & 1 & 0 & 0 & 0 \\
\hline
\end{tabular}

\begin{tabular}{llllllllllllllllll}
\hline Granada & 0 & 1 & 1 & 3 & 6 & 0 & 0 & 0 & 0 & 0 & 0 & 1 & 0 & 1 & 0 & 0 & 0
\end{tabular}

(Windward Isl.)

Guadeloupe

(Leeward Isl.)

\begin{tabular}{llllllllllllllllll}
\hline Guatemala & 0 & 0 & 2 & 10 & 22 & 0 & 5 & 2 & 0 & 1 & 1 & 0 & 0 & 7 & 0 & 0 & 0
\end{tabular}

\begin{tabular}{llllllllllllllllll}
\hline Haiti & 0 & 0 & 0 & 0 & 0 & 0 & 0 & 0 & 0 & 0 & 0 & 0 & 0 & 0 & 0 & 0 & 1
\end{tabular}

Hispaniola

(cf. Haiti)

\begin{tabular}{llllllllllllllllll}
\hline Honduras & 0 & 0 & 0 & 0 & 0 & 0 & 0 & 0 & 0 & 0 & 0 & 0 & 0 & 0 & 0 & 0 & 1 \\
\hline Martinique & 0 & 0 & 0 & 1 & 0 & 0 & 0 & 0 & 0 & 0 & 0 & 0 & 0 & 0 & 0 & 0 & 0
\end{tabular}

(Windward Isl.)

Mexico

$\begin{array}{lllllllllllllllll}0 & 1 & 6 & 10 & 53 & 0 & 15 & 7 & 1 & 0 & 1 & 0 & 5 & 11 & 0 & 0 & 1\end{array}$

Nicaragua

$\begin{array}{lllllllllllllllll}0 & 0 & 0 & 0 & 2 & 0 & 0 & 0 & 0 & 0 & 0 & 0 & 0 & 2 & 0 & 0 & 0\end{array}$

\begin{tabular}{llllllllllllllllll}
\hline Panama & 0 & 0 & 4 & 4 & 6 & 1 & 8 & 0 & 1 & 0 & 0 & 0 & 0 & 7 & 0 & 0 & 0 \\
\hline
\end{tabular}

\begin{tabular}{lllllllllllllllll}
\hline Panama Canal Zone 0 & 0 & 6 & 6 & 15 & 1 & 4 & 6 & 1 & 0 & 0 & 0 & 0 & 8 & 0 & 0 & 0
\end{tabular}

(Barro Colo. Isl.)

\begin{tabular}{llllllllllllllllll}
\hline Paraquay & 0 & 0 & 3 & 0 & 3 & 0 & 8 & 0 & 1 & 0 & 0 & 0 & 0 & 6 & 0 & 0 & 0 \\
\hline Pearl
\end{tabular}

Pearl Islands

(Panama)

\begin{tabular}{llllllllllllllllll}
\hline Peru & 0 & 0 & 0 & 0 & 3 & 0 & 5 & 0 & 0 & 0 & 0 & 0 & 0 & 1 & 0 & 0 & 1
\end{tabular}

\begin{tabular}{llllllllllllllllll}
\hline Puerto Rico & 0 & 0 & 0 & 3 & 1 & 0 & 0 & 0 & 0 & 0 & 0 & 0 & 0 & 0 & 0 & 0 & 0
\end{tabular}

St. Thomas

(Virgin Isl.)

St. Vincent

(Windward Isl.)

\begin{tabular}{llllllllllllllllll}
\hline Uruguay & 0 & 0 & 0 & 1 & 0 & 0 & 0 & 0 & 0 & 0 & 0 & 0 & 0 & 0 & 0 & 0 & 0
\end{tabular}

Venezuela

Water Island

(Virgin Isl.)

Totals

$\begin{array}{rrrrrrrrrrrrrrrrr}0 & 0 & 8 & 7 & 12 & 0 & 4 & 2 & 1 & 0 & 0 & 0 & 0 & 18 & 2 & 0 & 0 \\ 0 & 0 & 0 & 1 & 0 & 0 & 0 & 0 & 0 & 0 & 0 & 0 & 0 & 0 & 0 & 0 & 0\end{array}$

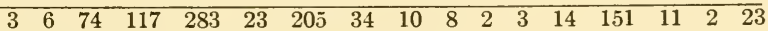

Certain areas are better known than others. For example there are increasing data showing considerable similarity of the pselaphid fauna of southern Brazil and northern Argentina; of northwestern Brazil and Colombia and Venezuela; of Colombia and Panama; of southern Mexico and Guatemala.

The discussion may be furthered by bringing horizontal area into the problems which beset us. 
TABLE VIII

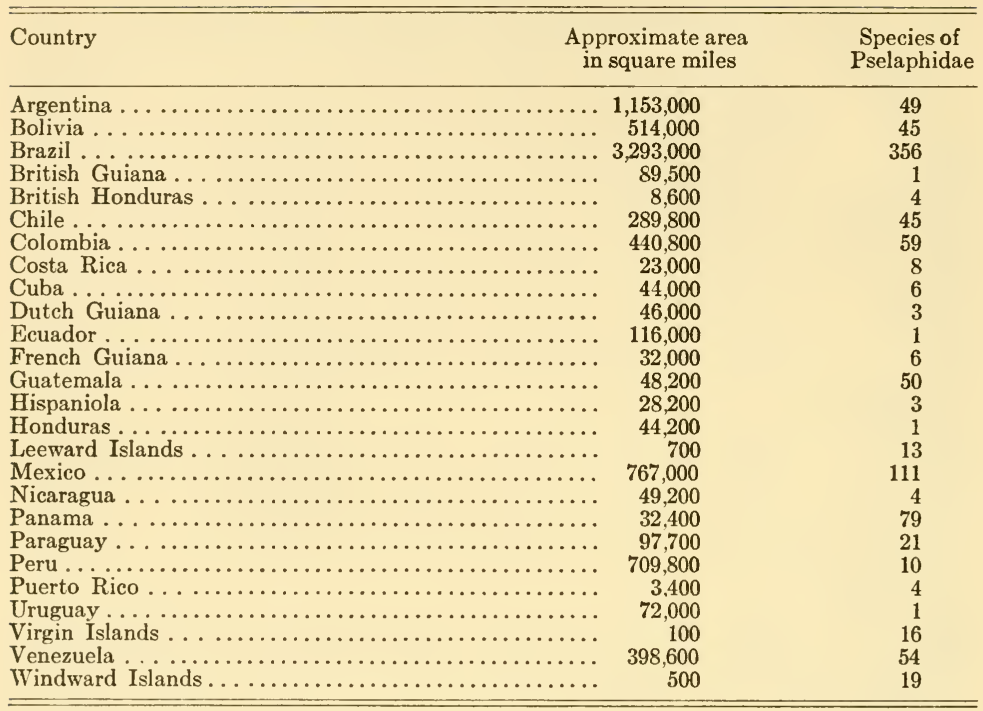

All three columns have been adjusted. Some areas, notably Jamaica (4200 square miles) have no Pselaphidae reported! Haiti and the Dominican Republic are combined under the older name of Hispaniola because of doubt of the original type localities in two of the three species. The Pearl Islands, Panama Canal Zone, and the Republic of Panama are united. The area data are atlas simplifications, with fractions of one hundred square miles not used ; furthermore, recent boundary settlements are not integrated as exact data are lacking. The third column represents the species reported, in all save a few cases where overlap was taken into account. These faunal figures represent the situation to the best of my ability but are not necessarily exact as there is always the possibility of overlooking a paper. The only large regional study is that of Sharp (1887) for Central America. We have nothing comparable to Bequaert (1940) on the Tabanidae of the Antilles, or a modern faunal analysis of a limited area such as Wetmore and Swales (1931) or Cochran (1941) on the birds and herpetology, respectively, of Hispaniola.

This eighth table brings out some correlations of interest. Thus we find that the United States, with an area of about $3,026,700$ square miles has had the advantage of relatively very intensive study, and lists 384 species of Pselaphidae; Brazil, with an area of about 3,293,000 square miles, of relatively very little studied territory, lists 356 species of Pselaphidae! This latter figure represents nearly half the described neotropical species, and attests to the amount of work to be done. That is, it is not as though the pselaphid fauna of the United States were poorly known. Even as early as 1850 , LeConte, in his classical paper 
on the pselaphid fauna of the United States, shows that the then known fauna compared very favorably with the even far better known pselaphid fauna of Europe. Also, this is not to say that a great deal has been done in Nearctic pselaphids-there are many new species undiscovered, no thorough zoögeography-the large size of the Brazilian fauna simply means that the neotropics abound in these beetles.

The lowest taxonomic density (area divided by species) is in Ecuador, 1 species per 116,000 square miles. The highest t.d. is in the Isthmus of Panama, 1 species per 410 square miles, as far as the mainland is concerned. As seen in the following table, certain Antillean groups have a higher taxonomic density.

TABLE IX

TAXONOMIC DENSITY OF NEOTROPICAL PSELAPHIDAE

\begin{tabular}{|c|c|c|c|}
\hline \multirow[t]{2}{*}{ Country } & \multicolumn{3}{|c|}{ Taxonomic Density } \\
\hline & 1 & & 6 \\
\hline Windward Islands . . . . . . . . & 1 & & 26 \\
\hline Leeward Islands . . . . . . . . . . & $i$ & : & 53 \\
\hline 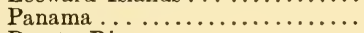 & 1 & $\vdots$ & 410 \\
\hline Puerto Rico . . . . & 1 & $\vdots$ & 850 \\
\hline Guatemala $\ldots \ldots \ldots \ldots \ldots \ldots$ & 1 & : & 964 \\
\hline British Honduras . . . . . . . . . . . & 1 & : & 2,150 \\
\hline Costa Rica . . . . . . . . . . . . . & 1 & : & 2,875 \\
\hline Paraguay $\ldots \ldots \ldots \ldots \ldots \ldots \ldots$ & 1 & : & 4,652 \\
\hline French Guiana ............. & $\hat{1}$ & : & 5,333 \\
\hline Chile $\ldots \ldots \ldots \ldots \ldots \ldots \ldots \ldots$ & 1 & : & 6,440 \\
\hline Mexico $\ldots \ldots \ldots \ldots \ldots \ldots \ldots$ & 1 & $\vdots$ & 6,909 \\
\hline Cuba...$\ldots \ldots \ldots \ldots \ldots \ldots$ & 1 & $\vdots$ & 7,333 \\
\hline Venezuela $\ldots \ldots \ldots \ldots \ldots \ldots$ & 1 & : & 7,381 \\
\hline Colombia $\ldots \ldots \ldots \ldots \ldots \ldots$ & 1 & : & 7,471 \\
\hline Brazil $\ldots \ldots \ldots \ldots \ldots \ldots \ldots$ & 1 & : & 9,221 \\
\hline Hispaniola $\ldots \ldots \ldots \ldots \ldots \ldots$ & $i$ & : & 9,400 \\
\hline Bolivia..$\ldots \ldots \ldots \ldots \ldots \ldots \ldots$ & 1 & : & 11,422 \\
\hline Nicaragua..$\ldots \ldots \ldots \ldots \ldots$ & 1 & : & 12,300 \\
\hline Dutch Guiana ............. & 1 & : & 15,333 \\
\hline Argentina..$\ldots \ldots \ldots \ldots \ldots$ & 1 & $\vdots$ & 23,530 \\
\hline Honduras $\ldots \ldots \ldots \ldots \ldots \ldots$ & 1 & $\vdots$ & $\mathbf{4 4 , 2 0 0}$ \\
\hline Peru $\ldots \ldots \ldots \ldots \ldots \ldots \ldots \ldots$ & 1 & : & 70,980 \\
\hline Uruguay $\ldots \ldots \ldots \ldots \ldots \ldots$ & 1 & : & 72,000 \\
\hline British Guiana $\ldots \ldots \ldots \ldots \ldots$ & . 1 & : & 89,500 \\
\hline Ecuador $\ldots \ldots \ldots \ldots \ldots \ldots \ldots$ & 1 & : & 116,000 \\
\hline
\end{tabular}

These ratios merely reflect our present state of information, and show no relation to size of range, but when we consider that much of the Neotropical Region is occupied by a single biome, namely the Rain Forest, with abundant moisture, food and vegetation, it is clear that the taxonomic densities, at least between the Tropics of Cancer and Capricorn, should approach each other at last. That is, a uniform biome should have a uniform taxonomic density, other conditions remaining favorable.

But what is this maximum taxonomic density? To reach an approximate answer we must return to the best known area. This is a rocky, little mountain peak, Barro Colorado Island, cut off when the Chagres River was dammed in 1914 to form the Panama Canal. It lies in Gatun Lake, athwart the north-south 
dispersal highway between Central and South America, and although it has about forty miles of shore-line, contains but six odd square miles of surface. About half of this area is in relatively untouched rain forest, and the island houses the Institute for Research in Tropical America. The climate, flora, fauna, ecology have been often and well studied (Allee, 1926, 1926a; Carpenter, 1934; Chapman, 1929; Dunn, 1931; Enders, 1935; Gross, 1930; Kenoyer, 1929; Park, 1938; Park, Barden and Williams, 1940; Rau, 1933; Schneirla, 1938; Standley, 1927 , will serve to open the bibliography for those unfamiliar with work done on the region).

Now Barro Colorado Island has been subjected to two summers of collecting Pselaphidae by the author, and in addition I have worked over the forest floor and termitophilous pselaphids of Dr. Alfred Emerson and Dr. Laura Hare from this forest, as well as the pselaphids obtained by quadrat and Berlese sample of Dr. Eliot Williams on the island forest floor; finally Dr. Bradley collected here and these pselaphids have been described by Fletcher (1927). I mention this in detail as the point is important. That is, the pselaphid fauna of this six square miles may be said to be fairly well known, and thus will serve as a guide to taxonomic density. I have little doubt that many other species await discovery here, but there are at present forty-five species of Pselaphidae known from the island. Therefore the taxonomic density of Barro Colorado Island is about 1 species per one-tenth square mile.

When this ratio of $1: 0.12$ is contrasted with the densities in Table IX, the gaps in our knowledge are better appreciated. A density of less than 1 : 10,000 in Pselaphidae represents practically unexplored territory, and hence Peru, Uruguay, British Guiana, and Ecuador are areas where collections are desirable.

Having the Barro Colorado Island figures to use as a basis for estimation, some effort should be made to give a speculative figure of the actual (described and undescribed) number of species of neotropical Pselaphidae.

TABLE X

SUBREGIONS OF NEOTROPICAL PSELAPHIDAE

\begin{tabular}{|c|c|c|c|c|c|}
\hline \multirow{2}{*}{$\begin{array}{l}\text { Subregion } \\
\text { Central American }\end{array}$} & \multirow{2}{*}{$\begin{array}{l}\text { Approximate area } \\
\text { in square miles }\end{array}$} & \multirow{2}{*}{$\begin{array}{c}\begin{array}{c}\text { Reported species } \\
\text { of Pselaphidae }\end{array} \\
257\end{array}$} & \multicolumn{3}{|c|}{$\underset{\text { Density }}{\text { Taxonomic }}$} \\
\hline & & & 1 & & 2,334 \\
\hline Antillean $\ldots \ldots \ldots \ldots \ldots \ldots$ & .. $\quad 90,000$ & 61 & 1 & : & 1,476 \\
\hline South American ............. & $6,600,000$ & 651 & 1 & : & 10,138 \\
\hline
\end{tabular}

It will be noted that the South American area is not divided into a Chilean and a Brazilian subregion of Wallace (1876). We have insufficient information on pselaphids of Peru and Ecuador for such a division. The three subregions recognized have a sufficiently distinct pselaphid fauna to warrant their existence. These three areas have an average taxonomic density of $1: 4649$, which by coincidence is nearly that of Paraguay. 
The Central American subregion includes Salvador, from which no pselaphids are known. The northern part of Mexico is nearctic, as is also an inland extension southwards involving the Rocky Mountain-Andean Cordillera. This part of Mexico has been subtracted to give the 600,000 square miles for the subregion. In general terms, from the Tropic of Cancer to South America. This area holds many endemic genera and is exposed to dispersal from the South American subregion on the south and possibly from the Nearctic Region on the north. This is to be discussed in detail shortly.

The Antillean subregion now consists of a chain of islands which begins near the mouth of the Orinoco River and extends northwestward nearly to Florida. Therefore it is discontinuous and its insular units collectively have considerable variation in local weather and terrain. The taxonomic density of $1: 1476$ is superficially impressive. Actually the pselaphid fauna is poorly known. Two local studies would be of interest: a comparative analysis of Trinidad and the Orinoco delta; a similar study of the pselaphids of three areas, namely extreme southern Florida, northwestern Cuba, and eastern Yucatan. From purely faunal needs, specimens from Jamaica are greatly to be desired. The figure of 90,000 square miles includes Jamaica, Trinidad, Barbados, and the Bahamas from which no pselaphids are known.

The third is the South American Subregion, with a density of $1: 10,138$ for the whole. The figure of $6,600,000$ is arrived at by subtracting the southern half of Argentina and southern Chile. At this early stage there appear to be at least two centers of speciation. The Matto Grosso area of southwestern Brazil, eastern Bolivia, and northern Paraguay; the upper reaches of the Amazon in northwestern Brazil, southern Colombia, and southern Venezuela.

The three subregions having been outlined, it is possible to examine the affinities of Barro Colorado Island. This small locality is well known in Pselaphidae, and such an analysis is profitable since the Panamanian Isthmus separates two of the three subregions.

On this island there are thirty-one genera, and forty-four or possibly forty-five, species. Of these genera, eleven are found nowhere else; of the species, only two are found elsewhere. This high degree of endemism is undoubtedly a consequence of lack of information in large measure. It is not even a peculiar situation in neotropical pselaphids, as we know them. That is, an area thoroughly worked will present the same picture, whether it be in Mexico, or Brazil.

Taking the situation on the island as we find it today, the genera Sebaga, Jubus, Eurhexius, Eupsenina, Xybarida, Xybaris, Arthmius, Oxarthrius, Euphalepsus, Batrybraxis, Neotyrus, and Hamotus are predominantly South American.

The genera Thesium, Trimiopsis, Scalenarthrus, Drasinus, Dalmoburis predominantly Central American - not taking into account the eleven endemic genera, which may prove to be either northern or southern in distribution.

The genus Berdura is Antillean.

The genus Reichenbachia is cosmopolitan and the genus Decarthron al- 
TABLE XI

FAUNAL AFFINITIES OF BARRO COLORADO ISLAND

\begin{tabular}{|c|c|c|c|c|}
\hline \multirow[b]{2}{*}{$\begin{array}{l}\text { Genus and Species } \\
\text { of B.C.I. }\end{array}$} & \multirow[b]{2}{*}{$\begin{array}{l}\text { Genus } \\
\text { Endemic }\end{array}$} & \multicolumn{3}{|c|}{ Species of Genus in: } \\
\hline & & $\begin{array}{c}\text { Central Am. } \\
\text { Subregion } \\
\text { (Including } \\
\text { B.C.I./ } \\
\text { Excluding) }\end{array}$ & $\begin{array}{l}\text { South Am. } \\
\text { Subregion }\end{array}$ & $\begin{array}{c}\text { Antillean } \\
\text { Subregion }\end{array}$ \\
\hline
\end{tabular}

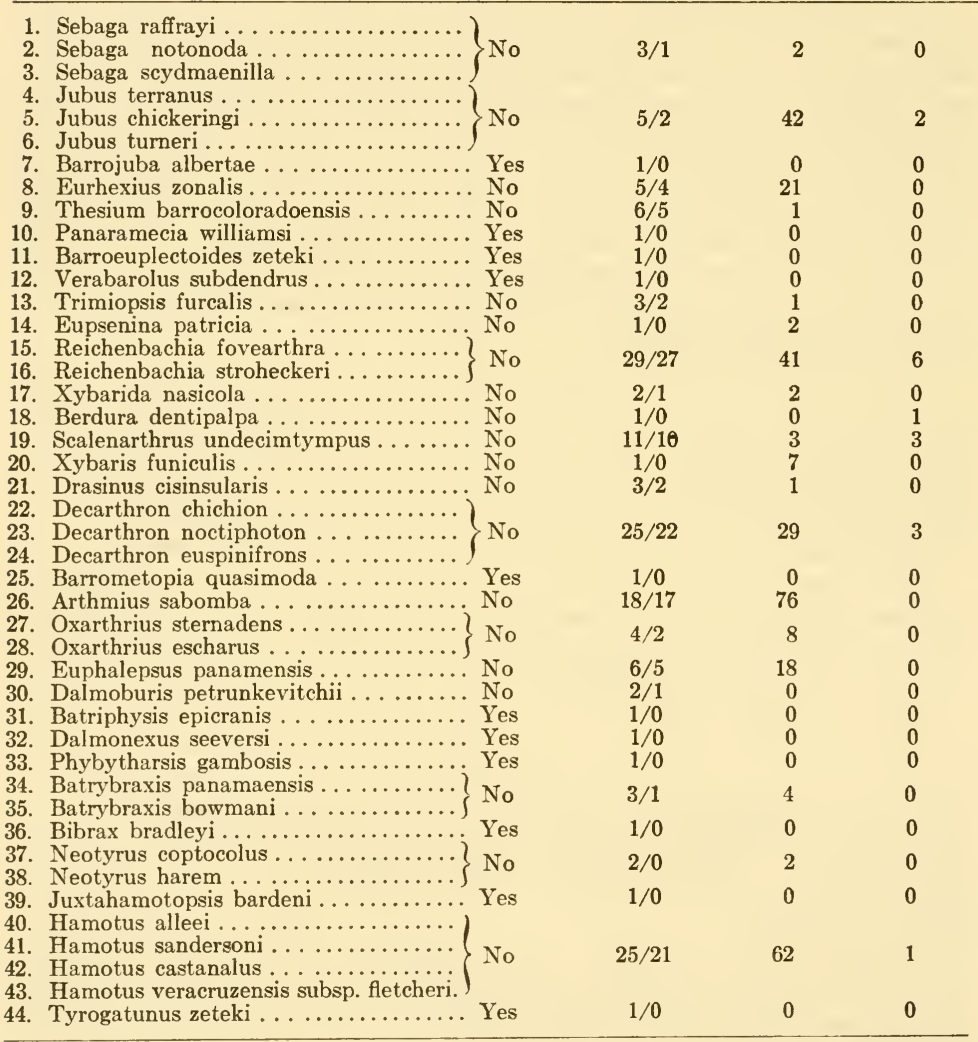

though American, is seemingly evenly distributed between the northern and southern subregions of the neotropics.

From these considerations we conclude that the pselaphid fauna of Barro Colorado Island is generically thirty per cent novel. By allowing 3 per cent to each genus, then the fauna may be stated: 


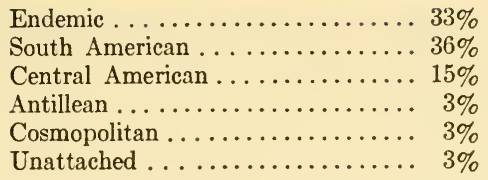

Six genera have nearctic species (Thesium, Arthmius, Scalenarthrus, Reichenbachia, Decarthron, and Hamotus). None of these genera are preponderantly nearctic; all save Reichenbachia are neotropical in proportion of species, yet the island holds six out of nineteen genera common to the nearctic and neotropical regions. It holds one of the five genera (Reichenbachia) found in the neotropics, nearctic, and also with species outside the Western Hemisphere.

Since this analysis was possible only after the taxonomic work was finished in the preceding pages, the author feels that the above discussion is without bias, and consequently represents the situation as far as is known. If this is so, the Panamanian Isthmus is represented as just such a cross-roads as theory would expect, with considerable local speciation and a marked South American element the outstanding characteristics.

Professor Dunn (1940) finds the rich herpetological fauna of Nicaragua, Costa Rica, and Panama to be relatively homogeneous and to have a high percentage of endemic species. From our survey of Barro Colorado we find this high endemism coinciding with the high endemism of Pselaphidae.

With these data before us we are in a position to estimate the total number of species of neotropical Pselaphidae (Pl. XXI). In the first place, the total area of this region is placed at $7,290,000$ square miles. If the B.C.I. index of ten species per square mile be used, then the fantastic total of 72,900,000 faunal units is obtained as a starting point. Let us examine the problem with as much care as possible. Such an assumption would infer that:

1. There were no subspecies.

2. There was a maximum taxonomic density for the entire neotropical area.

3. There was no competition for food.

4. Within the range of a species there was equal population density.

5. There was no overlapping in range between species.

1. If there were $72,900,000$ taxonomic units, this large number would presuppose a highly developed taxonomy with all ranges mapped. If this were so, these units would not be species but subspecies. The most advanced taxonomy is probably that of the ornithologists. Taking one of the largest families of American birds, the warblers, we find about 50 species and 150 subspecies. ${ }^{1}$ Assuming that the Pselaphidae subspeciate no more than three

${ }^{1}$ These figures on species and subspecies of warblers are taken from Pearson's Birds of America (1936). It should be noted that they do not agree with the 1935 Abridged Checklist of North American Birds of the American Ornithologists' Union. Other subspeciation studies, within Coleoptera, attest the probability of this general process, for example the work of Valentine $(1935,1936)$. 
subspecies on the average to one species, this gives us $24,300,000$ species populations. In our speculative argument this first step may be characterized as the Subspeciation Factor. (Pl. XXI).

2. It is obvious that the number of species is subject to great variation over such a large area. Area always covered by water (lakes, river systems, water of swamps) would be wholly uninhabited. Grasslands have a much lower yield in species. The periodically inundated forests (Haviland, 1926) and swamps would have a lower yield than moist higher lying forests. Palm swamps where the floor is thigh-deep mud, Mangrove areas, and all coastal zones periodically invaded by tides, and brackish water communities, would have very few species. Dissected rocky terrain, or areas with little or no humus, would be almost barren of species. Montane zones above the treeline would be similarly almost barren, and the impoverishment above the rain forest proper would be notable and progressive.

If this is so then the fixed subspeciation rate may not be employed as the process does not take into account the distinctive communities involved. Unfortunately exact information is lacking for most pselaphid records, for example, exact altitude in feet, whether the collection was from the plains of southern Brazil or the brazilian rain forest. Grassland or pampas of Argentina, plains of Paraguay or Uruguay, these and their many gradations may be reflected in the sum total of subspecies selection pressure and, without information, a purely artificial but logical reduction must be made.

Let us assume one-tenth of the area has maximum density, that is onetenth the area has one-tenth of $24,300,000$ or $2,430,000$; one-tenth of the area has nine-tenths maximum density, and so on:

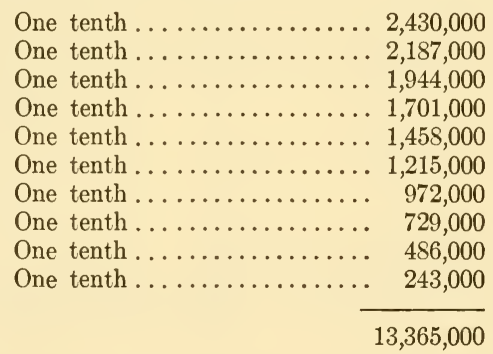

This revised total does not take into account the probability that some portions could not support any pselaphids. This should allow for at least some reduction and at a conservative figure would reduce the total to $13,000,000$ species. This second step may be characterized as the Community Factor. (Pl. XXI).

3. Species are populations of individuals and these latter must eat. Since, with few exceptions, predaceous species feed upon animals smaller than themselves, they are ecologically fixed by their size within one of the horizontal strata of the Eltonian pyramid (Elton, 1927; Park, Allee and Shelford, 1939; 
Williams, 1941). This means that there is competition for the smaller food animals between the species of predators in the same size class. To use a hypothetical example in which only food is used: if there are ten pounds of food in X time, and the predators require one pound each in $\mathrm{X}$ time, then the number of species of predators will lie between ten (monoecious or parthenogenetic) species each consisting of one individual, or one species with ten individuals.

The 13,000,000 species derived above assumed optimal food and no competition within the community. This is patently not the case. The only study in which neotropical Pselaphidae have been quantitatively collected in relation to all other animals of their size range is that of Williams (1941) on the forest floor of Barro Colorado Island. Williams analysed eighteen small quadrats twenty-five centimeters square and eleven large quadrats one meter square, both manually and with Berlese samples. This analysis produced 498 specimens of Coleoptera, including 26 specimens of Pselaphidae. These beetles were of small size, averaging between one to two millimeters. They belonged chiefly to seven characteristic families (Carabidae, Staphylinidae, Pselaphidae, Histeridae, Ptilliidae, Tenebrionidae, and Scarabaeidae). The first five families are either wholly or partially carnivorous and compete for the same food in all probability. Not all of these beetles were identified by experts in time for publication so the number of competing species of beetles must be arrived at in some other way. There were eight species of pselaphids with an average length of 1.7 millimeters. If we reorganize the Williams data, then the simple proportion of $498: 26$ as $\mathrm{X}: 8$ gives 153 species of possible coleopterous competitors.

In addition to these beetles there were numerous animals present in the leaf mold, many of which were predaceous. These included species in the same size range of one to three millimeters, small Oniscidae, Araneida, Chilopoda, Dermaptera, Reduviidae, and ants. The ants are characteristic, abundant, omnivorous and at least some species are arhythmic (Park, 1941, 1941a). These and the other animals are important competitors. Williams' tables list about 102 possible competing species other than beetles. This brings the number of competitors to 255 species.

In addition another hundred were not identified. Assuming thirty of these small forms to compete, the total possible competing species is 285 to 8 species of Pselaphidae, or 35 species to one pselaphid species.

This gives a competing ratio within the community but does not take into account inequalities in intra-community distribution within the same stratum, namely the forest floor. Both in this and the nearctic region I have found some nights to have a high yield to lights while other nights produced no pselaphids; some logs on Berlesing a sample have a high yield, nearby logs few or no pselaphids. This must be taken into account. Williams found that pselaphids occurred on 60 per cent of all quadrats.

Therefore: $13,000,000 \times 60 \%$ gives 222,857 species. 
This figure of 222,857 species may be said to be adjusted for interfamily competition within the community and this third step (Pl. XXI) may be characterized as the Competitive Factor. It assumes a more or less perfect equilibration between food and feeders, and attempts to compensate for the third and fourth postulates previously listed.

4. This does not take cognizance of the fact that species of Pselaphidae have overlapping ranges. Intrafamily competition should be more severe than interfamily competition since pselaphids would tend to have similar predators and parasites; and their food and niche requirements are satisfied during the same period of the twenty-four hour cycle. Here I have no rule to guide speculation. The present maximum of one species per one-tenth square mile may represent one-fifteenth to one-thirtieth the fauna without intrafamily competition. This would postulate 7000 to 15,000 neotropical species adjusted for total competition at this level of integration.

What has been said here refers to the Range Factor, and all of these influences (Pl. XXI) have been treated as operating independently. This is undoubtedly false, as they probably operate jointly at every part of the argument. Furthermore, there is no information upon the effects of human activity upon pselaphids. Such effects obviously exist in populated areas. These effects are certainly adverse and there is every reason to believe that this adverse influence will increase in magnitude.

Similarly there are no data on the net evolution of pselaphids, that is the relation between the establishment of successful mutants and the extinction of species.

Nor are the guests of ants and termites properly treated since selection pressures within the nest of the host must be very different from those in the forest floor or tropical grassland.

The author is aware that different methods of treatment, or rearrangement of the same treatment, might be more desirable; that different values can be set up. The considered maximum of 14,000 to 15,000 species may seem high when not quite 1000 are described, but the figure appears reasonable when we realize how little is actually known of the area estimated. When all insects have been described, the one and a half million described between 1758 and 1940 (Metcalf, 1940) will not appear nearly as imposing to us as it does now, when the tropics are just revealing their richness.

A second question to be asked is, what is the total population of individuals? This is much more readily answered as we have at least one quantitative figure. Williams found 26 specimens in thirteen square meters, or one per square meter of leaf mold in the Barro Colorado forest. This works out roughly at 300,000 per square mile. This must be reduced by half to allow for that part of the floor covered by tree trunks, et cetera, but is trebled by the $\log$ mold species, the majority of which do not inhabit the leaf duff, but pass the day beneath the loose bark of trees fallen on the ground, and this does not include the ant and termite nest forms which work out at five per cent. This gives a conservative estimate of 465,000 per square mile, for maximum forest 
cover under optimal conditions. Applying the scale for varying density of species population previously used, the total estimated population may be derived proportionally:

$\begin{array}{cccc}465,000 & : \begin{array}{c}10 \text { as } \\ \text { maximum } \\ \text { maximum } \\ \text { population } \\ \text { peries }\end{array} & \begin{array}{c}\text { sq. mi. } \\ \text { per sq. mi. }\end{array} & \begin{array}{c}14,000 \\ \text { total } \\ \text { estimated } \\ \text { species }\end{array}\end{array}$

This utilizes the precautionary steps taken in estimating number of species, since it has been held that species populations are populations of competing individuals. Therefore the estimated population of neotropical Pselaphidae is $651,000,000$.

Naturally many species are uncommon, others very abundant, but these figures enable us to set the average population at 46,500 individuals per species. This brings up a picture of many species with relatively small populations, annually maintained, competing in a relatively densely populated, relatively uniform biome.

There remains the biomass (Pickles, 1937), or living weight per unit of area. Weight data are at hand for the Chicago area only. These are the unpublished thesis figures of one of my students, Dr. Elizabeth Lunn, since used by Williams (1941), in which the average weights were obtained by weighing numbers of animals in a chemical balance. These were of beetles of the forest floor beyond the size range of pselaphids, as well as leaf and log mold oribatid mites and collembolans upon which pselaphids feed. Dr. Lunn's data were of organisms from a rich forest in the Chicago area. The beetles averaged 0.03 gram, the mites and collembolans 0.000025 gram. They are frankly average weights and in using them here we have to assume that beetles of the same general size have the same general weight. This Chicago figure is about seven times too heavy for pselaphids. If the figure of .004 gram is used, then the $651,000,000$ neotropical pselaphids have a biomass of 2,604 kilograms.

These ideas on the population may be summarized:

TABle XII

THE NEOTROPICAL PSELAPHID POPULATION

Number of described species................................... 895

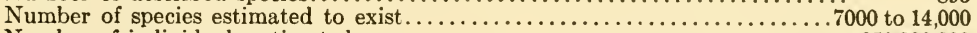

Number of individuals estimated...................................... $651,000,000$

Biomass estimated in kilograms............................................... $\quad 2,604$

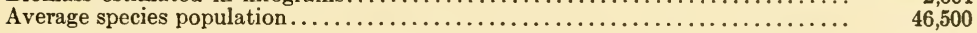




\section{Abstract}

The methods of collecting both free-living and inquilinous Pselaphidae are discussed.

The preparation of these organisms for study is outlined with respect to pinned specimens on points, whole-mounts for microscopic study, and special techniques suggested for the study of special structures, such as foveae or genitalia under very high magnification.

The historical development of pselaphid taxonomy is sketched, with especial emphasis on the Western Hemisphere.

The comparative morphology of Pselaphidae is discussed with reference to taxonomic and phylogenetic problems, especially emphasizing the parallelisms and divergences between Pselaphidae and Staphylinidae. Special reference is made to the following: number and flexibility of abdominal segments; male genitalia; maxillary palpi; tarsal segments and tarsal claws; antennae; pubescence; foveae, especially vertexal, gular and sternal; a system of numbering sternal foveae is suggested and its phylogenetic significance discussed; endoskeleton; compound eyes. This section concludes with a definition of Pselaphidae.

A key to the seventeen tribes of neotropical pselaphids is given, following which, each tribe is treated by a key to genera. The genera are variously discussed, a key to species is given in each genus where feasible, and each genus concludes with a catalogue of its species in which author, date of description, geographic range, synonymy and genotype are listed.

The several changes in the system of neotropical pselaphids, and new genera and species follow:

\section{Jubinini}

Sebaga raffrayi, S. notonoda new species, Panama Canal Zone.

Sebaga scydmaenilla (Sharp) redescribed.

Jubus terranus, J. chickeringi, J. turneri new species, Panama Canal Zone.

Barrojuba albertae, new genus and new species, Panama Canal Zone.

\section{Euplectini (including Trichonychini)}

Fletcherexius new genus for macrodactylus (Fletcher).

Group IV of Eurhexius divided into two sections.

Eurhexius zonalis new species, Panama Canal Zone.

Rhinoscepsis falli new species, Brazil.

Rhinoscepsis dybasi new species, Mexico.

Thesium barrocoloradoensis new species, Panama Canal Zone.

Panaramecia williamsi, new genus and new species, Panama Canal Zone.

Barroeuplectoides zeteki new genus and new species, Panama Canal Zone.

Verabarolus subdendrus new genus and new species, Panama Canal Zone.

Trimiopsis furcalis new species, Panama Canal Zone. 
Ramelbida new genus for quadrifoveata (Raffray).

Melba divided into Melba s.s., and the following new subgenera: Asymmelba, Rameloidea, Vertelba, Quadrelba and Frontelba.

\section{Brachyglutini}

Eupsenina patricia new species, Panama Canal Zone.

Group LXIV, new group, added to Reichenbachia.

Reichenbachia fovearthra, R. stroheckeri, new species, Panama Canal Zone.

Panabachia new genus for vulnerata (Sharp).

Xybarida nasicola new species, Panama Canal Zone.

Berdura dentipalpa new species, Panama Canal Zone.

Group V, new group, added to Scalenarthrus.

Scalenarthrus undecimtympus new species, Panama Canal Zone.

Xybaris funiculis new species, Panama Canal Zone.

Drasinus divided into Drasinus s.s., and Paradrasinus new subgenus.

Drasinus cisinsularis new species, Panama Canal Zone.

Decarthron divided into Decarthron s.s., and Decarfuss new subgenus.

Decarthron chichion, D. noctiphoton new species, Panama Canal Zone.

Decarthron euspinifrons new species, Panama Canal Zone.

\section{Metopiini}

Metopioxys seeversi new species, Colombia.

Metopioxys mattogrossoensis new species, Brazil.

Barrometopia quasimoda new genus and new species, Panama Canal Zone.

\section{Batrisini}

Arthius sabomba new species, Panama Canal Zone.

Syrmocerus guarinus new species, Brazil.

Oxarthrius divided into Oxarthrius s.s., and Baroxarthrius new subgenus.

Oxarthrius sternadens, O. escharus new species, Panama Canal Zone.

Batoctenus barberi new species, Brazil.

Euphalepsus myrmecocolus new species, Mexico.

\section{Tychini}

Dalmodes emended.

Bythinophysis emended.

Dalmoburis petrunkevitchi new genus and new species, Panama Canal Zone.

Batriphysis epicranis new genus and new species, Panama Canal Zone.

Dalmonexus seeversi new genus and new species, Panama Canal Zone.

Phybytharsis gambosis new genus and new species, Panama Canal Zone.

Anoplobraxis guianensis new genus and new species, British Guiana.

Batrybraxis panamaensis, B. Bowmani new species, Panama Canal Zone.

\section{Tyrini}

Phylogeny of neotropical genera suggested, based on maxillary palpi.

Neotyrus coptocolus new species, Panama Canal Zone.

Neotyrus harem new species, Panama Canal Zone.

Juxtahamotopsis bardeni new genus and new species, Panama Canal Zone.

Apharus colombiensis new species, Colombia.

Hamotoides a subgenus of Hamotus, not a separate genus. 
Hamotus costaricensis, new species, Costa Rica.

Hamotus alleei new species, Panama Canal Zone.

Hamotus sandersoni new species, Panama Canal Zone.

Hamotus castanalus new species, Panama Canal Zone.

Hamotus aztekus new species, Mexico.

Hamotus veracruzensis new species, Mexico.

Hamotus veracruzensis fletcheri, new subspecies, Panama Canal Zone.

Hamotus electrae, new species, Mexico.

Hamotus thomasi new species, Colombia.

Cercoceroides sternalis new species, Brazil.

Tyrogatunus zeteki new genus and new species, Panama Canal Zone.

\section{Arhytodini}

Arhytodes achillei new species, Brazil.

\section{Clavigerinae}

Clavigerinae a subfamily of Pselaphidae, not a separate family.

Fustiger veracruzensis new species, Mexico.

The names of undescribed species of Motschulsky are listed but have no validity.

There are 17 tribes, 141 genera, and 895 species of neotropical Pselaphidae. These are discussed zoögeographically. The neotropics have over twice the number of both genera and species as the nearctic region. Nineteen genera are common to the Nearctic and Neotropical Regions; five genera have species outside the Western Hemisphere.

The Neotropical Region is outlined with respect to Pselaphidae, and the area placed at about 7,290,000 square miles, with three subregions: Central American, Antillean, and South American.

Vertical distribution and population by floating rafts are discussed.

The number of species in each tribe, for each country of the neotropics is given in tabular form. These data are combined with square miles of area to work out Taxonomic Density.

The fauna of Barro Colorado Island, Panama Canal Zone, is discussed in detail and shown to have the highest taxonomic density known for the neotropics, with its pselaphid elements showing much endemism and also a strong South American influence.

By means of a theoretical approach, involving a subspeciation factor, community factor, competitive factor and a range factor, the total number of species of neotropical Pselaphidae is estimated to be between 7000 and 14,000 .

The total neotropical population of individual pselaphids is estimated at $651,000,000$ with a biomass of 2,604 kilograms. 


\section{Bibliography}

Allee, W. C. 1926. Measurement of environmental factors in the tropical rain-forest of Panama. Ecology, $7: 273-302$.

1926a. Distribution of animals in a tropical rain-forest with relation to environmental factors. Ecology, 7:445-468.

Aube, Carolo. 1833. Monographia Pselaphiorum. Lequien, Paris. 94 pp., 17 pl.

1844. Revision de la famille des Pselaphiens. Annales de la Societe Entomologique de France, 2:73-160.

Blackwelder, R. E. 1936. Morphology of the Coleopterous family Staphylinidae. Smithsonian Miscl. Collection, 94: No. 13.

Bequaert, J. 1940. The Tabanidae of the Antilles. Revista de Entomologia, 11:253-369.

Blatchley, W. S. 1910. Coleoptera or beetles known to occur in Indiana, exclusive of Rhynchophora. Nature Pub. Co., Indianapolis. 1,386 pp.

Böving, A. G. and F. C. Craighead. 1931. Larvae of Coleoptera. Brooklyn Entom. Soc., Vol. 11 (pub, in book form).

Bowman, J. R. 1934. The Pselaphidae of North America. Pub. privately, Pittsburgh. $149 \mathrm{pp}$.

Bradley, J. C. 1930. A manual of the genera of beetles of America, north of Mexico. Daw, Illston \& Co., Ithaca.

Brendel, Emil. 1865. On some new species of Pselaphidae. Proc. Ent. Soc. Philadelphia, pp. $28-32$.

1865a. New species and corrections in Pselaphidae. Proc. Ent. Soc. Philadelphia, pp. 255-260.

1866. Synopsis of the genera and species of the family Pselaphidae. Proc. Ent. Soc. Philadelphia, pp. 31-38.

- 1866a. Description of some new species of Pselaphidae. Proc. Ent. Soc. Philadelphia, pp. 189-194.

1889. Descriptions of Scydmaenidae and Pselaphidae. Entomologica Americana 5:193-197.

1892. On the pselaphid genus Trimium. Trans. Am. Ent. Soc., 19:165-168.

1893. Notes and descriptions of Pselaphidae. Trans. Am. Ent. Soc., 20:277-284. and H. F. Wickham. 1890. The Pselaphidae of North America. Bull. Lab. Nat.

Hist., State Univ. Iowa, 1:216-304; 2:1-84.

Bruch, Carlos. 1917. Nuevos capturas de insectos mirmecofilos. Physis, 3:450-465.

1918. Nuevos huespedes de hormigas procedentes de Cordoba. Physis, 4:186-195. 1929. Neue myrmekophile Histeriden und Verzeichnis der aus Argentinien bekannten Ameisengaste. Zoologischen Anzeiger, Wasmann-Festband, pp. 421-437. 1929a. (Description of Neofustiger cochlearis, new genus and new species). Rev. Soc. ent. Argentina, Buenos Aires, 2:159. (not seen).

1931. Algunos mirmecofilos y termitofilos nuevos y poco conocidos de la Argentina. Revista de Entomologia (Sao Paulo, Brazil), 1:387-395.

1933. Coleopteros mirmecofilos de Misiones. Revista de Entomologia (Rio de Janeiro, Brazil), 3:12-37.

Bryant. 1915. (Description of Fustiger nitidus) Ent. Mag., 51:213. (not seen).

Carpenter, C. R. 1934. A field study of the behavior and social relations of howling monkeys. Comp. Psychol. Monogr., 10: Ser. No. 48, Johns Hopkins Press, Baltimore.

Casey, T. L. 1884. Contributions to the descriptive and systematic Coleopterology of North America. Parts I and II. Published privately, Collins House, Philadelphia. 198 pp. 
1886. Descriptive Notices, I. California Acad. Sci., 157-264.

1887. On some new North American Pselaphidae. Bull. California Acad. Sci.,

2:455-482.

1893. Coleopterological Notices, V. Ann. New York Acad. Sci., 7:281-606.

1897. Coleopterological Notices, VII. Ann. New York Acad. Sci., 9:285-684.

1908. Remarks on some new Pselaphidae. Canadian Entomologist, 40:207-211.

Chapman, F. M. 1929. My tropical air castle. Nature studies in Panama. New York:

D. Appleton \& Co.

- 1933. Autobiography of a bird-lover. New York: D. Appleton-Century Co.

Cochran, Doris M. 1941. The Herpetology of Hispaniola. U. S. Nat. Mus., Bull. No. 177.

Crawley, W. C. 1916. Note on Myrmecophily. Ann. Nat. Hist., 17:377.

Cutright, P. R. 1940. The great naturalists explore South America. New York: Macmillan $\mathrm{Co}$.

Denny, Henry. 1825. Monographia Pselaphidarum et Scydmaenidarum. Norwich, Gr. Brit. vi +72 pp. 14 pl.

Dobzhansky, Theodosium. 1937. Genetics and the origin of species. New York: Columbia Univ. Press.

Donisthorpe, H. St. J. K. 1909. On the origin and ancestral form of myrmecophilous Coleoptera. Trans. Ent. Soc. London, pp. 397-411.

1927. The guests of British Ants. London: G. Routledge \& Sons. 244 pp.

Dunn, E. R. 1931. The amphibians of Barro Colorado Island. Occ. Papers Boston Soc. Nat. Hist., 5:403-421.

1940. Some aspects of Herpetology in Lower Central America. Trans. New York Acad. Sci., 2:156-158.

Dury, Charles. 1884. Notes on Coleoptera, with additions to the list of the Coleoptera of Cincinnati. Jour. Cincinnati Soc. Nat. Hist., 7:91-92.

1892. (Note). Entomological News, 3:96.

1898. (Note). Jour. Cincinnati Soc. Nat. Hist., 19:140.

1903. A revised list of the Coleoptera observed near Cincinnati, Ohio. Jour.

Cincinnati Soc. Nat. Hist., 20:107-196.

Elton, Charles. 1927. Animal Ecology. London: Sidgwick \& Jackson.

Enders, R. K. 1935. Mammalian life histories from Barro Colorado Island, Panama. Bull. Mus. Comp. Zool., 78:387-502.

Fall, H. C. 1927. The North American species of Rybaxis. Psyche 34:218-226.

Fletcher, F. C. 1927. Undescribed Pselaphidae collected by Dr. J. C. Bradley in Panama. Entomological News 38:149-153.

1928. The Cornell University expedition to South America 1919-1920. Scientific results No. 4. Pselaphidae. Trans. Am. Ent. Soc., 54:69-77.

- 1928a. Pselaphidae collected by Dr. Alfons Dampf in Central America. Ann. Ent. Soc. Am., 21:203-231.

- 1930. Notes on neotropical Pselaphidae, with descriptions of new species. Ann. and Mag. Nat. Hist., Ser. 10. 5:95-100.

1932. Undescribed North American species of Pselaphidae, including a synopsis of the genus Rhexidius Casey. Canadian Entomologist 64:29-35.

Gallardo, Angel. 1915. Observaciones sobre algunas hormigas de la Republica Argentina.

Annales del Museo Nacional de Historia Natural 27:1-35.

- 1916. El mirmecofilo sinfilo Fustiger elegans Raffray. Physis (Revista de la

Sociedad Argentina de Cien. Nat.), 2:254-257.

Ganglbauer, Ludwig. 1895. Die Käfer von Mittel Europa, Vol. II. Familienreihe Staphylinoidea. Wien. 880 pp.

Gory, H. L. 1832. (Description of Metopias curculionoides) Mag. Zool. (not seen).

Gross, A. O. 1930. A jungle laboratory. Nature Magazine, Vol. 15.

Hamilton, John. 1886. Natural history notes on certain Coleoptera. No. 1. Canadian

Entomologist 18:26-30. (Suggests that rarity of larvae of myrmecophiles in host 
nest a consequence of beetles leaving host in spring and summer to breed elsewhere).

- 1885. Catalogue of the myrmecophilous Coleoptera with bibliography and notes. Canadian Entomologist 20:161-166.

Haviland, Maud D. 1926. Forest, Steppe and Tundra. Cambridge Univ. Press.

Henshaw, Samuel. 18S5. List of the Coleoptera of America, north of Mexico. Philadelphia. $161 \mathrm{pp.}$

Herbst, J. F. W. 1792. Natursystem Käfer, Vol. IV. Berlin. (Pselaphidae as a family first recognized in this work).

Hersh, A. H. 1934. On Mendelian dominance and the serial order of phenotypic effects in the bar series of Drosophila melanogaster. American Naturalist 68:186-190.

- 1934a. The time curve of facet determination in an ultrabar stock of Drosophila melanogaster. Jour. General Physiology 17:487-498.

Hesse, Richard, W. C. Allee and K. P. Schmidt. 1937. Ecological Animal Geography. New York: John Wiley \& Sons. 597 pp.

Hetschko, Alfred. 1896. Zur Biologie von Claviger testaceus Preyssl. Berliner Ent. Zeit., $41: 45-50$.

Holmquist, A. M. 1926. Studies in arthropod hibernation. Ann. Ent. Soc. Am., 19:395428.

1928. The hibernation of the ant, Formica ulkei Emery. Physiol. Zool., 1:325-357. 1928a. Notes on the life-history and habits of the mound-building ant, Formica ulkei Emery. Ecology, 9:70-87.

Humboldt, Alexander von. 1850. Views of Nature. London: George Bell \& Sons. (Trans. Otte and Bohn).

Jacot, Arthur P. 1935. Wild life of the forest carpet. Scientific Monthly 40:425-430.

1936. Quantitative litter sampling. Ecology 17: No. 2.

1936a. Soil structure and soil biology. Ecology 17:359-379.

Janet, C. 1896. Sur le Lepismina polypoda et sur ses rapports avec les Fourmis. Bull. Soc. Ent. France 65:131.

Kenoyer, L. A. 1929. General and successional ecology of the lower tropical rain-forest at Barro Colorado Island, Panama. Ecology 10:201-222.

Kinsey, A. C. 1930. The gall wasp genus Cynips. A study in the origin of species. Indiana Univ. Stud., 16:1-577.

- 1936. The origin of the higher categories in Cynips. Indiana Univ. Pub., Sci. Ser., No. 4.

Knaus, Warren. 1908. Notes on Coleoptera. Canadian Entomlogist, 40:91-93.

Krueger, Erich. 1910. Beiträge zur Anatomie und Biologie des Claviger testaceus Preyssl. Zeit. f. wissensch. Zool., 95:327-381.

Kükenthal, Willy. 1933-1936. Handbuch der Zoologie, Vol. 4, Part 2. (Pselaphidae, p. 1270, by Josef Meixner).

LeConte, J. L. 1850. On the Pselaphidae of the United States. Boston Jour. Nat. Hist., 6:64-110.

- 1863. New species of North American Coleoptera. Part 1. Smithsonian Miscellaneous Coll. VI, No. 167:1-92.

- 1874. Descriptions of new Coleoptera chiefly from the Pacific Slope of North America. Trans. Am. Ent. Soc., 5:43-72.

— 1878. Coleoptera of Florida. Proc. Am. Philos. Soc., 17:353-472.

— 1878a. Coleoptera of Michigan. Pros. Am. Philos. Soc., 17:593-699.

18S0. Short studies of North American Coleoptera. Trans. Am. Ent. Soc., 8:163-218.

— and G. H. Horn. 1883. Classification of the Coleoptera of North America. Smithsonian Miscellaneous Coll., No. 507.

Leng, C. W. 1920. Catalogue of the Coleoptera of America, North of Mexico. Mt. Vernon, N. Y.: J. D. Sherman, Jr. 470 pp. 
1928. A list of the insects of New York. Cornell Univ. Agr. Exp. Sta., Mem. 101.

Mann, W. M. 1911. Notes on guests of Californian ants. Psyche 18:27-31.

1911a. On some North West ants and guests. Psyche 18:102-9.

1914. Some myrmecophilous insects from Mexico. Psyche 21:171-184.

1915. Some myrmecophilous insects from Hayti. Psyche 22:161-166.

1918. Myrmecophilous insects from Cuba. Psyche 25:104-106.

1921. Three new myrmecophilous beetles. Proc. U. S. Nat. Mus., 59:547-552.

1924. Myrmecophiles from the western United States and Lower California.

Ann. Ent. Soc. Am., 17:87-95.

Margolis, O. S. 1935. The effect of the gene vestigial on facet number in Bar. Genetics 20:156-171.

McCook, H. C. 1877. The mound-making ants of the Alleghanies. Trans. Am. Ent. Soc., 6:253-296.

Metcalf, Z. P. 1940. How many insects are there in the world? Entomological News $51: 219-222$.

Morgan, T. H. 1919. The physical basis of heredity. Philadelphia: J. B. Lippincott. $305 \mathrm{pp}$.

1926. The theory of the gene. New Haven: Yale Univ. Press. 343 pp.

Motschulsky, Victor de. 1855. (Letter) Etudes Entomologiques, pp. 8-25.

Müller, P. W. J. (Mueller). 1818. Beiträge zur Naturgeschichte der Gattung Claviger. Magazin der Entomologie (Germar) 3:69-112. (First ecological study of myrmecophilous pselaphids).

Park, Orlando. 1929. Ecological observations upon the myrmecocoles of Formica ulkei Emery, especially Leptinus testaceus Mueller. Psyche 36:195-215.

1932. The myrmecocoles of Lasius umbratus mixtus aphidicola Walsh. Ann. Ent. Soc. Am., 25:77-88.

1932a. The food of Batrisodes globosus (LeConte). Jour. New York Ent. Soc., 40:377-378.

1933. The food and habits of Tmesiphorus costalis LeConte. Entomological News 44:149-151.

- 1933a. Ecological study of the ptiliid myrmecocole, Limulodes paradoxus Matthews. Ann. Ent. Soc. Am., 26:255-261.

1933b. A new species of Pselaphidae from Costa Rica. Ann. Ent. Soc. Am., 26:563-566.

— 1935. Hamotus turalbus, a new species from Costa Rica. Ann. Ent. Soc. Am., 28:131-134.

- 1935a. Further records of beetles associated with ants. Entomological News $46: 212-215$.

1935b. Beetles associated with the mound-building ant, Formica ulkei Emery.

Psyche 42:217-231.

- 1938. Studies in Nocturnal Ecology, VII. Preliminary observations on Panama Rain Forest animals. Ecology 19:208-223.

1940. Nocturnalism-the development of a problem. Ecological Monographs 10:485-536.

— 1941. Concerning Community Symmetry. Ecology 22:164-167.

- W. C. Allee and V. E. Shelford. 1939. A Laboratory Introduction to Animal Ecology and Taxonomy. University of Chicago Press. $272 \mathrm{pp}$.

- A. A. Barden and E. C. Williams, Jr. 1940. Studies in Nocturnal Ecology, IX. Further analysis of activity of Panama Rain Forest animals. Ecology 21:122-134. Paykull, Gustaf von. 1789. Staphylinorum Sueciae, Upsala. pp. 365-366. (First pselaphid described but placed in Staphylinidae).

Pickles, W. 1937. Populations, territories, and biomasses of ants at Thornhill, Yorkshire in 1936. Journal Animal Ecology 6:54-61. 
Raffray, Achille. 1882. Pselaphides nouveaux ou peu connus, I. Revue d'Entomologie, $1: 1$.

1883. Pselaphides nouveaux ou peu connus, II. Revue d'Entomologie, 2:229-250.

1887. Pselaphides nouveaux ou peu connus, III. Revue d'Entomologie, 6:18.

1890. Etude sur les Pselaphides: Genera et descriptions d'especes nouvelles.

Revue d'Entomologie, 9:1-264.

- 1891. Voyage de M. E. Simon au Venezuela. Pselaphides. Ann. Soc. ent. France,

$60: 297-330$.

- 1893. Essai Monographique sur la tribu des Faronini (Psellaphiens). Revue

d'Entomologie, 12:1-53.

1895. Revision du genre Tyropsis. Ann. Soc. ent. France, 64.

- 1896. Pselaphides du Bresil meridional. Ann. Soc. ent. France, 65.

- 1896a. Notes synonymiques sur les Pselaphides. Ann. Soc. ent. France, 65.

-1896b. Nouvelles etudes sur les Pselaphides et les Clavigerides. Ann. Soc. ent.

France, 65:227-284.

1897. Revision des Batrisus et genres voisins de l'Amerique centrale et meridionale. Ann. Soc. ent. France, 66:431-516.

- 1898. Notes sur les Pselaphides-Revision Generique de la Tribu des Euplectini

—descriptions d'especes Nouvelles. Revue d'Entomologie 17:198-273.

-1903-1904. Genera et Catalogue des Pselaphides. Ann. Soc. ent. France, 72:484-

$604(1903) ; 73: 1-476,636-658$ (1904). (This is the first complete World Catalogue

of the family).

1908. Pselaphidae. Genera Insectorum, 64th. Fascicule, P. Wytsman, ed.

Bruxelles. 487 pp. 9 pl. (This is probably the most important single work on the family).

1908a. Supplement a la liste des Coleopteres de la Guadeloupe (Pselaphidae),

2nd. Supplement. Ann. Soc. ent. France, 77:33-40.

- 1908b. Pselaphides de la Republique Argentine. Description des especes nouvelles. Revista del Museo de la Plata, 15:61-83.

1909. Nouvelles especes de Pselaphides. Ann. Soc. ent. France, 78:15-52.

1911. Pselaphidae. Junk's Coleopterorum Catalogus. Part 27:1-222.

1911a. Pselaphides de la Republique Argentine. Ann. Mus. Nac. Hist. Nat.

Buenos Aires (1912), 22:447-450.

_ 1911b. Especes nouvelles de Pselaphides exotiques. Ann. Soc. ent. France, $80: 425-450$.

- 1912. Supplement a la liste des Coleopteres de la Guadeloupe (Pselaphidae), 3rd. Supplement. Ann. Soc. ent. France, 81:289-290.

- 1912a. Pselaphides de la Republique Argentine. Anales del Museo Nacional de Historia Natural de Buenos Aires 22:445-450.

- 1917. Nouvelles especes de Pselaphides (Paraguay). Ann. Soc. ent. France, S6:473-502.

Rau, Phil. 1933. Jungle Island bees and wasps of Barro Colorado Island, Panama. Kirkwood, Missouri.

Redtenbacher, Ludwig. 1849. Fauna Austriaca. 1st. ed., Wien. (2nd. ed. 185S). Die Käfer.

Reichenbach, H. T. L. 1816. Monographia Pselaphorum. Lipsiae. 80 pp. 2 pl. (This is an important early work on the family).

Reichensperger, August. 1931. Zwei neue Clavigerinen aus Costa Rica. Entomologische Blätter, 27:4-7.

1933. Ecitophilen aus Costa Rica, Brasilien und Peru. Revista de Entomologia (Rio de Janeiro), 3:179-194.

- 1936. Beitrag zur Kenntnis der myrmecophilen-und termitophilen-fauna Brasiliens und Costa Ricas. IV. Revista de Entomologia (Rio de Janeiro), $6: 222-242$. 
1939. Beitrage zur Kenntnis der myrmecophilenfauna Costa Rica und Brasiliens, VII, nebst Beschreibung der Königin von Eciton pilosum. Zool. Jahrb. Syst., Jena, 73:261-300.

Reitter, Edmund. 1881. Versuch einer systematischen Eintheilung der Clavigerinen und Pselaphiden. Verh. naturf. Ver. Brünn, 20:177-211.

- 1882. Neue Pselaphiden und Scydmaeniden aus Central-und Sudamerika. Verh. k. k. zool.-bot. Gesell. Wien, 32:371-386.

1882a. Neue Pselaphiden und Scydmaeniden aus Brasilien. Deuts. Ent. Zeitschr., 26:129-152.

1883. Beitrag zur Kenntniss der Pselaphiden Fauna von Valdivia. Deuts. Ent. Zeitschr., 27.

1883a. Beitrag zur Kenntniss der Clavigeriden, Pselaphiden und Scydmaeniden von Westindien. Deuts. Ent. Zeitschr., 27:31-46.

- 1884. Ueber die bekannten Clavigeriden-Gattungen. Verh. k. k. zool.-bot. Gesell. Wien, 34.

1885. Beitrag zur Kenntniss der Pselaphiden Fauna von Valdivia. Deuts. Ent. Zeitschr., 29.

- 1885a. Abbildungen und Bemerkungen zu wenig gekannten PselaphidenGattungen mit Beschreibungen neuer Arten. Deuts: Ent. Zeitschr., 29:333-339.

1888. Neue von Herr. L. Hetschko um Blumenau in Südlichen Brasilien gesammelt Pselaphiden. Deuts. Ent. Zeitschr., 32.

1889. Eine neue interessante Rybaxis aus Valdivia. Wien. Ent. Zeit. (not seen).

- 1909. Fauna Germanica. Die Käfer des Deutschen Reiches. Vol. II, pp. 201-220. Stuttgart.

Ross, H. H. 1934. How to collect and preserve insects. Illinois State Nat. Hist. Surv., Circular 25.

Sanderson, M. W. 1940. Two new species of Batrisodes from South Carolina. Entomological News, 51:169-172.

Schaeffer, C. F. A. 1906. Six new Pselaphidae. Trans. Am. Ent. Soc., 32:261-266.

Schaufuss, L. W. 1872. Beschreibung einiger Pselaphiden. Nunquam Otiosus, 2:259-274.

Dresden.

— 1872a. Ueber Pselaphidengattungen. Nunquam Otiosus, 2:450-460. Dresden.

- 1879-1880. Sechzig neue Pselaphiden. Museum Ludwig Salvator. DresdenOberblasewitz. $35 \mathrm{pp}$.

— 1886. Beschreibung Neuer Pselaphiden. Tijdschrift voor Entomologie, 29:241-296.

— 1887. Beschreibung Neuer Pselaphiden. Tijd. voor Ent., 30:103.

Schmidt, K. P. 1936. Guatemalan salamanders of the genus Oedipus. Field Museum Zool. Ser., 20:135-166.

Schneirla, T. C. 1938. A theory of army-ant behavior based upon the analysis of activities in a representative species. Jour. Comp. Psychol., 25:51-90.

- 1940. Further studies on the army-ant behavior pattern. Mass organization in the swarm-raiders. Jour. Comp. Psychol., 29:401-460.

Schwarz, E. A. 1889. Myrmecophilous Coleoptera found in Temperate North America. Proc. Ent. Soc. Washington, 1:237-247.

1890. A list of blind or nearly eyeless Coleoptera hitherto found in North America. Proc. Ent. Soc. Wash., 2:23-27.

1896. Additions to the lists of North American termitophilous and myrmecophilous Coleoptera. Proc. Ent. Soc. Wash., 3:73-77.

Sharp, David. 1887. Pselaphidae. Biologia Centrali-Americana, Coleoptera. Vol. 2, Part 1. pp. 1-46, 1 pl. (The only faunal paper on the neotropical pselaphids).

Smith, H. B. 1940. An analysis of the biotic provinces of Mexico, as indicated by the distribution of the lizards of the genus Sceloporus. An. Escuela Nacion. Cienc. Biol., Mexico, 2:95-102. 1 map. 
Standley, P. C. 1927. The flora of Barro Colorado Island, Panama. Smithsonian Misc. Coll., 78: No. 8 .

Stickney, F. S. 1923. The head-capsule of Coleoptera. Illinois Biol. Monogr., Vol. 8: No. 1.

Tanner, V. M. 1927. A preliminary study of the genitalia of female Coleoptera. Trans. Am. Ent. Soc., 53:5-50.

Valentine, J. M. 1934. Technique in the preparation of Coleoptera. Elisha Mitchell Sci. Soc., 50:255-262.

- 1935. Speciation in Steniridia, a group of Cychrine beetles. Elisha Mitchell Sci. Soc., 51:341-375.

1936. Raciation in Steniridia andrewsi Harris, a supplement to speciation in Steniridia. Elisha Mitchell Sci. Soc., 52:223-234.

Wallace, A. R. 1876. The Geographical Distribution of Animals. Two volumes. New York: Harper. 1,110 pp.

1880. Island Life. Macmillan, London (3rd. ed. 1911), 563 pp.

Wasmann, E. 1890. Neue myrmekophile Staphyliniden aus Brasilien. Deutsch. Ent. Zeitschr., 34:305-318.

1890a. Vergleichende Studien über Ameisengäste und Termitengäste. Tijdschr. Ent., 33:27-97.

- 1891. Eine neue Clavigeride aus Madagaskar. Stett. Ent. Zeitg., 52:3-10.

1891a. Vorbemerkungen zu den internationalen Beziehungen der Ameisengäste.

Biol. Centralb. 11:331-343.

1892. Die internationalen Beziehungen von Lomechusa strumosa. Biol. Centralb.,

12: $18-21$; 584-559; 638-669.

1892a. Zur Biologie einiger Ameisengäste. Deutsch. Ent. Zeitschr., 36:347-351. 1894. Kritisches Verzeichniss der myrmekophilen und termitophilen Arthropoden. Mit Angabe der Lebensweise und Beschreibung neuer Arten. Berlin. 231 pp. (This is the earliest complete treatment of inquilines).

1895. Die Ameisen- und Termitengäste von Brasilien. Verh. Zool. Bot. Gesell. Wien., 4:137-179.

1896. Kritische Bemerkungen über einige Myrmekophilen und Termitophilen.

Wien. Ent. Zeitg., 1:32-36.

1897. Zur Entwicklung der Instinkte (Entwicklung der Symphilie). Verh. Zool.

Bot. Gesell. Wien., 6:168-183.

- 1897a. Eine neue Xenodusa aus Colorado, mit einer Tabelle der Xenodusa-

Arten. Deutschr. Ent. Zeitschr., 41:273-274.

- 1904. Neue Beiträge zur Kenntniss der Paussiden mit biologischen und phylogenetischen Bemerkungen. Leyden Mus., 25:1-82.

1906. Beispiele rezenter Artenbildung bei Ameisengästen und Termitengäste.

Biol. Centralb., 26:565-580.

— 1911. Die Anpassungsmerkmale der Atemeles, mit Einer Uebersicht über die

Mitteleuropäischen Verwandten von "Atemeles paradoxus Grav." Ier. Congrés Internat. d'Ent., Bruxelles, 1910, 2:265-272.

Westwood, J. O. 1856. Descriptions of various species of the Coleopterous family Pselaphidae, natives of New South Wales and South America. Trans. Ent. Soc. London, New Series, 3:268-280.

1870. Descriptions of twelve new species of the Coleopterous family Pselaphidae. Trans. Ent. Soc. London, (not seen).

- 1874. Thesaurus Entomologicus Oxoniensis. Oxford. 205 pp.

Wetmore, Alexander and B. H. Swales. 1931. The birds of Haiti and the Dominican Republic. U. S. Nat. Mus. Bull. No. 155.

Wheeler, W. M. 1910. (1926). Ants: Their Structure, Development and Behavior. New York: Columbia Univ. Press. $663 \mathrm{pp}$. (This contains a large bibliography on inquilines and much information on myrmecophiles).

- 1923. Social Life among the Insects. Harcourt, Brace \& Co., Boston, 375 pp. 
1928. The Social Insects: Their Origin and Development. Harcourt, Brace \& Co., Boston. 378 pp.

Wickham, H. F. 1889. Collecting notes. Ent. Am., 5:77-78.

— 1892. Notes on some myrmecophilous Coleoptera. Psyche, 6:321-323.

- 1894. Further notes on Coleoptera with ants. Psyche, 7:79-81.

— 1896. On Coleoptera found with ants. Psyche, 7:370-372.

- 1898. On Coleoptera found with ants. Psyche, 8:219-221.

- 1900. On Coleoptera found with ants. Psyche, 9:3-5.

- 1901. Two new blind beetles, of the genus Adranes, from the Pacific Coast. Canadian Entomologist, 33:25-28.

Williams, E. C., Jr. 1941. An ecological study of the floor fauna of the Panama rain forest. Bull. Chicago Acad. Sci., 6:63-124.

Zeleny, Charles. 1917. Selection for high-facet and for low-facet number in the Bareyed race of Drosophila. Am. Assoc. Adv. Sci., 15th. Ann. Meeting. Abstract.

1917a. Full-eye and emarginate-eye from Bar-eye in Drosophila without change in the Bar gene. Am. Assoc. Adv. Sci., 15th. Ann. Meeting. Abstract. and E. W. Mattoon. 1915. The effect of selection upon the "Bar-eye" mutant of Drosophila. Journal Experimental Zoology, 20. 


\section{General Index}

Names of new genera, subgenera, species and subspecies are italicized. Valid species of neotropical Pselaphidae are followed by the genera in parentheses. Species not so treated refer to synonyms, or are not species of Pselaphidae, or are pselaphids not known from the neotropical region.

A

abbreviatus 58

abdomen $15-18$

abdominalis (Eurhexius) 82

aberrans (Jubus) 58

Abies 72

Abryxis 165, 173

Acarina 3

achillei (Arhytodes) 345-346

Achillia 19, 154-157

acignathus 274

Acotebra 107

Actinoma 65, 108

Actium 63, 65, 97, 107-108

acutangulus (Bythinoplectus) 37

Adalmus 97

adparatus (Scalenarthrus) 173

Adranes 4, 6, 7, 13, 20, 22, 23, 26, 28, 29, $349,350,351,352$

Adrocerus 285

Adrogaster 107

adulator (Arthmius) 232

adumbrata (Tyropsis) 299

aedeagus, see genitalia

aequinoctialis (Ctenisis) 293

Africa 214, 233, 283, 284, 292, 338

aglenus (Metopiellus) 205

albertae (Barrojuba) 60-62

Aleocharinae 18

Aleocharini 14, 19

Algeria 135

alleei (Hamotus) 309, 310, 320-321, 331

Allobrox 71

alternans (Jubus) 58

altitude $363-365$

Amaurops 29

amazonica (Ctenisis) 293

amazonicus (Fustiger) 358

americanus 7

ampliventris (Phalepsus) 298

Anarmodius 72, 73, 75

anas 157

anatomy, see morphology

Anchylarthron 176

Andes 364, 371

anguina (Trimiosella) 112

angulata (Rhexinia) 73

angustata (Ctenisis) 293

angustatus (Eurhexius) 82 anophthalmus (Goniacerus) 285

Anoplobraxis 277-279

Anoplotermes 279

antennae 19-20,135, 185, 204, 283, 350

antennator (Syrbatus) 236

Antennophorus 352

anthicoides (Oxarthrius) 246

Antilles 362, 363, 367

subregion $370-371$

ants $7,37,40,81,99,120,175,197,205$, $210,215,246,291,293,294,295,309$, $310,332,347,348,349,350-352,353,354$, $356,357-358,376$

Aphaenogaster 7, 309, 357

Apharus 305-307

aphidicola 7,352

Aplodea 156, 157, 298, 303, 305

Aploderina 332

Apoderiger 350

Aporhexius $67,72,73,74$

Apothinus 89, 93

appendicularis (Hamotus) 329

appendiculata (Reichenbachia) 147

appendiculatus (Hamotus) 331

approximatus (Achillia) 156

Araneida 375

Arctophysis 41

area 368

areolatus (Arthmius) 231

Argentina 31, 362, 367, 368, 369, 371

argentina (Reichenbachia) 152

argentinus (Hamotus) 329

argus (Jubus) 58

argus (Thesiastes) 98

Arhytodes 21, 344, 347

Arhytodini 19, 23, 31, 34, 343-347

Arianops 29

armatellus (Arthmius) 231

armatus (Oxarthrius) 246

armatus (Phoberus) 134

armiceps (Bryaxina) 159

armipes (Apharus) 307

Arthmius 21, 215-233, 236, 237, 238, 240

arthriticum (Decarthron) 198

Articerus 350,353

articularis (Arthmius) 230

asteriscus 248

Asymmelba 121

Atelura 4 
Atemeles 21

Atinus 19

atomaria (Xybaris) 179

atratus 98

atricapillus 237

Atta $37,99,120,175,246,348,349$

attaphilus (Oxarthrius) 246

Attapseniini 19, 21, 31, 33, 34, 348-349, 351

Attapsenius 349

aubeana (Reichenbachia) 139

aubeanus (Hamotus) 329

aubei 292

aubei (Arthmius) 231

auricapillus (Hamotus) 329

auriculatus (Arthmius) 232

auritulus (Syrbatus) 237

aurivillii (Decarthron) 200

auropunctata 347

Australia 135, 214, 338

australis 347

Autoplectus 29

aztekus (Hamotus) 323-324, 330

\section{B}

badius (Hamotus) 329

Bahamas 371

Balega 62

Barada 122, 126

Barbados 371

barbatus (Hamotus) 329

barberi (Batoctenus) 250-253

barbiellinii (Arthmius) 230

bardeni (Juxtahamotopsis) 303-305

Baroxarthrius 241, 244, 246

barretoi (Metopiosoma) 205

barrocoloradoensis (Thesium) 91-93

Barro Colorado Island 367, 369, 370, 371, 372-373

Barrojuba 20, 39, 59-62

Barroeuplectoides 101-104

Barrometopia 29, 210-213, 284.

basisternum 25

Basolum 65

batesellus (Phalepsus) 298

Batoctenus 249-253

Batriphysis 270-272

Batrisobryaxis 263

Batrisodes 4, 5, 6, 7, 8, 11, 16, 17, 20, 214, 246,248

batrisoides 309

batrisoides (Dalmoplectus) 111

batrisoides (Pselaptus) 175

Batrisini 17, 18, 23, 29, 31, 32, 214-259

Batrisus 215, 216, 230, 231, 232, 233, 240, $246,248,282$

Batrybraxis 265, 279-282

belfragei 174

bellicosus (Metopioxys) 210

bellus (Hamotus) 332
Berdura 163-165, 174

Bergrothiella 29

Berlara 163

Berlese method 2, 3

Biblomimus 93-94, 97

Bibloplectus 3, 15, 22, 28, 64, 97

Bibloporus 63

Bibrax 29, 204, 213, 283, 284

biarmatus (Iteticus) 248

biclavata (Reichenbachia) 145

bicolor (Arthmius) 230

bicolor (Decarthron) 198

bicolor (Eurhexius) 82

bicolor (Hamotus) 330

bicolor (Lioplectus) 99

bicolor (Pselaphellus) 287

bicornis (Arthmius) 231

bidenticulatus (Syrbatus) 237

bifossifrons (Achillia) 156

bifossulatus (Jubus) 59

bifoveata (Reichenbachia) 147

bifoveatus (Anarmodius) 72

bifurcatus (Syrbatus) 237

bilineatus (Euphalepsus) 258

binodosum (Decarthron) 198

binodula (Reichenbachia) 147

binodulus (Drasinus) 184

biocellata (Reichenbachia) 152

biomass 377

Biotus 19

bipunctatum 199

bisinuata (Reichenbachia) 152

bison (Arthmius) 231

bispinosus (Oxarthrius) 246

bistriatus 26

bistriatus (Euphalepsus) 258

bisulciceps (Mitona) 176

bituberculata (Achillia) 157

bituberculatus (Arthmius) 231

bizonatus (Pselaphus) 287

blanchardi (Achillia) 156

Bledius 30

Bolitocharini 19

Bolivia 364, 367, 368, 369, 371

boliviensis (Arhytodes) 346

boliviensis (Arthmius) 232

boliviensis (Hamotus) 329

boliviensis (Reichenbachia) 139

bowmani (Batrybraxis) 281-282

Brachygluta 3, 71, 154

Brachyglutini 16, 17, 23, 32, 122-203, 214

Brachyscelia 34, 35-285

brachyscelis 197

bradleyi (Bibrax) 284

brasilianum (Decarthron) 199

brasiliensis (Fustiger) 358

brasiliensis (Jubus) 59

brasiliensis (Rhexius) 83

Braxyda 19, 157, 159-160 
Brazil 362, 364, 367, 368, 369, 371

oreviceps (Arthmius) 232

brevicollis 293

brevicollis (Arthmius) 231

brevicollis (Bythinophysis) 264

brevicollis (Dalmoburis) 270

brevicollis (Thesium) 93

brevicornis (Achillia) 156

brevicornis (Arhytodes) 346

brevicornis (Globa) 203

brevimarginatus (Hamotus) 330

brevipennis (Pselaphomorphus) 40

brevipennis (Salagosa) 36

brevis (Jubus) 58

brevispina (Syrbatus) 237

brevispinus 237

breviventris (Strombopsis) 154

British Guiana 367, 368, 369, 370

British Honduras 367, 368, 369

bruchi (Arhytodes) 346

bruchi (Decarthron) 199

bruchi (Pselaphomorphus) 40

bruchi (Syrbatus) 237

brucki (Jubus) 59

brunneus (Buris) 266, 269

brunneus (Hamotus) 329

Bryaxina 19, 157, 158-159

Bryaxis 135, 139, 141, 142, 145, 146, 147, $148,151,152,153,154,159,165,173,175$, $179,180,185,197,198,199,200,201,214$, 231,233

bryaxoides (Hamotus) 308, 329

bubalus (Arthmius) 230

bubalus (Syrbatus) 237

bulbifer (Hamotus) 329

Bunoderus 111, 154

burchelli 197

Buris 266, 269

bythinoceros (Arthmius) 231

Bythinogaster 203

bythinoides (Reichenbachia) 152

Bythinophysis 263-264

Bythinoplectus 37

\section{C}

Caccoplectus 13, 288

calcaratus (Pselaptus) 175

calcarifer (Syrbatus) 237

californicus 357

callosa (Reichenbachia) 142

Canthoderus 62

capitatus (Lioplectus) 99

Carabidae 375

carinae, ocular 179

carinatus 232

carinatus (Arthmius) 232

carinatus (Neodalmus) 111

carinicollis (Bunoderus) 154

carinifer (Reichenbachia) 148 carinipes (Metopias) 205

carnivores 3

castanalus (Hamotus) 322-323, 330

castanea (Tyropsis) 298, 299

castaneus (Arthmius) 231

caudatus (Syrbatus) 237

cavangula (Faronoma) 71

caviceps 111

caviceps (Actium) 108

caviceps (Dalmomima) 265

caviceps (Melba) 120

cavicornis (Adrocerus) 285

cavicornis (Hamotus) 330

cavicornis (Phalepsus) 298

cavicornis (Scalenarthrus) 173

cavifrons 89

cavifrons (Bryaxina) 159

cavifrons (Euphalepsus) 258

cavifrons (Eurhexius) 82

cavifrons (Tyropsis) 299

cavipalpus (Hamotus) 330

caviventris (Jubus) 58

Cayenne, see French Guiana

cearae (Decarthron) 199

Cedius 4, 5, 7, 15, 16, 17

celata (Reichenbachia) 147

celatus (Caccoplectus) 288

Central America 363, 368, 370

subregion $370-371$

centralis (Euphalepsus) 258

centralis (Hamotus) 330

centralis (Sebaga) 48

centralis (Syrbatus) 237

Ceophyllus 4, 5, 6, 7, 17, 20

Cephaloplectus 197

cerastes (Arthmius) 231

Cercoceroides 334-336

Cercoceropsis 333-334

Cercocerulus 338

Cercocerus 4, 7, 308, 309

cervical foveae 25

cervus (Syrbatus) 240

Chalcididae 22

Chenniopsis 19

Chennium 19

chernosvitovi (Attapsenius) 349

chevrolati 299

chevrolati (Reichenbachia) 141

chichion (Decarthron) 190-192, 198, 201

chickeringi (Jubus) 52-54, 58

Chile 35, 367, 368, 369, 371

chilensis 156

Chilopoda 375

cicatricosus (Arthmius) 231

cinnamomeus (Arthmius) 231

circumscriptus (Arthmius) 232

cisinsularis (Drasinus) 183-184, 185, 200

clandestinus (Enoptostomus) 292

clavata 22 
clavata (Achillia) 156

clavata (Bryaxina) 159

clavata (Harmophola) 264

clavata (Melba) 121

clavata (Xybarida) 163

clavatus (Jubus) 59

clavatus (Scalenarthrus) 173

clavatus (Thesium) 93

claviceps (Trimiopsis) 111

clavicornis 173

clavicornis (Apharus) 307

clavicornis (Hamotus) 329

clavicornis (Melbamima) 112

clavicornis (Trimiopsis) 111

Claviger 29, 350, 351, 352

claviger (Hamotus) 329

Clavigerinae 1, 4, 5, 8, 15, 17, 18, 19, 21,

$23,29,31,343,344,348,349,350-358$

Clavigerini, see Clavigerinae

Clavigerodes 350

Clavigeropsis 350

clavipilis (Fustiger) 358

clypeata (Melba) 120

clypeatus (Syrbatus) 237

cochlearifer (Decarthron) 198

cochlearis (Neofustiger) 353

coeculus (Jubus) 59

cognata (Endytocera) 62

collecting 1-7

Collembola 3

Colombia 366, 367, 368, 369, 371

colombiensis (Apharus) 306-307

Commatocerinus 353, 357

Commatocerus 353,357

commodus (Hamotus) 332

community factor 374

competition 374-376

complicatum (Decarthron) 199

concavus (Scalenarthrus) 173

concolor (Arthmius) 233

concolor (Trimiodina) 108

confluens 8

conjunctus (Pseudohamotus) 337

constricta (Macta) 40

convexa (Nodulina) 154

convexiceps (Achillia) 156

convexiusculus (Jubus) 59

convexinscutus 59

convexus (Pselaphellus) 287

coptocolus (Neotyrus) 299-301, 303

Coptotermes 246, 301, 302, 303, 340

copulation 3,115

cordicollis (Achillia) 156

cordicollis (Tomoplectus) 107

cordicollis (Xherius) 73

cornicen (Fustiger) 358

Cornitermes 274

cornutus 231

cornutus (Arthmius) 231 coronatus (Arthmius) 233

corpulentum (Decarthron) 198

cosmoptera 299

cosmoptera (Achillia) 156

costalis $1,5,27$

Costa Rica 364, 366, 367, 368, 369, 373

costaricensis (Hamotus) $319-320,330$

crassicornis (Arthmius) 230

crassicornis (Bryaxina) 159

crassicornis (Ephimia) 290

crassicornis (Eremomus) 134

crassicornis (Eurhexius) 82

crassipalpis (Reichenbachia) 152

crassipalpus (Hamotus) 330

crassipes 249

crassipes (Braxyda) 160

crassipes (Jubus) 59

crassipes (Melba) 120

Cremastogaster 354, 357

cribratus 358

cristatifrons (Arthmius) 232

critstatus (Pselaptus) 175

cristulatus (Arthmius) 231

cruralis (Arthmius) 231

cruralis (Euphalepsus) 259

Cryptophagidae 88

Cryptorhinula 154, 174, 179-180

Ctenisis 292-293

Ctenisodes 294

Ctenistes 294

Ctenistini 16, 17, 19, 21, 26, 31, 33, 289,

291-294, 343, 344, 348

Cuba 367, 368, 369, 371

curculionoides (Metopias) 205

current

Florida 365

Gulf Stream 365

South Equatorial 365

curticorne (Decarthron) 199

curtipalpis (Pseudohamotus) 337

curtula (Batrybraxis) 282

curvicornis (Arthmius) 230

curvipes (Reichenbachia) 140

curvispina (Syrbatus) 237

Cyathiger 285, 351

Cyathigerini 15, 31, 285, 351

Cylindrarctus 11, 15, 16, 260

Cylindrembolus 165

cylindrica (Dalmophysis) 277

Cynipidae 14

D

Dalmoburis 266-270

Dalmodes 111, 262-263, 264

Dalmomima 265

Dalmonexus 272-274

Dalmophysis 276-277

Dalmoplectus 111

Dalmosella 11, 15, 17, 21, 22, 65, 116 
dama (Syrmocerus) 240

dampfi (Allobrox) 71

debilis 98

Decarfuss 187, 194, 200, 201

Decarthron 3, 122, 185-201, 202

decipiens (Hamotus) 331

decipiens (Jubus) 58

delicatus (Arthmius) 232

Demerara, see British Guiana

demoniacus (Syrbatus) 237

dentata (Balega) 62

denticollis 17

denticollis (Sebaga) 48

denticorne 197

denticorne (Decarthron) 200

denticornis 197

denticornis (Bythinoplectus) 37

denticornis (Scalenarthrus) 173

denticulatum (Decarthron) 199

dentipalpa (Berdura) 164-165

dentipes 253

deplanatus (Hamotus) 329

Dermaptera 375

designata (Reichenbachia) 152

Desimia 292, 293

Diartiger 350

dichrous (Arthmius) 230

difficilis (Hamotus) 331

difformis (Tyropsis) 299

dilatata (Sebaga) 48

Dimerini 19, 31

Dimerus 19

dimidiata (Bryaxina) 159

dimidiatus (Batoctenus) 253

dimissionis (Decarthron) 198

Dinopsis 19

Disarthricerus 350

discedens 293

dispar 293

dispar (Ctenisis) 293

divergens (Syrbatus) 237

diversa 151

diversicornis (Reichenbachia) 145

diversula (Reichenbachia) 151

Dominica 367

dominicanus (Eupsenius) 129

dominulus (Jubus) 59

dorsopunctata (Reichenbachia) 153

Drasinus 122, 181-185, 187

dresdensis 12

Drosophilidae 14

Duciola 45, 48, 58

Dutch Guiana 367, 368, 369

dybasi (Rhinoscepsis) 88-89

\section{E}

Eciton 197, 310

ecitophilus 14,310

ecitophilus (Hamotus) 332
Ectopocerus 185

Ecuador $367,368,369,370$

Edaphus 21

edithae (Arthmius) 231

edmundi (Arthmius) 232

eggersi (Melba) 120

eidmanni (Attapsenius) 349

electrae (Hamotus) 327-328, 331

elegans (Balega) 62

elegans (Fustiger) 358

elegans (Metopias) 205

elegans (Rhexius) 83

elegantissimus (Pselaphellus) 287

elegantulus 357

elegantulus (Arthmius) 232

elephas (Arthmius) 232

Eleusomatus 18

elevatus (Arthmius) 232

elfridae (Achillia) 156

elfridae (Prosagola) 36

elongata (Jubus) 59

elongatus 308

elongatus (Metopias) 205

elsbethae 299

Eltonian pyramid 374

elytral foveae 25

emeryi (Hamotus) 331

endoskeleton 20, 24

Endytocera 62

Enoptostomus 292

ensipes (Bythinophysis) 264

Ephimia 22, 33, 289-290, 291, 295, 297, 305, 348

epicranis (Batriphysis) 270

equator 365

erectus (Arthmius) 232

Eremomus 133-134

escharus (Oxarthrius) 244-246, 247

estebanensis (Reichenbachia) 140

Euasthetinae 19, 29

Euasthetus 14

eucera (Reichenbachia) 146

Eudranes 338

Euphalepsus 19, 24, 253-259

Eupines 165, 166, 173, 203

Euplectini 1, 3, 17, 18, 24, 29, 31, 32, 63121

Euplectus 8, 15, 16, 20, 21, 22, 24, 26, 28, $63,97,98,99-101,362$

Euprenius 129

Eupsenina 21, 22, 65, 122, 129-133

Eupsenius 21, 65, 122, 126-129

Eurhexius 67, 72, 73, 74-82, 363, 364

Europe 101, 135, 352

euspinifrons (Decarthron) 194-197, 200

Euteleia 181, 184, 187, 201

Eutermes 84

Eutrichites 175

Eutyphlus 29, 90 
excisa (Achillia) 157

excisa (Xybaris) 179

excisula (Berdura) 165

exiguus (Euplectus) 101

exsectoides 7

externedens (Decarthron) 199

extraneus (Arthmius) 231

eye $28-29,338$

\section{F}

fallaciosum (Decarthron) 199

falli (Rhinoscepsis) 86-88, 89

falsa (Reichenbachia) 142

Faronoma 71

Faronus 29, 35

Faronini 18, 29, 31, 32, 35-36

fasciculata (Ctenisis) 293

fasciculatus (Euphalepsus) 258

fauveli (Arthmius) 232

fauveli (Fustiger) 358

fauveli (Hamotus) 330

felix (Listriophorus) 284

femoralis (Reichenbachia) 152

femoralis (Trimiopsis) 111

femoratus (Arthmius) 231

festina (Reichenbachia) 153

festivus (Fustiger) 358

flavopilosus (Hamotus) 332

flavus 7

Fletcherexius $67,72-73,75$

fletcheri (Hamotus) 327, 332

fleutiauxi (Melba) 120

flight, see lights, 3,276

Florida 362, 363, 371

flumincola (Phalepsus) 298

fluviatilis (Reichenbachia) 153

food, see habitat, 3, 214

Formica 7

formicaria 4

formicarius (Pselaptus) 175

formiceti 186

formicetorum (Bythinoplectus) 37

forticornis (Oxarthrius) 246

fortis (Batrybraxis) 282

fossulatus 98

foveae, see

cervical, elytral, frontal,

gular, phylogenesis, pronotal, sternal, vertexal

fovearthra (Reichenbachia) 144-145, 146

foveatus (Bythinoplectus) 37

foveifrons (Bryaxina) 159

fracticornis (Eupsenina) 133

fractifrons (Decarthron) 198

frater 329

fraudatrix (Bryaxina) 159

French Guiana 362, 367, 368, 369

frontale (Decarthron) 200

frontalis (Hamotus) 329 frontalis (Melba) 120

frontalis (Raxybis) 157

Frontelba 120

fuchsi $24,354,357$

fulva 7

funiculis (Xybaris) 177-179

furcalis (Trimiopsis) 109-111

furcasternum 25

furcatus 17

furcifer (Hamotus) 329

fuscocapillus (Euphalepsus) 259

fuscopilosus (Hamotus) 330

Fustiger 4, 6, 17, 20, 24, 29, 279, 349, 350, 353-358

\section{G}

gallardoi (Metopioxys) 210

Gamba 48, 59

gambosis (Phybytharsis) 275-276

Gasola 48, 59

Gatun Lake 369

gazella (Syrmocerus) 240

geniculatus (Arthmius) 230

genitalia $10-11,15-17,269,272,327,351$, 355

geographic range 366

germaini (Arthmius) 232

germaini (Cercoceroides) 336

germari (Iteticus) 248

gibbicollis (Eupsenius) 129

gibbicollis (Neotyrus) 303

gibbous pronotum defined 254

gibbula (Melba) 120

gibbus (Anarmodius) 72

gibbus (Goniacerus) 285

gigantea (Arctophysis) 41

giganteus 283

glaber 127

gladiator (Metopioxys) 210

Globa 202-203

globicollis 215

globifer (Hamotus) 329

globipennis (Euphalepsus) 258

globulifer (Hamotus) 329

globulosa (Reichenbachia) 142

globosus 1, 5, 17

globosus (Scalenarthrus) 173

Glyptophorus 88

Golasa 36

Goniacerini $19,29,33,204,213,283-285$, $288,350,351$

Goniaceroides 285

Goniacerus 283, 285

Goniastes 285

goryi (Reichenbachia) 141

gounellei (Arhytodes) 346

gounellei (Euphalepsus) 258

gounellei (Fustiger) 358

gounellei (Reichenbachia) 139 
gracili (Actium) 108

gracilicorne (Decarthron) 200

gracilicornis (Hamotus) 329

gracilicornis (Jubus) 58

gracilipes (Dalmodes) 263

gracilipes (Hamotus) 330

gracilis (Ctenisis) 293

gracilis (Euphalepsus) 129

gracilis (Jubus) 59

gracilis (Rhinoscepsis) 89

grandiceps (Harmomima) 265

grandicornis (Pteroplectus) 97

grandipalpis (Hamotus) 329

- Grenada 367

grenadensis (Melba) 120

grenadensis (Reichenbachia) 142

griseopubescens (Reichenbachia) 153

grouvellei (Eupsenius) 129

grouvellei (Hamotus) 330

grouvellei (Jubus) 59

grouvellei (Pselaptus) 175

grouvellei (Reichenbachia) 139

grouvellei (Syrbatus) 237

Guadeloupe 367

guadelupensis (Reichenbachia) 146

guadelupensis (Scalenarthrus) 173

guarinus (Syrmocerus) 239-240

Guatemala 362, 363, 364, 367, 368, 369

guatemalensis (Reichenbachia) 146

guatemalenus (Euplectus) 101

guianensis (Anoplobraxis) 277-279

gular foveae 20

\section{$\mathrm{H}$}

habitat 1-7, 197, 204, 214, 216, 295, 350-352

see nocturnalism

myrmecophiles

termitophiles

Haiti 367

hamata (Braxyda) 160

hamaticollis (Oxarthrius) 246

hamatus 246

hamatus (Metopioxys) 210

Hamotocellus 21, 295, 333

Hamotoides 13, 14, 21, 309, 310, 331-332

Hamotus 13, 14, 20, 21, 22, 28, 29, 305, $308-332,362,364,366$

Harmomima 265

Harmophola 264

Harmophorus 264

Hayti, see Haiti

haytiana (Fustiger) 357

harem (Neotyrus) 301-303

heisei 12

henrici (Fustiger) 358

heterocerus (Jubus) 58

hetschkoi 332

hetschkoi (Decarthron) 198

hetschkoi (Euphalepsus) 259 hetschkoi (Fustiger) 358

hetschkoi (Jubus) 58

hetschkoi (Syrbatus) 237

hiatusus (Syrbatus) 237

hibernation 3

hilaris (Hamotus) 332

hippopotamus (Reichenbachia) 153

hirsutum (Decarthron) 198

hirsutus (Cercocerulus) 338

hirsutus (Drasinus) 185

hirsutus (Hamotocellus) 333

hirta (Tyropsis) 299

hirtus (Hamotus) 332

hirtus (Metopiellus) 205

Hispaniola 367, 368, 369

Histeridae 375

Holzodini 32,288

Holozodus 288

Honduras 367, 368, 369

Homalini 35

honestus (Arthmius) 232

Hoplodermatidae 3

horni 166

horroris (Phamisulus) 332

humeralis 308

humeralis (Euphalepsus) 258

humidula (Achillia) 156

humilior (Arthmius) 232

humilis (Bythinophysis) 264

Hybocephalini 31, 33, 289-290

hydropicus (Arthmius) 231

hystrix 99

\section{I}

iheringi (Hamotus) 329

iheringi (Iniocyphus) 277

illepida (Reichenbachia) 141

illepidus (Euplectus) 101

immodica (Reichenbachia) 147

imperialis (Iteticus) 248

impressa (Biblomimus) 94

impressicollis (Harmomima) 265

impressicollis (Reichenbachia) 153

impressifrons (Bythinoplectus) 37

impressifrons (Melba) 121

impressifrons (Thesium) 93

impubis (Reichenbachia) 153

impunctata (Reichenbachia) 153

impunetatus (Hamotus) 330

inaequalis (Hamotus) 329

incertus (Batoctenus) 253

inconspicua (Melba) 120

indicus 357

Indo-Malay 214, 285, 337

inermis (Jubus) 58

inermis (Phtegnomus) 84

infirmus (Arthmius) 232

inflatus (Hamotus) 329

inflatipalpus (Pseudohamotus) 337 
inflatipes (Arthmius) 230

inflatus (Scalenarthrus) 173

inflexa (Batrybraxis) 282

infossus (Dalmodes) 263

inhonestus (Euplectus) 101

Iniocyphus 277

inquilines, see myrmecophiles termitophiles

insculptus 82

insignis (Fustiger) 357

insignis (Eurhexius) 82

insignis (Thesium) 93

insulare (Decarthron) 199

insulario (Euplectus) 101

insularis (Jubus) 58

intacta (Reichenbachia) 142

intermedius (Jubus) 59

interruptus 25, 26

irrita (Reichenbachia) 140

Isoptera, see termites

Italy 19

Itamus 201-202

Iteticus 246-248, 249

\section{J}

Jamaica 368,371

Japan 293

Java 163

Jubinini $31,32,38-62$

Jubomorphus 41

Jubus 48-59, 62, 74

juncorum 135

Juxtahamotopsis 22, 290, 303-305, 348

K

kindermanni (Achillia) 156

knausii 357

L

labialis (Dalmodes) 263

labial palpi 18

labiatus (Arthmius) 232

lacustris 22, 24, 293

laetus (Hamotus) 330

laetus (Jubus) 59

laeviceps 287

laeviceps (Iteticus) 248

laeviceps (Jubus) 58

laevicolle (Decarthron) 199

laevicollis (Euphalepsus) 259

laevipennis (Arthmius) 232

laevis 357

laevis (Globa) 203

laevis (Eurhexius) 81

laevissimus (Phalepsoides) 259

lamellata (Sebaga) 48

lamellatus (Arthmius) 231 lamellipes 249

lamellipes (Decarthron) 199

larvae 8,30

larvata (Achillia) 156

Lasius 7, 352, 357

lateritius (Hamotus) 308, 310, 316, 331

laticeps (Cercoceroides) 336

laticeps (Ctenisodes) 294

laticeps (Itamus) 202

laticollis (Jubus) 58

latifrons (Achillia) 156

latipalpis (Pseudohamotus) 337

latipes (Arthmius) 231

latipes (Reichenbachia) 146

lativentris (Jubus) 58

laviceps 287

lebasi (Reichenbachia) 142

lecontei 26,352

Leeward Islands 362, 367, 368, 369

lenticornis (Lioplectus) 99

Lesser Antilles 365

Lethenomus 305

letisimulation 1

levuanus 358

lewisi (Drasinus) 184

lights, flying to, $3,43,135,145,150,163$, $165,172,178,184,186,188,192,194,197$, $204,216,221,276,278,281,282,366$

liliputanus (Jubus) 58

liliputanus (Thesiastes) 98

liljebladi (Euphalepsus) 258

limpida (Reichenbachia) 139

Limulodes 197

limuloids 197

Lioplectus $98-99$

Listriophorus 284

Lomechusa 21

longepilosus (Hamotus) 331

longiceps (Achillia) 157

longiceps (Cryptorhinula) 180

longiceps (Hamotus) 331

longiceps (Phalepsoides) 259

longiceps (Pselaphellus) 287

longiceps (Pselaphomorphus) 40

longiclava (Cryptorhinula) 180

longiclava (Pselaptus) 175

longicollis (Eupsenius) 129

longicollis (Melba) 120

longicorne (Decarthron) 200

longicornis (Euphalepsus) 258

longicornis (Eurhexius) 81

longicornis (Jubus) 58

longipennis (Adrogaster) 107

longipennis (Batrybraxis) 282

longipennis (Jubus) 59

longipennis (Metopioxys) 210

longipennis (Mitracephala) 84

longipes (Cercoceropsis) 334

longipes (Globa) 203 
longipilis (Bunoderus) 154

longispina (Iteticus) 248

longulus (Lioplectus) 99

loricate synoeketes 4

lothari (Euphalepsus) 259

lucida (Bryaxina) 159

lundi $37,120,175$

lutea (Reichenbachia) 153

luteola (Reichenbachia) 140

luzerae (Arthmius) 232

\section{M}

macrocephalum (Decarthron) 198

macrocephalus (Arthmius) 232

macrodactylus (Fletcherexius) 72-73

Macroscelia 34, 286-349

Macta 40

Madagascar 214, 288, 353

magnus (Arthmius) 232

major (Pilopius) 294

majorinus (Eurhexius) 81

mancus (Arthmius) 231

manifestus (Arthmius) 231

manticoroides (Harmophorus) 264

Manzanillo 363

marelloides (Phalepsus) 298

margaritaceus (Arhytodes) 346

marginalis (Scalenarthrus) 173

martha 237

marthae (Syrbatus) 237

Martinique 365,367

mashona 233

Mastiger 350

Matto Grosso 371

mattogrossoensis (Metopioxys) 209-210

maxillary palpi $18-19,164,195,245,283$,

$284,286,289,295$, ff, $340-342,343,350$

Mazatlan 363

megacephalus (Eurhexius) 81

meinerti 84

melanocephalus (Arthmius) 232

Melba 1, 15, 21, 22, 25, 28, 65, 111, 112,

$113-121,362$

Melbamima 111

mesosternum 23

metasternum 23

Metopias 205, 210

Metopiellus 205

Metopiini 29, 31, 33, 204-213, 214, 283, 284

Metopioides 285

Metopiosoma 205, 213

Metopioxys 205-210

mexicana 294

mexicana (Reichenbachia) 146

mexicanus (Eupsenius) 129

Mexico 362, 363, 364, 365, 366, 367, 368, 369,370

micans (Hamotus) 331

microcephala (Golasa) 36 microcephalum (Pseudotrimium) 108

microcephalus (Jubus) 59

Microclaviger 350

Micropeplus 14, 19

microphthalmus (Jubus) 59

microphthalmus (Pselaphomorphus) 40

militaris (Rhinoscepsis) 89

mimetic synoeketes 4

mimula (Melba) 120

minassanae 141

$\operatorname{minax} 231$

minuta (Melba) 120

minutum (Decarthron) 199

minutus (Biblomimus) 94

mirabilis 18

mirabilis (Syrbatus) 237

Mirini 31

Mirus 29

mites 352

Mitona 174, 175-176

Mitracephala 83-84

mniszechi (Mitona) 176

modestus (Arthmius) 232

monachus (Hamotus) 331

monoceros 197

monoceros (Decarthron) 200

monstrata (Achillia) 157

monstrosus 8,17

morphology 12-30

morsus 216

Motschulsky 359

mucronata (Barada) 126

mucronatus 308

mülleri (Apharus) 307

mus 197

muticus 40

muticus (Eurhexius) 82

mycetoecus 88

myrmecocleptics 4

myrmecocoles, see myrmecophiles

myrmecocolus (Euphalepsus) 256-259

myrmecophiles $4-7,14,37,40,81,99,120$,

$135,175,197,204,205,210,214,215,246$

$291,293,294,295,309,310,332,347,348-$

$349,350-353,354,356,357-358,376$

myrmecophilus (Arhytodes) 347

myrmecophilus (Lioplectus) 99

Myrmedoniini 19

\section{$\mathrm{N}$}

nanum (Decarthron) 199

nanus (Phalepsus) 298

nasalis (Reichenbachia) 146

nasicola (Xybarida) 19, 160-163

nasina 157

naso (Phtegnomus) 84

naso (Syrbatus) 237

nasuta 146,157

nasuta (Ctenisis) 293 
Nasutitermes 163

nasutus (Syrbatus) 237

natural rafts 365

Neodalmus 111

Neofustiger 353

Neophamisus 332

Neotropical Region 31, see zoögeography

Neotyrus 23, 28, 295, 298, 299-303

neutral synoeketes 4

New Grenada, see Colombia

New Zealand 18, 35, 135, 214, 352

Nicaragua $366,367,368,369,370$

niger $12,246,301,303,340$

nigra (Mitona) 76

nigricans (Decarthron) 199

nigropilosus (Hamotus) 331

Nisaxis 20

nitidus (Fustiger) 358

nitidus (Lioplectus) 99

noctiphoton (Decarthron) 193-194, 199, 201

nocturnalism $3,43,135,145,150,163,165$,

$172,178,184,186,188,192,194,197,204$.

$215,216,221,366$

nodicollis (Hamotus) 331

nodicornis 184

nodifera (Cryptorhinula) 180

nodosa (Euteleia) 201

nodosa (Raxybis) 157

Nodulina 153

nominata (Reichenbachia) 148

notonoda (Sebaga) 44-45, 48

Nylanderia 294

\section{O}

oberthüri (Arhytodes) 347

oberthüri (Phtegnomus) 84

oberthüri (Reichenbachia) 147

obesa (Reichenbachia) 141

obesum (Actinoma) 108

obesus (Eremomus) 134

obliquus (Scalenarthrus) 173

obnubila (Reichenbachia) 148

obscurus (Thesium) 93

octopunctatus (Eurhexius) 82

Oedipus 363

oedipus (Cryptorhinula) 180

oglobini (Fustiger) 358

Ogmocerus 283, 284

Oligota 14,19

Omalinae 29

Omalium 14

Oniscidae 375

opacus (Pselaphellus) 287

opimus 13,308

optatus (Rhexius) 83

Oribatidae 3, 214

orion (Arthmius) 231

Oropus 63 ovipennis (Euphalepsus) 259

Oxarthrius 240-246, 249

Oxytelinae 15, 16

Oxytelini 14, 19, 29, 35

\section{$\mathrm{P}$}

pacificus (Metopiosoma) 205

Paederinae 18, 19

pallidum 107

pallidus (Jubus) 58

pallipes (Pselaphellus) 287

papal cone 18

palpalis (Tyropsis) 299

palpi, see labial, maxillary

Panabachia 153

Panama 3, 362, 363, 364, 366, 367, 368, 369, 373

Panama Canal Zone 367, see Barro Colorado

panamaensis 213

panamaensis (Batrybraxis) 280-282

panamensis (Euphalepsus) 258

Panaphantus 89

Panaramecia 63, 67, 94-97

Paradrasinus 181-182, 185

Paraguay 367, 368, 369, 370, 371

parallelus (Arthmius) 232

paramo 365

Parasitidae 3

Paratrechina 353, 358

parmata (Melba) 121

parviceps (Eurhexius) 81

parviceps (Hamotus) 329

parviceps (Reichenbachia) 141

parvipalpis (Hamotus) 330

patricia (Eupsenina) 130-133

patruelis (Arthmius) 232

Paussidae 5, 19

Paussiger 350

Pearl Islands 367

pectinicornis (Scalenarthrus) 173

pectoralis (Cercoceroides) 336

pedestrianus (Arthmius) 230

penis, see genitalia

peniculus (Arthmius) 232

penita (Reichenbachia) 153

pentachiroides (Reichenbachia) 142

perforatue 285

perforatus 283

perforatus (Goniacerus) 285

Pernambuco 365

Peru 367, 368, 369, 370

peruvianus (Arthmius) 232

petrunkevitchii (Dalmoburis) 266-270

Phalepsoides 259

Phalepsus 295, 297-298

Phamisus 62, 332

Phamisulus 332

phantasma (Syrbatus) 237 
Pheidole 357

Phoberus 134

phorecy 352

Phtegnomus 84

Phybytharsis 274-276

phylogenesis

aedeageal $15-17$

clavigerine $350-356$

euplectine $65-66$

foveal 24-28

tyrine $350-356$

picea (Achillia) 156

pilicornis (Euphalepsus) 258

pilifera (Tyropsis) 299

pilopius $11,16,21,22,24,28,293-294$

pilosa (Reichenbachia) 141

pilosella 141

pilosella (Reichenbachia) 141

planiceps (Decarthron) 199

planiceps (Pseudohamotus) 337

planifrons (Arthmius) 233

planifrons (Decarthron) 199

platycerus (Arthmius) 230

plicatulus (Bythinophysis) 264

plicicollis (Arthmius) 230

politissimus (Pselaptus) 175

politus (Eupsenius) 129

Ponera 358

population $373-377$

praeclara (Achillia) 157

praeses 299

Prenolepis 294

preparation 8-11

prepectoid area 23,26

primarius (Arthmius) 230

princeps (Iteticus) 248

Proctotrupidae 22

productus (Arthmius) 233

pronotal foveae 25

Proplectus 63, 107

Prosagola 36

prosternum 22-23, 24, 25

Pselaphellus 287

Pselaphidae, definition of $29-30$ phylogenesis, see species, see

Pselaphinae 8, 18, 34-349

Pselaphini 23, 26, 29, 31, 33, 286-287

Pselaphiscnus 29

Pselaphocompsus 337-338

Pselaphomorphus 40

Pselaphus 12, 18, 20, 21, 29, 156, 157, 286287, 298, 362

Pselaptus 173-175

Pseudacerus 350

Pseudofustiger 353

Pseudohamotus 336-337

Pseudophanius 337

Pseudoplectus 108
Pseudotrimium 65, 108

Pseudotychus 338

Pteracmes 98

Pteroplectus 64, 97

Ptiliidae 14, 375

pubescence $21-22,338,350,351$

pubescens (Aporhexius) 73

pubescens (Reichenbachia) 139

pubescens (Rhinoscepsis) 89

pubiventris (Hamotus) 331

Puerto Rico 367, 368, 369

pullus (Dalmodes) 263

pumilus 98

puna 365

punctatissimus (Phalepsoides) 259

punctatum (Decarthron) 199

punctatus (Arthmius) 233

punctatus (Pselaphocompsus) 338

punctatus (Jubus) 58

puncticeps (Achillia) 157

puncticollis (Batoctenus) 253

puncticollis (Euphalepsus) 259

punctipennis (Batrybraxis) 282

punctipennis (Bythinophysis) 264

punctipennis (Hamotus) 329

punctulatus (Hamotus) 332

punctulatus (Jubus) 58

punctulum (Xybarida) 163

pupation 22, 268, 274, 276, 321

pusilla (Xybarida) 163

putzeisi 81

putzeitsi 81

putzeysi (Eurhexius) 81

Pycnoplectus 26

pygmaea (Reichenbachia) 153

Pyxidicerini 31,37

Q

quadraticeps (Decarthron) 199

quadraticeps (Mitona) 176

quadraticeps (Xybaris) 179

quadratus (Jubus) 59

Quadrelba 120

quadriceps (Achillia) 156

quadrifoveatum (Decarthron) 199

quadrifoveatus (Eurhexius) 81

quadrifoveata (Ramelbida) 113

quadrioculatus (Syrbatus) 237

quadripunctatus (Arthmius) 231

quasimoda (Barrometopia) 211-213

quinquefoveolatus 231

quinquesulcatus 248

$\mathrm{R}$

Radama 350

raffrayi 358

raffrayi (Ctenisis) 293

raffrayi (Sebaga) 41-44, 48 
Rafonus 26

rain forest 369

Ramecia 15, 64, 93, 97

Ramelbida 112-113

Rameloidea 121

ranavalonae 357

range factor 376

Raxybis 19, 157

recens (Euteleia) 201

Reduviidae 375

regius (Iteticus) 248

reichei (Hamotus) 332

reichei (Metopioxys) 210

reichei (Reichenbachia) 147

reicheiana 147

reichenbachi (Phamisus) 62

Reichenbachia $3,11,16,21,133,135-153$,

$154,159,362,366$

reitteri 205, 232

reitteri (Arthmius) 231

reitteri (Eurhexius) 82

reitteri (Euphalepsus) 259

reitteri (Fustiger) 358

reitteri (Phamisus) 62

resectus (Arthmius) 233

restitutum (Decarthron) 199

Rhexidius 1, 3, 13, 17, 22, 28, 67, 73, 74

Rhexinia $67,72,73,74$

Rhexius $3,28,74,81,81-83,88$

rhinoceros (Arthmius) 232

Rhinoscepsis $3,15,26,28,29,63,66,85-89$

Rhinosceptis 85

Rhynchoclaviger 350

Rhynoscepsis 85,89

richteri $40,81,210,293$

richteri (Rhinoscepsis) 89

riparius 17

river

Amazon 365, 371

Chagres 369

Esequibo 365

Madeira 364

Orinoco 365,371

rivularis (Oxarthrius) 246

robustus (Hamotus) 329

rossii (Hamotus) 332

rostellatus 230

rostratus (Hamotus) 329

rubecula (Reichenbachia) 153

rubra (Reichenbachia) 141

rubriculus (Arthmius) 231

rubripenne (Decarthron) 199

rubripennis (Arhytodes) 347

rubripennis (Eurhexius) 82

rufipes (Arthmius) 232

rufus 127

rugiceps (Arthmius) 233

rugiceps (Syrmocerus) 240

rugicollis (Jubus) 59 rugicornis (Cercoceropsis) 334

rugipes (Euphalepsus) 258

rugosicollis (Oxarthrius) 246

rugosus (Hamotus) 330

rugosus (Oxarthrius) 246

rugulosum (Decarthron) 199

rugulosus (Eurhexius) 82

Rybaxis 5, 13, 22, 88

rybaxoides (Dalmodes) 263

Rytus 338

S

sabomba (Arthmius) 219-222, 230

Sagola 36

sahlbergi (Xybaris) 179

Salagosa 36

sallaei (Reichenbachia) 146

sallei 146

sandersoni (Hamotus) 321-322, 330

sanguinifer 331

sanguinipes (Hamotus) 331

sarcinaria (Reichenbachia) 142

saucium (Decarthron) 200

Sealenarthrus 3, 160, 163, 165-173, 174

scaphiger (Arthmius) 230

Scarabaeidae 375

Sceloporus 363

schaufussi 58

schaufussi (Bryaxina) 159

schaufussi (Bythinophysis) 264

schaufussi (Cryptorhinula) 180

schaufussi (Decarthron) 200

schaufussi (Pteracmes) 98

schaufussi (Scalenarthrus) 173

schaumi 17

Schistodactylini 19,31

schmidti (Fustiger) 357

schmitti (Decarthron) 199

schwarzi (Fustiger) 357

scitus (Syrbatus) 237

Scotoplectus 29

sculpturatus (Pselaphomorphus) 40

scydmaenilla (Sebaga) 45, 48

Sebaga $41-48$

secondary sexual characters $29,39,47,48$,

$51,57,80,81,83,96,99,136$, ff. 158,159 ,

$162,166,172,176,186,192,194,196,204$,

$212,215,216,221,244,246,268-269,274$,

$276,281,284,302,306,310,324,326,327$,

$340,351,356$

seeversi (Dalmonexus) 272-274

seeversi (Metopioxys) 207-208, 210

semihyalinus 82

semipunctatus (Iteticus) 248

semipunctatus (Jubus) 58

semisanguinea (Reichenbachia) 141

semisulcatus (Arhytodes) 347

separabilis (Scalenarthrus) 173

setifer (Goniacerus) 285 
setipes (Hamotus) 330

sexdens 246, 348, 349

sexpunctatus (Eurhexius) 81

sharpi (Thesium) 93

signatus 101

signifer 101

signifera (Euplectus) 101

silvaticus (Metopiellus) 205

similare (Decarthron) 199

simoni (Acotebra) 107

simoni (Ephimia) 290

simoni (Eurhexius) 81

simoni (Jubomorphus) 41

simoni (Jubus) 59

simonis 81

simplex (Batoctenus) 253

simplex (Bythinogaster) 203

simplex (Cercoceroides) 336

simplex (Decarthron) 198

simplex (Hamotus) 330

simplex (Lioplectus) 99

simplex (Oxarthrius) 246

simplex (Scalenarthrus) 173

simplicicornis (Arthmius) 231

simplicifrons (Syrbatus) 237

simplicior (Arthmius) 230

simulans (Achillia) 156

simulatrix (Pselaptus) 175

singularis (Arthmius) 231

singularis (Hamotus) 330

sinuatus (Jubus) 59

size 14

smithi (Fustiger) 357

social arhythmicity 352

Solenopsis 40, 81, 210, 293, $35 \mathrm{~S}$

solitarius (Euplectus) 101

Solivagus 237

Sonoma $15,16,18,26,28,35$

soror 237

soror (Decarthron) 198

soror (Hamotus) 330

South America 363,370

subregion $370,371,373$

Spain 292

spathulatus (Syrbatus) 237

species

by authors 366

by neotropical countries 367

estimated in neotropics 376

in mold 1-4

nearctic 360

neotropical 360

new $378-380$

on Barro Colorado 372

phylogenesis, see

myrmecophilous, see

termitophilous, see

specularis (Melba) 120

spiculatus (Metopioxys) 210 spiniceps (Xybaris) 179

spinicollis 248

spinicollis (Jubus) 58

spinipes 13,288

spinosum (Decarthron) 199

spinosus 17,199

spinula (Tyropsis) 299

spuria (Reichenbachia) 153

squamosus (Decarthron) 199

Staphylininae 18

Staphylinidae 5, 14, 18, 19, 20, 21, 25, 29, 375

staphylinoides 19

Steninae 18, 19

sternadens (Oxarthrius) 242-244, 246

sternal foveae $25-28$

sternalis (Cercoceroides) 335-336

sternalis (Hamotus) 329

sternalis (Pselaptus) 175

Stratus 38,62

strictocornis (Pseudofustiger) 353

strigilators 4

stroheckeri (Reichenbachia) 149-151

Strombopsis 154

St. Thomas 367

stultor 231

stussineri (Reichenbachia) 148

St. Vincent 367

subacuminatus (Eurhexius) 82

subcarinatus (Metopioxys) 210

subcarinatus (Scalenarthrus) 173

subdendrus (Verabolus) 104-107

subfoveolatus (Reichenbachia) 141, 148

subfusus (Arthmius) 231

subglobosus (Phalepsus) 298

sublaminatus (Syrbatus) 237

sublyratus (Syrbatus) 237

subnitida (Ephimia) 290

subnitida (Reichenbachia) 141

subopacus (Jubus) 58

subrectus (Jubus) 59

subspeciation factor 374

subtilis (Hamotus) 329

sulcatula 116

sulcicornis (Aploderina) 332

sulcifrons (Eupsenina) 133

sulcifrons (Goniastes) 285

sulcipalpus (Hamotus) 330

sulcipes (Decarthron) 198

supratentorium 20

sus (Arthmius) 232

suturale (Decarthron) 200

Surinam, see Dutch Guiana

symphiles 5

symphiloid synoeketes 4

synechthrans 4

synoeketes 4

Syrbatus 216, 233-237, 238, 248

Syrmocerus 216, 233, 238-240 
$\mathrm{T}$

Tabanidae 368

Tamaulipas 363

tarsi $19,63,157,158,176,343,351$

taxonomic density 369,370

temporalis (Melba) 121

Tenebrionidae 375

tennesseensis 7

tenuicornis (Reichenbachia) 141

tenuis 116

Termes 213

termites $84,163,213,246,274,279,301,303$, $338,340,376$

termitocoles, see termitophiles

termitophiles, as for termites

terranus (Jubus) 49-52, 58

testaceus 352

testudineus (Fustiger) 358

Tetracis 292

Tetratomium 205

tetratomus (Jubus) 58

Thesiastes $3,15,22,97-98,99$

Thesium 15, 21, 67, 89-93, 278

thomasi (Hamotus) 328-329, 332

thoracica 113, 116

Thysanoptera 22

tibialis (Arthmius) 231

tibialis (Euphalepsus) 259

tibialis (Hamotus) 330

Tmesiphorus 1, 5, 7, 11, 17, 22, 26, 27, 28

tolulae $15,16,26$

tomentosum (Decarthron) 199

Tomoplectus 107

torticorne (Decarthron) 199

torticornis (Bryaxina) 159

trabeculatus (Metopioxys) 210

transversalis (Arthmius) 232

transversalis (Hamotus) 330

transversalis (Syrbatus) 237

transversiceps (Bythinoplectus) 37

triangularis (Arthmius) 232

triangulifera (Reichenbachia) 153

triangulifera (Xybaris) 179

tricarinatus (Euphalepsus) 258

trichomes 6, 21

Trichonychini 1, 17, 31, 32, 63-64, 107

Trichonyx 63, 72, 264

tricuspidatus (Metopioxys) 210

trifoveata (Euteleia) 201

trifoveatus (Arthmius) 233

Trilobitideini 18

Trilobitideus 18

trimiiforme (Actium) 108

trimiodes (Eurhexius) 81

Trimiodina 108

trimioides 81

trimioides (Cryptorhinula) 180

Trimiomelba 20, 21, 22, 28, 65

Trimioplectus 15
Trimiopsis 63, 108-111, 113, 120, 121

Trimiosella 65, 112

Trimium 108, 113

Trinidad 365,371

trinodulus (Syrbatus) 237

tripunctata (Achillia) 156

tripunctatus 233

tritomum (Decarthron) 198

tritomus (Hamotus) 331

Troglamaurops 29

troglocera (Xybaris) 179

Tropic of

cancer $31,308,309,362,369,370$

capricorn 308,369

tropicum (Decarthron) 200

trouessarti (Jubus) 58

truncata (Reichenbachia) 153

truncaticeps (Arthmius) 231

tuberculatus (Cercoceroides) 336

tuberculifer (Pselaptus) 175

tubericornis (Reichenbachia) 142

turalbus (Hamotus) 22, 330

turneri (Jubus) 54-58

Tychini 16, 17, 33, 111, 260-282, 283

Tychus $12,22,260$

Tyrini 17, 18, 19, 24, 33, 289, 295-342, 348

Tyrogatunus 15, 23, 29, 303, 338-340

Tyropsis $156,157,298-299$

Tyrus 15, 17, 303, 308

U

ulkei 7

umbilicatus (Goniaceroides) 285

undecimtympus (Scalenarthrus) 170-173

unifoveolatum (Decarthron) 199

United States 368,369

ursinus 38,62

ursulus (Hamotus) 331

Uruguay $367,368,369,370$

\section{V}

vagepunctatus (Phalepsoides) 259

validicornis (Achillia) 157

valdiviensis (Achillia) 157

valdiviensis (Tyropsis) 299

Venezuela $362,367,368,369,371$

ventralis (Eurhexius) 81

ventricosa (Melba) 121

ventricosus (Scalenarthrus) 173

venustulus (Bythinophysis) 264

Verabolus 104-107

Vera Cruz 362, 363, 364

veracruzensis (Fustiger) 17, 354-357

veracruzensis (Hamotus) 325-326, 332

versicolor (Rhexinia) 73

Vertelba 120

vertexal foveae $20-21,270,280,281$

verticicornis (Ectopocerus) 185 
vesiculifer (Hamotus) 330 vestita (Endytocera) 62 vestitus (Arhytodes) 347 vestitus (Eurhexius) 81 vestitus (Neotyrus) 303 vestitus (Pselaphellus) 287 vicinus (Hamotus) 331 villosulus (Stratus) 62 villosus (Lethenomus) 305 vincentiana (Reichenbachia) 142 Virgin Islands $367,368,369$ vitiensis 358 vividus (Arthmius) 232 vulgaris (Phalepsus) 298 vulnerata (Panabachia) 153 vulneratum (Decarthron) 199 vulneratus (Arthmius) 232 vulpinus (Hamotus) 331 vulpinus (Jubus) 58

\section{IV}

walkeri 274

warblers 373

wasmanni 352,358

Wasmannia 347 wasmanni (Arthmius) 232

Water Island 367 westwoodi (Goniastes) 285 williamsi (Panaramecia) 94-97
Windward Islands $362,367,368,369$ wings, see lights

X

Xenodusa 21

Xherius 72,73

Xybarida 19, 154, 160-163, 174

xybaridoides (Cryptorhinula) 180

Xybaris 19, 154, 160, 174, 175, 176-179

xybaroides 180

\section{Y}

Yucatan 365,371

\section{Z}

zeteki (Barroeuplectoides) 102-104

zeteki (Tyrogatunus) 339-340

ziegleri 17

zimmermani (Pilopius) 293, 294

Zolium 113

zonalis (Eurhexius) 78-80, 82

zones, see altitude

zoögeography $89,97,99,113,127,135-136$, $154,166,176,186,188,204,214,216,233$, $238,240,246-247,253,283,285,288,289$, $291,294,308,309,310,330,331,332,352$, 356

general $360-377$ 

Plates 



\section{Index to Plates}

Adranes lecontei, IV

Anoplobraxis guianensis, XIX

Apharus. XX

Aploderina, XX

Arhytodes achillei, VI, XIX

Arthmius sabomba, VI

Barroeuplectoides zeteki, XV

Barrojuba albertae, XVIII

Barrometopia quasimoda, XVIII

Batoctenus barberi. XVIII

Batrisodes denticollis. II

Batrisodes furcatus, I

Batrisodes globosus, I

Batrisodes monstrosus, II

Batrisodes schaumi. II

Batrisodes riparius, I

Berdura dentipalpa, VII

Berdura excisula, VII

Bibloplectus ruficeps, XI, XII

Cedius cruralis. III

Cedius spinosus, III

Cedius ziegleri, III, IV

Ceophyllus monilis, II, IV

Cercoceroides, XY

Cercoceroides laticeps, VI

Cercoceropsis, $\mathrm{XX}$

Cercocerulus, XX

Cercocerus batrisoides, IV

Cylindrarctus americanus, I

Cylindraretus longipalpis, I, XVII

Dalmosella, XII

Dalmosella tenuis, IV, XI, XII

Decarthron chichion, VI, XVI

Decarthron euspinifrons, XVIII

Decarthron noctiphoton. XVI

Decarthron tropicum. V'II

Euphalepus, XV

Euphalepsus myrmecocolus, XVIII

Euplectus difficilis, XII

Euplectus interruptus. V. XII, XIII

Eupsenius glaber, XIII. XIV

Eurhexius zonalis, VIII

Eutyphlus prominens, XII

Fletcherexius macrodactylus, VIII

Fustiger clavipilis, XV

Fustiger havtiana, XV

Fustiger veracruzensis, II, VI, VII, XVII, XIX

Hamotocellus, XX

Hamotus, XX

Hamotus electrae, XVII

Hamotus fletcheri, XVII

Hamotus monachus. XVII. XIX

Hamotus thomasi. VI. XVII

Hamotus tibialis, XVII

Hamotus turalbus, XVII. XIX

Hamotus veracruzensis, VI, XVII
Jubus turneri, VII

Juxtahamotopsis, XX

Lethenomus, XX

- Melba, XII

Nelba thoracica, IV, XI, XII

Nelba sulcatula, XI

Melbamima elavicornis. VI

Metopioxys mattogrossoensis, XVIII

Panaramecia williamsi, $\mathrm{XV}$

Phalepsus, XX

Phloeocharis subtilissima, I

Pilopius lacustris, IV, V

Pilopius piceus, I

Pselaphocompsus, XX

Pselaphus bellax, IV

Pselaphus erichsonii. IV

Pselaphus fustifer, IV

Pselaphus longiclavus, IV

Pseudohamotus, XX

Reichenbachia appendiculata, XVI

Reichenbachia diversula. XVI

Reichenbachia callosa. XVII

Reichenbachia carinifer. XVII

Reichenbachia falsa, XVII

Reichenbachia fovearthra, XVI

Reichenbachia globulosa, XVII

Reichenbachia grenadensis, XVII

Reichenbachia guatemalensis, XVI

Reichenbachia latipes, XVI

Reichenbachia mexicana, XVII

Reichenbachia pluridentata. I

Reichenbachia sarcinaria, XVII

Reichenbachia stroheckeri. XVI

Rhexidius canaliculatus, V, VIII

Rhexius insculptus, VIII

Rhinoscepsis bistriatus. IX, X

Rhinoscepsis falli. XVIII

Rybaxis clavata, IV

Scalenarthrus undecimtympus, VII

Sebaga centralis, XV

Sebaga notonoda. XV

Sebaga raffravi, XV

Sebaga scydmaenilla, VII

Sonoma tolulae, V, VI. XIII

Svrmocerus guarinus, XIX

Tmesiphorus costalis. II. IV. V

Trimiomelba dubia, V, XI. XII, XIII

Trimioplectus obsoletus. XII

Trimiopsis furcalis, XIX

Tychus minor, IV

Tyrogatunus, XX

Tyrogatunus zeteki, III, XVII

Tyropsis, $\mathrm{XX}$

Tyrus humeralis. III

Xybaris funiculis, VII

Xybarida nasicola, VII 
Plate I

\section{INTRAFAMILY VARIATION ()F THE PSELAPHII) AEDEAGUS}

a (accessory piece); ad (apical diaphragm) ; bb (basal bulb of median lobe) ; bd (basal diaphragm); bm (bulbar muscles); ll (lateral lobes); ml (median lobe); vl (ventral lobe); pp (penial plate).

Fig. 1. A staphylinid aedeagus, Phloeocharis subtilissima Mann, subfamily Oxytelinae, tribe Phloeocharini. Redrawn from Blackwelder, 1936. Lateral view. Included for comparison; see text.

Fig. 2. Reichenbachia pluridentata Park. Lateral view.

Fig. 3. Reichenbachia pluridentata Park. Dorsal view. $0.475 \times 0.225 \mathrm{~mm}$.

Fig. 4. Pilopius piceus (LeConte). Lateral view. This and subsequent lateral views have the morphological dorsal side uppermost, and the apical (morphological posterior) end to the right.

Fig. 5. Pilopius piceus (LeConte). Last sternite, with minute penial plate partially exserted.

Fig. 6. Pilopius piceus (LeConte). Aedeagus, dorsal view. $0.225 \times 0.1 \mathrm{~mm}$.

Fig. 7. Pilopius piceus (LeConte). Apical view.

Fig. 8. Cylindraictus longipalpis (LeConte). Dorsal view. $0.389 \times 0.201 \mathrm{~mm}$. Note penial plate exserted to right, the bilaterally symmetrical bulbar muscles, and the rentral lobe.

Fig. 9. Cylindraretus americanus schaufuss. Dorsal view similar save for difference in apical end of ventral lobe.

Fig. 10. Cylindrarctus americanus Schaufuss. Lateral view.

Fig. 11. Batrisodes furcatus (Brendel). Dorsal view. $0.28 \times 0.08 \mathrm{~mm}$.

Fig. 12. Batrisodes riparius (Say). Dorsal view. $0.201 \times 0.134 \mathrm{~mm}$.

Fig. 13. Batrisodes globosus (LeConte). Dorsal view. 0.233 x $0.133 \mathrm{~mm}$.

Fig. 14. Batrisodes globosus (LeConte). Lateral view. 

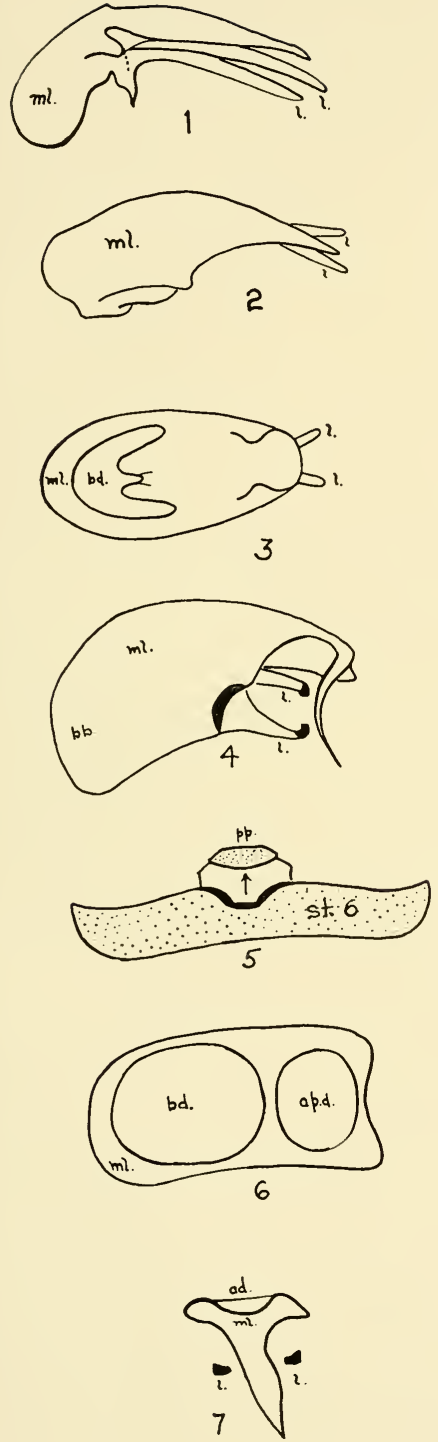

\section{Plate I}
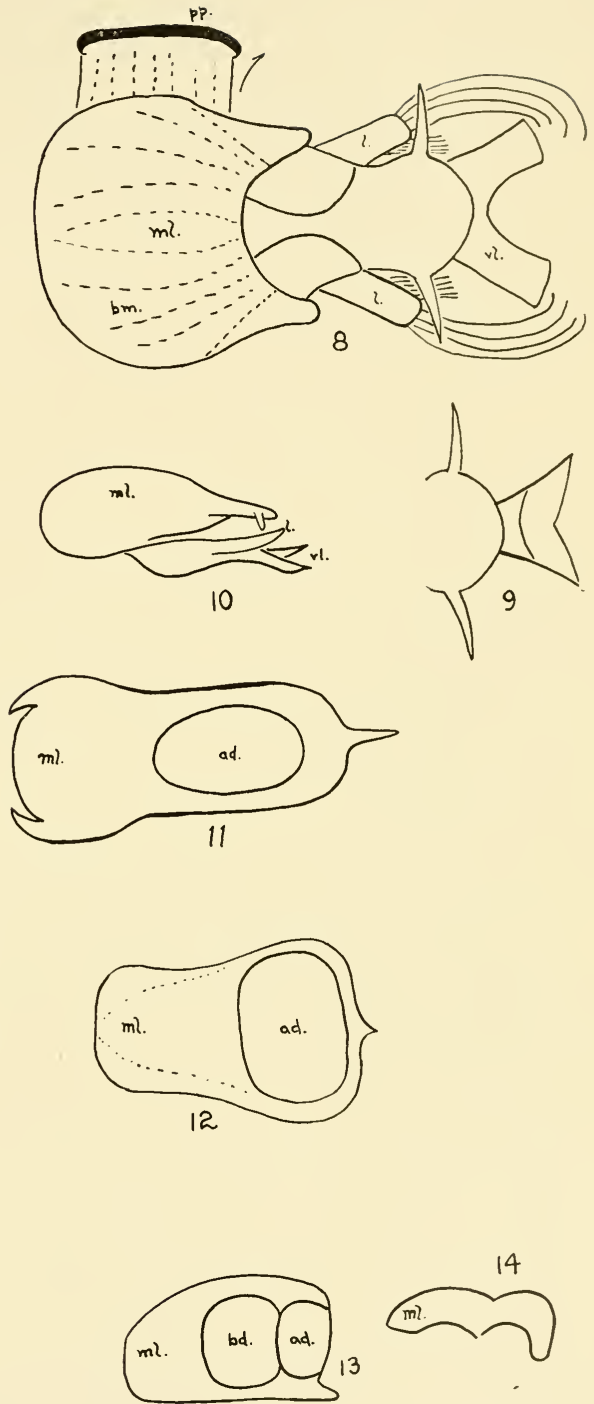
Plate II

\section{INTRAFAMILY VARIATION OF THE PSELAPHID AEDEAGUS (Continued)}

Fig. 1. Batrisodes denticollis (Casey). Lateral view.

Fig. 2. Batrisodes denticollis (Casey). Dorsal view. $0.275 \times 0.15 \mathrm{~mm}$.

Fig. 3. Batrisodes schaumi (Aube). Lateral view. Note membranous lateral lobe.

Fig. 4. Batrisodes schaumi (Aube). Dorsal view. $0.435 \times 0.167 \mathrm{~mm}$.

Fig. 5. Batrisodes monstrosus (LeConte). Dorsal view. $0.49 \times 0.268 \mathrm{~mm}$. Note extreme asymmetry; the accessory piece which moves to the right on contraction of the asymmetrical bulbar muscles; the arcuate, bifureated extension of the median lobe; the membranous lateral lobes.

Fig. 6. Fustiger veracruzensis Park. Dorsal view, from paratype. $0.39 \times 0.134$ $\mathrm{mm}$. Note homologies with ceophylline aedeagus.

Fig. 7. Ceophyllus monilis LeConte. Dorsal view.

Fig. 8. Ceophyllus monilis LeConte. Lateral view.

Fig. 9. Tmesiphorus costalis LeConte. Lateral view.

Fig. 10. Tmesiphorus costalis LeConte. Dorsal view. $0.4 \times 0.25 \mathrm{~mm}$.

Fig. 11. Tmesiphorus costalis LeConte. Apical view. 
Plate II
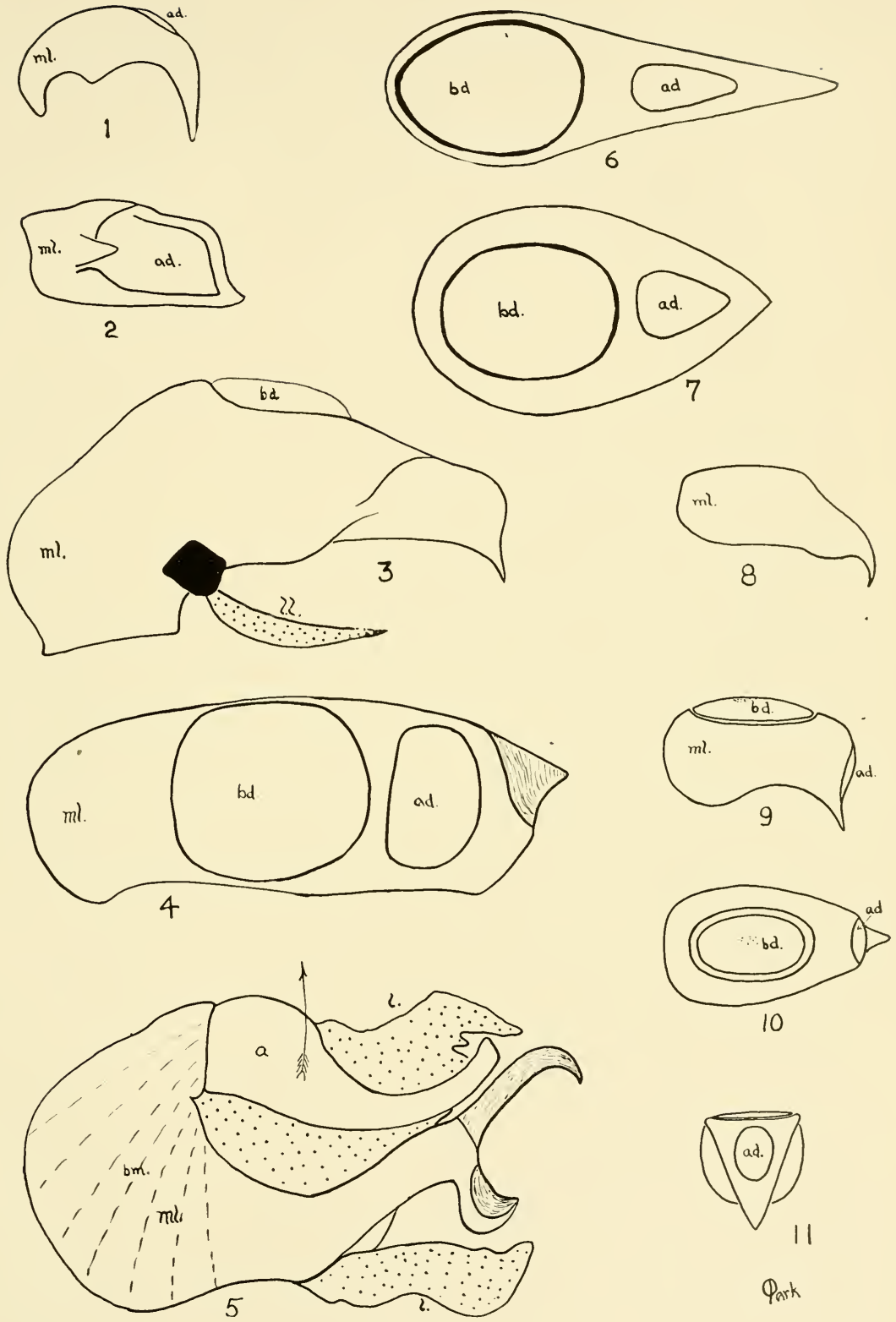

Qark 
Plate III

\section{INTRAFAMILY VARIATION OF THE PSELAPHID AEDEAGLS (Continued) AND THE PENIAL PLATE}

Fig. 1. Tyrus humeralis (Aube). Male pygirlial area. \$6 (sixth sternite); T5 (fifth tergite); pp (penial plate).

Fig. 2. Tyrus humeralis (Aube). Female pygidial area.

Fig. 3. Tyrus humeralis (Aube). Aedeagus, dorsal view. $0.381 \times 0.167 \mathrm{~mm}$.

Fig. 4. Tyrus humeralis (Aube). Right lateral view. (Reversed drawing)

Fig. 5. Tyrus humeralis (Aube). Left lateral view. (Normal orientation)

Fig. 6. Tyrogatunus zeteki Park. Ventral abdominal surface: female on left; male on right. Drawn from types. Note remarkable long, matted pubescence, shown on right. pp ipenial plate, note the homology with Tyrus).

Fig. 7. Cedius ziegleri LeConte. Aedeagus, dorsal view. $0.502 \times 0.167 \mathrm{~mm}$. Note that the asymmetry is to the left. The penial plate swings to the left.

Fig. 8. Cedius spinosus LeConte. Dorsal riew. $0.361 \times 0.124 \mathrm{~mm}$. Note that the asmmetry is to the right. The penial plate swings to the right.

Fig. 9. Cedius cruralis Park. Dorsal view. $0.335 \times 0.134 \mathrm{~mm}$. Note that the asymmetry is to the left. The penial plate swings to the left. 
Plate III
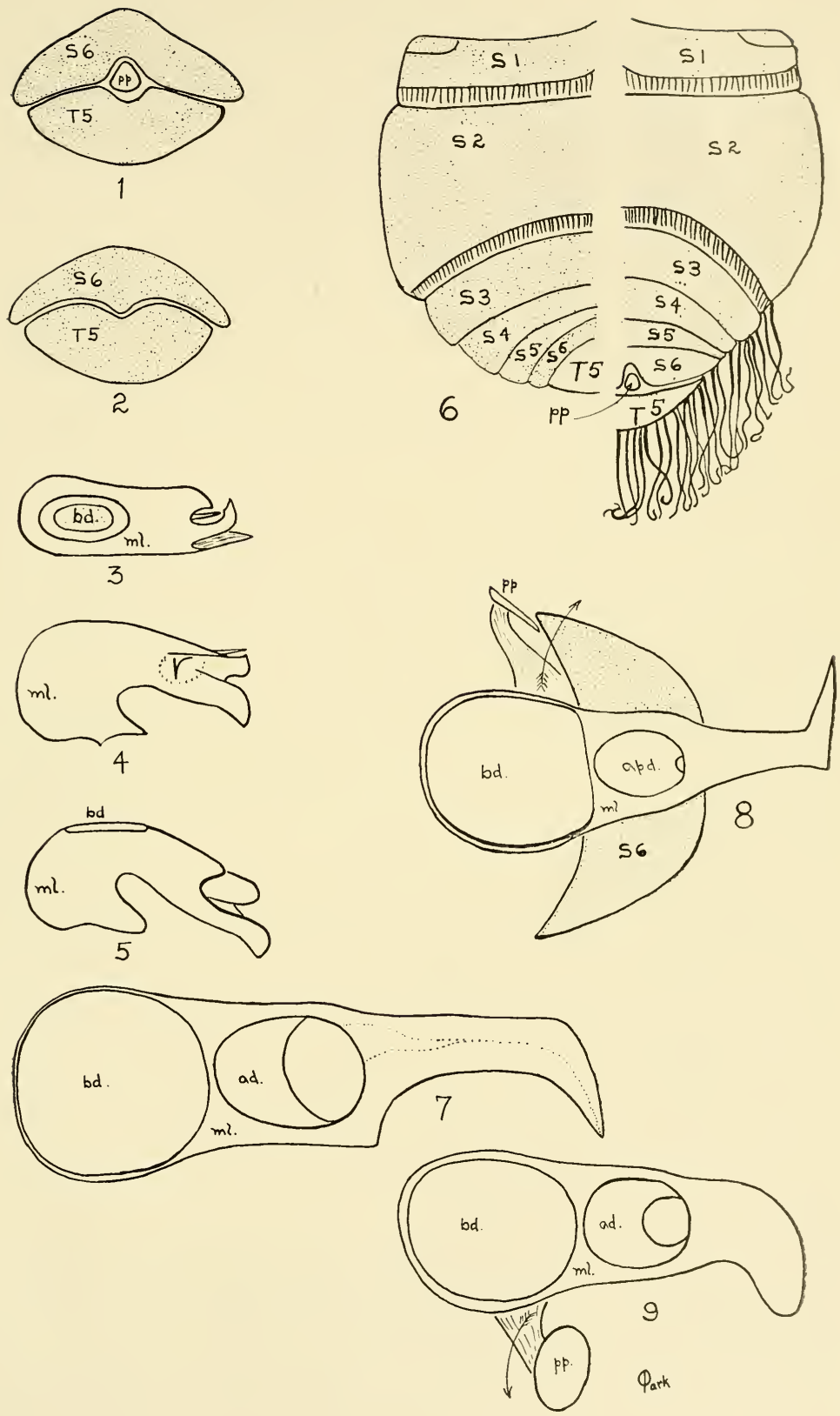


\section{PUBESCENCE}

\section{Adranes lecontei Brendel}

Fig. 1. Abdominal trichome. $0.25 \mathrm{~mm}$.

Fig. 2, Bifureated seta from disk of elytron. $0.09 \mathrm{~mm}$.

Fig. 3. Bifureated seta from disk of elytron. $0.09 \mathrm{~mm}$.

Fig. 4. Seta from apieal margin of elytron. $0.072 \mathrm{~mm}$.

Fig. 5. Elytral trichome. $0.198 \mathrm{~mm}$.

Pilopius lacustris Casey

Fig. 6. General integumental scale of body and legs. $0.03 \mathrm{~mm}$.

Fig. 7. Seale with reeurved tip, from posterior elytral margin. $0.07 \mathrm{~mm}$.

Fig. 8. Spade seale found on posterior elytral margin, basal elytral foreae, sternal foveae and depressions, ventro-posterior area of head and mesial faces of prothoracic coxae. $0.31 \mathrm{~mm}$.

Fig. 9. Asperate seale. A form of scale which is set on an asperity found on ventral faces of prothoraeic trochanter and femur. $0.041 \mathrm{~mm}$.

Fig. 10. Umbrella seta, on processes of maxillary palpi. $0.072 \mathrm{~mm}$.

Fig. 11. Type of very minute seta on segments of maxillary palpi. $0.009 \mathrm{~mm}$.

Tmesiphorus costalis LeConte

Fig. 12. Capitate seta on processes of maxillary palpi. 0.009 to $0.01 \mathrm{~mm}$.

Tychus minor LeConte

Fig. 13. Normal seta of eleventh antennal segment. 0.04 to $0.07 \mathrm{~mm}$.

Fig. 14. Antennal cone of eleventh antennal segment. 0.54 to $0.72 \mathrm{~mm}$.

Rybaxis clavata Brendel

Fig. 15. Asperate setae from mesio-ventral face of eleventh antennal segment of male. 0.54 to $0.07 \mathrm{~mm}$.

Fig. 16. Normal seta of antenna. 0.04 to $0.05 \mathrm{~mm}$.

Dalmosella teruis Casey

Fig. 17. Distal eone on fourth segment of maxillary palpi. 0.009 to $0.01 \mathrm{~mm}$.

Fig. 18. Antennal eone on eleventh segment of antemna. 0.01 to $0.04 \mathrm{~mm}$.

Melba thoracica (Brendel)

Fig. 19. Antennal cone on eleventh antennal segment. 0.04 to $0.05 \mathrm{~mm}$.

Fig. 20. Normal seta of antenna. $0.01 \mathrm{~mm}$.

Fig. 21. Capitulate seta of ventral area of head.

\section{MAXILLARY PALPI}

Fig. 22. Pilopius lacustris Casey. Note the remarkable development of umbrella setae on the processes of segments II, III, IV. Slide mount, 450 diameters.

Fig. 23. Pselaphus longiclavus LeConte. Fourth segment, lacking normal pubescence in figure.

Fig. 24. Pselaphus fustifer Casey. Fourth segment, lacking normal pubesecnce in figure.

Fig. 25. Pselaphus crichsonii LeConte. Fourth segment, lacking normal pubeseence in figure. Note distal groove at base of palpal cone.

Fig. 26. Pselaphus bellax Casey. Fourth segment, lacking normal pubescence. Note eharacteristic asperities of segment.

Fig. 27. Ceophyllus monilis LeConte.

Fig. 28. Cedius ziegleri LeConte.

Fig. 29. Cercocerus batrisoides LeConte. Note that the palpal cone is set obliquely within the apex of the fourth segment, and in a broad shallow groove on the mesial face. This arrangement is rare among temperate, but common in tropical trrine pselaphids.

Fig. 30. Tmesiphorus costalis LeConte.

Fig. 31. Tychus minor LeConte. 

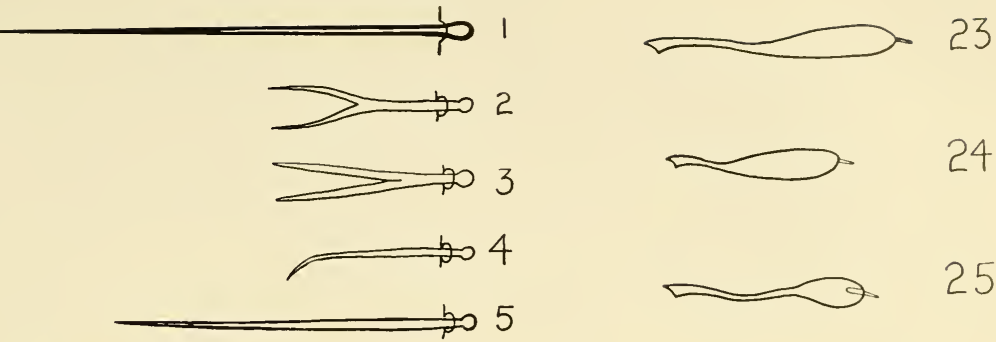

$6 \leadsto$

$7 \propto$
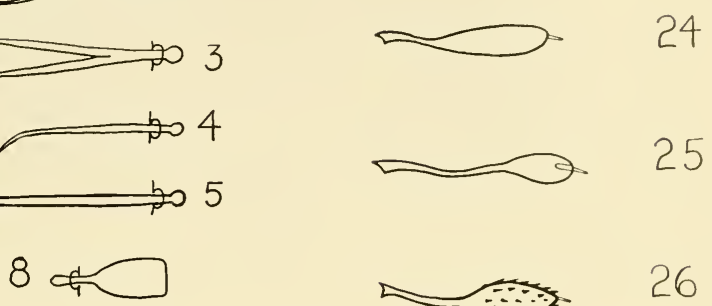

$10 \leftrightarrow$

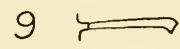

$11 \overbrace{1}^{11}$

120

$13 \quad 2 t$

$1 4 \longdiv { }$
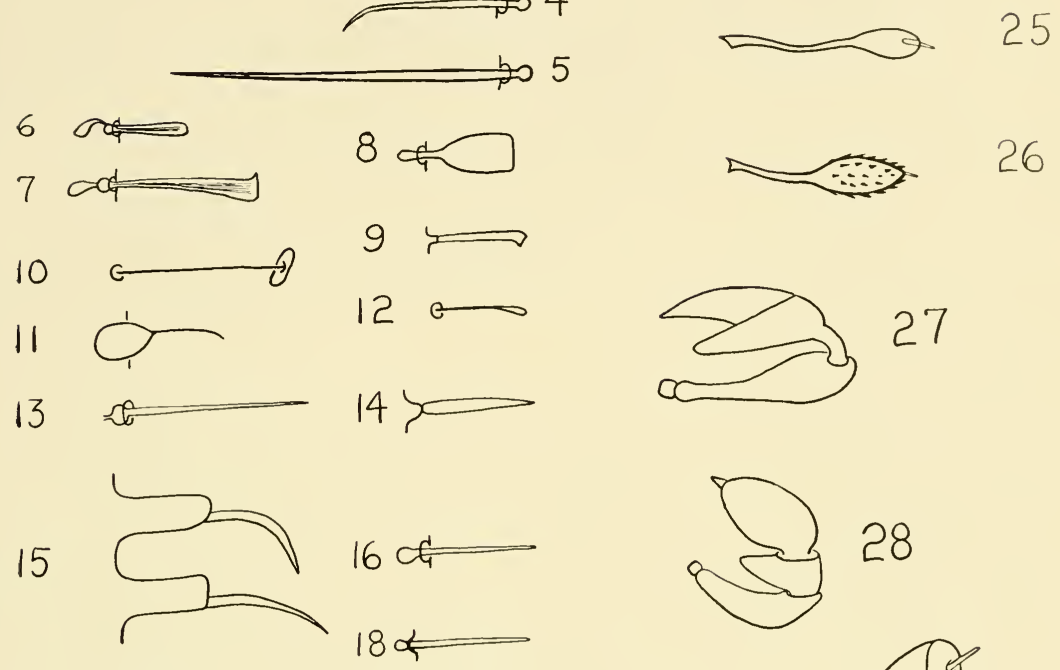

17 I 19 क

$20 \longleftarrow$

$21 \div 0$
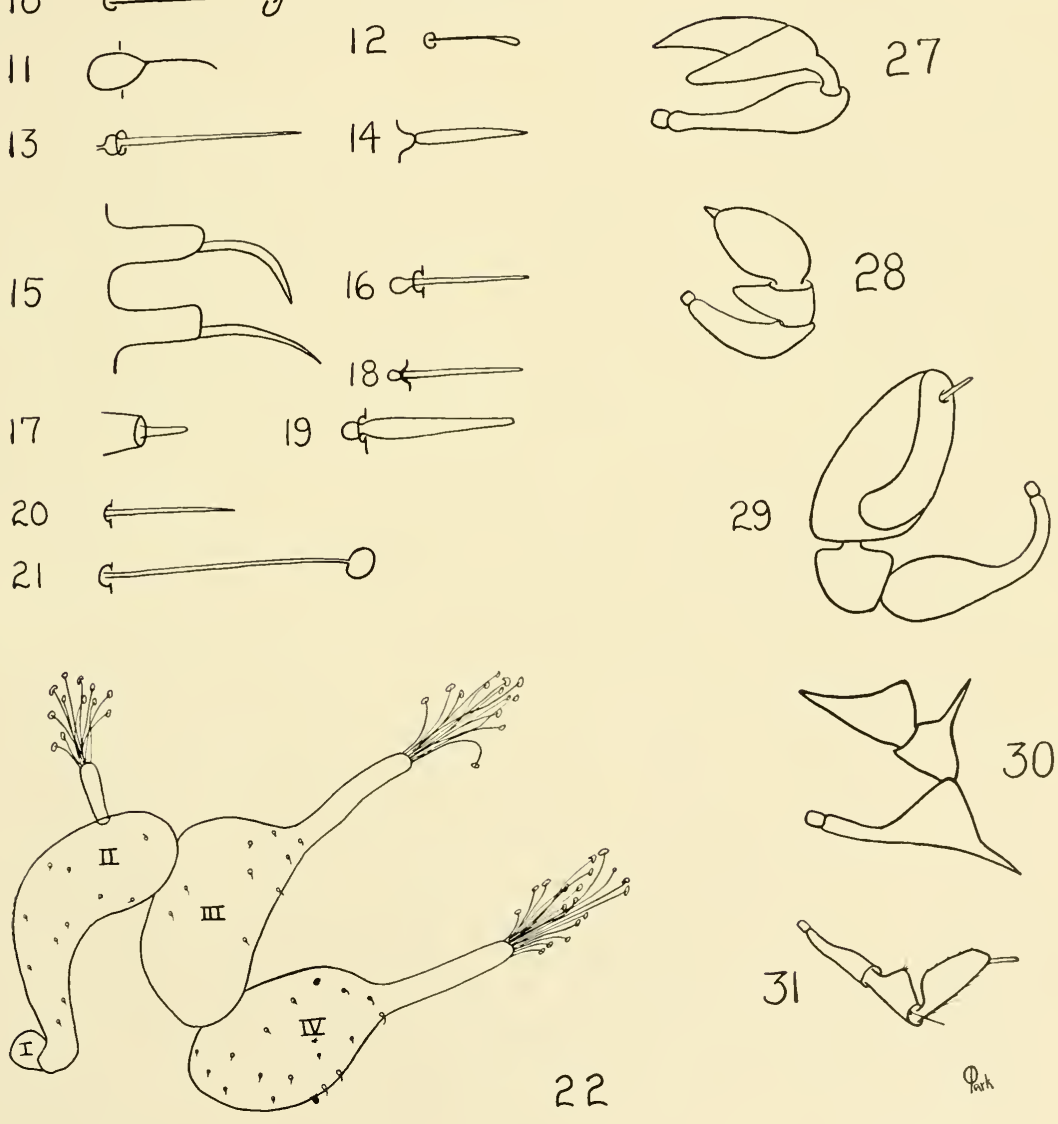

22

$\varphi_{\text {akk }}$ 


\section{Plate V}

Fig. 1. Primitive Generalized Diagram of Pselaphid mesosternal and metasternal field. P, prepectoid area; MOS, mesosternum; MOES, mesoepisternum; MOEP, mesoepimeron; MOCC, mesosternal coxal cavities; MEs, metasternum; MEES, metaepisternum.

I, Prepectoid foveae. IV. Lateral mesocoxal foveae.

II, Lateral mesosternal forese. V, Posterior mesocoxal foreae.

III, Median mesosternal fovese. VI, Metasternal foveae.

Fig. 2. Sonoma (Rafomus) tolulae (LeConte).

Mesosternal and metasternal field. Legend as in Fig. 1. Note that this species has eleven foreae, that is, all are present save the metasternal foveae, which are medianly fused into one fovea.

Fig. 3. Euplectus (Pycnoplectus) interruptus LeConte.

Mesosternal and metasternal field. Legend as in Fig. 1. Of the three pair of foreae present (II, III, IV), note that two are pubescent (II, IV), indicated diagrammatically by short straight lines in the mouth of the forea. Foveae III externally might pass unnoticed, the foreal mouth is so inconspicuous. Fig. 3a. Shows Foveae II and III in a transparent integument, to illustrate the characteristic whorling of the walls of the foreae. Note (a) in Fig. 3, of attachment to mesothoracic wing.

Fig. 4. Trimiomelba dubia (LeConte). Male.

Mesosternal and metasternal field. Legend as in Fig. 1. Two pair of foveae present (II, V), while III is median and umpaired. The foreae are all represented as transparent, so that the whorling of their walls can be observed; II are remarkable in size, and in cleared slides these foreae meet in the midline, above median III, but do not intercommunicate. Note the metasternal furca (MEF) indicated by dotted lines.

Fig. 5. Tmesiphorus costalis LeConte.

Mesosternal and metasternal field. Right side of figure presented with transparent integument (cold KOH $50 \%$ for 14 hours, 700 diancters magnification) to show the mesosternal furca (MOF) and metasternal furca (MEF), as well as the whorled tubes of the foreae II and IV. Note relation of mesosternal furca to fovea IV. Fovea III is median and unpaired. All foreae (II, III, IV) and pubescent.

Fig. 6. Rhexidius canaliculatus (LeConte) and Rhexius insculptus LeConte. In these two trichonychine species fovea II of the mesosternal field is large but typical of Pselaphidae. However, in fovea III on each side the forea in reality is bifurcated into two foreae with a common orifice. This condition is shown in the figure. slide mount, sco diameters.

Fig. 7. Pilopius lacustris Casey.

Mesosternal and metasternal fields. Legend as in Fig. 1. MOF, mesosternal furca; MEF, metasternal furca; MOC, mesothoracic coxa; T, mesothoracic trochanter; F, mesothoracic femur; MEC, metathoracic coxa. Note that foreae II and III are paired, while fovea VI is median and umpaired. All foveae are nude. Fovea VI is shown with transparent integument to show whorling of fovea. The characteristic scale pubescence (a) is enlarged to show its elongate, thin paddle-shape, the deep puncture in which it is set, and the long tube or air space which runs from its tip through the base of the bulb of the scale into the integument where it expands into what appears to be a sac.

Fig. 7a. Foreae II and III of Fig. 7, enlarged at 700 diameters to show whorled walls in the prepectoid area. 
Plate V
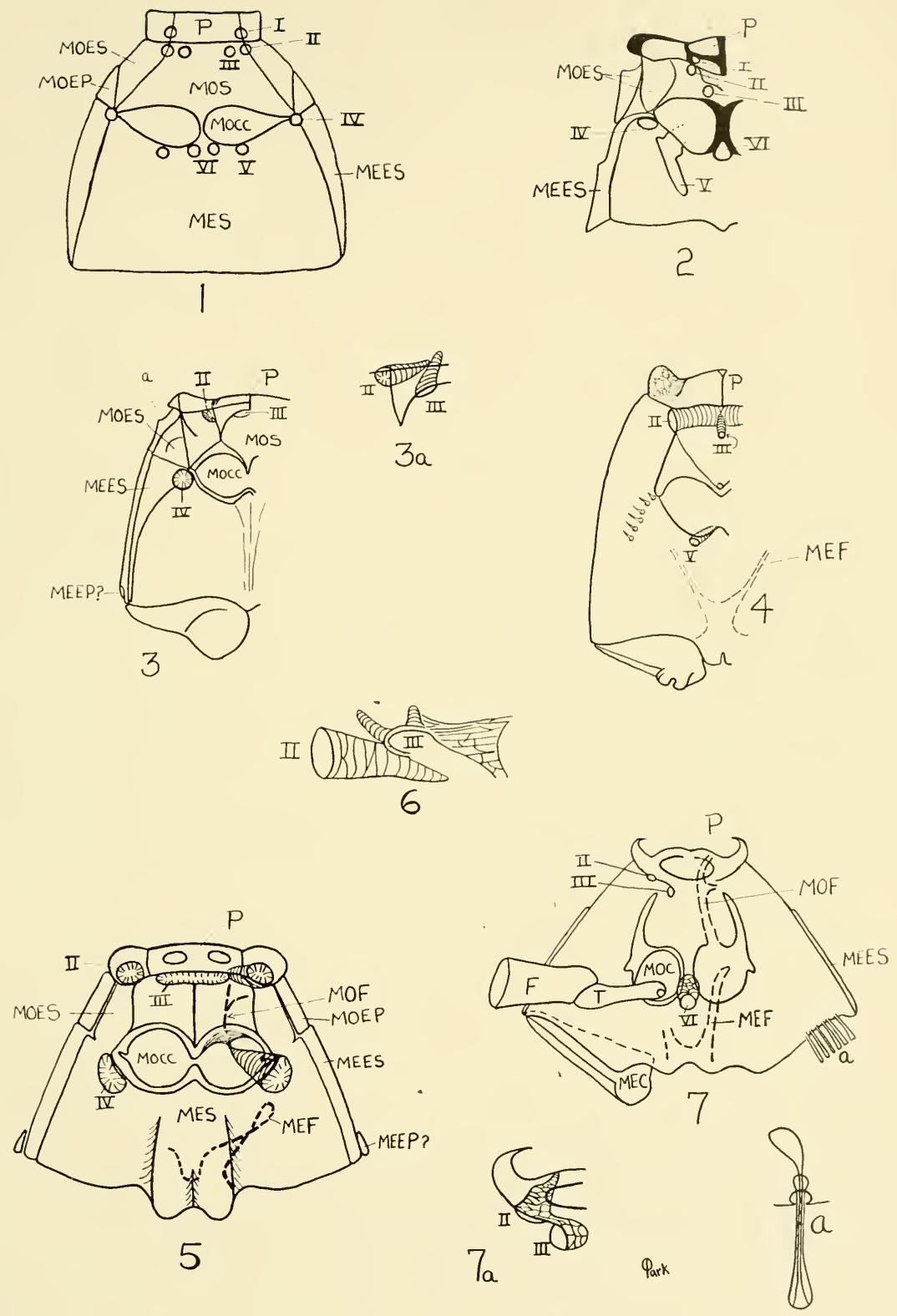

5

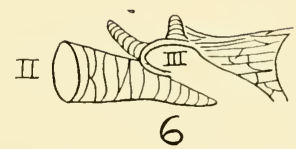




\section{Plate VI \\ TRIBAL KEY CHARACTERS}

Fig. 1. Sonoma tolulae (LeConte). Anterior tarsus.

Fig. 2. Hamotus thomasi Park. Posterior tarsus, from type.

Fig. 3. Arhytodes achillei Park. Posterior tarsus, lateral view, from type.

Fig. 4. Arhytodes achillei Park. Posterior tarsus, dorsal view, from type.

Fig. 5. Fustiger veracruzensis Park. Three-segmented antenna (only the last two are visible from above). Drawn from female paratype.

Fig. 6. Decarthron chichion Park. Ten-segmented antenna. Drawn from male paratype.

Fig. 7. Hamotus veracruzensis Park. Eleven-segmented antenna. Drawn from male lolotype.

Fig. 8. Cercoceroides laticeps Raffray. Intermediate trochanter-femur articultion. Drawn from the female.

Fig. 9. Arthmius sabomba Park. Intermediate trochanter-femur articulation. Drawn from female paratype.

Fig. 10. Melbamima clavicornis Raffray. An eleven-segmented antenna with asymmetrically articulated tenth antennomere. Modified after Raffray, 1909. 
Plate VI
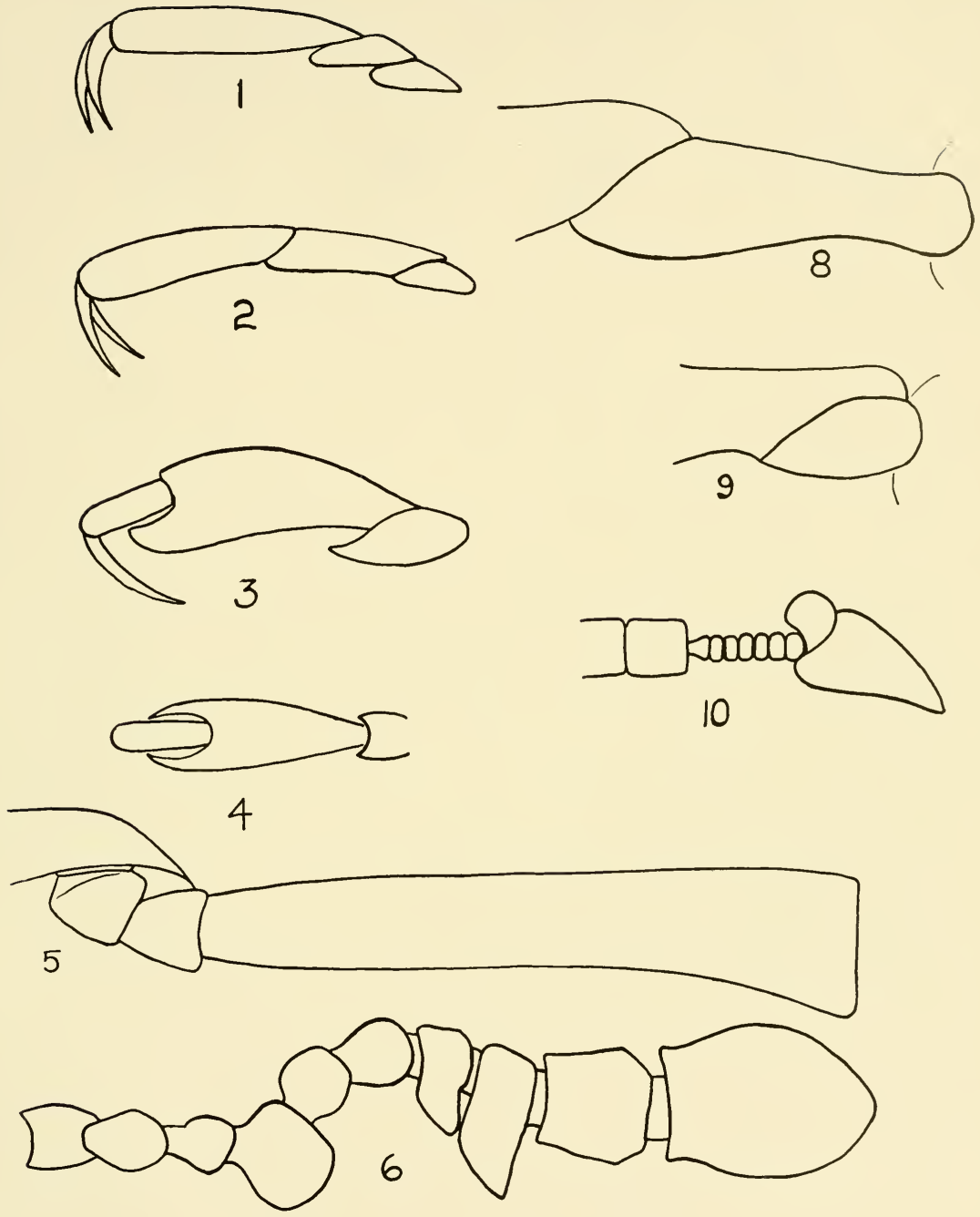

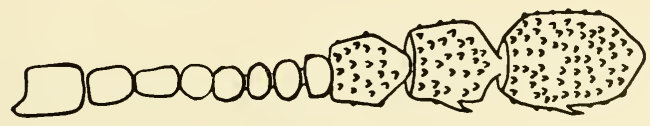


Plate ViI

\section{MISCELLANEOUS CHARACTERS}

Fig. 1. Jubus turneri Park. Ventral aspect of head. Note especially the Vshaped jubine earina, and the expanded mentum with its jubine sidepieces (stippled). Paratype male from a slide at 700 diameters.

Fig. 2. Scalenarthrus undecimtympus Park. Dorsal aspeet of head. The left side shown as opaque, from point-mount. Note the tuberele at external mandibular base. The right side from slide-mount at 400 diameters; the antennal acetabulum is shown as transparent to indieate the pselaphoid method of antennal articulation; the funnelshaped fovea is shown as a stippled invagination; the tentorial arm is shown conneeting the vertexal and gular foveae.

Fig. 3. Scalenarthrus undecimtympus Park. Antenna. Slide at 400 diameters.

Fig. 4. Berdura dentipalpa Park. Maxillary palpus, type, from slide at 400 diameters.

Fig. 5. Berdura excisula Reitter. Maxillary palpus, after Raffray, 1908.

Fig. 6. Decarthron tropicum Fleteher. Posterior coxal articulation.

Fig. 7. Sebaga scydmaenilla (Sharp). Posterior coxal articulation.

Fig. 8. Fustiger veracruzensis Park. Ventral aspect of abdomen of female, from paratype.

Fig. 9. Fustiger veracruzensis Park. Tentral aspeet of abdomen of male, from paratrpe. Drawn on same scale as fig. 8 .

Fig. 10. Tybarida nasicola Park. Carinal pattern of rentral surface of head.

Fig. 11. Yybaris funiculis Park. Carinal pattern of ventral surface of head.

Fig. 12. Scalenarthrus undecimtympus Park and Berdura dentipalpa Park. Carinal pattern of rentral surface of head. 
Plate VII
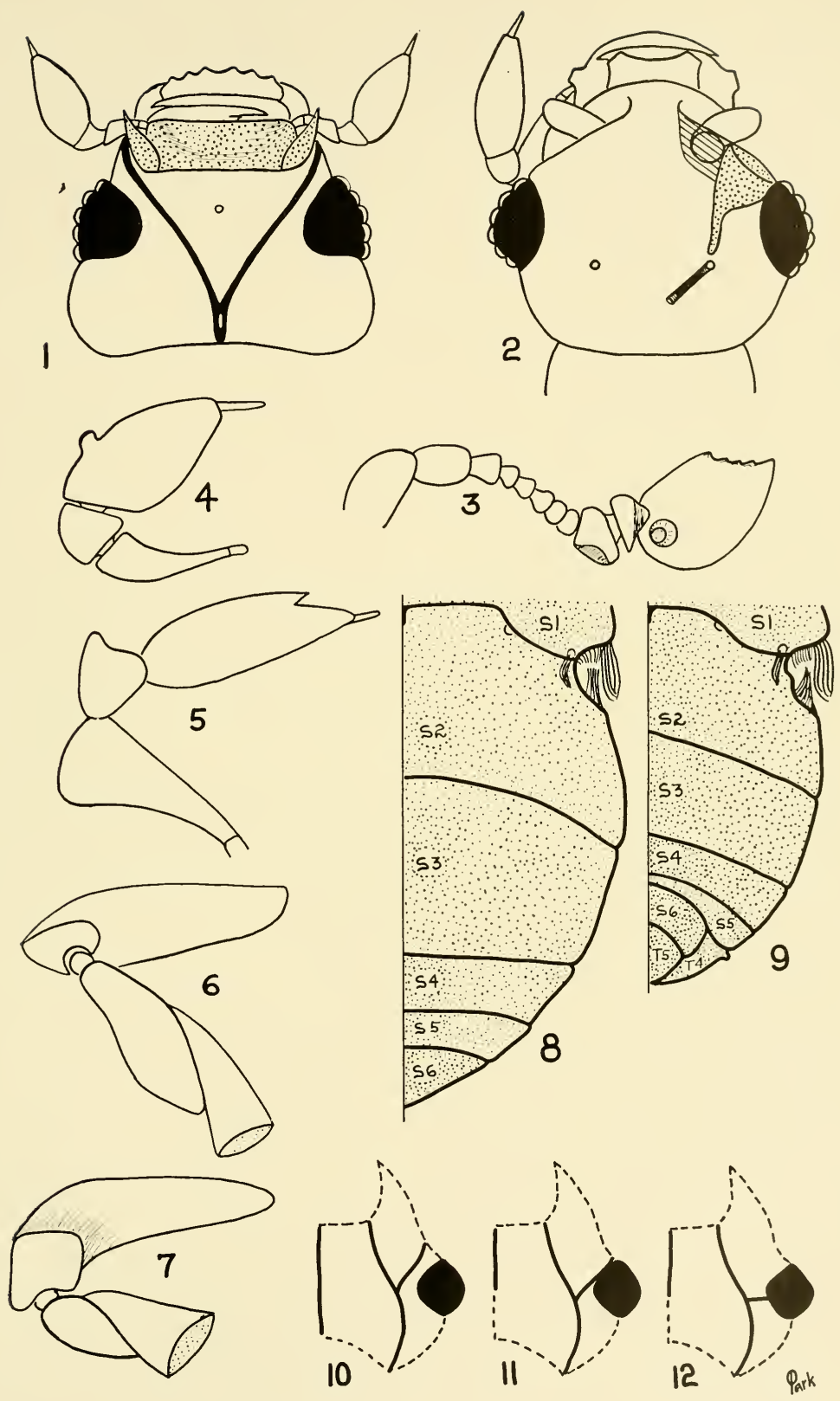


\section{Plate Vili \\ MISCELLANEOUS TRICHONIFORMIS}

Fig. 1. Rhexidius canaliculatus (LeConte). Dorsal aspect.

Fig. 2. Rhexidius canaliculatus (LeConte). Head, lateral aspect.

Fig. 3. Rhexidius canaliculatus (LeConte). Head of male, note median frontal cusp.

Fig. 4. Rhexidius canaliculatus (LeConte). Head of female, cusp absent.

Fig. 5. Rhexidius canaliculatus (LeConte). Penis. Note structural similarity with penis of Dalmosella tenuis Casey, Plate XII.

Fig. 6. Rhexius insculptus LeConte. Sternites.

Fig. 7. Rhexius insculptus LeConte. Dorsal aspect.

Fig. 8. Rhexius insculptus LeConte. Prothoracic tarsus, 700 diameters.

Fig. 9. Rhexius insculptus LeConte. Maxillary palpus, 400 diameters.

Fig. 10. Eurhexius zonalis Park. Pronotum. From male paratype.

Fig. 11. Fletcherexius macrodactylus (Fletcher). Pronotum. From paratype U.S.N.M. No. 44612. 
Plate Vili

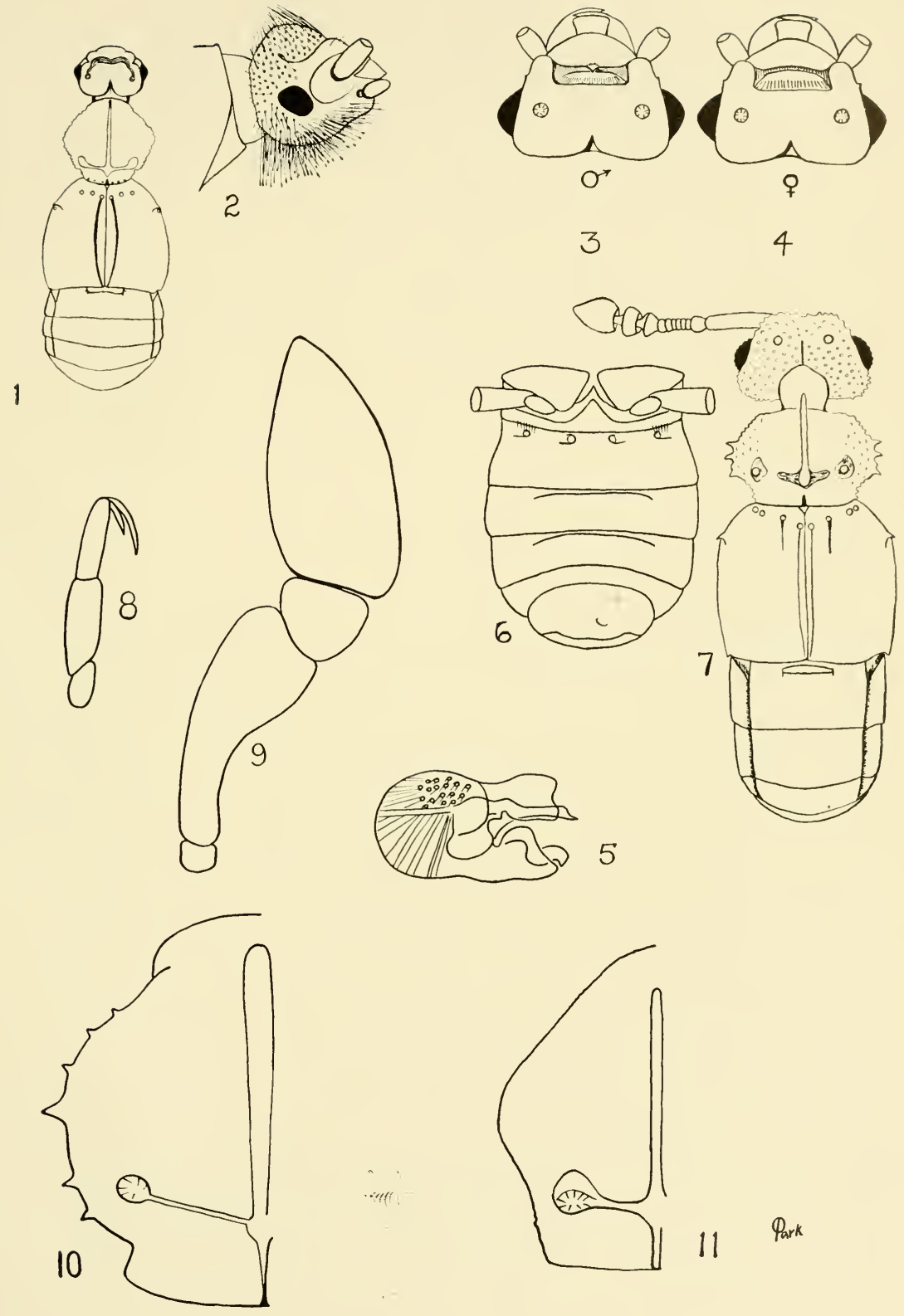




\section{Rhinoscepsis bistriatus LeConte}

Fig. 1. Ventral view of head of female. Note the character of the mandible; crenulate labrum; labium with labial palpus, mentum and submentum, maxillary palpus with cardo, stipes, lacinia and first segment of palpus; rudimentary, large-faceted eye, partially set in the rudder-shaped ventral portion of the cephalic groove; right gular fovea at point where gulo-genal suture disappears anteriorly, the fovea representing externally the attachment of the right arm of the supratentorium where it joins the ventral surface of the head, and this indicated by a pair of dotted lines; the broad "gular field."

Fig. 2. Dorsal surface of head of female. Note anteriorly the approximate first or basal antennal segments, with their dorsal articulation to the front indicated by dotted circles; the rough character of the integument; median longitudinal oval sulcus and strong longitudinal median carina; the right vertexal fovea, with its attachment to the right arm of the supratentorium indicated by dotted lines; the rudimentary, large-faceted eye, partially set in the sigmoid dorsal portion of the cephalic groove which ends posteriorly on each occiput; the medianly notched and posteriorly striulated character of the base of the head.

Fig. 3. Seta found on the ventral surface of the head.

Fig. 4. Last four segments of right antenna of female.

Fig. 5. Distal (fourth) segment of right maxillary palpus showing the palpal cone on the apex.

Fig. 6. Right lateral aspect of female, after treatment in cold $5 \% \mathrm{KOH}$ for two hours to soften the integument. Reading from right to left is noted the typical pselaphid antenna of eleven segments with a three-segmented club and the characteristic dorsal articulation of the antenna to the head; beneath the excavated fronto-clypeal area is seen the horizontally directed labrum and below the labrum the long, arcuate mandible; the complex cephalic groove of the right side is shown passing obliquely ventral to the right vertexal fovea and turning abruptly ventral anteriad of the rudimentary eye, which lies partly in the groove, and then passing anteriorly for a short distance and expanding posteriorly, ending near the back of the head; the compact prothorax with its large prothoracic coxa; the rudimentary metathoracic wings; the elytron represented by a straight line above the wing; the meso- and metathoracic coxae; the abdomen with eight tergites discernible, of which the first two are membranous and the last six are visible and sclerotized; six pleurites and spiracles are present and nine sternites are indicated.

Fig. 7. Ventral aspect of prothorax of female showing the large basisternum and confluent prothoracic coxal cavities (PCC). Note the welldeveloped lateral prosternal foveae (LPF).

Fig. 8. Detail of the left Lateral Prosternal Fovea. Note the characteristic whorling of the course of the fovea, when seen in slide mounts at high magnification.

Fif. 9. Dorsal surface of mesothorax of female under high magnification. a. mesoscutum; b. and c. elytral articulations on the scutellum and side pieces; d. axillary cord of right elytron; e. small posterior portion of mesoscutellum ("scutellum") which is visible between closed elytra; f. mesoscutellum, showing the characteristic striulation; g. mesoprescutum. 
Plate IX
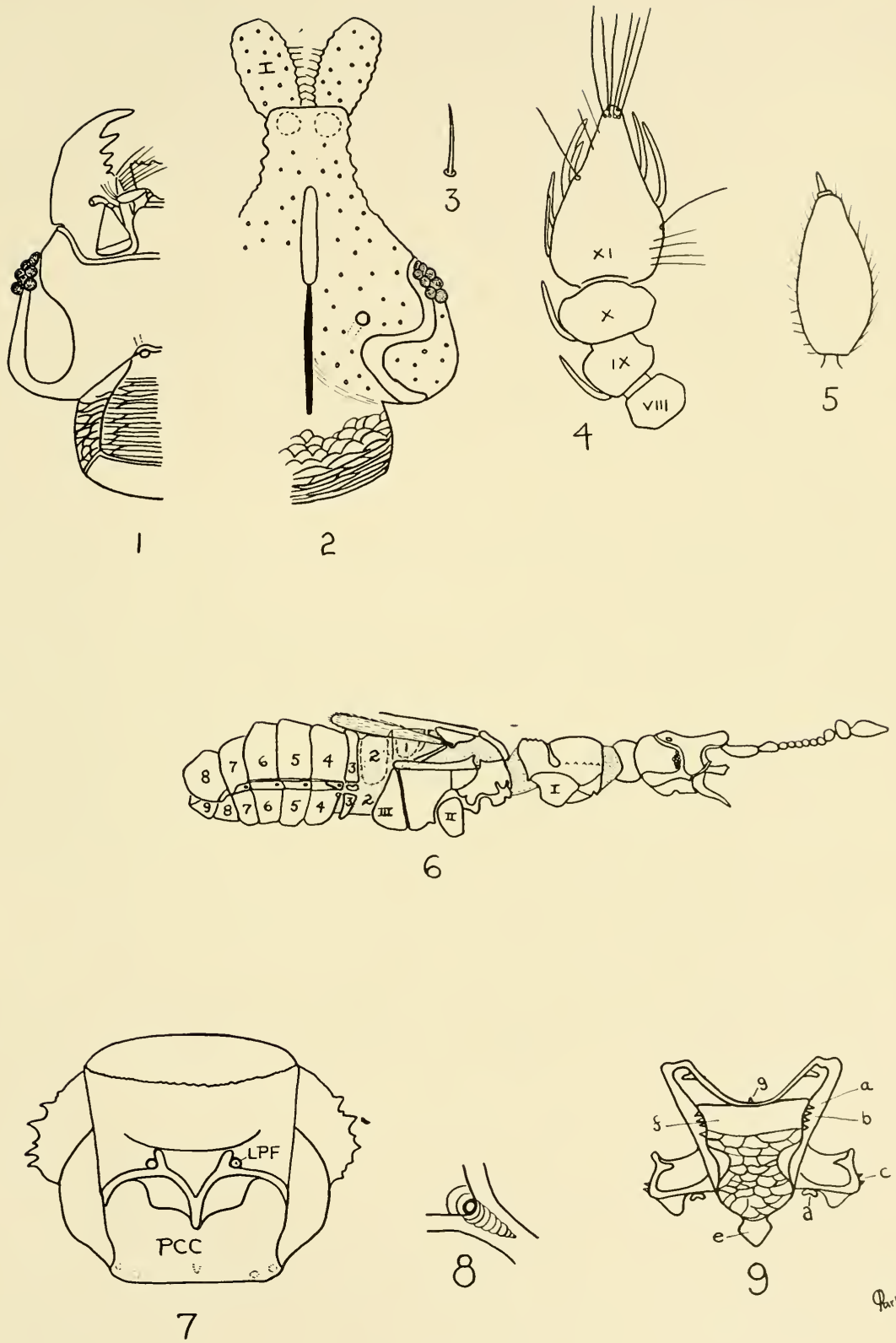

Qaik 


\section{Plate X}

Rhinoscepsis bistriatus LeConte

Fig. 1. Metanotum of female, under high magnification. a.b. metascutum; c.d. metascutellum; e. rudimentary left metathoracic wing.

Fig. 2. Right elytron of female. Note characteristic striulation of the integument on the articular anterior surface, and the posterior margin. The three basal foveae, named from left to right the sutural, discal and humeral, are drawn under high magnification to bring out the characteristic whorling of the lumen of the fovea into the integument. a. The lock-notch which fits over the first visible pleurite and sternite.

Fig. 2a. Right metathoracic leg of female. a. Coxa; b. Trochanter; c. Femur; d. Tibia and e. The three-segmented Tarsus.

Fig. 2b. Third tarsal segment to show detail of the tarsal claw and accessory claw.

Fig 2c. Detail of integumental surface of metathoracic coxa along the line $x$ in 2 a above, under high magnification, to show striulation.

Fig. 3. Mesosternal and metasternal field of female. MOS, mesosternum; MOES, mesoepisternum; MOCC, confluent mesocoxal cavities; MES, metasternum; MESS, metaepisternum; P, prepectoid area; II, lateral mesosternal fovea; III, median mesosternal fovea; IV, lateral mesocoxal fovea and $V$, posterior mesocoxal fovea. Note that these foveae are shown as though the integument was transparent, to bring out the characteristic whorling of their walls. These sternal fovea are important structures (see p. $24 \mathrm{ff}$ ).

Fig. 4. Ventral aspect of abdomen, female. S1-7, visible sternites; T6, sixth visible tergite.

Fig. 5. Ventral aspect of abdomen, male. S1-7, visible sternites, with the seventh, the "pygidium," with the arcuate longitudinal "carina"; T6, sixth visible tergite.

Fig. 6. Ventral aspect of posterior sternites of male abdomen showing the penis being exserted between the right and left pygidial plates, which together make up the seventh sternite, and when closed, their line of union forms the longitudinal median "carina." 


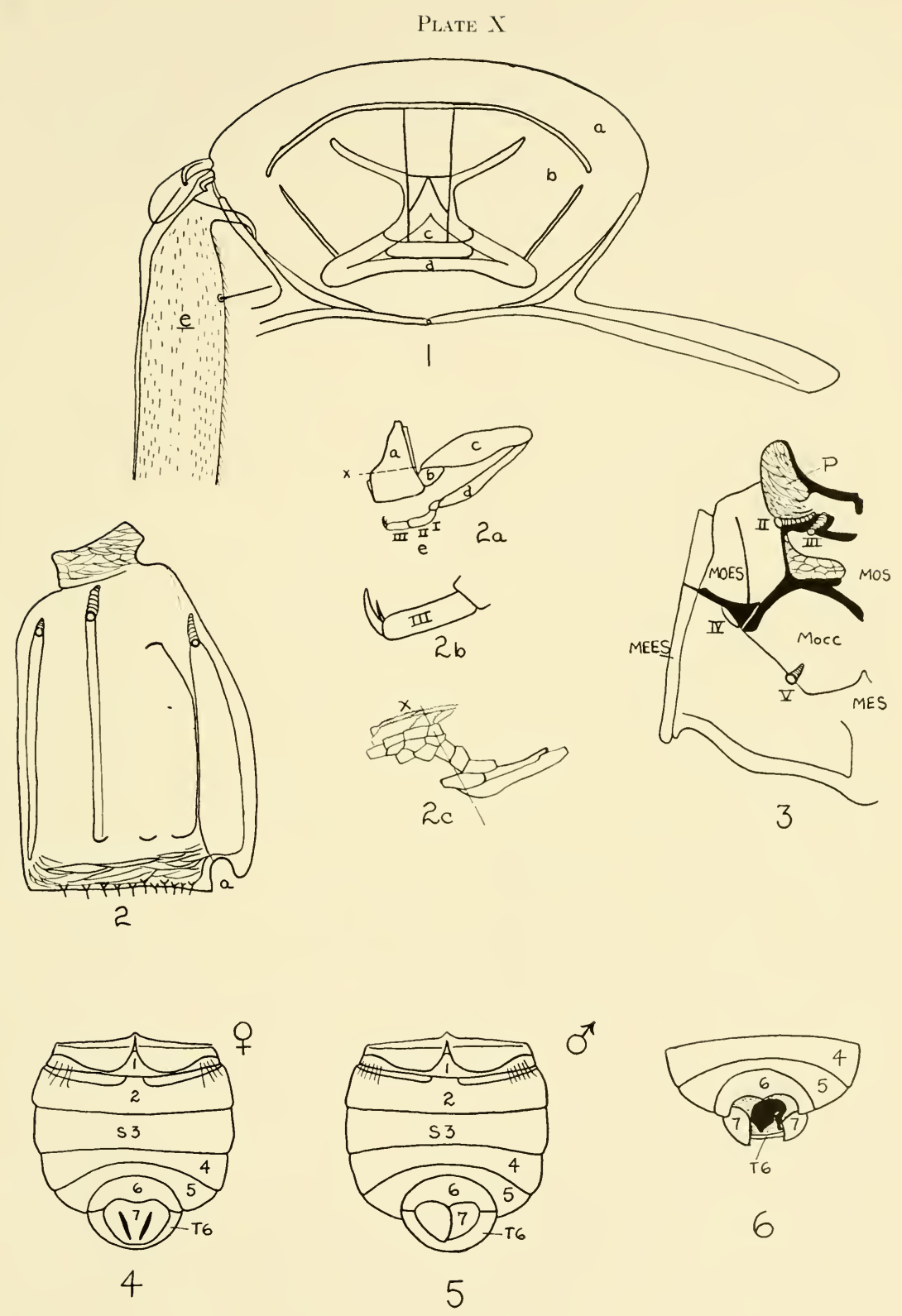




\section{Plate XI}

\section{MISCELLANEOUS EUPLECTINI}

Fig. 1. Trimiomelba dubia (LeConte). Male head and pronotum, dorsal aspect. 400 diameters. Note minute vertexal foveae, coarse punctation and vertexal tubercle.

Fig. 2. Dalmosella tenuis Casey. Male head and pronotum, dorsal aspect. 400 diameters. Note large pubescent vertexal foveae, associated sulcus and the distinctive character of the transverse basal pronotal sulcus.

Fig. 3. Bibloplectus ruficeps (LeConte). Head, dorsal aspect. 700 diameters.

Fig. 4. Bibloplectus ruficeps (LeConte). Head, ventral aspect. 700 diameters. Note spiniform setoid processes.

Fig. 5. Melba thoracica (Brendel) and Melba sulcatula Casey. Dorsal aspect of head, 400 diameters. $25 \% \mathrm{KOH}$ for 24 hours. Note relation of vertexal foveae to supratentoria, and the metatentoria of the cervical region.

Fig. 6. Melba thoracica (Brendel). Ventral aspect of head, 400 diameters. $25 \% \mathrm{KOH}$ for 24 hours. Note capitulate setae.

Fig. 7. Melba thoracica (Brendel). Head and pronotum, dorsal aspect, 100 diameters. Note asperate punctation. Male mesothoracic femur and tibia, 100 diameters. Male mesothoracic tibia, distal end, 700 diameters to show padules.

Fig. 8. Melba sulcatula (Casey). Head and pronotum, dorsal aspect, 100 diameters. Note normal punctulation. Male mesothoracic femur and tibia, 100 diameters. Male mesothoracic tibia, distal end, 700 diameters to show padules. 
Plate XI

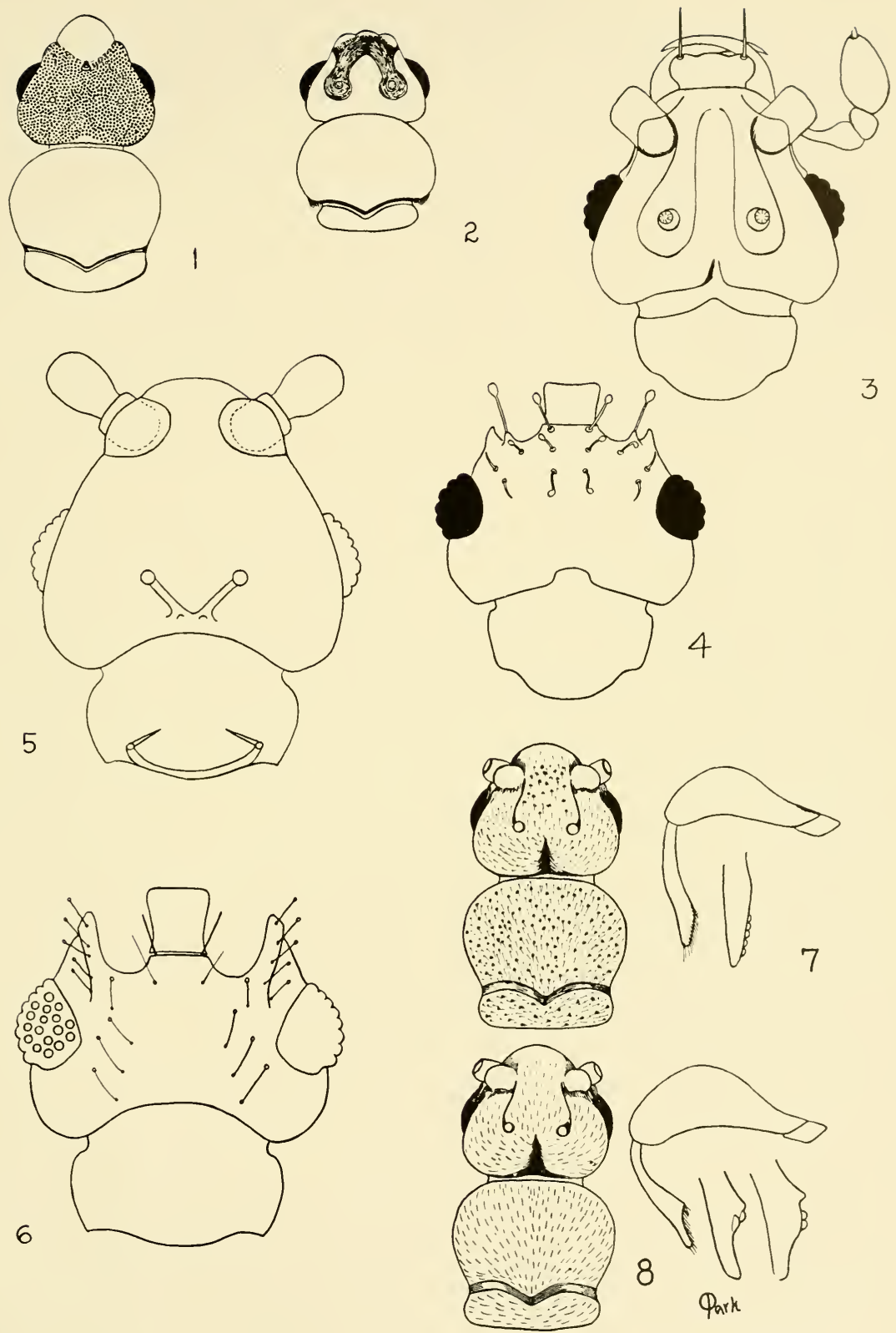




\section{Plate XII}

\section{MISCELLANEOUS EUPLECTINI}

Fig. 1. Trimioplectus obsoletus Brendel. Genal seta, 700 diameters.

Fig. 2. Eutyphlus prominens Casey. Genal setae, 700 diameters. Abundant in this species but very scarce in $E$. similis LeConte.

Fig. 3. Bibloplectus ruficeps (LeConte). Male metathoracic leg, 400 diameters.

Fig. 4. Bibloplectus ruficeps (LeConte). Male metathoracic tibial spur and tarsus, 700 diameters.

Fig. 5. Euplectus interruptus LeConte. Male prothoracic tarsus, 700 diameters, mesial face. Note primary and secondary claws and contrast with Fig. 4 .

Fig. 6. Euplectus difficilis LeConte. Maxillary palpus, 700 diameters.

Fig. 7. Trimiomelba dubia (LeConte). Male maxillary palpus, 700 diameters.

Fig. 8. Trimiomelba dubia (LeConte). Male metathoracic leg, 400 diameters.

Fig. 9. Trimiomelba dubia (LeConte). Male metathoracic tarsal claws, 700 diameters. Note minute secondary elaw and contrast with Figs. 4 and 5 .

Fig. 10. Melba thoracica (Brendel) and Melba sulcatula Casey. Mesothoracis tarsus, 400 diameters.

Fig. 11. Melba thoracica (Brendel). Mesothoracic leg, 150 diameters.

Fig. 12. Melba thoracica (Brendel). Metathoracic leg, 150 diameters.

Fig. 13. Melba thoracica (Brendel). Prothorax, anterior face.

Fig. 14. Melba thoracica (Brendel). Prothorax, posterior face. Note the endoskeleton, conical coxae, brachyscelid articulation, and sensory pores on the femora. 700 diameters.

Fig. 15. Dalmosella tenuis Casey. Male sternites $(0.3 \mathrm{x} 0.3 \mathrm{~mm}$. $)$ showing peculiar secondary sexual modification of second sternite. Tote exserted penis and pygidium asymmetrically articulated to the right. Penis $0.12 \times 0.07 \mathrm{~mm}$.

Fig. 16. Dalmosella tenuis Casey. Male sexual modification of second sternite, lateral view.

Fig. 17. Melba thoracica (Brendel). Head, lateral view.

Fig. 18. Trimiomelba dubia (LeConte). Head of male, lateral view.

Fig. 19. Euplectus interruptus LeConte. Head, lateral view.

Fig. 20. Melba. Right elytron, lateral face. Note oblique pleural line.

Fig. 21. Dalmosella. Right elytron, lateral face. Note parallel pleural line. 
Plate NII
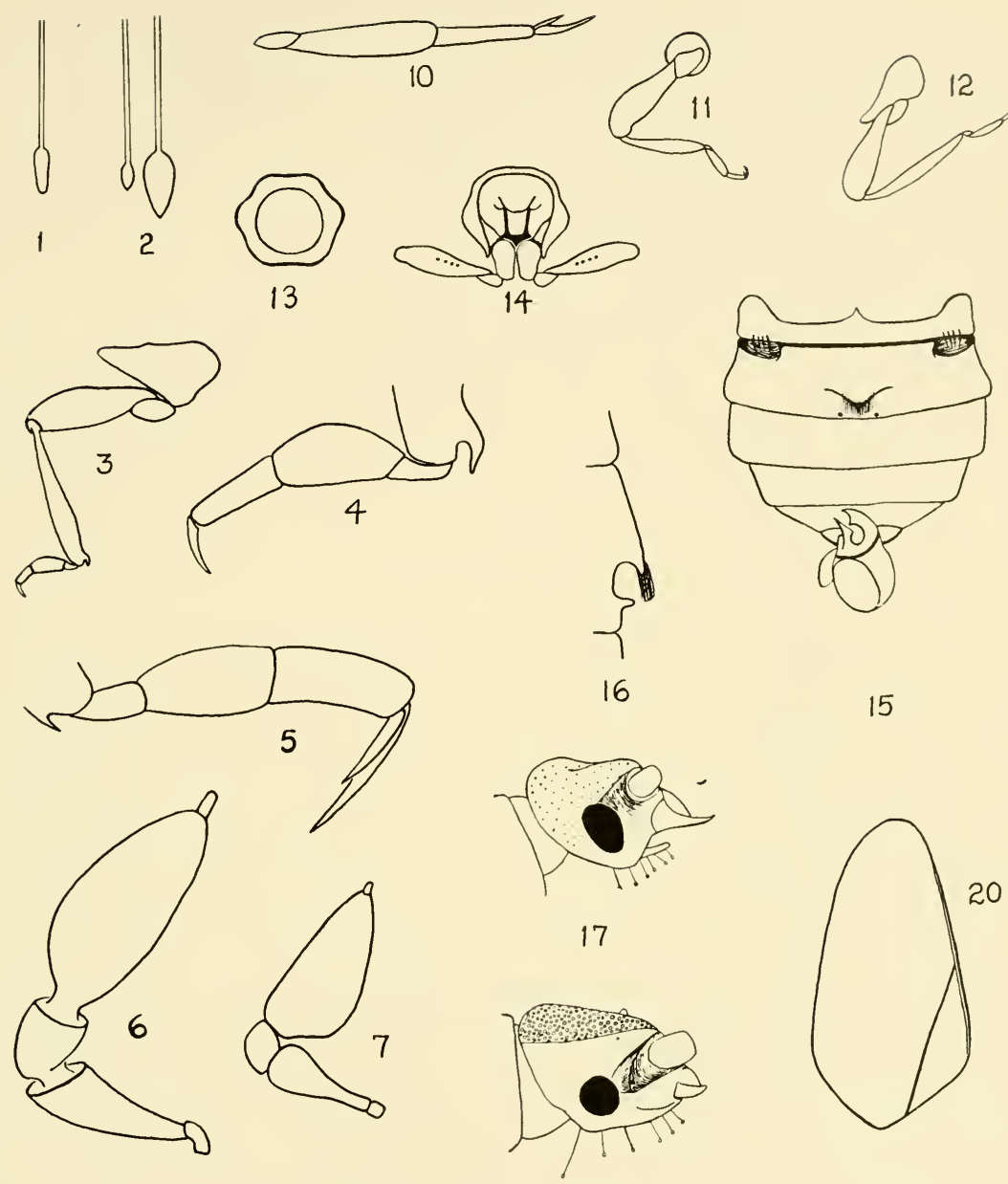

15
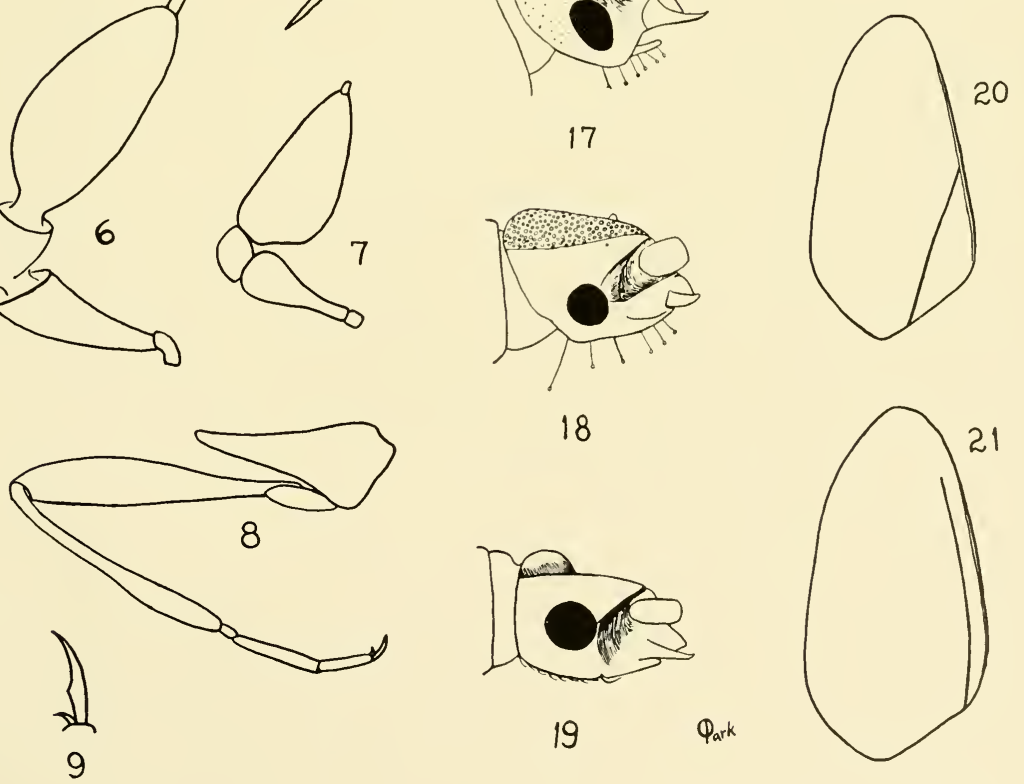


\section{Plate XiII}

Fig. 1. Trimiomelba dubia (LeConte). Right eye, male, 40 to 45 facets. ant., anterior; ven., ventral. Slide mount, 700 diameters.

Fig. 2. Eupsenius glaber LeConte. Head, antennae and pronotum from dorsal face.

Fig. 3. Trimiomelba dubia (LeConte). Toadstool-shaped vertexal spine on the head of male. Pubescence not shown. Note coarse, shallow integumental punctures around pedicel of spine. Slide mount, 700 diameters.

Fig. 4. Sonoma (Rafonus) tolulae (LeConte). Ventral aspect of prothorax. PS, prosternum; PCC, prothoracic coxal cavities; APF, anterior prosternal foveae; LPF, lateral prosternal foveae; MPF, median prosternal fovea (unpaired). This is a generalized, primitive prosternal field with five out of a theoretical six foveae.

Fig. 5. Sonoma (Rafonus) tolulae (LeConte). Right elytron, male. This is a primitive elytron with a row of foveae on the flange fitting under the pronotum, and ten rows of punctures on the integument. The small foveae near the sutural margin may vary from 2 to 5 in number, the first basal fovea may be present or absent, the second row of discal foveae is more constant.

Fig. 6. Euplectus (Pycnoplectus) interruptus LeConte. Ventral aspect of prothorax, female. PS, prosternum; PCC, prothoracic coxal cavities; LPF, pubescent lateral prosternal foveae.

Fig. 7. Sonoma (Rafonus) tolulae (LeConte). Lateral aspect of abdomen, male. MCA, metathoracic coxal acetabulum in first sternite. Seven sternites shown (S1-7) and six tergites shown (T1-6), however in dry mounts only five tergites are visible.

Fig. 8. Euplectus (Pycnoplectus) interruptus LeConte. Right elytron, female. Note four large foveae, one sutural and three discal. The subhumeral fovea does not show from this view, but is indicated in Fig. 8a, a lateral view of the elytron. Note that the subhumeral fovea is pubescent and almost surrounded by a cariniform line.

Fig. 9. Sonoma (Rafonus) tolulae (LeConte). Ventral aspect of abdomen, male. MCA, metathoracic coxal acetabulum on each side the first visible sternite. Seven visible sternites (S1-7). Note that the seventh is composed of three asymmetrical pieces, a right and left lateral and a median, pygidial plate. 


\section{Plate XIII}
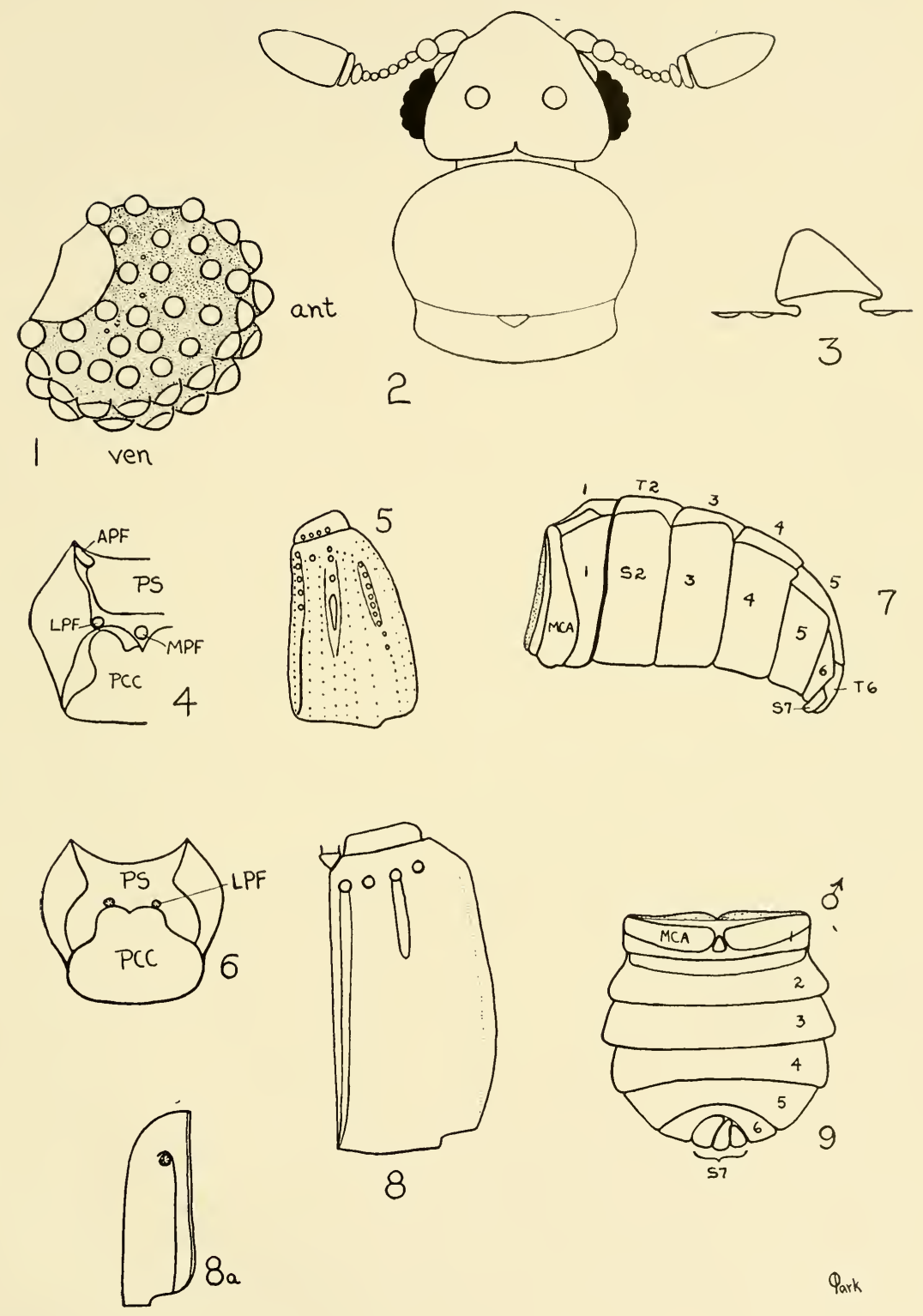

Qark 
Plate XIV

Fig. 1. Eupsenius glaber LeConte. Ventral aspect on the left; dorsal aspect on the right. For discussion see text. 


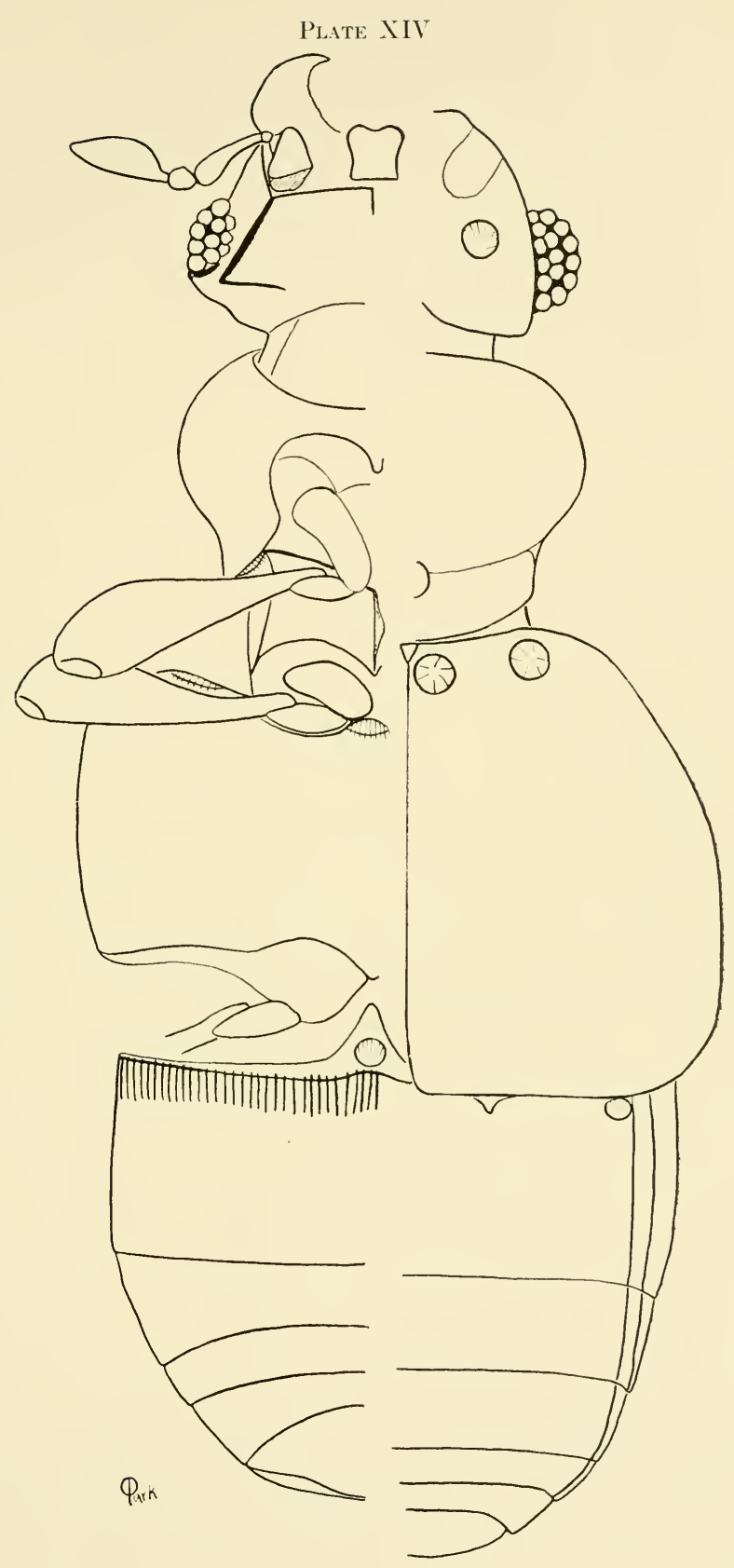




\section{Plate NV}

Fig. 1. Barroeuplectoides zeteki Park. Antenna in silhoutte. Drawn from type. Fig. 2. Panaramecia williamsi Park. Apical portion of intermediate tibia and tarsus. Drawn from holotype.

Fig. 3. Elytra of Euphalepsus, in which the humeral calus of each elytron is extended posteriorly as a carina. Contrast with Fig. 7, Plate XVIII.

Fig. 4. Outline sketch of Fustiger clavipilis Mann, showing a common outline in the genus. Contrast with Fig. 5. (After Mann, 1921)

Fig. 5. Outline sketch of Fustiger haytiana Mann, showing a rare outline in the genus. Contrast with Fig. 4. (After Mann, 1915)

Fig. 6. Fustiger haytiana Mann. Male intermediate femur and trochanter, with the unusually long, blunt femoral spine. (After Mann, 1915)

Fig. 7. Outline sketch of pronotum of Sebaga centralis Raffray, after Raffray, 1891.

Fig. 8. Sebaga centralis Raffray. Antebasal pronotal platform.

Fig. 9. Sebaga raffrayi Park. Antebasal pronotal platform.

Fig. 10. Sebaga notonoda Park. Antebasal pronotal platform. 
Plate $\mathrm{XV}$

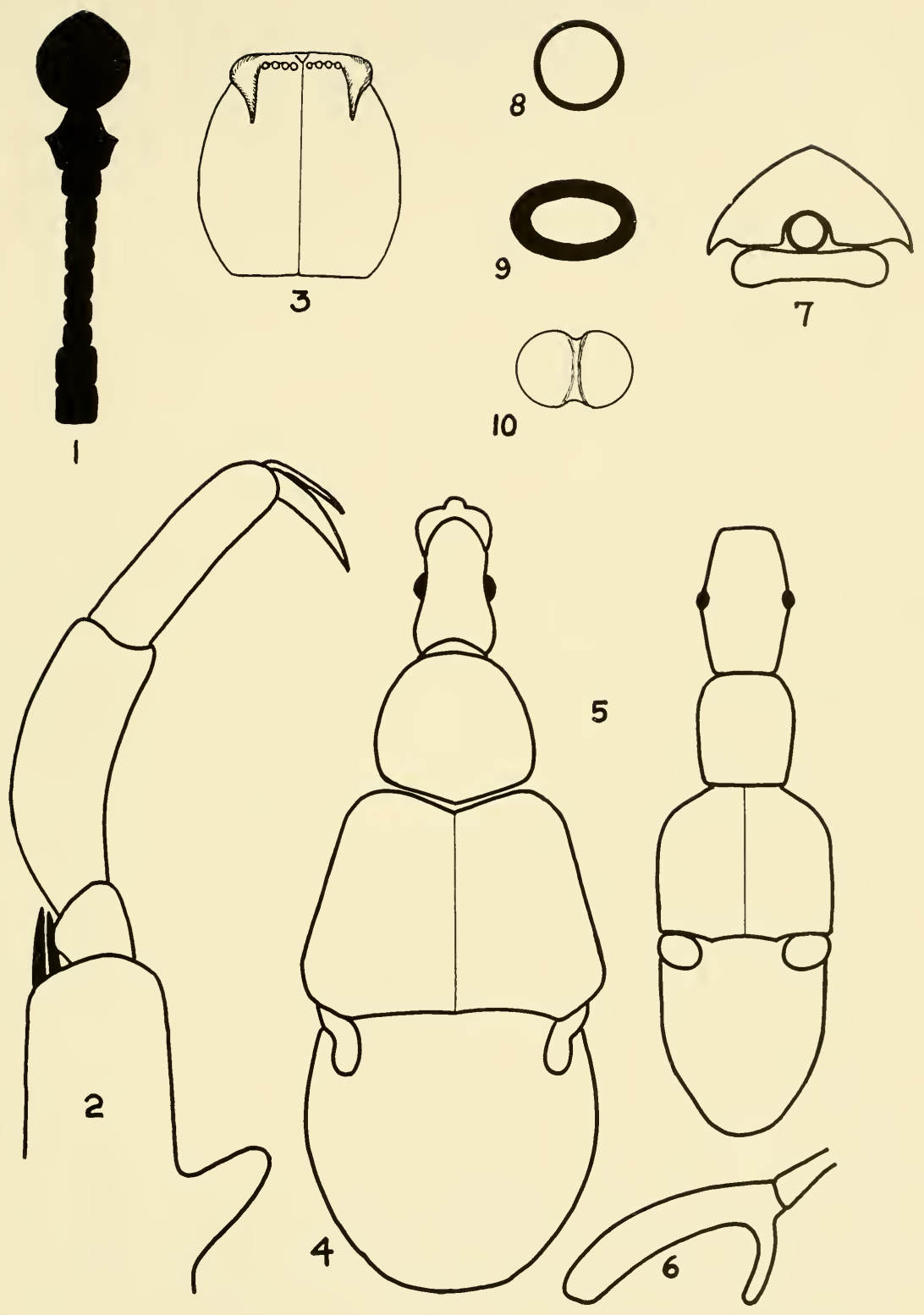




\section{Plate XVI}

Fig. 1. Reichenbachia guatemalensis Fletcher. Right mandible, drawn from male paratype (U.S.N.M., No. 44608).

Fig. 2. Reichenbachia latipes Fletcher. Right mandible, drawn from male paratype (U.S.N.M., No. 44605).

Fig. 3. Decarthron chichion Park. Intermediate femur. Male type.

Fig. 4. Decarthron noctiphoton Park. Intermediate femur. Male type. a. Proximal spine; b. carinoid crest on floor of excaration. Note the complete absence of a spine at the apical end of excavation; $D$. denticulatum Fletcher has the apical spine developerl.

Fig. 5. Decarthron noctiphoton Park. Detail of male intermediate femoral excavation, slide mount at 700 diameters. Note a, proximal spine is tubular, with secondary striations (canals?) radiating from base; $\mathrm{b}$, the carinoid ridge is bifurcated, and "feathered" by secondary striations.

Fig. 6. Decarthron noctiphoton Park. Anterior femur. Male type.

Fig. 7. Decarthron noctiphoton Park. Antenna. Male type.

Fig. 8. Reichenbachia stroheckeri Park. Distal nine antennomeres, from male paratype. Dorsal aspect.

Fig. 9. Reichenbachia stroheckeri Park. Lateral aspect of the fifth and sixth antennomeres, from male paratype.

Fig. 10. Reichenbachia appendiculata Raffray. Lateral aspect of the fifth and sixth antennomeres of male. Modified after Raffray, 1904.

Fig. 11. Reichenbachia appendiculata Raffray. Dorsal aspect of the fifth and sixth antennomeres of male. Modified after Raffray, 1904.

Fig. 12. Reichenbachia diversula Raffray. Dorsal aspect of the fifth and sixth antennomeres of male. Modified after Sharp, 1887.

Fig. 13. Reichenbachia fovearthra Park. Dorsal aspect of the third, fourth, fifth and sixth antennomeres of male, from holotype.

Fig. 14. Reichenbachia fovearthra Park. Ventral aspect of the fifth and sixth antennomeres of male, from holotype. 
Plate NVI
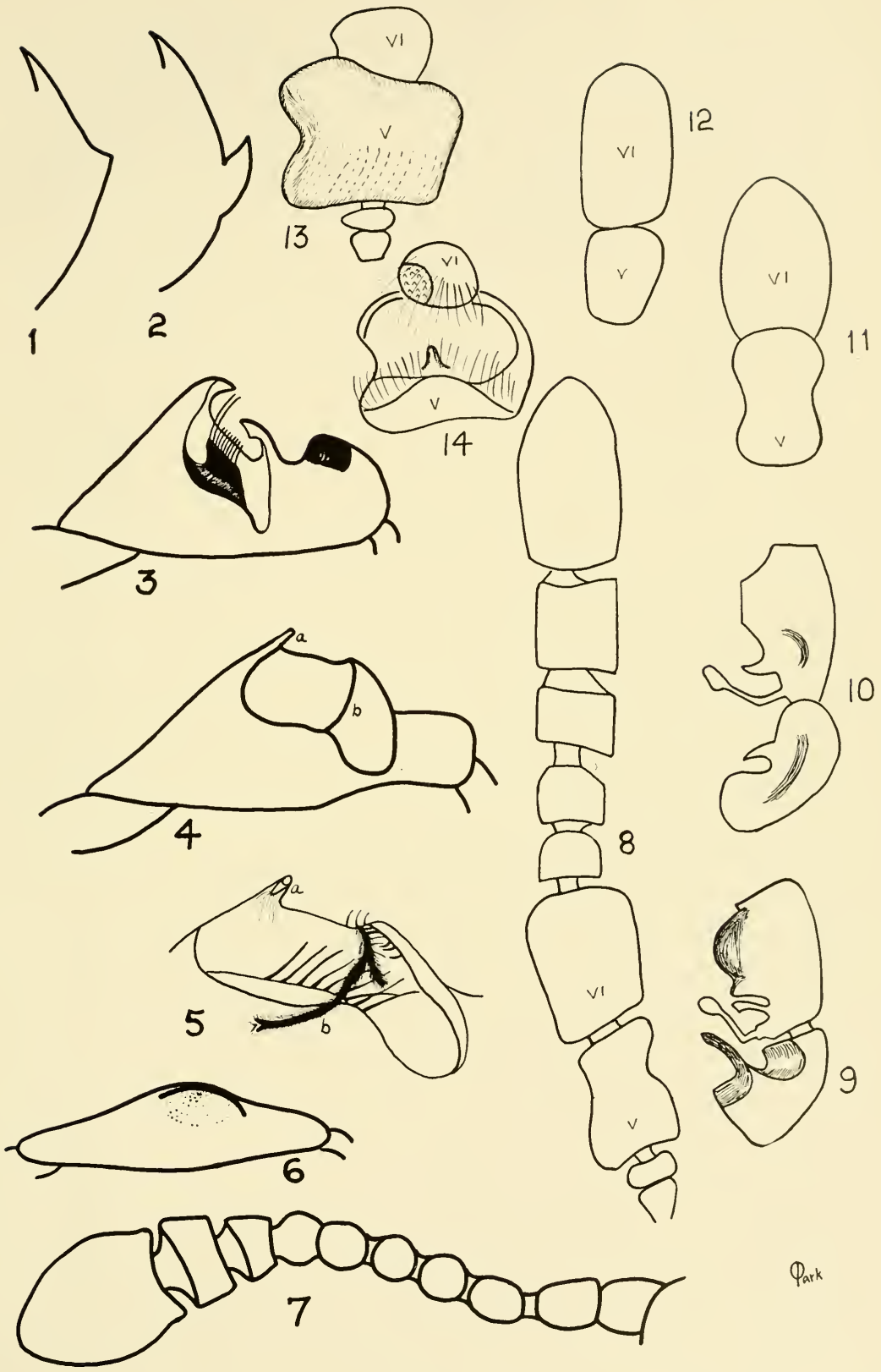

Qark 


\section{Plate XVII}

Fig. 1. Tyrogatunus zetehi Park. Left eye, from holotype male. Stippled facets represent pigment present, or expanded; white facets represent pigment absent, or contracted. See text for detail.

Fig. 2. Fustiger veracruzensis Park. Left eye, from holotype male.

Fig. 3. Cylindrarctus longipalpis (LeConte). Right side of head. I, first antennomere; a, flattened sensory area; b, antennal acetabulum; c, translucent window between acetabulae; d, clypeus; e, labrum; f, mandible; $g$, stipes-palpifer of maxilla; h, first and second maxillary palpomeres; i, gena; $\mathrm{j}$, cervical constriction; $\mathrm{k}$, occiput; 1 , vertex; $m$, front; $n$, vertexal fovea; $o$, antennal tubercle; $p$, compound eye; q, vertexal spicule.

Fig. 4. Hamotus (Hamotoides): small median pronotal forea, as found in thomasi, veracruzensis, and fletcheri.

Fig. 5. Hamotus (Hamotoides): large median pronotal forea, as found in monachus and electrae.

Fig. 6. Hamotus (Hamotoides) thomasi Park. Distal four antennomeres, from male type.

Fig. 7. Hamotus (Hamotoides) veracruzensis fletcheri Park. Distal four antennomeres. Contrast with Fig. 7, Plate. VI.

Fig. 8. Hamotus (Hamotus) tibialis Raffray. Male, posterior femur. Modified from Raffray, 1904.

Fig. 9. Hamotus (Hamotus) turalbus Park. Male, posterior femur. Modified from Park, 1935.

Intrageneric variation of male antennae in Neotropical Reichenbachia. Figs. 10 to 16 after Raffray, 1904; Fig. 17 after Fletcher, 1928.

Fig. 10. Reichenbachia grenadensis Raffray.

Fig. 11. Reichenbachia sarcinaria Schaufuss.

Fig. 12. Ventral surface of fifth antennomere, sarcinaria Schaufuss.

Fig. 13. Ventral surface of fifth antennomere, callosa Raffray.

Fig. 14. Ventral surface of fifth antennomere, falsa Raffray.

Fig. 15. Reichenbachia globulosa Raffray.

Fig. 16. Reichenbachia mexicana Raffray.

Fig. 17. Reichenbachia carinifer Fletcher. 
Plate XVII

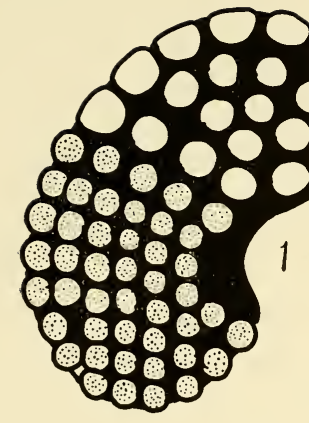

809
8090
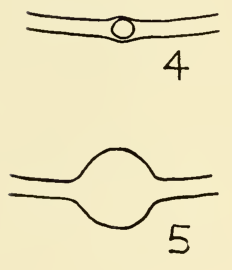

暒:

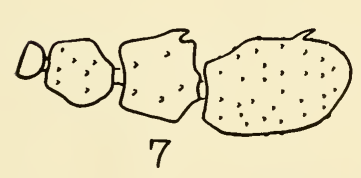

Qark
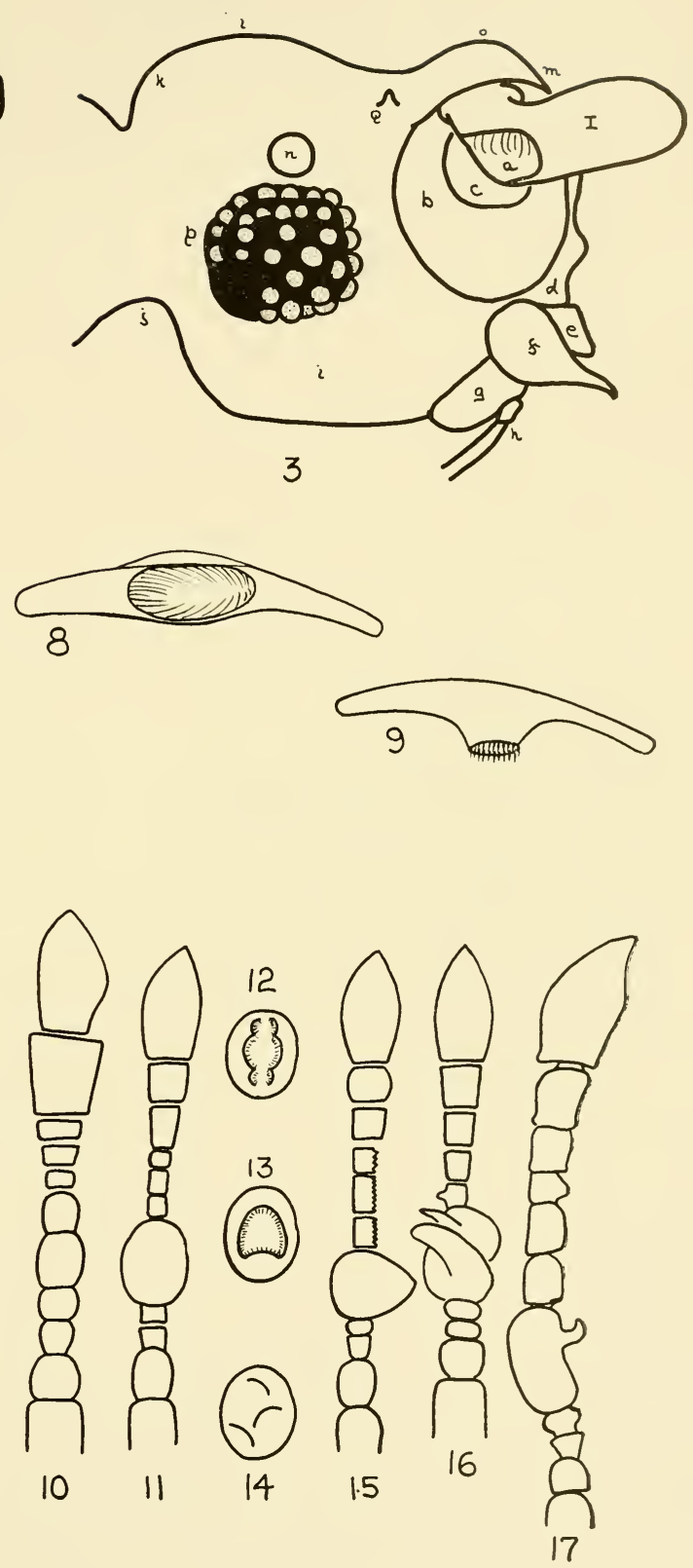
Plate XVIII

\section{INTRAFAMILY VARIATION OF HABITUS IN NEOTROPICAL PSELAPHIDAE}

Fig. 1. Barrojuba albertae Park, Panama Canal Zone. Dorsal aspect, from male type. Note complete absence of vertexal foreae.

Fig. 2. Rhinoscepsis falli Park, Brazil. Dorsal aspect, from type.

Fig. 3. Decarthron euspinifrons Park, an ecitophile from the Panama Canal Zone. The frontal horn is novel in the genus. Dorsal aspect from male type.

Fig. 4. Metopioxys mattogrossoensis Park, Brazil. Dorsal aspect, from male type. Note geniculate antenna.

Fig. 5. Barrometopia quasimoda Park, a termitophile from the Panama Canal Zone. The pronotum is strongly gibbous on either side of the median sulcus. Dorsal aspect, male type.

Fig. 6. Batoctenus barberi Park, Brazil. Dorsal aspect, male type.

Fig. 7. Euphalepsus myrmecocolus Park, Mexico. Dorsal aspect, female type. 
Plate NVIII
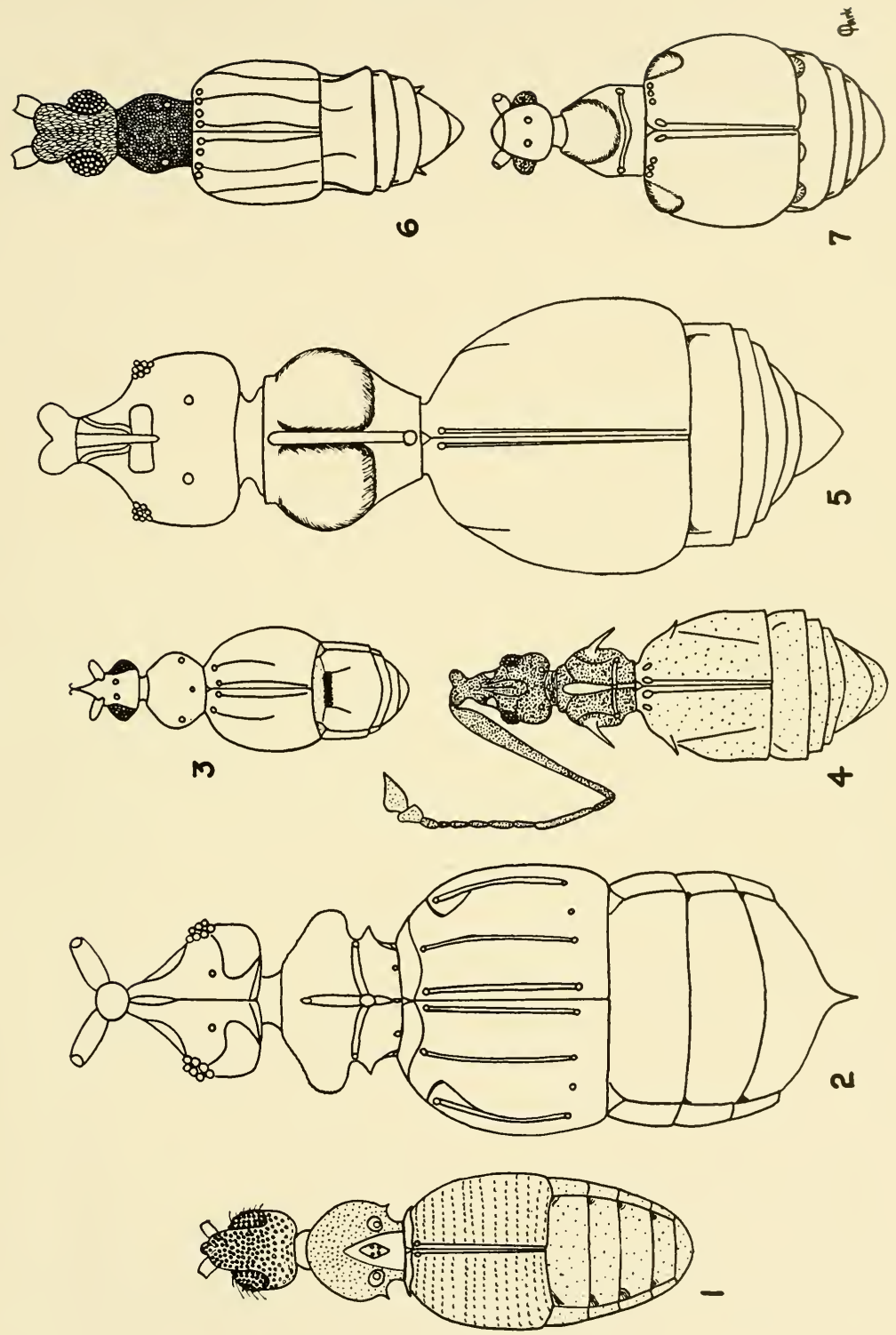


\section{Plate NIN}

INTRAFAMILY VARIATION OF HABITUS IN NEOTROPICAL PSELAPHIDAE (Continued)

Fig. 1. Syrmocerus guarimus Park, Brazil. Dorsal aspect, male type.

Fig. 2. Anoplobraxis guianensis Park, a termitophile from British Guiana. Dorsal aspect, male type.

Fig. 3. Hamotus (Hamotus) turalbus Park, Costa Rica. Redrawn from Park, 1935.

Fig. 4. Hamotus (Hamotoides) monachus Reitter, Costa Rica. Dorsal aspect.

Fig. 5. Arhytodes achillei Park, Brazil. Dorsal aspect, from type.

Fig. 6. Fustiger veracruzensis Park, a symphile from Mexico. Dorsal aspect, male paratype.

Fig. 7. Trimiopsis furcalis Park, Panama Canal Zone. Dorsal aspect, male holotype. 
Plate XIX
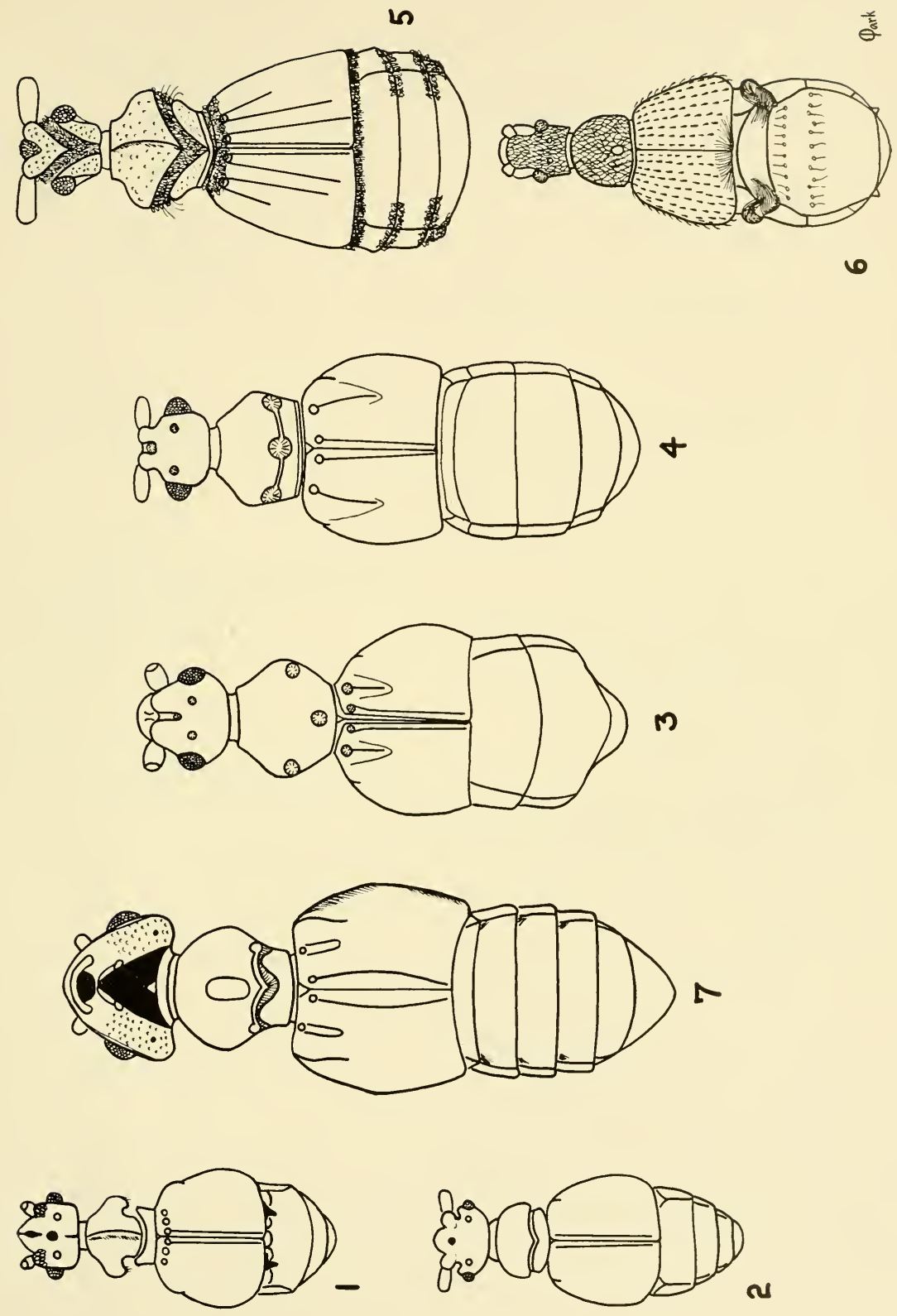


\section{Plate XX}

\section{GENERIC VARIATION OF MAXILLARY PALPI IN NEOTROPICAL TYRINI}

Palpi are in silhoutte to facilitate generic diagnosis. All normal pubescence and species differences omitted. The figures are of left palpi as seen from the dorsal surface. For evolution please see text.

Fig. 1. Phalepsus Westwood (Redrawn after Raffray, 1908)

Fig. 2. Lethenomus Raffray (Redrawn after Raffray, 1908)

Fig. 3. Tyropsis Saulcy and Neotyrus Raffray (Original)

Fig. 4. Tyrogatunus Park (Original)

Fig. 5. Juxtahamotopsis Park (Original)

Fig. 6. Apharus Reitter (Original)

Fig. 7. Hamotus Aube (Original)

Fig. 8. Hamotus Aube (Original)

Fig. 9. Aploderina Raffray (Redrawn after Raffray, 1904)

Fig. 10. Pseudohamotus Raffray (Redrawn after Raffray, 1908)

Fig. 11. Cercoceropsis Raffray (Redrawn after Raffray, 1904, 1908)

Fig. 12. Cercoceroides Raffray (Original)

Fig. 13. Hamotocellus Raffray (Redrawn after Raffray, 1911)

Fig. 14. Pselaphocompsus Raffray (Redrawn after Raffray, 1908, 1911)

Fig. 15. Cercocerulus Raffray (Redrawn after Raffray, 1904) 
Plate XX
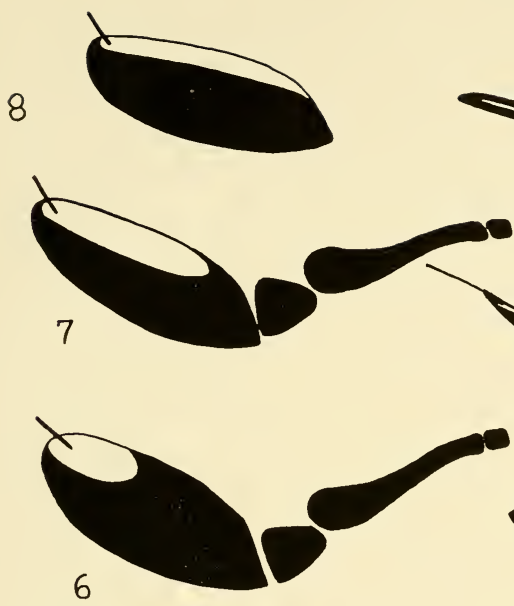

15
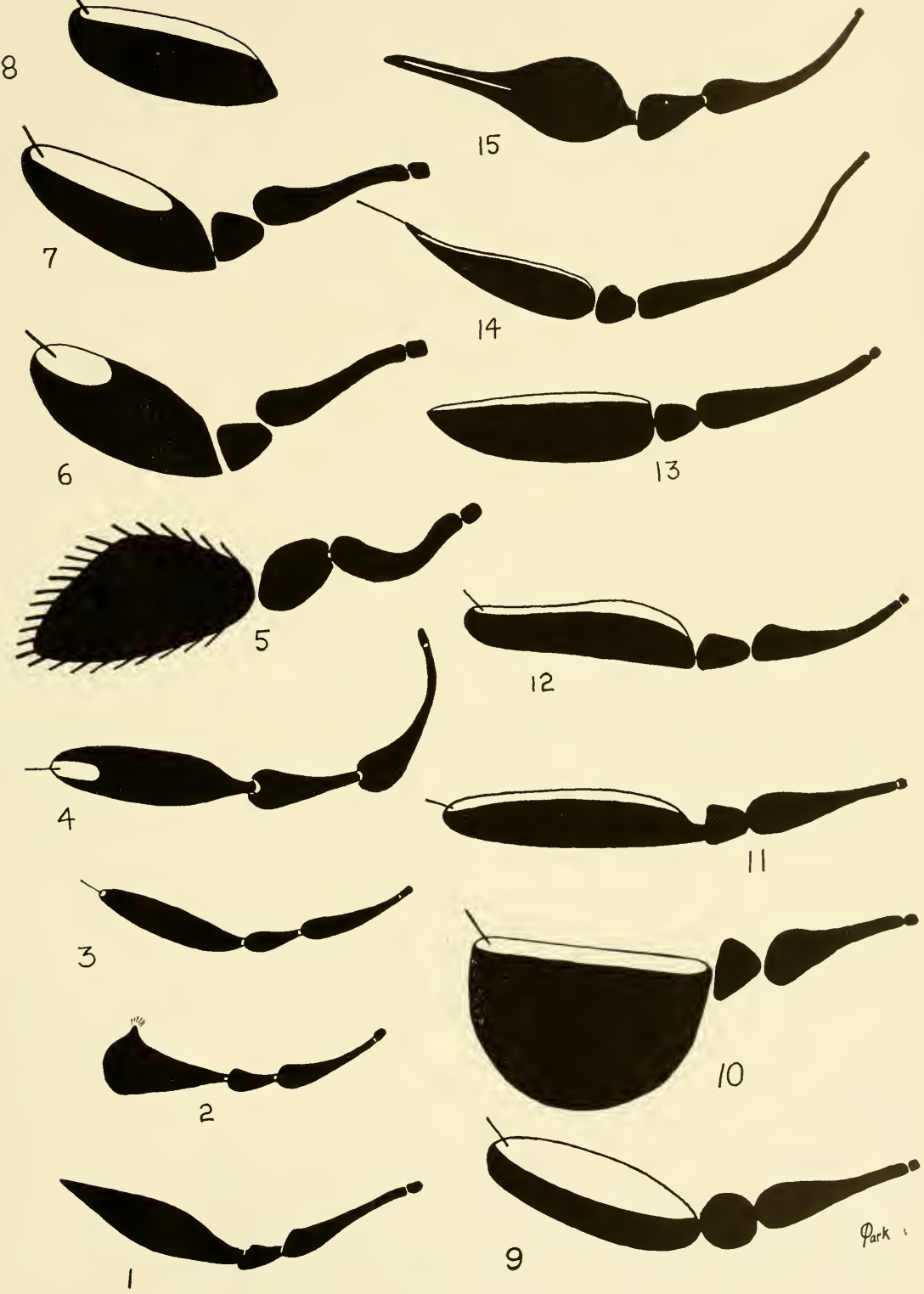


\section{Plate XXI}

SOME INFLUENCES PROBABLY OPERATING UPON PSELAPHIDAE

(For documentation please see text)

Fig. 1. Theoretical, evenly distributed, taxonomic units at maximum density.

Fig. 2. Operation of the Subspeciation Factor. The numerous taxonomic units are in reality subspecies of a relatively few species populations.

Fig. 3. Operation of the Community Factor. The differential biotic potential of the several communities imposes differential distribution and reduces the number of species populations for the whole area.

Fig. 4. Operation of the Competitive Factor. Predators in the same stratum of the Eltonian Pyramicl compete with pselaphid species populations, for food and shelter, greatly reducing the number of species.

Fig. 5. Operation of the Range Factor. Species populations of pselaphids overlap within a given biome. This sets up intra-family competition and may or may not reduce the number of species, depending upon overlap in activity pattern, extra-family competition, et cetera. 


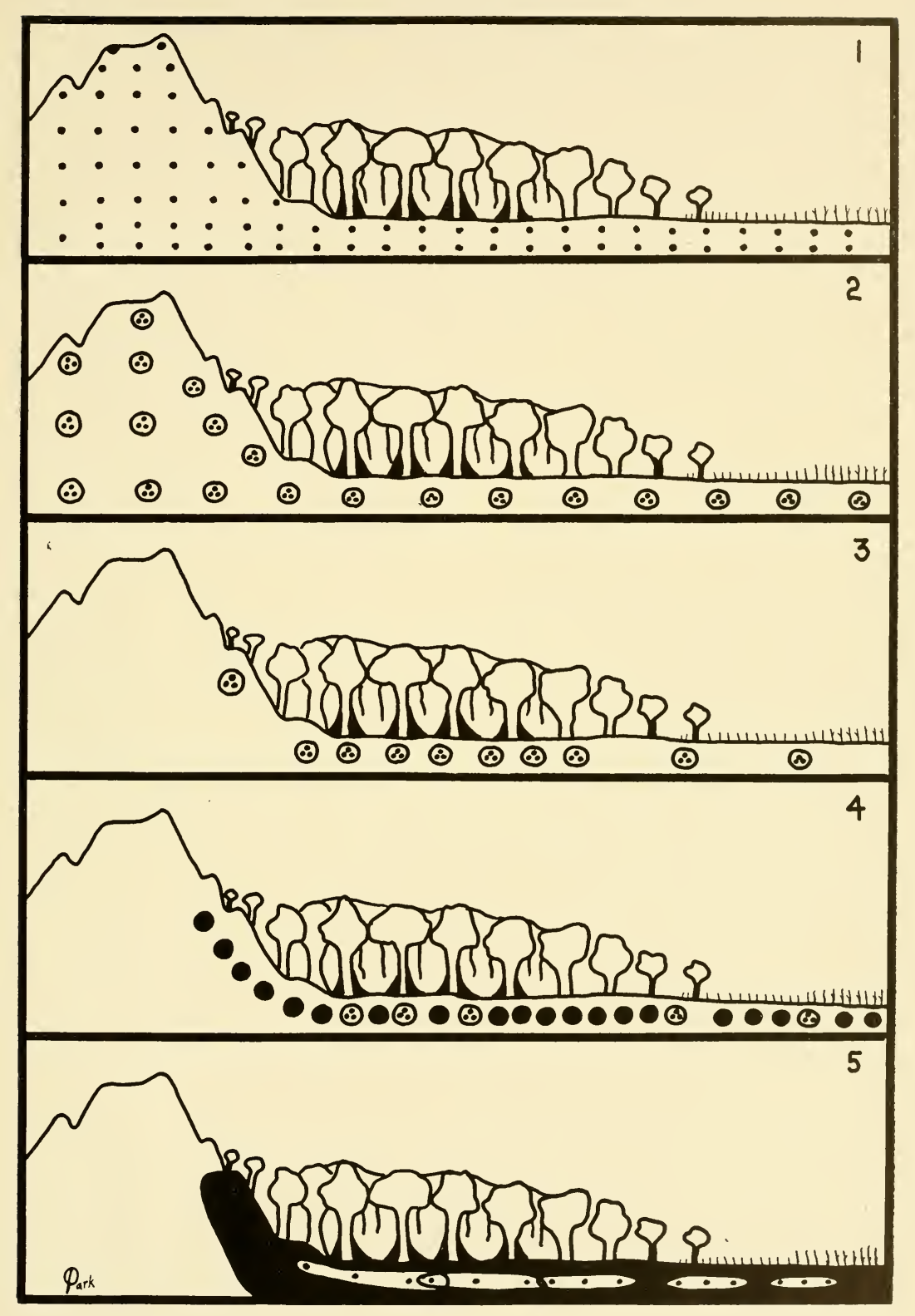





